Universidad de Lima

Escuela Universitaria de Ingeniería

Carrera de Ingeniería de Sistemas

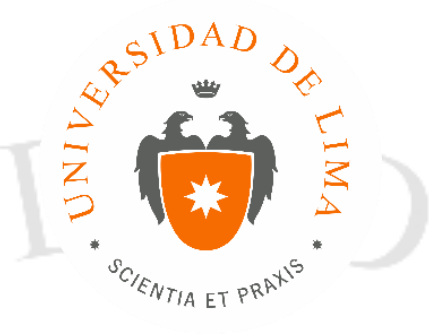

\title{
MODELO DE MEJORA DEL CICLO DE VIDA DEL DESARROLLO DE SOFTWARE CON REFERENCIA A LA ISO/IEC 29110 CASO: MYPE HOLINSYS
}

Trabajo de investigación para optar el título profesional en Ingeniería de Sistemas

\author{
Hugo Jhonny Egusquiza Herrada \\ Código 20081365 \\ Raúl Alonso Navarro Macurí \\ Código 20080698
}

Asesor

Miriam Elizabeth Amable Ciudad

Lima - Perú

JUNIO DE 2016 


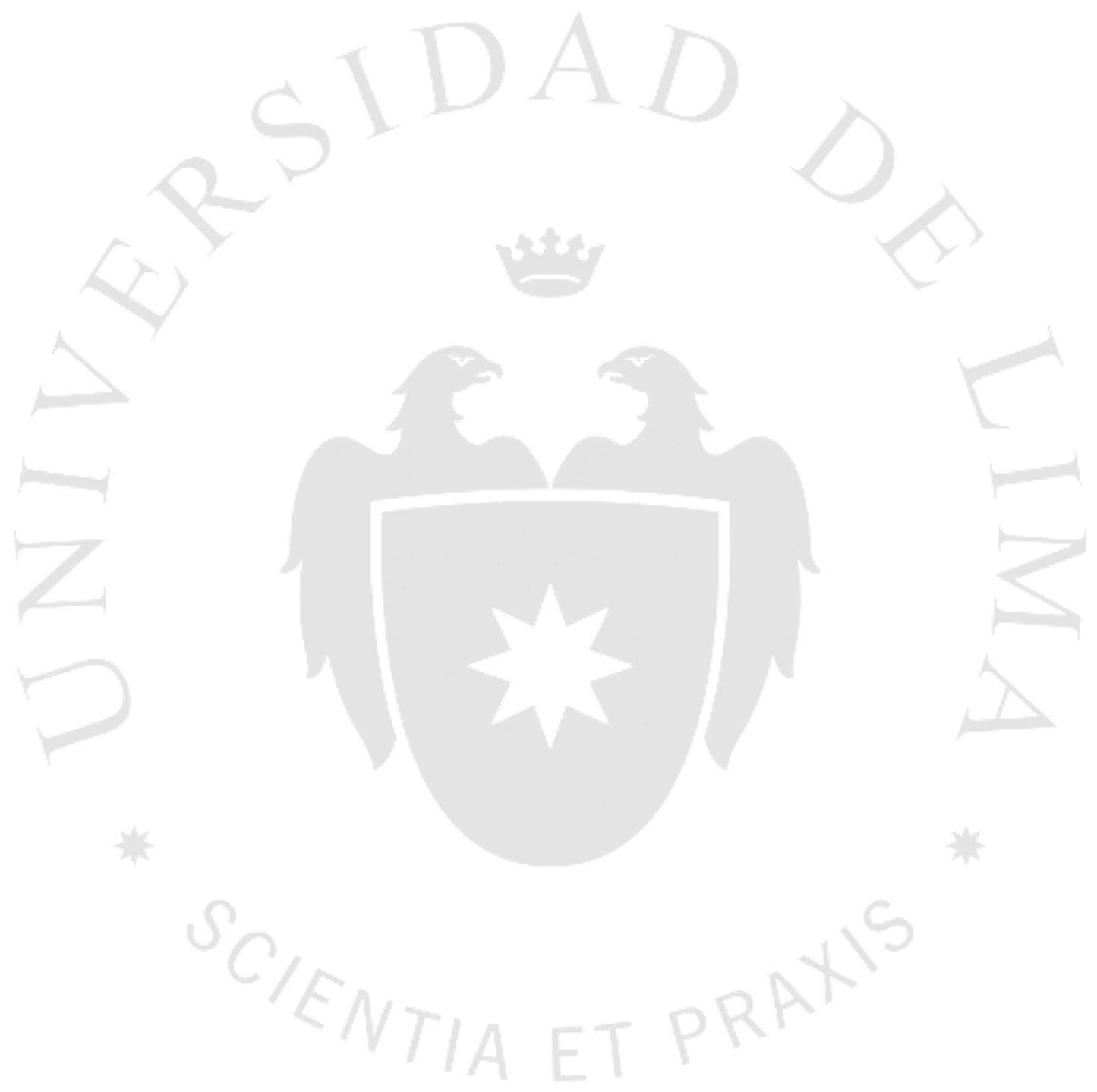


MODELO DE MEJORA DEL CICLO DE VIDA DEL DESARROLLO DE SOFTWARE CON REFERENCIA A LA ISO/IEC 29110 CASO: MYPE HOLINSYS 


\section{TABLA DE CONTENIDO}

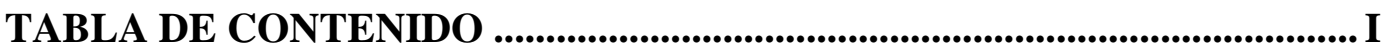

ÍNDICE DE TABLAS ..................................................................................... III

ÍNDICE DE FIGURAS ................................................................................. V

ÍNDICE DE ANEXOS .................................................................................. VII

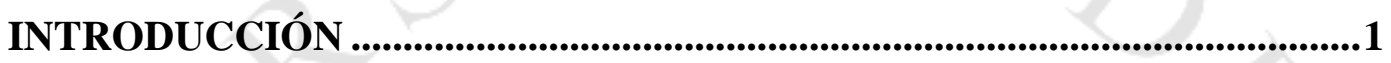

DESCRIPTORES TEMÁTICOS ................................................................................3

CAPÍTULO I: PLANTEAMIENTO DEL PROBLEMA ...............................4

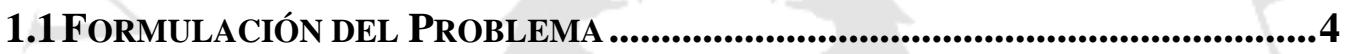

I.2 OBJETIVO DE LA INVESTIGACIÓN .............................................................11

I.3 JUSTIFICACIÓN...............................................................................................11

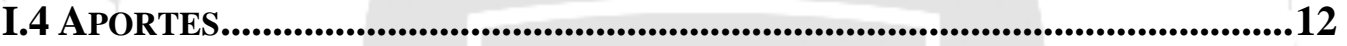

CAPÍTULO II: REVISIÓN DE LITERATURA ............................................13

2.1 ANTECEDENTES .....................................................................................13

2.2 ESTUDIOS RELACIONADOS CON EL TEMA DE INVESTIGACIÓN ...................14

2.2.1 Relevancia de las MyPEs ........................................................................... 14

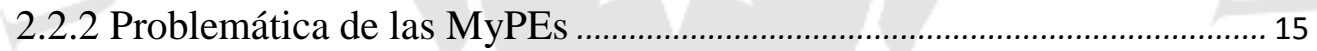

2.2.3 Importancia de las Normas de Calidad del Desarrollo de .......................

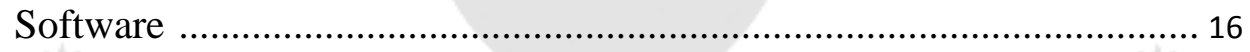

2.2.4 Proyectos de investigación Implementados en el Perú ............................. 17

CAPÍTULO III: MARCO TEÓRICO ................................................................19

3.1 LAS MYPES EN LA INDUSTRIA DEL DESARROLLO DE SOFTWARE .............19

3.2 RUP Y UML ................................................................................20

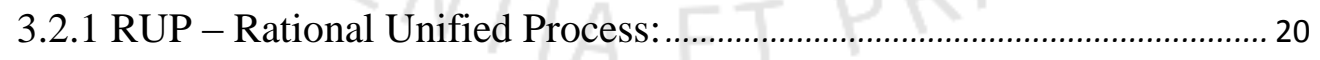

3.2.2 UML - Lenguaje unificado para la modelación: ......................................... 23

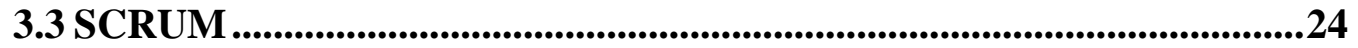

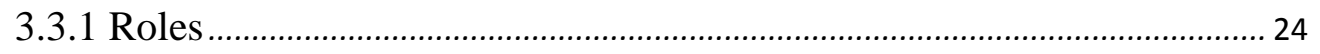

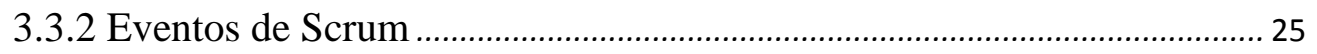

3.3.3 Artefactos de Scrum..................................................................................... 27

3.4 ISO/IEC 29110 - PERFILES DEL CICLO DE VIDA PARA LAS PO ..................28

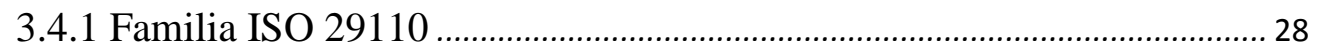

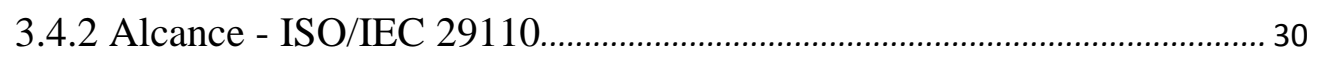

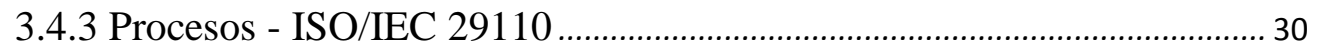


3.4.4 Roles Involucrados en el ciclo de vida del desarrollo de software ...........

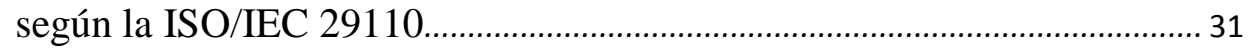

3.4.5 Proceso de Gestión del Proyecto (GP) - ISO/IEC 29110 ............................ 33

3.4.6 Proceso de Implementación de Software (IS)- ISO/IEC 29110............... 36

3.4.7 Productos de trabajo del ciclo de vida del desarrollo de software........... 40

3.4.8 Herramienta de evaluación de actividades (Activity Assessment)......... 41

3.4.9 Herramientas requeridas en el ciclo de vida del Desarrollo de .................

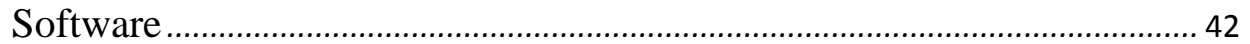

3.4.10 Requisitos para demostrar el cumplimiento de la ISO/IEC $29110 \ldots . . . .43$

CAPÍTULO IV: PROPUESTA DE SOLUCIÓN ..............................................44

4.1 ENFOQUE .......................................................................................................44

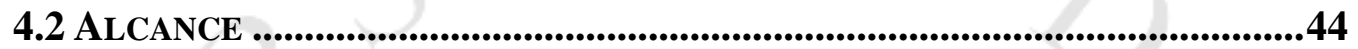

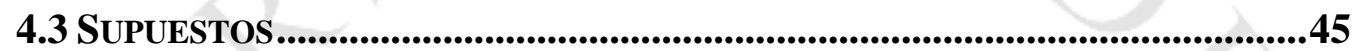

4.4 ENTREGABLES ...................................................................................46

4.5 PlaN dE TRABAJO Y EVALUACIÓN ECONÓMICA ......................................47

4.5.1 Plan de Trabajo del Objetivo General I....................................................... 47

4.5.2 Plan de Trabajo del Objetivo General II ........................................................ 49

CAPÍTULO V: DESARROLLO DE LA SOLUCIÓN PROPUESTA ...........52

5.1 MODELO DE MEJORA ........................................................................................52

5.1.1. Evaluación del ciclo de vida del desarrollo de software .......................... 52

5.1.2. Plan de Implementación del Modelo de Mejora para el ciclo de ............. vida del desarrollo de software.................................................................... 120

5.2 Herramienta Para el Seguimiento y Control de Proyectos .....126

5.2.1. Requerimientos Funcionales de la herramienta ....................................... 126

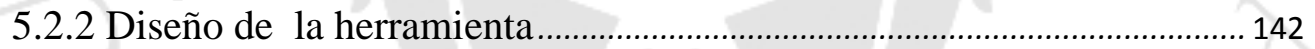

5.2.3 Documentos referentes a la herramienta .............................................. 150

CAPÍTULO VI: VERIFICACIÓN Y VALIDACIÓN ....................................152

6.1 ANÁlisis de RESUltAdos del MOdELO DE MEJORA .............................152

6.2 ANÁliSiS de RESUltAdos de la HERRAMIENTA DE SOFTWARE.............154

CAPÍTULO VII: CONCLUSIONES Y RECOMENDACIONES .................155

7.1 CONCLUSIONES.................................................................................155

7.2 RECOMENDACIONES.......................................................................156

GLOSARIO DE TÉRMINOS..........................................................................157

REFERENCIAS ..............................................................................................................167

BIBLIOGRAFÍA ..............................................................................................170

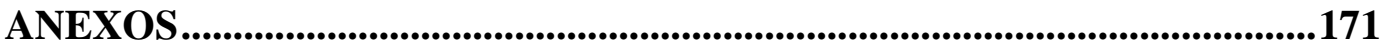




\section{ÍNDICE DE TABLAS}

Tabla 1 Estructura de las MyPEs en el Perú....................................................... 19

Tabla 2 Descripción del Equipo SCRUM.......................................................25

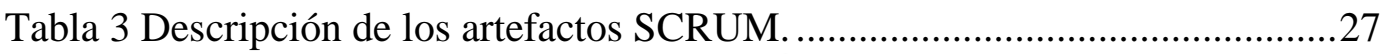

Tabla 4 ISO/IEC 29110 Público Objetivo......................................................28

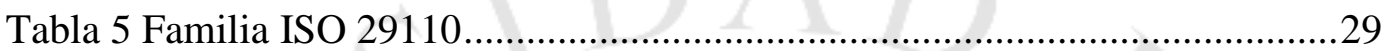

Tabla 6 Estado de los Perfiles del grupo de perfil genérico. ...............................30

Tabla 7 Rol Analista - ISO/IEC 29110-5-1-2 .....................................................

Tabla 8 Rol Cliente - ISO/IEC 29110-5-1-2 ...................................................... 31

Tabla 9 Rol Diseñador - ISO/IEC 29110-5-1-2 .............................................. 31

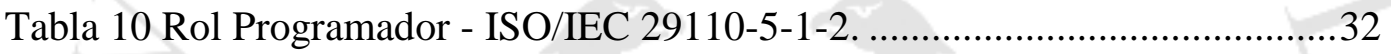

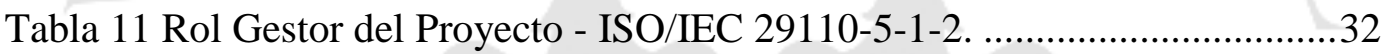

Tabla 12 Rol Líder Técnico - ISO/IEC 29110-5-1-2 ........................................32

Tabla 13 Rol Equipo de Trabajo - ISO/IEC 29110-5-1-2 . ................................32

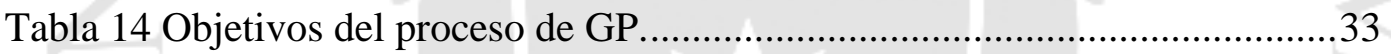

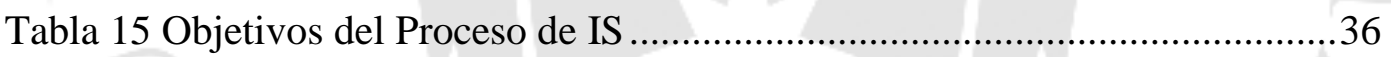

Tabla 16 Mapeo de la herramienta de evaluación ISO 29110 Perfil Básico .........41

Tabla 17 Plan de Trabajo - Objetivo I .........................................................49

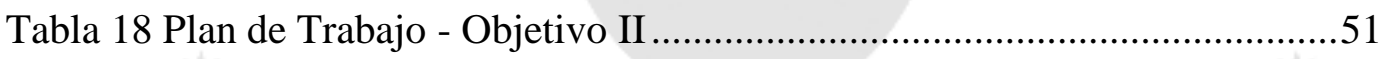

Tabla 19 Mapeo del contenido de los productos de trabajo de la empresa ...........66

Tabla 20 Evaluación de la Actividad Planificación del Proyecto de la ....................

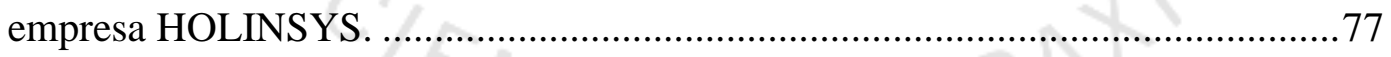

Tabla 21 Evaluación de la Actividad Ejecución del Plan del Proyecto de

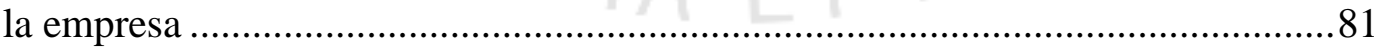

Tabla 22 Evaluación de la Actividad Evaluación y Control del Proyecto ................

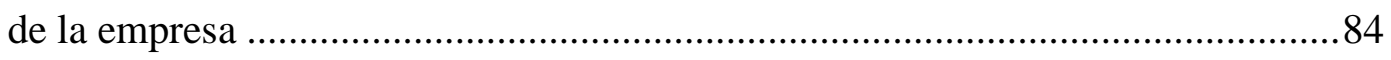

Tabla 23 Evaluación de la Actividad Cierre el proyecto de la empresa ...................

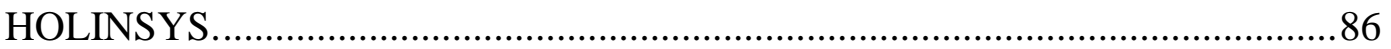

Tabla 24 Evaluación de la Actividad Iniciación de la Implementación de 
Software de la empresa.

Tabla 25 Evaluación de la Actividad Análisis de Requerimientos y Diseño del Software de la empresa.

Tabla 26 Evaluación de la Actividad: Construcción del Software de la empresa. 106

Tabla 27 Evaluación de la Actividad Pruebas e Integración del Software de la empresa. 113

Tabla 28 Evaluación de la Actividad Entrega del Producto. .116

Tabla 29 Dashboard de la Evaluación de Actividades del Desarrollo según la ISO 29110-5-1-2 118

Tabla 30 Brechas y Propuestas de Mejora .123

Tabla 31 Manuales de funciones Propuestos .124

Tabla 32 Productos de trabajo propuestos a la empresa..... 125

Tabla 33 Tipos de usuario, Roles y Permisos.... 127

Tabla 34 Componentes de Software requeridos .142

Tabla 35 Diseño del sistema desarrollado 144

Tabla 36 Convenciones de denominación de los datos 146

Tabla 37 Campo de datos de la herramienta desarrollada

Tabla 38 Especificación de la estructura del programa .....................................150

Tabla 39 Listado de Documentos referentes al software desarrollado

Tabla 40 Observaciones y Recomendaciones respecto a la evaluación de la organización

Tabla 41 Observaciones y Recomendaciones respecto a la Propuesta de Mejora de los Productos de Trabajo 153

Tabla 42 Observaciones y Recomendaciones respecto a los manuales de funciones .153

Tabla 43 Observaciones y Recomendaciones respecto a la herramienta de software desarrollada 


\section{ÍNDICE DE FIGURAS}

Figura 1 Modelo CANVAS de la empresa HOLINSYS. .....................................5

Figura 2 Diagrama de Ishikawa del proceso de desarrollo de software

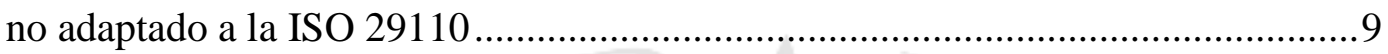

Figura 3 Tipo de empresas y crecimiento de la industria del desarrollo

de software en el Perú ............................................................................................ 14

Figura 4 Modelo Gráfico Iterativo del desarrollo de software ...........................20

Figura 5 Procesos del Perfil Básico ISO/IEC 29110-5-2-1 ..................................30

Figura 6 Diagrama del proceso de GP según la ISO/IEC 29110-5-1-2.................34

Figura 7 Diagrama del proceso de IS según la ISO/IEC 29110-5-1-2 .................37

Figura 8 Diagrama BPMN del Proceso Gestión del Proyecto de la empresa ........67

Figura 9 Diagrama BPMN de la Actividad: Planificación del Proyecto

de la empresa

Figura 10 Diagrama BPMN de la Actividad: Ejecución del Plan del

Proyecto de la empresa

Figura 11 Diagrama BPMN de la Actividad: Evaluación y Control del

Proyecto de la empresa

Figura 12 Diagrama BPMN de la Actividad: Cierre el proyecto de la empresa.

Figura 13 Dashboard de la Evaluación de Actividades de GP según la ISO 29110-5-1-2 .87

Figura 14 Diagrama BPMN del Proceso de Implementación de Software de la empresa. .88

Figura 15 Diagrama BPMN de la Actividad: Inicio de la Implementación de Software de la empresa

Figura 16 Diagrama BPMN de la Actividad: Análisis de Requerimientos

y Diseño del Software de la empresa.

Figura 17 Diagrama BPMN de la Actividad: Construcción del Software

de la empresa. 
Figura 18 Diagrama BPMN de la Actividad: Pruebas e Integración del

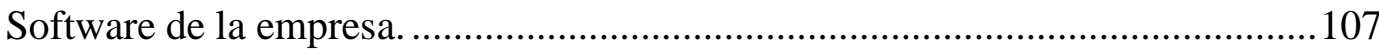

Figura 19 Diagrama BPMN de la Actividad: Entrega del Producto.....................114

Figura 20 Dashboard de la Evaluación de Actividades de IS según la

ISO 29110-5-1-2

Figura 21 Dashboard de la Evaluación de Actividades del Desarrollo

según la ISO 29110-5-1-2....

Figura 22 Diagrama de Casos de uso de la Herramienta de Desarrollo

Auditor 29110.

Figura 23 Diagrama de Secuencia de la Herramienta de Software:

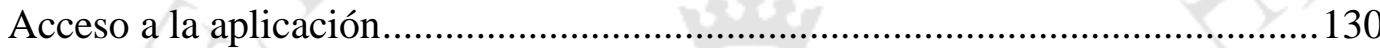

Figura 24 Interfaz Acceso a la aplicación.........................................................131

Figura 25 Diagrama de secuencia de la Herramienta de Software:

Registrar Usuario.

Figura 26 Interfaz Registrar Usuario

Figura 27 Interfaz Pantalla Principal.

Figura 28 Diagrama de secuencia de la Herramienta de Software:

Registrar Empresa.

Figura 29 Interfaz Mostrar/Registrar Empresa .

Figura 30 Diagrama de secuencia de la Herramienta de Software:

Crear Proyecto .137

Figura 31 Interfaz Mostrar/Registrar Proyecto .138

Figura 32 Diagrama de secuencia de la Herramienta de Software:

Definir Documento .139

Figura 33 Interfaz Definir Documentos

Figura 34 Diagrama de secuencia de la Herramienta de Software:

Evaluar Proyectos 141

Figura 35 Relación entre los componentes de software .142

Figura 36 Interfaces de hardware, software y humanas. .143

Figura 37 Estructura de datos de la herramienta desarrollada .147 


\section{ÍNDICE DE ANEXOS}

ANEXo 1: Cuestionario de Preguntas referente al modelo ................. DE NEGOCIOS CANVAS...........................................................................172

ANEXo 2: Productos de Trabajo Modelo del Ciclo de Vida .................

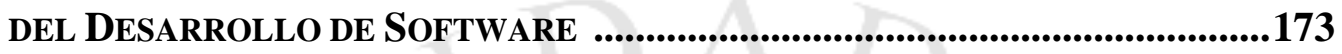

2.1 Plan del Proyecto...................................................................................... 173

2.2 Acta de Reunión ..................................................................................... 193

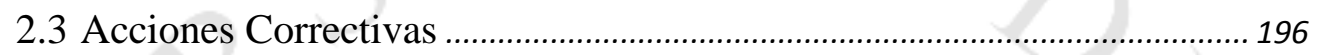

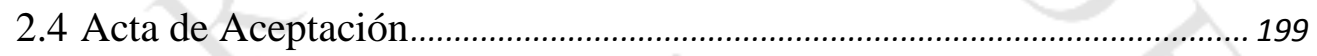

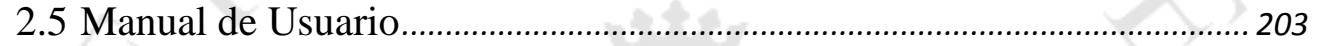

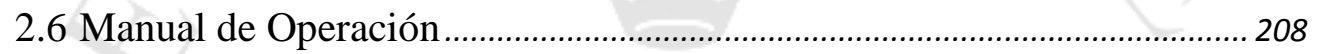

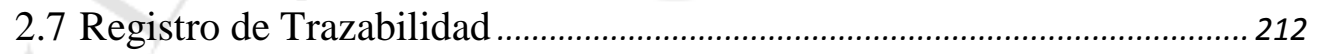

2.8 Resultados de Verificación........................................................................ 213

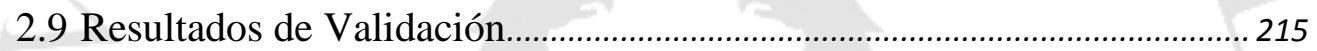

ANEXO 3: MANUAL DE FUnCIONES DEL EQUIPO DE TRABAJO (MOFs) ....217

3.1 Manual de Funciones para Analista de Calidad ............................................ 217

3.2 Manual de Funciones para Analista Programador ........................................ 219

3.3 Manual de Funciones para Gestor del proyecto ........................................... 221

3.4 Manual de Funciones para el Líder Técnico ................................................ 224

ANEXO 4: EVIDENCIA - DOCUMENTOS DE LA EMPRESA HOLINSYS .........226

4.1 Plan del Proyecto - Proyecto GUARDIAN .................................................. 226

4.2 Acta de Aceptación - Proyecto GUARDIAN ………..................................... 231

4.3 Historia de Usuario - Proyecto RFID ............................................................. 232

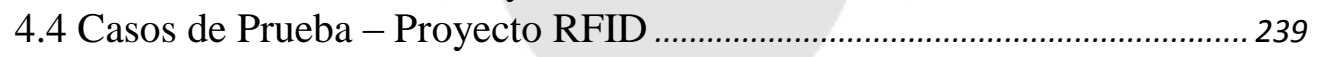

4.5 Solicitud de Cambio - Proyecto GALI ………............................................. 244

4.6 Reporte de Pruebas - Proyecto GUARDIAN …………………………...... 246

4.7 Enunciado de Trabajo - Proyecto RFID.................................................... 247

4.8 Registro de Trazabilidad - Proyecto GUARDIAN .................................... 251

4.9 Reporte de Avance - Proyecto RFID ......................................................... 252

4.10 Manual de Usuario - Proyecto GUARDIAN …......................................... 255

4.11 Manual de Operaciones - Proyecto GUARDIAN ..................................... 258

4.12 Manual de Mantenimiento - Proyecto GUARDIAN ….............................. 262

4.13 Diseño del Software - Proyecto RFID ....................................................... 265

ANEXO 5: ACTAS DE REUNIÓN ............................................................269

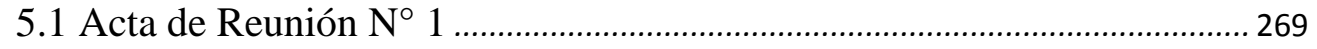

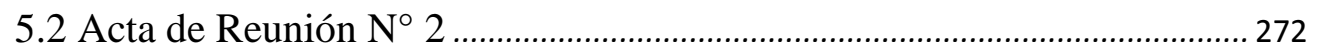

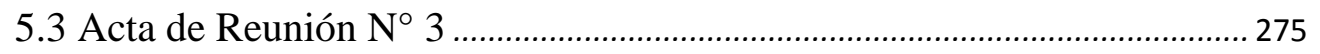

5.4 Acta de Reunión $N^{\circ} 4$........................................................................... 277

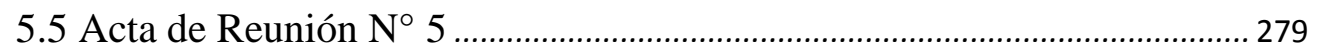


ANEXO 6: ANÁlISIS FODA DEL RESULTADO dE LA EVALUACIÓN......................

DE LA EMPRESA HOLINSYS ..................................................................283

ANEXO 7: DOCUMENTOS PARA LA ELABORACIÓN DE LA......................................

HERRAMIENTA DE SOFTWARE ...................................................................285

7.1 Casos y Procedimientos de Prueba.................................................................... 285

7.2 Manual de Usuario ............................................................................................ 301

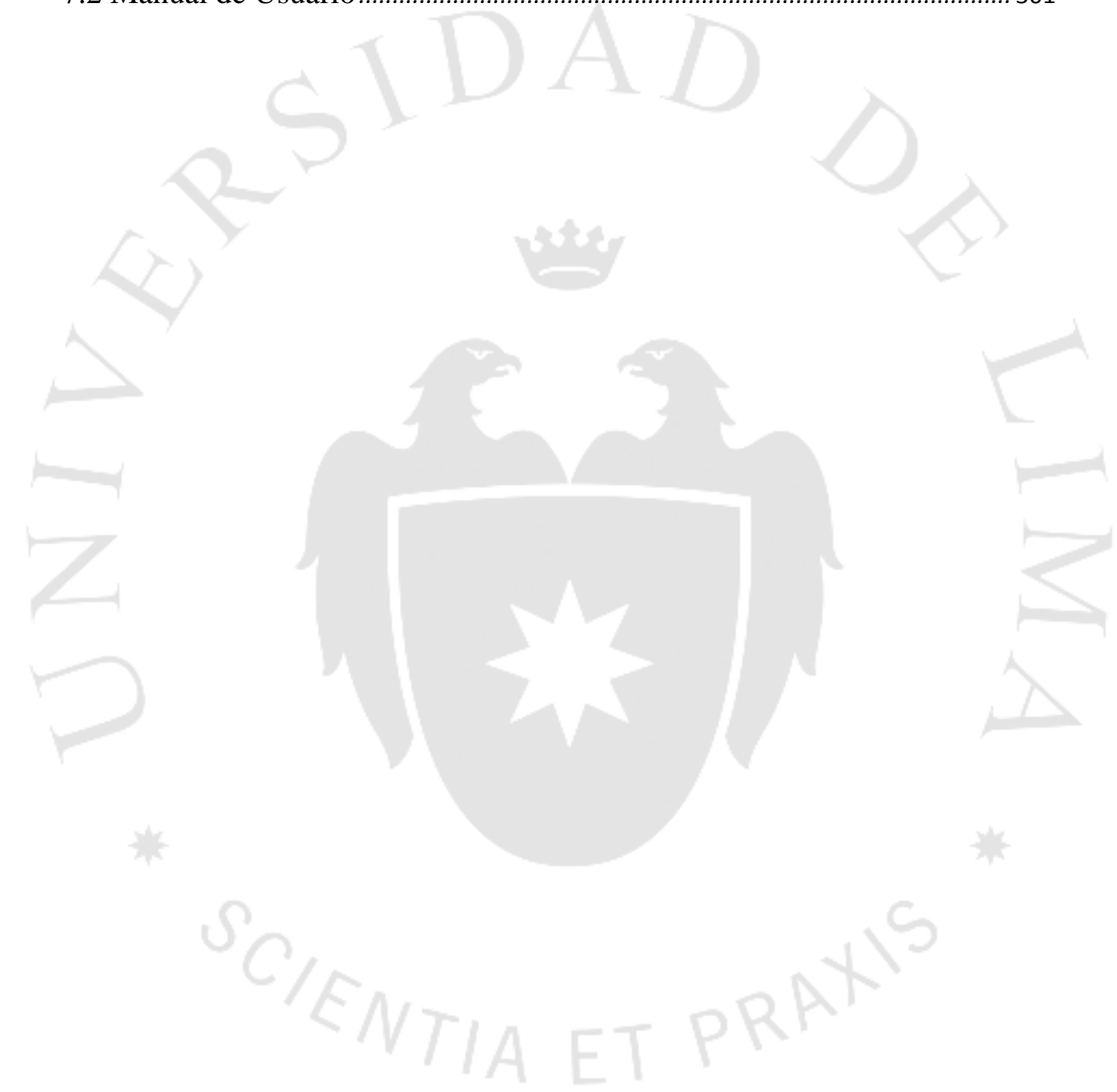




\section{INTRODUCCIÓN}

Las MyPEs, consideradas como micro y pequeñas empresas, han adquirido una mayor participación en el sector industrial del desarrollo de software. Debido a la abundante competencia de este sector y a un modelo de negocio en el que grandes empresas delegan sus proyectos a pequeñas empresas, hay un creciente interés por parte de estas empresas en certificarse y diferenciarse de la competencia.

El objetivo principal del presente trabajo de investigación es el desarrollo de un modelo de mejora para el ciclo de vida del desarrollo de software de la empresa de estudio HOLINSYS, la cual pretende certificarse en la norma internacional ISO/IEC 29110. Siendo esta ISO, la primera orientada a mejorar la calidad de los proyectos de desarrollo de software de las pequeñas y medianas empresas, presentando los perfiles del ciclo de vida del desarrollo de software.

Para el desarrollo del modelo de mejora, se revisaron los proyectos de desarrollo de software GALI, RFID y GUARDIAN para evaluar el estado actual del ciclo de vida del desarrollo de software de la empresa de estudio utilizando la herramienta de evaluación Activity Assessment, que sirve de apoyo para la evaluación de los procesos: Gestión del Proyecto e Implementación del software según lo establecido en la ISO 29110 e identificar sus brechas y oportunidades.

Continuando con el desarrollo del modelo de mejora, se elabora la propuesta para solucionar las brechas identificadas en los procesos y productos de trabajo y cumplir con lo descrito en la ISO 29110. Teniendo como resultado recomendaciones para las actividades y procesos desarrollados como también la documentación de las funciones de cada rol y plantillas para los productos de trabajo desarrolladas en el ciclo de vida del desarrollo de software. 
Como segundo objetivo del trabajo de investigación, se desarrolló la herramienta web Auditor 29110 Plus para apoyar en el control del cumplimiento de los proyectos de desarrollo de software de la empresa de estudio según la norma ISO 29110.

Para el desarrollo de la herramienta web se utilizó el diagrama de flujo de actividades orientado al contenido de la metodología RUP. Esta herramienta válida el contenido de los productos de trabajo de un proyecto para asegurar que cada producto cumpla con las secciones requeridas por la ISO 29110. 


\section{DESCRIPTORES TEMÁTICOS}

ISO/IEC 29110, calidad de procesos, desarrollo de software, gestión del proyecto, implementación de software, metodologías de desarrollo de software, modelo de mejora, MyPEs.

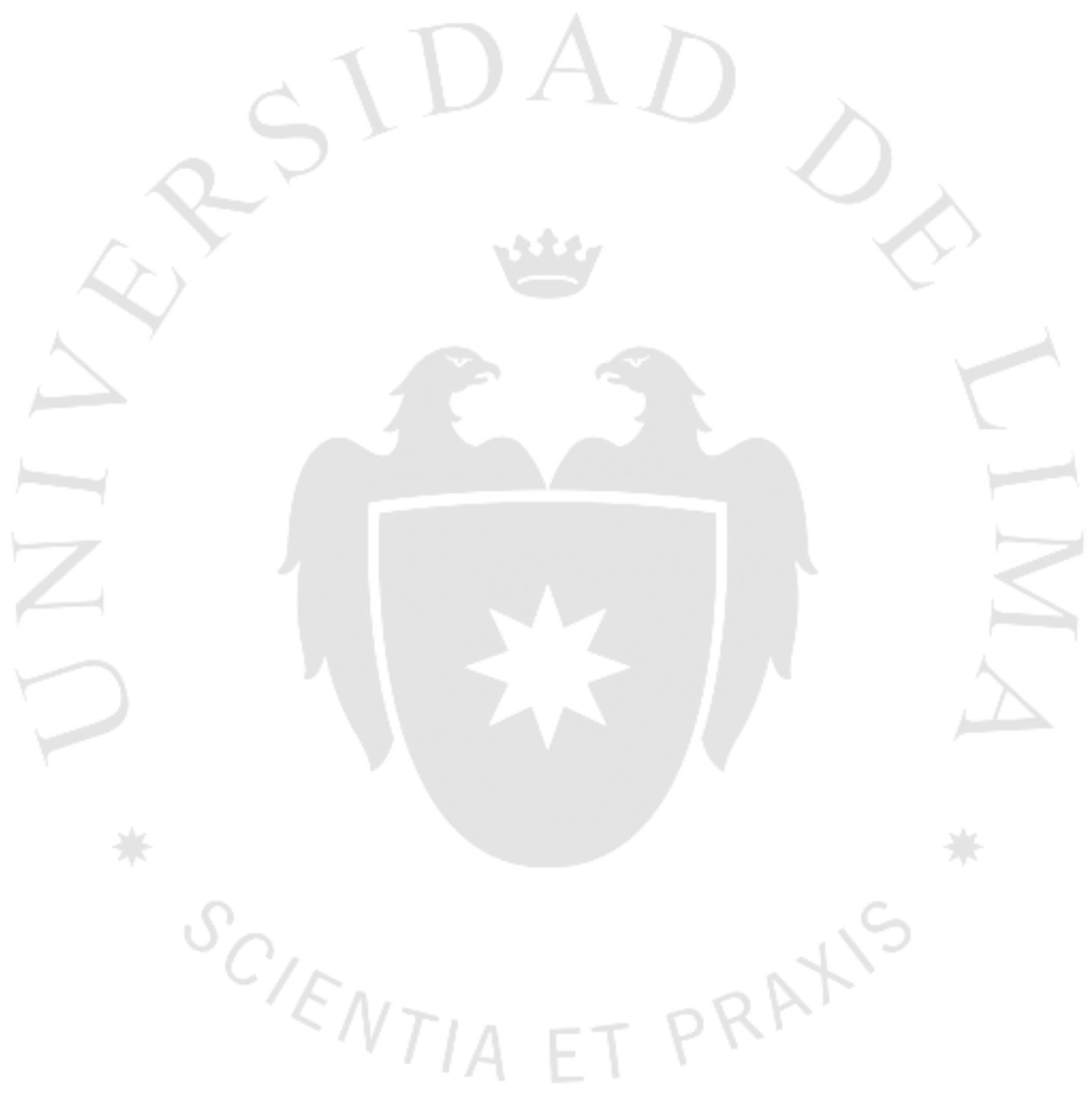




\section{CAPÍTULO I: PLANTEAMIENTO DEL PROBLEMA}

\subsection{Formulación del Problema}

Las MyPEs (micro y pequeñas empresas) han adquirido un mayor grado de participación en la economía mundial en diferentes sectores industriales, dentro de los cuales se encuentra la industria del desarrollo de software.

"El sector del software peruano es joven, las 300 empresas que lo componen tienen un promedio de 16 años. El $63 \%$ son microempresas y $27 \%$ son pequeñas empresas, realidad muy similar a la de otros países de Latinoamérica” (PROMPERU, 2011, pág. 3).

Para el presente trabajo de investigación, el caso de estudio es la MyPE HOLISTIC INNOVATION SYSTEM, denominado comercialmente HOLINSYS, la cual se dedica principalmente a brindar soluciones de desarrollo de software.

En la Figura 1, se presenta el estado actual del negocio de la empresa representado en el siguiente Modelo Canvas: 


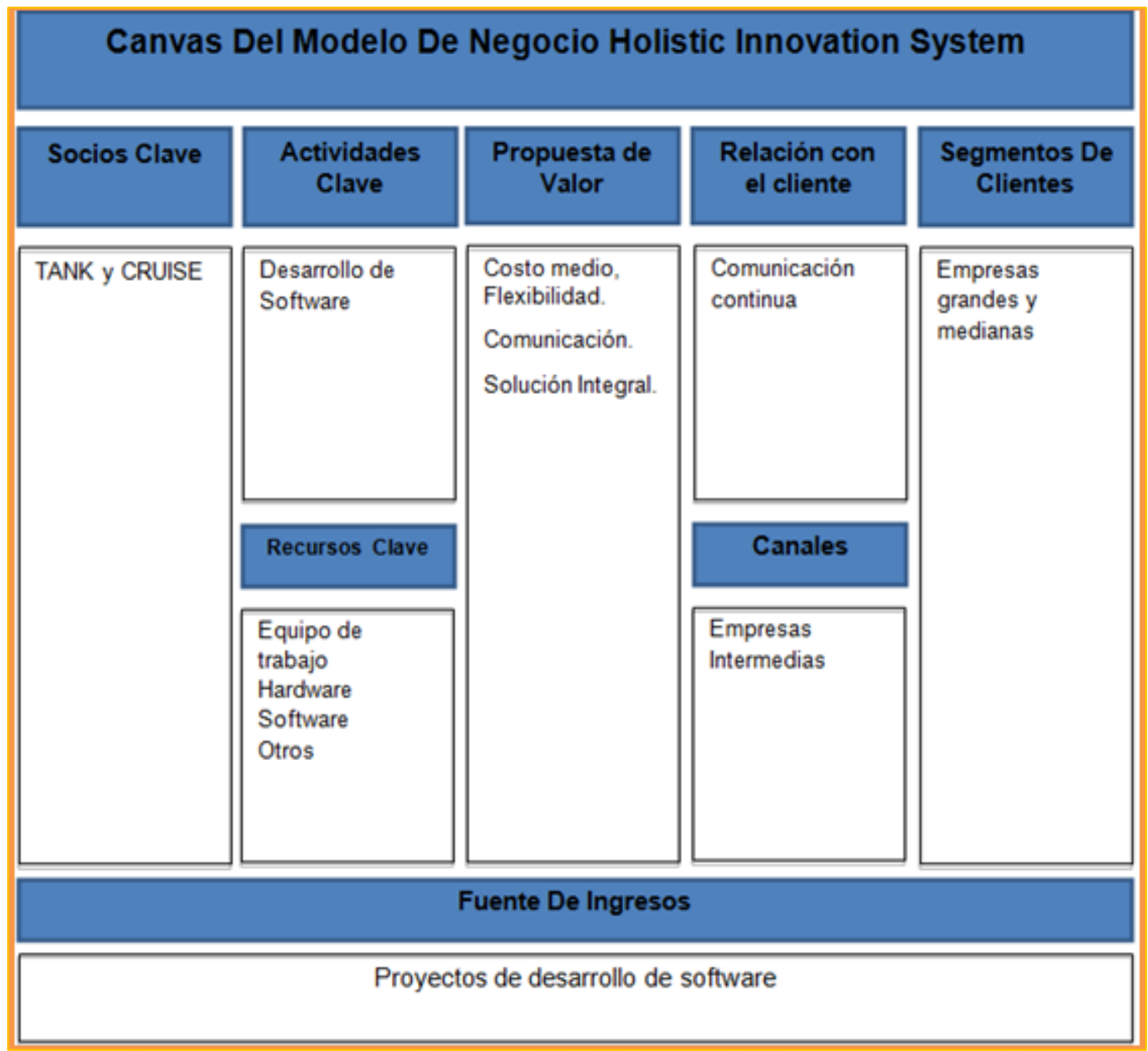

Figura 1 Modelo CANVAS de la empresa HOLINSYS.

Fuente: Elaboración Propia.

A continuación detallamos la información del modelo, como resultado de la aplicación del cuestionario detallado en el Anexo 1.

\section{Socios Clave:}

Sus principales socios son las empresas:

- TANK

Consultora dedicada a la implementación de Oracle. Es un intermediario completo que trabaja muchos aspectos directamente con el cliente y transfiere el requerimiento a la empresa HOLINSYS para que esta realice el desarrollo. 


\section{- CRUISE}

Empresa dedicada a la venta y promoción de servicios. Conformada por dos consultores que se encargan de comunicar a HOLINSYS con el cliente (los cuales provienen de Estados Unidos). La empresa principalmente realiza proyectos de Oracle, pero en la actualidad, se encuentra viendo oportunidades de desarrollo en aplicaciones para móviles.

\section{Actividades Clave:}

Desarrollo de Software: Construcción y/o modificación de soluciones en base a las necesidades del cliente. La empresa tiene por política aceptar proyectos con una duración menor a 6 meses.

\section{Propuesta de valor:}

La empresa brinda al cliente los siguientes beneficios:

- Costo medio respecto a la oferta en el mercado.

- Flexibilidad durante el proyecto: Experiencia gestionando el cambio en el alcance del proyecto.

- Comunicación con el cliente: Alto acercamiento al cliente y sus requerimientos (adecuadamente comprendidos), asistencia personalizada brindada por la empresa.

- Solución integral: Soluciones que abarcan toda la arquitectura del software.

A continuación, se muestran las áreas de la organización, cada una ofrece productos diferentes:

- Branding Web: Área dedicada a la elaboración de páginas web que contribuyan al valor de la marca de la empresa cliente.

- Desarrollos Oracle: Área dedicada al desarrollo de soluciones técnicas con herramientas Oracle.

- Cloud Development (.NET): Área dedicada a la elaboración de portales Web.

- Móviles: Android y iOS: Área dedicada al desarrollo de soluciones móviles (apps) para negocios, ya sea conectando a las empresas con sus clientes frecuentes como también a proveedores y/o empleados. 


\section{Relación con el cliente:}

Comunicación continua con el cliente, la empresa considera que mantiene una buena comprensión de los requerimientos del software a desarrollar.

La asistencia y el trato son personalizados.

\section{Segmentos de Clientes:}

La empresa tiene por clientes a empresas grandes y medianas (Siendo las grandes empresas, su principal segmento de clientes):

- Desarrollo Oracle: Atiende principalmente a empresas grandes y medianas.

- Cloud Development (Caso de estudio del trabajo de investigación): Atiende a empresas grandes y medianas.

\section{Recursos Clave:}

- Equipo de Trabajo: La empresa considera que es su recurso más importante, está conformado por la Gerencia, Líderes técnicos, Consultores y Desarrolladores.

- Hardware:

- Equipos de escritorio actualizados.

- Servidor de la empresa: Web NET: Windows Server 2008.

- Servidores en la nube: GoDoday, SoftLayer.

- Software:

- Visual Studio Team Foundation Server ( Programación .NET)

- Google Drive (Gestión de documentos a nivel de tareas)

- Mercurial (Gestión de código)

- Jira (Gestión de los proyectos, requerimientos(issues), tareas, cambios)

- WareFrame Sketcher Studio (Mockup)

- Start UML.

- Filezilla FTP.

- Microsoft: Excel, Word, PowerPoint y Project. 
- Otros:

- Marco de Trabajo SCRUM: Es utilizado parcialmente por la empresa para hacer seguimiento al proceso de desarrollo de software. Para ello se realizan reuniones diarias (Daily Meetings) con el equipo de trabajo y se generan pilas de Productos (Product Backlog). Ambos productos son utilizados para el seguimiento y control del proyecto.

\section{Canales:}

La comunicación inicial con la mayoría de los clientes de la organización se da a través de las siguientes empresas que sirven de intermediarios: TANK y CRUISE (Socios clave de HOLINSYS).

\section{Fuente de ingresos:}

Los proyectos de desarrollo de software son la fuente de ingresos de la empresa. El cliente realiza pagos a la empresa en función a los hitos acordados.

- La empresa trabaja por hitos, al terminarlos se genera una factura.

- Para proyectos de corta duración, la facturación se da al final.

- Cuando el cliente es nuevo y el proyecto es grande, se realiza un pago inicial.

La empresa de estudio, previamente expuesta, desea diferenciarse de la competencia y ofrecer un producto con un valor significativo en el mercado nacional e internacional para aumentar sus ingresos.

En este contexto, surge el interés por certificarse en la ISO/IEC 29110, que asegura la calidad en el ciclo de vida de desarrollo del software entregado al cliente, orientado a pequeñas organizaciones.

Para obtener la certificación, la empresa se encuentra en la necesidad de adaptar y alinear sus procesos de desarrollo de software al modelo descrito en la norma ISO/IEC 29110. 
Finalmente, como problema para el presente trabajo de investigación determinamos los factores en la MyPE Holinsys que dificultan la adaptación de sus procesos a lo establecido en la ISO/IEC 29110.

En la Figura 2, se identifican las causas que existen en la empresa HOLINSYS, como también en las pequeñas empresas de la industria del desarrollo de software que dificultan el poder adaptarse con lo establecido en la norma internacional ISO/IEC 29110, considerando como problemática al presente trabajo de investigación.

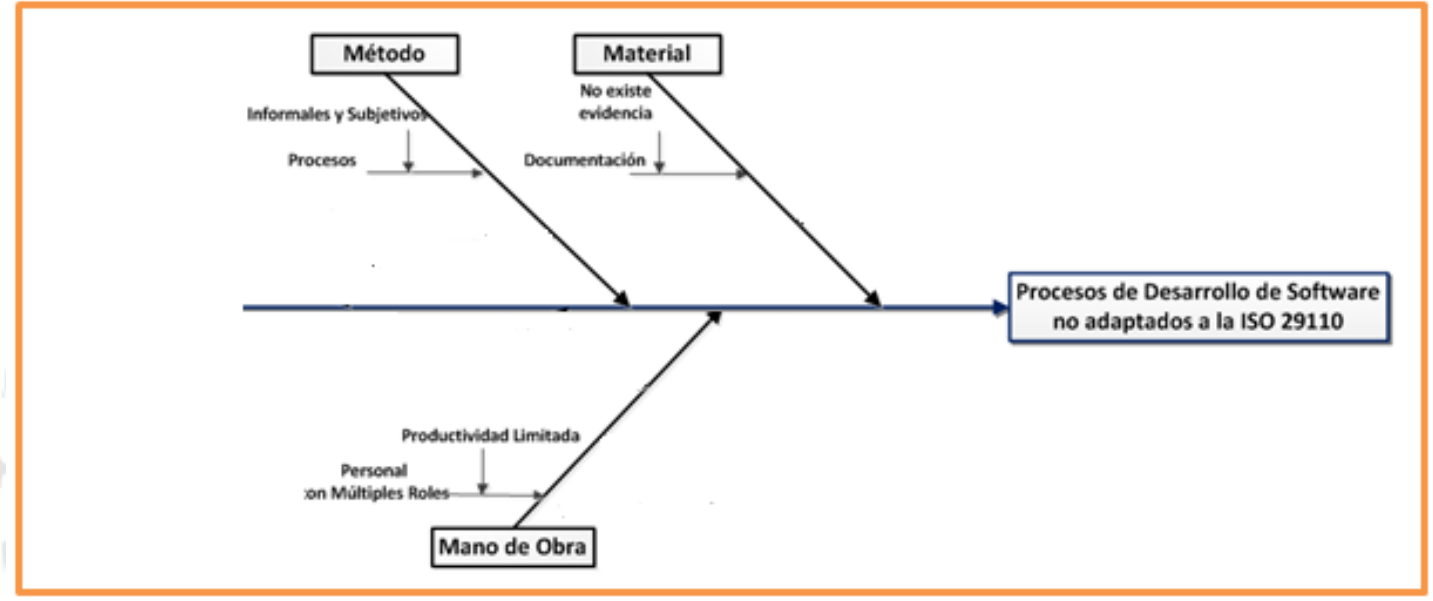

Figura 2 Diagrama de Ishikawa del proceso de desarrollo de software no adaptado a la ISO 29110. Fuente: Elaboración Propia.

A continuación detallamos las causas identificadas en el diagrama de Ishikawa:

- En la sección Método, se detecta que las pequeñas empresas tienen serios problemas de madurez en sus procesos de desarrollo, en muchos casos son informales y subjetivos (Alarcón, González \& Rodríguez, 2011). La empresa HOLINSYS carece de un proceso formalmente definido, por lo que se tomó como iniciativa elaborar los flujogramas de procesos según su forma de trabajo.

- En la sección Material, la empresa HOLINSYS no considera inicialmente la importancia de generar todos los productos de trabajo del desarrollo de software, los cuales pueden carecer de evidencia.

Es importante tomar en cuenta que para desarrollar software de calidad, es indispensable tomar medidas para controlar y mejorar dicho proceso elaborando 
documentos formales para que el equipo de trabajo pueda implementarlos (Gallegos, A. \& Ortiz, P., 2011).

- En la sección Mano de Obra, las pequeñas empresas cuentan con personal que realizan multifunciones. La empresa tiene productividad limitada debido al número del personal.

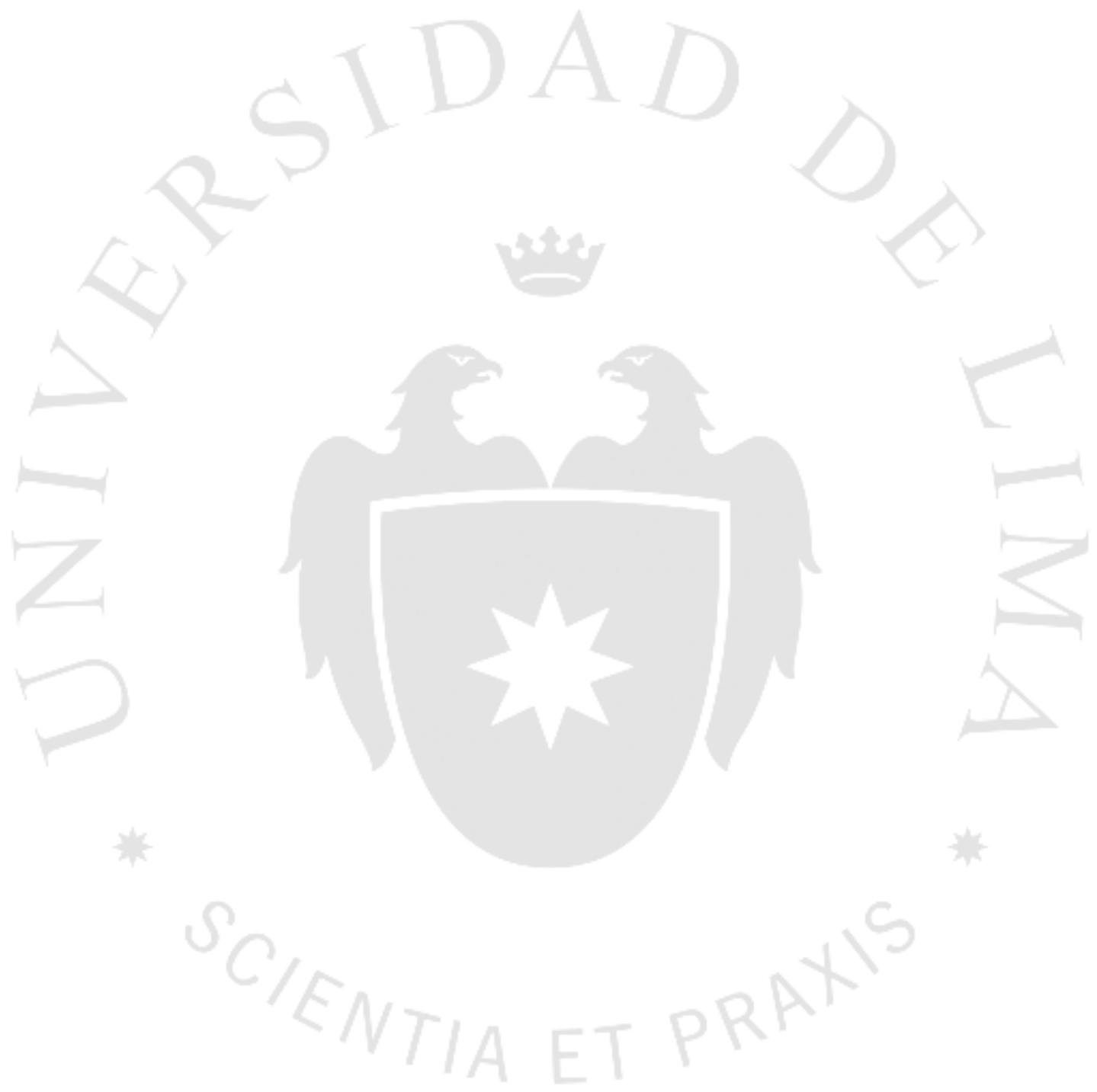




\section{I.2 Objetivo de la investigación}

\section{Objetivo General I}

Desarrollar un modelo de mejora para adaptar el ciclo de vida del desarrollo de software a lo establecido en la norma ISO 29110.

1. Evaluar el estado actual del ciclo de vida del desarrollo de software en la empresa de estudio con referencia a la ISO 29110.

2. Elaborar propuesta de mejora para el ciclo de vida del desarrollo de software de la empresa de estudio.

3. Diseñar el plan de implementación del modelo de mejora.

\section{Objetivo General II}

Desarrollar una herramienta web para asegurar el cumplimiento de los proyectos de desarrollo de software de una empresa según la norma ISO 29110.

1. Identificar los requerimientos de la herramienta para facilitar el cumplimiento de lo establecido en la ISO 29110.

2. Realizar el Análisis y Diseño de las funcionalidades de una herramienta de software.

3. Implementar los componentes de la herramienta de software.

4. Probar la herramienta de software desarrollada.

5. Realizar el despliegue de la herramienta de software.

\section{I.3 Justificación}

En el presente trabajo de investigación, se expone un ejemplo de cómo la empresa de estudio puede evaluar su ciclo de vida de desarrollo de software aplicado a sus proyectos para identificar sus brechas con respecto a lo establecido en la ISO 29110 haciendo énfasis en los requerimientos mandatorios para demostrar el cumplimiento de la norma. Como también, el de brindar un conjunto de herramientas, artefactos y recomendaciones que cubran las brechas identificadas. 


\section{I.4 Aportes}

El presente trabajo de investigación brinda un modelo de mejora con buenas prácticas y recomendaciones, que describen las actividades del ciclo de vida del desarrollo de software y la interrelación con los productos de trabajo generados durante estas actividades.

Además, se presenta una aplicación web que facilita el seguimiento a los proyectos de desarrollo de software midiendo el grado de cumplimiento según lo establecido en la ISO 29110 a través de la evaluación los documentos generados como productos de salida. Esta aplicación tiene como público objetivo empresas o áreas de trabajo dedicadas al desarrollo de software y/o interesados en la ISO 29110.

La propuesta de solución contiene un gran valor en cuanto a la garantía de ofrecer calidad en los proyecto de desarrollo, ya que sigue una serie de actividades que permiten la identificación de hallazgos y brechas para las oportunidades de solución.

La adaptación de los procesos de desarrollo es un proceso continuo de aprendizaje para la organización que requiere cambios en base a la administración, tiempo, recursos y participación del equipo de trabajo. 


\section{CAPÍTULO II: REVISIÓN DE LITERATURA}

\subsection{Antecedentes}

En el siglo XXI, han surgido un gran número de estándares y modelos internacionales relacionados con la mejora de procesos de software (como las normas internacionales ISO 15504, ISO 12207, y modelos de madurez como Moprosoft y CMMI) con prácticas y guías eficientes adaptadas a sus características, donde se reconocen su importancia en la industria de software a nivel mundial y países en desarrollo, como es el caso de Perú.

Sin embargo, gran parte de las pequeñas empresas tienen ciertas barreras en el proceso de adaptarse a una norma internacional, debido a la inversión en tiempo, dinero, recursos, y otros factores como la complejidad del proceso de implementación que las normas internacionales requieren.

(Pino, Garcia, Ruiz \& Piattini, 2006).

A pesar de ello, las empresas desarrolladoras de software continúan con la necesidad e interés de encontrar un modelo que pueda adaptarse a su forma de trabajo e inversión mencionados, de esta manera, puedan obtener una ventaja competitiva frente a la competencia y tener la evidencia y capacidad de ofrecer servicios de calidad.

Existen diferentes proyectos en nuestro entorno peruano que describen y recomiendan la importancia de implementar modelos de desarrollo de software dirigidas a pequeñas empresas y los resultados obtenidos, por ello, se toma como casos de análisis el "Proyecto Competisoft-LAMBDA" (Vergara, Dianne, 2008) para la mejora de procesos y el trabajo de investigación "Implementación del Estándar ISO/IEC 29110-4-1 (Ramos, C. \& Mendoza, L., 2014), ambas dirigidas a pequeñas empresas de desarrollo de software", creados por la Universidad Católica del Perú y Universidad Peruana de Ciencias Aplicadas del Perú. 


\subsection{Estudios relacionados con el tema de investigación}

\subsubsection{Relevancia de las MyPEs}

"El sector del software peruano es joven, las 300 empresas que lo componen tienen un promedio de 16 años. El $63 \%$ son microempresas y $27 \%$ son pequeñas empresas, realidad muy similar a la de otros países de Latinoamérica” (PROMPERU, 2011).

En la Figura 3, se evidencian los tipos de empresas y su representación en el mercado peruano. Adicionalmente, en el segundo cuadro de la Figura 3, se muestra la facturación anual de la industria de software, que no incluye al de las empresas multinacionales extranjeras instaladas en nuestro país.

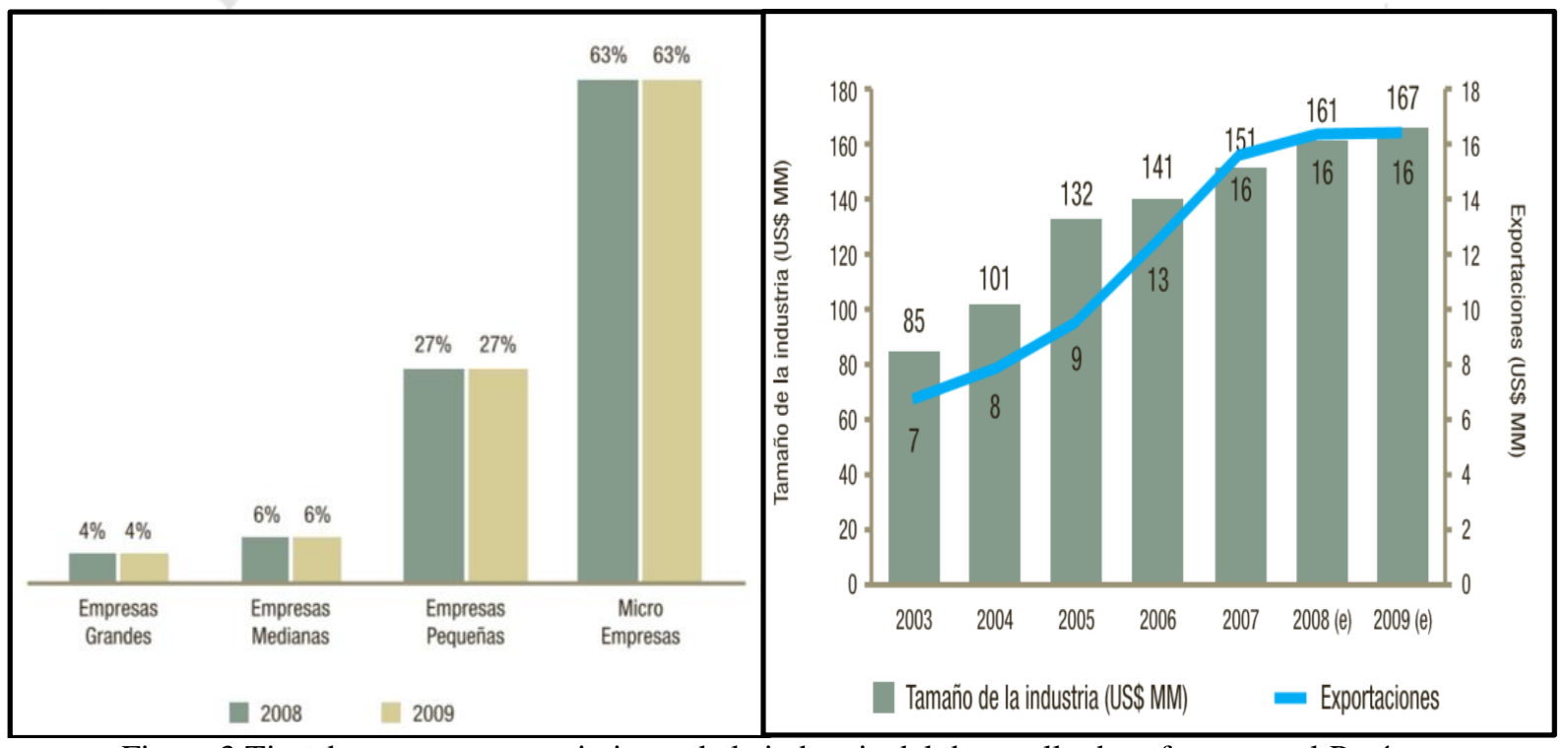

Figura 3 Tipo de empresas y crecimiento de la industria del desarrollo de software en el Perú. Fuente: (PROMPERU, 2011).

Las soluciones, dadas por la industria peruana del desarrollo de software se encuentran en 17 mercados de Latinoamérica, y también en Estados Unidos (clientes hispanos) y Europa, interpretando de esta manera que existe gran parte del crecimiento económico en este rubro.

(PROMPERU, 2011) 
Como resultado, se tiene que las empresas desarrolladoras de software tienen diferentes canales de acceso para brindar al cliente las soluciones a sus necesidades.

\subsubsection{Problemática de las MyPEs}

Las empresas que predominan en el mercado peruano de desarrollo de software son, especialmente, micro y pequeñas organizaciones, las cuales tienen un gran desafío por demostrar que su producto final cumpla con las necesidades y requerimientos del cliente, sin embargo existen ciertas brechas dentro del proceso de desarrollo.

En países como el nuestro, la industria de software es incipiente e inmadura, lo cual conlleva a la falta de competitividad que a su vez es muy difícil para su crecimiento, especialmente, las pequeñas empresas tienen serios problemas de madurez en sus procesos de desarrollo, en muchos casos son informales y subjetivos, lo cual demuestra una escasez en las mediciones de los procesos, importante para asegurar la calidad.

(Alarcón, González \& Rodríguez, 2011)

Para desarrollar software de calidad, es indispensable tomar medidas para controlar y mejorar aspectos como: análisis de requerimientos del software, documentación que se debe generar, procesos que intervienen en el desarrollo de un aplicativo, entre otros; dichas medidas deben estar establecidas en un documento formal para que los participantes del desarrollo de software las implementen.

(Gallegos, A. \& Ortiz, P., 2011, pág. 4)

Así mismo, define sobre el desarrollo de software como un proceso bastante complejo que requiere de una metodología eficiente y sistemática. En este proceso pueden presentarse problemas como: no cumplir con los requerimientos del cliente, mal manejo de los tiempos que conlleva un desarrollo, no contar con un lenguaje unificado que permita en un futuro el crecimiento del aplicativo, entre otros.

(Gallegos, A. \& Ortiz, P., 2011) 
Según Esponda (2011) \& Mon (2010) reafirman que la madurez del proceso en estas organizaciones todavía se encuentran en un estado crítico, por lo cual se hace indispensable de promover modelos adecuados a sus características e infraestructura.

Las pequeñas empresas desarrolladoras de software al intentar crecer al ritmo de la industria lo hicieron de forma desordenada, viviendo el día a día, resultando así cada proyecto todo un reto, estimando mal los tiempos, costos, horas hombre, logrando con ello clientes enojados e insatisfechos.

(Vergara, Dianne, pág. 1)

Otra debilidad que tienen son las características que tiene el personal de las micro y pequeñas empresas que lo diferencian de los trabajadores de medianas y grandes empresas, como limitaciones en cuanto a la calificación y experiencia del personal, el tamaño de los equipos de desarrollo de uno a cinco personas son insuficientes, por ello, el personal ejecuta múltiples roles que reduce la productividad. Las funciones por rol son limitadas, debido a que las MyPEs consideran a los cursos de capacitación como un costo.

(Montilva, Barrios \& Rivero, 2009)

\subsubsection{Importancia de las Normas de Calidad del Desarrollo de Software}

Las organizaciones de software han tomado como importancia y necesidad, establecer sus procesos a un nivel aceptable de calidad para sus clientes y usuarios. De esta manera, para cumplir el aseguramiento de calidad han aparecido modelos de proceso de software y normas de calidad para aquellas que desean certificarse (ISO/IEC 15504-2, ISO 90003, CMMI), sin embargo, su implementación requiere un arduo esfuerzo en inversión y adaptación de actividades para conducir a sus organizaciones a un proceso de certificación. Por ello, las empresas buscan modelos o normas de calidad adaptadas a su entorno.

(Mon, Estayno \& Arancio, 2008)

De esta manera, surge la norma ISO 29110 que señala la importancia de disponer con un estándar de calidad, y estar asociada a las características de una pequeña 
organización (PO). Pese a ello, las empresas requieren pautas y recomendaciones de COMO pueden implementar y cumplir los objetivos trazados en la norma.

Según la ISO, publicada en su página web, describe los beneficios al contar con los estándares internacionales en dos niveles: Negocios y sociedad (ISO Benefits of International Standars, 2015).

\section{Para los Negocios:}

- Ahorro de costos - ayudan a optimizar las operaciones y por lo tanto mejoran la línea de negocio.

- Mejor satisfacción del cliente- ayudan a mejorar la calidad, aumentar las ventas y aumentar la satisfacción del cliente.

- El acceso a nuevos mercados - ayudan a prevenir las barreras comerciales y la apertura de los mercados mundiales.

\section{Para la Sociedad:}

Cuando los productos y servicios cumplen con las Normas Internacionales pueden tener la confianza de ser seguros, fiables y brinden buena calidad para los clientes y usuarios.

\subsubsection{Proyectos de investigación Implementados en el Perú}

La evaluación de un proceso se define como el examen disciplinado de los procesos usados en una organización junto a un conjunto de criterios para determinar la capacidad de esos procesos para ser realizados dentro de los objetivos de calidad, coste y planificación. El

propósito es caracterizar la práctica actual, identificando debilidades y fortalezas y la habilidad del proceso para controlar o evitar las causas de baja calidad, desviaciones en coste o planificación.

(ISO/IEC TR 15504-1:1998).

A continuación, se explica los antecedentes de los modelos y la implementación de los proyectos desarrollados en Perú: 


\section{Mejora del Proceso Software de una pequeña empresa desarrolladora de software aplicando el modelo Competisoft}

El objetivo del proyecto mencionado se basa en ejecutar un ciclo de mejora de procesos en una pequeña empresa peruana desarrolladora de software implementando el modelo Competisoft. (Vergara, Dianne, 2008)

El proyecto fue desarrollado inicialmente a través de un análisis del estado actual elaborando los procesos en una etapa inicial. Posteriormente, se programaron reuniones las cuales pudieron definir los objetivos de negocio y problemas de la empresa que permitieron identificar que procesos mejorar y establecer soluciones para las brechas detectadas. (Vergara, Dianne, 2008)

\section{Implementación del estándar ISO/IEC 29110-4-1 para pequeñas organizaciones de desarrollo de software - Proyecto COLE}

El objetivo del proyecto mencionado se basa en implementar el estándar ISO 29110 Parte 4-1: Especificaciones del Perfil: Grupo del perfil genérico en una pequeña empresa peruana desarrolladora de software, traduciendo paquetes de despliegue (PD) al idioma hispanohablante, generando plantillas tomadas como línea base de los PD. (Ramos, C. \& Mendoza, L., 2014),

El proyecto de investigación fue desarrollado inicialmente verificando que cumpla las condiciones de una PO. Posteriormente, se elaboraron cuestionarios para conocer el estado actual de los procesos del ciclo de vida de desarrollo, y puedan ser alineados al estándar. Las plantillas fueron creadas para evidenciar los productos a través de documentos o registros electrónicos. Todo ello, para cumplir la conformidad del Perfil Básico. (Ramos, C. \& Mendoza, L., 2014),

Los resultados obtuvieron la conformidad del estándar, debido a que generaron evidencia nece

saria de los productos y el cumplimiento de las actividades y procesos de la empresa. 


\section{CAPÍTULO III: MARCO TEÓRICO}

\subsection{Las MyPEs en la industria del Desarrollo de Software}

Según la Legislación Peruana:

La Micro y Pequeña empresa es la unidad económica constituida por una persona natural o jurídica bajo cualquier forma de organización o gestión empresarial contemplada en la legislación vigente, que tiene como objeto desarrollar actividades de extracción, transformación, producción, comercialización de bienes o prestación de servicios.

(Congreso de la República, 2008, pág. 3).

En cuanto a sus características, se diferencian en base al número de trabajadores y las unidades impositivas tributarias. En la Tabla 1, se presenta la distribución de número de trabajadores y facturación anual por tipo de empresa:

\begin{tabular}{|l|l|l|}
\hline Tipo de Empresas & $\mathbf{N}^{\circ}$ de Trabajadores & Facturación Anual \\
\hline Microempresa & 1 a 10 & 150 UIT máximo \\
\hline Pequeña Empresa & 1 a 100 & 1700 UIT máximo \\
\hline
\end{tabular}

Tabla 1 Estructura de las MyPEs en el Perú.

Fuente: Adaptado del Artículo 5 del TUO de la Ley de Impulso de Desarrollo Productivo y al Crecimiento Empresarial (Congreso de la República, 2008, pág. 3).

“Una PO (pequeña organización) es una entidad (empresa, organización, departamento o proyecto) conformada por hasta 25 personas” (NTP-RT-ISO/IEC TR 29110-5-1-2, 2012, pág. X). Estas empresas se dedican al desarrollo y/o mantenimiento de software que es utilizado en grandes sistemas, por ende, el reconocimiento de estas empresas como proveedores de software de alta calidad es requerido (NTP-RT-ISO/IEC TR 29110-5-1-2, 2012).

Según lo expuesto, se considera que para el presente trabajo de investigación una MyPE está dentro de lo que la ISO 29110 define como una PO. 


\subsection{RUP y UML}

Para el desarrollo del segundo objetivo del trabajo de investigación: Desarrollar una herramienta web, se utilizó RUP. Los objetivos específicos tienen como guía el flujo de trabajo en base al contenido presente en RUP como también el uso de diagramas UML.

\subsubsection{RUP - Rational Unified Process:}

"RUP-Rational Unified Process es un proceso de ingeniería de software. Este proceso presenta un enfoque disciplinado para la asignación de tareas y responsabilidades dentro de una organización de desarrollo de software" (Rational, 2001, pág. 1).

Además, RUP es un proceso de ingeniería de software bien definido y estructurado. Este proceso define claramente quien es responsable de hacer una tarea determinada, como y cuando hacer la tarea (Per \& Philippe, 2003).

En la Figura 4, se detalla el proceso de desarrollo de software descrito en dos ejes o dimensiones:

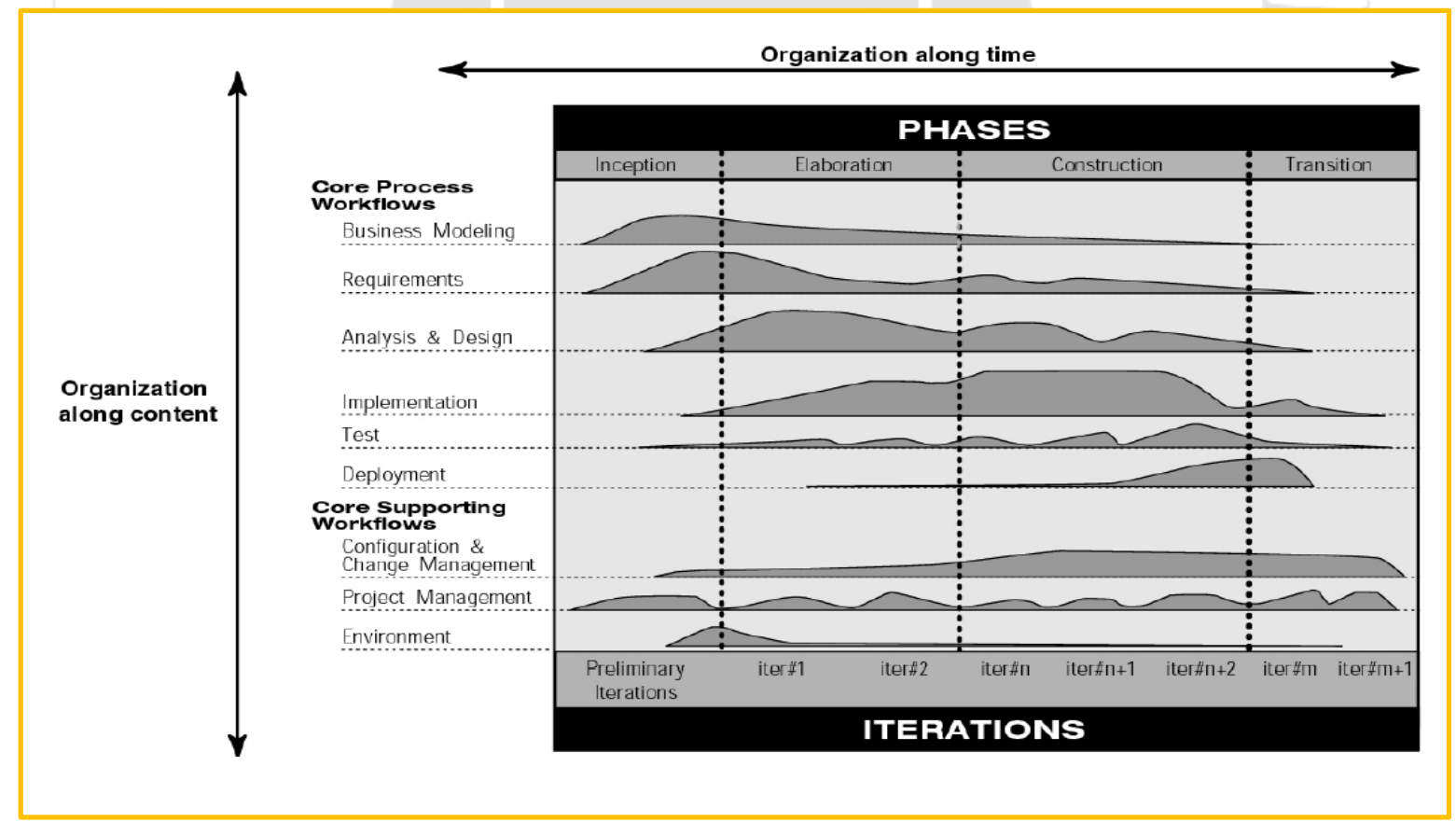

Figura 4 Modelo Gráfico Iterativo del desarrollo de software Fuente: (Rational Software, 2001, pág. 3) 


\section{Eje Horizontal - Flujos de Trabajo de ingeniería en base al contenido.}

Representa el tiempo y muestra el aspecto dinámico del proceso desde su adopción, expresado en términos de ciclos, fases, iteraciones e hitos. (Rational Software, 2001).

\section{Inicio}

En esta fase, se elaboran los casos de uso del negocio para el sistema y el alcance del proyecto. Para ello, se identifican todas las entidades externas con los que el sistema interactúa y se define la naturaleza de la interacción en un alto nivel.

(Rational Software, 2001).

\section{Elaboración}

El propósito de la fase de elaboración es analizar el dominio del problema: Establecer una base arquitectónica sólida, desarrollar el plan del proyecto y mitigar los elementos de mayor riesgo del proyecto. (Rational Software, 2001).

\section{Construcción}

Durante la fase de construcción, se desarrollan todos los componentes involucrados y características de aplicación. Para luego integrarse en el producto, y probar todas las funciones a fondo (Rational Software, 2001).

\section{Transición}

El propósito de esta fase es la transición del producto de software a la comunidad de usuarios. Una vez que el producto ha sido entregado a los usuarios finales, pueden surgir problemas que obliguen a desarrollar nuevas versiones, realizar correcciones, o terminar las características que quedaron pendientes (Rational Software, 2001).

\section{Eje Vertical - Flujos de Trabajo de ingeniería en base al contenido.}

Representa el aspecto estático del proceso: Se describe como elementos del proceso, actividades, disciplinas, artefactos y trabajadores que son agrupados en flujos de trabajo (Rational Software, 2001). 


\section{Modelado del Negocio}

"En esta sección, se modela los procesos del negocio en documentos, mediante los casos de uso del negocio. Esto genera un entendimiento común de los procesos de la empresa" (Rational Software, 2001, pág. 10).

\section{Requerimientos}

"El objetivo de este flujo de trabajo es describir lo que el sistema debe hacer, y permite a los desarrolladores y al cliente negociar esta descripción” (Rational Software, 2001, pág. 11).

\section{Análisis y diseño}

"El objetivo de este flujo de trabajo es describir como el sistema será realizado en la fase de implementación” (Rational Software, 2001, pág. 11).

\section{Implementación}

El propósito de este flujo de trabajo es (Rational Software, 2001, pág. 12):

- Definir la organización del código, en términos de subsistemas de ejecución organizados en capas.

- Implementar las clases y objetos en términos de los componentes (archivos de código fuente, binarios, ejecutables y otros) para probar los componentes desarrollados como unidades.

- Integrar los resultados producidos por los ejecutores individuales (o equipos), en un sistema ejecutable.

\section{Pruebas}

El objetivo de las pruebas es verificar la interacción entre los objetos, como también que todos los requisitos han sido correctamente implementados. Y finalmente, garantizar que los defectos se corrigieron antes del despliegue de software (Rational Software, 2001). 


\section{Despliegue}

"El propósito de este flujo de trabajo es producir con éxito versiones de productos, y entregar el software a sus usuarios finales. Abarca una amplia gama de actividades que incluyen" (Rational Software, 2001, pág. 13):

- Producir el lanzamiento del software.

- Empaquetamiento del software.

- Distribuir el software.

- Instalación del software.

- Proporcionar ayuda y asistencia a los usuarios.

- En muchos casos, esto también incluye actividades tales como:

- Planificación y realización de pruebas beta.

- Migración de software o datos existentes.

- Aceptación formal.

\subsubsection{UML - Lenguaje unificado para la modelación:}

UML es un lenguaje gráfico o notación de modelado visual que utiliza diagramas para mostrar distintos aspectos de un sistema y procesos (Debrauwer, 2013; Fontela, 2011).

A continuación se muestra la descripción de los diagramas utilizados para el objetivo número dos del presente trabajo de investigación:

- Para el modelado de requisitos se utilizó diagramas de casos de uso:

Los diagramas de casos de uso muestran la relación entre casos de uso o casos de uso y actores (Fontela, 2011).

Mientras que: "Los casos de uso explicitan los requisitos funcionales del sistema relativos a uno de los objetivos del usuario" (Debrauwer, 2013). Además, "un caso de uso especifica una interacción entre un actor y un sistema, de modo tal que pueda ser entendida por una persona sin conocimientos técnicos” (Fontela, 2011, pág. 28).

- Para el modelado de la dinámica del sistema se utilizó diagramas de secuencia: 
"El diagrama de secuencia describe la dinámica del sistema, la dinámica completa se representará mediante un conjunto de diagramas de secuencia, cada uno de ellos vinculado generalmente a una subsunción del sistema” (Debrauwer, 2013).

"El diagrama de secuencia describe las interacciones entre un grupo de objetos mostrando de forma secuencial los envíos de mensajes entre objetos" (Debrauwer, 2013).

\subsection{SCRUM}

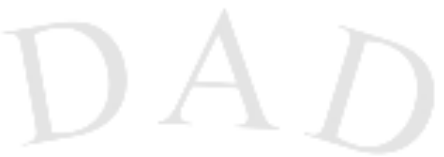

Scrum es un marco de trabajo dentro del cual se pueden emplear varias técnicas y procesos. Scrum muestra la eficacia relativa de las prácticas de gestión de producto y las prácticas de desarrollo, de modo que se puedan mejorar (Schwaber \& Sutherland, Julio).

El marco de trabajo SCRUM está compuesto por: Roles, Eventos y Artefactos.

\subsubsection{Roles}

En la Tabla 2, se describen los roles del marco de trabajo SCRUM.

\begin{tabular}{|l|l|}
\hline Equipo & Descripción \\
\hline $\begin{array}{l}\text { Equipo } \\
\text { Desarrollo } \\
\text { (Development } \\
\text { Team })\end{array}$ & $\begin{array}{l}\text { El Equipo de Scrum posee profesionales que desempeñan el trabajo de construir y entregar } \\
\text { un producto potencialmente Terminado. Este producto se puede poner en producción, al } \\
\text { final de cada Sprint. Sólo los miembros del Equipo de Desarrollo participan en la creación } \\
\text { del Producto (Schwaber \& Sutherland, Julio). } \\
\text { El Equipo de Scrum incluye al Dueño de Producto, Scrum Master y los miembros del } \\
\text { equipo. Todo el equipo de Scrum se centra en torno a un problema, que vendría a ser a un } \\
\text { requerimiento de una lista ordenada conocida como Listado del Producto (Product Backlog) } \\
\text { (Viscardi, 2013). } \\
\text { El equipo de Scrum consta de cinco a nueve miembros dedicados a la vida del proyecto } \\
\text { siendo multifuncionales, capaces y organizados. El equipo de Scrum planea, estima y se } \\
\text { compromete a su trabajo, más que un gestor en la realización de sus funciones. El objetivo } \\
\text { final del equipo es entregar un producto potencial que se encuentren acordados y definidos } \\
\text { en cada Sprint (Viscardi, 2013). }\end{array}$ \\
\hline $\begin{array}{l}\text { Dueño } \\
\text { Producto } \\
\text { (Product } \\
\text { Owner) }\end{array}$ & $\begin{array}{l}\text { El Dueño del Producto es el encargado de maximizar el valor del producto y del trabajo del } \\
\text { Equipo de Desarrollo. El Dueño de Producto el único responsable de gestionar el Listado del } \\
\text { Producto (Producto BackLog) (Schwaber \& Sutherland, Julio). } \\
\text { El Dueño del Producto es el responsable por el éxito del producto, conocer su mercado y } \\
\text { necesidades de los usuarios lo suficientemente bien para guiar al equipo en la liberación de } \\
\text { Sprints (Viscardi, 2013). }\end{array}$ \\
\hline $\begin{array}{l}\text { Scrum } \\
\text { Master }\end{array}$ & $\begin{array}{l}\text { El Scrum Master es el responsable de asegurar que Scrum es entendido y adoptado. Los } \\
\text { Scrum Masters hacen esto asegurándose de que el Equipo Scrum trabaja ajustándose a la }\end{array}$ \\
\hline
\end{tabular}




\begin{tabular}{|l|l|}
\hline Equipo & Descripción \\
\hline & $\begin{array}{l}\text { teoría, prácticas y reglas de Scrum. (Schwaber \& Sutherland, Julio) } \\
\text { El Scrum Master salvaguarda el proceso. Entiende las razones detrás y de un proceso } \\
\text { mejor manera posible. Protege al equipo de interrupciones con el fin de mantenerlos } \\
\text { enfocados en sus compromisos de velocidad, así como ayudar al dueño del producto } \\
\text { (Product } \text { Owner) en obtener el entender el listado del producto (Product Backlog). Facilita } \\
\text { todas las reuniones de Scrum, asegurándose de que todos en el equipo entiendan las metas y } \\
\text { que compartan un compromiso en conjunto como un verdadero equipo (Viscardi, 2013). }\end{array}$ \\
\hline
\end{tabular}

Tabla 2 Descripción del Equipo SCRUM.

Fuente: Elaboración Propia

\subsubsection{Eventos de Scrum}

En Scrum existen eventos predefinidos con el fin de crear regularidad y minimizar la necesidad de reuniones no definidas en Scrum. Todos los eventos son bloques de tiempo (time-boxes), en el cual todos tienen una duración determinada. Una vez que comienza un Sprint, su duración es fija y no puede acortarse o alargarse.

\section{- El Sprint}

"Es un bloque de tiempo (time-box) de un mes o menos durante el cual se crea un incremento de producto terminado, utilizable y potencialmente desplegable. Cada nuevo Sprint comienza inmediatamente después de la finalización del Sprint previo" (Schwaber \& Sutherland, Julio).

Es una iteración definida en una fecha de comienzo y fin fija. Se da inicio a la planificación del sprint y concluye en la revisión del sprint. El equipo se reúne todos los días en una reunión de Scrum diario, para hacer su trabajo visible entre sí y sincronizar la base de lo que han aprendido (Viscardi, 2013).

\section{- Scrum Diario (Daily Scrum)}

El Scrum Diario es una reunión con un bloque de tiempo de 15 minutos para que el Equipo de Desarrollo sincronice sus actividades y cree un plan para las siguientes 24 horas. Esto se lleva a cabo inspeccionando el trabajo avanzado desde el último Scrum Diario y haciendo una proyección acerca del trabajo que podría completarse antes del siguiente. (Schwaber \& Sutherland, Julio, pág. 12) 
El Scrum Diario hace que los miembros del equipo muestren su progreso visible para que puedan revisar y adaptar en el cumplimiento de sus objetivos. En la reunión, los miembros discuten lo que hicieron desde la reunión de ayer, lo que planean hacer por la reunión de mañana, y para hablar de todos los obstáculos que puedan estar en su camino. En esta reunión participan los miembros del equipo, Product Owner y Scrum Master. Pueden asistir más, pero sólo como observadores. (Viscardi, 2013, pág. 21).

\section{- Revision del Sprint (Sprint Review)}

Al final del Sprint se lleva a cabo una Revisión de Sprint para inspeccionar el Incremento y adaptar la Lista de Producto si fuese necesario. Durante la Revisión de Sprint, el Equipo Scrum y los interesados colaboran acerca de lo que se hizo durante el Sprint. Basándose en esto, y en cualquier cambio a la Lista de Producto durante el Sprint, los asistentes colaboran para determinar las siguientes cosas que podrían hacerse para optimizar el valor.

La revisión del Sprint ofrece la oportunidad para los interesados para dar retroalimentación sobre el producto en un entorno colaborativo(Viscardi, 2013).

Se trata de una reunión informal, no una reunión de seguimiento, y la presentación del Incremento tiene como objetivo facilitar la retroalimentación de información y fomentar la colaboración(Schwaber \& Sutherland, Julio).

\section{- Retrospectiva de Sprint (Sprint Retrospective)}

La Retrospectiva de Sprint es una oportunidad para el Equipo Scrum de inspeccionarse a sí mismo y crear un plan de mejoras que sean abordadas durante el siguiente Sprint.

La Retrospectiva de Sprint tiene lugar después de la Revisión de Sprint y antes de la siguiente Reunión de Planificación de Sprint. Se trata de una reunión restringida a un bloque de tiempo de tres horas para Sprints de un mes. Para Sprints más cortos se reserva un tiempo proporcionalmente menor.

(Schwaber \& Sutherland, Julio, pág. 14).

La Retrospectiva de Sprint es realizada en la última reunión del sprint. El equipo de trabajo discute los eventos del sprint, identifica lo que funciono bien y no para ellos, 
y adquieren tomar acciones para algún cambio que les gustaría para el siguiente sprint. Esta reunión abarca tres horas donde se discute en detalle las revisiones del Sprint (Viscardi, 2013).

\subsubsection{Artefactos de Scrum}

En la Tabla 3, se reflejan los artefactos de Scrum que representan el trabajo o valor en diversas formas, útiles para proporcionar transparencia y oportunidades para la inspección y adaptación en el desarrollo de software.

\begin{tabular}{|l|l|}
\hline Artefacto & Descripción \\
\hline $\begin{array}{l}\text { Listado de } \\
\text { Productos } \\
\text { (Product } \\
\text { Backlog) }\end{array}$ & $\begin{array}{l}\text { "Lista ordenada de todo lo que podría ser necesario en el producto a desarrollar, y } \\
\text { es la única fuente de requisitos para cualquier cambio a realizarse en el producto" } \\
\text { (Schwaber \& Sutherland, Julio). } \\
\text { Es la lista de deseos del propietario del producto. Todo lo que desee y piense se } \\
\text { encontrará en el Product Backlog. Esta podría ser infinita, ya que siempre hay } \\
\text { nuevas ideas sobre cómo ampliar las características del producto. Mantiene la } \\
\text { cartera de pedido de productos, aunque otros interesados deben tener la } \\
\text { visibilidad y la capacidad de sugerir nuevos temas para la lista. Prioriza el } \\
\text { Product Backlog, lista lo más importante en prioridad. Existen diez (10) } \\
\text { elementos críticos que son ordenados de acuerdo a la prioridad o urgencia, y ellos } \\
\text { aparecen en la lista top del Product Backlog, uno después del otro. (Viscardi, } \\
\text { 2013) }\end{array}$ \\
\hline $\begin{array}{l}\text { Listado de } \\
\text { Sprints } \\
\text { Sprint } \\
\text { Backlog) }\end{array}$ & $\begin{array}{l}\text { "Lista del conjunto de elementos del Product Backlog seleccionados para el } \\
\text { Sprint más un plan para conseguir el objetivo del Sprint" (Schwaber \& } \\
\text { Sutherland, Julio). } \\
\text { Es propio del equipo, refleja los elementos del Product Backlog que el equipo } \\
\text { compromete en la planificación del sprint, así como las tareas y recordatorios } \\
\text { posteriores. Los miembros del equipo actualizan todos los días la cantidad de } \\
\text { horas restantes y estos pueden añadir, eliminar o cambiar tareas cuando el sprint } \\
\text { está en marcha. (Viscardi, 2013) }\end{array}$ \\
\hline $\begin{array}{l}\text { Sprint } \\
\text { Burndown }\end{array}$ & $\begin{array}{l}\text { Durante un sprint particular, cada equipo actualiza el Sprint Backlog con el } \\
\text { número de horas por tarea cada día, en el cual el equipo puede ver si ellos son } \\
\text { capaces de quemar completamente el número de horas pendientes para el final del } \\
\text { sprint. Uno puede ver la relación de las horas restantes en cada día del Sprint. } \\
\text { (Viscardi, 2013) }\end{array}$ \\
\hline
\end{tabular}

Tabla 3 Descripción de los artefactos SCRUM.

Fuente: Elaboración Propia 


\subsection{ISO/IEC 29110 - Perfiles del ciclo de vida para las PO}

\subsubsection{Familia ISO 29110}

La Familia ISO 29110 es una serie de normas internacionales que describen los perfiles del ciclo de vida del desarrollo de software orientado a POs (Pequeñas Organizaciones). En la Tabla 4, se muestran las distintas partes que contiene la norma ISO/IEC 29110 como también su audiencia objetivo.

\begin{tabular}{|c|c|c|}
\hline ISO/IEC 29110 & Título & Audiencia objetivo \\
\hline Parte 1 & Visión general & $\begin{array}{l}\text { PO, evaluadores, } \\
\text { productores de estándares, } \\
\text { vendedores de } \\
\text { herramientas y vendedores } \\
\text { de metodologías. }\end{array}$ \\
\hline Parte 2 & Marco de trabajo y taxonomía & $\begin{array}{l}\text { Productores de estándares, } \\
\text { vendedores } \\
\text { herramientas } \\
\text { metodologías. No dirigido } \\
\text { a las PO }\end{array}$ \\
\hline Parte 3 & Guía de evaluación & Evaluadores y PO \\
\hline Parte 4 & Especificaciones del perfil & $\begin{array}{l}\text { Productores de estándares, } \\
\text { vendedores } \\
\text { herramientas } \\
\text { metodologías. No dirigido } \\
\text { a las PO }\end{array}$ \\
\hline Parte 5 & Guía de Gestión e Ingeniería & $\mathrm{PO}$ \\
\hline
\end{tabular}

\section{Partes de la norma ISO 29110:}

En la Tabla 5, se describen las partes de la norma ISO 29110:

\begin{tabular}{|l|l|l|}
\hline Código & Titulo & Descripción \\
\hline $\begin{array}{l}\text { ISO/IEC } \\
29110-1\end{array}$ & Visión General & $\begin{array}{l}\text { "Define los términos de negocio comunes al Conjunto de Documentos } \\
\text { del Perfil de la PO. Esta Parte 1 introduce los conceptos de procesos, } \\
\text { ciclo de vida y normalización, y la serie ISO/IEC 29110" (NTP-RT- } \\
\text { ISO/IEC TR 29110-5-1-2, 2012, pág. XI). }\end{array}$ \\
\hline $\begin{array}{l}\text { ISO/IEC } \\
29110-2\end{array}$ & $\begin{array}{l}\text { Marco de Trabajo y } \\
\text { Taxonomía }\end{array}$ & $\begin{array}{l}\text { "Introduce conceptos para el perfil normalizado de ingeniería de } \\
\text { software para las PO y términos comunes para el conjunto de } \\
\text { documentos del Perfil de las PO" (NTP-RT-ISO/IEC TR 29110-5-1-2, } \\
\text { 2012, pág. XI). }\end{array}$ \\
\hline $\begin{array}{l}\text { ISO/IEC } \\
29110-3\end{array}$ & Guía de evaluación & $\begin{array}{l}\text { "Define los lineamientos y requisitos de conformidad de la evaluación } \\
\text { de proceso, necesarios para alcanzar el propósito de los perfiles de la } \\
\text { PO definidos (NTP-RT-ISO/IEC TR 29110-5-1-2, 2012, pág. XI). }\end{array}$ \\
\hline $\begin{array}{l}\text { ISO/IEC } \\
29110-4-1\end{array}$ & $\begin{array}{l}\text { Especificación de } \\
\text { perfil: }\end{array}$ & $\begin{array}{l}\text { Provee la especificación para todos los perfiles del Grupo de Perfiles } \\
\text { Genérico, los cuales son aplicables a las PO que no desarrollan }\end{array}$ \\
\hline
\end{tabular}




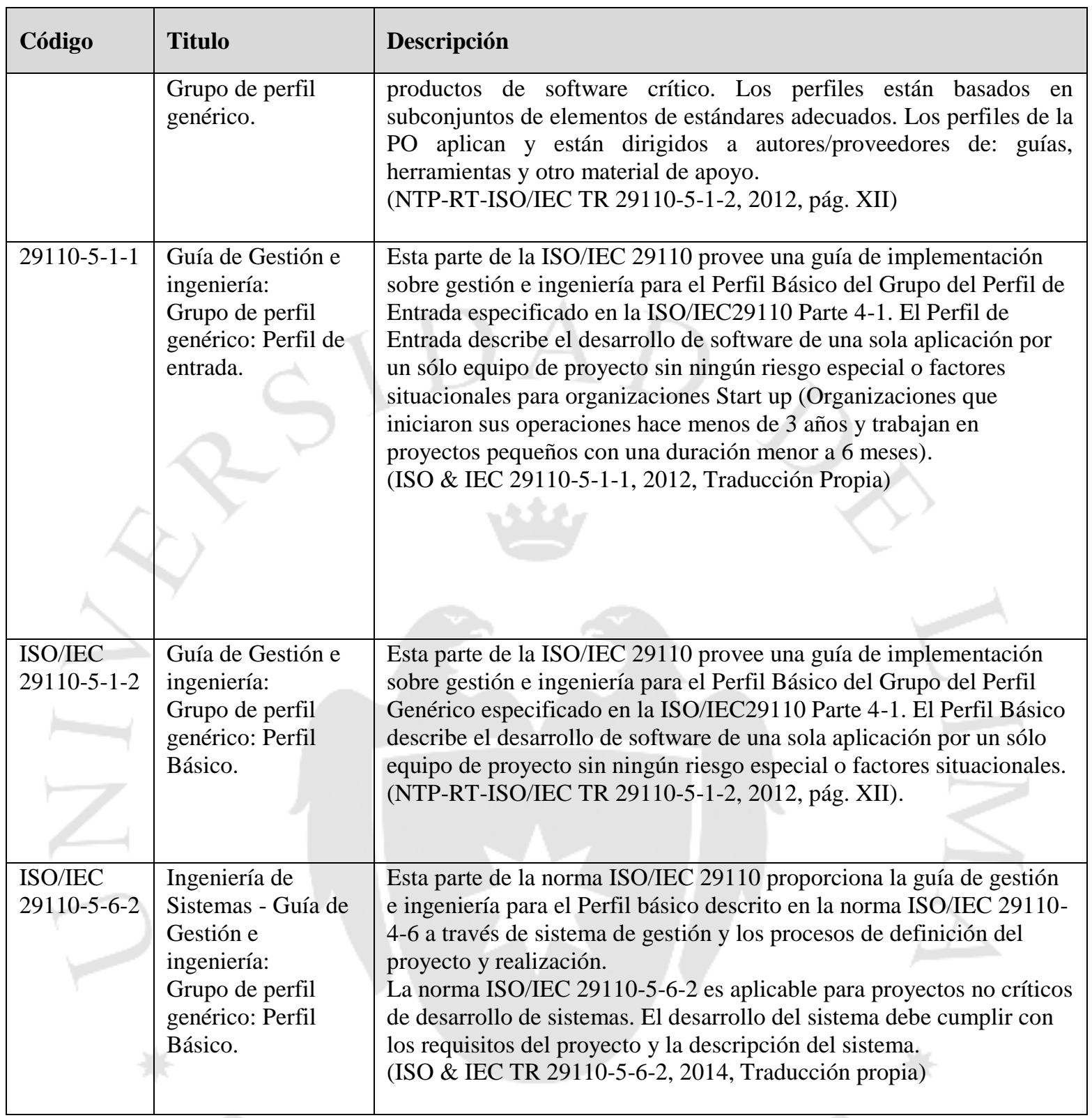

Tabla 5 Familia ISO 29110

Fuente: Elaboración Propia

\section{Especificación de perfiles:}

"Si un nuevo perfil es necesario, se puede desarrollar nuevas ISO/IEC 29110 Partes 4 y 5 sin afectar a los documentos existentes y se les denominarían ISO/IEC 29110 Parte 4-m y Parte 5-m-n respectivamente, a través del proceso ISO/IEC" (NTP-RT-ISO/IEC TR 291105-1-2, 2012, pág. XI). 
En la Tabla 6, se muestran los estados de los perfiles del grupo de perfil genérico:

\begin{tabular}{|l|l|l|}
\hline $\begin{array}{l}\text { Grupo de } \\
\text { Perfil }\end{array}$ & Perfil & Estado \\
\hline Genérico & De entrada & Terminado \\
\hline Genérico & Básico & Terminado \\
\hline Genérico & Intermedio & En proceso \\
\hline Genérico & Avanzado & En proceso \\
\hline
\end{tabular}

Tabla 6 Estado de los Perfiles del grupo de perfil genérico. Fuente: Elaboración Propia.

\subsubsection{Alcance - ISO/IEC 29110}

Para el uso de la ISO/IEC 29110 la PO necesita cumplir con las siguientes condiciones de entrada (NTP-RT-ISO/IEC TR 29110-5-1-2, 2012, pág. 6):

- El enunciado de Trabajo del proyecto está documentado.

- La viabilidad del proyecto fue realizada antes de su inicio.

- El equipo del proyecto, incluyendo el Gestor del Proyecto, está asignado y entrenado; y los bienes, servicios e infraestructura para iniciar el proyecto están disponibles.

\subsubsection{Procesos - ISO/IEC 29110}

La ISO/IEC 29110 describe dos procesos del ciclo de vida del desarrollo de software:

En la Figura 5, se muestran los procesos del perfil básico de la ISO/IEC 29110:

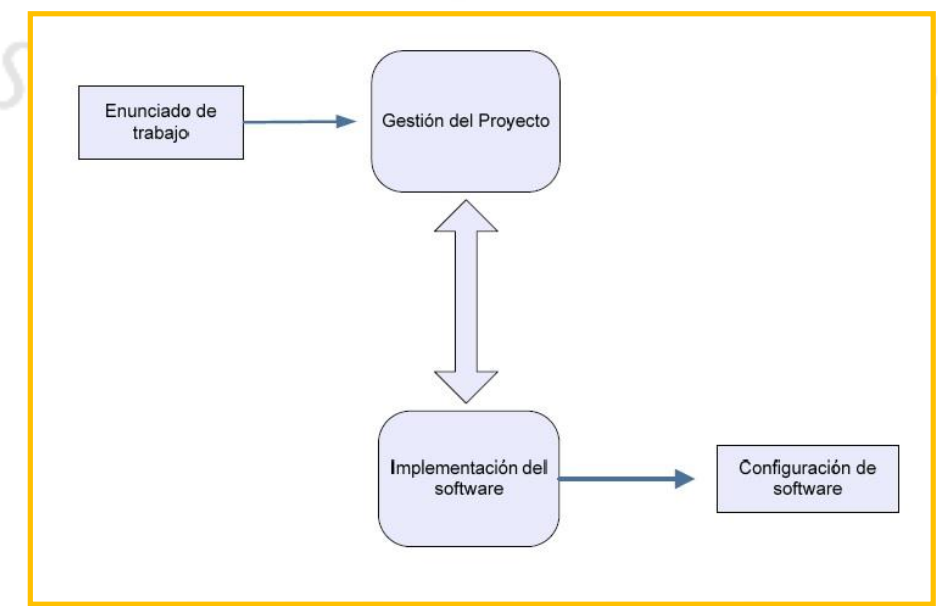

Figura 5 Procesos del Perfil Básico ISO/IEC 29110-5-2-1. Fuente: (NTP-RT-ISO/IEC TR 29110-5-1-2, 2012, pág. 7) 


\subsubsection{Roles Involucrados en el ciclo de vida del desarrollo de software según la}

ISO/IEC 29110

A continuación, se muestra cada uno de los Roles que intervienen en el ciclo de vida de desarrollo. En cada una de las tablas se muestran el código (abreviado en inglés), nombre del rol y su descripción de competencias según la ISO/IEC 29110.

\begin{tabular}{|l|l|}
\hline Cód. & AN(AN) \\
\hline Nombre & Analista (Analyst) \\
\hline Competencias: \\
-Conocimiento y experiencia que permita obtener, especificar y analizar los requisitos. \\
-Conocimiento en el diseño de interfaces de usuario y criterios ergonómicos. \\
-Conocimiento de técnicas de revisión. \\
-Conocimiento de Técnicas de edición. \\
-Experiencia en desarrollo y mantenimiento de software.
\end{tabular}

Tabla 7 Rol Analista - ISO/IEC 29110-5-1-2.

Fuente: (NTP-RT-ISO/IEC TR 29110-5-1-2, 2012, pág. 51)

Cód. $\quad$ CL(CUS)

Nombre Cliente (Customer)

Competencias:

-Conocimiento de los procesos del Cliente y habilidad para explicar los requerimientos del cliente.

-El Cliente (representante del Cliente) debe tener la autoridad para aprobar los requisitos y sus cambios.

-El cliente incluye usuarios representativos con la finalidad de asegurar que el entorno operacional sea dirigido de forma correcta.

-Conocimiento y experiencia en el dominio de la aplicación.

Tabla 8 Rol Cliente - ISO/IEC 29110-5-1-2.

Fuente: (NTP-RT-ISO/IEC TR 29110-5-1-2, 2012, pág. 52)

\begin{tabular}{|l|l|}
\hline Cód. & DI(DES) \\
\hline Nombre & Diseñador \\
\hline Competencias: \\
-Conocimiento y Experiencia en Componente de Software y diseño de Arquitectura. \\
-Conocimiento de técnicas de revisión. \\
-Conocimiento y Experiencia en Planificación y ejecución de pruebas de integración. \\
-Conocimiento de técnicas de edición. \\
-Experiencia en desarrollo y mantenimiento de software.
\end{tabular}

Tabla 9 Rol Diseñador - ISO/IEC 29110-5-1-2

Fuente: (NTP-RT-ISO/IEC TR 29110-5-1-2, 2012, pág. 52) 
Cód.

$\mathrm{PR}(\mathrm{PR})$

Nombre Programador

\section{Competencias:}

-Conocimiento y Experiencia en Programación, integración y pruebas unitarias.

-Conocimiento de técnicas de revisión.

-Conocimiento de técnicas de edición.

-Experiencia en desarrollo y mantenimiento de software.

Tabla 10 Rol Programador - ISO/IEC 29110-5-1-2.

Fuente: (NTP-RT-ISO/IEC TR 29110-5-1-2, 2012, pág. 52)

\begin{tabular}{|l|l|}
\hline Cód. & GP(PM) \\
\hline Nombre & Gestor del Proyecto \\
\hline
\end{tabular}

Competencias:

Capacidad de liderazgo con experiencia para toma de decisiones, planificación, gestión de personal, delegación y supervisión, conocimiento de finanzas y desarrollo de software.

Tabla 11 Rol Gestor del Proyecto - ISO/IEC 29110-5-1-2.

Fuente: (NTP-RT-ISO/IEC TR 29110-5-1-2, 2012, pág. 52)

\begin{tabular}{|l|l|}
\hline Cód. & LT(TL) \\
\hline Nombre & Líder Técnico \\
\hline
\end{tabular}

Competencias:

-Conocimiento y Experiencia en el dominio del proceso de Software.

Tabla 12 Rol Líder Técnico - ISO/IEC 29110-5-1-2.

Fuente: (NTP-RT-ISO/IEC TR 29110-5-1-2, 2012, pág. 53)

\begin{tabular}{|l|l|}
\hline Cód. & ET(WT) \\
\hline Nombre & Equipo de Trabajo \\
\hline & $\begin{array}{l}\text { Competencias: } \\
\text {-Conocimiento y Experiencia de acuerdo a sus roles dentro del proyecto: LT, AN, DIS y/o PR. } \\
\text {-Conocimiento de los estándares usados por el Cliente y/o por la PO. }\end{array}$
\end{tabular}

Tabla 13 Rol Equipo de Trabajo - ISO/IEC 29110-5-1-2.

Fuente: (NTP-RT-ISO/IEC TR 29110-5-1-2, 2012, pág. 53) 


\subsubsection{Proceso de Gestión del Proyecto (GP) - ISO/IEC 29110}

El propósito del proceso Gestión del Proyecto es establecer y llevar a cabo de manera sistemática las Tareas de un proyecto de implementación de Software, que permitan cumplir con los Objetivos del proyecto en calidad, tiempo y costos esperados.

(NTP-RT-ISO/IEC TR 29110-5-1-2, 2012, pág. 7).

\section{Objetivos del proceso de Gestión del Proyecto}

En la Tabla 14, se describen los objetivos del proceso de Gestión del Proyecto:

\begin{tabular}{|c|c|}
\hline Código & bjetivo \\
\hline GP.O1. & $\begin{array}{l}\text { El Plan del Proyecto para la ejecución del proyecto es desarrollado de acuerdo al Enunciado de } \\
\text { Trabajo y revisado y aceptado por el Cliente. Las Tareas y los Recursos necesarios para } \\
\text { completar el trabajo son dimensionados y estimados. }\end{array}$ \\
\hline GP.O2. & $\begin{array}{l}\text { El avance del proyecto es monitoreado contra el Plan del Proyecto y registrados en el Registro } \\
\text { de Estado del Avance. Las correcciones para resolver los problemas y desviaciones respecto } \\
\text { del plan son realizadas cuando los objetivos del proyecto no son logrados. El cierre del } \\
\text { proyecto es ejecutado para conseguir la aceptación documentada del Cliente en el Documento } \\
\text { de Aceptación. }\end{array}$ \\
\hline GP.O3. & $\begin{array}{l}\text { Las Solicitudes de Cambio son atendidas mediante su recepción y análisis. Los cambios a los } \\
\text { requisitos de Software son evaluados por su impacto técnico, en costo y en el cronograma. }\end{array}$ \\
\hline GP.O4. & $\begin{array}{l}\text { Reuniones de revisión con el Equipo de Trabajo y el Cliente son realizadas. Los acuerdos que } \\
\text { surgen de estas reuniones son documentados y se les hace seguimiento. }\end{array}$ \\
\hline GP.O5. & Los riesgos son identificados en el desarrollo y durante la realización del proyecto. \\
\hline GP.O6. & $\begin{array}{l}\text { Una Estrategia de Control de Versiones de Software es desarrollada. Los elementos de } \\
\text { Configuración del Software son identificados, definidos e incorporados a la línea base. Las } \\
\text { modificaciones y actualizaciones de los elementos son controladas y puestas a disposición del } \\
\text { Cliente y del Equipo de Trabajo. El almacenamiento, la manipulación y la entrega de los } \\
\text { elementos son controlados. }\end{array}$ \\
\hline GP.O7. & $\begin{array}{l}\text { El Aseguramiento de Calidad del Software es realizado para proporcionar garantía de que los } \\
\text { productos y procesos de trabajo cumplen con el Plan del Proyecto y Especificación de } \\
\text { Requisitos. }\end{array}$ \\
\hline
\end{tabular}

Tabla 14 Objetivos del proceso de GP.

Fuente: (NTP-RT-ISO/IEC TR 29110-5-1-2, 2012), Elaboración Propia. 


\section{Actividades del proceso de Gestión del Proyecto - ISO/IEC 29110:}

En la Figura 6, se puede apreciar el proceso de Gestión del Proyecto y sus actividades:

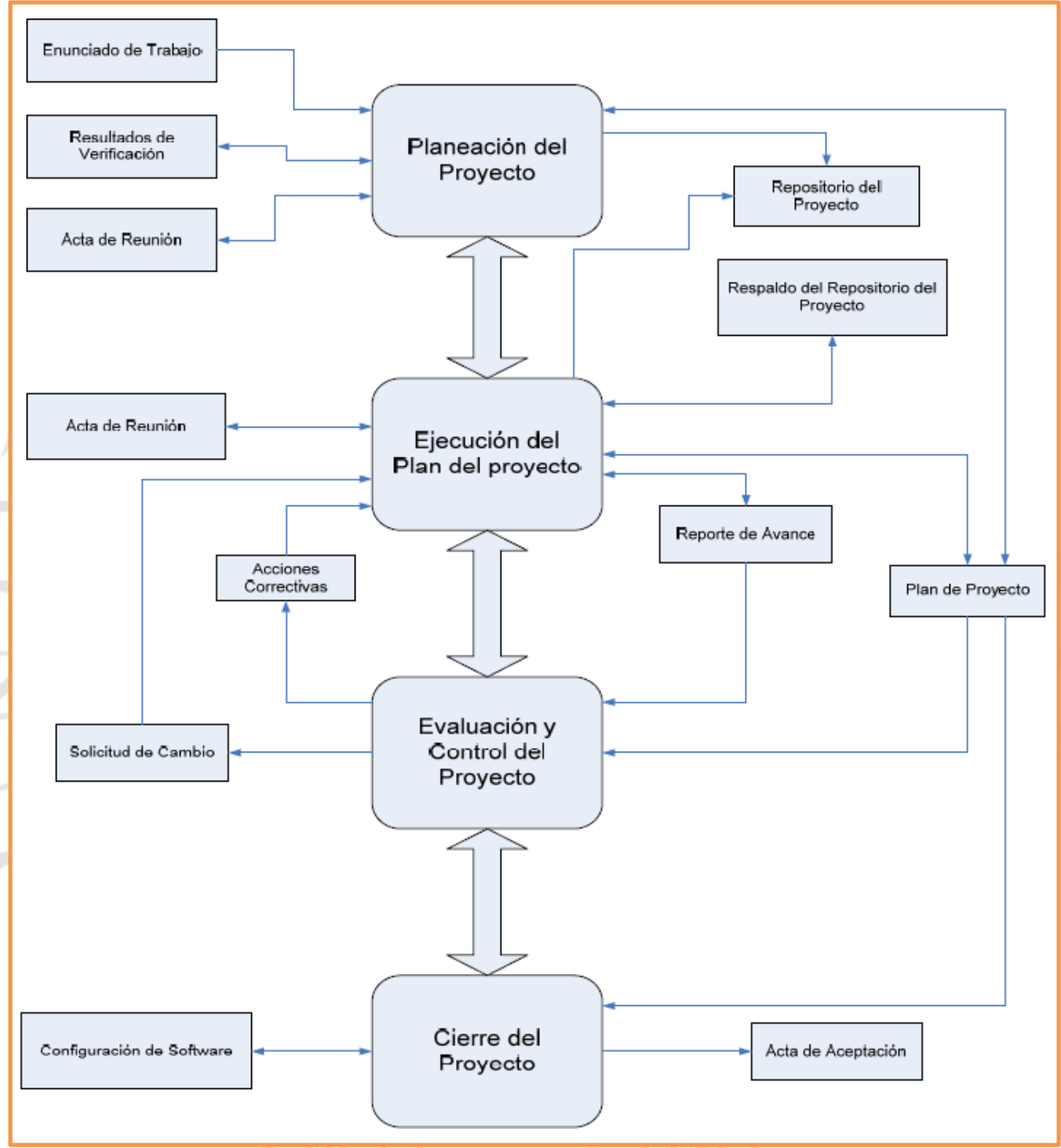

Figura 6 Diagrama del proceso de GP según la ISO/IEC 29110-5-1-2.

Fuente: (NTP-RT-ISO/IEC TR 29110-5-1-2, 2012, pág. 15). 
El proceso de Gestión del Proyecto consiste de las siguientes actividades:

\section{Planificación del Proyecto:}

"La actividad de Planificación del Proyecto documenta los detalles de la planificación necesarios para gestionar el proyecto" (NTP-RT-ISO/IEC TR 29110-5-1-2, 2012, pág. 16). Roles Involucrados: GP, LT, CL.

\section{Ejecución del Plan del Proyecto:}

"Las actividades de la ejecución del Plan del Proyecto implementan el plan documentado en el proyecto" (NTP-RT-ISO/IEC TR 29110-5-1-2, 2012, pág. 20).

Roles Involucrados: LT, ET, AN, CL.

\section{Evaluación y Control del Proyecto:}

"La actividad de Evaluación y Control del Proyecto evalúa el desempeño del plan contra los compromisos documentados”(NTP-RT-ISO/IEC TR 29110-5-1-2, 2012, pág. 22). Roles Involucrados: LT, AN, DIS.

\section{Cierre del Proyecto:}

"La actividad de Cierre del Proyecto proporciona documentación y productos del proyecto de acuerdo con los requisitos del contrato" (NTP-RT-ISO/IEC TR 29110-5-1-2, 2012, pág. 24).

Roles Involucrados: LT, PR. 


\subsubsection{Proceso de Implementación de Software (IS)- ISO/IEC 29110}

"El propósito del proceso de Implementación de Software es la realización sistemática de las actividades de análisis, diseño, construcción, integración y pruebas para los productos Software, nuevos o modificados, de acuerdo a los requisitos especificados” (NTP-RT-ISO/IEC TR 29110-5-1-2, 2012, pág. 7).

\section{Objetivos del proceso de Implementación de Software:}

En la Tabla 15, se describe los objetivos del proceso de Implementación de Software:

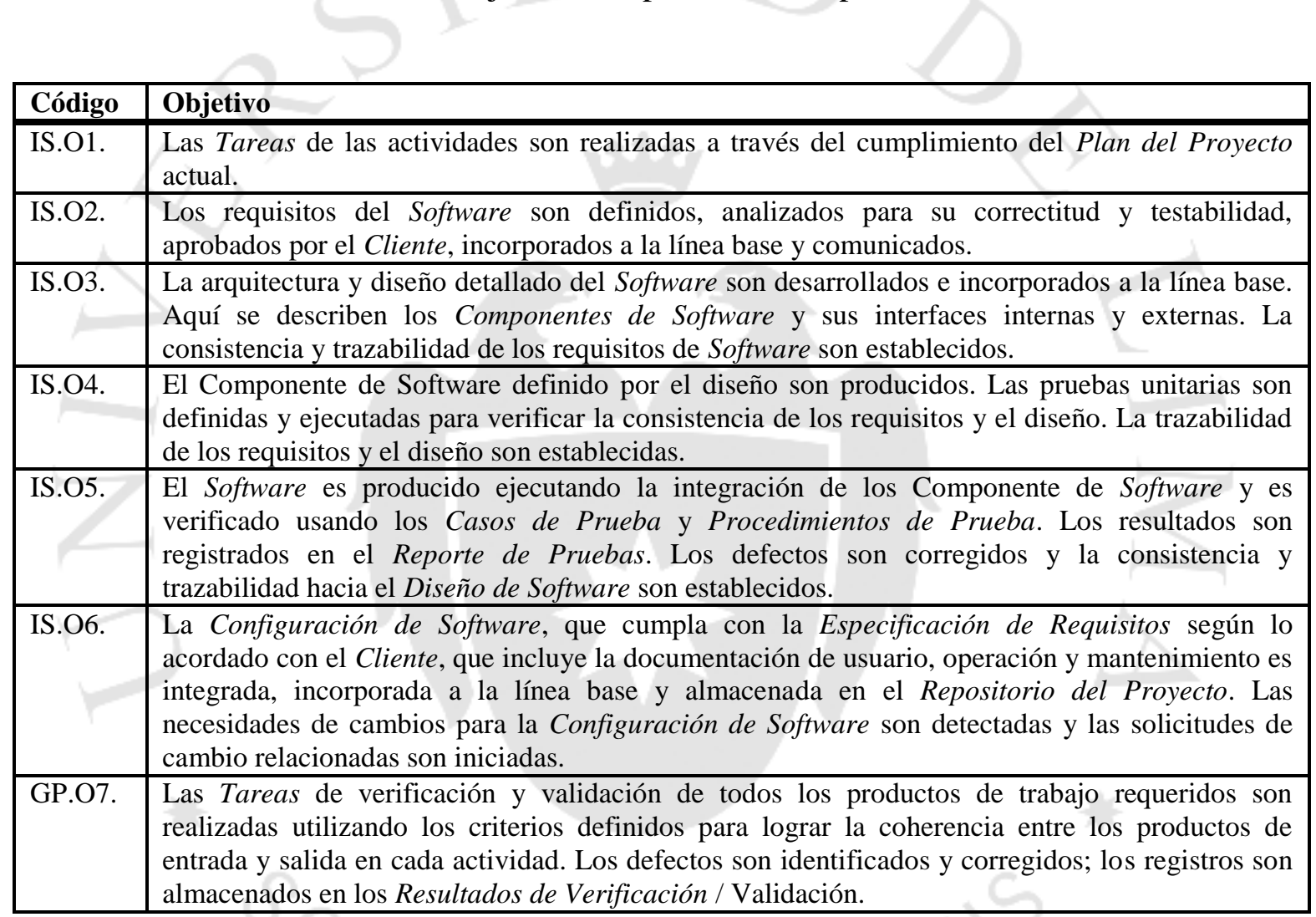

Tabla 15 Objetivos del Proceso de IS

Fuente: (NTP-RT-ISO/IEC TR 29110-5-1-2, 2012), Elaboración Propia 
Actividades del proceso de Implementación de Software - ISO/IEC 29110:

En la Figura 7, se puede apreciar el proceso de Implementación de Software y sus actividades:

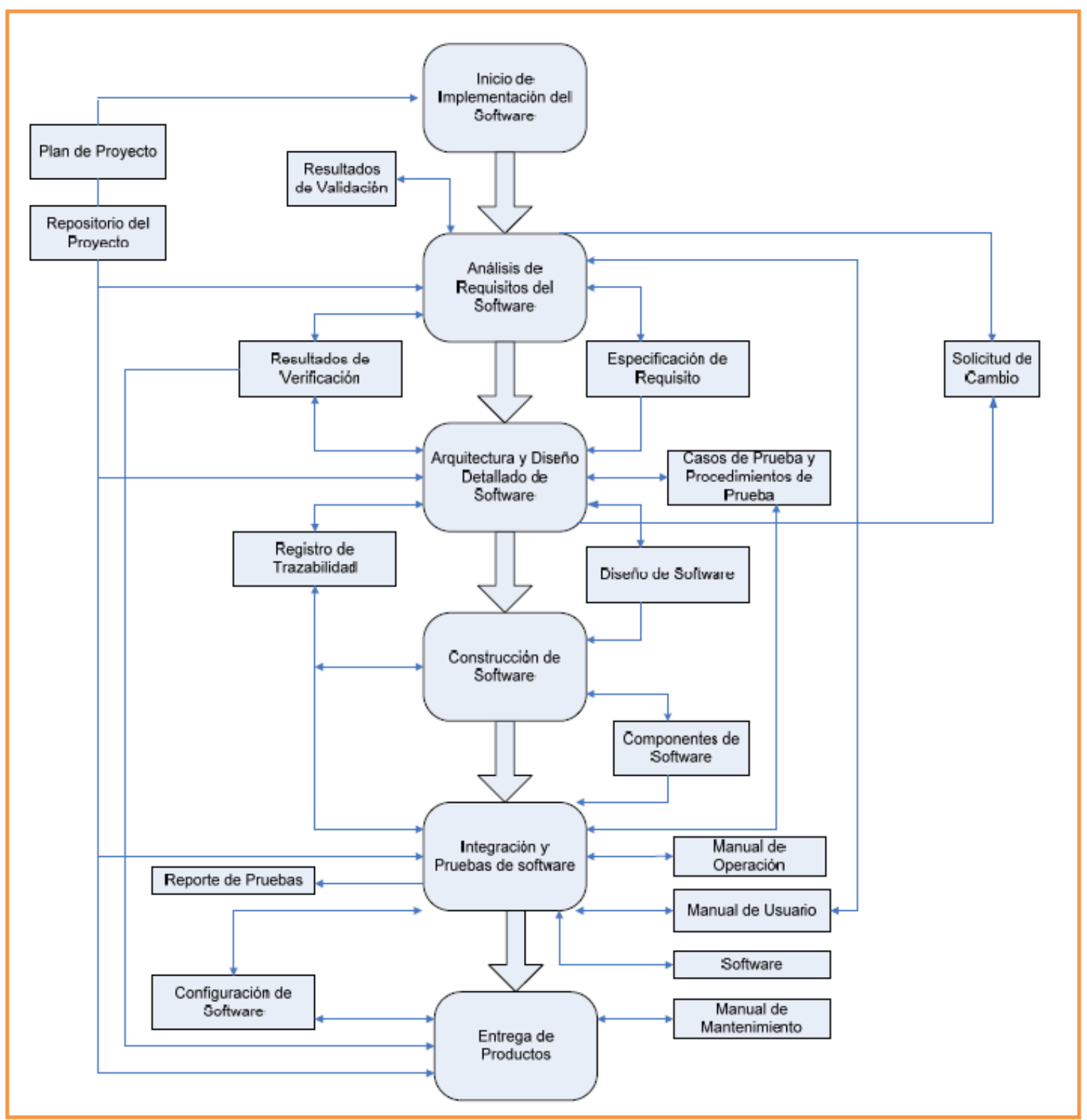

Figura 7 Diagrama del proceso de IS según la ISO/IEC 29110-5-1-2.

Fuente: (NTP-RT-ISO/IEC TR 29110-5-1-2, 2012, pág. 35) 
El proceso de Implementación de software consiste de las siguientes actividades:

\section{Inicio de la Implementación de Software:}

"La actividad Inicio de la Implementación del Software asegura que el Plan del Proyecto establecido en la actividad Planeación del Proyecto es llevado a cabo por el Equipo de Trabajo" (NTP-RT-ISO/IEC TR 29110-5-1-2, 2012, pág. 36).

Roles Involucrados: GP, LT, ET.

\section{Análisis de Requisitos de Software:}

"La actividad de Análisis de Requisitos de Software analiza los requisitos acordados con el Cliente y establece los requisitos del proyecto validados" (NTP-RT-ISO/IEC TR 29110-51-2, 2012, pág. 37).

Roles Involucrados: LT, ET, AN, CL.

\section{Arquitectura y Diseño Detallado del Software:}

"La actividad de Arquitectura y Diseño Detallado del Software transforma los requisitos de Software en la arquitectura Software del sistema y en el diseño detallado del Software" (NTP-RT-ISO/IEC TR 29110-5-1-2, 2012, pág. 40).

Roles Involucrados: LT, AN, DIS.

\section{Construcción de Software:}

"La actividad de Construcción de Software desarrolla el código y los datos del Software a partir del Diseño de Software” (NTP-RT-ISO/IEC TR 29110-5-1-2, 2012, pág. 44).

Roles Involucrados: LT, PR.

\section{Integración y Pruebas del Software:}

"La actividad de Integración y Pruebas del Software asegura que los Componentes de Software integrados satisfacen los requisitos del Software” (NTP-RT-ISO/IEC TR 291105-1-2, 2012, pág. 46).

Roles Involucrados: LT, PR, CL, DIS, AN. 


\section{Entrega del Producto:}

"La actividad de Entrega de Productos provee el producto de Software integrado al Cliente” (NTP-RT-ISO/IEC TR 29110-5-1-2, 2012, pág. 49).

Roles Involucrados: LT,

ET, DIS, LT.

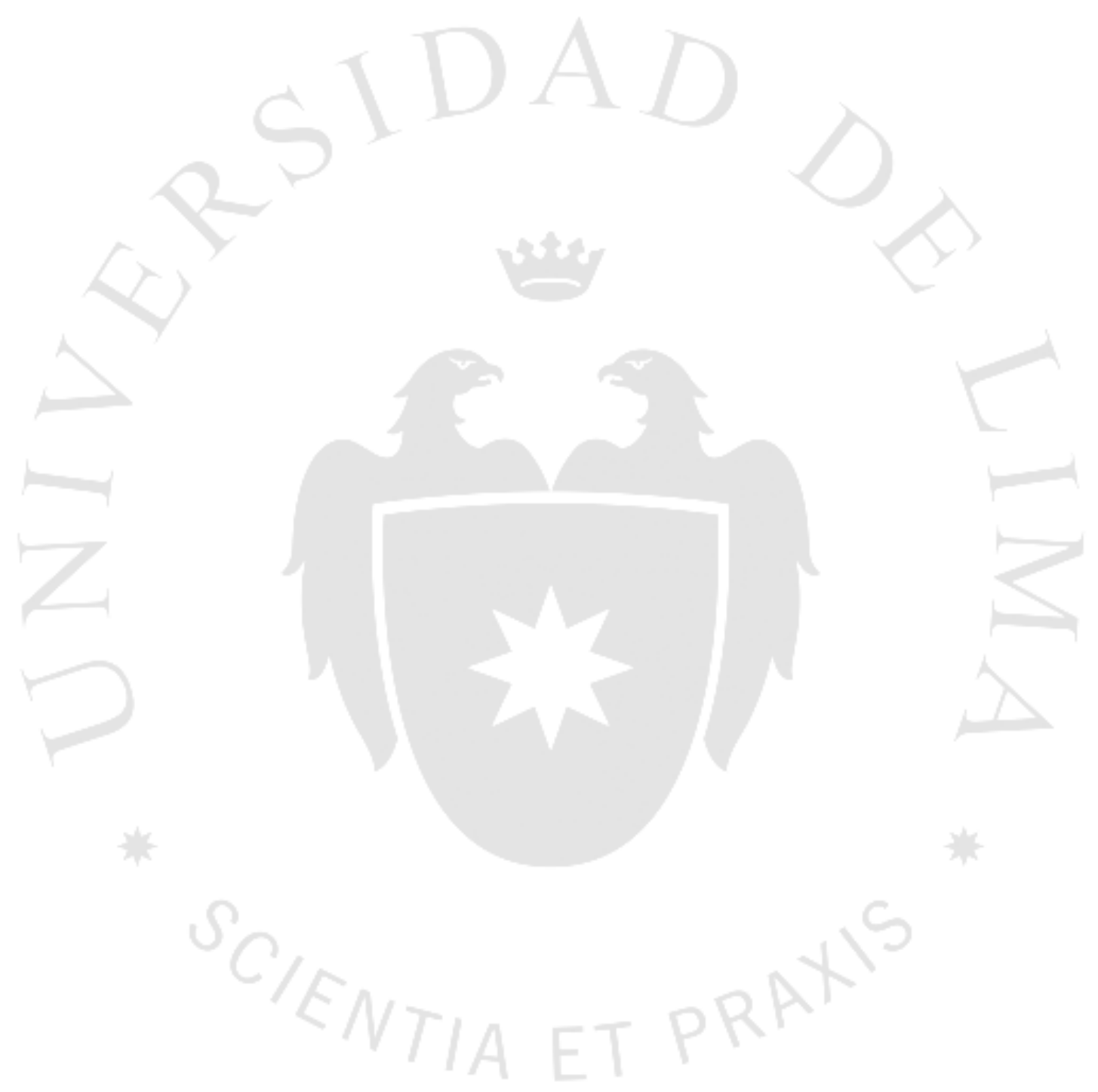




\subsubsection{Productos de trabajo del ciclo de vida del desarrollo de software}

A continuación, listamos los productos de trabajo presentes en los procesos del ciclo de vida del desarrollo de software descritos en la ISO 29110 (NTP-RT-ISO/IEC TR 29110-5$1-2,2012)$ :

- Acciones Correctivas

- Acta de Aceptación

- Acta de Reunión

- Casos de Prueba y Procedimientos de Prueba

- Componentes del Software

- Configuración del Software

- Diseño de Software

- Enunciado del Trabajo

- Especificación De Requisitos

- Manual de Mantenimiento

- Manual de Operación

- Manual de Usuario

- Plan del Proyecto

- Registro de Trazabilidad

- Repositorio Del Proyecto

- Reporte de Avance

- Reporte de Pruebas

- Respaldo del Repositorio del Proyecto

- Resultados de Validación

- Resultados de Verificación

- Solicitud de Cambio

- Software 


\subsubsection{Herramienta de evaluación de actividades (Activity Assessment)}

Para la evaluación del ciclo de vida del desarrollo de software de la empresa de estudio se utilizó el paquete de despliegue "ISO 29110 Perfil Básico - Evaluación de Actividades (Activity Assessment)". Esta herramienta de evaluación fue desarrollada por Claude Y Laporte de Canadá y J. Triñanes de Uruguay. En la Tabla 16, se presenta el mapeo de las secciones principales de la herramienta de evaluación:

\begin{tabular}{|l|l|}
\hline Pagina & Descripción \\
$\begin{array}{l}\text { Tablero de Control } \\
\text { (Dashboard) }\end{array}$ & $\begin{array}{l}\text { En esta página de muestra los resultados de la evaluación de } \\
\text { los 2 procesos del ciclo de vida del desarrollo de software y } \\
\text { sus respectivas actividades. }\end{array}$ \\
\hline $\begin{array}{l}\text { Tabla de Gestión de } \\
\text { Proyectos (PM Table) }\end{array}$ & $\begin{array}{l}\text { En esta página se muestran y evalúan las actividades y tareas } \\
\text { del proceso de Gestión del proyecto. }\end{array}$ \\
\hline $\begin{array}{l}\text { Tabla de Implementación de } \\
\text { Software (SI Table) }\end{array}$ & $\begin{array}{l}\text { En esta página se muestran y evalúan las actividades y tareas } \\
\text { del proceso de Implementación del Software. }\end{array}$ \\
\hline Roles (Role) & $\begin{array}{l}\text { En esta página se hace una comparación entre los roles } \\
\text { establecidos en la ISO 29110 y los roles de la organización. }\end{array}$ \\
\hline
\end{tabular}

Tabla 16 Mapeo de la herramienta de evaluación ISO 29110 Perfil Básico

Fuente: Elaboración Propia. 


\subsubsection{Herramientas requeridas en el ciclo de vida del Desarrollo de Software}

A continuación, se describen las características de las herramientas que pueden ser utilizadas para realizar las actividades del ciclo de vida del software.

Herramientas para la Gestión del Proyecto (NTP-RT-ISO/IEC TR 29110-5-1-2, 2012, pág. 66):

- Herramientas para documentar, gestionar y controlar el plan del Proyecto.

- Repositorio del Proyecto

Herramientas para la Implementación de Software (NTP-RT-ISO/IEC TR 29110-5-1-2, 2012, pág. 66):

- Herramientas de Documentación.

- Herramientas de Especificación de Requisitos.

- Herramientas de Diseño de Software.

- Herramientas de Construcción.

- Herramientas de Prueba y Seguimiento de Defectos. 


\subsubsection{Requisitos para demostrar el cumplimiento de la ISO/IEC 29110}

Una PO que pretende demostrar conformidad con lo establecido en ISO/IEC 29110-4-1 debería implementar y usar todos los elementos mandatorios identificados en la Cláusula 7 (Especificaciones del perfil básico de una PO) de la ISO 29110-4-1, y propiedades asociadas y requerimientos descritos cuando sean aplicables (ISO \& IEC, 2010, pág. 1, Traducción Propia).

La conformidad es lograda a través de la demostración de:

- Los requerimientos mandatorios de los productos del ciclo de vida deben ser satisfechos usando la conformidad del contenido de los productos de trabajo como evidencia.

- Los requerimientos mandatorios de los procesos del ciclo de vida deben ser satisfechos usando los objetivos (Productos de salida) y productos como evidencia.

\section{Especificaciones del perfil básico de una PO:}

A continuación, se muestra las especificaciones del perfil básico y su calificación: Mandatorio u Opcional. (ISO \& IEC, 2010, pág. 10-11, Traducción Propia)

Especificación de la definición y composición de procesos:

- Todos los procesos son mandatorios.

- Todas las actividades son mandatorios.

- Todas las tareas son opcionales.

Especificación de los objetivos del proceso:

- Todos los objetivos son mandatorios.

Especificación de los productos de trabajo:

- Todos los productos de trabajo son mandatorios.

Especificación de los productos de entrada y salida de las actividades:

- Todos los productos de salida son mandatorios.

- Todos los productos de entrada son opcionales. 


\section{CAPÍTULO IV: PROPUESTA DE SOLUCIÓN}

\subsection{Enfoque}

El método del trabajo de investigación que se utiliza, según el nivel de evidencia es:

\section{- Método secundario:}

Para el presente trabajo de investigación se recopilo de manera sistemática y rigurosa estudios relacionados al trabajo de investigación como evidencia y línea base para el desarrollo de la solución.

El tipo de investigación que se utiliza, según el propósito es:

\section{- Mejora:}

Se propone un modelo de mejora como respuesta a la problemática de la empresa, para ello, se revisaron trabajos de investigación similares como línea base para el desarrollo de la solución, así como describir el estado actual de la empresa de estudio con referencia a la ISO 29110, y detallando la propuesta de solución.

\subsection{Alcance}

El modelo de mejora tiene como línea base la evaluación de los proyectos GALI, RFID y GUARDIAN del área Cloud Computing de la empresa HOLINSYS. La generación de evidencia se encuentra en el ANEXO 4: Evidencia de los productos de trabajo del proyecto GUARDIAN de la empresa HOLINSYS.

\section{- El Modelo de Mejora abarca lo siguiente:}

\section{Desde:}

- Evaluación de los procesos del ciclo de vida del desarrollo de software de la empresa de estudio respecto a lo descrito en la ISO 29110.

- Propuestas para mejorar el ciclo de vida del desarrollo de software de la empresa:

- Propuesta para los procesos y actividades del ciclo de vida del desarrollo de software.

- Propuesta para los productos de trabajo (Documentos) del ciclo de vida del desarrollo de software. 
- Propuesta para los roles involucrados en el ciclo de vida del desarrollo de software.

\section{Hasta:}

- Diseño del Plan de Implementación del Modelo de mejora.

- La Herramienta de Software abarca lo siguiente:

\section{Desde:}

- Identificar los requerimientos de la herramienta a desarrollar

- El Análisis y Diseño de las funcionalidades de una herramienta de software.

\section{Hasta:}

- Realizar el despliegue de la herramienta de software.

\subsection{Supuestos}

- Se considera que la forma de trabajo utilizada en los proyectos mencionados en el alcance es replicada a las otras áreas de desarrollo de software de la empresa en estudio.

- Se considera que la empresa solo realiza proyectos de creación y modificación de software, excluyendo mantenimiento y adquisición.

- La ejecución del plan de implementación del modelo de mejora desarrollado en el presente trabajo abarca la propuesta de mejora hecha a la empresa de estudio como también el desarrollo de los productos de trabajo; más no la ejecución del plan de implementación y la evaluación de resultados. 


\subsection{Entregables}

A continuación, se describen los entregables del presente trabajo de investigación:

\section{Entregables del Objetivo I:}

El resultado de la evaluación del ciclo de vida del desarrollo de software comprende:

- Resultado de la evaluación de los productos de trabajo.

- Resultado de la evaluación del proceso de Gestión de Proyectos.

- Resultado de la evaluación del proceso de Implementación de Software.

La propuesta de mejora para el ciclo de vida del desarrollo de software comprende:

- Propuesta de mejora para los procesos del ciclo de vida del desarrollo de software.

- Propuesta de mejora para los productos de trabajo.

\section{Entregables del Objetivo II:}

La herramienta de Software desarrollada que sirve para apoyar en el cumplimiento de los proyectos de desarrollo de software de una empresa según la norma ISO 29110 comprende lo siguiente:

$>$ Requerimientos funcionales de la herramienta.

Diseño de la herramienta.

C Casos y Procedimientos de Prueba.

> Manual de Usuario. 


\subsection{Plan de Trabajo y Evaluación Económica}

A continuación, se presenta el cronograma de actividades para el cumplimiento de los objetivos generales del presente trabajo de investigación como también el costo de las actividades realizadas. El costo total es calculado en base a los números de días de esfuerzo en las tareas que generan los entregables.

\subsubsection{Plan de Trabajo del Objetivo General I}

\section{Duración Total del Proyecto:}

\section{4 meses y 7 días}

\section{Costo Total del Proyecto:}

\section{$\mathrm{S} / \mathbf{1 9 0 4 0 . 0 0}$}

\begin{tabular}{|c|c|c|c|c|c|}
\hline Nombre de la Tarea & Duración & Comienzo & Fin & $\begin{array}{l}\text { Acumulación } \\
\text { de costos fijos }\end{array}$ & Costo total \\
\hline $\begin{array}{l}\text { Evaluar el estado actual del ciclo de vida } \\
\text { del desarrollo de software en la empresa } \\
\text { de estudio con referencia a la ISO } 29110\end{array}$ & 77 días & $15 / 06 / 15$ & $31 / 08 / 15$ & Prorrateo & $\mathrm{S} / . \mathbf{1 2 0 0 0 . 0 0}$ \\
\hline $\begin{array}{l}\text { 1.1 Programar reuniones con el Gerente } \\
\text { General y equipo de trabajo de la empresa } \\
\text { HOLINSYS: } \\
\text {-Entregables: Acta de Reunión } 01 \text { - Alcance } \\
\text { del Proyecto. }\end{array}$ & 2 días & $15 / 06 / 15$ & $16 / 06 / 15$ & Prorrateo & $\mathrm{S} / \mathbf{0 . 0 0}$ \\
\hline $\begin{array}{l}\text { 1.2 Recopilar Información relevante de los } \\
\text { procesos: Gestión del Proyecto e } \\
\text { Implementación de Software de la empresa. }\end{array}$ & 10 días & $01 / 07 / 15$ & $10 / 07 / 15$ & Prorrateo & $\mathrm{S} / \mathbf{0 . 0 0}$ \\
\hline $\begin{array}{l}\text { 1.3 Definir el alcance de la evaluación del } \\
\text { modelo utilizando como base el los procesos } \\
\text { del ciclo de vida del desarrollo de software } \\
\text { descritos en la ISO } 29110 .\end{array}$ & 5 días & $11 / 07 / 15$ & $15 / 07 / 15$ & Prorrateo & $\mathrm{S} / \mathbf{0 . 0 0}$ \\
\hline $\begin{array}{l}\text { 1.4 Definir herramientas para apoyar en la } \\
\text { evaluación en los procesos de } \\
\text { Implementación de software. }\end{array}$ & 2 días & $23 / 07 / 15$ & $24 / 07 / 15$ & Prorrateo & $\mathrm{S} / \mathbf{0 . 0 0}$ \\
\hline $\begin{array}{l}\text { 1.5 Utilizar la herramienta de Activity } \\
\text { Assessment para evaluar las actividades } \\
\text { realizadas por la empresa HOLINSYS en los } \\
\text { procesos del ciclo de vida del desarrollo de } \\
\text { software con el modelo descrito en la NTP } \\
\text { ISO 29110-5-1-2. }\end{array}$ & 21 días & $27 / 08 / 15$ & $17 / 09 / 15$ & Prorrateo & $\mathrm{S} / \mathbf{0 . 0 0}$ \\
\hline
\end{tabular}




\begin{tabular}{|c|c|c|c|c|c|}
\hline Nombre de la Tarea & Duración & Comienzo & Fin & $\begin{array}{l}\text { Acumulación } \\
\text { de costos fijos }\end{array}$ & Costo total \\
\hline $\begin{array}{l}\text { 1.6 Comparar los productos de trabajo } \\
\text { realizados por la empresa HOLINSYS en los } \\
\text { procesos del ciclo de vida del desarrollo de } \\
\text { software con los productos de trabajo } \\
\text { descritos en la NTP ISO 29110-5-1-2. }\end{array}$ & 3 días & $18 / 08 / 15$ & $20 / 08 / 15$ & Prorrateo & $\mathrm{S} / \mathbf{0 . 0 0}$ \\
\hline $\begin{array}{l}1.7 \text { Identificar las fortalezas, debilidades, } \\
\text { amenazas y oportunidades de los procesos: } \\
\text { Gestión del Proyecto e Implementación de } \\
\text { Software de la empresa. }\end{array}$ & 9 días & $21 / 08 / 15$ & $30 / 08 / 15$ & Prorrateo & $\mathrm{S} / \mathbf{0 . 0 0}$ \\
\hline $\begin{array}{l}\text { 1.8 Presentar la evaluación de procesos: } \\
\text { Gestión del Proyecto e Implementación de } \\
\text { Software de la empresa. } \\
\text { Entregables: } \\
\text { - Resultado de la evaluación de los productos } \\
\text { de trabajo. } \\
\text { - Resultado de la evaluación del proceso de } \\
\text { Gestión de Proyectos. } \\
\text { - Resultado de la evaluación del proceso de } \\
\text { Implementación de Software. }\end{array}$ & 1 día & $31 / 08 / 15$ & $31 / 08 / 15$ & Prorrateo & $\mathrm{S} / \mathbf{1 2 0 0 0 . 0 0}$ \\
\hline $\begin{array}{l}\text { Elaborar propuesta de mejora para el } \\
\text { ciclo de vida del desarrollo de software de } \\
\text { la empresa de estudio. }\end{array}$ & 24 días & $04 / 09 / 15$ & 27/09/15 & Prorrateo & $\mathrm{S} / \mathbf{3 8 4 0 . 0 0}$ \\
\hline $\begin{array}{l}2.1 \text { Analizar los resultados de la evaluación } \\
\text { de la empresa des estudio para identificar } \\
\text { brechas y oportunidades. }\end{array}$ & 3 días & $04 / 09 / 15$ & $06 / 09 / 15$ & Prorrateo & $\mathrm{S} / \mathbf{0 . 0 0}$ \\
\hline $\begin{array}{l}2.2 \text { Definir las propuestas para solucionar } \\
\text { las brechas identificadas en los procesos del } \\
\text { ciclo de vida del desarrollo de software }\end{array}$ & 7 días & $08 / 09 / 15$ & 14/09/15 & Prorrateo & S/0.00 \\
\hline $\begin{array}{l}2.3 \text { Elaborar propuestas de mejora que } \\
\text { permita adaptarse a la norma ISO } 29110 . \\
\text { Entregables: } \\
\text {-Propuesta de mejora para los productos de } \\
\text { trabajo. } \\
\text {-Propuesta de mejora para los procesos del } \\
\text { ciclo de vida del desarrollo de software. }\end{array}$ & 10 días & $18 / 09 / 15$ & $27 / 09 / 15$ & Prorrateo & $\mathrm{S} / \mathbf{3 8 4 0 . 0 0}$ \\
\hline $\begin{array}{l}\text { Diseñar el plan de implementación del } \\
\text { modelo de mejora }\end{array}$ & 20 días & $02 / 10 / 15$ & $21 / 10 / 15$ & Prorrateo & $\mathrm{S} / \mathbf{3 2 0 0 . 0 0}$ \\
\hline $\begin{array}{l}\text { 31. Determinar los recursos necesarios para } \\
\text { el plan de implantación del proyecto de } \\
\text { mejora }\end{array}$ & 8 días & $02 / 10 / 15$ & $09 / 10 / 15$ & Prorrateo & $\mathrm{S} / \mathbf{0 . 0 0}$ \\
\hline $\begin{array}{l}\text { 32. Definir las estrategias de } \\
\text { Implementación del modelo de mejora. }\end{array}$ & 9 días & $09 / 10 / 15$ & $17 / 10 / 15$ & Prorrateo & $\mathrm{S} / \mathbf{0 . 0 0}$ \\
\hline $\begin{array}{l}\text { 33. Establecer el presupuesto requerido para } \\
\text { el plan de implantación del proyecto de } \\
\text { mejora }\end{array}$ & 4 días & $17 / 10 / 15$ & $18 / 10 / 15$ & Prorrateo & $\mathrm{S} / \mathbf{0 . 0 0}$ \\
\hline
\end{tabular}




\begin{tabular}{|c|c|c|c|c|c|}
\hline Nombre de la Tarea & Duración & Comienzo & Fin & $\begin{array}{l}\text { Acumulación } \\
\text { de costos fijos }\end{array}$ & Costo total \\
\hline $\begin{array}{l}\text { 34. Establecer el tiempo aproximado para el } \\
\text { plan de implantación del proyecto de mejora }\end{array}$ & 4 días & $17 / 10 / 15$ & $18 / 10 / 15$ & Prorrateo & $\mathrm{S} / \mathbf{0 . 0 0}$ \\
\hline $\begin{array}{l}\text { 35. Presentación del Modelo de Mejora y } \\
\text { validación de los entregables. } \\
\text { Entregable: Plan de Implementación del } \\
\text { modelo de mejora para la empresa de } \\
\text { estudio. }\end{array}$ & 1 día & $21 / 10 / 15$ & $21 / 10 / 15$ & Prorrateo & $\mathrm{S} / \mathbf{3 2 0 0 . 0 0}$ \\
\hline Cierre del Proyecto & & & & & \\
\hline
\end{tabular}

Tabla 17 Plan de Trabajo - Objetivo I

Fuente: Elaboración Propia

\subsubsection{Plan de Trabajo del Objetivo General II}

\section{Duración Total del Proyecto: \\ 4 meses y 7 días \\ Costo Total del Proyecto: \\ S/.11520.00}

\begin{tabular}{|c|c|c|c|c|c|}
\hline Nombre de la Tarea & Duración & Comienzo & Fin & $\begin{array}{l}\text { Acumulación de } \\
\text { costos fijos }\end{array}$ & $\begin{array}{l}\text { Costo } \\
\text { total } \\
\end{array}$ \\
\hline $\begin{array}{l}\text { Identificar los requerimientos de la } \\
\text { herramienta para facilitar el } \\
\text { cumplimiento de lo establecido en la } \\
\text { ISO } 29110 \text {. }\end{array}$ & 3 días & $15 / 06 / 15$ & $17 / 06 / 15$ & Prorrateo & $\mathrm{S} / \mathbf{0 . 0 0}$ \\
\hline $\begin{array}{l}\text { 1.1 Recopilar información respecto a la } \\
\text { evidencia necesaria para demostrar el } \\
\text { cumplimiento de la ISO } 29110\end{array}$ & 3 día & $15 / 06 / 15$ & $17 / 06 / 15$ & Prorrateo & $\mathrm{S} / \mathbf{0 . 0 0}$ \\
\hline Realizar el Análisis y Diseño & 10 días & $18 / 06 / 15$ & 27/06/15 & Prorrateo & S/1920.00 \\
\hline $\begin{array}{l}\text { 2.1 Realizar el análisis de las } \\
\text { funcionalidades de la herramienta de } \\
\text { software. } \\
\text { Entregable: Requerimientos funcionales } \\
\text { de la herramienta. }\end{array}$ & 5 días & $17 / 06 / 15$ & $21 / 06 / 15$ & Prorrateo & $\mathrm{S} / \mathbf{8 0 0 . 0 0}$ \\
\hline
\end{tabular}




\begin{tabular}{|c|c|c|c|c|c|}
\hline Nombre de la Tarea & Duración & Comienzo & Fin & $\begin{array}{l}\text { Acumulación de } \\
\text { costos fijos }\end{array}$ & $\begin{array}{l}\text { Costo } \\
\text { total }\end{array}$ \\
\hline $\begin{array}{l}2.2 \text { Realizar el diseño de las } \\
\text { funcionalidades de la herramienta de } \\
\text { software: Diseño de la herramienta }\end{array}$ & 7 días & $21 / 06 / 15$ & $27 / 06 / 15$ & Prorrateo & $\mathrm{S} / \mathbf{1 1 2 0 . 0 0}$ \\
\hline $\begin{array}{l}\text { Implementar los componentes de la } \\
\text { herramienta de software. }\end{array}$ & 35 días & $27 / 06 / 15$ & $31 / 08 / 15$ & Prorrateo & $\mathrm{S} / 4160.00$ \\
\hline $\begin{array}{l}\text { 3.1. Construir los componentes de la } \\
\text { herramienta. }\end{array}$ & 14 días & $27 / 06 / 15$ & $10 / 07 / 15$ & Prorrateo & $S / 2240.00$ \\
\hline $\begin{array}{l}\text { 3.2. Realizar pruebas en los componentes } \\
\text { y módulos desarrollados. }\end{array}$ & 12 días & $06 / 07 / 15$ & $17 / 07 / 15$ & Prorrateo & $\mathrm{S} / \mathbf{1 9 2 0 . 0 0}$ \\
\hline $\begin{array}{l}\text { 3.3. Integrar los componentes de la } \\
\text { herramienta }\end{array}$ & 15 días & $15 / 07 / 15$ & $29 / 07 / 15$ & Prorrateo & $\mathrm{S} / \mathbf{0 . 0 0}$ \\
\hline $\begin{array}{l}\text { Probar la herramienta de software } \\
\text { desarrollada. }\end{array}$ & 34 días & 29/07/15 & $31 / 08 / 15$ & Prorrateo & $\mathrm{S} / 4960.00$ \\
\hline $\begin{array}{l}\text { 4.1. Definir los Casos de Prueba de la } \\
\text { herramienta }\end{array}$ & 3 días & $29 / 07 / 2015$ & $31 / 07 / 2015$ & Prorrateo & $\mathrm{S} / \mathbf{0 . 0 0}$ \\
\hline $\begin{array}{l}\text { 4.2. Realizar Casos de Prueba de la } \\
\text { herramienta de Software. }\end{array}$ & 31 días & $01 / 08 / 2015$ & $31 / 08 / 2015$ & Prorrateo & $\mathrm{S} / \mathbf{0 . 0 0}$ \\
\hline $\begin{array}{l}\text { 4.3. Realizar las Correcciones } \\
\text { identificadas para asegurar el } \\
\text { cumplimiento de las pruebas. }\end{array}$ & 31 días & $01 / 08 / 2015$ & $31 / 08 / 2015$ & Prorrateo & $\mathrm{S} / 4960.00$ \\
\hline $\begin{array}{l}\text { Realizar el despliegue de la } \\
\text { herramienta de software. }\end{array}$ & 15 días & 07/10/2015 & 21/10/2015 & Prorrateo & $\mathrm{S} / 480.00$ \\
\hline
\end{tabular}




\begin{tabular}{|l|l|l|l|l|l|}
\hline Nombre de la Tarea & Duración & Comienzo & Fin & $\begin{array}{l}\text { Acumulación de } \\
\text { costos fijos }\end{array}$ & $\begin{array}{l}\text { Costo } \\
\text { total }\end{array}$ \\
\hline $\begin{array}{l}\text { 5.1. Determinar las características que } \\
\text { brindará el servicio de Hosting y } \\
\text { dominio. }\end{array}$ & 9 días & $07 / 10 / 2015$ & $15 / 10 / 2015$ & Prorrateo & S/0.00 \\
\hline $\begin{array}{l}\text { 5.2. Determinar el proveedor que } \\
\text { brindará el servicio de Hosting y } \\
\text { dominio. }\end{array}$ & 1 día & $16 / 10 / 2015$ & $16 / 10 / 2015$ & Prorrateo & S/0.00 \\
\hline $\begin{array}{l}\text { 5.3. Definir el nombre del Hosting. } \\
\text { 5.4. Validar que el servicio se encuentre } \\
\text { desplegado en la web. }\end{array}$ & 1 día & $17 / 10 / 2015$ & $17 / 10 / 2015$ & Prorrateo & S/0.00 \\
\hline $\begin{array}{l}\text { 5.5. Entrega de Licencia por 30 días para } \\
\text { el uso de la herramienta de software } \\
\text { a la empresa cliente. }\end{array}$ & 1 día & $18 / 10 / 2015$ & $20 / 10 / 2015$ & Prorrateo & S/320.00 \\
\hline \begin{tabular}{l} 
Cierre del Proyecto \\
\hline
\end{tabular} & $21 / 10 / 2015$ & $21 / 10 / 2015$ & Prorrateo & S/160.00 \\
\hline
\end{tabular}

Tabla 18 Plan de Trabajo - Objetivo II Fuente: Elaboración Propia 


\section{CAPÍTULO V: DESARROLLO DE LA SOLUCIÓN PROPUESTA}

\subsection{Modelo de Mejora}

\subsubsection{Evaluación del ciclo de vida del desarrollo de software}

La evaluación consiste en evaluar el estado actual del ciclo de vida de desarrollo de software presente en los proyectos de la empresa HOLINSYS con el propósito de medir el grado de cumplimiento de la empresa con respecto a la NTP ISO/IEC 29110-5-1-2 y analizar los resultados obtenidos.

Como se mencionó en la de la propuesta de solución (Sección 4.2 Alcance), para la evaluación del ciclo de vida del desarrollo de software se está utilizando la información de los proyectos de la empresa de estudio HOLINSYS:

\section{- GUARDIAN:}

El proyecto consiste en la elaboración de un sistema web que permita sistematizar y facilitar la gestión de los contratos de la empresa Cliente. Área: Cloud Computing. Duración: 4 meses. Inicio: 2014.

- GALI:

El proyecto consiste en una aplicación móvil que permite al usuario visualizar y buscar prendas de vestir sincronizando con sus cuentas de redes sociales Área: Móvil Android. El cliente es la misma empresa. Duración: 3 meses. Inicio: 2014.

- RFID:

El proyecto consiste en una aplicación móvil que permita a los usuarios utilizar los periféricos de lectura RFID para el seguimiento y control de su inventario. Área: Móvil Android. Duración: 2 meses. Inicio: 2014. 


\subsubsection{Evaluación de los Productos de Trabajo de la Empresa}

En esta sección se muestra la evaluación detallada de los productos de trabajo de la empresa HOLINSYS con respecto a los productos de trabajo descritos en la norma. En la Tabla 19, se refleja el mapeo del contenido de los productos de trabajo de la empresa con respecto a lo descrito en la NTP ISO/IEC 29110-5-1-2, y el nivel de cumplimiento clasificado en: Alta, Media, Baja, No Cumple.

Para el mapeo del contenido, se considera que los productos de trabajo de los proyectos desarrollados por la empresa tienen las mismas secciones. Se señala con color negrita las secciones que cumplen con la NTP ISO/IEC 29110-5-1-2.

\begin{tabular}{|c|c|c|c|c|}
\hline \multirow{2}{*}{ NTP ISO/IEC 29110-5-1-2 } & \multicolumn{4}{|c|}{ Proyectos de la Empresa HOLINSYS } \\
\hline & Plantillas & $\begin{array}{l}\text { Proyecto: } \\
\text { GALI }\end{array}$ & $\begin{array}{l}\text { Proyecto: } \\
\text { RFID }\end{array}$ & $\begin{array}{c}\text { Proyecto: } \\
\text { GUARDIAN }\end{array}$ \\
\hline $\begin{array}{l}\text { Plan del Proyecto (PP) } \\
\text { Mapeo: } \\
\text { - Descripción de producto } \\
\text { - Propósito } \\
\text { - Requisitos generales del } \\
\text { Cliente } \\
\text { - Alcance } \\
\text { - Objetivos del proyecto } \\
\text { - Entregables } \\
\text { - Tareas } \\
\text { - Duración estimada de las } \\
\text { Tareas } \\
\text { - Recursos } \\
\text { - Composición del Equipo } \\
\text { de Trabajo. } \\
\text { - Calendario de las Tareas } \\
\text { del proyecto. } \\
\text { - Esfuerzo y el costo } \\
\text { estimado. } \\
\text { - Identificación de los } \\
\text { riesgos del proyecto }\end{array}$ & $\begin{array}{l}\text { Nombre: Plan del Proyecto } \\
\text { Mapeo: } \\
\text { - Alcance del Proyecto: En } \\
\text { el alcance se encuentran la } \\
\text { descripción de producto y } \\
\text { objetivos del proyecto. } \\
\text { - Entregables del Proyecto } \\
\text { - Estrategia de Control de } \\
\text { Versiones } \\
\text { - Datos del Proyecto } \\
\text { - Estructura Organizacional: } \\
\text { Equivale a Composición del } \\
\text { Equipo de Trabajo. } \\
\text { - Condiciones asumidas, } \\
\text { exclusiones y restricciones: } \\
\text { Equivale a los Requisitos } \\
\text { generales del Cliente. } \\
\text { - Gestión de Riesgos: Sólo } \\
\text { existe la sección, más no hay } \\
\text { contenido. } \\
\text { - Recursos }\end{array}$ & No Encontrado. & No Encontrado. & $\begin{array}{l}\text { Nombre: GUARDIAN- Plan de } \\
\text { Proyecto } \\
\text { Mapeo: } \\
\text { - Alcance del Proyecto: En el alcance se } \\
\text { encuentran la descripción de producto y } \\
\text { objetivos del proyecto. } \\
\text { - Entregables del Proyecto } \\
\text { - Estrategia de Control de Versiones } \\
\text { - Datos del Proyecto } \\
\text { - Estructura Organizacional: Equivale a } \\
\text { Composición del Equipo de Trabajo. } \\
\text { - Condiciones asumidas, exclusiones y } \\
\text { restricciones: Equivale a los Requisitos } \\
\text { generales del Cliente. } \\
\text { - Gestión de Riesgos: Sólo existe la } \\
\text { sección, más no hay contenido. } \\
\text { - Recursos } \\
\text { - Diagrama de Gantt: Describen las } \\
\text { tareas, cronograma y duración del } \\
\text { proyecto, en un archivo con formato Ms } \\
\text { Project. }\end{array}$ \\
\hline
\end{tabular}




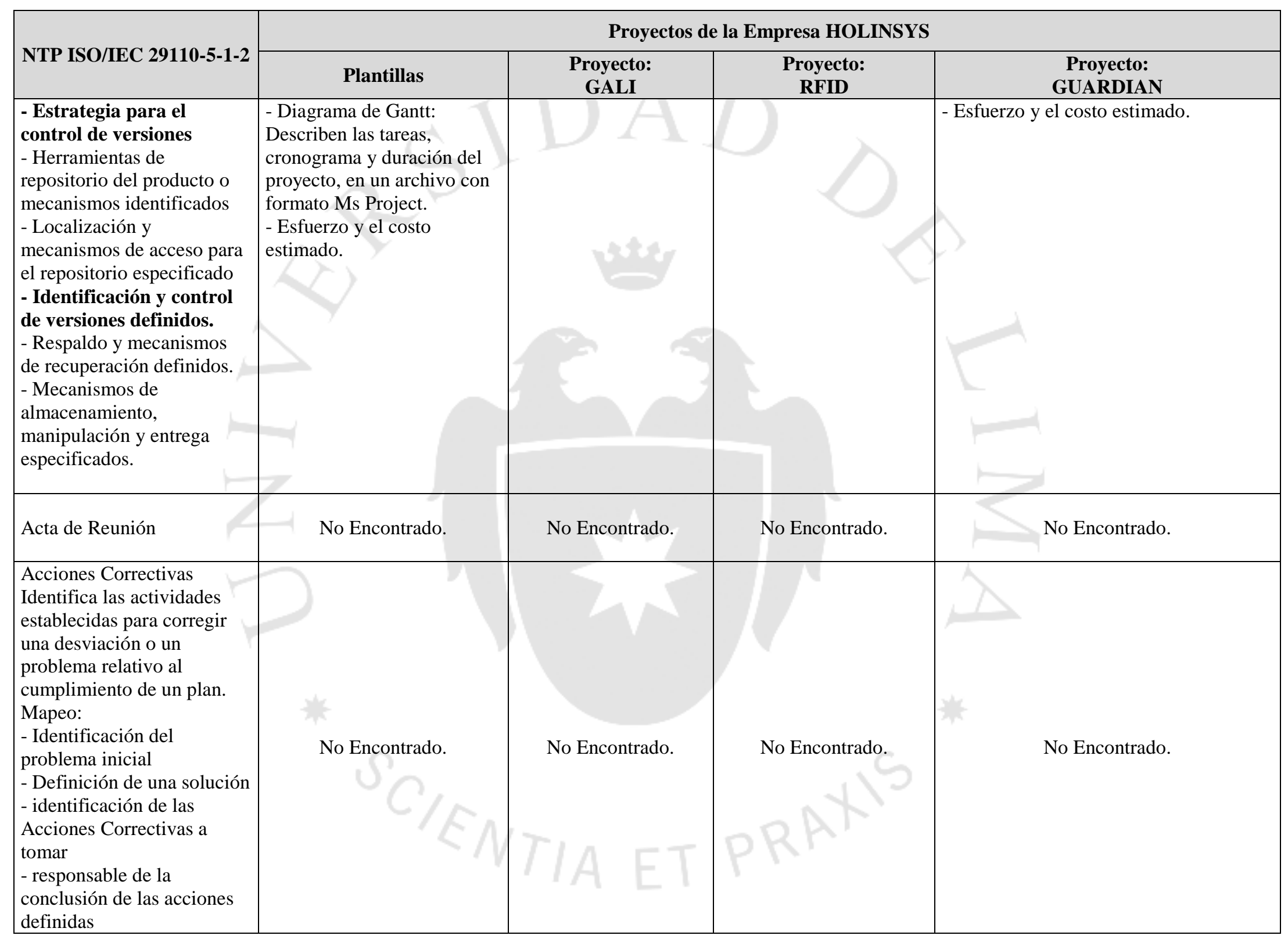




\begin{tabular}{|c|c|c|c|c|}
\hline \multirow{2}{*}{ NTP ISO/IEC 29110-5-1-2 } & \multicolumn{4}{|c|}{ Proyectos de la Empresa HOLINSYS } \\
\hline & Plantillas & $\begin{array}{l}\text { Proyecto: } \\
\text { GALI }\end{array}$ & $\begin{array}{l}\text { Proyecto: } \\
\text { RFID }\end{array}$ & $\begin{array}{c}\text { Proyecto: } \\
\text { GUARDIAN }\end{array}$ \\
\hline $\begin{array}{l}\text { - fecha de apertura y fecha } \\
\text { de cierre esperada } \\
\text { - un indicador de estado } \\
\text { - acciones de seguimiento }\end{array}$ & & & & \\
\hline $\begin{array}{l}\text { Acta de Aceptación } \\
\text { Mapeo: } \\
\text { - Registro de la recepción } \\
\text { de la entrega } \\
\text { - Identificación de la fecha } \\
\text { de recepción } \\
\text { - Identificación de los } \\
\text { elementos entregados } \\
\text { - Registro de la verificación } \\
\text { de los criterios de } \\
\text { aceptación definidos por } \\
\text { parte del Cliente } \\
\text { - Identificación de cualquier } \\
\text { asunto pendiente (en caso } \\
\text { de ser aplicable) } \\
\text { - Firmado como recibido } \\
\text { por parte del Cliente. }\end{array}$ & $\begin{array}{l}\text { Nombre: Acta de } \\
\text { Aceptación } \\
\text { Mapeo: } \\
\text { Descripción de } \\
\text { Entregables: } \\
\text { Responsables de } \\
\text { Aceptación: Se encuentra la } \\
\text { descripción de la recepción, } \\
\text { fechas de recepción, } \\
\text { elementos entregados. } \\
\text { Responsables de } \\
\text { Aceptación: } \\
\text { las firmas correspondientes } \\
\text { por parte del Cliente y el } \\
\text { sponsor. No existen las } \\
\text { secciones de verificación de } \\
\text { criterios de aceptación y } \\
\text { asuntos pendientes. } \\
\end{array}$ & No Encontrado. & No Encontrado. & $\begin{array}{l}\text { Nombre: Acta de Aceptación Guardián } \\
\text { Mapeo: } \\
\text { Descripción de Entregables: } \\
\text { Responsables de Aceptación: Se } \\
\text { encuentra la descripción de la recepción, } \\
\text { fechas de recepción, elementos } \\
\text { entregados. } \\
\text { Responsables de Aceptación: } \\
\text { las firmas correspondientes por parte } \\
\text { del Cliente y el sponsor. No existen las } \\
\text { secciones de verificación de criterios de } \\
\text { aceptación y asuntos pendientes. }\end{array}$ \\
\hline $\begin{array}{l}\text { Enunciado de Trabajo } \\
\text { Descripción del trabajo a ser } \\
\text { realizado en relación al } \\
\text { desarrollo de Software. } \\
\text { Mapeo: } \\
\text { - Descripción del producto } \\
\text { - Propósito } \\
\text { - Requisitos generales del } \\
\text { Cliente } \\
\text { - Alcance, que describa } \\
\text { que sí y qué no está } \\
\text { incluido } \\
\text { - Objetivos del proyecto } \\
\text { - Entregables, lista de }\end{array}$ & $\begin{array}{l}\text { Nombre: Propuesta del } \\
\text { Proyecto } \\
\text { Mapeo: } \\
\text { El enunciado de trabajo } \\
\text { cumple con las secciones } \\
\text { requeridas en la ISO } 29110 .\end{array}$ & $\begin{array}{l}\text { No Encontrado. } \\
\text {-En lugar de un } \\
\text { enunciado de Trabajo, } \\
\text { se mostró un Mockup } \\
\text { con la interfaz de la } \\
\text { aplicación. }\end{array}$ & $\begin{array}{l}\text { Nombre: APLICATIVO } \\
\text { MOVIL RFID } \\
\text { Mapeo: } \\
\text { El enunciado de trabajo } \\
\text { cumple con las secciones } \\
\text { requeridas en la ISO } \\
29110 .\end{array}$ & No Encontrado. \\
\hline
\end{tabular}




\begin{tabular}{|c|c|c|c|c|}
\hline \multirow{3}{*}{$\begin{array}{l}\text { NTP ISO/IEC 29110-5-1-2 } \\
\text { productos a entregar al } \\
\text { CL. }\end{array}$} & \multicolumn{4}{|c|}{ Proyectos de la Empresa HOLINSYS } \\
\hline & Plantillas & $\begin{array}{l}\text { Proyecto: } \\
\text { GALI }\end{array}$ & $\begin{array}{l}\text { Proyecto: } \\
\text { RFID }\end{array}$ & \multirow[t]{2}{*}{$\begin{array}{c}\text { Proyecto: } \\
\text { GUARDIAN }\end{array}$} \\
\hline & & & & \\
\hline $\begin{array}{l}\text { Reporte de Avance } \\
\text { Mapeo: } \\
\text { - Estado actual de las } \\
\text { Tareas contra las Tareas } \\
\text { planeadas } \\
\text { - Estado de los resultados } \\
\text { reales contra los } \\
\text { objetivos/metas establecidos } \\
\text { - Estado de los Recursos } \\
\text { asignados reales contra los } \\
\text { Recursos planeados } \\
\text { - Estado de los costos } \\
\text { reales contra los } \\
\text { presupuestos estimados } \\
\text { - Estado calendario real } \\
\text { contra el calendario } \\
\text { planeado } \\
\text { - Estado de los riesgos } \\
\text { actuales con respecto a los } \\
\text { identificados previamente } \\
\text { - Registro de cualquier } \\
\text { desviación de las Tareas } \\
\text { planeadas y su causa }\end{array}$ & $\begin{array}{l}\text { Nombre: Reporte de Avance } \\
\text { Mapeo: El producto de } \\
\text { trabajo cumple con la } \\
\text { mayoría de secciones } \\
\text { descritas en la ISO } 29110 . \\
\text { Sin embargo, no se } \\
\text { encuentra una sección } \\
\text { similar a los resultados de } \\
\text { los objetivos. }\end{array}$ & ntrado & $\begin{array}{l}\text { Nombre: Reporte de } \\
\text { Avance } \\
\text { Mapeo: } \\
\text { El producto de trabajo } \\
\text { cumple con la mayoría } \\
\text { de secciones descritas en } \\
\text { la ISO } 29110 . \\
\text { Sin embargo no se } \\
\text { encuentra una sección } \\
\text { similar a los resultados } \\
\text { de los objetivos. }\end{array}$ & No Encontrado. \\
\hline $\begin{array}{l}\text { Casos y Procedimientos de } \\
\text { Prueba } \\
\text { Elementos necesarios para } \\
\text { probar el código. } \\
\text { Los Casos de Prueba } \\
\text { pueden incluir: } \\
\text { - Identificación del Caso } \\
\text { de Prueba } \\
\text { - Elementos a probar } \\
\text { - Especificaciones de }\end{array}$ & $\begin{array}{l}\text { Nombre: Casos de Prueba } \\
\text { Mapeo: } \\
\text { Los Casos de Prueba pueden } \\
\text { incluir: } \\
\text { - Identificación del Caso de } \\
\text { Prueba } \\
\text { - Elementos a probar } \\
\text { - Especificaciones de } \\
\text { entrada } \\
\text { - Especificaciones de salida }\end{array}$ & $\begin{array}{l}\text { No Encontrado } \\
{[\sqrt{-1}}\end{array}$ & $\begin{array}{l}\text { Nombre: CP_RFID_11- } \\
\text { 09-2014 } \\
\text { Mapeo: } \\
\text { Los Casos de Prueba } \\
\text { pueden incluir: } \\
\text { - Identificación del Caso } \\
\text { de Prueba } \\
\text { - Elementos a probar } \\
\text { - Especificaciones de } \\
\text { entrada }\end{array}$ & No Encontrado. \\
\hline
\end{tabular}




\begin{tabular}{|c|c|c|c|c|}
\hline \multirow{2}{*}{ NTP ISO/IEC 29110-5-1-2 } & \multicolumn{4}{|c|}{ Proyectos de la Empresa HOLINSYS } \\
\hline & Plantillas & $\begin{array}{l}\text { Proyecto: } \\
\text { GALI }\end{array}$ & $\begin{array}{l}\text { Proyecto: } \\
\text { RFID }\end{array}$ & $\begin{array}{c}\text { Proyecto: } \\
\text { GUARDIAN }\end{array}$ \\
\hline \begin{tabular}{|l} 
entrada \\
- Especificaciones de \\
salida \\
- Necesidades del entorno \\
- Requisitos de \\
procedimientos especiales \\
- Dependencias de interfaz \\
Los Procedimientos de \\
Prueba pueden incluir: \\
- Identificación: nombre \\
de la prueba, descripción \\
de la prueba y la fecha de \\
finalización de la prueba. \\
- Identificación de posibles \\
problemas de \\
implementación \\
- Identificación de la \\
persona que complete el \\
Procedimientos de Prueba \\
- Identificación de los \\
requisitos previos \\
- Identificación de los \\
pasos del procedimiento \\
incluyendo el número de \\
paso, la acción \\
requerida por el probador \\
y los resultados esperados
\end{tabular} & $\begin{array}{l}\text { - Necesidades del entorno } \\
\text { - Requisitos de } \\
\text { procedimientos especiales } \\
\text { - Dependencias de interfaz } \\
\text { Los Procedimientos de } \\
\text { Prueba pueden incluir: } \\
\text { - Identificación: nombre de } \\
\text { la prueba, descripción de la } \\
\text { prueba y la fecha de } \\
\text { finalización de la prueba. } \\
\text { - Identificación de posibles } \\
\text { problemas de } \\
\text { implementación } \\
\text { - Identificación de la persona } \\
\text { que complete el } \\
\text { Procedimientos de Prueba } \\
\text { - Identificación de los } \\
\text { requisitos previos } \\
\text { - Identificación de los pasos } \\
\text { del procedimiento } \\
\text { incluyendo el número de } \\
\text { paso, la acción } \\
\text { requerida por el probador y } \\
\text { los resultados esperados. } \\
\end{array}$ & 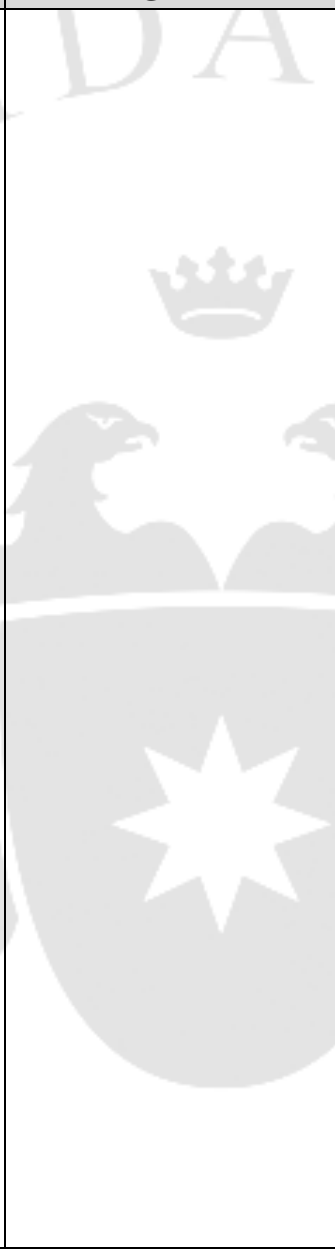 & \begin{tabular}{|l|} 
- Especificaciones de \\
salida \\
- Necesidades del \\
entorno \\
- Requisitos de \\
procedimientos \\
especiales \\
- Dependencias de \\
interfaz \\
Los Procedimientos de \\
Prueba pueden incluir: \\
- Identificación: nombre \\
de la prueba, descripción \\
de la prueba y la fecha de \\
finalización de la prueba. \\
- Identificación de \\
posibles problemas de \\
implementación \\
- Identificación de la \\
persona que complete el \\
Procedimientos de \\
Prueba \\
- Identificación de los \\
requisitos previos \\
- Identificación de los \\
pasos del procedimiento \\
incluyendo el número de \\
paso, la acción \\
requerida por el probador \\
y los resultados \\
esperados.
\end{tabular} & $\infty$ \\
\hline \begin{tabular}{|l|} 
Diseño del Software \\
Información textual y \\
gráfica de la estructura de \\
Software. \\
Diseño arquitectónico (de \\
\end{tabular} & \begin{tabular}{|l} 
Nombre: Diseño de \\
Software \\
Mapeo: \\
Diseño arquitectónico (de \\
alto nivel) del Software:
\end{tabular} & $\begin{array}{l}\text { Nombre: Diseño de } \\
\text { Software - Aplicación } \\
\text { GALI } \\
\text { Mapeo: } \\
\text { Diseño arquitectónico }\end{array}$ & $\begin{array}{l}\text { Nombre: } \\
\text { Diseño_RFID_29-08- } \\
2014 \\
\text { Mapeo: } \\
\text { Diseño arquitectónico }\end{array}$ & No Encontrado. \\
\hline
\end{tabular}




\begin{tabular}{|c|c|c|c|c|}
\hline \multirow{2}{*}{ NTP ISO/IEC 29110-5-1-2 } & \multicolumn{4}{|c|}{ Proyectos de la Empresa HOLINSYS } \\
\hline & Plantillas & $\begin{array}{c}\text { Proyecto: } \\
\text { GALI }\end{array}$ & $\begin{array}{c}\text { Proyecto: } \\
\text { RFID }\end{array}$ & $\begin{array}{c}\text { Proyecto: } \\
\text { GUARDIAN }\end{array}$ \\
\hline $\begin{array}{l}\text { alto nivel) del Software: } \\
\text { - Identifica los } \\
\text { Componente de Software } \\
\text { requeridos } \\
\text { - Identifica la relación } \\
\text { entre los Componente de } \\
\text { Software } \\
\text { Consideraciones } \\
\text { requeridas: } \\
\text { - Características de } \\
\text { desempeño de Software } \\
\text { - Interfaces de hardware, } \\
\text { Software y humanas } \\
\text { - Características de } \\
\text { seguridad } \\
\text { - Requisitos de diseño de } \\
\text { base de datos } \\
\text { - Manejo de errores y } \\
\text { atributos de recuperación } \\
\text { Diseño Detallado (de bajo } \\
\text { nivel) del Software } \\
\text { - Proporciona diseño } \\
\text { detallado (puede ser } \\
\text { representado como un } \\
\text { prototipo, diagrama de } \\
\text { flujo, diagrama entidad- } \\
\text { relación, pseudo código, } \\
\text { etc.) } \\
\text { - Proporciona el formato } \\
\text { de entrada / salida de los } \\
\text { datos } \\
\text { - Proporciona } \\
\text { especificaciones de las } \\
\text { necesidades de } \\
\text { almacenamiento de los } \\
\text { datos }\end{array}$ & $\begin{array}{l}\text { - Componentes de Software } \\
\text { - Relación entre los } \\
\text { Componente de Software } \\
\text { Consideraciones requeridas: } \\
\text { - Características de } \\
\text { desempeño de Software } \\
\text { - Interfaces de hardware, } \\
\text { Software y humanas } \\
\text { - Características de } \\
\text { seguridad } \\
\text { - Requisitos de diseño de } \\
\text { base de datos } \\
\text { - Manejo de errores y } \\
\text { atributos de recuperación } \\
\text { Diseño Detallado (de bajo } \\
\text { nivel) del Software } \\
\text { - Presentación del Diseño } \\
\text { del Sistema: Equivale a la } \\
\text { representación de un } \\
\text { prototipo, diagrama de flujo, } \\
\text { etc. } \\
\text { - Formato de entrada / salida } \\
\text { de los datos } \\
\text { - Proporciona } \\
\text { especificaciones de las } \\
\text { necesidades de } \\
\text { almacenamiento de los datos } \\
\text { - Convenciones de } \\
\text { denominación de los datos } \\
\text { requeridos } \\
\text { - Modelo físico de la Base } \\
\text { de Datos } \\
\text { - Campos de datos y el } \\
\text { propósito de cada elemento } \\
\text { de datos requerido } \\
\text { - Proporciona las }\end{array}$ & $\begin{array}{l}\text { (de alto nivel) del } \\
\text { Software: } \\
\text { - Componentes de } \\
\text { Software } \\
\text { - Relación entre los } \\
\text { Componente de } \\
\text { Software } \\
\text { Consideraciones } \\
\text { requeridas: } \\
\text { - Características de } \\
\text { desempeño de } \\
\text { Software } \\
\text { - Interfaces de } \\
\text { hardware, Software y } \\
\text { humanas } \\
\text { - Características de } \\
\text { seguridad } \\
\text { - Requisitos de diseño } \\
\text { de base de datos } \\
\text { - Manejo de errores y } \\
\text { atributos de } \\
\text { recuperación } \\
\text { Diseño Detallado (de } \\
\text { bajo nivel) del } \\
\text { Software } \\
\text { - Presentación del } \\
\text { Diseño del Sistema: } \\
\text { Equivale a la } \\
\text { representación de un } \\
\text { prototipo, diagrama de } \\
\text { flujo, etc. } \\
\text { - Formato de entrada / } \\
\text { salida de los datos } \\
\text { - Proporciona } \\
\text { especificaciones de las } \\
\text { necesidades de }\end{array}$ & $\begin{array}{l}\text { (de alto nivel) del } \\
\text { Software: } \\
\text { - Componentes de } \\
\text { Software } \\
\text { - Relación entre los } \\
\text { Componente de Software } \\
\text { Consideraciones } \\
\text { requeridas: } \\
\text { - Características de } \\
\text { desempeño de Software } \\
\text { - Interfaces de hardware, } \\
\text { Software y humanas } \\
\text { - Características de } \\
\text { seguridad } \\
\text { - Requisitos de diseño de } \\
\text { base de datos } \\
\text { - Manejo de errores y } \\
\text { atributos de recuperación } \\
\\
\text { Diseño Detallado (de } \\
\text { bajo nivel) del Software } \\
\text { - Presentación del Diseño } \\
\text { del Sistema: Equivale a } \\
\text { la representación de un } \\
\text { prototipo, diagrama de } \\
\text { flujo, etc. } \\
\text { - Formato de entrada / } \\
\text { salida de los datos } \\
\text { - Proporciona } \\
\text { especificaciones de las } \\
\text { necesidades de } \\
\text { almacenamiento de los } \\
\text { datos } \\
\text { - Convenciones de } \\
\text { denominación de los } \\
\text { datos requeridos }\end{array}$ & \\
\hline
\end{tabular}




\begin{tabular}{|c|c|c|c|c|}
\hline \multirow{2}{*}{ NTP ISO/IEC 29110-5-1-2 } & \multicolumn{4}{|c|}{ Proyectos de la Empresa HOLINSYS } \\
\hline & Plantillas & $\begin{array}{l}\text { Proyecto: } \\
\text { GALI }\end{array}$ & $\begin{array}{l}\text { Proyecto: } \\
\text { RFID }\end{array}$ & $\begin{array}{l}\text { Proyecto: } \\
\text { GUARDIAN }\end{array}$ \\
\hline $\begin{array}{l}\text { - Establece convenciones } \\
\text { de denominación de los } \\
\text { datos requeridos } \\
\text { - Define el formato de las } \\
\text { estructuras de datos } \\
\text { requeridas } \\
\text { - Define los campos de } \\
\text { datos y el propósito de } \\
\text { cada elemento de datos } \\
\text { requerido } \\
\text { - Proporciona las } \\
\text { especificaciones de la } \\
\text { estructura del programa }\end{array}$ & $\begin{array}{l}\text { especificaciones de la } \\
\text { estructura del programa }\end{array}$ & \begin{tabular}{|l} 
almacenamiento de los \\
datos \\
- Convenciones de \\
denominación de los \\
datos requeridos \\
- Modelo físico de la \\
Base de Datos \\
- Campos de datos y el \\
propósito de cada \\
elemento de datos \\
requerido \\
- Proporciona las \\
especificaciones de la \\
estructura del \\
programa
\end{tabular} & $\begin{array}{l}\text { - Modelo físico de la } \\
\text { Base de Datos } \\
\text { - Campos de datos y el } \\
\text { propósito de cada } \\
\text { elemento de datos } \\
\text { requerido } \\
\text { - Proporciona las } \\
\text { especificaciones de la } \\
\text { estructura del programa }\end{array}$ & 4 \\
\hline $\begin{array}{l}\text { Especificación de } \\
\text { Requisitos (ER): } \\
\text { Identifica los requisitos de } \\
\text { Software. } \\
\text { Mapeo/ Descripción de los } \\
\text { Requisitos: } \\
\text { - Introducción - } \\
\text { descripción general del } \\
\text { Software y su uso dentro } \\
\text { del Alcance del negocio } \\
\text { del Cliente; } \\
\text { - Descripción de los } \\
\text { requisitos: } \\
\text { - Funcionalidad - } \\
\text { necesidades establecidas a } \\
\text { ser satisfechas por el } \\
\text { Software cuando se usa en } \\
\text { condiciones específicas. La } \\
\text { funcionalidad debe ser } \\
\text { adecuada, precisa y } \\
\text { segura (safe); }\end{array}$ & $\begin{array}{l}\text { Nombre: Historia de } \\
\text { Usuarios } \\
\text { Mapeo: } \\
\text { - Historia de Versiones } \\
\text { - Verificado por } \\
\text { - Validado por } \\
\text { - Objetivo } \\
\text { - Alcance del software } \\
\text { - Historio de usuario: } \\
\text { Descripción de la } \\
\text { funcionalidad } \\
\quad \text {-Nombre de historia } \\
\quad \text {-Prioridad en negocio } \\
\quad \text {-Riesgo de desarrollo } \\
\quad \text {-Duración estimada } \\
\text {-Programador } \\
\text { responsable } \\
\text {-Descripción } \\
\text {-Mockup } \\
\text {-Cuando } \\
\text {-Test de Aceptación } \\
\end{array}$ & $\begin{array}{l}\text { Nombre: Historia de } \\
\text { Usuarios } \\
\text { La Historia de usuario } \\
\text { no tiene secciones } \\
\text { específicas para el } \\
\text { llenado de las } \\
\text { secciones: Interfaz de } \\
\text { usuario, Interfaces } \\
\text { externas, Fiabilidad, } \\
\text { Eficiencia, entre otros. }\end{array}$ & $\begin{array}{l}\text { Nombre: HU_RFID 27- } \\
\text { 08-2014 } \\
\text { La Historia de usuario no } \\
\text { tiene secciones } \\
\text { específicas para el } \\
\text { llenado de las secciones: } \\
\text { Interfaz de usuario, } \\
\text { Interfaces externas, } \\
\text { Fiabilidad, Eficiencia, } \\
\text { entre otros. }\end{array}$ & No Encontrado. \\
\hline
\end{tabular}




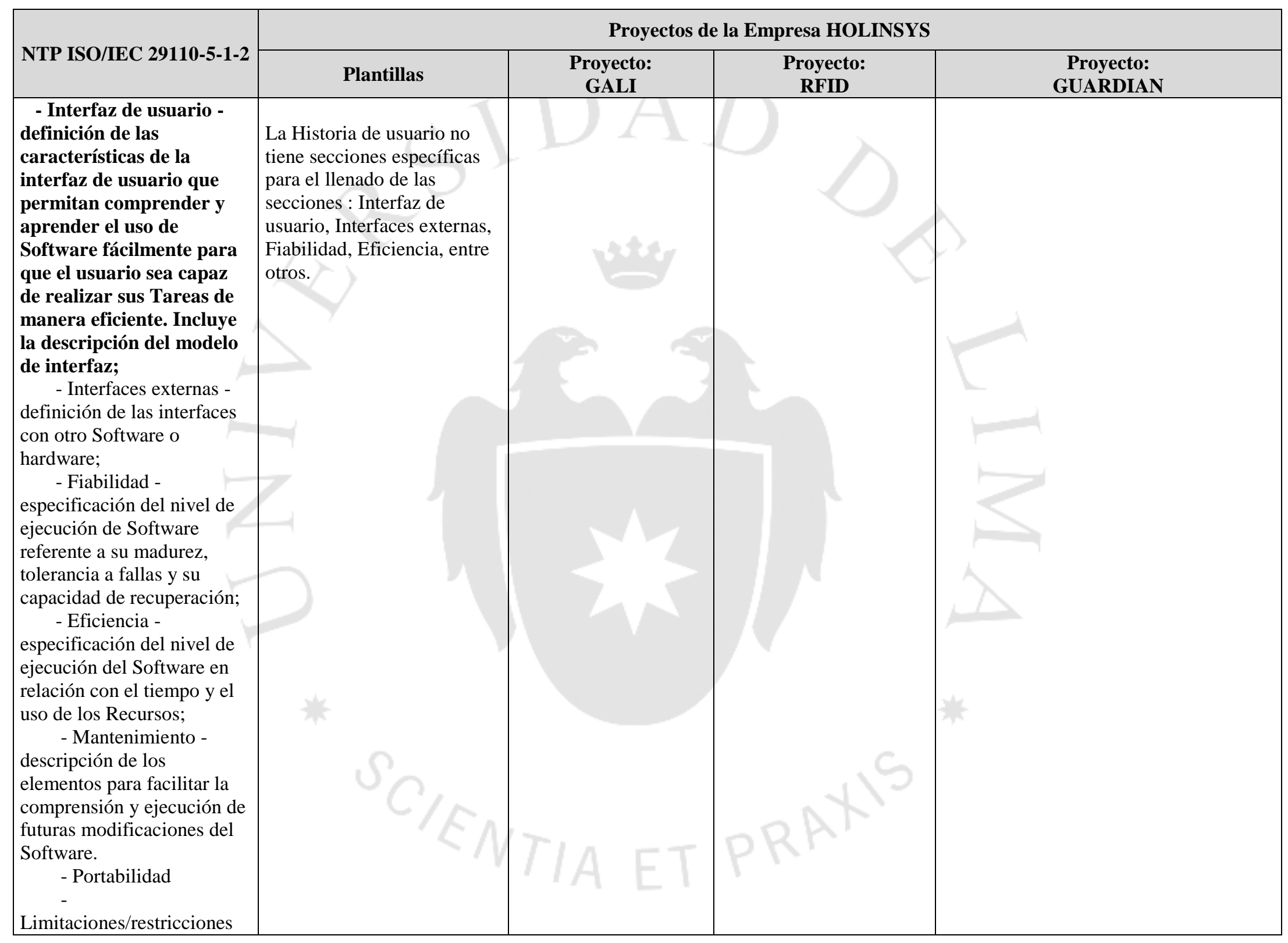




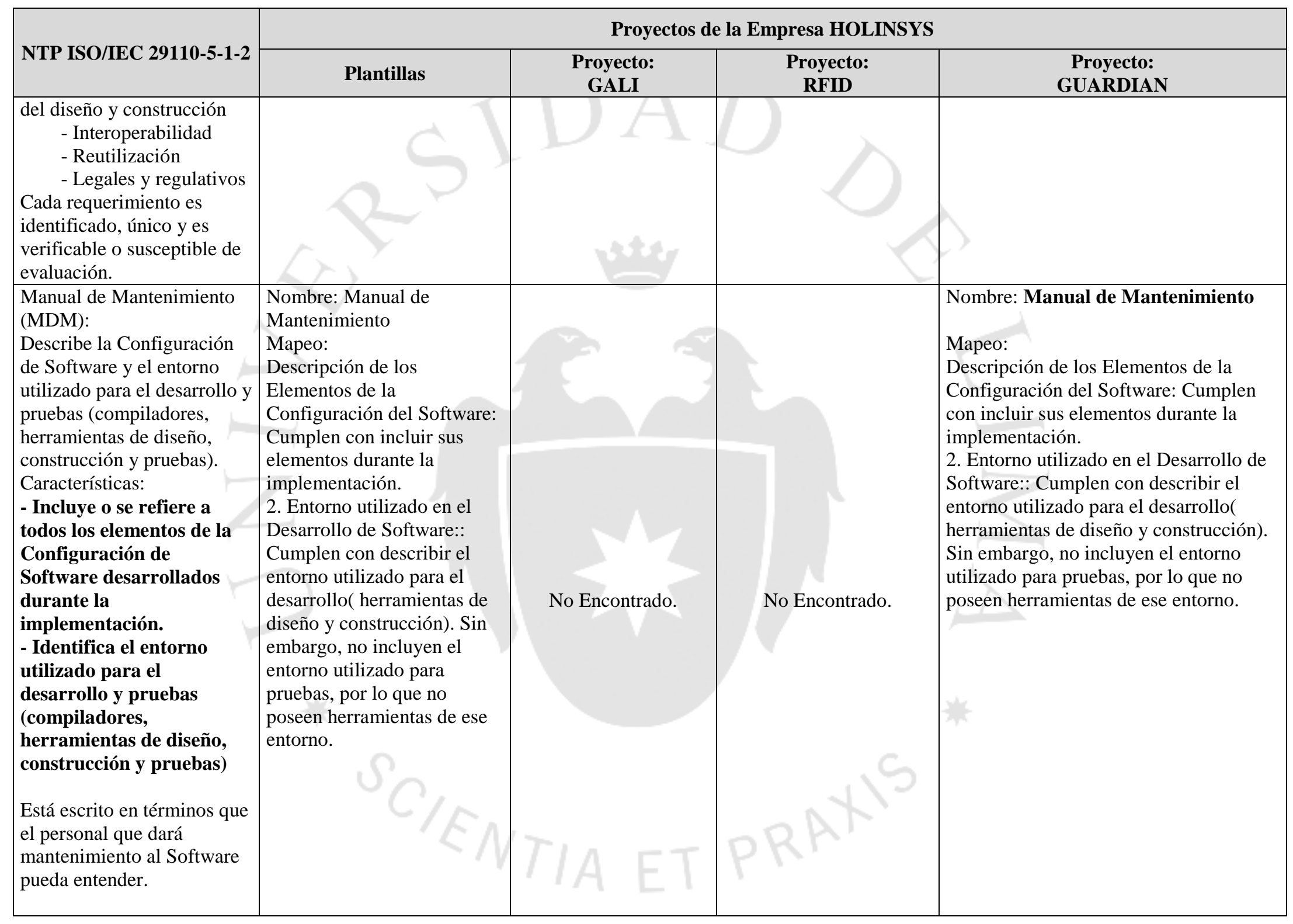




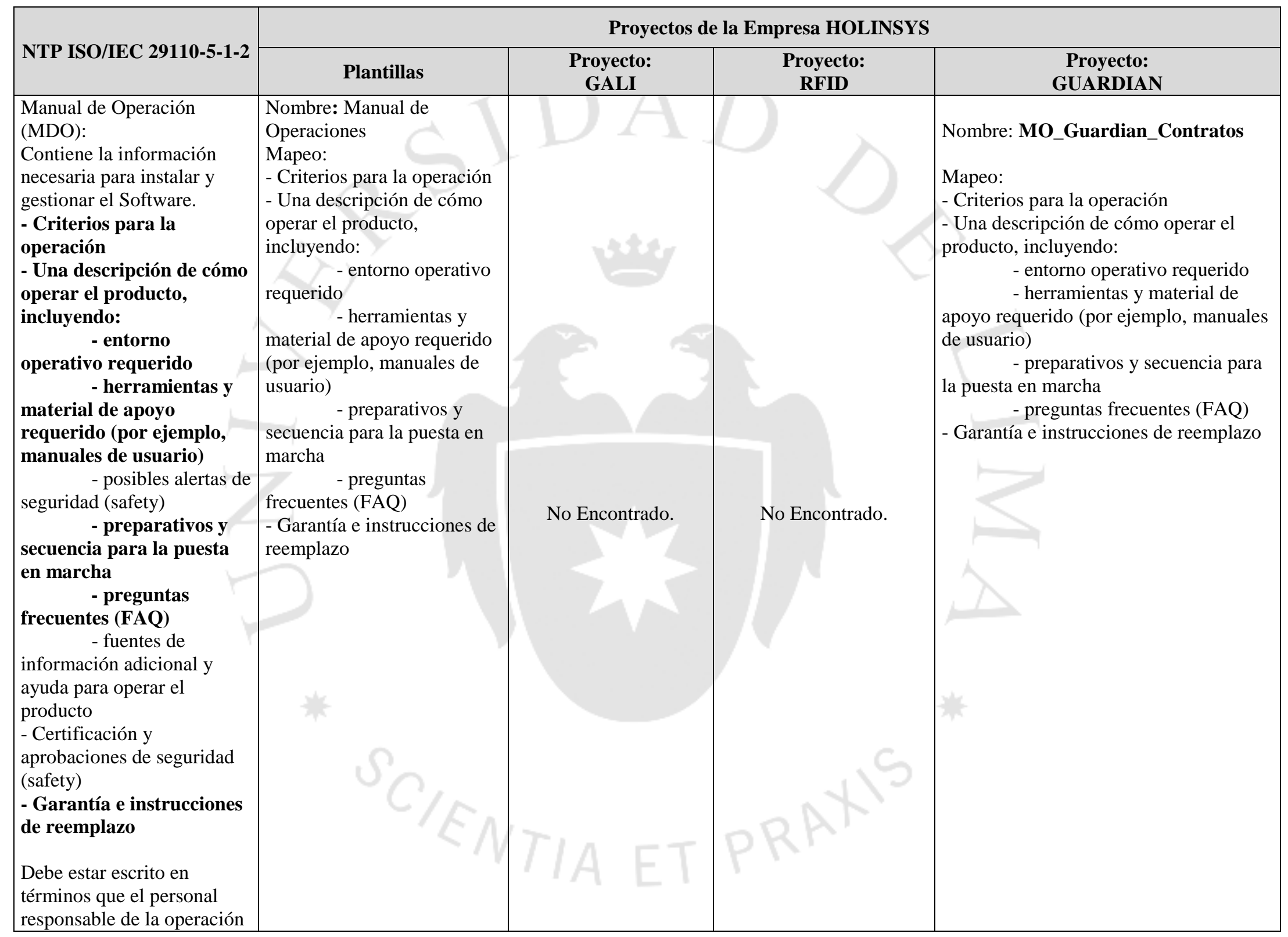




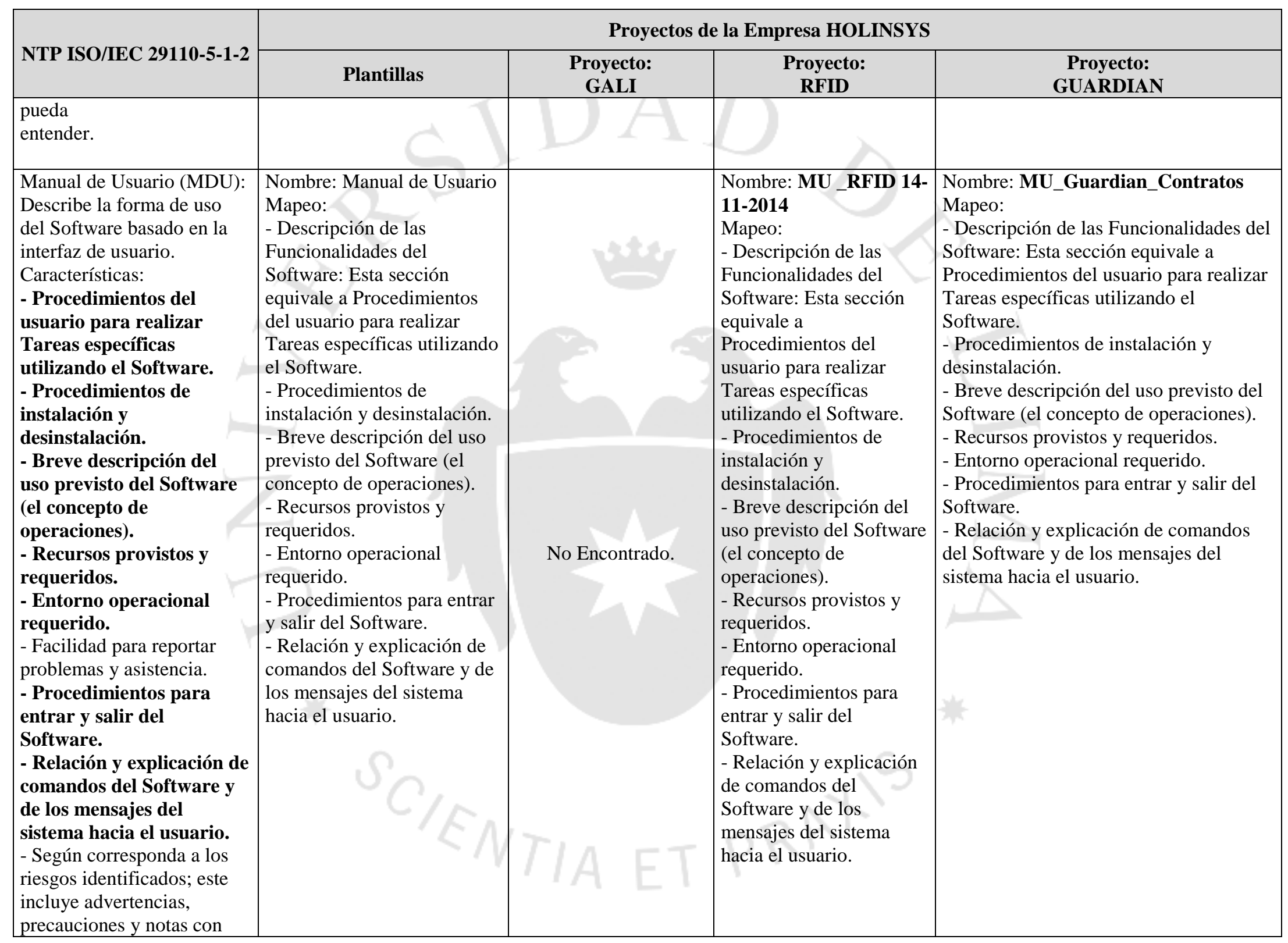




\begin{tabular}{|c|c|c|c|c|}
\hline \multirow{2}{*}{ NTP ISO/IEC 29110-5-1-2 } & \multicolumn{4}{|c|}{ Proyectos de la Empresa HOLINSYS } \\
\hline & Plantillas & $\begin{array}{l}\text { Proyecto: } \\
\text { GALI }\end{array}$ & $\begin{array}{l}\text { Proyecto: } \\
\text { RFID }\end{array}$ & $\begin{array}{c}\text { Proyecto: } \\
\text { GUARDIAN }\end{array}$ \\
\hline $\begin{array}{l}\text { correcciones. } \\
\text { - Incluye los procedimientos } \\
\text { para la solución de } \\
\text { problemas y corrección de } \\
\text { errores. }\end{array}$ & & & & \\
\hline $\begin{array}{l}\text { Registro de } \\
\text { Trazabilidad(RDT): } \\
\text { Documenta la relación } \\
\text { entre los requisitos } \\
\text { incluidos en la } \\
\text { Especificación de } \\
\text { Requisitos, los elementos } \\
\text { del Diseño de Software, los } \\
\text { Componente de Software, } \\
\text { los Casos y los } \\
\text { Procedimientos de Prueba. } \\
\text { Mapeo: } \\
\text { - Especificación de los } \\
\text { requisitos por rastrear. } \\
\text { - Proporciona el mapeo } \\
\text { (hacia adelante y hacia } \\
\text { atrás) de los requisitos a los } \\
\text { elementos del Diseño de } \\
\text { Software, el Componente de } \\
\text { Software, los Casos de } \\
\text { Prueba y los Procedimientos } \\
\text { de Prueba. }\end{array}$ & $\begin{array}{l}\text { Nombre: Traceability Matrix } \\
\text { Casos de uso por Requisitos } \\
\text { en la especificación de } \\
\text { Requisitos. }\end{array}$ & No Encontrado. & No Encontrado. & $\begin{array}{l}\text { Nombre: Traceability Reporte } \\
\text { Existe una Registro de Trazabilidad } \\
\text { parcial, el cual cumple solamente con la } \\
\text { relación entre los requisitos incluidos en } \\
\text { la Especificación de Requisitos y Casos } \\
\text { de Prueba. }\end{array}$ \\
\hline
\end{tabular}




\begin{tabular}{|c|c|c|c|c|}
\hline \multirow{2}{*}{ NTP ISO/IEC 29110-5-1-2 } & \multicolumn{4}{|c|}{ Proyectos de la Empresa HOLINSYS } \\
\hline & Plantillas & $\begin{array}{l}\text { Proyecto: } \\
\text { GALI }\end{array}$ & $\begin{array}{l}\text { Proyecto: } \\
\text { RFID }\end{array}$ & $\begin{array}{c}\text { Proyecto: } \\
\text { GUARDIAN }\end{array}$ \\
\hline $\begin{array}{l}\text { Reporte de Pruebas (RP): } \\
\text { Mapeo: } \\
\text { - Un resumen de cada } \\
\text { defecto. } \\
\text { - Identificación de los } \\
\text { Casos de Prueba en } \\
\text { cuestión. } \\
\text { - Nombre del probador } \\
\text { que encontró cada defecto. } \\
\text { - Severidad de cada } \\
\text { defecto. } \\
\text { - Identificación de la(s) } \\
\text { función(es) afectada(s) por } \\
\text { cada defecto. } \\
\text { - Fecha en que cada } \\
\text { defecto fue originado. } \\
\text { - Fecha en que cada } \\
\text { defecto fue resuelto. } \\
\text { - Nombre de la persona } \\
\text { quién resolvió cada } \\
\text { defecto. }\end{array}$ & $\begin{array}{l}\text { Nombre: Reporte de Pruebas } \\
\text { Mapeo: } \\
\text { NOMBRE MÓDULO: } \\
\text { Muestra una matriz de todos } \\
\text { los elementos que establece } \\
\text { la norma ISO } 29110 . \\
\end{array}$ & No Encontrado. & No Encontrad & $\begin{array}{l}\text { Nombre: Reporte de Pruebas } \\
\text { GUARDIAN } \\
\text { Mapeo: } \\
\text { NOMBRE MÓDULO: Muestra una } \\
\text { matriz de todos los elementos que } \\
\text { establece la norma ISO } 29110 \text {. }\end{array}$ \\
\hline \multicolumn{5}{|l|}{ Ambos procesos } \\
\hline $\begin{array}{l}\text { Solicitud de Cambio (SDC): } \\
\text { Requisición de una } \\
\text { modificación para corregir } \\
\text { un problema o incorporar } \\
\text { una mejora en el Software o } \\
\text { en su documentación. } \\
\text { Mapeo: } \\
\text { - Identifica el propósito } \\
\text { del cambio } \\
\text { - estado de la solicitud } \\
\text { - información de contacto } \\
\text { del solicitante } \\
\text { - Sistema(s) impactado(s) }\end{array}$ & \begin{tabular}{|l} 
Nombre: Solicitud de \\
Cambio \\
Mapeo: \\
- Identifica el propósito del \\
cambio: Equivale a la \\
sección "Razón". \\
- Estado de la Solicitud: \\
Equivale a Descripción de la \\
Solicitud. \\
- información de contacto \\
del solicitante \\
- Sistema(s) impactado(s): \\
Equivale a las fases del \\
\end{tabular} & \begin{tabular}{|l} 
Nombre: Solicitud de \\
Cambio-06-02-2015 \\
Nombre: Solicitud de \\
Cambio \\
Mapeo: \\
- Identifica el propósito \\
del cambio: Equivale a \\
la sección "Razón". \\
- Estado de la \\
Solicitud: Equivale a \\
Descripción de la \\
Solicitud. \\
- información de \\
\end{tabular} & No Encontrad & No Encontrado. \\
\hline
\end{tabular}




\begin{tabular}{|c|c|c|c|c|}
\hline \multirow[b]{2}{*}{ NTP ISO/IEC 29110-5-1-2 } & \multicolumn{4}{|c|}{ Proyectos de la Empresa HOLINSYS } \\
\hline & Plantillas & $\begin{array}{l}\text { Proyecto: } \\
\text { GALI }\end{array}$ & $\begin{array}{l}\text { Proyecto: } \\
\text { RFID }\end{array}$ & $\begin{array}{c}\text { Proyecto: } \\
\text { GUARDIAN }\end{array}$ \\
\hline $\begin{array}{l}\text { - Impacto en la operación } \\
\text { de sistemas existentes } \\
\text { - Impacto en la } \\
\text { documentación asociada } \\
\text { - Criticidad de la solicitud } \\
\text { y fecha en que se requiere }\end{array}$ & $\begin{array}{l}\text { proyecto. } \\
\text { - Impacto en la operación de } \\
\text { sistemas existentes } \\
\text { - Impacto en la } \\
\text { documentación asociada } \\
\text { - Criticidad de la solicitud y } \\
\text { fecha en que se requiere }\end{array}$ & $\begin{array}{l}\text { contacto del solicitante } \\
\text { - Sistema(s) } \\
\text { impactado(s): Equivale } \\
\text { a las fases del } \\
\text { proyecto. } \\
\text { - Impacto en la } \\
\text { operación de sistemas } \\
\text { existentes } \\
\text { - Impacto en la } \\
\text { documentación } \\
\text { asociada } \\
\text { - Criticidad de la } \\
\text { solicitud y fecha en } \\
\text { que se requiere } \\
\end{array}$ & & \\
\hline $\begin{array}{l}\text { Resultados de } \\
\text { Validación(RDV) }\end{array}$ & No Encontrado. & No Encontrado. & No Encontrado. & No Encontrado. \\
\hline $\begin{array}{l}\text { Resultados de } \\
\text { Verificación(RDV): }\end{array}$ & No Encontrado. & No Encontrado. & No Encontrado. & No Encontrado. \\
\hline
\end{tabular}

Tabla 19 Mapeo del contenido de los productos de trabajo de la empresa

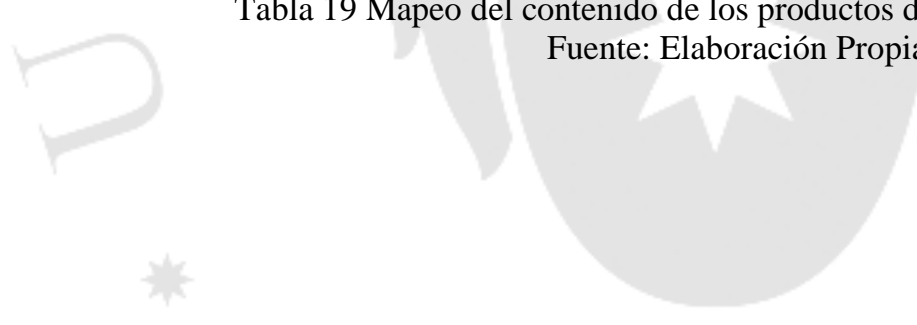




\subsubsection{Evaluación del Estado Actual de los Procesos de desarrollo de software de la empresa}

A continuación, se presentan los procesos y actividades de la organización modelados utilizando el diagrama de procesos Bizagi para mostrar el detalle de cada una de las tareas realizadas por la organización. Se utilizaron como referencia las actividades y procesos descritos en la NTP ISO/IEC 29110 5-1-2.

\subsection{Proceso de Gestión del Proyecto}

El Proceso de Gestión del Proyecto consiste en facilitar el cumplimiento de los objetivos de un proyecto de desarrollo de software. En la Figura 8, se presenta el estado actual del Proceso de Gestión del Proyecto.

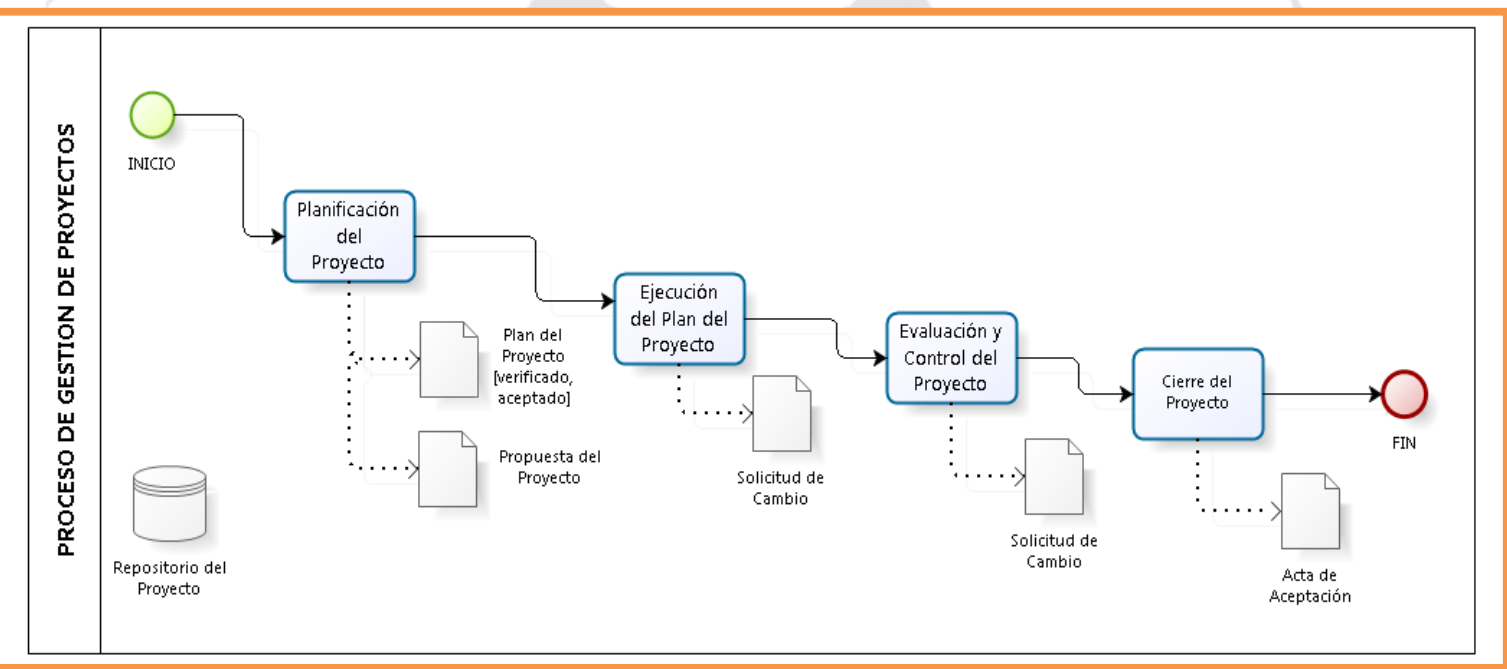

Figura 8 Diagrama BPMN del Proceso Gestión del Proyecto de la empresa

Fuente: Elaboración propia. 
Información a tener en cuenta respecto al proceso Gestión del Proyecto de la empresa HOLINSYS:

- Para mencionar los Roles se utilizó la abreviación de estos, en la sección 3.4.4 Roles Involucrados en el ciclo de vida del desarrollo de software según la ISO/IEC 29110.

- El documento Enunciado de Trabajo descrito en la ISO 29110 es equivalente al documento Propuesta del Proyecto de la empresa HOLINSYS.

- La verificación hecha por el LT consiste en revisar a detalle los artefactos de salida generados en una actividad del proceso de Implementación de Software.

- La validación hecha por el CL consiste en validar si los artefactos de salida reflejan lo que el CL necesita.

- En la sección Evaluación de los Productos de Trabajo de la Empresa (Sección 5 1.1.1) se encuentra el mapeo de la evaluación de los documentos de la empresa de estudio con respecto a lo expuesto en la NTP ISO/ IEC 29110.

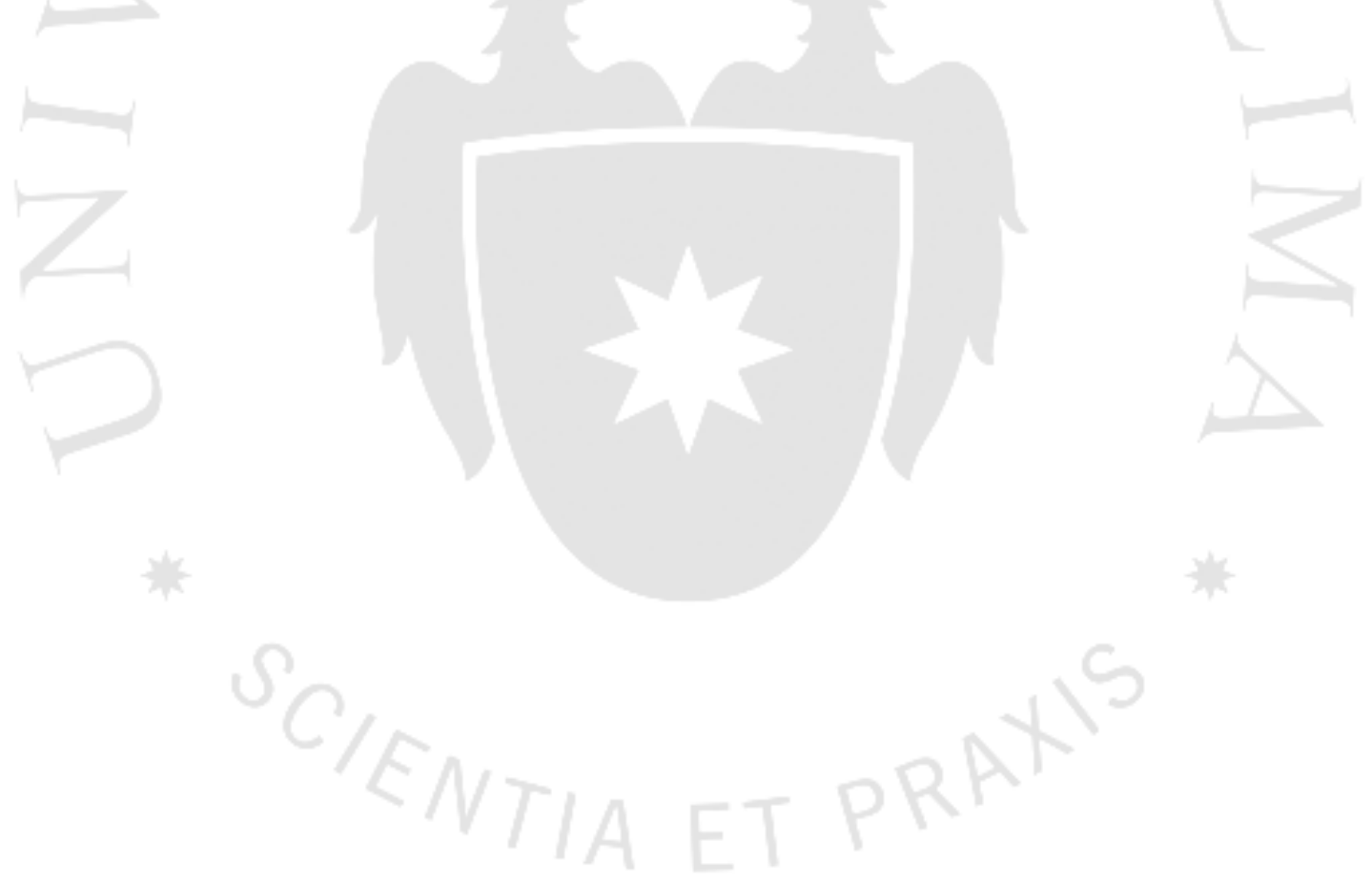




\section{Actividad 01: Planificación del Proyecto}

El objetivo de esta actividad es generar el "Plan del Proyecto" utilizando como base la Propuesta del Proyecto. En la Figura 9, se presenta la actividad Planificación del Proyecto de la empresa HOLINSYS.

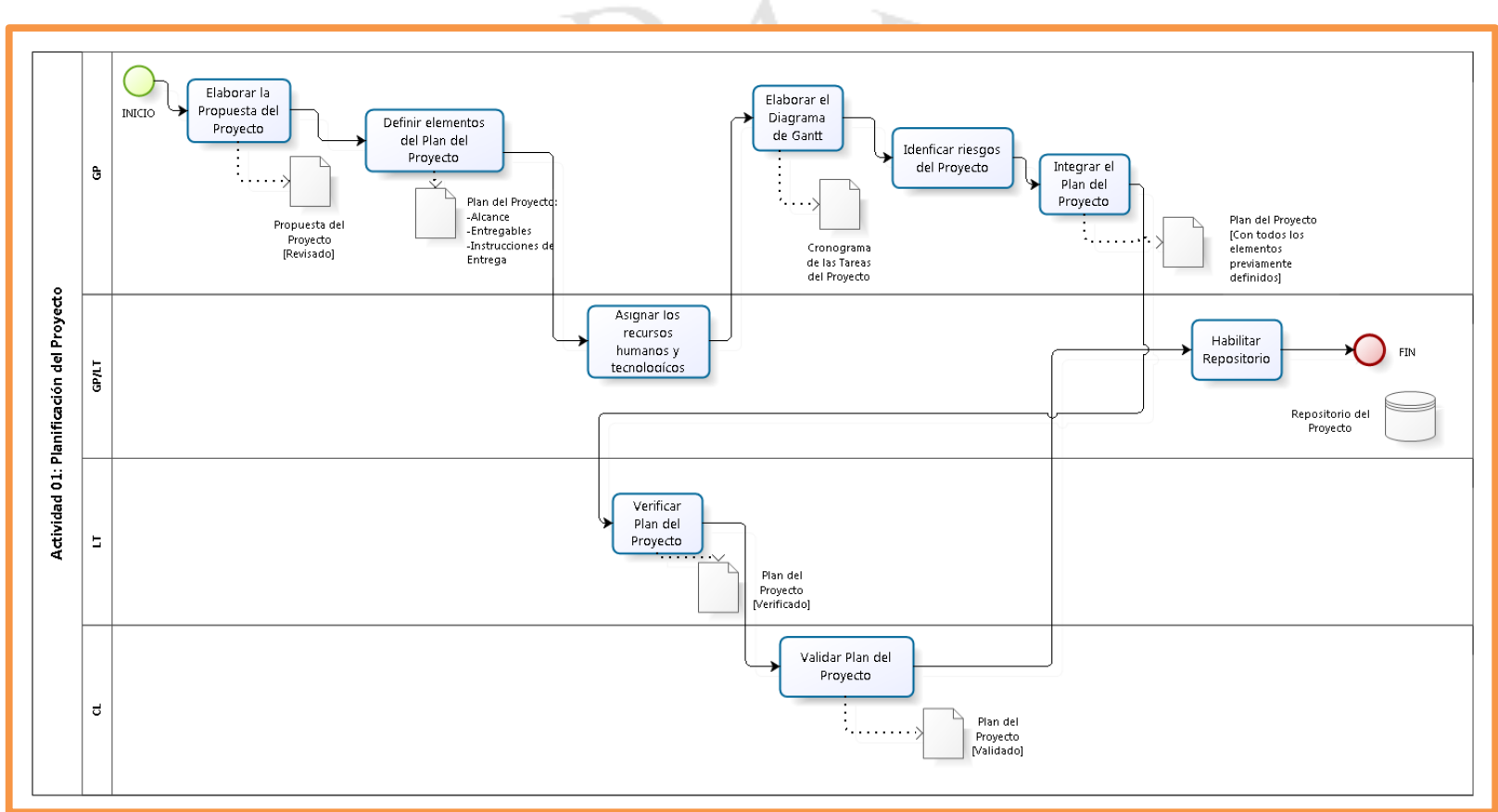

Figura 9 Diagrama BPMN de la Actividad: Planificación del Proyecto de la empresa

Fuente: Elaboración propia 
A continuación se detalla el nivel de cumplimiento de la actividad "Planificación del Proyecto" con respecto a la ISO 29110.

\begin{tabular}{|c|c|c|c|c|c|c|c|c|c|}
\hline ID & Lista de Tareas & $\begin{array}{l}\text { Productos } \\
\text { de entrada }\end{array}$ & $\begin{array}{l}\text { Productos } \\
\text { de salida }\end{array}$ & Rol & $\begin{array}{l}\text { Es } \\
\text { implementada }\end{array}$ & $\begin{array}{l}\text { Productos } \\
\text { de entrada }\end{array}$ & $\begin{array}{l}\text { Productos } \\
\text { de salida }\end{array}$ & Rol & $\begin{array}{l}\text { Comentarios y } \\
\text { Observaciones }\end{array}$ \\
\hline $\begin{array}{l}\text { GP. } \\
1.1\end{array}$ & $\begin{array}{l}\text { Revisar el } \\
\text { Enunciado } \\
\text { de Trabajo. }\end{array}$ & $\begin{array}{l}\text { Enunciado } \\
\text { de Trabajo }\end{array}$ & $\begin{array}{l}\text { Enunciado de } \\
\text { Trabajo } \\
\text { [revisado] }\end{array}$ & $\begin{array}{l}\text { GP } \\
\text { LT }\end{array}$ & Completamente & $\begin{array}{l}\text { Propuesta } \\
\text { del } \\
\text { Proyecto } \\
\text { (Anexo 4.7) }\end{array}$ & $\begin{array}{l}\text { Propuesta } \\
\text { del Proyecto } \\
\text { [revisado] } \\
\text { (Anexo 4.7) }\end{array}$ & $\begin{array}{l}\text { GP } \\
\text { LT }\end{array}$ & $\begin{array}{l}\text { El GP y LT } \\
\text { revisan la } \\
\text { Propuesta del } \\
\text { proyecto antes de } \\
\text { ser enviada al } \\
\text { CL. } \\
\text { Para la empresa, } \\
\text { En base a las } \\
\text { secciones, La } \\
\text { Propuesta de } \\
\text { Proyecto } \\
\text { equivale al } \\
\text { Enunciado de } \\
\text { Trabajo. }\end{array}$ \\
\hline $\begin{array}{l}\text { GP. } \\
1.2\end{array}$ & $\begin{array}{l}\text { Definir con el } \\
\text { Cliente las } \\
\text { Instrucciones de } \\
\text { entrega para cada } \\
\text { uno de los } \\
\text { entregables } \\
\text { especificados en } \\
\text { el Enunciado de } \\
\text { Trabajo. }\end{array}$ & $\begin{array}{l}\text { Enunciado } \\
\text { de Trabajo } \\
\text { [revisado] }\end{array}$ & $\begin{array}{l}\text { Plan del } \\
\text { Proyecto } \\
- \\
\text { Instrucciones } \\
\text { de entrega }\end{array}$ & $\begin{array}{l}\text { GP } \\
\mathrm{CL}\end{array}$ & Completamente & $\begin{array}{l}\text { Propuesta } \\
\text { del } \\
\text { Proyecto } \\
\text { [Revisado] } \\
\text { (Anexo 4.7) }\end{array}$ & $\begin{array}{l}\text { Plan del } \\
\text { Proyecto } \\
\text {-Objetivo } \\
\text {-Alcance } \\
\text { - } \\
\text { Instrucciones } \\
\text { de Entrega } \\
\text { (Anexo 4.1) }\end{array}$ & $\begin{array}{l}\text { GP } \\
\mathrm{CL}\end{array}$ & $\begin{array}{l}\text { La forma de } \\
\text { Instrucciones de } \\
\text { Entrega es } \\
\text { acordada por el } \\
\text { CL y el GP, } \\
\text { donde también } \\
\text { definen el } \\
\text { objetivo y } \\
\text { alcance del } \\
\text { proyecto. }\end{array}$ \\
\hline $\begin{array}{l}\text { GP. } \\
1.3\end{array}$ & $\begin{array}{l}\text { Identificar las } \\
\text { Tareas } \\
\text { específicas a } \\
\text { realizar para } \\
\text { producir los } \\
\text { Entregables y sus } \\
\text { Componentes de }\end{array}$ & $\begin{array}{l}\text { Enunciado } \\
\text { de Trabajo } \\
\text { [revisado] }\end{array}$ & $\begin{array}{l}\text { Plan del } \\
\text { Proyecto } \\
\text { - Tareas }\end{array}$ & $\begin{array}{l}\text { GP } \\
\text { LT }\end{array}$ & Ampliamente & $\begin{array}{l}\text { Propuesta } \\
\text { del } \\
\text { proyecto } \\
\text { (Anexo 4.7) }\end{array}$ & $\begin{array}{l}\text { Diagrama de } \\
\text { Gantt } \\
\text {-Tareas } \\
\text { (Anexo 4.1) }\end{array}$ & $\begin{array}{l}\text { GP } \\
\text { LT }\end{array}$ & $\begin{array}{l}\text { El AN en } \\
\text { coordinación con } \\
\text { el LT identifican } \\
\text { las tareas del } \\
\text { proyecto. }\end{array}$ \\
\hline
\end{tabular}




\begin{tabular}{|c|c|c|c|c|c|c|c|c|c|}
\hline ID & Lista de Tareas & $\begin{array}{l}\text { Productos } \\
\text { de entrada }\end{array}$ & \begin{tabular}{|l} 
Productos \\
de salida
\end{tabular} & Rol & \begin{tabular}{|l|} 
Es \\
implementada
\end{tabular} & $\begin{array}{l}\text { Productos } \\
\text { de entrada }\end{array}$ & \begin{tabular}{|l} 
Productos \\
de salida
\end{tabular} & \begin{tabular}{|l|} 
Rol \\
\end{tabular} & \begin{tabular}{|l|} 
Comentarios y \\
Observaciones
\end{tabular} \\
\hline & $\begin{array}{l}\text { Software } \\
\text { identificados en } \\
\text { el Enunciado de } \\
\text { Trabajo. } \\
\\
\text { Incluir las Tareas } \\
\text { del proceso de } \\
\text { Implementación } \\
\text { de Software } \\
\text { sobre } \\
\text { verificación, } \\
\text { validación y } \\
\text { revisiones con } \\
\text { los Clientes y el } \\
\text { Equipo de } \\
\text { Trabajo para } \\
\text { asegurar la } \\
\text { calidad de los } \\
\text { productos de } \\
\text { trabajo. } \\
\text { Identificar las } \\
\text { Tareas para } \\
\text { realizar las } \\
\text { Instrucciones de } \\
\text { entrega. } \\
\text { Documentar las } \\
\text { Tareas. }\end{array}$ & $\Delta$ & & & & & & & $\begin{array}{l}\text { El AN elabora un } \\
\text { Diagrama de } \\
\text { Gantt interno } \\
\text { indicando sólo } \\
\text { las tareas del } \\
\text { proyecto. } \\
\\
\text { No se incluyen } \\
\text { formalmente las } \\
\text { tareas de } \\
\text { verificación y } \\
\text { validación en el } \\
\text { Diagrama de } \\
\text { Gantt. }\end{array}$ \\
\hline $\begin{array}{l}\text { GP. } \\
1.4\end{array}$ & \begin{tabular}{|l|} 
Establecer la \\
Duración \\
estimada para \\
realizar cada \\
Tarea.
\end{tabular} & $\begin{array}{l}\text { Plan del } \\
\text { Proyecto } \\
\text { - Tareas }\end{array}$ & \begin{tabular}{|l} 
Plan del \\
Proyecto \\
- Duración \\
estimada
\end{tabular} & $\begin{array}{l}\text { GP } \\
\text { LT }\end{array}$ & Completamente & \begin{tabular}{|l} 
Diagrama \\
de Gantt \\
-Tareas \\
(Anexo 4.1)
\end{tabular} & \begin{tabular}{|l} 
Diagrama de \\
Gantt \\
-Tareas \\
-Duración \\
estimada \\
(Anexo 4.1)
\end{tabular} & $\begin{array}{l}\text { GP } \\
\text { LT } \\
\text { AN }\end{array}$ & $\begin{array}{l}\text { El AN, LT y GP } \\
\text { establecen las } \\
\text { duraciones } \\
\text { estimadas de las } \\
\text { tareas } \\
\text { representadas en } \\
\text { un diagrama de } \\
\text { Gantt. } \\
\text { La unidad de }\end{array}$ \\
\hline
\end{tabular}




\begin{tabular}{|c|c|c|c|c|c|c|c|c|c|}
\hline ID & Lista de Tareas & $\begin{array}{l}\text { Productos } \\
\text { de entrada }\end{array}$ & $\begin{array}{l}\text { Productos } \\
\text { de salida }\end{array}$ & Rol & \begin{tabular}{|l} 
Es \\
implementada
\end{tabular} & $\begin{array}{l}\text { Productos } \\
\text { de entrada }\end{array}$ & $\begin{array}{l}\text { Productos } \\
\text { de salida }\end{array}$ & Rol & $\begin{array}{l}\text { Comentarios y } \\
\text { Observaciones }\end{array}$ \\
\hline & & & & & & & & & $\begin{array}{l}\text { medida de la } \\
\text { duración } \\
\text { estimada está } \\
\text { basada en Horas } \\
\text { Hombre, } \\
\text { siguiendo la } \\
\text { metodología } \\
\text { SCRUM. } \\
\text { Diagrama de } \\
\text { Gantt } \\
\text {-Tareas. } \\
\text {-Duración } \\
\text { estimada. }\end{array}$ \\
\hline $\begin{array}{l}\text { GP. } \\
1.5\end{array}$ & $\begin{array}{l}\text { Identificar y } \\
\text { documentar los } \\
\text { Recursos: } \\
\text { humanos, } \\
\text { materiales, } \\
\text { equipo y } \\
\text { herramientas, } \\
\text { estándares, } \\
\text { incluyendo la } \\
\text { capacitación } \\
\text { requerida para } \\
\text { que el Equipo de } \\
\text { Trabajo pueda } \\
\text { realizar el } \\
\text { proyecto. } \\
\text { Incluir las fechas } \\
\text { en el calendario } \\
\text { cuando sean } \\
\text { requeridos los } \\
\text { Recursos y la } \\
\text { capacitación. }\end{array}$ & $\begin{array}{l}\text { Enunciado } \\
\text { de trabajo }\end{array}$ & $\begin{array}{l}\text { Plan del } \\
\text { Proyecto } \\
\text { - Recursos }\end{array}$ & $\begin{array}{l}\text { GP } \\
\mathrm{LT}\end{array}$ & Completamente & $\begin{array}{l}\text { Propuesta } \\
\text { del } \\
\text { proyecto } \\
\text { (Anexo 4.7) }\end{array}$ & $\begin{array}{l}\text { Plan del } \\
\text { Proyecto } \\
\text {-Recursos } \\
\text { (Anexo 4.1) } \\
\\
\end{array}$ & $\begin{array}{l}\text { GP } \\
\text { LT }\end{array}$ & $\begin{array}{l}\text { El GP selecciona } \\
\text { los recursos } \\
\text { humanos, } \\
\text { materiales, } \\
\text { equipo, y } \\
\text { herramientas en } \\
\text { base a su roles, } \\
\text { habilidades y } \\
\text { competencias. } \\
\text { Conjuntamente } \\
\text { se establece la } \\
\text { Composición del } \\
\text { Equipo } \\
\text { asignando roles y } \\
\text { responsabilidades } \\
\text { de acuerdo a los } \\
\text { recursos. }\end{array}$ \\
\hline
\end{tabular}




\begin{tabular}{|c|c|c|c|c|c|c|c|c|c|}
\hline ID & Lista de Tareas & $\begin{array}{l}\text { Productos } \\
\text { de entrada }\end{array}$ & $\begin{array}{l}\text { Productos } \\
\text { de salida }\end{array}$ & Rol & \begin{tabular}{|l} 
Es \\
implementada
\end{tabular} & $\begin{array}{l}\text { Productos } \\
\text { de entrada }\end{array}$ & $\begin{array}{l}\text { Productos } \\
\text { de salida }\end{array}$ & Rol & $\begin{array}{l}\text { Comentarios y } \\
\text { Observaciones }\end{array}$ \\
\hline $\begin{array}{l}\text { GP. } \\
1.6\end{array}$ & $\begin{array}{l}\text { Establecer la } \\
\text { Composición del } \\
\text { Equipo de } \\
\text { Trabajo, } \\
\text { asignando los } \\
\text { roles y } \\
\text { responsabilidades } \\
\text { acordes a los } \\
\text { Recursos. }\end{array}$ & $\begin{array}{l}\text { Plan del } \\
\text { Proyecto } \\
\text { - Recursos }\end{array}$ & $\begin{array}{l}\text { Plan del } \\
\text { Proyecto } \\
- \\
\text { Composición } \\
\text { del Equipo de } \\
\text { Trabajo }\end{array}$ & $\begin{array}{l}\text { GP } \\
\text { LT }\end{array}$ & Completamente & $\begin{array}{l}\text { Propuesta } \\
\text { del } \\
\text { proyecto } \\
\text { (Anexo 4.7) }\end{array}$ & $\begin{array}{l}\text { Plan del } \\
\text { Proyecto } \\
- \\
\text { Composición } \\
\text { del equipo de } \\
\text { trabajo } \\
\text { (Anexo 4.1) }\end{array}$ & $\begin{array}{l}\text { GP } \\
\text { LT }\end{array}$ & \begin{tabular}{|l} 
Esta tarea se \\
realiza \\
conjuntamente \\
cuando \\
seleccionan y \\
documentan los \\
recursos (Tarea \\
GP 1.5). \\
.En base a la \\
norma cumplen \\
con realizar la \\
Composición del \\
equipo de \\
trabajo.
\end{tabular} \\
\hline $\begin{array}{l}\text { GP. } \\
1.7\end{array}$ & $\begin{array}{l}\text { Asignar las } \\
\text { fechas de inicio y } \\
\text { fin estimadas } \\
\text { para cada Tarea } \\
\text { con el fin de } \\
\text { crear el } \\
\text { Cronograma de } \\
\text { las Tareas del } \\
\text { Proyecto } \\
\text { considerando los } \\
\text { Recursos } \\
\text { asignados, la } \\
\text { secuencia y } \\
\text { dependencia de } \\
\text { las Tareas. }\end{array}$ & \begin{tabular}{|l} 
Plan del \\
Proyecto \\
- Tareas \\
- Duración \\
estimada \\
- \\
Composición \\
del Equipo \\
de Trabajo
\end{tabular} & $\begin{array}{l}\text { Plan del } \\
\text { Proyecto } \\
- \\
\text { Cronograma } \\
\text { de las Tareas } \\
\text { del Proyecto }\end{array}$ & $\begin{array}{l}\text { GP } \\
\text { LT }\end{array}$ & Completamente & $\begin{array}{l}\text { Diagrama } \\
\text { de Gantt } \\
\text {-Tareas } \\
\text {-Duración } \\
\text { estimada } \\
\text { (Anexo 4.1) }\end{array}$ & $\begin{array}{l}\text { Cronograma } \\
\text { de las tareas } \\
\text { del Proyecto } \\
\text { (Anexo 4.1) }\end{array}$ & $\begin{array}{l}\text { GP } \\
\text { LT } \\
\text { AN }\end{array}$ & $\begin{array}{l}\text { El Analista } \\
\text { Programador } \\
\text { realiza un } \\
\text { Diagrama de } \\
\text { Gantt con las } \\
\text { actividades y } \\
\text { tareas del } \\
\text { proyecto } \\
\text { asignadas a su } \\
\text { rol. Dicha tarea } \\
\text { es realizada } \\
\text { previamente } \\
\text { (Tarea GP 1.4). } \\
\\
\text { El GP establece } \\
\text { las fechas de } \\
\text { inicio y fin } \\
\text { estimadas en } \\
\text { cada una de las } \\
\text { tareas en el } \\
\text { Diagrama de } \\
\text { Gantt. Dicha } \\
\text { tarea es realizada } \\
\text { previamente }\end{array}$ \\
\hline
\end{tabular}




\begin{tabular}{|c|c|c|c|c|c|c|c|c|c|}
\hline ID & Lista de Tareas & $\begin{array}{l}\text { Productos } \\
\text { de entrada }\end{array}$ & $\begin{array}{l}\text { Productos } \\
\text { de salida }\end{array}$ & Rol & $\begin{array}{l}\text { Es } \\
\text { implementada }\end{array}$ & $\begin{array}{l}\text { Productos } \\
\text { de entrada }\end{array}$ & $\begin{array}{l}\text { Productos } \\
\text { de salida }\end{array}$ & Rol & $\begin{array}{l}\text { Comentarios y } \\
\text { Observaciones }\end{array}$ \\
\hline & & & & & & & & & $\begin{array}{l}\text { (Tarea GP 1.4). } \\
\text { El LT verifica la } \\
\text { duración de las } \\
\text { tareas a fin de ser } \\
\text { viables. } \\
\text { Dicha tarea es } \\
\text { realizada } \\
\text { previamente } \\
\text { (Tarea GP 1.4). }\end{array}$ \\
\hline $\begin{array}{l}\text { GP. } \\
1.8\end{array}$ & $\begin{array}{l}\text { Calcular y } \\
\text { documentar el } \\
\text { Esfuerzo y Costo } \\
\text { estimado del } \\
\text { proyecto. }\end{array}$ & \begin{tabular}{|l|} 
Plan del \\
Proyecto \\
- Calendario \\
de las \\
Tareas del \\
Proyecto \\
- Recursos
\end{tabular} & $\begin{array}{l}\text { Plan del } \\
\text { Proyecto } \\
\text { - Esfuerzo y } \\
\text { Costo } \\
\text { estimado }\end{array}$ & & Completamente & NA. & NA. & NA. & $\begin{array}{l}\text { El GP realiza esta } \\
\text { tarea como parte } \\
\text { de la elaboración } \\
\text { de la Propuesta } \\
\text { del Proyecto. } \\
\\
\text { Dicha tarea se } \\
\text { realiza en una } \\
\text { tarea anterior } \\
\text { (Tarea GP } 1.7) .\end{array}$ \\
\hline $\begin{array}{l}\text { GP. } \\
1.9\end{array}$ & $\begin{array}{l}\text { Identificar y } \\
\text { documentar los } \\
\text { riesgos que } \\
\text { pueden afectar al } \\
\text { proyecto. }\end{array}$ & \begin{tabular}{|l} 
Todos los \\
elementos \\
previamente \\
definidos
\end{tabular} & \begin{tabular}{|l} 
Plan del \\
Proyecto \\
- \\
Identificación \\
de Riesgos \\
del Proyecto
\end{tabular} & $\begin{array}{l}\text { GP } \\
\text { LT }\end{array}$ & No cumple & NA. & NA. & $\begin{array}{l}\text { GP } \\
\text { LT }\end{array}$ & $\begin{array}{l}\text { Esta tarea no se } \\
\text { encuentra } \\
\text { implementada en } \\
\text { el Plan del } \\
\text { Proyecto. } \\
\\
\text { La Propuesta } \\
\text { para dicha tarea } \\
\text { se encuentra en la } \\
\text { "Propuesta de } \\
\text { mejora para los } \\
\text { Procesos del } \\
\text { ciclo de } \\
\text { vida“(Sección } \\
\text { 5.1.1.1). }\end{array}$ \\
\hline
\end{tabular}




\begin{tabular}{|c|c|c|c|c|c|c|c|c|c|}
\hline ID & Lista de Tareas & $\begin{array}{l}\text { Productos } \\
\text { de entrada }\end{array}$ & $\begin{array}{l}\text { Productos } \\
\text { de salida }\end{array}$ & Rol & $\begin{array}{l}\text { Es } \\
\text { implementada }\end{array}$ & $\begin{array}{l}\text { Productos } \\
\text { de entrada }\end{array}$ & $\begin{array}{l}\text { Productos } \\
\text { de salida }\end{array}$ & Rol & $\begin{array}{l}\text { Comentarios y } \\
\text { Observaciones }\end{array}$ \\
\hline $\begin{array}{l}\text { GP. } \\
1.10\end{array}$ & $\begin{array}{l}\text { Documentar la } \\
\text { Estrategia de } \\
\text { Control de } \\
\text { Versiones en el } \\
\text { Plan del } \\
\text { Proyecto. }\end{array}$ & & $\begin{array}{l}\text { Plan del } \\
\text { Proyecto } \\
\text { - Estrategia } \\
\text { de Control de } \\
\text { Versiones }\end{array}$ & $\begin{array}{l}\text { GP } \\
\text { LT }\end{array}$ & Completamente & NA. & $\begin{array}{l}\text { Plan del } \\
\text { Proyecto } \\
\text { - Estrategia } \\
\text { de Control } \\
\text { de Versiones } \\
\text { (Anexo 4.1) }\end{array}$ & $\begin{array}{l}\text { GP } \\
\text { LT }\end{array}$ & $\begin{array}{l}\text { El GP documenta } \\
\text { la estrategia para } \\
\text { el control de } \\
\text { versiones en el } \\
\text { Plan de Proyecto. }\end{array}$ \\
\hline $\begin{array}{l}\text { GP. } \\
1.11\end{array}$ & $\begin{array}{l}\text { Generar el Plan } \\
\text { del Proyecto } \\
\text { integrando los } \\
\text { elementos } \\
\text { previamente } \\
\text { identificados y } \\
\text { documentados. }\end{array}$ & $\begin{array}{l}\text { Todos los } \\
\text { elementos } \\
\text { previamente } \\
\text { definidos }\end{array}$ & $\begin{array}{l}\text { Plan del } \\
\text { Proyecto } \\
\text { - Tareas } \\
\text { - Duración } \\
\text { estimada } \\
\text { - Recursos } \\
\text { - } \\
\text { Composición } \\
\text { del Equipo de } \\
\text { Trabajo } \\
\text { - Calendario } \\
\text { de las Tareas } \\
\text { del Proyecto } \\
\text { - Estimación } \\
\text { del Esfuerzo } \\
\text { y Costo } \\
\text { - } \\
\text { Identificación } \\
\text { de Riesgos } \\
\text { del Proyecto } \\
\text { - Estrategia } \\
\text { de Control de } \\
\text { Versiones } \\
\text { - } \\
\text { Instrucciones } \\
\text { de Entrega } \\
\end{array}$ & GP & Completamente & $\begin{array}{l}\text { Todos los } \\
\text { elementos } \\
\text { previamente } \\
\text { definidos y } \\
\text { verificados }\end{array}$ & $\begin{array}{l}\text { Plan del } \\
\text { Proyecto } \\
\text {-Objetivo } \\
\text {-Alcance } \\
\text {-Tareas } \\
\text {-Duración } \\
\text { estimada } \\
\text {-Recursos } \\
\text { - } \\
\text { Composición } \\
\text { del equipo de } \\
\text { trabajo. } \\
\text {-Cronograma } \\
\text { de las tareas } \\
\text { del proyecto. } \\
\text { (Anexo 4.1) }\end{array}$ & GP & $\begin{array}{l}\text { El GP se encarga } \\
\text { de la revisión de } \\
\text { cada uno de los } \\
\text { elementos del } \\
\text { Plan del Proyecto } \\
\text { se encuentren } \\
\text { integrados y } \\
\text { documentados. }\end{array}$ \\
\hline
\end{tabular}




\begin{tabular}{|c|c|c|c|c|c|c|c|c|c|}
\hline ID & Lista de Tareas & $\begin{array}{l}\text { Productos } \\
\text { de entrada }\end{array}$ & $\begin{array}{l}\text { Productos } \\
\text { de salida }\end{array}$ & Rol & $\begin{array}{l}\text { Es } \\
\text { implementada }\end{array}$ & $\begin{array}{l}\text { Productos } \\
\text { de entrada }\end{array}$ & $\begin{array}{l}\text { Productos } \\
\text { de salida }\end{array}$ & Rol & $\begin{array}{l}\text { Comentarios y } \\
\text { Observaciones }\end{array}$ \\
\hline $\begin{array}{l}\text { GP. } \\
1.12\end{array}$ & $\begin{array}{l}\text { Incluir la } \\
\text { descripción del } \\
\text { producto, el } \\
\text { alcance, los } \\
\text { objetivos y los } \\
\text { entregables en el } \\
\text { Plan del } \\
\text { Proyecto. }\end{array}$ & \begin{tabular}{|l|} 
Enunciado \\
de Trabajo \\
- \\
Descripción \\
del Producto \\
- Alcance \\
- Objetivos \\
- \\
Entregables
\end{tabular} & $\begin{array}{l}\text { Plan del } \\
\text { Proyecto } \\
\text { - Descripción } \\
\text { del Producto } \\
\text { - Alcance } \\
\text { - Objetivos } \\
\text { - Entregables }\end{array}$ & $\begin{array}{l}\text { GP } \\
\text { LT }\end{array}$ & Completamente & $\begin{array}{l}\text { Propuesta } \\
\text { del } \\
\text { proyecto } \\
\text { (Anexo 4.7) }\end{array}$ & $\begin{array}{l}\text { Plan del } \\
\text { Proyecto } \\
\text {-Descripción } \\
\text { del Producto } \\
\text {-Objetivos } \\
\text {-Alcance } \\
\text {-Entregables } \\
\text { (Anexo 4.1) }\end{array}$ & $\begin{array}{l}\text { GP } \\
\text { LT }\end{array}$ & $\begin{array}{l}\text { Esta tarea se } \\
\text { realiza } \\
\text { previamente } \\
\text { cuando se define } \\
\text { la propuesta del } \\
\text { proyecto.(Tarea } \\
\text { GP 1.2). }\end{array}$ \\
\hline $\begin{array}{l}\text { GP. } \\
1.13\end{array}$ & $\begin{array}{l}\text { Verificar y } \\
\text { obtener } \\
\text { aprobación del } \\
\text { Plan del } \\
\text { Proyecto. } \\
\text { Verificar que } \\
\text { todos los } \\
\text { elementos del } \\
\text { Plan del Proyecto } \\
\text { son viables y } \\
\text { consistente. Los } \\
\text { resultados } \\
\text { encontrados son } \\
\text { documentados en } \\
\text { Resultado de } \\
\text { Verificación y las } \\
\text { correcciones son } \\
\text { realizadas hasta } \\
\text { que el documento } \\
\text { es aprobado por } \\
\text { el GP. }\end{array}$ & $\begin{array}{l}\text { Plan del } \\
\text { Proyecto }\end{array}$ & $\begin{array}{l}\text { Resultados } \\
\text { de } \\
\text { Verificación } \\
\text { Plan del } \\
\text { Proyecto } \\
\text { [verificado] }\end{array}$ & $\begin{array}{l}\text { GP } \\
\text { LT }\end{array}$ & Parcialmente & $\begin{array}{l}\text { Plan del } \\
\text { Proyecto } \\
\text { (Anexo 4.1) }\end{array}$ & $\begin{array}{l}\text { Plan del } \\
\text { Proyecto } \\
\text { [verificado] } \\
\text { (Anexo 4.1) } \\
\\
\end{array}$ & $\begin{array}{l}\text { GP } \\
\text { LT }\end{array}$ & 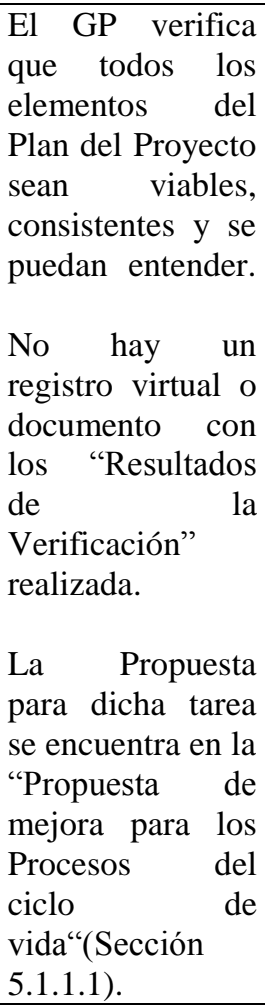 \\
\hline
\end{tabular}




\begin{tabular}{|c|c|c|c|c|c|c|c|c|c|}
\hline ID & Lista de Tareas & $\begin{array}{l}\text { Productos } \\
\text { de entrada }\end{array}$ & $\begin{array}{l}\text { Productos } \\
\text { de salida }\end{array}$ & Rol & \begin{tabular}{|l} 
Es \\
implementada
\end{tabular} & $\begin{array}{l}\text { Productos } \\
\text { de entrada }\end{array}$ & $\begin{array}{l}\text { Productos } \\
\text { de salida }\end{array}$ & Rol & $\begin{array}{l}\text { Comentarios y } \\
\text { Observaciones }\end{array}$ \\
\hline $\begin{array}{l}\text { GP. } \\
1.14\end{array}$ & $\begin{array}{l}\text { Revisar y obtener } \\
\text { la aprobación del } \\
\text { Plan del } \\
\text { Proyecto. } \\
\text { El Cliente revisa } \\
\text { y acepta el Plan } \\
\text { del Proyecto, } \\
\text { asegurándose que } \\
\text { los elementos } \\
\text { contenidos en el } \\
\text { Plan del Proyecto } \\
\text { corresponden con } \\
\text { el Enunciado de } \\
\text { Trabajo. }\end{array}$ & $\begin{array}{l}\text { Plan del } \\
\text { Proyecto } \\
\text { [Verificado] }\end{array}$ & $\begin{array}{l}\text { Acta de } \\
\text { Reunión } \\
\text { Plan del } \\
\text { Proyecto } \\
\text { [Aceptado] }\end{array}$ & $\begin{array}{l}\text { GP } \\
\text { CL }\end{array}$ & Parcialmente & NA. & NA. & $\begin{array}{l}\text { GP } \\
\text { CL }\end{array}$ & $\begin{array}{l}\text { El CL revisa el } \\
\text { Plan de Proyecto. } \\
\text { El Producto de } \\
\text { Trabajo "Acta de } \\
\text { Reunión" y tarea } \\
\text { no se encuentran } \\
\text { implementados } \\
\text { en la empresa. } \\
\\
\text { La Propuesta } \\
\text { para dicha tarea } \\
\text { se encuentra en la } \\
\text { "Propuesta de } \\
\text { mejora para los } \\
\text { Procesos del } \\
\text { ciclo de } \\
\text { vida“(Sección } \\
\text { 5.1.1.1). }\end{array}$ \\
\hline $\begin{array}{l}\text { GP. } \\
1.15\end{array}$ & $\begin{array}{l}\text { Establecer el } \\
\text { Repositorio del } \\
\text { Proyecto usando } \\
\text { la Estrategia de } \\
\text { Control de } \\
\text { Versiones. }\end{array}$ & $\begin{array}{l}\text { Estrategia } \\
\text { de Control } \\
\text { de Versiones }\end{array}$ & $\begin{array}{l}\text { Repositorio } \\
\text { del Proyecto }\end{array}$ & $\begin{array}{l}\text { GP } \\
\text { LT }\end{array}$ & Completamente & $\begin{array}{l}\text { Estrategia } \\
\text { de Control } \\
\text { de } \\
\text { Versiones }\end{array}$ & $\begin{array}{l}\text { Repositorio } \\
\text { de la } \\
\text { empresa. }\end{array}$ & $\begin{array}{l}\text { GP } \\
\text { LT }\end{array}$ & $\begin{array}{l}\text { La estrategia para } \\
\text { el control de } \\
\text { versiones es } \\
\text { utilizada en todos } \\
\text { los proyectos de } \\
\text { la empresa. }\end{array}$ \\
\hline
\end{tabular}

Tabla 20 Evaluación de la Actividad Planificación del Proyecto de la empresa HOLINSYS.

Fuente: Elaboración Propia 


\section{Actividad 02: Ejecución del Plan del Proyecto}

El objetivo de esta actividad es monitorear la ejecución del Plan del Proyecto En la Figura 10, se presenta la actividad Ejecución del Plan del Proyecto de la empresa HOLINSYS.

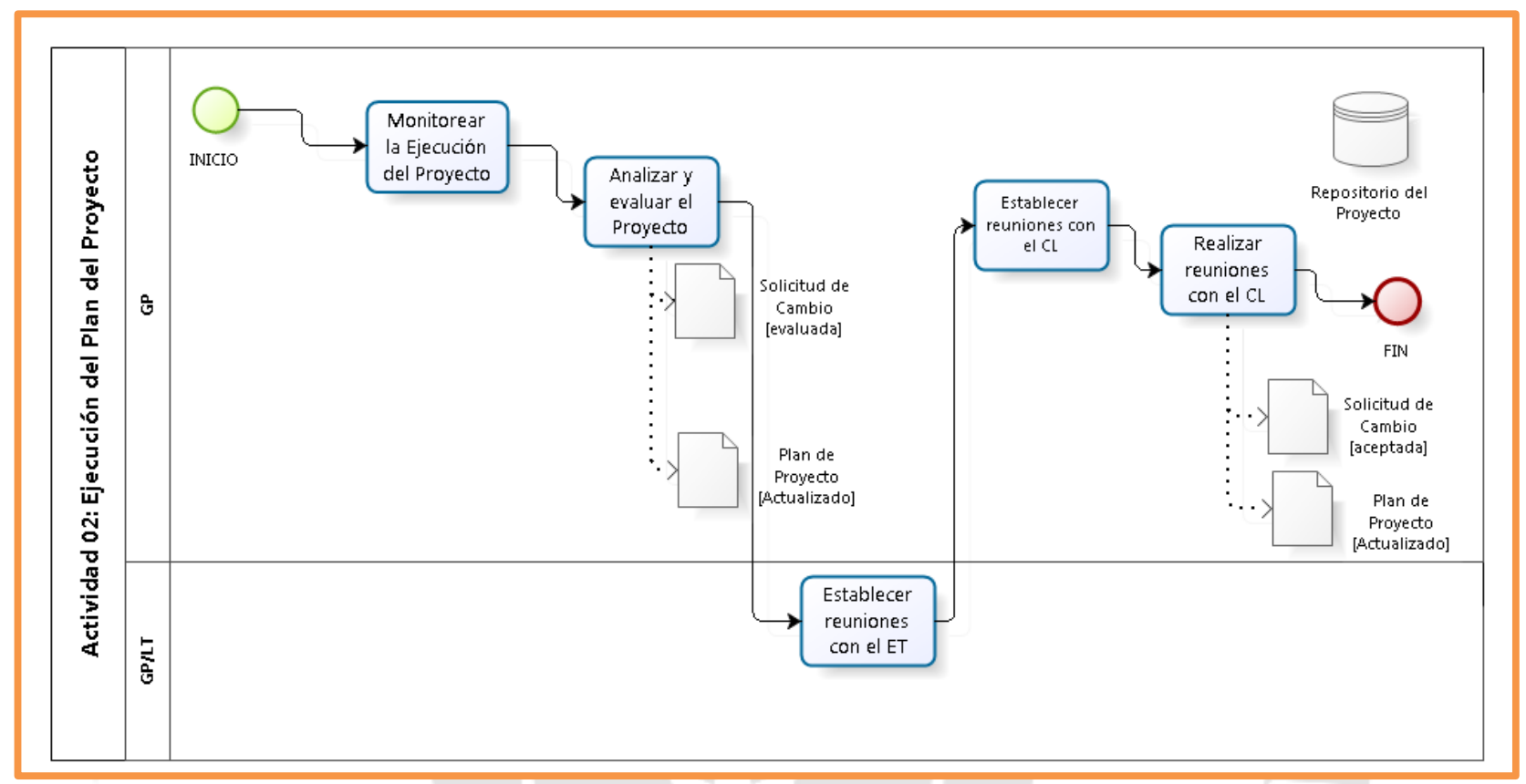

Figura 10 Diagrama BPMN de la Actividad: Ejecución del Plan del Proyecto de la empresa Fuente: Elaboración Propia. 
A continuación se detalla el nivel de cumplimiento de la actividad "Ejecución del plan del Proyecto" con respecto a la ISO 29110.

\begin{tabular}{|c|c|c|c|c|c|c|c|c|c|}
\hline ID & Lista de Tareas & $\begin{array}{c}\text { Productos de } \\
\text { entrada }\end{array}$ & $\begin{array}{l}\text { Productos de } \\
\text { salida }\end{array}$ & Rol & $\begin{array}{l}\text { Es } \\
\text { implementada }\end{array}$ & $\begin{array}{l}\text { Productos } \\
\text { de entrada }\end{array}$ & $\begin{array}{l}\text { Productos de } \\
\text { salida }\end{array}$ & Rol & $\begin{array}{l}\text { Comentarios y } \\
\text { Observaciones }\end{array}$ \\
\hline GP.2.1 & $\begin{array}{l}\text { Monitorear la } \\
\text { ejecución del Plan del } \\
\text { Proyecto y registrar la } \\
\text { información actual en } \\
\text { el Reporte de Avance. }\end{array}$ & $\begin{array}{l}\text { Plan del } \\
\text { Proyecto }\end{array}$ & $\begin{array}{l}\text { Reporte de } \\
\text { Avance }\end{array}$ & $\begin{array}{l}\text { GP } \\
\text { LT } \\
\text { ET }\end{array}$ & Completamente & $\begin{array}{l}\text { Plan del } \\
\text { Proyecto } \\
\text { Estado de } \\
\text { Tareas } \\
\text {-Jira. } \\
\text { (Anexo } \\
\text { 4.1) }\end{array}$ & $\mathrm{NA}$ & $\begin{array}{l}\text { GP } \\
\text { LT } \\
\text { ET }\end{array}$ & $\begin{array}{l}\text { El GP monitorea la } \\
\text { ejecución del Plan del } \\
\text { Proyecto a través del } \\
\text { estado de los issues } \\
\text { generados en la } \\
\text { herramienta Jira versus el } \\
\text { tiempo estimado de las } \\
\text { tareas establecidas el } \\
\text { Diagrama de Gantt y esta } \\
\text { información es reflejada } \\
\text { en el reporte de avance. } \\
\text { Adicionalmente, se tienen } \\
\text { reuniones diarias con el } \\
\text { ET para monitorear la } \\
\text { ejecución del plan. }\end{array}$ \\
\hline GP.2.2 & $\begin{array}{l}\text { Analizar y evaluar el } \\
\text { impacto en costo, } \\
\text { tiempo e impacto } \\
\text { técnico de la Solicitud } \\
\text { de Cambio. } \\
\text { La Solicitud de } \\
\text { Cambio puede ser } \\
\text { propuesta } \\
\text { externamente por el } \\
\text { Cliente o internamente } \\
\text { por el Equipo de } \\
\text { Trabajo. En caso de } \\
\text { que los cambios } \\
\text { aceptados no afecten } \\
\text { los acuerdos que se } \\
\text { tienen con el Cliente, } \\
\text { se debe actualizar el }\end{array}$ & $\begin{array}{l}\text { Solicitud de } \\
\text { Cambio } \\
\text { [iniciada] } \\
\text { Plan del } \\
\text { Proyecto }\end{array}$ & $\begin{array}{l}\text { Solicitud de } \\
\text { Cambio } \\
\text { [evaluada] } \\
\text { Plan del } \\
\text { Proyecto } \\
\text { [actualizado] }\end{array}$ & $\begin{array}{l}\text { GP } \\
\text { LT }\end{array}$ & Completamente & $\begin{array}{l}\text { Solicitud de } \\
\text { Cambio } \\
\text { [iniciada] } \\
\text { (Anexo } \\
\text { 4.5) } \\
\text { Plan del } \\
\text { Proyecto } \\
\text { (Anexo } \\
\text { 4.1) }\end{array}$ & \begin{tabular}{|l|} 
Solicitud de \\
Cambio \\
[iniciada] \\
(Anexo 4.5) \\
\\
Plan del \\
Proyecto \\
[actualizado] \\
(Anexo 4.1)
\end{tabular} & $\begin{array}{l}\text { GP } \\
\text { LT }\end{array}$ & $\begin{array}{l}\text { El GP analiza y evalúa el } \\
\text { impacto que puede tener } \\
\text { el proyecto en costo, } \\
\text { tiempo y alcance. } \\
\text { La Solicitud de Cambio se } \\
\text { puede dar externamente } \\
\text { por el cliente o } \\
\text { internamente por el GP o } \\
\text { LT. } \\
\text { Si los cambios no afectan } \\
\text { los acuerdos establecidos } \\
\text { con el CL, se debe } \\
\text { actualizar el Plan del } \\
\text { Proyecto. } \\
\text { La Solicitud de Cambio }\end{array}$ \\
\hline
\end{tabular}




\begin{tabular}{|c|c|c|c|c|c|c|c|c|c|}
\hline ID & Lista de Tareas & $\begin{array}{c}\text { Productos de } \\
\text { entrada }\end{array}$ & $\begin{array}{c}\text { Productos de } \\
\text { salida }\end{array}$ & Rol & \begin{tabular}{|l|} 
Es \\
implementada
\end{tabular} & $\begin{array}{l}\text { Productos } \\
\text { de entrada }\end{array}$ & $\begin{array}{l}\text { Productos de } \\
\text { salida }\end{array}$ & Rol & $\begin{array}{l}\text { Comentarios y } \\
\text { Observaciones }\end{array}$ \\
\hline & $\begin{array}{l}\text { Plan del Proyecto. La } \\
\text { Solicitud de Cambio } \\
\text { que afecte los } \\
\text { acuerdos previos, } \\
\text { necesita ser negociada } \\
\text { por ambas partes } \\
\text { (véase GP.2.4). }\end{array}$ & & & & & & & & $\begin{array}{l}\text { que logre tener un } \\
\text { impacto que afecte a los } \\
\text { acuerdos, debe ser } \\
\text { aprobada por ambas } \\
\text { partes, y de la misma } \\
\text { manera, se debe actualizar } \\
\text { el Plan del Proyecto. }\end{array}$ \\
\hline GP.2.3 & $\begin{array}{l}\text { Conducir reuniones de } \\
\text { revisión con el Equipo } \\
\text { de Trabajo, las cuales } \\
\text { permiten identificar } \\
\text { problemas, revisar el } \\
\text { estado de los riesgos, } \\
\text { registrar acuerdos y } \\
\text { darles seguimiento } \\
\text { hasta su conclusión. }\end{array}$ & $\begin{array}{l}\text { Plan del } \\
\text { Proyecto } \\
\text { Reporte de } \\
\text { Avance } \\
\text { Acciones } \\
\text { Correctivas } \\
\\
\text { Acta de } \\
\text { Reunión }\end{array}$ & \begin{tabular}{|l|} 
Acta de \\
Reunión \\
[actualizada]
\end{tabular} & $\begin{array}{l}\text { GP } \\
\text { LT } \\
\text { ET }\end{array}$ & Parcialmente & $\begin{array}{l}\text { Plan del } \\
\text { Proyecto } \\
\text { (Anexo } \\
\text { 4.1) } \\
\\
\text { Reporte de } \\
\text { Avance } \\
\text { (Anexo } \\
\text { 4.9) }\end{array}$ & 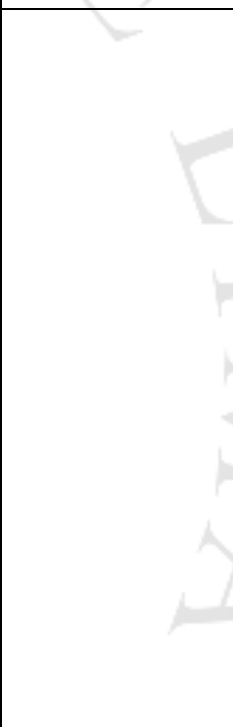 & \begin{tabular}{|l} 
GP \\
LT \\
ET
\end{tabular} & $\begin{array}{l}\text { El GP y el LT establece } \\
\text { reuniones con el ET, las } \\
\text { cuales permiten conocer } \\
\text { los problemas, estado de } \\
\text { riesgos, registrar acuerdos } \\
\text { y dar seguimiento } \\
\text { oportuno hasta el cierre } \\
\text { del proyecto. } \\
\text { No existe un documento } \\
\text { formal de Acta de reunión } \\
\text { y acciones } \\
\text { Correctivas. } \\
\text { La Propuesta para dicha } \\
\text { tarea se encuentra en la } \\
\text { "Propuesta de mejora para } \\
\text { los Procesos del ciclo de } \\
\text { vida“(Sección 5.1.1.1). }\end{array}$ \\
\hline GP.2.4 & $\begin{array}{l}\text { Realizar reuniones con } \\
\text { el Cliente, de las } \\
\text { cuales se registrarán } \\
\text { acuerdos y se dará } \\
\text { seguimiento hasta su } \\
\text { conclusión. } \\
\\
\text { La Solicitud de } \\
\text { Cambio propuesta por } \\
\text { el Cliente o por el } \\
\text { Equipo de Trabajo, }\end{array}$ & $\begin{array}{l}\text { Plan del } \\
\text { Proyecto } \\
\text { Reporte de } \\
\text { Avance } \\
\text { Solicitud de } \\
\text { Cambio } \\
\text { [evaluada] } \\
\text { Acta de }\end{array}$ & \begin{tabular}{|l} 
Acta de \\
Reunión \\
[actualizada] \\
\\
Solicitud de \\
Cambio \\
[aceptada] \\
\\
Plan del \\
Proyecto \\
[actualizado]
\end{tabular} & $\begin{array}{l}\text { GP } \\
\text { CL } \\
\text { LT } \\
\text { ET }\end{array}$ & Ampliamente & $\begin{array}{l}\text { Plan del } \\
\text { Proyecto } \\
\text { (Anexo } \\
\text { 4.1) } \\
\\
\text { Reporte de } \\
\text { Avance } \\
\text { (Anexo } \\
\text { 4.9) } \\
\text { Solicitud de }\end{array}$ & $\begin{array}{l}\text { Solicitud de } \\
\text { Cambio } \\
\text { [aceptada] } \\
\text { (Anexo 4.5) } \\
\\
\text { Plan del } \\
\text { Proyecto } \\
\text { [actualizado] } \\
\text { (Anexo 4.1) }\end{array}$ & $\begin{array}{l}\text { GP } \\
\text { CL } \\
\text { LT } \\
\text { ET }\end{array}$ & $\begin{array}{l}\text { El GP realiza reuniones } \\
\text { con el CL en las que se } \\
\text { registran acuerdos y se da } \\
\text { seguimiento hasta el } \\
\text { cierre del proyecto. } \\
\text { En las reuniones se } \\
\text { pueden establecer } \\
\begin{array}{l}\text { Solicitudes de Cambios } \\
\text { propuestas por el CL o } \\
\text { por el ET. Si afecta al CL }\end{array}\end{array}$ \\
\hline
\end{tabular}




\begin{tabular}{|c|c|c|c|c|c|c|c|c|c|}
\hline ID & Lista de Tareas & $\begin{array}{c}\text { Productos de } \\
\text { entrada }\end{array}$ & $\begin{array}{c}\text { Productos de } \\
\text { salida }\end{array}$ & Rol & $\begin{array}{l}\text { Es } \\
\text { implementada }\end{array}$ & $\begin{array}{l}\text { Productos } \\
\text { de entrada }\end{array}$ & $\begin{array}{l}\text { Productos de } \\
\text { salida }\end{array}$ & Rol & $\begin{array}{l}\text { Comentarios y } \\
\text { Observaciones }\end{array}$ \\
\hline & $\begin{array}{l}\text { que afecte al Cliente, } \\
\text { necesita ser negociada } \\
\text { para alcanzar un } \\
\text { acuerdo entre ambas } \\
\text { partes. Si es necesario, } \\
\text { se debe actualizar el } \\
\text { Plan del Proyecto } \\
\text { conforme a los nuevos } \\
\text { acuerdos con el } \\
\text { Cliente. }\end{array}$ & Reunión & & & & $\begin{array}{l}\text { Cambio } \\
\text { [evaluada] } \\
\text { (Anexo } \\
\text { 4.5) }\end{array}$ & & & $\begin{array}{l}\text { necesita ser negociada y } \\
\text { aceptada por ambas } \\
\text { partes. En caso sea } \\
\text { necesario, se debe } \\
\text { actualizar el Plan del } \\
\text { Proyecto conforme a los } \\
\text { nuevos acuerdos con el } \\
\text { CL. } \\
\text { No hay un documento } \\
\text { formal para el acta de } \\
\text { reunión. }\end{array}$ \\
\hline GP.2.5 & $\begin{array}{l}\text { Realizar el Respaldo } \\
\text { del Repositorio del } \\
\text { Proyecto de acuerdo a } \\
\text { la Estrategia de } \\
\text { Control de Versiones. }\end{array}$ & $\begin{array}{l}\text { Estrategia de } \\
\text { Control de } \\
\text { Versiones }\end{array}$ & $\begin{array}{l}\text { Respaldo del } \\
\text { Repositorio } \\
\text { del Proyecto }\end{array}$ & GP & No cumple & NA. & NA. & NA. & $\begin{array}{l}\text { Tarea No Implementada. } \\
\text { Se tiene un repositorio, } \\
\text { más no un Respaldo. } \\
\text { La Propuesta para dicha } \\
\text { tarea se encuentra en la } \\
\text { "Propuesta de mejora para } \\
\text { los Procesos del ciclo de } \\
\text { vida"(Sección 5.1.1.1). }\end{array}$ \\
\hline GP.2.6 & $\begin{array}{l}\text { Realizar la } \\
\text { recuperación del } \\
\text { Repositorio del } \\
\text { Proyecto utilizando el } \\
\text { Respaldo del } \\
\text { Repositorio del } \\
\text { Proyecto, en caso de } \\
\text { ser necesario. }\end{array}$ & $\begin{array}{l}\text { Respaldo del } \\
\text { Repositorio } \\
\text { del Proyecto }\end{array}$ & $\begin{array}{l}\text { Repositorio } \\
\text { de Proyecto } \\
\text { [Recuperado] }\end{array}$ & GP & No cumple & NA. & NA. & NA. & $\begin{array}{l}\text { La Propuesta para dicha } \\
\text { tarea se encuentra en la } \\
\text { "Propuesta de mejora para } \\
\text { los Procesos del ciclo de } \\
\text { vida“(Sección 5.1.1.1). }\end{array}$ \\
\hline
\end{tabular}

Tabla 21 Evaluación de la Actividad Ejecución del Plan del Proyecto de la empresa

Fuente: Elaboración Propia 


\section{Actividad 03: Evaluación y Control del Proyecto}

El objetivo de esta actividad es hacer seguimiento al progreso del proyecto para mantener la salud del mismo. En la Figura 12, se presenta la Evaluación y Control del Proyecto de la empresa HOLINSYS.

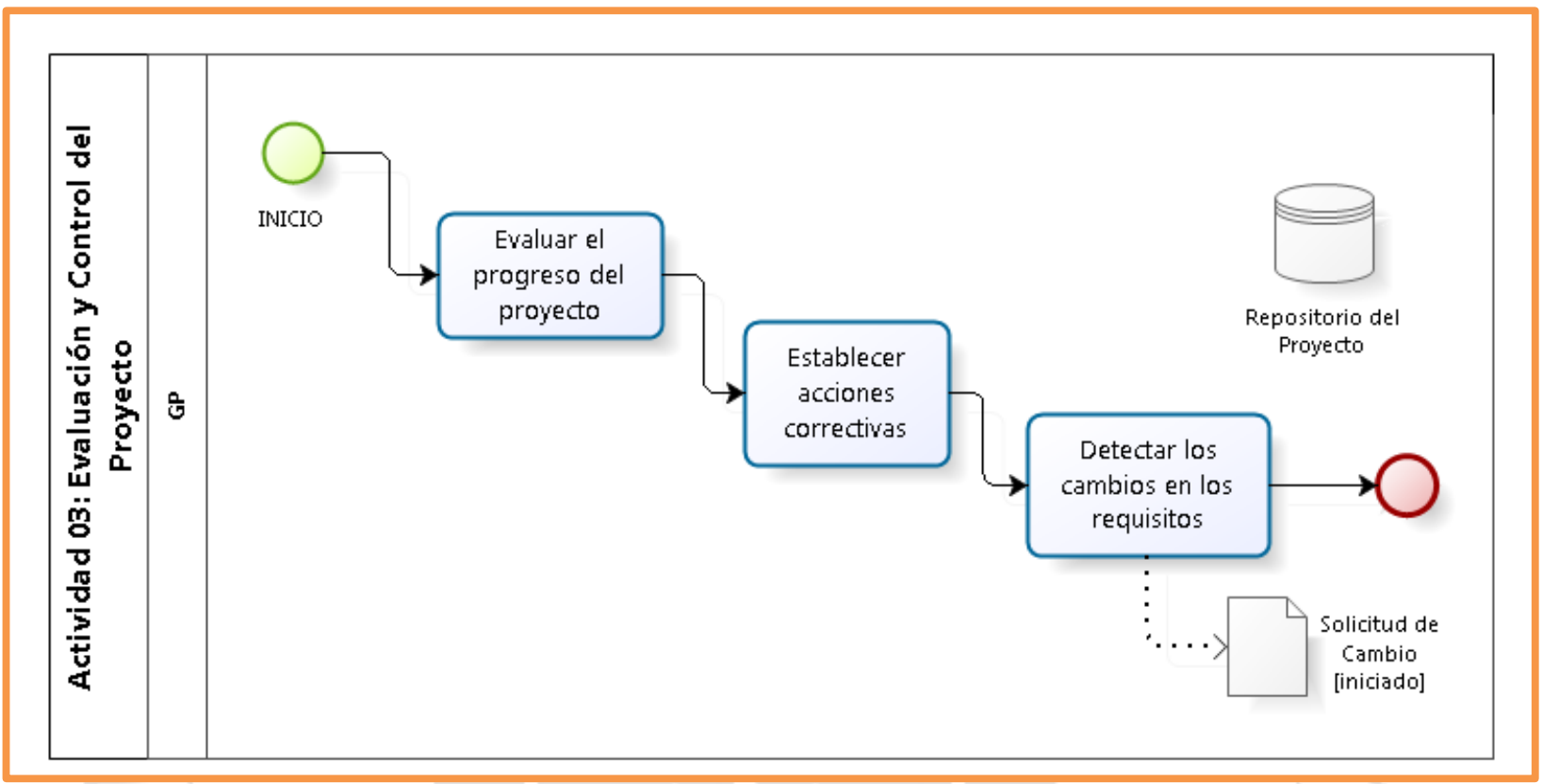

Figura 11 Diagrama BPMN de la Actividad: Evaluación y Control del Proyecto de la empresa Fuente: Elaboración Propia. 
A continuación se detalla el nivel de cumplimiento de la actividad "Evaluación y Control del Proyecto" con respecto a la ISO 29110.

\begin{tabular}{|c|c|c|c|c|c|c|c|c|c|}
\hline ID & Lista de Tareas & $\begin{array}{c}\text { Productos de } \\
\text { entrada }\end{array}$ & $\begin{array}{l}\text { Productos } \\
\text { de salida }\end{array}$ & Rol & $\begin{array}{l}\text { Es } \\
\text { implementada }\end{array}$ & $\begin{array}{l}\text { Productos } \\
\text { de entrada }\end{array}$ & $\begin{array}{l}\text { Productos de } \\
\text { salida }\end{array}$ & Rol & $\begin{array}{l}\text { Comentarios y } \\
\text { Observaciones }\end{array}$ \\
\hline $\begin{array}{l}\text { GP. } \\
3.1\end{array}$ & $\begin{array}{l}\text { Evaluar el progreso del } \\
\text { proyecto con respecto } \\
\text { al Plan del Proyecto, } \\
\text { comparando: } \\
\text { - Tareas reales contra } \\
\text { las Tareas planeadas } \\
\text { - resultados reales } \\
\text { contra los Objetivos } \\
\text { establecidos en el } \\
\text { proyecto } \\
\text { - recursos reales } \\
\text { asignados contra los } \\
\text { planeados } \\
\text { - costos reales contra } \\
\text { el presupuesto } \\
\text { estimado } \\
\text { - tiempo real utilizado } \\
\text { contra el programado } \\
\text { - riesgo real contra el } \\
\text { identificado } \\
\text { previamente }\end{array}$ & $\begin{array}{l}\text { Plan del } \\
\text { Proyecto } \\
\text { Reporte de } \\
\text { Avance }\end{array}$ & $\begin{array}{l}\text { Reporte de } \\
\text { Avance } \\
\text { [evaluado] }\end{array}$ & $\begin{array}{l}\text { GP } \\
\text { LT } \\
\text { ET }\end{array}$ & Ampliamente & $\begin{array}{l}\text { Plan del } \\
\text { Proyecto } \\
\text { (Anexo 4.1) } \\
\text { Reporte de } \\
\text { Avance } \\
\text { (Anexo 4.9) }\end{array}$ & $\begin{array}{l}\text { Reporte de } \\
\text { Avance } \\
\text { [evaluado] } \\
\text { (Anexo 4.9) }\end{array}$ & $\begin{array}{l}\text { GP } \\
\text { LT } \\
\text { ET }\end{array}$ & $\begin{array}{l}\text { El GP evalúa el progreso } \\
\text { del proyecto visualizando } \\
\text { el Diagrama de Gantt con } \\
\text { los estados reales. } \\
\text { El Producto de Trabajo } \\
\text { "Reporte de Avance" } \\
\text { carece de la sección } \\
\text { "Resultados reales contra } \\
\text { los Objetivos establecidos } \\
\text { en el proyecto". } \\
\text { Adicionalmente, se tienen } \\
\text { reuniones diarias con el } \\
\text { ET para monitorear el } \\
\text { proyecto. }\end{array}$ \\
\hline GP.3.2 & $\begin{array}{l}\text { Establecer acciones } \\
\text { para corregir } \\
\text { desviaciones o } \\
\text { problemas e identificar } \\
\text { riesgos que amenacen } \\
\text { el cumplimiento del } \\
\text { plan, en caso de ser } \\
\text { necesario, } \\
\text { documentarlos en } \\
\text { Acciones Correctivas } \\
\text { y dar seguimiento } \\
\text { hasta su conclusión. }\end{array}$ & $\begin{array}{l}\text { Reporte de } \\
\text { Avance } \\
\text { [Evaluado] }\end{array}$ & $\begin{array}{l}\text { Acciones } \\
\text { Correctivas }\end{array}$ & $\begin{array}{l}\text { GP } \\
\text { LT } \\
\text { ET }\end{array}$ & Parcialmente & \begin{tabular}{|l} 
Reporte de \\
Avance \\
[Evaluado] \\
(Anexo 4.9)
\end{tabular} & - & $\begin{array}{l}\text { GP } \\
\text { LT } \\
\text { ET }\end{array}$ & $\begin{array}{l}\text { El GP establece acciones } \\
\text { que permitan corregir los } \\
\text { defectos o problemas e } \\
\text { identificar riesgos que } \\
\text { afecten al cumplimiento } \\
\text { del Plan del Proyecto, en } \\
\text { caso lo amerita, } \\
\text { El Producto de Trabajo } \\
\text { "Acciones Correctivas" no } \\
\text { se encuentra } \\
\text { implementado en la }\end{array}$ \\
\hline
\end{tabular}




\begin{tabular}{|c|c|c|c|c|c|c|c|c|c|}
\hline ID & Lista de Tareas & $\begin{array}{c}\text { Productos de } \\
\text { entrada }\end{array}$ & $\begin{array}{l}\text { Productos } \\
\text { de salida }\end{array}$ & Rol & $\begin{array}{l}\text { Es } \\
\text { implementada }\end{array}$ & $\begin{array}{l}\text { Productos } \\
\text { de entrada }\end{array}$ & $\begin{array}{l}\text { Productos de } \\
\text { salida }\end{array}$ & Rol & $\begin{array}{l}\text { Comentarios y } \\
\text { Observaciones }\end{array}$ \\
\hline & & & & & & & & & $\begin{array}{l}\text { empresa. } \\
\text { La Propuesta para dicha } \\
\text { tarea se encuentra en la } \\
\text { "Propuesta de mejora para } \\
\text { los Procesos del ciclo de } \\
\text { vida“(Sección 5.1.1.1). }\end{array}$ \\
\hline GP.3.3 & $\begin{array}{l}\text { Identificar cambios a } \\
\text { requisitos y/o al Plan } \\
\text { del Proyecto para } \\
\text { hacer frente a } \\
\text { desviaciones } \\
\text { importantes, } \\
\text { potenciales riesgos o } \\
\text { problemas relativos al } \\
\text { cumplimiento del plan; } \\
\text { documentarlos en una } \\
\text { Solicitud de Cambio y } \\
\text { dar seguimiento hasta } \\
\text { su conclusión. }\end{array}$ & $\begin{array}{l}\text { Reporte de } \\
\text { Avance } \\
\text { [Evaluado] }\end{array}$ & $\begin{array}{l}\text { Solicitud de } \\
\text { Cambio } \\
\text { [iniciada] }\end{array}$ & $\begin{array}{l}\text { GP } \\
\text { LT } \\
\text { ET }\end{array}$ & Completamente & $\begin{array}{l}\text { Reporte de } \\
\text { Avance } \\
\text { [Evaluado] } \\
\text { (Anexo 4.9) }\end{array}$ & \begin{tabular}{|l} 
Solicitud de \\
Cambio \\
[iniciado] \\
(Anexo 4.5)
\end{tabular} & $\begin{array}{l}\text { GP } \\
\text { ET } \\
\end{array}$ & $\begin{array}{l}\text { El GP detecta si existen } \\
\text { cambios en los requisitos } \\
\text { del proyecto para poder } \\
\text { documentarlos en una } \\
\text { Solicitud de Cambio y dar } \\
\text { seguimiento hasta su } \\
\text { cierre. }\end{array}$ \\
\hline
\end{tabular}

Tabla 22 Evaluación de la Actividad Evaluación y Control del Proyecto de la empresa

Fuente: Elaboración Propia 


\section{Actividad 04: Cierre del Proyecto}

El objetivo de esta actividad es formalizar el cierre el proyecto luego de terminado el proceso de implementación de software. En la Figura 12, se presenta la actividad Cierre del Proyecto de la empresa HOLINSYS.

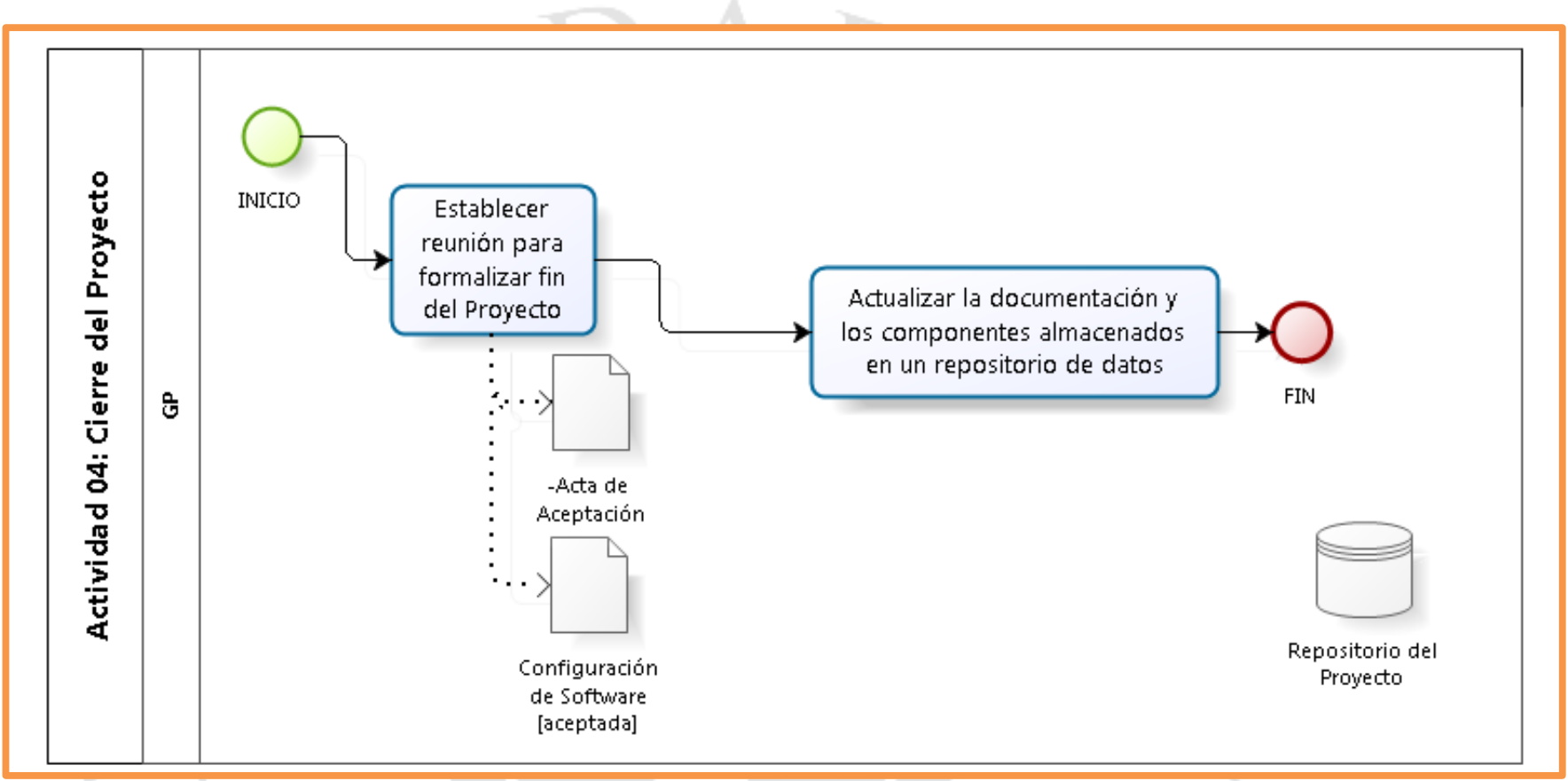

Figura 12 Diagrama BPMN de la Actividad: Cierre el proyecto de la empresa.

Fuente: Elaboración Propia. 
A continuación se detalla el nivel de cumplimiento de la actividad "Cierre del Proyecto" con respecto a la ISO 29110.

\begin{tabular}{|c|c|c|c|c|c|c|c|c|c|}
\hline ID & Lista de Tareas & $\begin{array}{c}\text { Productos de } \\
\text { entrada }\end{array}$ & $\begin{array}{l}\text { Productos de } \\
\text { salida }\end{array}$ & Rol & $\begin{array}{l}\text { Es } \\
\text { implementada }\end{array}$ & $\begin{array}{c}\text { Productos de } \\
\text { entrada }\end{array}$ & $\begin{array}{l}\text { Productos de } \\
\text { salida }\end{array}$ & Rol & $\begin{array}{l}\text { Comentarios y } \\
\text { Observaciones }\end{array}$ \\
\hline $\begin{array}{l}\text { GP. } \\
4.1\end{array}$ & $\begin{array}{l}\text { Formalizar la } \\
\text { conclusión del } \\
\text { proyecto de acuerdo a } \\
\text { las Instrucciones de } \\
\text { Entrega establecidas } \\
\text { en el Plan del } \\
\text { Proyecto, } \\
\text { proporcionando el } \\
\text { apoyo para su } \\
\text { aceptación y } \\
\text { obteniendo las firmas } \\
\text { correspondientes en el } \\
\text { Acta de Aceptación. }\end{array}$ & $\begin{array}{l}\text { Plan del } \\
\text { Proyecto } \\
\text {-Instrucciones } \\
\text { de Entrega } \\
\text { Configuración } \\
\text { de Software } \\
\text { [entregada] }\end{array}$ & $\begin{array}{l}\text { Acta de } \\
\text { Aceptación } \\
\text { Configuración } \\
\text { de Software } \\
\text { [aceptada] }\end{array}$ & $\begin{array}{l}\text { GP } \\
\mathrm{CL}\end{array}$ & Ampliamente & \begin{tabular}{|l} 
Plan del \\
Proyecto \\
-Instrucciones \\
de Entrega \\
(Anexo 4.1) \\
\\
Configuración \\
de Software \\
[entregada] \\
(Anexo 4.12)
\end{tabular} & $\begin{array}{l}\text { Acta de } \\
\text { Aceptación } \\
\text { (Anexo 4.2) } \\
\text { Configuración } \\
\text { de Software } \\
\text { [aceptada] } \\
\text { (Anexo 4.12) }\end{array}$ & $\begin{array}{l}\mathrm{GP} \\
\mathrm{CL}\end{array}$ & $\begin{array}{l}\text { El GP establece una } \\
\text { reunión con el CL para } \\
\text { formalizar la conclusión } \\
\text { del proyecto en base a las } \\
\text { Instrucciones de Entrega } \\
\text { en el Plan del Proyecto. } \\
\text { El CL muestra su } \\
\text { conformidad firmando el } \\
\text { Acta de Aceptación. } \\
\text { El acta de aceptación no } \\
\text { posee la sección } \\
\text { "Criterios de Aceptación } \\
\text { descrita en la norma". }\end{array}$ \\
\hline GP.4.2 & $\begin{array}{l}\text { Actualizar el } \\
\text { Repositorio del } \\
\text { Proyecto. }\end{array}$ & $\begin{array}{l}\begin{array}{l}\text { Configuración } \\
\text { de Software } \\
\text { [aceptada] }\end{array} \\
\text { Repositorio } \\
\text { del Proyecto }\end{array}$ & $\begin{array}{l}\text { Repositorio } \\
\text { del Proyecto } \\
\text { [actualizado] }\end{array}$ & GP & Completamente & $\begin{array}{l}\text { Configuración } \\
\text { de Software } \\
\text { [aceptada] } \\
\text { (Anexo 4.12) } \\
\text { Repositorio } \\
\text { del } \\
\text { Proyecto }\end{array}$ & $\begin{array}{l}\text { Repositorio } \\
\text { del } \\
\text { Proyecto } \\
\text { [actualizado] }\end{array}$ & $\begin{array}{l}\text { GP } \\
\text { LT }\end{array}$ & $\begin{array}{l}\text { El GP almacena y/o } \\
\text { actualiza la } \\
\text { documentación en un } \\
\text { Repositorio de datos. }\end{array}$ \\
\hline
\end{tabular}

Tabla 23 Evaluación de la Actividad Cierre el proyecto de la empresa HOLINSYS

Fuente: Elaboración Propia. 


\section{Resultado de Evaluación - Gestión del Proyecto}

En la Figura 13, se muestra el porcentaje de cumplimiento por cada actividad del proceso de Gestión del Proyecto.

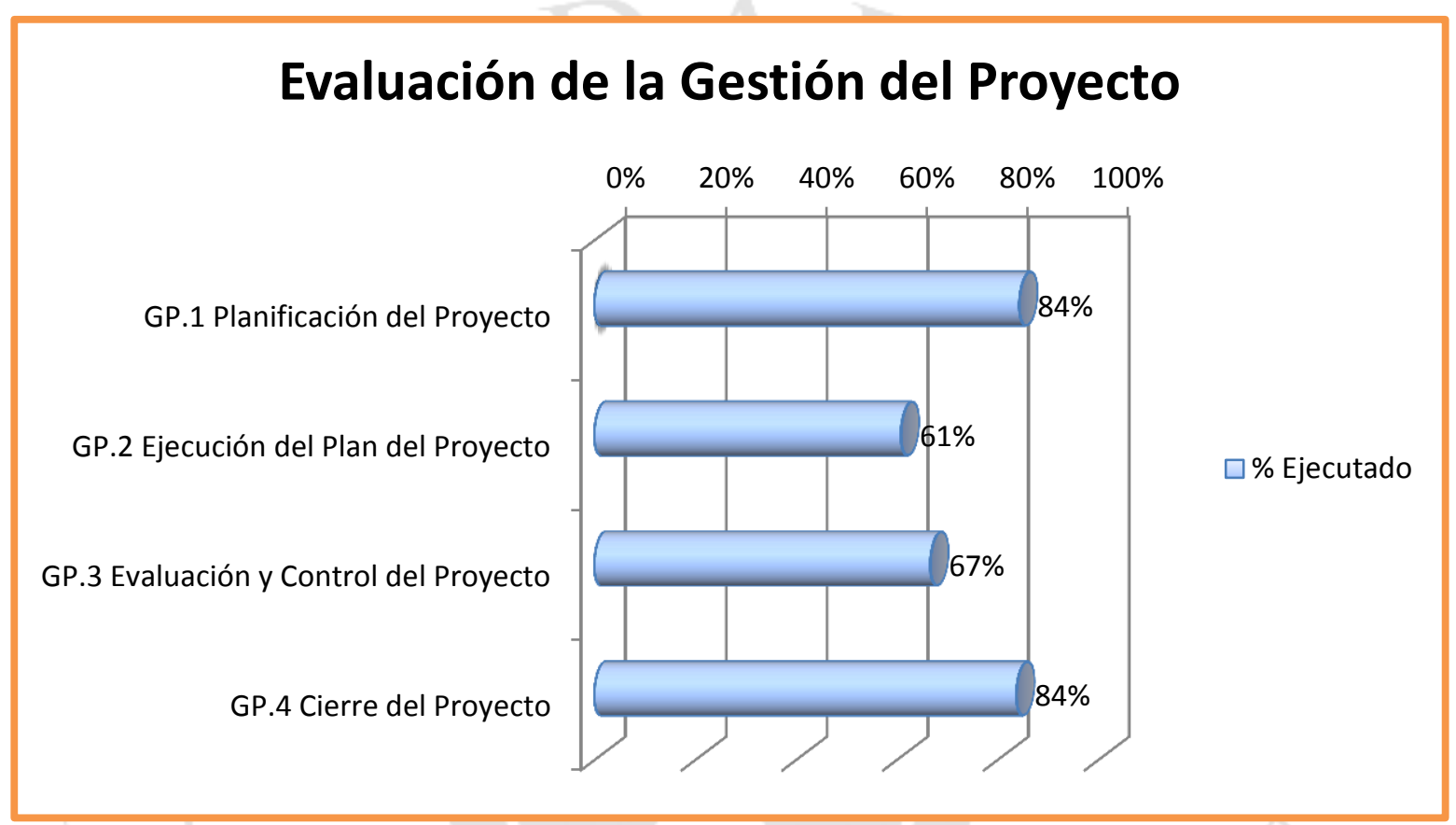

Figura 13 Dashboard de la Evaluación de Actividades de GP según la ISO 29110-5-1-2.

Fuente: Elaboración Propia. 


\subsection{Proceso de Implementación de software}

El Proceso de Implementación de Software consiste en realizar el análisis, diseño, construcción y pruebas del software utilizando como base los requerimientos del cliente. En la Figura 14, se presenta el diagrama del proceso de implementación de software de la empresa HOLINSYS.

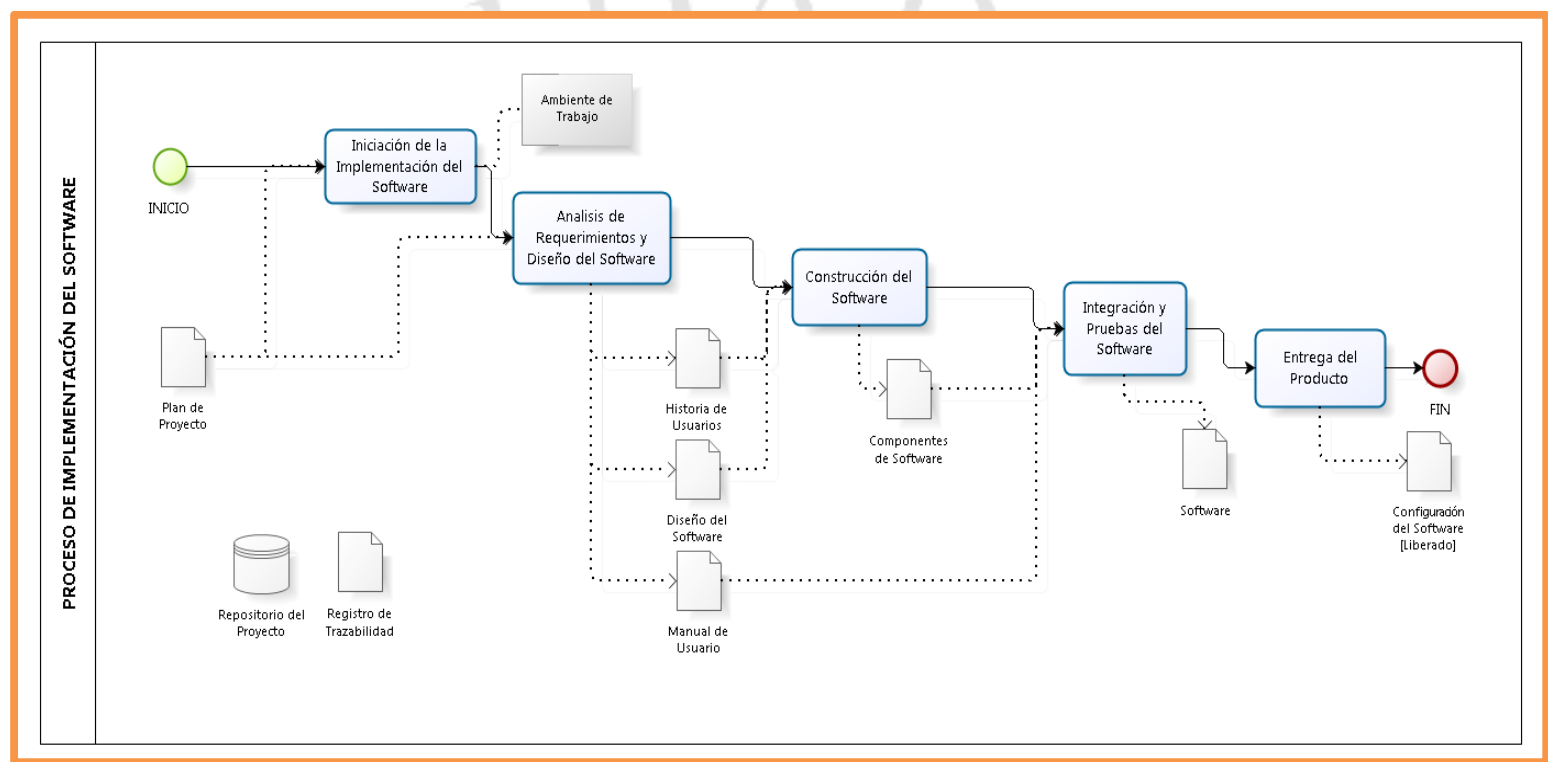

Figura 14 Diagrama BPMN del Proceso de Implementación de Software de la empresa.

Fuente: Elaboración Propia.

Información a tener en cuenta respecto al proceso de Implementación de software de la empresa HOLINSYS:

- Para mencionar los Roles se utilizara la abreviación de estos detallados en la Tabla 9 ROL

\section{CLIENTE - ISO/IEC 29110-5-1-2.}

- El documento "Especificación de Requisitos" descrito en la ISO 29110 es equivalente al documento "Historia de usuario" de la empresa HOLINSYS.

- Las actividades "Análisis de Requerimientos" y "Arquitectura y Diseño detallado" descritos en la ISO 29110 equivalen a la actividad Análisis de Requerimientos y Diseño del Software de la empresa HOLINSYS.

- La verificación hecha por el LT consiste en revisar a detalle los artefactos de salida generados en una actividad del proceso de Implementación de Software. 
- La validación hecha por el CL consiste en validar si los artefactos de salida reflejan lo que el CL necesita.

- En la sección Evaluación de los Productos de Trabajo de la Empresa (Capitulo 5 1.1.1) se encuentra el mapeo de la evaluación de los documentos de la empresa de estudio con respecto a lo expuesto en la NTP ISO/ IEC 29110.

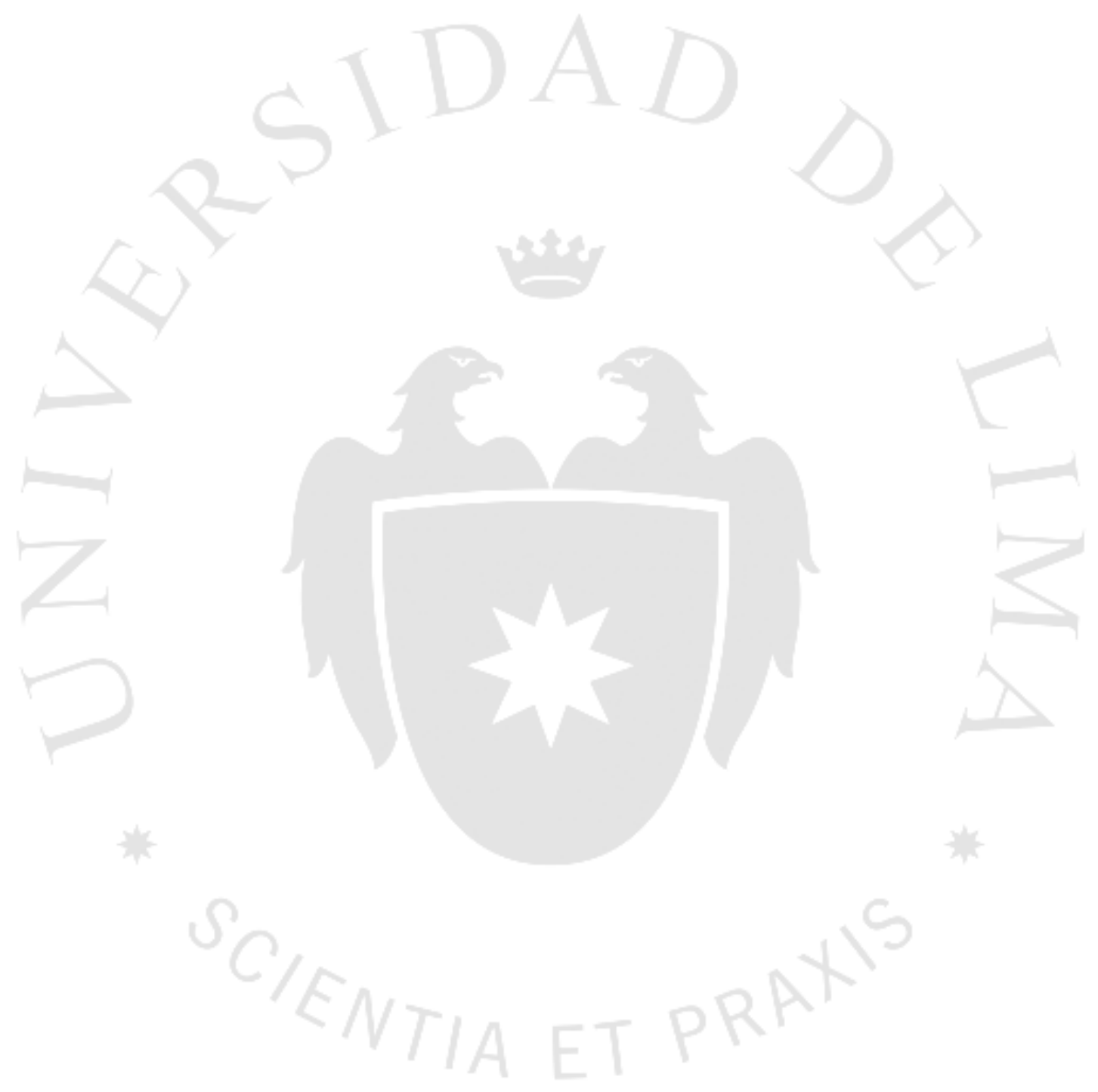




\section{Actividad 01: Inicio de la Implementación de Software}

El objetivo de esta actividad es establecer y/o actualizar el ambiente de trabajo utilizando como base el Plan del proyecto. En la Figura 15, se presenta la actividad Inicio de la Implementación de Software de la empresa HOLINSYS.

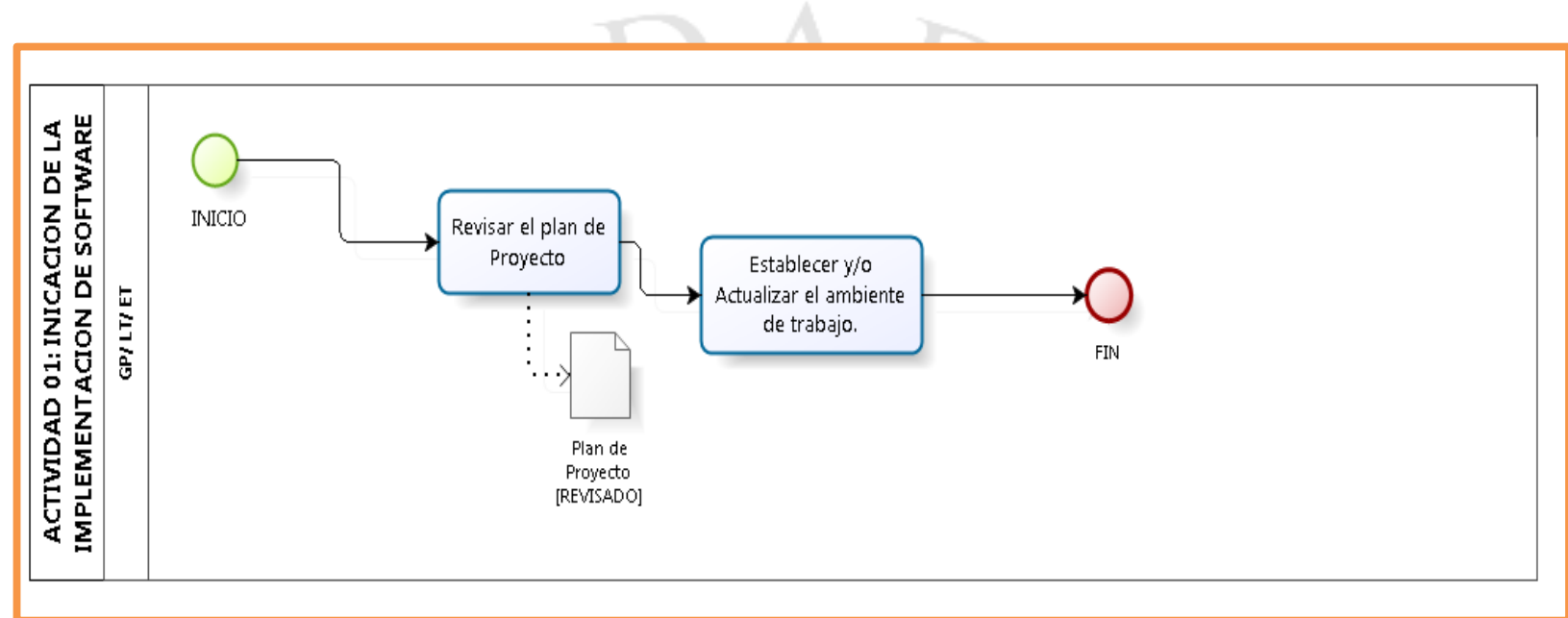

Figura 15 Diagrama BPMN de la Actividad: Inicio de la Implementación de Software de la empresa Fuente: Elaboración Propia. 
A continuación se detalla el nivel de cumplimiento de la actividad "Inicio de la Implementación de Software" con respecto a la ISO 29110.

\begin{tabular}{|c|c|c|c|c|c|c|c|c|c|}
\hline ID & Lista de Tareas & $\begin{array}{l}\text { Productos de } \\
\text { entrada }\end{array}$ & $\begin{array}{l}\text { Productos } \\
\text { de salida }\end{array}$ & Rol & $\begin{array}{l}\text { Es } \\
\text { implementada }\end{array}$ & $\begin{array}{l}\text { Productos } \\
\text { de entrada }\end{array}$ & $\begin{array}{l}\text { Productos de } \\
\text { salida }\end{array}$ & Rol & $\begin{array}{l}\text { Comentarios y } \\
\text { Observaciones }\end{array}$ \\
\hline $\begin{array}{l}\text { IS. } \\
1.1\end{array}$ & $\begin{array}{l}\text { Revisar el Plan del } \\
\text { Proyecto actual con } \\
\text { los miembros del } \\
\text { Equipo de Trabajo con } \\
\text { la finalidad de lograr } \\
\text { un entendimiento } \\
\text { común y obtener su } \\
\text { compromiso con el } \\
\text { proyecto. }\end{array}$ & $\begin{array}{l}\text { Plan del } \\
\text { Proyecto }\end{array}$ & $\begin{array}{l}\text { Plan del } \\
\text { Proyecto } \\
\text { [revisado] }\end{array}$ & $\begin{array}{l}\text { GP } \\
\text { LT } \\
\text { ET }\end{array}$ & Completamente & $\begin{array}{l}\text { Plan del } \\
\text { Proyecto } \\
\text { (Anexo 4.1) }\end{array}$ & $\begin{array}{l}\text { Plan del } \\
\text { Proyecto } \\
\text { [revisado] } \\
(\text { Anexo 4.1) }\end{array}$ & $\begin{array}{l}\text { GP } \\
\text { LT } \\
\text { ET }\end{array}$ & $\begin{array}{l}\text { El ET tiene acceso a una } \\
\text { versión del Plan del } \\
\text { Proyecto que no incluye } \\
\text { los costos del proyecto. } \\
\text { Adicionalmente, se } \\
\text { celebran reuniones diarias } \\
\text { con el ET para revisar el } \\
\text { estado del proyecto. }\end{array}$ \\
\hline $\begin{array}{l}\text { IS. } \\
1.2\end{array}$ & $\begin{array}{l}\text { Establecer o Actualizar } \\
\text { el Ambiente de } \\
\text { Implementación. }\end{array}$ & $\begin{array}{l}\text { Plan del } \\
\text { Proyecto } \\
\text { [revisado] }\end{array}$ & & $\begin{array}{l}\text { LT } \\
\text { ET }\end{array}$ & Completamente & $\begin{array}{l}\text { Plan del } \\
\text { Proyecto } \\
\text { [revisado] } \\
\text { (Anexo 4.1) }\end{array}$ & & $\begin{array}{l}\mathrm{LT} \\
\mathrm{ET}\end{array}$ & $\begin{array}{l}\text { El Ambiente de trabajo se } \\
\text { encuentra listo y no } \\
\text { necesita alteraciones. } \\
\text { En caso sea necesario, el } \\
\text { ET y el LT actualizan el } \\
\text { ambiente de trabajo. }\end{array}$ \\
\hline
\end{tabular}

Tabla 24 Evaluación de la Actividad Iniciación de la Implementación de Software de la empresa.

Fuente: Elaboración Propia. 


\section{Actividad 02: Análisis de Requerimientos y Diseño del Software}

El objetivo de esta actividad es analizar los requisitos del cliente y realizar el diseño del software. En esta actividad se evalúan dos actividades de la norma: Análisis de Requerimientos y Diseño de Software.

En la Figura 16, se presenta la actividad Análisis de Requerimientos y Diseño del Software como una sola actividad, esto es debido a que la empresa considera a la actividad como integrada.

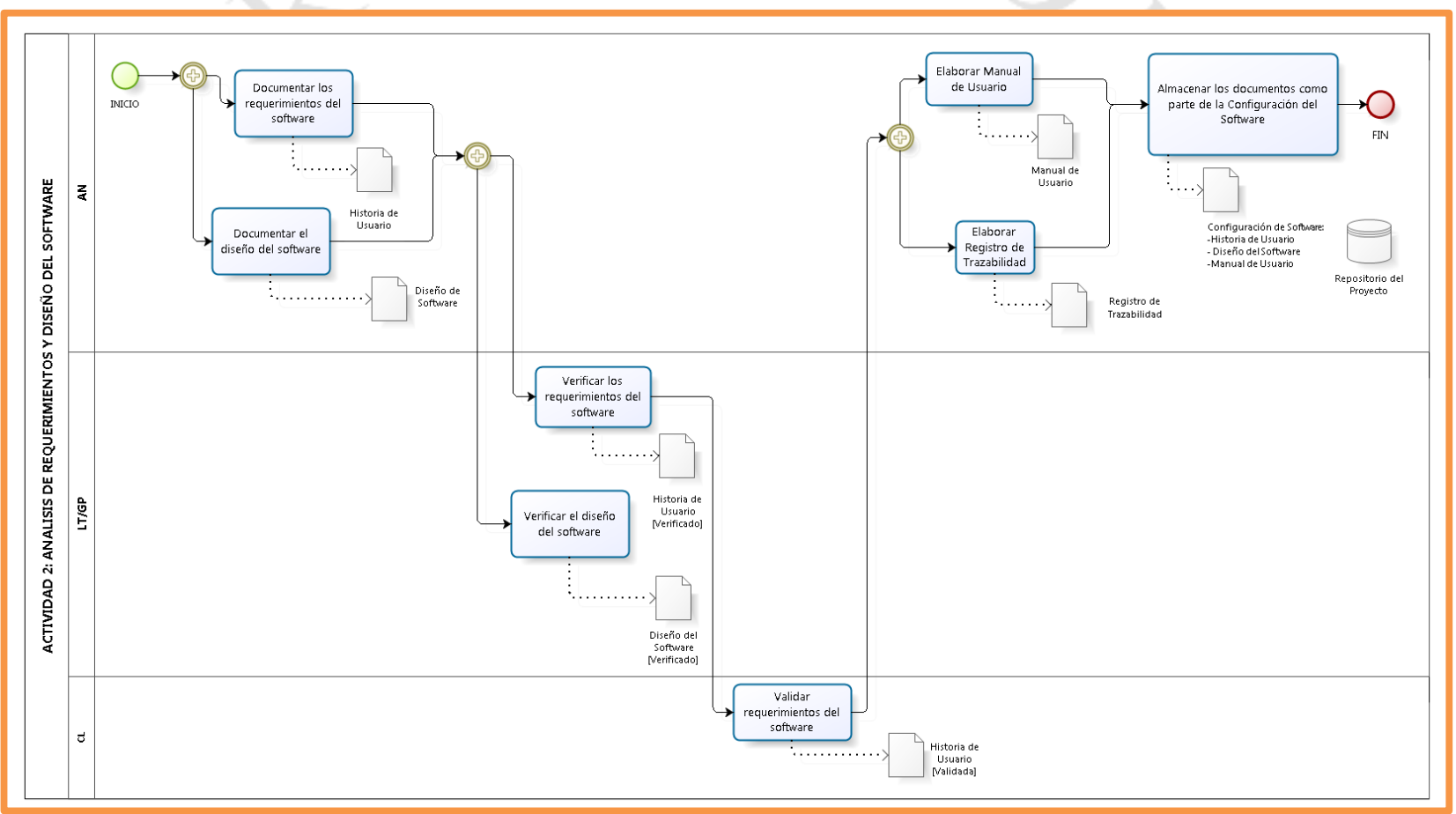

Figura 16 Diagrama BPMN de la Actividad: Análisis de Requerimientos y Diseño del Software de la empresa. Fuente: Elaboración Propia. 
A continuación se detalla el nivel de cumplimiento de la actividad "Análisis de Requerimientos y Diseño del Software" con respecto a la ISO 29110.

\begin{tabular}{|c|c|c|c|c|c|c|c|c|c|}
\hline ID & Lista de Tareas & $\begin{array}{l}\text { Productos de } \\
\text { entrada }\end{array}$ & $\begin{array}{l}\text { Productos de } \\
\text { salida }\end{array}$ & Rol & $\begin{array}{l}\text { Es } \\
\text { implementada }\end{array}$ & $\begin{array}{l}\text { Productos de } \\
\text { entrada }\end{array}$ & $\begin{array}{l}\text { Productos de } \\
\text { salida }\end{array}$ & Rol & $\begin{array}{l}\text { Comentarios y } \\
\text { Observaciones }\end{array}$ \\
\hline $\begin{array}{l}\text { IS. } \\
2.1\end{array}$ & $\begin{array}{l}\text { Asignar Tareas a los } \\
\text { miembros del ET de } \\
\text { acuerdo a cada rol, } \\
\text { basado en el Plan de } \\
\text { Proyectos actual. }\end{array}$ & $\begin{array}{l}\text { Plan del } \\
\text { Proyecto } \\
\text { [revisado] } \\
\text { - Tareas }\end{array}$ & & $\begin{array}{l}\text { LT } \\
\text { ET }\end{array}$ & Completamente & $\begin{array}{l}\text { Diagrama de } \\
\text { Gantt Detallado } \\
\text {-Tareas } \\
\text {-Duración } \\
\text { estimada } \\
\text { (Anexo 4.1) }\end{array}$ & - & $\begin{array}{l}\text { LT } \\
\text { ET }\end{array}$ & $\begin{array}{l}\text { Esta Tarea solo se } \\
\text { realiza solo una } \\
\text { vez en el Proceso } \\
\text { de Gestión del } \\
\text { Proyecto. } \\
\text { *Comúnmente, la } \\
\text { misma persona se } \\
\text { encarga del } \\
\text { análisis y } \\
\text { desarrollo del } \\
\text { proyecto. }\end{array}$ \\
\hline $\begin{array}{l}\text { IS. } \\
2.2\end{array}$ & $\begin{array}{l}\text { Documentar o } \\
\text { actualizar la } \\
\text { Especificación de } \\
\text { Requisitos. } \\
\text { Identificar y consultar } \\
\text { fuentes de } \\
\text { información (Cliente, } \\
\text { Usuarios, sistemas } \\
\text { previos, documentos, } \\
\text { etc.) Con el propósito } \\
\text { de obtener nuevos } \\
\text { requisitos. } \\
\text { Analizar los } \\
\text { requisitos } \\
\text { identificados para } \\
\text { determinar el alcance } \\
\text { y la viabilidad. } \\
\text { Generar o actualizar } \\
\text { la Especificación de } \\
\text { Requisitos. }\end{array}$ & $\begin{array}{l}\text { Plan del } \\
\text { Proyecto } \\
\text { - Descripción } \\
\text { del Producto }\end{array}$ & $\begin{array}{l}\text { Especificación } \\
\text { de Requisitos }\end{array}$ & $\begin{array}{l}\mathrm{AN} \\
\mathrm{CL}\end{array}$ & Completamente & $\begin{array}{l}\text { Plan del } \\
\text { Proyecto } \\
\text { - Descripción } \\
\text { del Producto } \\
\text { (Anexo 4.1) }\end{array}$ & $\begin{array}{l}\text { Historia de } \\
\text { Usuarios } \\
\text { (Anexo 4.3) } \\
\end{array}$ & AN & $\begin{array}{l}\text { El AN se encarga } \\
\text { de elaborar la } \\
\text { Historia de } \\
\text { Usuario. } \\
\text { La Historia de } \\
\text { Usuarios equivale } \\
\text { a la especificación } \\
\text { de Requisitos. } \\
\text { *Para proyectos } \\
\text { complejos, puede } \\
\text { haber más de una } \\
\text { Historia de } \\
\text { Usuario. } \\
\text { En caso sea } \\
\text { necesario, el } \\
\text { cliente es } \\
\text { consultado por el } \\
\text { AN. }\end{array}$ \\
\hline
\end{tabular}




\begin{tabular}{|c|c|c|c|c|c|c|c|c|c|}
\hline ID & Lista de Tareas & $\begin{array}{l}\text { Productos de } \\
\text { entrada }\end{array}$ & $\begin{array}{l}\text { Productos de } \\
\text { salida }\end{array}$ & Rol & $\begin{array}{l}\text { Es } \\
\text { implementada }\end{array}$ & $\begin{array}{l}\text { Productos de } \\
\text { entrada }\end{array}$ & $\begin{array}{l}\text { Productos de } \\
\text { salida }\end{array}$ & Rol & $\begin{array}{l}\text { Comentarios y } \\
\text { Observaciones }\end{array}$ \\
\hline $\begin{array}{l}\text { IS. } \\
2.3\end{array}$ & $\begin{array}{l}\text { Verificar y obtener la } \\
\text { aprobación de la } \\
\text { Especificación de } \\
\text { Requisitos. } \\
\text { Verificar que la } \\
\text { Especificación de } \\
\text { Requisitos sea } \\
\text { correcta, pueda ser } \\
\text { probada y que sea } \\
\text { consistente con la } \\
\text { Descripción del } \\
\text { Producto. } \\
\\
\text { Adicionalmente, } \\
\text { revisar que los } \\
\text { requisitos estén } \\
\text { completos, sin } \\
\text { ambigüedades ni } \\
\text { contradicciones. Los } \\
\text { resultados } \\
\text { encontrados se } \\
\text { documentan en } \\
\text { Resultados de } \\
\text { Verificación y las } \\
\text { correcciones se } \\
\text { realizan hasta que el } \\
\text { documento tenga } \\
\text { visto bueno del AN. } \\
\text { Si fueran necesarios } \\
\text { cambios } \\
\text { significativos, se } \\
\text { propone una } \\
\text { Solicitud de Cambio. }\end{array}$ & $\begin{array}{l}\text { Especificación } \\
\text { de Requisitos } \\
\text { Plan del } \\
\text { Proyecto } \\
\text { - Descripción } \\
\text { del Producto }\end{array}$ & $\begin{array}{l}\text { Resultados de } \\
\text { Verificación } \\
\text { Especificación } \\
\text { de Requisitos } \\
\text { [verificado] } \\
\text { Solicitud de } \\
\text { Cambio } \\
\text { [propuesta] }\end{array}$ & $\begin{array}{l}\text { AN } \\
\text { LT }\end{array}$ & Ampliamente & $\begin{array}{l}\text { Historia de } \\
\text { Usuarios } \\
\text { (Anexo 4.3) } \\
\text { Plan del } \\
\text { Proyecto } \\
\text { - Descripción } \\
\text { del Producto } \\
\text { (Anexo 4.1) }\end{array}$ & $\begin{array}{l}\text { Historia de } \\
\text { Usuarios } \\
\text { [Verificado] } \\
\text { (Anexo 4.3) }\end{array}$ & $\begin{array}{l}\text { AN } \\
\text { LT } \\
\text { GP }\end{array}$ & $\begin{array}{l}\text { EL LT y GP } \\
\text { realizan la revisión } \\
\text { de la Historia de } \\
\text { Usuario. } \\
\text { El LT y el GP } \\
\text { revisan la Historia } \\
\text { de Usuarios y } \\
\text { verifican que sea } \\
\text { consistente con lo } \\
\text { descrito en el Plan } \\
\text { del Proyecto y la } \\
\text { forma del } \\
\text { documento. } \\
\text { Adicionalmente, el } \\
\text { LT revisa el } \\
\text { documento a } \\
\text { detalle. } \\
\text { La Historia de } \\
\text { Usuario es } \\
\text { corregida por el } \\
\text { AN hasta que el } \\
\text { AN, LT y GP estén } \\
\text { conformes. } \\
\text { El AN puede } \\
\text { proponer una } \\
\text { Solicitud de } \\
\text { Cambio al GP. } \\
\text { No existe un } \\
\text { documento formal } \\
\text { donde se registre el } \\
\text { resultado de la } \\
\text { verificación. }\end{array}$ \\
\hline $\begin{array}{l}\text { IS. } \\
2.4\end{array}$ & $\begin{array}{l}\text { Validar y Obtener la } \\
\text { aprobación de la }\end{array}$ & $\begin{array}{l}\text { Especificación } \\
\text { de Requisitos }\end{array}$ & $\begin{array}{l}\text { Resultado de } \\
\text { Validación }\end{array}$ & CL & Ampliamente & $\begin{array}{l}\text { Historia de } \\
\text { Usuarios }\end{array}$ & $\begin{array}{l}\text { Historia de } \\
\text { Usuarios }\end{array}$ & $\mathrm{CL}$ & $\begin{array}{l}\text { El cliente revisa la } \\
\text { Historia de }\end{array}$ \\
\hline
\end{tabular}




\begin{tabular}{|c|c|c|c|c|c|c|c|c|c|}
\hline ID & Lista de Tareas & $\begin{array}{c}\text { Productos de } \\
\text { entrada }\end{array}$ & $\begin{array}{l}\text { Productos de } \\
\text { salida }\end{array}$ & Rol & $\begin{array}{l}\text { Es } \\
\text { implementada }\end{array}$ & $\begin{array}{l}\text { Productos de } \\
\text { entrada }\end{array}$ & $\begin{array}{l}\text { Productos de } \\
\text { salida }\end{array}$ & Rol & $\begin{array}{l}\text { Comentarios y } \\
\text { Observaciones }\end{array}$ \\
\hline & $\begin{array}{l}\text { Especificación de } \\
\text { Requisitos. } \\
\text { Validar que la } \\
\text { Especificación de } \\
\text { Requisitos satisfaga } \\
\text { las necesidades y sea } \\
\text { acorde a las } \\
\text { expectativas, } \\
\text { incluyendo la } \\
\text { usabilidad de la } \\
\text { interfaz de usuario. } \\
\text { Los resultados } \\
\text { encontrados son } \\
\text { documentados en el } \\
\text { Resultado de } \\
\text { Validación y se } \\
\text { realizan las } \\
\text { correcciones hasta } \\
\text { que el documento sea } \\
\text { aprobado por el CL } \\
\text { en Resultados de } \\
\text { Validación. Las } \\
\text { correcciones se } \\
\text { realizan hasta que el } \\
\text { documento tiene visto } \\
\text { bueno del CL. }\end{array}$ & [verificada] & $\begin{array}{l}\text { [validado] } \\
\text { Especificación } \\
\text { de Requisitos }\end{array}$ & AN & & \begin{tabular}{|l|} 
[Verificado] \\
(Anexo 4.3)
\end{tabular} & \begin{tabular}{|l} 
[Validado] \\
(Anexo 4.3)
\end{tabular} & $\begin{array}{l}\text { AN } \\
\text { LT }\end{array}$ & $\begin{array}{l}\text { Usuario y } \\
\text { Comunica las } \\
\text { correcciones } \\
\text { necesarias. } \\
\text { Las correcciones y } \\
\text { conformidad del } \\
\text { cliente se } \\
\text { almacenan en un } \\
\text { correo electrónico } \\
\text { (Si la revisión se } \\
\text { hizo vía Web) o a } \\
\text { través de un Acta } \\
\text { de Reunión (Si la } \\
\text { revisión se hizo en } \\
\text { las instalaciones de } \\
\text { la Empresa). } \\
\text { No hay evidencia } \\
\text { del Acta de } \\
\text { reunión } \\
\text { No existe los } \\
\text { documentos } \\
\text { formales: } \\
\text {-Resultado de la } \\
\text { verificación. } \\
\text {-Acta de Reunión }\end{array}$ \\
\hline $\begin{array}{l}\text { IS. } \\
2.5\end{array}$ & $\begin{array}{l}\text { Documentar la } \\
\text { versión preliminar del } \\
* \text { Manual de Usuario } \\
\text { o actualizar el manual } \\
\text { existente. Si es } \\
\text { apropiado } \\
\text { *(Opcional) }\end{array}$ & $\begin{array}{l}\text { Especificación } \\
\text { de Requisitos } \\
\text { [validado] }\end{array}$ & \begin{tabular}{|l|} 
*Manual de \\
Usuario \\
[preliminar]
\end{tabular} & AN & Parcialmente & \begin{tabular}{|l} 
Historia de \\
Usuarios \\
[validado] \\
(Anexo 4.3)
\end{tabular} & \begin{tabular}{|l|} 
*Manual de \\
Usuario \\
[preliminar] \\
(Anexo 4.10)
\end{tabular} & AN & $\begin{array}{l}\text { En ocasiones, el } \\
\text { AN documenta el } \\
\text { manual de } \\
\text { Usuario. } \\
\text { Actualmente, no } \\
\text { hay rol que } \\
\text { implemente la } \\
\text { documentación de } \\
\text { este producto. }\end{array}$ \\
\hline
\end{tabular}




\begin{tabular}{|c|c|c|c|c|c|c|c|c|c|}
\hline ID & Lista de Tareas & $\begin{array}{c}\text { Productos de } \\
\text { entrada }\end{array}$ & $\begin{array}{c}\text { Productos de } \\
\text { salida }\end{array}$ & Rol & $\begin{array}{l}\text { Es } \\
\text { implementada }\end{array}$ & $\begin{array}{l}\text { Productos de } \\
\text { entrada }\end{array}$ & $\begin{array}{l}\text { Productos de } \\
\text { salida }\end{array}$ & Rol & $\begin{array}{l}\text { Comentarios y } \\
\text { Observaciones }\end{array}$ \\
\hline & & 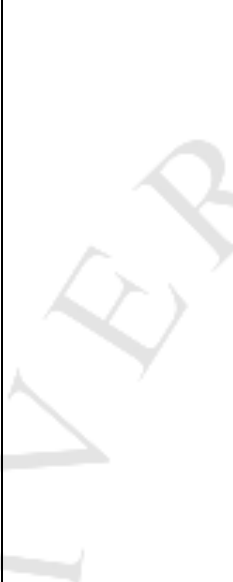 & & & & & 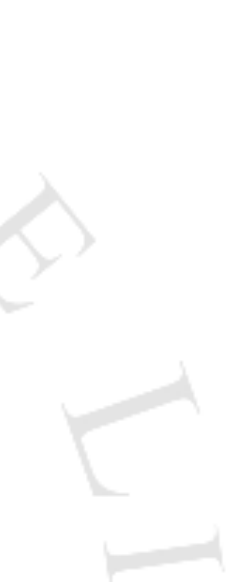 & & $\begin{array}{l}\text { El "Manual de } \\
\text { Usuario" no } \\
\text { cumple con } \\
\text { algunas secciones. } \\
\text { (Anexo 4.10) } \\
\text { La Propuesta para } \\
\text { dicha tarea se } \\
\text { encuentra en la } \\
\text { "Propuesta de } \\
\text { mejora para los } \\
\text { Procesos del ciclo } \\
\text { de vida“(Sección } \\
\text { 5.1.1.1). }\end{array}$ \\
\hline $\begin{array}{l}\text { IS. } \\
2.6\end{array}$ & $\begin{array}{l}\text { Verificar y Obtener la } \\
\text { aprobación del } \\
\text { Manual de Usuario, } \\
\text { si es apropiado. } \\
\\
\text { Verificar la } \\
\text { consistencia del } \\
\text { Manual de Usuario } \\
\text { con la Especificación } \\
\text { de Requisitos. Los } \\
\text { resultados } \\
\text { encontrados se } \\
\text { documentan en el } \\
\text { Resultado de } \\
\text { Verificación y las } \\
\text { correcciones se } \\
\text { realizan hasta que el } \\
\text { documento es } \\
\text { aprobado por el AN. } \\
\text { Si fueran necesarios } \\
\text { Cambios }\end{array}$ & $\begin{array}{l}\text { *Manual de } \\
\text { Usuario } \\
\text { [preliminar] } \\
\text { Especificación } \\
\text { de Requisitos }\end{array}$ & $\begin{array}{l}\text { Resultado de } \\
\text { Verificación } \\
\text { Manual de } \\
\text { Usuario } \\
\text { [preliminar, } \\
\text { verificado] } \\
\\
\text { Solicitud de } \\
\text { Cambio } \\
\text { [propuesta] }\end{array}$ & $\begin{array}{l}\text { AN } \\
\text { LT }\end{array}$ & Ampliamente & \begin{tabular}{|l|} 
*Manual de \\
Usuario \\
[preliminar] \\
(Anexo 4.10) \\
\\
Historia de \\
Usuarios \\
(Anexo 4.3)
\end{tabular} & $\begin{array}{l}\text { Manual de } \\
\text { Usuario } \\
\text { [preliminar, } \\
\text { verificado] } \\
\text { (Anexo 4.10) } \\
\text { Solicitud de } \\
\text { Cambio } \\
\text { [propuesta] } \\
\text { (Anexo 4.5) }\end{array}$ & NA. & \begin{tabular}{|l} 
El LT revisa y \\
verifica el estado \\
del Manual de \\
Usuario. \\
No existe un \\
documento formal \\
donde se registre el \\
resultado de la \\
verificación. \\
De ser necesario, \\
el AN puede \\
solicitar una \\
solicitud de \\
cambio.
\end{tabular} \\
\hline
\end{tabular}




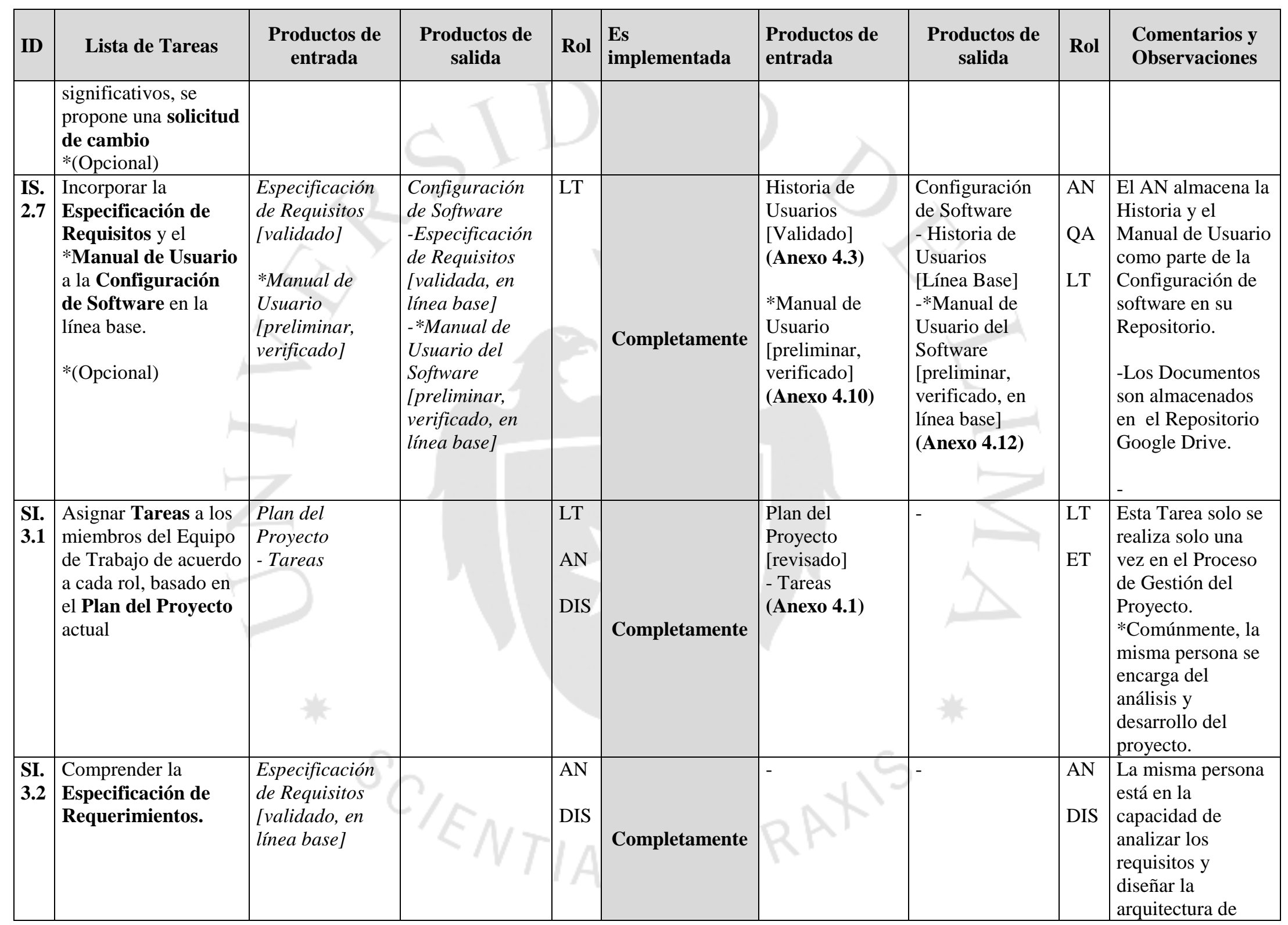




\begin{tabular}{|c|c|c|c|c|c|c|c|c|c|}
\hline ID & Lista de Tareas & $\begin{array}{c}\text { Productos de } \\
\text { entrada }\end{array}$ & $\begin{array}{c}\text { Productos de } \\
\text { salida }\end{array}$ & Rol & $\begin{array}{l}\text { Es } \\
\text { implementada }\end{array}$ & $\begin{array}{l}\text { Productos de } \\
\text { entrada }\end{array}$ & $\begin{array}{l}\text { Productos de } \\
\text { salida }\end{array}$ & Rol & $\begin{array}{l}\text { Comentarios y } \\
\text { Observaciones }\end{array}$ \\
\hline & & & & & & & & & software. \\
\hline $\begin{array}{l}\text { SI. } \\
\text { 3.3. }\end{array}$ & $\begin{array}{l}\text { Documentar o } \\
\text { actualizar el Diseño } \\
\text { de Software. } \\
\text { Analizar la } \\
\text { Especificación de } \\
\text { Requisitos para } \\
\text { generar el diseño } \\
\text { arquitectónico, su } \\
\text { conformación en } \\
\text { subsistemas y } \\
\text { componente de } \\
\text { Software, definir } \\
\text { interfaces internas y } \\
\text { externas. Describir a } \\
\text { detalle, la apariencia } \\
\text { y el comportamiento } \\
\text { de la interfaz, con } \\
\text { base en la } \\
\text { Especificación de } \\
\text { Requisitos de tal } \\
\text { forma que los } \\
\text { recursos para su } \\
\text { implantación puedan } \\
\text { preverse. } \\
\text { Proporcionar el } \\
\text { detalle de los } \\
\text { Componente de } \\
\text { software y sus } \\
\text { interfaces para } \\
\text { permitir la } \\
\text { construcción en una } \\
\text { forma clara. } \\
\\
\text { Generar o actualizar }\end{array}$ & $\begin{array}{l}\text { Especificación } \\
\text { de Requisitos } \\
\text { [validado, en } \\
\text { línea base] }\end{array}$ & $\begin{array}{l}\text { Diseño de } \\
\text { Software } \\
\text { Registro de } \\
\text { Trazabilidad }\end{array}$ & $\begin{array}{l}\text { AN } \\
\text { DIS }\end{array}$ & Completamente & \begin{tabular}{|l} 
Plan del \\
Proyecto \\
- Descripción \\
del Producto. \\
(Anexo 4.1)
\end{tabular} & \begin{tabular}{|l} 
Diseño de \\
Software \\
(Anexo 4.13)
\end{tabular} & AN & $\begin{array}{l}\text { *En la empresa de } \\
\text { Estudio, el Diseño } \\
\text { de Software puede } \\
\text { ser realizado al } \\
\text { mismo tiempo que } \\
\text { la especificación } \\
\text { de requisitos. } \\
\text { En el registro de } \\
\text { trazabilidad } \\
\text { entregado por la } \\
\text { empresa no } \\
\text { incluye la sección } \\
\text { Arquitectura y } \\
\text { Diseño }\end{array}$ \\
\hline
\end{tabular}




\begin{tabular}{|c|c|c|c|c|c|c|c|c|c|}
\hline ID & Lista de Tareas & $\begin{array}{c}\text { Productos de } \\
\text { entrada }\end{array}$ & $\begin{array}{c}\text { Productos de } \\
\text { salida }\end{array}$ & Rol & $\begin{array}{l}\text { Es } \\
\text { implementada }\end{array}$ & $\begin{array}{l}\text { Productos de } \\
\text { entrada }\end{array}$ & $\begin{array}{l}\text { Productos de } \\
\text { salida }\end{array}$ & Rol & $\begin{array}{l}\text { Comentarios y } \\
\text { Observaciones }\end{array}$ \\
\hline & $\begin{array}{l}\text { el Registro de } \\
\text { Trazabilidad. }\end{array}$ & & & & & & & & \\
\hline $\begin{array}{l}\text { SI. } \\
3.4\end{array}$ & $\begin{array}{l}\text { Verificar y obtener la } \\
\text { aprobación del } \\
\text { Diseño de Software. } \\
\text { Verificar que la } \\
\text { documentación del } \\
\text { Diseño de Software } \\
\text { sea correcta, viable y } \\
\text { consistente con la } \\
\text { especificación de } \\
\text { Requisitos. } \\
\text { Verificar que el } \\
\text { Registro de } \\
\text { Trazabilidad } \\
\text { contenga las } \\
\text { relaciones adecuadas } \\
\text { entre los requisitos y } \\
\text { los elementos del } \\
\text { Diseño de software. } \\
\text { Los resultados } \\
\text { encontrados son } \\
\text { documentados en } \\
\text { Resultado de } \\
\text { Verificación y las } \\
\text { correcciones se } \\
\text { realizan hasta que el } \\
\text { documento ha sido } \\
\text { probado por el DIS. } \\
\text { Si fueran necesarios } \\
\text { cambios } \\
\text { significativos, se } \\
\text { propone una }\end{array}$ & $\begin{array}{l}\text { Diseño del } \\
\text { Software } \\
\\
\text { Registro de } \\
\text { Trazabilidad } \\
\\
\text { Especificación } \\
\text { de Requisitos } \\
\text { [validado, en } \\
\text { línea base] }\end{array}$ & $\begin{array}{l}\text { Resultado de } \\
\text { Verificación } \\
\text { Diseño de } \\
\text { Software } \\
\text { [verificado] } \\
\text { Registro de } \\
\text { Trazabilidad } \\
\text { [verificado] } \\
\text { Solicitud de } \\
\text { Cambio } \\
\text { [propuesta] }\end{array}$ & $\begin{array}{l}\text { AN } \\
\text { DIS }\end{array}$ & Ampliamente & 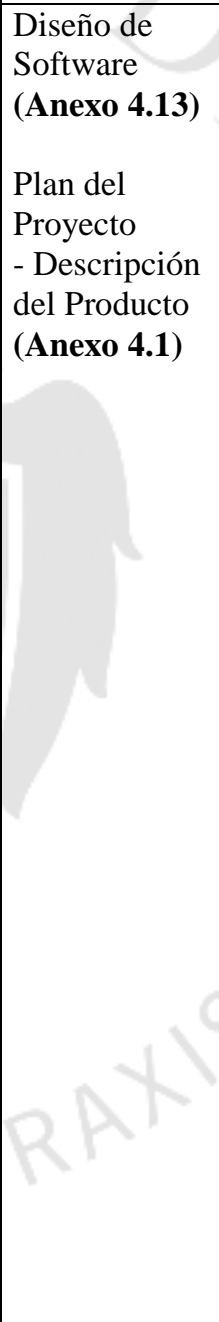 & $\begin{array}{l}\text { Diseño de } \\
\text { Software } \\
\text { [Verificado] } \\
\text { (Anexo 4.13) } \\
\end{array}$ & $\begin{array}{l}\text { AN } \\
\text { LT } \\
\text { GP }\end{array}$ & $\begin{array}{l}\text { EL LT y GP } \\
\text { realizan la revisión } \\
\text { del Diseño de } \\
\text { Software. } \\
\\
\text { El LT y el GP } \\
\text { revisan que el } \\
\text { Diseño de } \\
\text { Software y verifica } \\
\text { que sea consistente } \\
\text { con lo descrito en } \\
\text { el Plan del } \\
\text { Proyecto y la } \\
\text { forma del } \\
\text { documento. } \\
\\
\text { Adicionalmente, el } \\
\text { LT revisa el } \\
\text { documento a } \\
\text { detalle. } \\
\text { El Diseño de } \\
\text { Software es } \\
\text { corregido por el } \\
\text { AN hasta que el } \\
\text { LT y GP estén } \\
\text { conformes. } \\
\text { El AN puede } \\
\text { proponer una } \\
\text { Solicitud de } \\
\text { Cambio al GP. }\end{array}$ \\
\hline
\end{tabular}




\begin{tabular}{|c|c|c|c|c|c|c|c|c|c|}
\hline ID & Lista de Tareas & $\begin{array}{c}\text { Productos de } \\
\text { entrada }\end{array}$ & $\begin{array}{l}\text { Productos de } \\
\text { salida }\end{array}$ & Rol & $\begin{array}{l}\text { Es } \\
\text { implementada }\end{array}$ & $\begin{array}{l}\text { Productos de } \\
\text { entrada }\end{array}$ & $\begin{array}{c}\text { Productos de } \\
\text { salida }\end{array}$ & Rol & $\begin{array}{l}\text { Comentarios y } \\
\text { Observaciones }\end{array}$ \\
\hline & Solicitud de Cambio. & & & & & & & & \begin{tabular}{|l} 
Se realiza la \\
verificación de los \\
documentos, sin \\
embargo, no existe \\
documentación \\
para el Resultado \\
de Verificación.
\end{tabular} \\
\hline $\begin{array}{l}\text { SI. } \\
3.5\end{array}$ & \begin{tabular}{|l} 
Establecer o \\
actualizar los Casos \\
de Prueba y \\
Procedimientos de \\
Prueba para pruebas \\
de integración \\
basadas en las \\
Especificación de \\
Requisitos y el \\
Diseño de Software. \\
\\
El Cliente provee \\
datos de prueba, en \\
caso de ser necesario
\end{tabular} & $\begin{array}{l}\text { Especificación } \\
\text { de Requisitos } \\
\text { [validado, en } \\
\text { línea base] } \\
\text { Diseño de } \\
\text { Software } \\
\text { [verificado, en } \\
\text { línea base] }\end{array}$ & $\begin{array}{l}\text { Casos de Prueba } \\
y \\
\text { Procedimientos } \\
\text { de Prueba }\end{array}$ & DIS & Parcialmente & \begin{tabular}{|l} 
Historia de \\
usuario \\
[validado, en \\
línea base] \\
(Anexo 4.3) \\
\\
Diseño de \\
Software \\
[verificado, en \\
línea base] \\
(Anexo 4.13)
\end{tabular} & $\begin{array}{l}\text { Casos de Prueba } \\
\text { y } \\
\text { Procedimientos } \\
\text { de Prueba } \\
\text { (Anexo 4.4) } \\
\\
\end{array}$ & AN & $\begin{array}{l}\text { El AN elabora los } \\
\text { casos de Prueba y } \\
\text { Procedimientos de } \\
\text { Prueba utilizando } \\
\text { como base la } \\
\text { historia de } \\
\text { usuarios y el } \\
\text { diseño del } \\
\text { software. } \\
\text { Actualmente, no } \\
\text { hay un rol } \\
\text { encargado de la } \\
\text { elaboración de los } \\
\text { casos de prueba. } \\
\text { Se tiene una } \\
\text { plantilla para los } \\
\text { casos de Prueba } \\
\text { (Esta no cumple al } \\
\text { 100\% con la ISO). } \\
\\
\text { La Propuesta para } \\
\text { dicha tarea se } \\
\text { encuentra en la } \\
\text { "Propuesta de } \\
\text { mejora para los } \\
\text { Procesos del ciclo } \\
\text { de vida“(Sección } \\
\text { 5.1.1.1). }\end{array}$ \\
\hline
\end{tabular}




\begin{tabular}{|c|c|c|c|c|c|c|c|c|c|}
\hline ID & Lista de Tareas & $\begin{array}{l}\text { Productos de } \\
\text { entrada }\end{array}$ & $\begin{array}{l}\text { Productos de } \\
\text { salida }\end{array}$ & Rol & $\begin{array}{l}\text { Es } \\
\text { implementada }\end{array}$ & $\begin{array}{l}\text { Productos de } \\
\text { entrada }\end{array}$ & $\begin{array}{l}\text { Productos de } \\
\text { salida }\end{array}$ & Rol & $\begin{array}{l}\text { Comentarios y } \\
\text { Observaciones }\end{array}$ \\
\hline $\begin{array}{l}\text { SI. } \\
3.6\end{array}$ & $\begin{array}{l}\text { Verificar y Obtener la } \\
\text { aprobación de los } \\
\text { Casos de Prueba y } \\
\text { Procedimientos de } \\
\text { Prueba. } \\
\text { Verificar la } \\
\text { consistencia entra la } \\
\text { Especificación de } \\
\text { Requerimientos, } \\
\text { Diseño de Software } \\
\text { y los Casos de } \\
\text { Prueba y } \\
\text { Procedimientos de } \\
\text { Prueba. Los } \\
\text { resultados } \\
\text { encontrados están } \\
\text { documentados en } \\
\text { Resultado de } \\
\text { Verificación y las } \\
\text { correcciones son } \\
\text { realizadas hasta que } \\
\text { el documento es } \\
\text { aprobado por el AN. } \\
\end{array}$ & $\begin{array}{l}\text { Casos de } \\
\text { Prueba y } \\
\text { Procedimientos } \\
\text { de Prueba. } \\
\text { Especificación } \\
\text { de Requisitos } \\
\text { [validado, en } \\
\text { línea base] } \\
\text { Diseño de } \\
\text { Software } \\
\text { [verificado, en } \\
\text { línea base] }\end{array}$ & $\begin{array}{l}\text { Resultados de } \\
\text { Verificación. } \\
\text { Casos de Prueba } \\
\text { y } \\
\text { Procedimientos } \\
\text { de Prueba } \\
\text { [verificado] }\end{array}$ & $\begin{array}{l}\text { DIS } \\
\text { AN }\end{array}$ & Ampliamente & $\begin{array}{l}\text { Casos de Prueba } \\
\text { y } \\
\text { Procedimientos } \\
\text { de Prueba. } \\
\text { (Anexo 4.4) } \\
\\
\text { Historia de } \\
\text { Usuario } \\
\text { [validado, en } \\
\text { línea base] } \\
\text { (Anexo 4.3) } \\
\\
\text { Diseño de } \\
\text { Software } \\
\text { [verificado, en } \\
\text { línea base] } \\
\text { (Anexo 4.13) }\end{array}$ & $\begin{array}{l}\text { Casos de Prueba } \\
\text { y } \\
\text { Procedimientos } \\
\text { de Prueba } \\
\text { [verificado] } \\
\text { (Anexo 4.4) }\end{array}$ & $\begin{array}{l}\text { AN } \\
\text { LT }\end{array}$ & $\begin{array}{l}\text { El LT verifica la } \\
\text { consistencia de los } \\
\text { Casos de prueba } \\
\text { con respecto a los } \\
\text { productos de } \\
\text { trabajo: } \\
\text {-Casos de Prueba y } \\
\text { Procedimientos } \\
\text { de Prueba. } \\
\text {-Historia de } \\
\text { Usuario } \\
\text { *Actualmente, no } \\
\text { hay un rol } \\
\text { encargado de la } \\
\text { elaboración de los } \\
\text { casos de prueba. } \\
\text { *Actualmente, no } \\
\text { hay un documento } \\
\text { formal con los } \\
\text { resultados de la } \\
\text { verificación }\end{array}$ \\
\hline $\begin{array}{l}\text { SI. } \\
3.7\end{array}$ & $\begin{array}{l}\text { Actualizar el } \\
\text { Registro de } \\
\text { Trazabilidad } \\
\text { incorporando los } \\
\text { Casos de Prueba y } \\
\text { Procedimientos de } \\
\text { Prueba }\end{array}$ & $\begin{array}{l}\text { Casos de } \\
\text { Prueba y } \\
\text { Procedimientos } \\
\text { de Prueba } \\
\text { [verificados] } \\
\\
\text { Registro de } \\
\text { Trazabilidad } \\
\text { [actualizado] }\end{array}$ & $\begin{array}{l}\text { Registro de } \\
\text { Trazabilidad } \\
\text { [actualizado] }\end{array}$ & DIS & Parcialmente & $\begin{array}{l}\text { Casos de Prueba } \\
\text { y } \\
\text { Procedimientos } \\
\text { de Prueba } \\
\text { [verificados] } \\
\text { (Anexo 4.4) } \\
\text { Registro de } \\
\text { Trazabilidad } \\
\text { [actualizado] } \\
\text { (Anexo 4.8) }\end{array}$ & \begin{tabular}{|l} 
Registro de \\
Trazabilidad \\
[actualizado] \\
(Anexo 4.8)
\end{tabular} & AN & $\begin{array}{l}\text { El AN elabora el } \\
\text { Registro de } \\
\text { Trazabilidad donde } \\
\text { se hace el mapeo } \\
\text { entre los requisitos } \\
\text { y los casos de uso. } \\
\\
\text { El registro de } \\
\text { Trazabilidad no } \\
\text { cumple con la } \\
\text { información } \\
\text { solicitada: Diseño } \\
\text { y arquitectura no }\end{array}$ \\
\hline
\end{tabular}




\begin{tabular}{|c|c|c|c|c|c|c|c|c|c|}
\hline ID & Lista de Tareas & $\begin{array}{c}\text { Productos de } \\
\text { entrada }\end{array}$ & $\begin{array}{l}\text { Productos de } \\
\text { salida }\end{array}$ & Rol & $\begin{array}{l}\text { Es } \\
\text { implementada }\end{array}$ & $\begin{array}{l}\text { Productos de } \\
\text { entrada }\end{array}$ & $\begin{array}{l}\text { Productos de } \\
\text { salida }\end{array}$ & Rol & $\begin{array}{l}\text { Comentarios y } \\
\text { Observaciones }\end{array}$ \\
\hline & & & & & & & & & $\begin{array}{l}\text { está incluido en el } \\
\text { registro de } \\
\text { trazabilidad. }\end{array}$ \\
\hline $\begin{array}{l}\text { SI. } \\
3.8\end{array}$ & $\begin{array}{l}\text { Incorporar el Diseño } \\
\text { de Software, y el } \\
\text { Registro de } \\
\text { Trazabilidad a la } \\
\text { Configuración de } \\
\text { Software como parte } \\
\text { de la línea base. } \\
\\
\text { Incorporar los Casos } \\
\text { de Prueba y } \\
\text { Procedimientos de } \\
\text { Prueba al } \\
\text { Repositorio del } \\
\text { Proyecto. }\end{array}$ & $\begin{array}{l}\text { Diseño de } \\
\text { Software } \\
\text { [verificado] } \\
\text { Casos de } \\
\text { Prueba y } \\
\text { Procedimientos } \\
\text { de Prueba } \\
\text { [verificados] } \\
\text { Registro de } \\
\text { Trazabilidad } \\
\text { [actualizado] }\end{array}$ & $\begin{array}{l}\text { Configuración } \\
\text { de Software } \\
\text { - Diseño de } \\
\text { Software } \\
\text { [verificado, en } \\
\text { línea base] } \\
\text { - Casos de } \\
\text { Prueba y } \\
\text { Procedimientos } \\
\text { de Prueba } \\
\text { [verificados] } \\
\text { - Registro de } \\
\text { Trazabilidad } \\
\text { [verificado, en } \\
\text { línea base] }\end{array}$ & LT & Completamente & $\begin{array}{l}\text { Diseño de } \\
\text { Software } \\
\text { [Validado] } \\
\text { (Anexo 4.13) }\end{array}$ & $\begin{array}{l}\text { Configuración } \\
\text { de Software } \\
\text { actualizado. } \\
\text { - Diseño de } \\
\text { Software } \\
\text { [verificado, en } \\
\text { línea base] } \\
\text { (Anexo 4.12) }\end{array}$ & AN & $\begin{array}{l}\text { El AN almacena } \\
\text { los documentos } \\
\text { como parte de la } \\
\text { Configuración de } \\
\text { software en el } \\
\text { Repositorio } \\
\text { Google Drive } \\
\text { Los Documentos } \\
\text { son almacenados } \\
\text { en el Repositorio } \\
\text { Google Drive. } \\
\text { La Propuesta para } \\
\text { dicha tarea se } \\
\text { encuentra en la } \\
\text { "Propuesta de } \\
\text { mejora para los } \\
\text { Procesos del ciclo } \\
\text { de vida“(Sección } \\
\text { 5.1.1.1). }\end{array}$ \\
\hline
\end{tabular}

Tabla 25 Evaluación de la Actividad Análisis de Requerimientos y Diseño del Software de la empresa.

Fuente: Elaboración Propia. 


\section{Actividad 03: Construcción del Software}

El objetivo de esta actividad es desarrollar o modificar los componentes de software a partir utilizando como base el documento Diseño del Software. En la Figura 17, se presenta la actividad Construcción del Software:

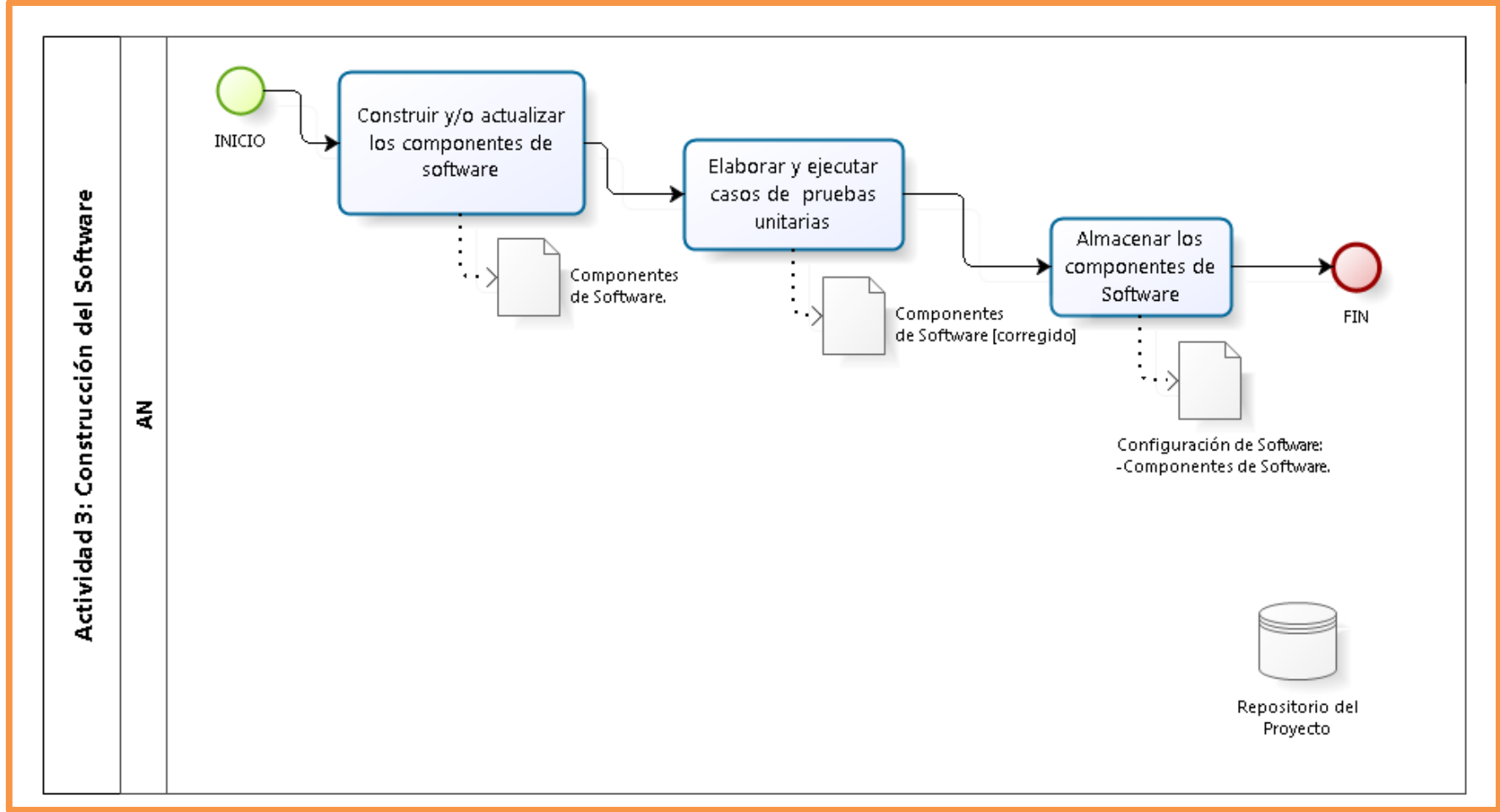

Figura 17 Diagrama BPMN de la Actividad: Construcción del Software de la empresa.

Fuente: Elaboración Propia. 
A continuación se detalla el nivel de cumplimiento de la actividad "Construcción del Software" con respecto a la ISO 29110.

\begin{tabular}{|c|c|c|c|c|c|c|c|c|c|}
\hline ID & Lista de Tareas & $\begin{array}{l}\text { Productos de } \\
\text { entrada }\end{array}$ & $\begin{array}{l}\text { Productos de } \\
\text { salida }\end{array}$ & Rol & $\begin{array}{l}\text { Es } \\
\text { implementada }\end{array}$ & $\begin{array}{l}\text { Productos de } \\
\text { entrada }\end{array}$ & $\begin{array}{l}\text { Productos de } \\
\text { salida }\end{array}$ & Rol & $\begin{array}{l}\text { Comentarios y } \\
\text { Observaciones }\end{array}$ \\
\hline $\begin{array}{l}\text { IS. } \\
4.1\end{array}$ & \begin{tabular}{|l} 
Asignar Tareas a los \\
miembros del Equipo de \\
Trabajo en relación a su \\
rol de acuerdo al Plan \\
del Proyecto actual.
\end{tabular} & $\begin{array}{l}\text { Plan del } \\
\text { Proyecto } \\
\text { - Tareas }\end{array}$ & & $\begin{array}{l}\mathrm{TL} \\
\mathrm{PR}\end{array}$ & Completamente & \begin{tabular}{|l|} 
Plan del \\
Proyecto \\
[revisado] \\
- Tareas \\
(Anexo 4.1)
\end{tabular} & & $\begin{array}{l}\text { LT } \\
\text { ET }\end{array}$ & $\begin{array}{l}\text { Esta Tarea solo se } \\
\text { realiza solo una vez } \\
\text { en el Proceso de } \\
\text { Gestión del Proyecto. } \\
\text { *Comúnmente, la } \\
\text { misma persona se } \\
\text { encarga del análisis y } \\
\text { desarrollo del } \\
\text { proyecto. }\end{array}$ \\
\hline $\begin{array}{l}\text { IS. } \\
4.2\end{array}$ & $\begin{array}{l}\text { Entender el Diseño de } \\
\text { Software. }\end{array}$ & $\begin{array}{l}\text { Diseño de } \\
\text { Software } \\
\text { [verificado, en } \\
\text { línea base] }\end{array}$ & & PR & Completamente & NA. & NA. & PR & $\begin{array}{l}\text { Comúnmente, la } \\
\text { misma persona } \\
\text { cumple el Rol de AN, } \\
\text { DIS y PR. } \\
\\
\text { La misma persona } \\
\text { está en la capacidad } \\
\text { de analizar los } \\
\text { requisitos y diseñar la } \\
\text { arquitectura y } \\
\text { Construir de } \\
\text { Software. }\end{array}$ \\
\hline $\begin{array}{l}\text { IS. } \\
4.3\end{array}$ & $\begin{array}{l}\text { Construir o actualizar } \\
\text { los Componentes de } \\
\text { Software basados en la } \\
\text { parte detallada del } \\
\text { Diseño de Software. }\end{array}$ & $\begin{array}{l}\text { Diseño de } \\
\text { Software } \\
\text { [verificado, en } \\
\text { línea base] } \\
\\
\text { Registro de } \\
\text { Trazabilidad } \\
\text { [verificado, en } \\
\text { línea base] }\end{array}$ & $\begin{array}{l}\text { Componente de } \\
\text { Software }\end{array}$ & PR & Completamente & \begin{tabular}{|l} 
Historia de \\
Usuario \\
[Validado] \\
(Anexo 4.3) \\
\\
Diseño de \\
Software \\
[Verificado] \\
(Anexo 4.13)
\end{tabular} & $\begin{array}{l}\text { Componente de } \\
\text { Software }\end{array}$ & PR & 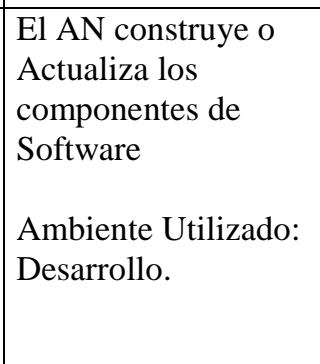 \\
\hline
\end{tabular}




\begin{tabular}{|c|c|c|c|c|c|c|c|c|c|}
\hline ID & Lista de Tareas & $\begin{array}{l}\text { Productos de } \\
\text { entrada }\end{array}$ & $\begin{array}{l}\text { Productos de } \\
\text { salida }\end{array}$ & Rol & $\begin{array}{l}\text { Es } \\
\text { implementada }\end{array}$ & $\begin{array}{l}\text { Productos de } \\
\text { entrada }\end{array}$ & $\begin{array}{l}\text { Productos de } \\
\text { salida }\end{array}$ & Rol & $\begin{array}{l}\text { Comentarios y } \\
\text { Observaciones }\end{array}$ \\
\hline \begin{tabular}{|l|} 
IS. \\
4.4 \\
\end{tabular} & $\begin{array}{l}\text { Diseñar o actualizar los } \\
\text { Casos de Pruebas } \\
\text { unitarias y aplicarlos } \\
\text { para verificar que los } \\
\text { componentes de } \\
\text { Software implementan } \\
\text { la parte detallada de } \\
\text { Diseño de Software. }\end{array}$ & $\begin{array}{l}\text { Componente de } \\
\text { Software }\end{array}$ & $\begin{array}{l}\text { Componente de } \\
\text { Software } \\
\text { [unidades } \\
\text { probadas] }\end{array}$ & PR & Completamente & $\begin{array}{l}\text { Componente } \\
\text { de Software }\end{array}$ & $\begin{array}{l}\text { Componente de } \\
\text { Software } \\
\text { [unidades } \\
\text { probadas] }\end{array}$ & PR & $\begin{array}{l}\text { EL AN realiza } \\
\text { pruebas unitarias para } \\
\text { los componentes de } \\
\text { software construidos } \\
\text { o actualizados. }\end{array}$ \\
\hline \begin{tabular}{|l|} 
IS. \\
4.5 \\
\end{tabular} & $\begin{array}{l}\text { Corregir los defectos } \\
\text { encontrados hasta lograr } \\
\text { la prueba unitaria } \\
\text { exitosa (logrando el } \\
\text { criterio de salida) }\end{array}$ & $\begin{array}{l}\text { Componente de } \\
\text { Software } \\
\text { [unidades } \\
\text { probadas] }\end{array}$ & $\begin{array}{l}\text { Componente de } \\
\text { Software } \\
\text { [corregidos] }\end{array}$ & PR & Completamente & $\begin{array}{l}\text { Componente } \\
\text { de Software } \\
\text { [unidades } \\
\text { probadas] }\end{array}$ & $\begin{array}{l}\text { Componente de } \\
\text { Software } \\
\text { [corregidos] }\end{array}$ & PR & $\begin{array}{l}\text { EL AN corrige los } \\
\text { defectos encontrados } \\
\text { al hacer sus pruebas } \\
\text { unitarias. } \\
\text { Ambiente Utilizado: } \\
\text { Desarrollo. }\end{array}$ \\
\hline \begin{tabular}{|l|} 
IS. \\
4.6 \\
\end{tabular} & $\begin{array}{l}\text { Actualizar el Registro } \\
\text { de Trazabilidad } \\
\text { incorporando } \\
\text { Componente de } \\
\text { Software construidos o } \\
\text { modificados. }\end{array}$ & $\begin{array}{l}\text { Componente de } \\
\text { Software } \\
\text { [corregidos] } \\
\text { Registro de } \\
\text { Trazabilidad } \\
\text { [verificado, en } \\
\text { línea base] }\end{array}$ & \begin{tabular}{|l} 
Registro de \\
Trazabilidad \\
[actualizado]
\end{tabular} & PR & No cumple & NA. & NA. & NA. & $\begin{array}{l}\text { El Registro no tiene } \\
\text { una sección } \\
\text { componentes de } \\
\text { software. } \\
\text { La Propuesta para } \\
\text { dicha tarea se } \\
\text { encuentra en la } \\
\text { "Propuesta de mejora } \\
\text { para los Procesos del } \\
\text { ciclo de } \\
\text { vida“(Sección } \\
5.1 .1 .1) .\end{array}$ \\
\hline \begin{tabular}{|l|} 
IS. \\
4.7 \\
\end{tabular} & \begin{tabular}{|l|} 
Incorporar \\
Componente de \\
Software y Registro de \\
Trazabilidad para la \\
Configuración de \\
Software como parte de \\
la línea base. \\
\end{tabular} & $\begin{array}{l}\text { Componente de } \\
\text { Software } \\
\text { [corregidos] } \\
\\
\text { Registro de } \\
\text { Trazabilidad } \\
\text { [actualizado] }\end{array}$ & \begin{tabular}{|l|} 
Configuración \\
de \\
Software \\
- Componente \\
de Software \\
[corregidos, en \\
línea base] \\
\end{tabular} & LT & Completamente & $\begin{array}{l}\text { Componente } \\
\text { de Software } \\
\text { [corregidos] }\end{array}$ & $\begin{array}{l}\text { Configuración } \\
\text { de Software } \\
\text { actualizado. } \\
\text { - Componente } \\
\text { de Software } \\
\text { [corregidos, en } \\
\text { línea base] } \\
\end{array}$ & $\begin{array}{l}\text { AN } \\
\text { LT }\end{array}$ & $\begin{array}{l}\text { El AN almacena los } \\
\text { componentes de } \\
\text { software como parte } \\
\text { de la Configuración } \\
\text { de software en el } \\
\text { Repositorio Windows } \\
\text { Server 2008. } \\
\end{array}$ \\
\hline
\end{tabular}




\begin{tabular}{|c|c|c|c|c|c|c|c|c|c|}
\hline ID & Lista de Tareas & $\begin{array}{c}\text { Productos de } \\
\text { entrada }\end{array}$ & $\begin{array}{l}\text { Productos de } \\
\text { salida }\end{array}$ & Rol & $\begin{array}{l}\text { Es } \\
\text { implementada }\end{array}$ & $\begin{array}{l}\text { Productos de } \\
\text { entrada }\end{array}$ & $\begin{array}{l}\text { Productos de } \\
\text { salida }\end{array}$ & Rol & $\begin{array}{l}\text { Comentarios y } \\
\text { Observaciones }\end{array}$ \\
\hline & & & $\begin{array}{l}\text { - Registro de } \\
\text { Trazabilidad } \\
\text { [actualizado, en } \\
\text { línea base] }\end{array}$ & & & & & & $\begin{array}{l}\text { *Los Componentes } \\
\text { son almacenados en } \\
\text { el Repositorio } \\
\text { Windows Server } \\
2008 \text {. }\end{array}$ \\
\hline
\end{tabular}

Tabla 26 Evaluación de la Actividad: Construcción del Software de la empresa.

Fuente: Elaboración Propia

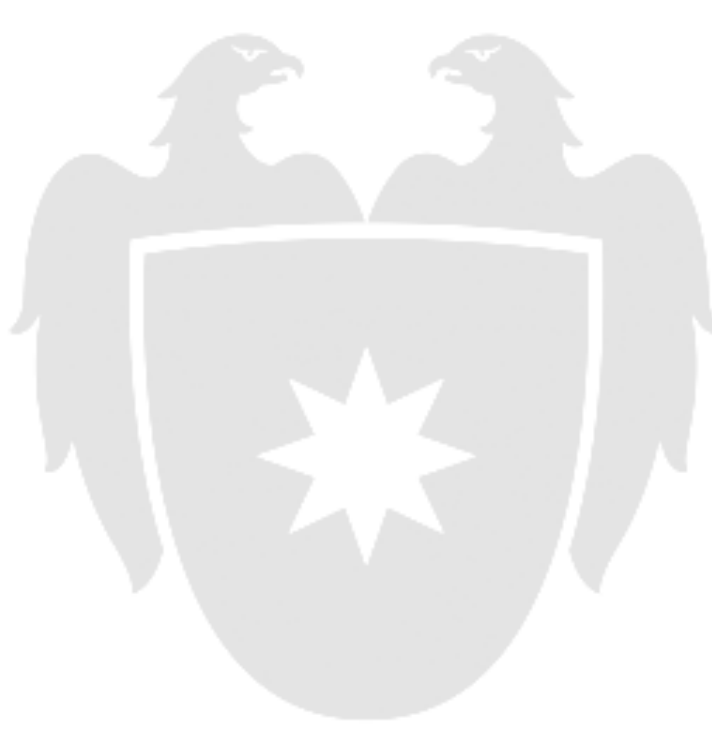




\section{Actividad 04: Integración y Pruebas del Software}

El de esta actividad es asegurar que los Componentes de Software sean integrados, probados y corregidos. En la Figura 18, se presenta la actividad Pruebas e Integración del Software.

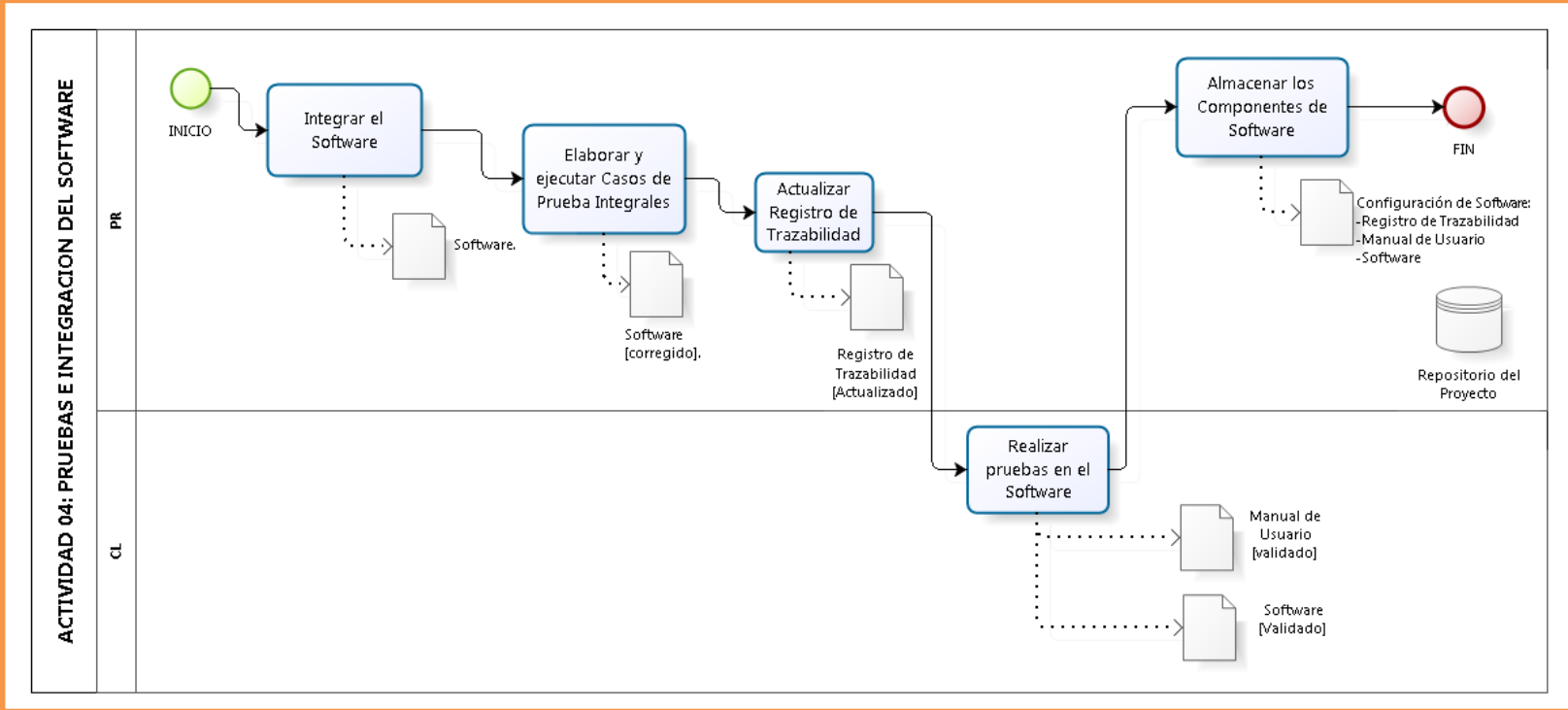

Figura 18 Diagrama BPMN de la Actividad: Pruebas e Integración del Software de la empresa.

Fuente: Elaboración Propia. 
A continuación se detalla el nivel de cumplimiento de la actividad "Pruebas e Integración del Software" con respecto a la ISO 29110:

\begin{tabular}{|c|c|c|c|c|c|c|c|c|c|}
\hline ID & Lista de Tareas & $\begin{array}{l}\text { Productos de } \\
\text { entrada }\end{array}$ & $\begin{array}{c}\text { Productos de } \\
\text { salida }\end{array}$ & Rol & $\begin{array}{l}\text { Es } \\
\text { implementada }\end{array}$ & $\begin{array}{l}\text { Productos de } \\
\text { entrada }\end{array}$ & $\begin{array}{l}\text { Productos de } \\
\text { salida }\end{array}$ & Rol & $\begin{array}{l}\text { Comentarios y } \\
\text { Observaciones }\end{array}$ \\
\hline $\begin{array}{l}\text { IS. } \\
5.1\end{array}$ & $\begin{array}{l}\text { Asignar Tareas a los } \\
\text { miembros del Equipo } \\
\text { de Trabajo en relación } \\
\text { a su rol, de acuerdo al } \\
\text { Plan del Proyecto } \\
\text { actual. }\end{array}$ & $\begin{array}{l}\text { Plan del } \\
\text { Proyecto } \\
\text { - Tareas }\end{array}$ & & $\begin{array}{l}\text { LT } \\
\text { PR }\end{array}$ & Completamente & $\begin{array}{l}\text { Plan del } \\
\text { Proyecto } \\
\text { [revisado] } \\
\text { - Tareas } \\
\text { (Anexo 4.1) }\end{array}$ & - & $\begin{array}{l}\text { LT } \\
\text { ET }\end{array}$ & $\begin{array}{l}\text { Esta Tarea solo se } \\
\text { realiza solo una } \\
\text { vez en el Proceso } \\
\text { de Gestión del } \\
\text { Proyecto. } \\
\text { *Comúnmente, la } \\
\text { misma persona se } \\
\text { encarga del } \\
\text { análisis y } \\
\text { desarrollo del } \\
\text { proyecto. }\end{array}$ \\
\hline $\begin{array}{l}\text { IS. } \\
5.2\end{array}$ & $\begin{array}{l}\text { Entender los Casos de } \\
\text { Prueba y } \\
\text { Procedimientos de } \\
\text { Prueba. } \\
\text { Establecer o actualizar } \\
\text { el ambiente de } \\
\text { Prueba. }\end{array}$ & \begin{tabular}{|l} 
Casos de \\
Prueba y \\
Procedimientos \\
de Prueba \\
[verificados]
\end{tabular} & & PR & Ampliamente & NA. & NA. & AN & $\begin{array}{l}\text { Actualmente, el } \\
\text { mismo AN que } \\
\text { realiza los casos y } \\
\text { Procedimientos de } \\
\text { Prueba es el } \\
\text { encargado de la } \\
\text { construcción del } \\
\text { software. }\end{array}$ \\
\hline $\begin{array}{l}\text { IS. } \\
5.3\end{array}$ & $\begin{array}{l}\text { Integrar el Software } \\
\text { usando los } \\
\text { Componentes de } \\
\text { Software y actualizar } \\
\text { los Casos de Prueba y } \\
\text { Procedimientos de } \\
\text { Prueba para las } \\
\text { pruebas de integración, } \\
\text { conforme sea } \\
\text { necesario. }\end{array}$ & $\begin{array}{l}\text { Componente de } \\
\text { Software } \\
\text { [corregidos, en } \\
\text { línea base] } \\
\\
\text { Casos de } \\
\text { Prueba y } \\
\text { Procedimientos } \\
\text { de Prueba } \\
\text { [verificados] } \\
\\
\text { Registro de } \\
\text { Trazabilidad } \\
\end{array}$ & $\begin{array}{l}\text { Software } \\
\text { Casos de Prueba } \\
y \\
\text { Procedimientos } \\
\text { de Prueba }\end{array}$ & PR & Completamente & $\begin{array}{l}\text { Componente de } \\
\text { Software } \\
\text { [corregidos, en } \\
\text { línea base] } \\
\text { Casos de Prueba } \\
\text { y } \\
\text { Procedimientos } \\
\text { de Prueba } \\
\text { [verificados] } \\
\text { (Anexo 4.4) } \\
\text { Registro de }\end{array}$ & \begin{tabular}{|l} 
Software \\
Casos de Prueba \\
y \\
Procedimientos \\
de Prueba \\
(Anexo 4.4)
\end{tabular} & AN & Conforme \\
\hline
\end{tabular}




\begin{tabular}{|c|c|c|c|c|c|c|c|c|c|}
\hline ID & Lista de Tareas & $\begin{array}{l}\text { Productos de } \\
\text { entrada }\end{array}$ & $\begin{array}{l}\text { Productos de } \\
\text { salida }\end{array}$ & Rol & $\begin{array}{l}\text { Es } \\
\text { implementada }\end{array}$ & $\begin{array}{l}\text { Productos de } \\
\text { entrada }\end{array}$ & $\begin{array}{l}\text { Productos de } \\
\text { salida }\end{array}$ & Rol & $\begin{array}{l}\text { Comentarios y } \\
\text { Observaciones }\end{array}$ \\
\hline & & $\begin{array}{l}\text { [actualizado, en } \\
\text { línea base] }\end{array}$ & & & & $\begin{array}{l}\text { Trazabilidad } \\
\text { [actualizado, en } \\
\text { línea base] } \\
\text { (Anexo 4.8) }\end{array}$ & & & \\
\hline $\begin{array}{l}\text { IS. } \\
5.4\end{array}$ & $\begin{array}{l}\text { Realizar pruebas de } \\
\text { Software usando } \\
\text { Casos de Prueba y } \\
\text { procedimientos de } \\
\text { Prueba para la } \\
\text { integración y } \\
\text { documentar los } \\
\text { resultados en el } \\
\text { Reporte de pruebas. }\end{array}$ & $\begin{array}{l}\text { Software } \\
\text { Casos y } \\
\text { Procedimientos } \\
\text { de Prueba }\end{array}$ & $\begin{array}{l}\text { Software } \\
\text { [probado] } \\
\text { Reporte de } \\
\text { Pruebas }\end{array}$ & $\begin{array}{l}\mathrm{PR} \\
\mathrm{CL}\end{array}$ & Completamente & $\begin{array}{l}\text { Software } \\
\text { Casos y } \\
\text { Procedimientos } \\
\text { de Prueba } \\
\text { (Anexo 4.4) }\end{array}$ & $\begin{array}{l}\text { Software } \\
\text { [probado] } \\
\text { Reporte de } \\
\text { Pruebas } \\
\text { (Anexo 4.6) }\end{array}$ & $\begin{array}{l}\text { AN } \\
\text { QA }\end{array}$ & Conforme. \\
\hline $\begin{array}{l}\text { IS. } \\
5.5\end{array}$ & $\begin{array}{l}\text { Corregir los defectos } \\
\text { encontrados y realizar } \\
\text { una prueba de } \\
\text { regresión hasta } \\
\text { satisfacer el criterio de } \\
\text { finalización. }\end{array}$ & \begin{tabular}{|l} 
Software \\
[probado], \\
Reporte de \\
Pruebas \\
Casos de \\
Prueba y \\
Procedimientos \\
de Prueba \\
Registro de \\
Trazabilidad \\
[actualizado, en \\
linea base]
\end{tabular} & $\begin{array}{l}\text { Software } \\
\text { [corregido] } \\
\\
\text { Reporte de } \\
\text { Pruebas } \\
\text { [defectos } \\
\text { eliminados] }\end{array}$ & PR & Completamente & \begin{tabular}{|l} 
Software \\
[probado], \\
Reporte de \\
Pruebas \\
Casos de \\
Prueba y \\
Procedimientos \\
de Prueba \\
(Anexo 4.4) \\
Registro de \\
Trazabilidad \\
[actualizado, en \\
linea base] \\
(Anexo 4.8)
\end{tabular} & \begin{tabular}{|l} 
Software \\
[corregido] \\
Reporte de \\
Pruebas \\
[defectos \\
eliminados] \\
(Anexo 4.6)
\end{tabular} & AN & $\begin{array}{l}\text { El AN corrige los } \\
\text { defectos } \\
\text { encontrados en las } \\
\text { pruebas Integrales } \\
\text { propias. } \\
\text { * Actualmente, no } \\
\text { hay un rol } \\
\text { encargado de la } \\
\text { elaboración de los } \\
\text { casos de prueba. }\end{array}$ \\
\hline
\end{tabular}




\begin{tabular}{|c|c|c|c|c|c|c|c|c|c|}
\hline ID & Lista de Tareas & $\begin{array}{l}\text { Productos de } \\
\text { entrada }\end{array}$ & $\begin{array}{c}\text { Productos de } \\
\text { salida }\end{array}$ & Rol & $\begin{array}{l}\text { Es } \\
\text { implementada }\end{array}$ & $\begin{array}{l}\text { Productos de } \\
\text { entrada }\end{array}$ & $\begin{array}{c}\text { Productos de } \\
\text { salida }\end{array}$ & Rol & $\begin{array}{l}\text { Comentarios y } \\
\text { Observaciones }\end{array}$ \\
\hline $\begin{array}{l}\text { IS. } \\
5.6\end{array}$ & $\begin{array}{l}\text { Actualizar el Registro } \\
\text { de Trazabilidad en } \\
\text { caso de ser necesario. }\end{array}$ & $\begin{array}{l}\text { Software } \\
\text { [corregido] } \\
\\
\text { Registro de } \\
\text { Trazabilidad } \\
\text { [actualizado, en } \\
\text { linea base] }\end{array}$ & $\begin{array}{l}\text { Registro de } \\
\text { Trazabilidad } \\
\text { [actualizado] }\end{array}$ & PR & No cumple & $\begin{array}{l}\text { Software } \\
\text { [corregido] } \\
\\
\text { Registro de } \\
\text { Trazabilidad } \\
\text { [actualizado, en } \\
\text { línea base] } \\
\text { (Anexo 4.8) }\end{array}$ & \begin{tabular}{|l|} 
Registro de \\
Trazabilidad \\
[actualizado] \\
(Anexo 4.8)
\end{tabular} & AN. & \begin{tabular}{|l}
$\begin{array}{l}\text { El Registro no } \\
\text { tiene una sección } \\
\text { para los } \\
\text { componentes del } \\
\text { software. }\end{array}$ \\
La Propuesta para \\
dicha tarea se \\
encuentra en la \\
"Propuesta de \\
mejora para los \\
Procesos del ciclo \\
de vida"(Sección \\
5.1.1.1).
\end{tabular} \\
\hline $\begin{array}{l}\text { IS. } \\
5.7\end{array}$ & $\begin{array}{l}\text { Documentar el } \\
\text { *Manual de } \\
\text { Operación o } \\
\text { actualizar el manual } \\
\text { actual, en caso de ser } \\
\text { apropiado. }\end{array}$ & $\begin{array}{l}\text { Software } \\
\text { [probado] }\end{array}$ & $\begin{array}{l}\text { Manual de } \\
\text { Operación }\end{array}$ & PR & Ampliamente & \begin{tabular}{|l} 
Software \\
[probado]
\end{tabular} & \begin{tabular}{|l|} 
Manual de \\
Operación \\
(Anexo 4.11) \\
\\
\end{tabular} & AN. & $\begin{array}{l}\text { El AN elabora el } \\
\text { manual de } \\
\text { Operaciones, sin } \\
\text { embargo el } \\
\text { documento no } \\
\text { cumple ciertas } \\
\text { secciones. } \\
\text { - Alertas de } \\
\text { seguridad } \\
\text { - Fuentes de } \\
\text { información } \\
\text { adicional y ayuda } \\
\text { para operar el } \\
\text { producto } \\
\text { - Certificación y } \\
\text { aprobaciones de } \\
\text { seguridad }\end{array}$ \\
\hline $\begin{array}{l}\text { IS. } \\
5.8\end{array}$ & $\begin{array}{l}\text { Verificar y Obtener la } \\
\text { aprobación del } \\
\text { *Manual de } \\
\text { Operación del } \\
\text { Producto, en caso de }\end{array}$ & $\begin{array}{l}\text { *Manual de } \\
\text { Operación } \\
\text { [probado] } \\
\text { Software }\end{array}$ & $\begin{array}{l}\text { Resultado de } \\
\text { Verificación } \\
\\
\text { *Manual de } \\
\text { Operación }\end{array}$ & $\begin{array}{l}\text { PR } \\
\text { DIS }\end{array}$ & Ampliamente & $\begin{array}{l}\text { *Manual de } \\
\text { Operación } \\
\text { [probado] } \\
\text { (Anexo 4.11) }\end{array}$ & $\begin{array}{l}\text { *Manual de } \\
\text { Operación } \\
\text { [verificado] } \\
\text { (Anexo 4.11) }\end{array}$ & $\begin{array}{l}\text { LT } \\
\text { AN }\end{array}$ & \begin{tabular}{|l} 
El LT revisa el \\
Software y el \\
Manual de \\
Operación a \\
detalle, se verifica
\end{tabular} \\
\hline
\end{tabular}




\begin{tabular}{|c|c|c|c|c|c|c|c|c|c|}
\hline ID & Lista de Tareas & $\begin{array}{c}\text { Productos de } \\
\text { entrada }\end{array}$ & $\begin{array}{c}\text { Productos de } \\
\text { salida }\end{array}$ & Rol & $\begin{array}{l}\text { Es } \\
\text { implementada }\end{array}$ & $\begin{array}{l}\text { Productos de } \\
\text { entrada }\end{array}$ & $\begin{array}{c}\text { Productos de } \\
\text { salida }\end{array}$ & Rol & $\begin{array}{l}\text { Comentarios y } \\
\text { Observaciones }\end{array}$ \\
\hline & $\begin{array}{l}\text { ser necesario (vea IS } \\
5.7) \\
\text { Verificar la } \\
\text { consistencia de la } \\
\text { Guía de Operación } \\
\text { del Producto con el } \\
\text { Software. Los } \\
\text { resultados encontrados } \\
\text { son documentados en } \\
\text { Resultado de } \\
\text { Verificación y se } \\
\text { realizan las } \\
\text { correcciones hasta que } \\
\text { el documento sea } \\
\text { aprobado por el DIS. } \\
\text { *(Opcional) }\end{array}$ & [probado] & [verificado] & & & \begin{tabular}{|l} 
Software \\
[probado]
\end{tabular} & $=$ & & $\begin{array}{l}\text { la consistencia. } \\
\text { No existe } \\
\text { documentación } \\
\text { formal del } \\
\text { Resultado de } \\
\text { Verificación. }\end{array}$ \\
\hline $\begin{array}{l}\text { IS. } \\
5.9\end{array}$ & $\begin{array}{l}\text { Documentar el } \\
\text { *Manual de Usuario } \\
\text { o actualizar el actual, } \\
\text { si aplica. } \\
\text { *(Opcional) }\end{array}$ & \begin{tabular}{|l|}
$\begin{array}{l}\text { Software } \\
\text { [probado] }\end{array}$ \\
Manual de \\
Usuario \\
[preliminar]
\end{tabular} & $\begin{array}{l}\text { *Manual de } \\
\text { Usuario }\end{array}$ & AN & Parcialmente & \begin{tabular}{|l|} 
Software \\
[probado] \\
\\
Manual de \\
Usuario \\
[preliminar] \\
(Anexo 4.10)
\end{tabular} & $\begin{array}{l}\text { *Manual de } \\
\text { Usuario } \\
\text { (Anexo 4.10) } \\
\end{array}$ & AN & \begin{tabular}{|l}
$\begin{array}{l}\text { El AN documenta/ } \\
\text { Actualiza el } \\
\text { manual de usuario. }\end{array}$ \\
Actualmente, no \\
hay rol que \\
elabore el Manual \\
de Usuario. \\
Se tiene el \\
documento \\
"Manual de \\
Usuario" con \\
observaciones. \\
La Propuesta para \\
dicha tarea se \\
encuentra en la \\
"Propuesta de \\
mejora para los
\end{tabular} \\
\hline
\end{tabular}




\begin{tabular}{|c|c|c|c|c|c|c|c|c|c|}
\hline ID & Lista de Tareas & $\begin{array}{l}\text { Productos de } \\
\text { entrada }\end{array}$ & $\begin{array}{l}\text { Productos de } \\
\text { salida }\end{array}$ & Rol & $\begin{array}{l}\text { Es } \\
\text { implementada }\end{array}$ & $\begin{array}{l}\text { Productos de } \\
\text { entrada }\end{array}$ & $\begin{array}{l}\text { Productos de } \\
\text { salida }\end{array}$ & Rol & $\begin{array}{l}\text { Comentarios y } \\
\text { Observaciones }\end{array}$ \\
\hline & & & & & & & & & $\begin{array}{l}\text { Procesos del ciclo } \\
\text { de vida“(Sección } \\
\text { 5.1.1.1). }\end{array}$ \\
\hline $\begin{array}{l}\text { IS. } \\
5 . \\
10\end{array}$ & $\begin{array}{l}\text { Verificar y Obtener la } \\
\text { aprobación del } \\
\text { *Manual de Usuario, } \\
\text { en caso de ser } \\
\text { necesario (vea IS 5.9) } \\
\text { Verificar la } \\
\text { consistencia del } \\
\text { Manual de Usuario } \\
\text { con el Software. Los } \\
\text { resultados encontrados } \\
\text { son documentados en } \\
\text { Resultado de } \\
\text { Verificación y se } \\
\text { realizan las } \\
\text { correcciones hasta que } \\
\text { el documento sea } \\
\text { aprobado por el CL. } \\
\text { *(Opcional) }\end{array}$ & $\begin{array}{l}\text { Manual de } \\
\text { Usuario } \\
\text { [probado] } \\
\text { Software } \\
\text { [probado] }\end{array}$ & $\begin{array}{l}\text { Resultado de } \\
\text { Verificación } \\
\text { *Manual de } \\
\text { Usuario } \\
\text { [verificado] }\end{array}$ & $\begin{array}{l}\mathrm{AN} \\
\mathrm{CL}\end{array}$ & Ampliamente & $\begin{array}{l}\text { Manual de } \\
\text { Usuario } \\
\text { [probado] } \\
\text { (Anexo 4.10) } \\
\text { Software } \\
\text { [probado] }\end{array}$ & $\begin{array}{l}\text { *Manual de } \\
\text { Usuario } \\
\text { [verificado] } \\
\text { (Anexo 4.10) }\end{array}$ & $\begin{array}{l}\mathrm{AN} \\
\mathrm{CL}\end{array}$ & $\begin{array}{l}\text { El CL verifica el } \\
\text { Manual de Usuario } \\
\text { No existe un } \\
\text { documento formal } \\
\text { para los resultados } \\
\text { de verificación } \\
\text { Se tiene el } \\
\text { documento } \\
\text { "Manual de } \\
\text { Usuario" con } \\
\text { observaciones. }\end{array}$ \\
\hline $\begin{array}{l}\text { IS. } \\
5 . \\
11\end{array}$ & $\begin{array}{l}\text { Incorporar los Casos } \\
\text { de Prueba y } \\
\text { Procedimientos de } \\
\text { Prueba, Software, } \\
\text { Registro de } \\
\text { Trazabilidad, } \\
\text { Reporte de Pruebas, } \\
\text { *Manual de } \\
\text { Operación y *Manual } \\
\text { de Usuario a la } \\
\text { Configuración de } \\
\text { Software como parte } \\
\text { de la línea base } \\
\end{array}$ & $\begin{array}{l}\text { Casos de } \\
\text { Prueba y } \\
\text { Procedimientos } \\
\text { de Prueba } \\
\text { Software } \\
\text { [probado] } \\
\text { Reporte de } \\
\text { Pruebas } \\
\text { Registro de } \\
\text { Trazabilidad }\end{array}$ & $\begin{array}{l}\text { Configuración } \\
\text { de Software } \\
\text { - Casos de } \\
\text { Prueba y } \\
\text { Procedimientos } \\
\text { de Prueba [en } \\
\text { línea base] } \\
\text { - Software } \\
\text { [probado, en } \\
\text { línea base] } \\
\text { - Registro de } \\
\text { Trazabilidad } \\
\text { [actualizado, en }\end{array}$ & LT & Completamente & $\begin{array}{l}\text { Casos de } \\
\text { Prueba y } \\
\text { Procedimientos } \\
\text { de Prueba } \\
\text { (Anexo 4.4) } \\
\text { Software } \\
\text { [probado] } \\
\text { Reporte de } \\
\text { Pruebas } \\
\text { (Anexo 4.6) }\end{array}$ & $\begin{array}{l}\text { Configuración } \\
\text { de Software } \\
\text { - Casos de } \\
\text { Prueba y } \\
\text { Procedimientos } \\
\text { de Prueba [en } \\
\text { línea base] } \\
\text { - Software } \\
\text { [probado, en } \\
\text { línea base] } \\
\text { - Registro de } \\
\text { Trazabilidad } \\
\text { [actualizado, en }\end{array}$ & AN & $\begin{array}{l}\text { El AN almacena } \\
\text { los componentes } \\
\text { de software como } \\
\text { parte de la } \\
\text { Configuración de } \\
\text { software en el } \\
\text { Repositorio } \\
\text { Windows Server } \\
2008 . \\
\text { *Los } \\
\text { Componentes son } \\
\end{array}$ \\
\hline
\end{tabular}




\begin{tabular}{|c|c|c|c|c|c|c|c|c|c|}
\hline ID & Lista de Tareas & $\begin{array}{c}\text { Productos de } \\
\text { entrada }\end{array}$ & $\begin{array}{c}\text { Productos de } \\
\text { salida }\end{array}$ & Rol & $\begin{array}{l}\text { Es } \\
\text { implementada }\end{array}$ & $\begin{array}{l}\text { Productos de } \\
\text { entrada }\end{array}$ & $\begin{array}{l}\text { Productos de } \\
\text { salida }\end{array}$ & Rol & $\begin{array}{l}\text { Comentarios y } \\
\text { Observaciones }\end{array}$ \\
\hline & *(Opcional) & $\begin{array}{l}\text { [actualizado] } \\
\text { Manual de } \\
\text { Operación } \\
\text { [verificado] } \\
\text { Manual de } \\
\text { Usuario } \\
\text { [verificado] }\end{array}$ & $\begin{array}{l}\text { línea base] } \\
\text { - Reporte de } \\
\text { Pruebas [en } \\
\text { línea base] } \\
\text { - *Manual de } \\
\text { Operación } \\
\text { [verificado, en } \\
\text { línea base] } \\
\text { - *Manual de } \\
\text { Usuario } \\
\text { [verificado, en } \\
\text { línea base] }\end{array}$ & & & \begin{tabular}{|l} 
Registro de \\
Trazabilidad \\
[actualizado] \\
(Anexo 4.8) \\
\\
Manual de \\
Operación \\
[verificado] \\
(Anexo 4.11) \\
Manual de \\
Usuario \\
[verificado] \\
(Anexo 4.10)
\end{tabular} & \begin{tabular}{|l} 
línea base] \\
- Reporte de \\
Pruebas [en \\
línea base] \\
- *Manual de \\
Operación \\
[verificado, en \\
línea base] \\
- *Manual de \\
Usuario \\
[verificado, en \\
línea base] \\
(Anexo 4.12)
\end{tabular} & & $\begin{array}{l}\text { almacenados en el } \\
\text { Repositorio } \\
\text { Windows Server } \\
2008 . \\
\\
\text { No se utilizan los } \\
\text { documentos: } \\
\text {-Casos de Prueba } \\
\text { y Procedimientos } \\
\text { de Prueba } \\
\text {-Reporte de } \\
\text { Pruebas }\end{array}$ \\
\hline
\end{tabular}

Tabla 27 Evaluación de la Actividad Pruebas e Integración del Software de la empresa.

Fuente: Elaboración Propia. 


\section{Actividad 05: Entrega del Producto}

El objetivo de esta actividad es realizar la entrega de la solución de software de acuerdo a las instrucciones de entrega definidas en el plan del proyecto. En la Figura 19, se presenta la actividad Entrega del Producto:

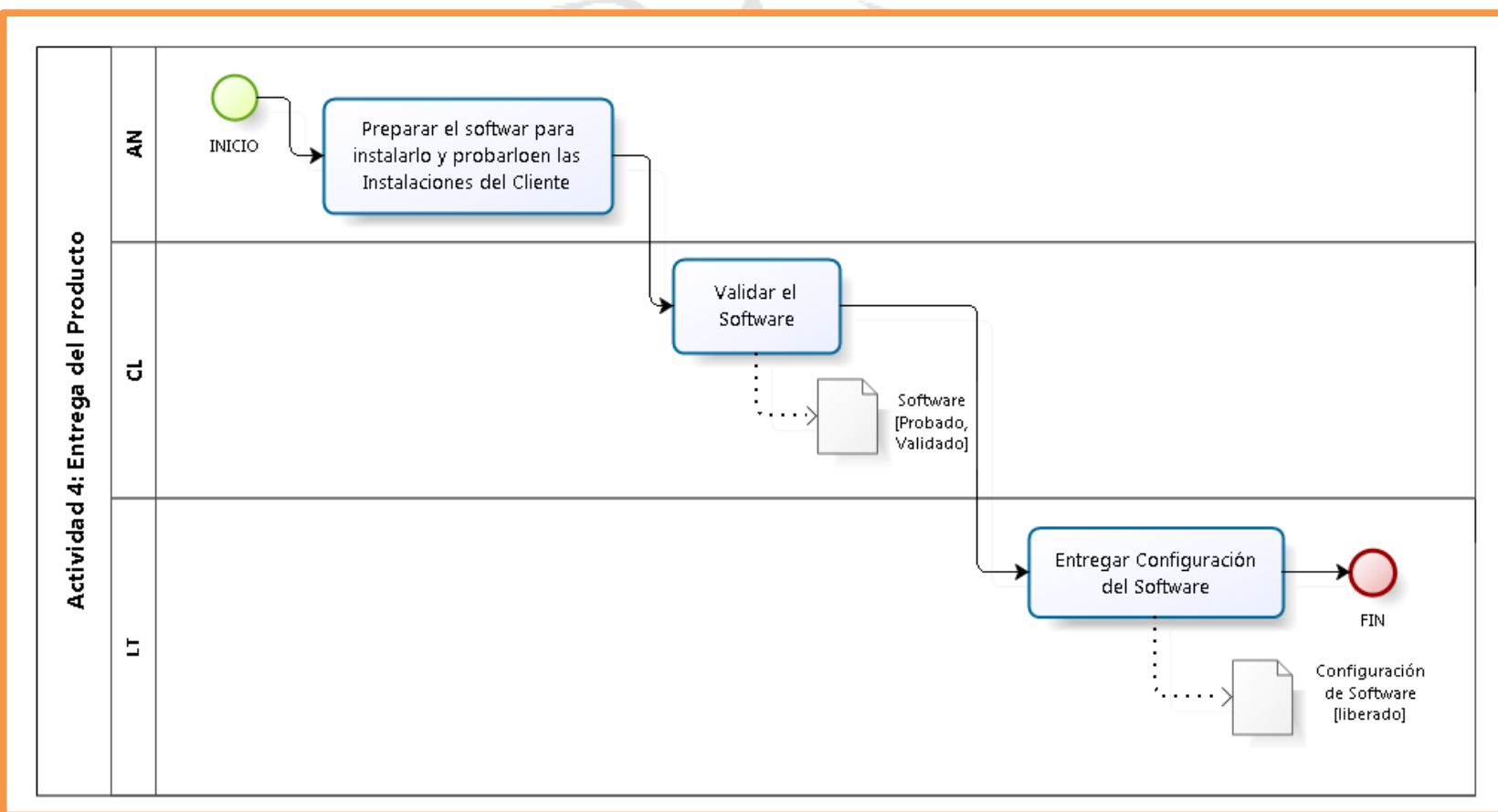

Figura 19 Diagrama BPMN de la Actividad: Entrega del Producto.

Fuente: Elaboración Propia. 
A continuación se detalla el nivel de cumplimiento de la actividad "Entrega del Producto" con respecto a la ISO 29110:

\begin{tabular}{|c|c|c|c|c|c|c|c|c|c|}
\hline ID & Lista de Tareas & $\begin{array}{l}\text { Productos de } \\
\text { entrada }\end{array}$ & $\begin{array}{c}\text { Productos de } \\
\text { salida }\end{array}$ & Rol & $\begin{array}{l}\text { Es } \\
\text { implementada }\end{array}$ & $\begin{array}{l}\text { Productos de } \\
\text { entrada }\end{array}$ & $\begin{array}{c}\text { Productos de } \\
\text { salida }\end{array}$ & Rol & $\begin{array}{l}\text { Comentarios y } \\
\text { Observaciones }\end{array}$ \\
\hline $\begin{array}{l}\text { IS. } \\
6.1\end{array}$ & \begin{tabular}{|l} 
Asignar Tareas a los \\
miembros del Equipo de \\
Trabajo relacionadas con \\
su Rol, de acuerdo al \\
Plan del Proyecto actual.
\end{tabular} & $\begin{array}{l}\text { Plan del } \\
\text { Proyecto } \\
\text { - Tareas }\end{array}$ & & \begin{tabular}{|l|} 
LT \\
ET
\end{tabular} & Completamente & \begin{tabular}{|l} 
Plan del \\
Proyecto \\
[revisado] \\
- Tareas
\end{tabular} & & $\begin{array}{l}\text { LT } \\
\text { ET }\end{array}$ & $\begin{array}{l}\text { Esta Tarea solo se } \\
\text { realiza solo una } \\
\text { vez en el Proceso } \\
\text { de Gestión del } \\
\text { Proyecto. } \\
\text { *Comúnmente, la } \\
\text { misma persona se } \\
\text { encarga del análisi } \\
\text { y desarrollo del } \\
\text { proyecto. }\end{array}$ \\
\hline $\begin{array}{l}\text { IS. } \\
6.2\end{array}$ & $\begin{array}{l}\text { Comprender la } \\
\text { Configuración de } \\
\text { Software. }\end{array}$ & $\begin{array}{l}\text { Configuración } \\
\text { de Software }\end{array}$ & & DIS & Completamente & NA. & NA. & AN & $\begin{array}{l}\text { El AN/PR/DIS } \\
\text { comúnmente es el } \\
\text { mismo que elaboro } \\
\text { la configuración de } \\
\text { software. }\end{array}$ \\
\hline $\begin{array}{l}\text { IS. } \\
6.3\end{array}$ & $\begin{array}{l}\text { Documentar el Manual } \\
\text { de Mantenimiento o } \\
\text { actualizar el actual. }\end{array}$ & $\begin{array}{l}\text { Configuración } \\
\text { de Software }\end{array}$ & $\begin{array}{l}\text { Manual de } \\
\text { Mantenimiento }\end{array}$ & DIS & Completamente & $\begin{array}{l}\text { Configuración } \\
\text { de Software }\end{array}$ & $\begin{array}{l}\text { Manual de } \\
\text { Mantenimiento }\end{array}$ & & $\begin{array}{l}\text { El AN desarrolla el } \\
\text { Manual de } \\
\text { Mantenimiento. }\end{array}$ \\
\hline $\begin{array}{l}\text { IS. } \\
6.4\end{array}$ & $\begin{array}{l}\text { Verificar y obtener la } \\
\text { aprobación del Manual } \\
\text { de Mantenimiento. } \\
\text { Verificar la consistencia } \\
\text { del Manual de } \\
\text { Mantenimiento con la } \\
\text { Configuración de } \\
\text { Software. Los resultados } \\
\text { encontrados son } \\
\text { documentados en } \\
\text { Resultado de } \\
\text { Verificación y las }\end{array}$ & $\begin{array}{l}\text { Manual de } \\
\text { Mantenimiento } \\
\text { Configuración } \\
\text { de Software }\end{array}$ & \begin{tabular}{|l} 
Resultados de \\
Verificación \\
\\
Manual de \\
Mantenimiento \\
[verificado]
\end{tabular} & \begin{tabular}{|l|} 
DIS \\
LT
\end{tabular} & Ampliamente & \begin{tabular}{|l} 
Manual de \\
Mantenimiento \\
Configuración \\
de Software
\end{tabular} & $\begin{array}{l}\text { Resultados de } \\
\text { Verificación } \\
\\
\text { Manual de } \\
\text { Mantenimiento } \\
\text { [verificado] }\end{array}$ & $\begin{array}{l}\text { LT } \\
\text { AN }\end{array}$ & $\begin{array}{l}\text { LT revisa el } \\
\text { Software y el } \\
\text { Manual de } \\
\text { mantenimiento a } \\
\text { detalle, se verifica } \\
\text { la consistencia. } \\
\\
\text { No existe } \\
\text { documentación } \\
\text { formal del } \\
\text { Resultado de } \\
\text { Verificación. }\end{array}$ \\
\hline
\end{tabular}




\begin{tabular}{|c|c|c|c|c|c|c|c|c|c|}
\hline ID & Lista de Tareas & $\begin{array}{l}\text { Productos de } \\
\text { entrada }\end{array}$ & $\begin{array}{l}\text { Productos de } \\
\text { salida }\end{array}$ & Rol & $\begin{array}{l}\text { Es } \\
\text { implementada }\end{array}$ & $\begin{array}{l}\text { Productos de } \\
\text { entrada }\end{array}$ & $\begin{array}{l}\text { Productos de } \\
\text { salida }\end{array}$ & Rol & $\begin{array}{l}\text { Comentarios y } \\
\text { Observaciones }\end{array}$ \\
\hline & $\begin{array}{l}\text { correcciones se realizan } \\
\text { hasta que el documento } \\
\text { sea aprobado por L.T. }\end{array}$ & & & & & & & & \\
\hline $\begin{array}{l}\text { IS. } \\
6.5\end{array}$ & $\begin{array}{l}\text { Incorporar el Manual de } \\
\text { Mantenimiento a la línea } \\
\text { base de la Configuración } \\
\text { de Software. }\end{array}$ & $\begin{array}{l}\text { Configuración } \\
\text { de Software } \\
\text { Manual de } \\
\text { Mantenimiento } \\
\text { [verificado] }\end{array}$ & $\begin{array}{l}\text { Configuración } \\
\text { de Software } \\
\text {-Manual de } \\
\text { Mantenimiento } \\
\text { [verificado, en } \\
\text { línea base] }\end{array}$ & LT & Completamente & $\begin{array}{l}\text { Configuración } \\
\text { de Software } \\
\text { Manual de } \\
\text { Mantenimiento } \\
\text { [verificado] }\end{array}$ & $\begin{array}{l}\text { Configuración } \\
\text { de Software } \\
\text {-Manual de } \\
\text { Mantenimiento } \\
\text { [verificado, en } \\
\text { línea base] }\end{array}$ & LT & $\begin{array}{l}\text { El LT almacena el } \\
\text { Manual de } \\
\text { mantenimiento } \\
\text { como parte de la } \\
\text { Configuración de } \\
\text { Software en el } \\
\text { Repositorio. }\end{array}$ \\
\hline \begin{tabular}{l|} 
IS. \\
6.6
\end{tabular} & $\begin{array}{l}\text { Llevar a cabo la entrega } \\
\text { de acuerdo a las } \\
\text { Instrucciones de } \\
\text { Entrega. }\end{array}$ & $\begin{array}{l}\text { Plan del } \\
\text { Proyecto } \\
\text { - Instrucciones } \\
\text { de Entrega } \\
\text { Configuración } \\
\text { de Software }\end{array}$ & $\begin{array}{l}\text { Configuración } \\
\text { de Software } \\
\text { [liberado] }\end{array}$ & LT & Completamente & \begin{tabular}{|l} 
Plan del \\
Proyecto \\
- Instrucciones \\
de Entrega \\
Configuración \\
de Software
\end{tabular} & $\begin{array}{l}\text { Configuración } \\
\text { de Software } \\
\text { [liberado] }\end{array}$ & LT & $\begin{array}{l}\text { El LT entrega al } \\
\text { Cliente el producto } \\
\text { según lo } \\
\text { documentado en el } \\
\text { Plan del Proyecto. }\end{array}$ \\
\hline
\end{tabular}




\section{Resultado de Evaluación - Implementación de Software}

En la Figura 20, se muestra el porcentaje de cumplimiento por cada actividad del proceso Implementación de Software.

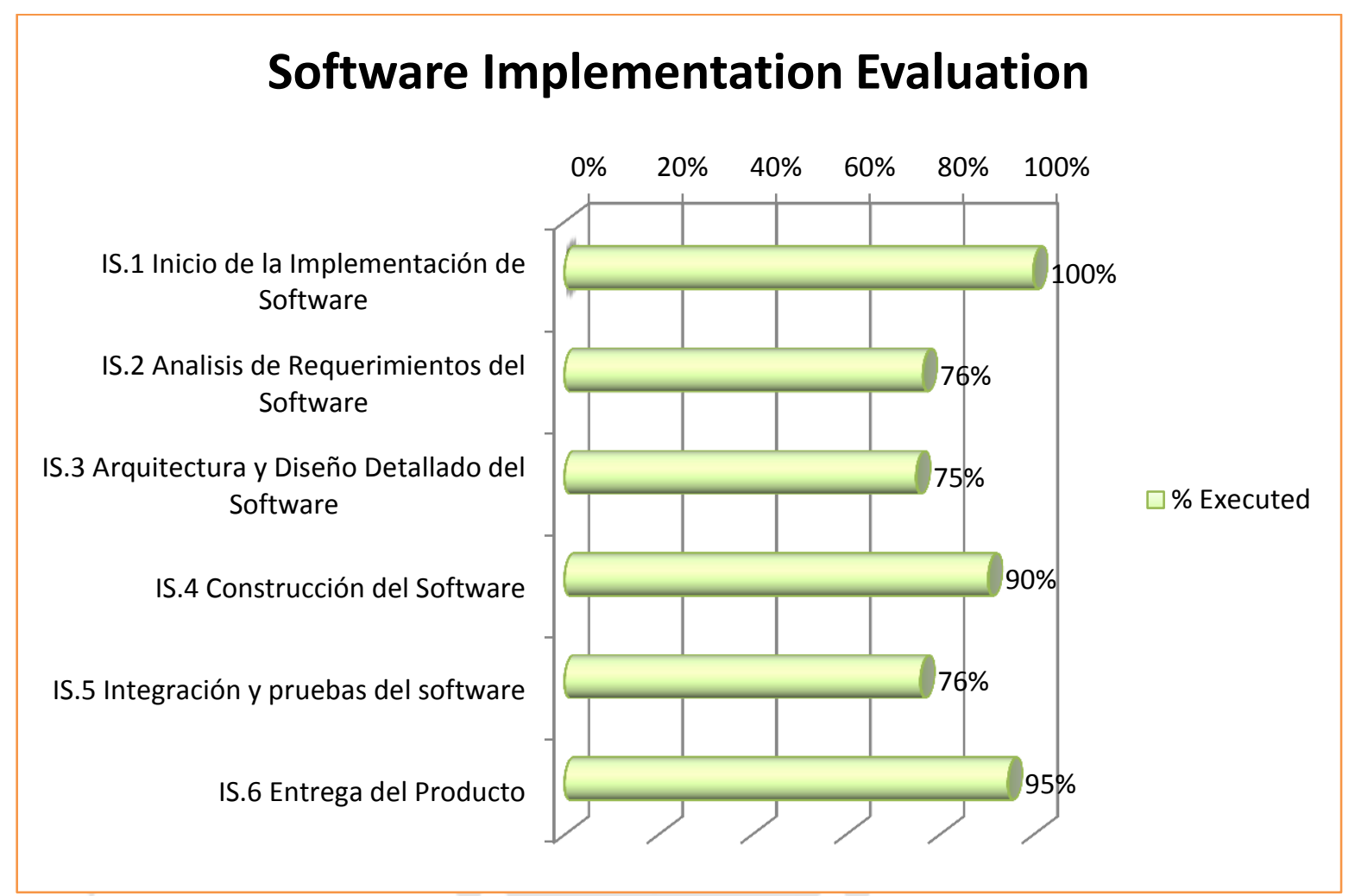

Figura 20 Dashboard de la Evaluación de Actividades de IS según la ISO 29110-5-1-2

Fuente: Elaboración Propia 


\subsection{Resultado de Evaluación - Desarrollo de Software}

En la Tabla 29, se muestra el porcentaje de cumplimiento de las actividades a lo largo del ciclo de vida de Desarrollo de Software.

\begin{tabular}{|c|c|c|c|c|c|c|c|c|}
\hline & \multirow{2}{*}{ \% Ejecutado } & \multirow{2}{*}{ Es implementado } & \multirow{2}{*}{$\begin{array}{c}\% \text { las } 67 \\
\text { tareas }\end{array}$} & \multirow{2}{*}{ Actividad } & \multicolumn{4}{|c|}{ Ejecución de Tareas } \\
\hline & & & & & Tot. & Alt. & Parc. & No \\
\hline \multicolumn{9}{|c|}{ Actividades de la Gestión del Proyecto } \\
\hline & $84 \%$ & Ampliamente & $19 \%$ & GP.1 Planificación del Proyecto & 11 & 1 & 2 & 1 \\
\hline & $61 \%$ & Ampliamente & $5 \%$ & GP.2 Ejecución del Plan del Proyecto & 2 & 1 & 1 & 2 \\
\hline & $67 \%$ & Ampliamente & $3 \%$ & GP.3 Evaluación y Control del Proyecto & 1 & 1 & 1 & 0 \\
\hline & $84 \%$ & Ampliamente & $3 \%$ & GP.4 Cierre del Proyecto & 1 & 1 & 0 & 0 \\
\hline $\begin{array}{l}\text { Promedio del } \\
\text { Proceso }\end{array}$ & $74 \%$ & $+\frac{1}{2}$ & & 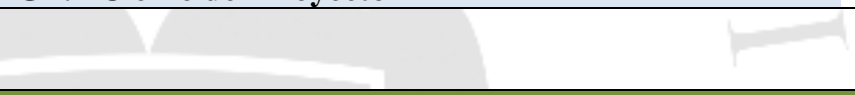 & 15 & 4 & 4 & 3 \\
\hline & $100 \%$ & Completamente & $3 \%$ & IS.1 Inicio de la Implementación de Software. & 2 & 0 & 0 & 0 \\
\hline & $76 \%$ & Ampliamente & $8 \%$ & IS.2 Análisis de Requisitos del Software. & 3 & 3 & 1 & 0 \\
\hline & $75 \%$ & Ampliamente & $9 \%$ & IS.3 Arquitectura y Diseño Detallado del Software. & 4 & 2 & 2 & 0 \\
\hline & $90 \%$ & Completamente & $9 \%$ & IS.4 Construcción del Software. & 6 & 0 & 0 & 1 \\
\hline & $76 \%$ & Ampliamente & $12 \%$ & IS.5 Integración y Pruebas del Software. & 5 & 4 & 1 & 1 \\
\hline & $95 \%$ & Completamente & $8 \%$ & IS.6 Entrega del Producto. & 5 & 1 & 0 & 0 \\
\hline $\begin{array}{l}\text { Promedio del } \\
\text { Proceso }\end{array}$ & $\mathbf{8 5 \%}$ & (x) & & 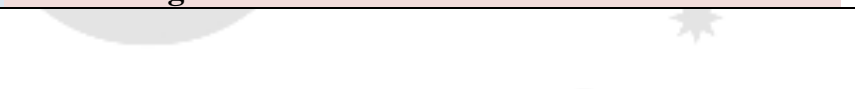 & 25 & 10 & 4 & 2 \\
\hline $\begin{array}{l}\text { Total - Tareas no } \\
\text { ejecutadas }\end{array}$ & & & $29 \%$ & & & & & \\
\hline $\begin{array}{l}\text { Promedio de } \\
\text { Cumplimiento del } \\
\text { Proceso }\end{array}$ & $81 \%$ & & & & & & & \\
\hline
\end{tabular}


En la Figura 21, se muestra el peso (\%) del cumplimiento de las tareas por actividad según lo descrito en la ISO 29110.

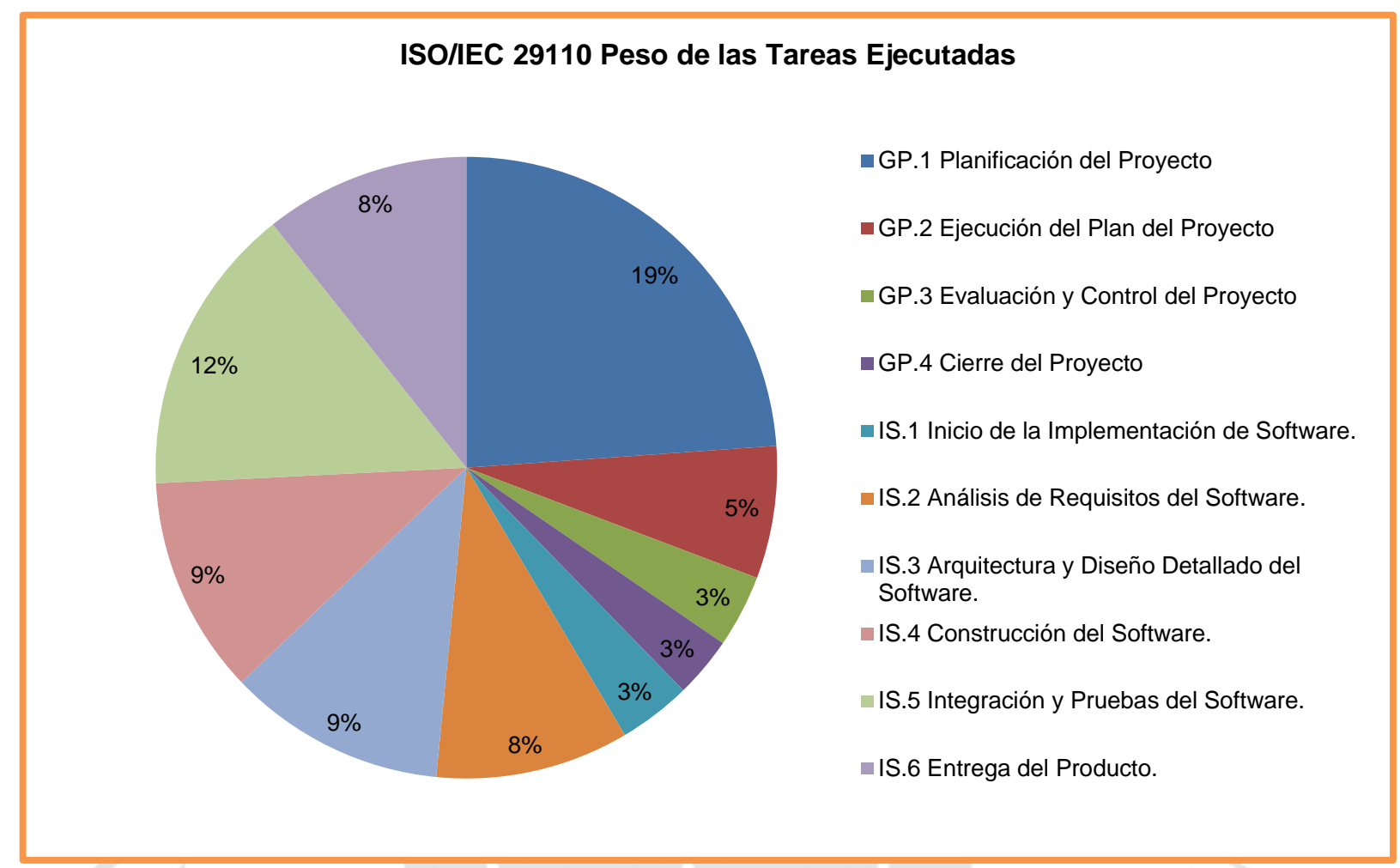

Figura 21 Dashboard de la Evaluación de Actividades del Desarrollo según la ISO 29110-5-1-2 Fuente: Elaboración Propia

En el Anexo 6, se presenta el análisis FODA como parte del Resultado de la evaluación de la Empresa Holinsys. 


\subsubsection{Plan de Implementación del Modelo de Mejora para el ciclo de vida del}

\section{desarrollo de software}

A continuación, se presenta la propuesta de mejora utilizando como base la los resultados de la evaluación presentes en la sección 5.1.1.2.3.

\subsubsection{Evaluación del ciclo de vida del desarrollo de software}

\subsection{Propuesta de mejora para los Procesos del ciclo de vida}

Según lo expuesto en la evaluación del ciclo de vida del desarrollo de software se tienen las siguientes brechas:

En la Tabla 30, mostramos las brechas identificadas en la evaluación de los procesos del ciclo de vida del desarrollo de software. Estas brechas se producen en las tareas que tienen un resultado con un nivel de cumplimiento: "No cumple" o "Cumple Parcialmente".

\begin{tabular}{|c|c|c|c|c|}
\hline $\begin{array}{l}\text { Cód. } \\
\text { de la } \\
\text { Tarea } \\
\end{array}$ & Nivel de Cumplimiento & $\begin{array}{l}\text { Nivel de } \\
\text { Cumplimiento }\end{array}$ & $\begin{array}{l}\text { Comentarios y } \\
\text { Observaciones }\end{array}$ & Propuesta de Solución \\
\hline $\begin{array}{l}\text { GP } \\
1.9\end{array}$ & $\begin{array}{l}\text { Identificar y documentar } \\
\text { los riesgos que pueden } \\
\text { afectar al proyecto. }\end{array}$ & No cumple & $\begin{array}{l}\text { Sección no } \\
\text { implementada en el Plan } \\
\text { del Proyecto de la } \\
\text { empresa }\end{array}$ & $\begin{array}{l}\text { Elaborar el producto de } \\
\text { trabajo "Plan de Proyecto" } \\
\text { donde se explique la } \\
\text { información necesaria } \\
\text { para la describir los } \\
\text { riesgos del proyecto. } \\
\text { Con esta información el } \\
\text { GP podrá documentar la } \\
\text { gestión de riesgos. }\end{array}$ \\
\hline $\begin{array}{l}\text { GP } \\
1.13\end{array}$ & $\begin{array}{l}\text { Verificar y obtener } \\
\text { aprobación del Plan del } \\
\text { Proyecto. } \\
\text { Verificar que todos los } \\
\text { elementos del Plan del } \\
\text { Proyecto son viables y } \\
\text { consistentes. Los } \\
\text { resultados encontrados } \\
\text { son documentados en } \\
\text { Resultado de } \\
\text { Verificación y las } \\
\text { correcciones son } \\
\text { realizadas hasta que el } \\
\text { documento es aprobado } \\
\text { por el GP. }\end{array}$ & $\begin{array}{l}\text { Cumple } \\
\text { Parcialmente }\end{array}$ & $\begin{array}{l}\text { El GP verifica que todos } \\
\text { los elementos del Plan } \\
\text { del Proyecto sean } \\
\text { viables, consistentes y se } \\
\text { puedan entender. } \\
\text { No hay un documento } \\
\text { formal con los } \\
\text { resultados de la } \\
\text { verificación hecha. }\end{array}$ & $\begin{array}{l}\text { Elaborar el Producto de } \\
\text { trabajo "Resultados de } \\
\text { Verificación" con todos } \\
\text { los campos requeridos } \\
\text { para guiar al proceso de } \\
\text { evaluación. } \\
\text { Documentar el rol } \\
\text { encargado de la } \\
\text { Elaboración del Reporte } \\
\text { de evaluación. }\end{array}$ \\
\hline GP & Revisar y obtener la & Cumple & El CL revisa el Plan de & Elaborar el Producto de \\
\hline
\end{tabular}




\begin{tabular}{|c|c|c|c|c|}
\hline $\begin{array}{l}\text { Cód. } \\
\text { de la } \\
\text { Tarea }\end{array}$ & Nivel de Cumplimiento & $\begin{array}{l}\text { Nivel de } \\
\text { Cumplimiento }\end{array}$ & $\begin{array}{l}\text { Comentarios y } \\
\text { Observaciones }\end{array}$ & Propuesta de Solución \\
\hline 1.14 & $\begin{array}{l}\text { aprobación del Plan del } \\
\text { Proyecto. } \\
\text { El Cliente revisa y } \\
\text { acepta el Plan del } \\
\text { Proyecto, asegurándose } \\
\text { que los elementos } \\
\text { contenidos en el Plan del } \\
\text { Proyecto corresponden } \\
\text { con el Enunciado de } \\
\text { Trabajo. }\end{array}$ & Parcialmente & $\begin{array}{l}\text { Proyecto. } \\
\text { Documento “Acta de } \\
\text { Reunión" no } \\
\text { implementado en la } \\
\text { empresa. }\end{array}$ & $\begin{array}{l}\text { trabajo "Acta de Reunión" } \\
\text { con todos los campos } \\
\text { requeridos para guiar al } \\
\text { proceso de evaluación. } \\
\text { Documentar el rol } \\
\text { encargado del llenado del } \\
\text { Acta de Reunión con el } \\
\text { Cliente. }\end{array}$ \\
\hline $\begin{array}{l}\text { GP } \\
2.3\end{array}$ & $\begin{array}{l}\text { Conducir reuniones de } \\
\text { revisión con el Equipo } \\
\text { de Trabajo, las cuales } \\
\text { permiten identificar } \\
\text { problemas, revisar el } \\
\text { estado de los riesgos, } \\
\text { registrar acuerdos y } \\
\text { darles seguimiento hasta } \\
\text { su conclusión. }\end{array}$ & $\begin{array}{l}\text { Cumple } \\
\text { Parcialmente }\end{array}$ & $\begin{array}{l}\text { El GP y el LT establece } \\
\text { reuniones con el ET, las } \\
\text { cuales permiten conocer } \\
\text { los problemas, estado de } \\
\text { riesgos, registrar } \\
\text { acuerdos y dar } \\
\text { seguimiento oportuno } \\
\text { hasta el cierre del } \\
\text { proyecto. } \\
\text { No existe un documento } \\
\text { formal de Acta de } \\
\text { reunión y acciones } \\
\text { Correctivas. }\end{array}$ & $\begin{array}{l}\text { Elaborar el Producto de } \\
\text { trabajo "Acta de Reunión" } \\
\text { con todos los campos } \\
\text { requeridos para guiar al } \\
\text { proceso de evaluación. } \\
\text { Documentar el rol encargo } \\
\text { del llenado del Acta de } \\
\text { Reunión con el Cliente. }\end{array}$ \\
\hline $\begin{array}{l}\text { GP } \\
2.5\end{array}$ & $\begin{array}{l}\text { Realizar el Respaldo del } \\
\text { Repositorio del Proyecto } \\
\text { de acuerdo a la } \\
\text { Estrategia de Control de } \\
\text { Versiones. }\end{array}$ & No & $\begin{array}{l}\text { Tarea No Implementada. } \\
\text { Se tiene un repositorio, } \\
\text { pero no un } \\
\text { Respaldo del repositorio. }\end{array}$ & $\begin{array}{l}\text { Promover el uso de un } \\
\text { respaldo para los } \\
\text { productos de trabajo } \\
\text { desarrollados. }\end{array}$ \\
\hline $\begin{array}{l}\text { GP } \\
2.6\end{array}$ & $\begin{array}{l}\text { Realizar la recuperación } \\
\text { del Repositorio del } \\
\text { Proyecto utilizando el } \\
\text { Respaldo del Repositorio } \\
\text { del Proyecto, en caso de } \\
\text { ser necesario. }\end{array}$ & No Cumple & $\begin{array}{l}\text { Tarea No Implementada. } \\
\text { Se tiene un repositorio, } \\
\text { pero no un } \\
\text { Respaldo del repositorio. }\end{array}$ & $\begin{array}{l}\text { Promover el uso de un } \\
\text { respaldo para los } \\
\text { productos de trabajo } \\
\text { desarrollados. }\end{array}$ \\
\hline $\begin{array}{l}\text { GP } \\
3.2\end{array}$ & $\begin{array}{l}\text { Establecer acciones para } \\
\text { corregir desviaciones o } \\
\text { problemas e identificar } \\
\text { riesgos que amenacen el } \\
\text { cumplimiento del plan, } \\
\text { en caso de ser necesario, } \\
\text { documentarlos en } \\
\text { Acciones Correctivas y } \\
\text { dar seguimiento hasta su } \\
\text { conclusión. }\end{array}$ & $\begin{array}{l}\text { Cumple } \\
\text { Parcialmente }\end{array}$ & $\begin{array}{l}\text { El GP establece acciones } \\
\text { que permitan corregir } \\
\text { los defectos o problemas } \\
\text { e identificar riesgos que } \\
\text { afecten al cumplimiento } \\
\text { del Plan del Proyecto, en } \\
\text { caso lo amerita, } \\
\text { No se documenta las } \\
\text { acciones correctivas. }\end{array}$ & $\begin{array}{l}\text { Elaborar el Producto de } \\
\text { trabajo "Acciones } \\
\text { Correctivas" con todos los } \\
\text { campos requeridos para } \\
\text { guiar al proceso de } \\
\text { evaluación. } \\
\text { Documentar el rol encargo } \\
\text { de la documentación de } \\
\text { las acciones correctivas. }\end{array}$ \\
\hline IS 2. & $\begin{array}{l}\text { Documentar la versión } \\
\text { preliminar del } * \text { Manual }\end{array}$ & $\begin{array}{l}\text { Cumple } \\
\text { Parcialmente }\end{array}$ & $\begin{array}{l}\text { En ocasiones, el AN } \\
\text { documenta el manual de }\end{array}$ & $\begin{array}{l}\text { Elaborar el Producto de } \\
\text { trabajo "Manual de }\end{array}$ \\
\hline
\end{tabular}




\begin{tabular}{|c|c|c|c|c|}
\hline $\begin{array}{l}\text { Cód. } \\
\text { de la } \\
\text { Tarea }\end{array}$ & Nivel de Cumplimiento & $\begin{array}{l}\text { Nivel de } \\
\text { Cumplimiento }\end{array}$ & $\begin{array}{l}\text { Comentarios y } \\
\text { Observaciones }\end{array}$ & Propuesta de Solución \\
\hline & $\begin{array}{l}\text { de Usuario o actualizar } \\
\text { el manual existente. Si es } \\
\text { apropiado } \\
\text { *(Opcional) }\end{array}$ & & $\begin{array}{l}\text { Usuario. Actualmente, } \\
\text { no hay rol que } \\
\text { implemente la } \\
\text { documentación de este } \\
\text { producto. } \\
\text { El "Manual de Usuario" } \\
\text { no cumple con algunas } \\
\text { secciones. (Anexo 4.10) }\end{array}$ & $\begin{array}{l}\text { Usuario" con todos los } \\
\text { campos requeridos para } \\
\text { guiar al proceso de } \\
\text { evaluación. } \\
\text { Documentar el rol que se } \\
\text { encargue de las } \\
\text { Tareas referentes al } \\
\text { "Manual de Usuario". }\end{array}$ \\
\hline IS 3.5 & $\begin{array}{l}\text { Establecer o actualizar } \\
\text { los Casos de Prueba y } \\
\text { Procedimientos de } \\
\text { Prueba para pruebas de } \\
\text { integración basadas en } \\
\text { las Especificación de } \\
\text { Requisitos y el Diseño } \\
\text { de Software. } \\
\text { El Cliente provee datos } \\
\text { de prueba, en caso de ser } \\
\text { necesario }\end{array}$ & $\begin{array}{l}\text { Cumple } \\
\text { Parcialmente }\end{array}$ & $\begin{array}{l}\text { El AN elabora los casos } \\
\text { de Prueba y } \\
\text { Procedimientos de } \\
\text { Prueba utilizando como } \\
\text { base la historia de } \\
\text { usuarios y el diseño del } \\
\text { software. } \\
\text { Actualmente, no hay un } \\
\text { rol encargado de la } \\
\text { elaboración de los casos } \\
\text { de prueba. } \\
\text { Se tiene una plantilla } \\
\text { para los casos de Prueba } \\
\text { (Esta no cumple al } \\
100 \% \text { con la ISO). }\end{array}$ & $\begin{array}{l}\text { Elaborar el Producto de } \\
\text { trabajo "Casos y } \\
\text { Procedimientos de } \\
\text { Prueba" con todos los } \\
\text { campos requeridos para } \\
\text { guiar al proceso de } \\
\text { evaluación. } \\
\text { Documentar el rol que se } \\
\text { encargue de las } \\
\text { Tareas referentes al } \\
\text { "Casos y Procedimientos } \\
\text { de Prueba". }\end{array}$ \\
\hline IS 3.7 & $\begin{array}{l}\text { Actualizar el Registro de } \\
\text { Trazabilidad } \\
\text { incorporando los Casos } \\
\text { de Prueba y } \\
\text { Procedimientos de } \\
\text { Prueba }\end{array}$ & $\begin{array}{l}\text { Cumple } \\
\text { Parcialmente }\end{array}$ & $\begin{array}{l}\text { El AN elabora el } \\
\text { Registro de Trazabilidad } \\
\text { donde se hace el mapeo } \\
\text { entre los requisitos y los } \\
\text { casos de uso. } \\
\text { El registro de } \\
\text { Trazabilidad no cumple } \\
\text { con la información } \\
\text { solicitada: Diseño y } \\
\text { arquitectura no está } \\
\text { incluido en el registro de } \\
\text { trazabilidad. }\end{array}$ & $\begin{array}{l}\text { Elaborar el Producto de } \\
\text { trabajo "Registro de } \\
\text { Trazabilidad" con todos } \\
\text { los campos requeridos } \\
\text { para guiar al proceso de } \\
\text { evaluación. }\end{array}$ \\
\hline IS 4.6 & $\begin{array}{l}\text { Actualizar el Registro } \\
\text { de Trazabilidad } \\
\text { incorporando } \\
\text { Componente de } \\
\text { Software construidos o } \\
\text { modificados. }\end{array}$ & No Cumple & $\begin{array}{l}\text { El Registro no tiene una } \\
\text { sección componentes de } \\
\text { software. }\end{array}$ & $\begin{array}{l}\text { Elaborar el Producto de } \\
\text { trabajo "Registro de } \\
\text { Trazabilidad" con todos } \\
\text { los campos requeridos } \\
\text { para guiar al proceso de } \\
\text { evaluación. }\end{array}$ \\
\hline IS 5.6 & $\begin{array}{l}\text { Actualizar el Registro de } \\
\text { Trazabilidad en caso de } \\
\text { ser necesario. }\end{array}$ & No Cumple & $\begin{array}{l}\text { El Registro de } \\
\text { trazabilidad no tiene una } \\
\text { sección para los } \\
\text { componentes del } \\
\text { software. }\end{array}$ & $\begin{array}{l}\text { Elaborar el Producto de } \\
\text { trabajo "Registro de } \\
\text { Trazabilidad" con todos } \\
\text { los campos requeridos } \\
\text { para guiar al proceso de } \\
\text { evaluación. }\end{array}$ \\
\hline
\end{tabular}




\begin{tabular}{|l|l|l|l|l|}
\hline $\begin{array}{l}\text { Cód. } \\
\text { de la } \\
\text { Tarea }\end{array}$ & Nivel de Cumplimiento & $\begin{array}{l}\text { Nivel de } \\
\text { Cumplimiento }\end{array}$ & $\begin{array}{l}\text { Comentarios y } \\
\text { Observaciones }\end{array}$ & Propuesta de Solución \\
\hline & $\begin{array}{l}\text { Documentar el *Manual } \\
\text { de Usuario o actualizar } \\
\text { el actual, si aplica. } \\
\text { IS 5.9 }\end{array}$ & $\begin{array}{l}\text { Cumple } \\
\text { Parcialmente }\end{array}$ & $\begin{array}{l}\text { El AN documenta/ y/o } \\
\text { actualiza el manual de } \\
\text { usuario, en referencia a } \\
\text { la ISO 29110. } \\
\text { Actualmente, no hay un } \\
\text { rol que elabore el } \\
\text { Manual de Usuario. }\end{array}$ & $\begin{array}{l}\text { Elaborar el Producto de } \\
\text { trabajo "Manual de } \\
\text { Usuario" con todos los } \\
\text { campos requeridos para } \\
\text { guiar al proceso de } \\
\text { evaluación. }\end{array}$ \\
$\begin{array}{l}\text { Documentar el rol que se } \\
\text { encargue de las } \\
\text { Tareas referentes al } \\
\text { "Manual de Usuario". }\end{array}$ \\
\hline
\end{tabular}

Tabla 30 Brechas y Propuestas de Mejora

Fuente: Elaboración Propia

La Propuesta de Mejora sirve para asegurar el cumplimiento de las actividades, tareas y elaboración de documentos es:

- Definir los roles del equipo de trabajo y especificar al responsable de elaborar cada documento.

- Crear el nuevo Rol para apoyar en la ejecución de las pruebas del software y seguimiento al cumplimiento de la norma internacional.

En la Tabla 31, se presenta la Propuesta de Mejora Manual de Funciones como parte de cumplir las brechas identificadas en las Actividades de los Procesos de Gestión del Proyecto e Implementación de Software de la empresa de estudio:

\begin{tabular}{|l|l|l|}
\hline $\begin{array}{l}\text { Manual de } \\
\text { funciones }\end{array}$ & Objetivo & Anexo \\
\hline Roles actuales en la empresa de estudio: & Anexo 3.2 \\
\hline $\begin{array}{l}\text { Analista } \\
\text { Programador }\end{array}$ & $\begin{array}{l}\text { Analizar las necesidades del cliente y brindar una solución } \\
\text { de desarrollo de software. }\end{array}$ & Anexo 3.3 \\
\hline $\begin{array}{l}\text { Gestor de } \\
\text { Proyectos }\end{array}$ & $\begin{array}{l}\text { Realizar el seguimiento y control a cada una de las } \\
\text { actividades del proyecto. }\end{array}$ & $\begin{array}{l}\text { Anexo 3.4 } \\
\text { Lirigir y apoyar al equipo de trabajo a fin de obtener el } \\
\text { cumplimiento de las actividades y tareas del proyecto. }\end{array}$ \\
\hline
\end{tabular}




\begin{tabular}{|l|l|l|}
\hline $\begin{array}{l}\text { Manual de } \\
\text { funciones }\end{array}$ & Objetivo & Anexo \\
\hline Nuevo Rol en la empresa de estudio: & $\begin{array}{l}\text { Asegurar la calidad del producto de software desarrollando } \\
\text { en práctica estándares, procesos, herramientas y métodos } \\
\text { de evaluación. }\end{array}$ & Anexo 3.1 \\
\hline $\begin{array}{l}\text { Analista de } \\
\text { Calidad }\end{array}$ & \\
\hline
\end{tabular}

Tabla 31 Manuales de funciones Propuestos

Fuente: Elaboración Propia

\subsection{Propuesta de mejora para los Productos de Trabajo}

Para la elaboración de los productos de trabajo se utilizó:

- Las brechas identificadas en los Productos de Trabajo, descritas en la sección "Mapeo del contenido de los productos de trabajo de la empresa" (Sección 5.1.1.1).

- La Propuesta de solución identificadas en la tabla "Brechas y Propuestas de Mejora" (Sección 5.1.2.1.)

En la Tabla 32, se recomienda el uso de los productos de trabajo listados como productos de trabajo y responsables para la implementación de los proyectos de la empresa de estudio con el objetivo de asegurar el cumplimiento de lo descrito en la ISO 29110.

El nivel de criticidad mostrado hace referencia a la brecha identificada en el documento evaluado.

\begin{tabular}{|l|l|l|l|l|}
\hline $\begin{array}{l}\text { Productos de } \\
\text { Trabajo }\end{array}$ & Observación & $\begin{array}{l}\text { Nivel de } \\
\text { Criticidad }\end{array}$ & Plantillas & Responsable \\
\hline Plan del Proyecto & $\begin{array}{l}\text { El documento de la empresa Holinsys no } \\
\text { cumple con las secciones descritas en la } \\
\text { ISO: } \\
\text { - Identificación de los riesgos del proyecto } \\
\text { - Herramientas de repositorio del producto. } \\
\text { - Localización y mecanismos de acceso para } \\
\text { el repositorio especificado. } \\
\text { - Respaldo y mecanismos de recuperación } \\
\text { definidos. } \\
\text { - Mecanismos de almacenamiento, } \\
\text { manipulación y entrega especificados. }\end{array}$ & Bajo 2.1 & $\begin{array}{l}\text { Gestor del } \\
\text { Proyecto }\end{array}$ \\
\hline Acta de Reunión & $\begin{array}{l}\text { Documento No implementado en la } \\
\text { empresa. }\end{array}$ & Alta & Anexo 2.2 & $\begin{array}{l}\text { Gestor del } \\
\text { Proyecto }\end{array}$ \\
\hline
\end{tabular}




\begin{tabular}{|c|c|c|c|c|}
\hline $\begin{array}{l}\text { Productos de } \\
\text { Trabajo }\end{array}$ & Observación & $\begin{array}{l}\text { Nivel de } \\
\text { Criticidad } \\
\end{array}$ & Plantillas & Responsable \\
\hline $\begin{array}{l}\text { Acciones } \\
\text { Correctivas }\end{array}$ & $\begin{array}{l}\text { Documento No implementado en la } \\
\text { empresa. }\end{array}$ & Alta & Anexo 2.3 & $\begin{array}{l}\text { Gestor del } \\
\text { Proyecto }\end{array}$ \\
\hline $\begin{array}{l}\text { Acta de } \\
\text { Aceptación }\end{array}$ & $\begin{array}{l}\text { El documento de la empresa Holinsys no } \\
\text { cumple con las secciones descritas en la } \\
\text { ISO: } \\
\text { - Registro de la verificación de los criterios } \\
\text { de aceptación definidos por parte del } \\
\text { Cliente } \\
\text { - Identificación de cualquier asunto } \\
\text { pendiente (en caso de ser aplicable). }\end{array}$ & Bajo & Anexo 2.4 & $\begin{array}{l}\text { Gestor del } \\
\text { Proyecto }\end{array}$ \\
\hline $\begin{array}{l}\text { Manual de } \\
\text { Usuario }\end{array}$ & $\begin{array}{l}\text { El documento de la empresa Holinsys no } \\
\text { cumple con las secciones descritas en la } \\
\text { ISO: } \\
\text { - Facilidad para reportar problemas y } \\
\text { asistencia. - Según corresponda a los riesgos } \\
\text { identificados; este incluye advertencias, } \\
\text { precauciones y notas con correcciones. } \\
\text { - Incluye los procedimientos para la } \\
\text { solución de problemas y corrección de } \\
\text { errores. }\end{array}$ & Baja & Anexo 2.5 & $\begin{array}{l}\text { Analista } \\
\text { Programador }\end{array}$ \\
\hline $\begin{array}{l}\text { Manual de } \\
\text { Operación }\end{array}$ & $\begin{array}{l}\text { El documento de la empresa Holinsys no } \\
\text { cumple con las secciones descritas en la } \\
\text { ISO: } \\
\text { - Posibles alertas de seguridad (safety) } \\
\text { - Fuentes de información adicional y ayuda } \\
\text { para operar el producto. } \\
\text { - Certificación y aprobaciones de seguridad } \\
\text { (safety) }\end{array}$ & Baja & Anexo 2.6 & $\begin{array}{l}\text { Analista } \\
\text { Programador }\end{array}$ \\
\hline $\begin{array}{l}\text { Registro de } \\
\text { Trazabilidad }\end{array}$ & $\begin{array}{l}\text { El documento de la empresa Holinsys no } \\
\text { cumple con las características descritas en } \\
\text { la ISO: } \\
\text { - Proporcionar el mapeo de los requisitos a } \\
\text { los elementos del Diseño de Software, los } \\
\text { Componentes de Software, los Casos de } \\
\text { Prueba y los Procedimientos de Prueba. } \\
\end{array}$ & Media & Anexo 2.7 & $\begin{array}{l}\text { Analista } \\
\text { Programador }\end{array}$ \\
\hline $\begin{array}{l}\text { Resultados de } \\
\text { Validación }\end{array}$ & $\begin{array}{l}\text { Documento No implementado en la } \\
\text { empresa. }\end{array}$ & Alta & Anexo 2.8 & $\begin{array}{l}\text { Analista de } \\
\text { Calidad }\end{array}$ \\
\hline $\begin{array}{l}\text { Resultados de } \\
\text { Verificación }\end{array}$ & $\begin{array}{l}\text { Documento No implementado en la } \\
\text { empresa. }\end{array}$ & Alta & Anexo 2.9 & $\begin{array}{l}\text { Analista de } \\
\text { Calidad }\end{array}$ \\
\hline
\end{tabular}

Tabla 32 Productos de trabajo propuestos a la empresa

Elaboración Propia 


\subsection{Herramienta para el seguimiento y Control de Proyectos}

\subsubsection{Requerimientos Funcionales de la herramienta}

A continuación se describe los requerimientos funcionales de la herramienta de software desarrollada:

\subsubsection{Desarrollar la aplicación Auditor 29110}

\section{Funcionalidad}

En la Figura 22, se muestra los casos de uso de la herramienta de desarrollo Auditor 29110.

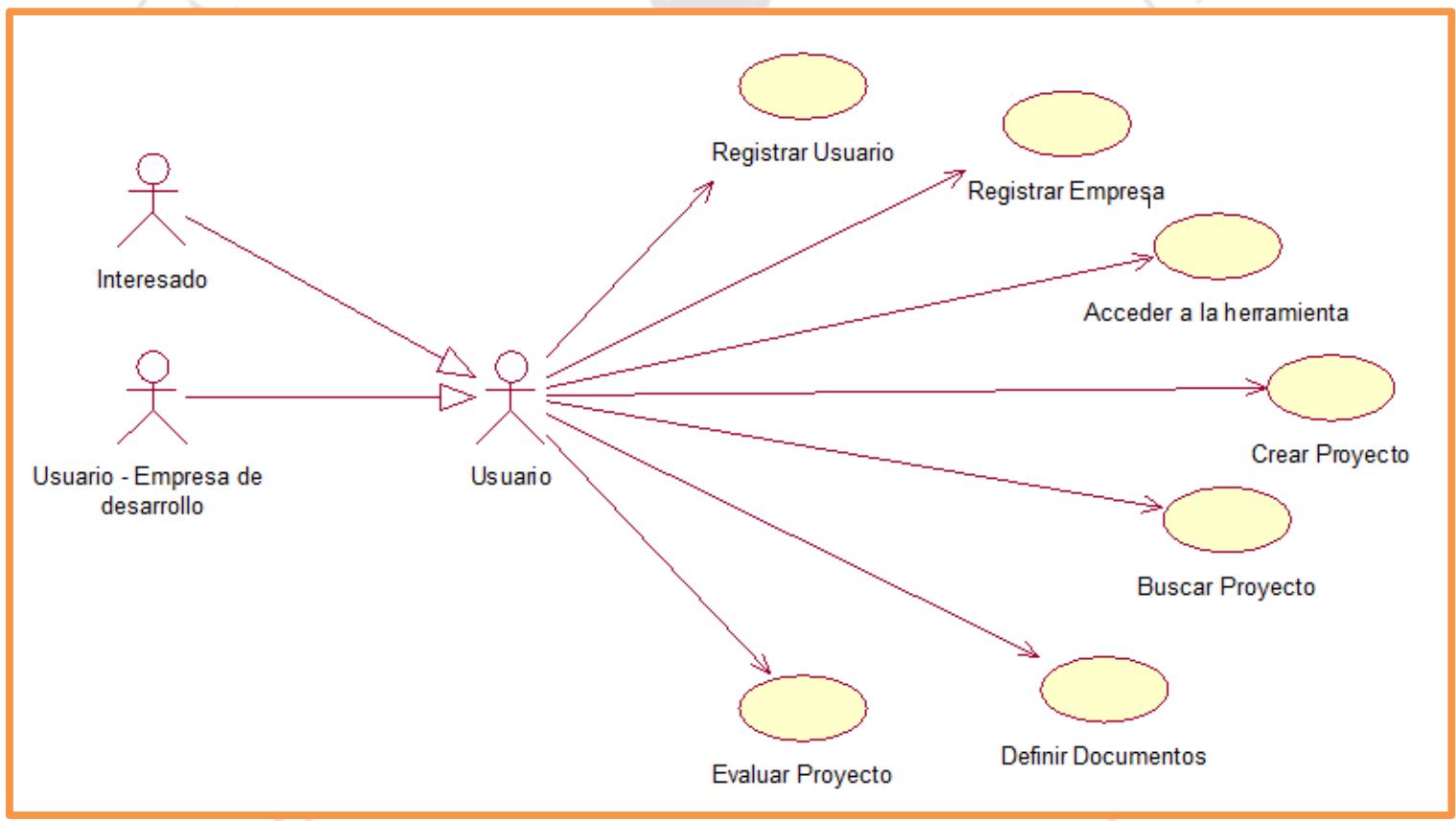

Figura 22 Diagrama de Casos de uso de la Herramienta de Desarrollo Auditor 29110. Fuente: Elaboración Propia 
La herramienta a desarrollar soporta los siguientes casos de uso:

$>$ Registrar Usuario.

Registrar Empresa.

Acceder a la herramienta.

$>$ Crear Proyecto.

Buscar Proyecto.

Definir Documentos.

Evaluar proyecto.

Las funcionalidades de la aplicación tienen restricciones según el tipo de usuario como se muestra a continuación:

\begin{tabular}{|c|c|c|}
\hline $\begin{array}{l}\text { Tipos de } \\
\text { Usuario } \\
\end{array}$ & Rol de Usuario & Permisos \\
\hline Administrador & - & $\begin{array}{l}\text { Acceso a todos los módulos del sistema } \\
\text { Crear/Editar/Eliminar Empresa } \\
\text { Asignar Representante a Empresa } \\
\text { Gestiona todas las opciones del sistema } \\
\text { Gestiona todos los usuarios }\end{array}$ \\
\hline $\begin{array}{l}\text { Representante } \\
\text { de la empresa }\end{array}$ & $\begin{array}{l}\text { Gestor del } \\
\text { proyecto }\end{array}$ & $\begin{array}{l}\text { Validar Usuarios } \\
\text { Ver Registro de Usuarios } \\
\text { Eliminar Usuarios } \\
\text { Crear/Editar/Eliminar Proyectos } \\
\text { Definir Documentos } \\
\text { Evaluar Proyectos }\end{array}$ \\
\hline \multirow[t]{4}{*}{ Desarrollador } & $\begin{array}{l}\text { Gestor del } \\
\text { proyecto }\end{array}$ & $\begin{array}{l}\text { Crear/Editar/Eliminar Proyectos } \\
\text { Definir Documentos } \\
\text { Evaluar Proyectos }\end{array}$ \\
\hline & Líder Técnico & $\begin{array}{l}\text { Evaluar Proyectos } \\
\text { Definir Documentos }\end{array}$ \\
\hline & Analista & Evaluar Proyectos \\
\hline & Programador & Evaluar Proyectos \\
\hline
\end{tabular}

Tabla 33 Tipos de usuario, Roles y Permisos

Fuente: Elaboración Propia. 


\section{Interfaces externas}

El proceso principal interactúa con documentos del tipo Word/ Excel, los cuales son leídos e interpretados por el sistema. Si el sistema lo requiere, este puede interactuar con algún proceso o interfaz externa.

\section{Fiabilidad}

Los procesos deben cumplir con los requisitos definidos anteriormente, por lo tanto la funcionalidad del sistema no debe verse afectada en ningún caso.

La utilización de los módulos debe ser completamente confiable.

\section{Eficiencia}

La función principal debe cumplir correctamente con el requisito planteado y este debe responder lo inmediatamente en un tiempo considerable.

\section{Mantenimiento}

Según los diseños y requisitos planteados, el mantenimiento sistema debe de poder gestionarse a través de un CMS.

\section{Portabilidad}

El sistema debe de ser multiplataforma y estar disponible cada vez que el usuario lo requiera.

\section{Limitaciones/restricciones del diseño y construcción}

Dentro de las limitaciones del sistema se mencionan:

- $\quad$ Aplicación funcional únicamente en entorno web

- Desarrollo de las interfaces definidas en este documento.

- Aplicación dirigida para clientes asociados/registrados

- $\quad$ Alcances del proyecto

\section{Interoperabilidad}

El proceso principal del sistema requiere que este pueda interactuar con algunos documentos, los cuales tienen un formato totalmente distinto. 


\section{Reutilización}

- El sistema debe de ser desarrollado utilizando algún paradigma de programación.

- Las clases/funciones deben estar detalladas.

- Los procesos deben poder ser accesibles por más de un módulo.

- Reutilización de código.

- Reutilización de módulos.

- Reutilización de procesos.

\section{Legales y regulativos}

Las exigencias legales con respecto a la documentación y desarrollo, recaen específicamente sobre la propia empresa que desarrolla este proyecto.

En cuanto a los aspectos sobre privacidad:

- No se guardara ningún tipo de información con respecto a los documentos desarrollados por las empresas.

- Se guardara la información enviada por la empresa, para su registro.

- Solo se almacenan resultados, de acuerdo al nivel de cumplimiento determinado por sistema. 


\subsubsection{Acceso a la aplicación}

\section{Funcionalidad}

Para acceder a la herramienta, el usuario debe confirmar su identidad con un código de usuario y una contraseña (Previamente, el usuario ya debe estar registrado en la aplicación). En la Figura 23, se muestra el Diagrama de Secuencia de la Herramienta de Software: Acceso a la aplicación.

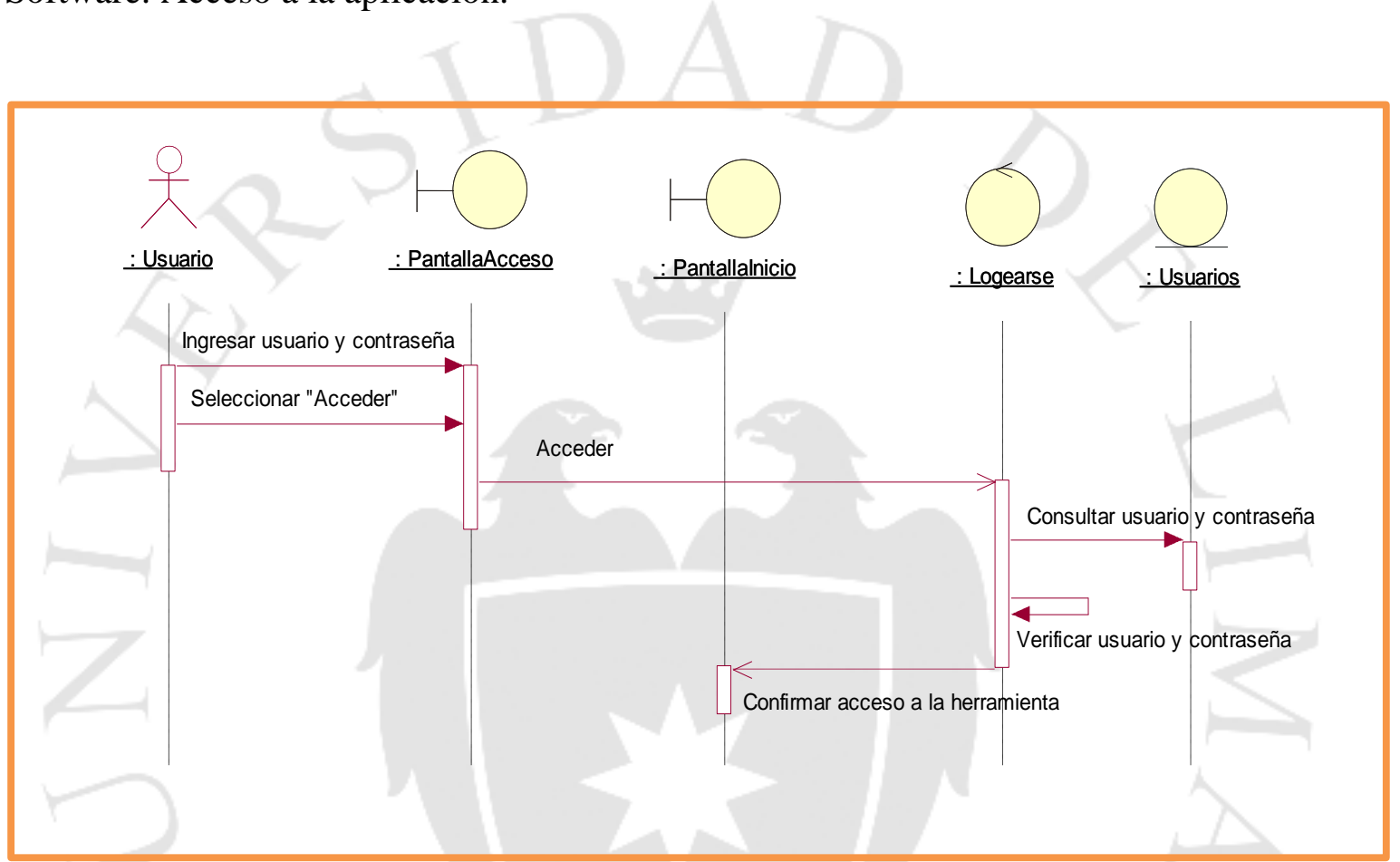

Figura 23 Diagrama de Secuencia de la Herramienta de Software: Acceso a la aplicación Fuente: Elaboración Propia. 
Interfaz de usuario: Pantalla de Acceso

En la Figura 24, se muestra la interfaz que limita el acceso a la aplicación. Para acceder a la aplicación es necesario un usuario y una contraseña.

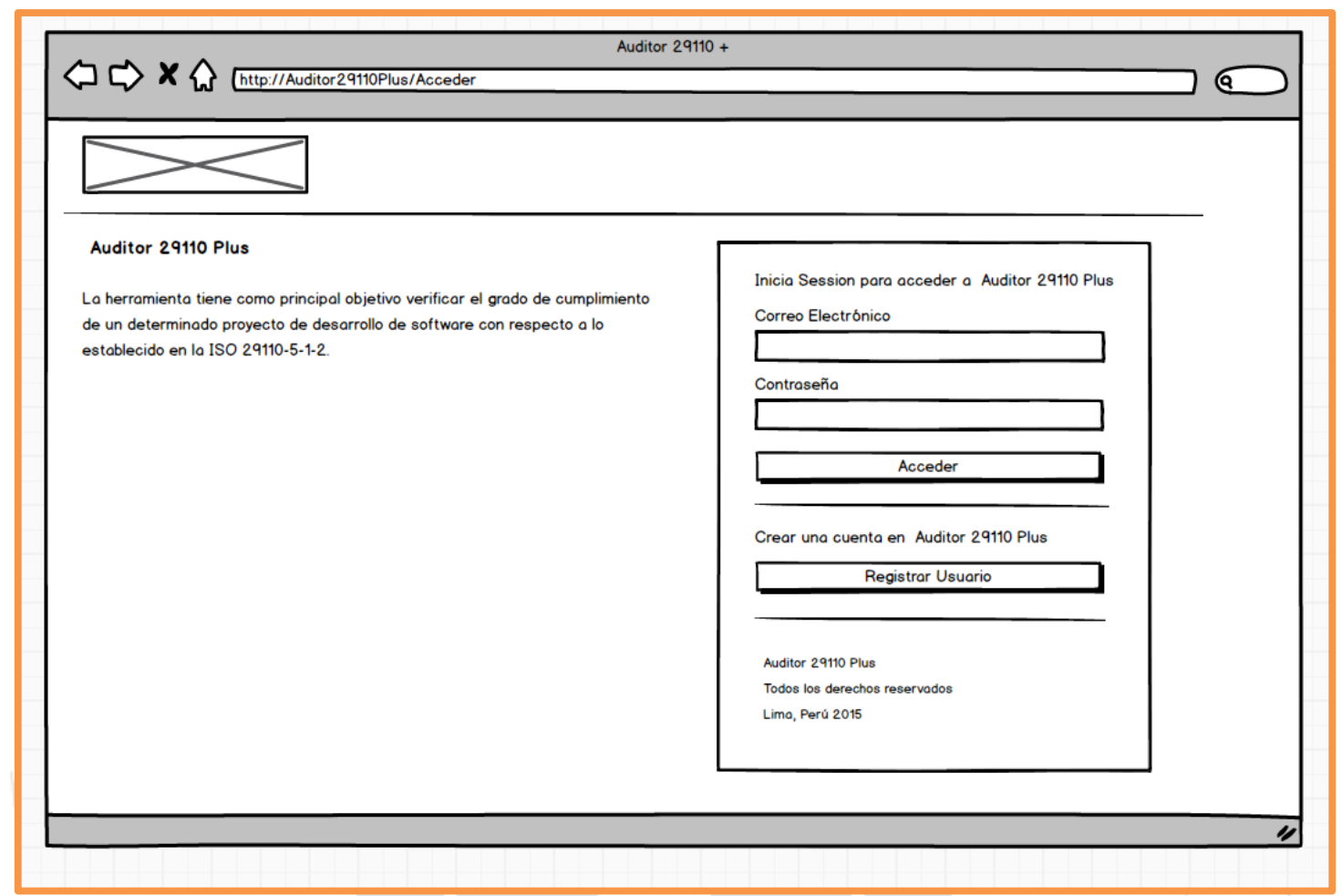

Figura 24 Interfaz Acceso a la aplicación Fuente: Elaboración Propia 


\subsubsection{Registrar Usuario}

\section{Funcionalidad}

La herramienta tiene la opción de registrar usuarios y asignarlos a una empresa.

Para registrarse, el usuario debe llenar los siguientes campos:

- Nombres, Apellidos, Ubicación y Correo electrónico del usuario.

- Nombre de la empresa y Rol.

- Código de usuario y contraseña.

- Código Captcha.

Adicionalmente, la identidad del usuario debe validarse por correo electrónico.

- Diagrama de secuencia:

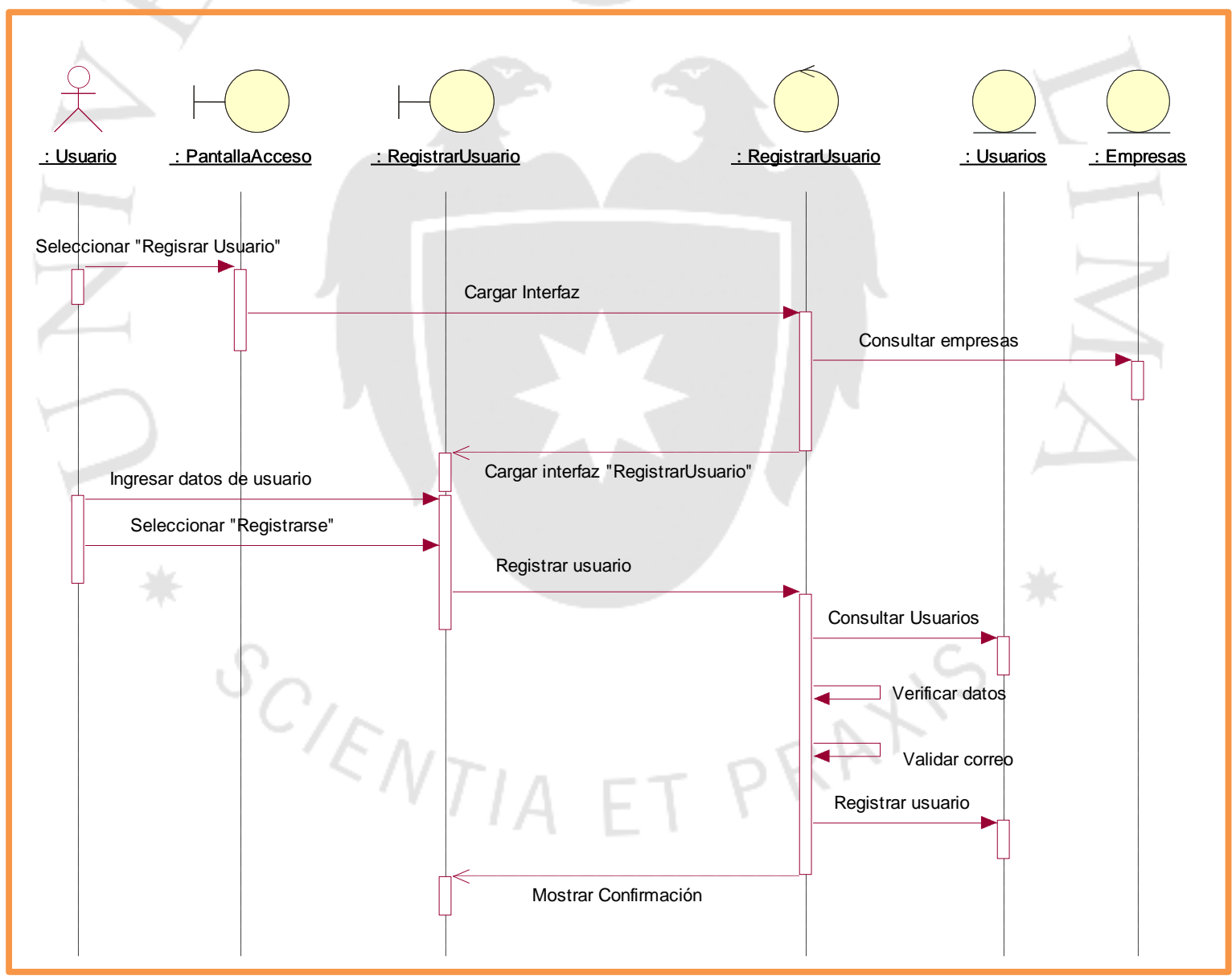

Figura 25 Diagrama de secuencia de la Herramienta de Software: Registrar Usuario. Fuente: Elaboración Propia. 


\section{Interfaz de usuario}

Interfaz utilizara para registrarse en la aplicación.

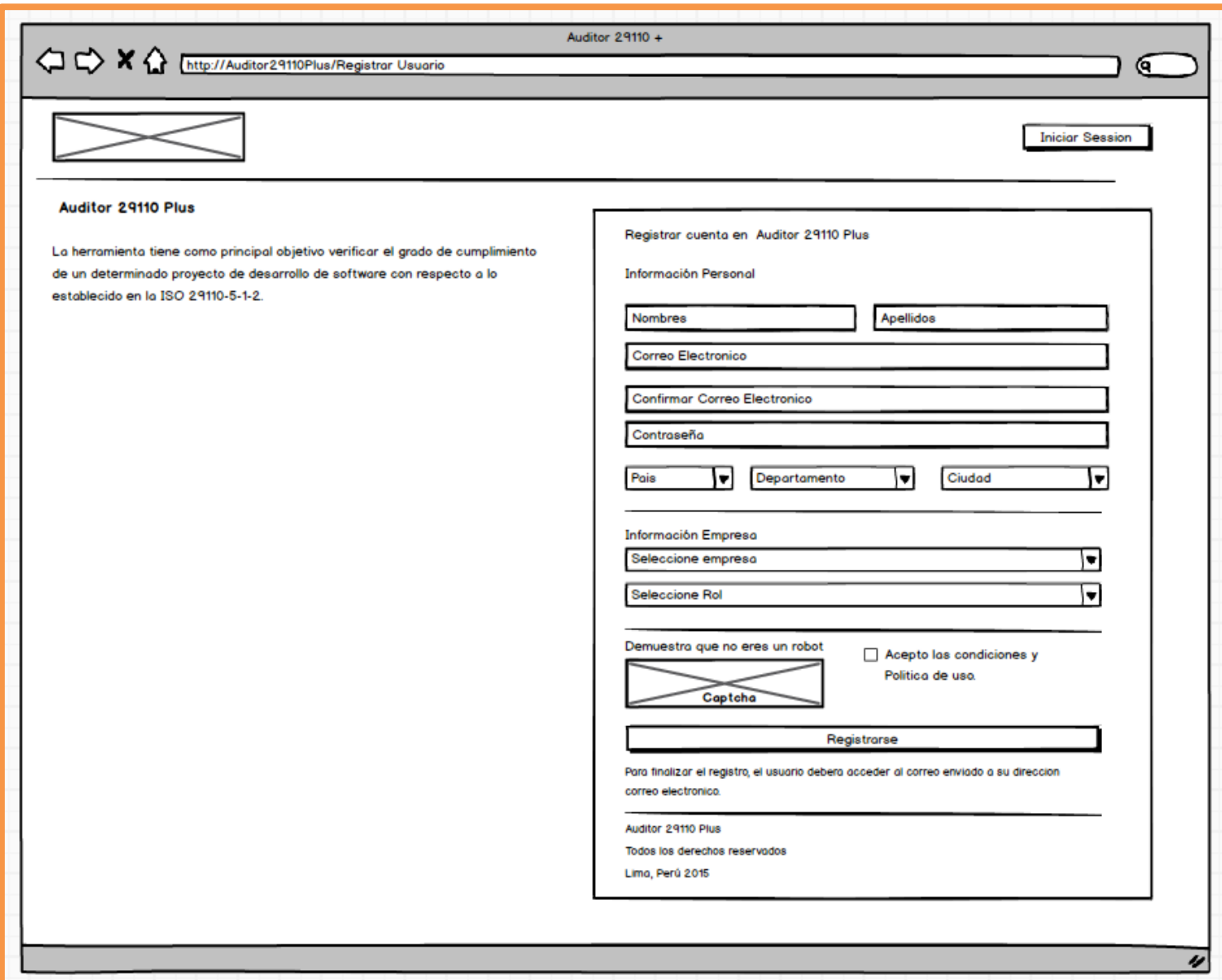

Figura 26 Interfaz Registrar Usuario

Fuente: Elaboración Propia. 


\subsubsection{Pantalla Principal}

\section{Funcionalidad}

Luego de Acceder al sistema, el usuario tiene acceso a la pantalla principal donde puede acceder a la mayoría de las otras funciones de la aplicación.

\section{Interfaz de usuario: Pantalla Principal del proyecto.}

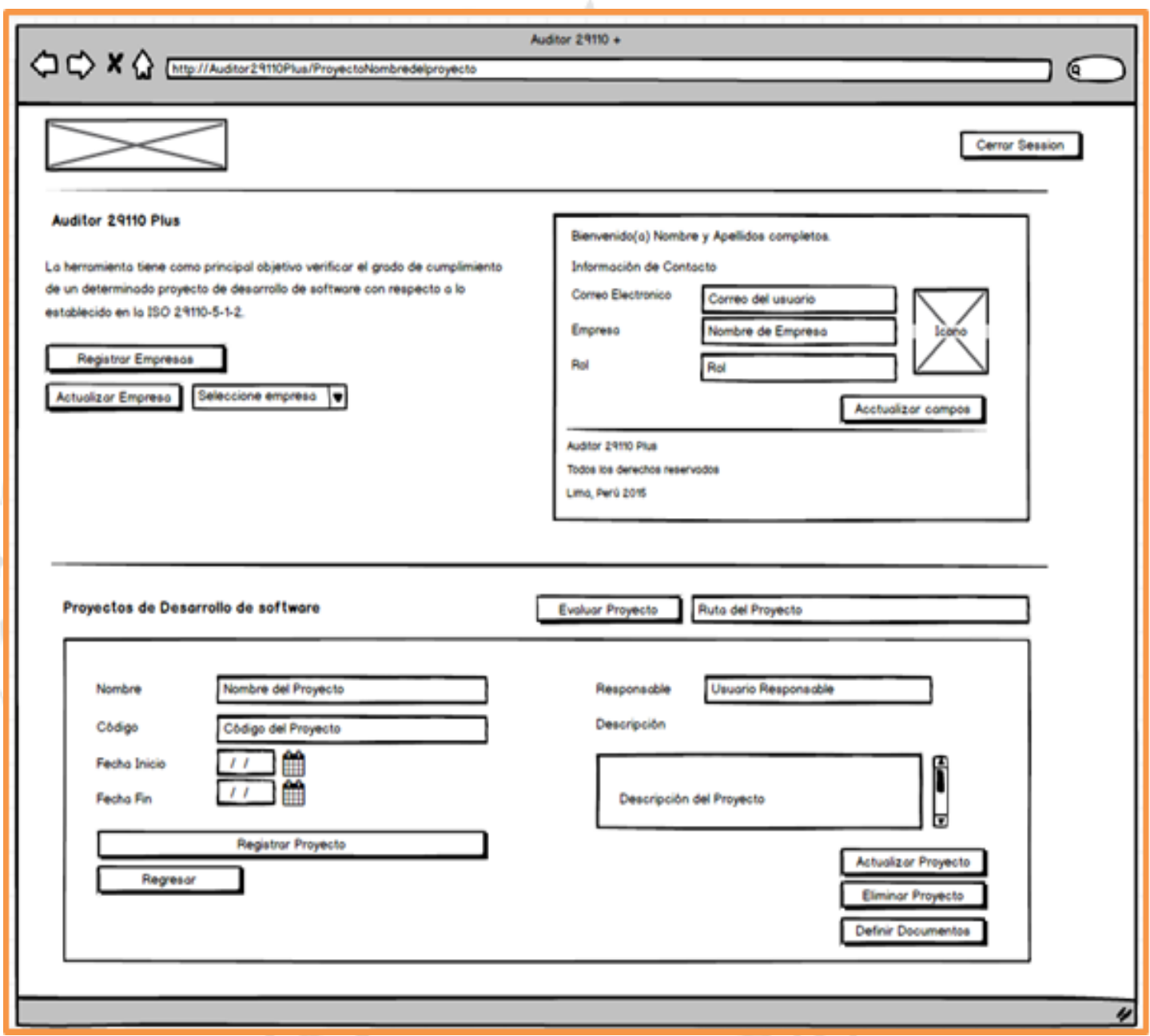

Figura 27 Interfaz Pantalla Principal.

Fuente: Elaboración Propia. 


\subsubsection{Registrar Empresa}

\section{Funcionalidad}

La herramienta permite a los usuarios administradores registrar nuevas empresas.

El tipo de usuario administrador solo se puede configurar por base de datos.

Para registrar una empresa, el usuario debe llenar los siguientes campos:

- Nombre comercial de la empresa

- Razón social, RUC y Actividad económica de la empresa.

- Número de usuarios máximo de la empresa

- Usuario responsable de la empresa. (Al modificar registro luego que el usuario ya este asignado a la empresa).

- Diagrama de secuencia:

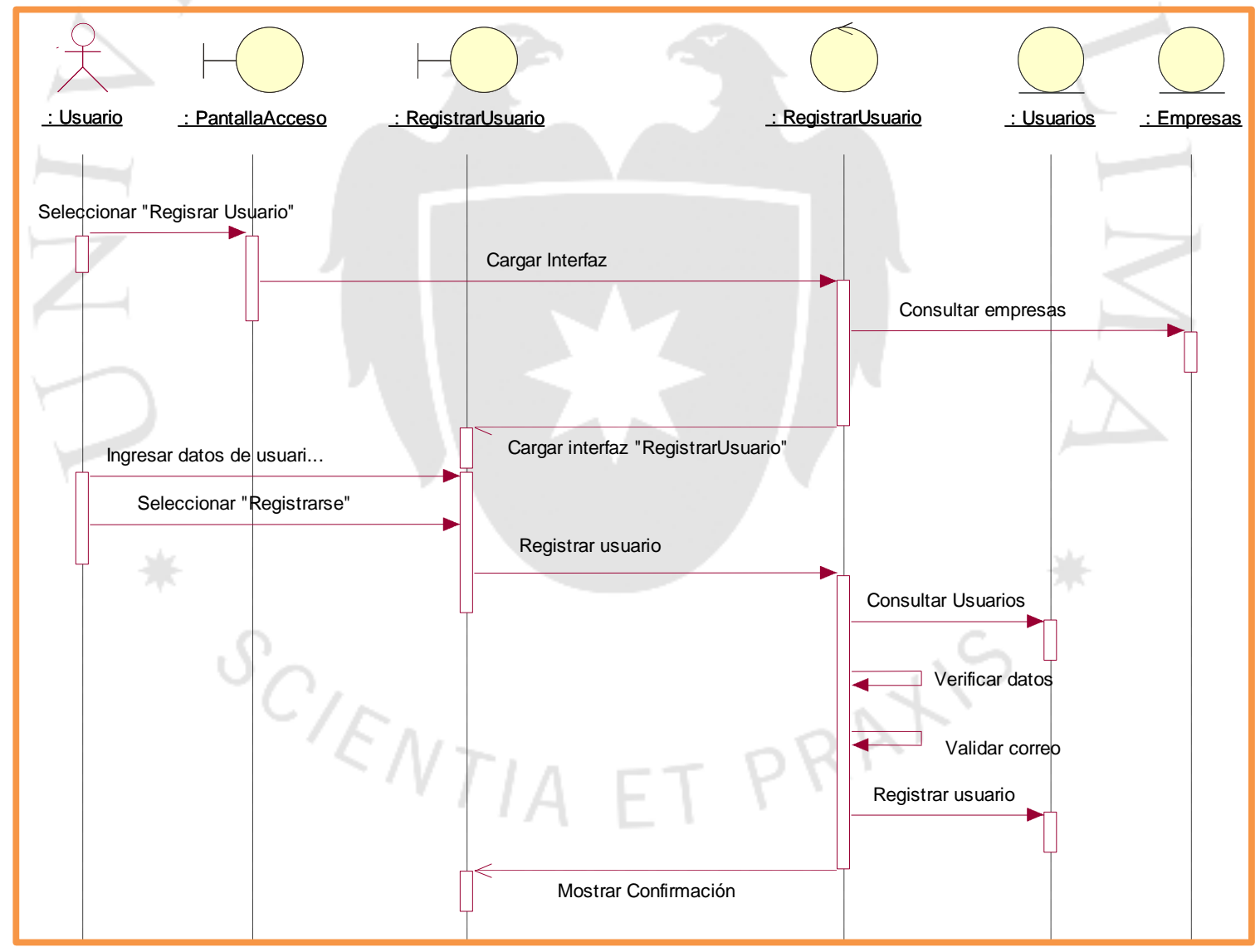

Figura 28 Diagrama de secuencia de la Herramienta de Software: Registrar Empresa. Fuente: Elaboración Propia. 


\section{Interfaz de usuario: Interfaz Mostrar/Registrar Empresa}

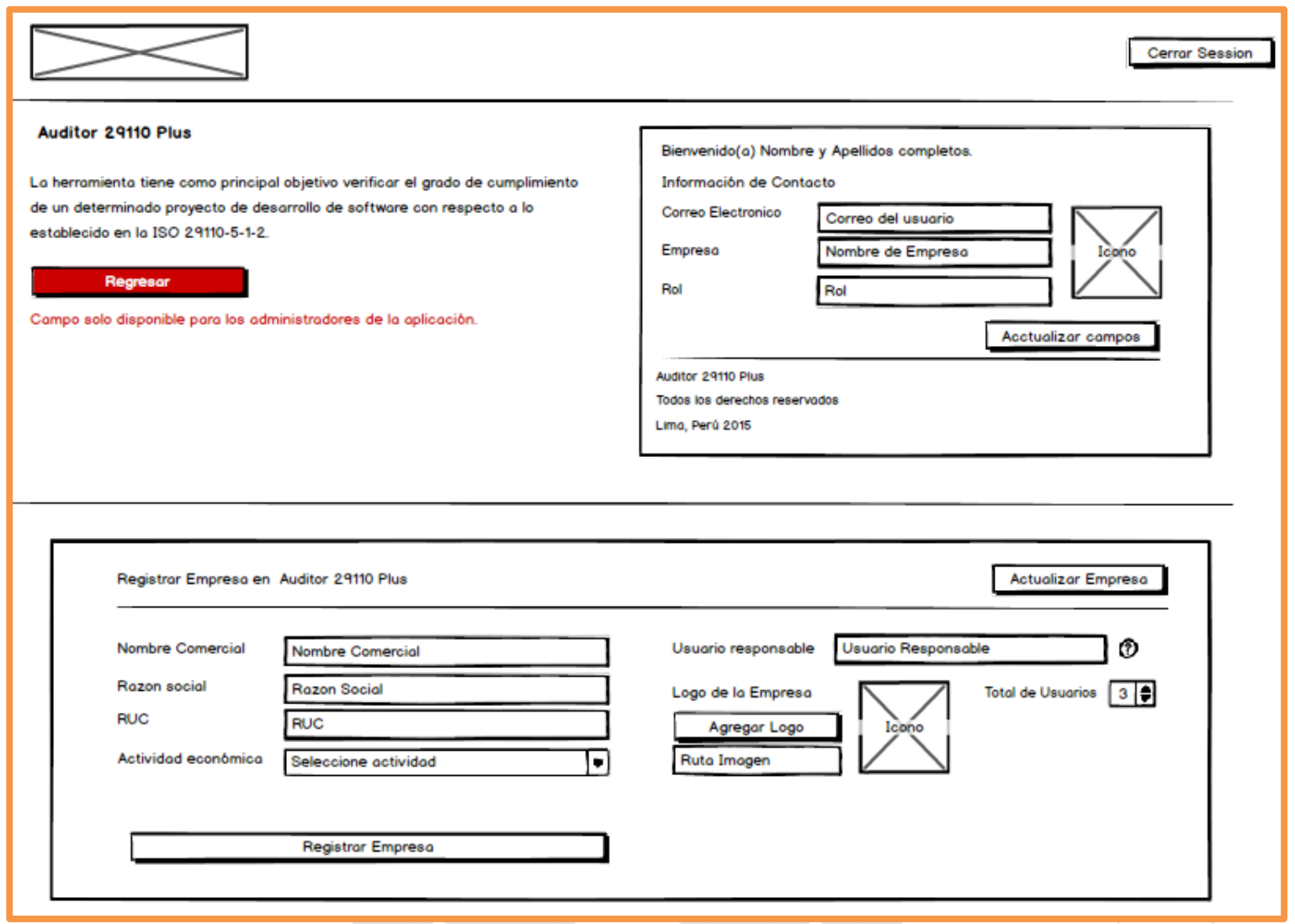

Figura 29 Interfaz Mostrar/Registrar Empresa

Fuente: Elaboración Propia. 


\subsubsection{Crear Proyecto}

\section{Funcionalidad}

El usuario puede crear un nuevo proyecto en la herramienta.

Para crear un proyecto, el usuario debe llenar los siguientes campos:

- Nombre del proyecto.

- Código del proyecto y descripción.

- Fecha de inicio y fin del proyecto.

- Responsable.

- Diagrama de secuencia:

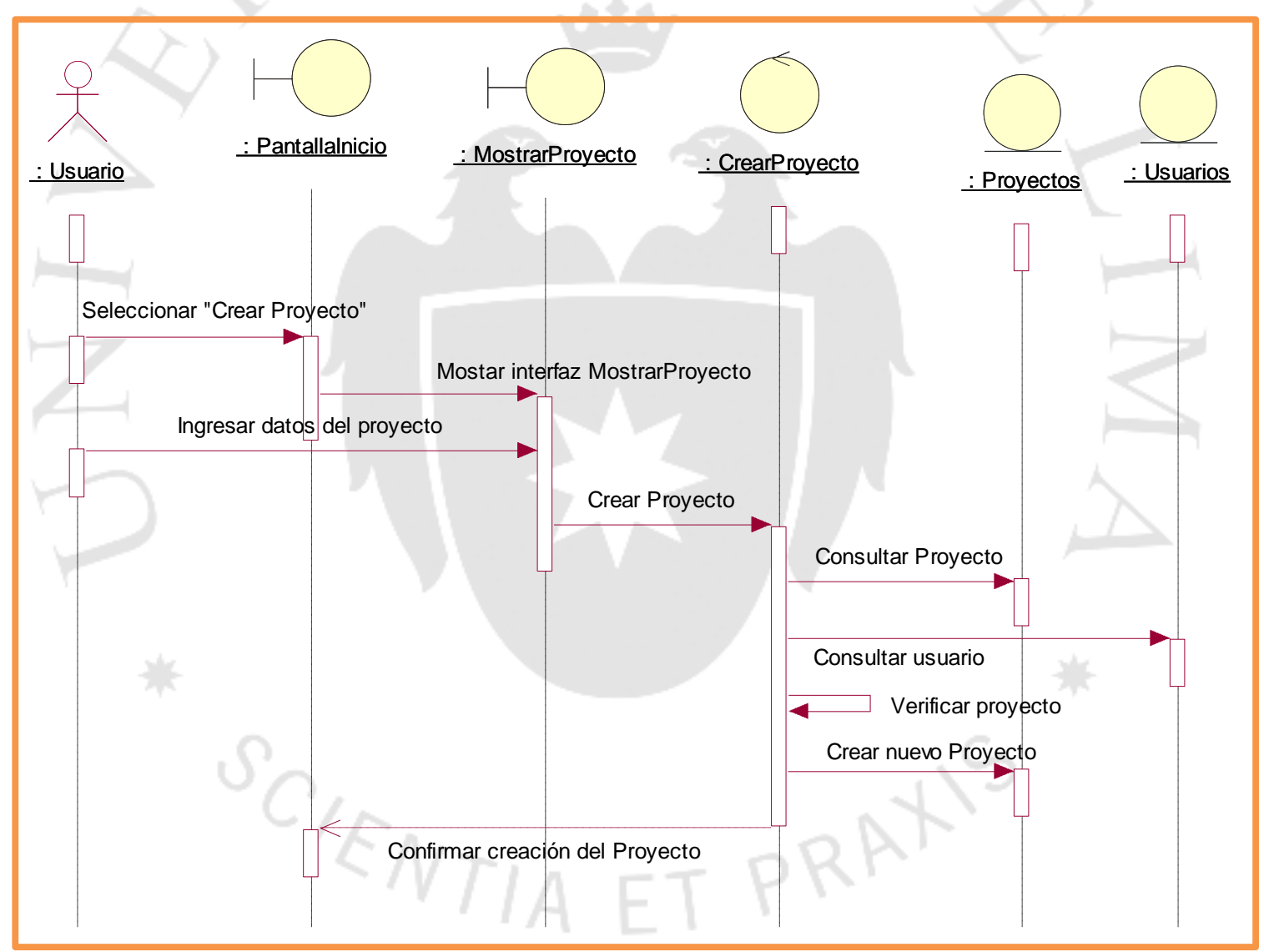

Figura 30 Diagrama de secuencia de la Herramienta de Software: Crear Proyecto Fuente: Elaboración Propia. 


\section{Interfaz de usuario: Mostrar/Registrar Proyecto}

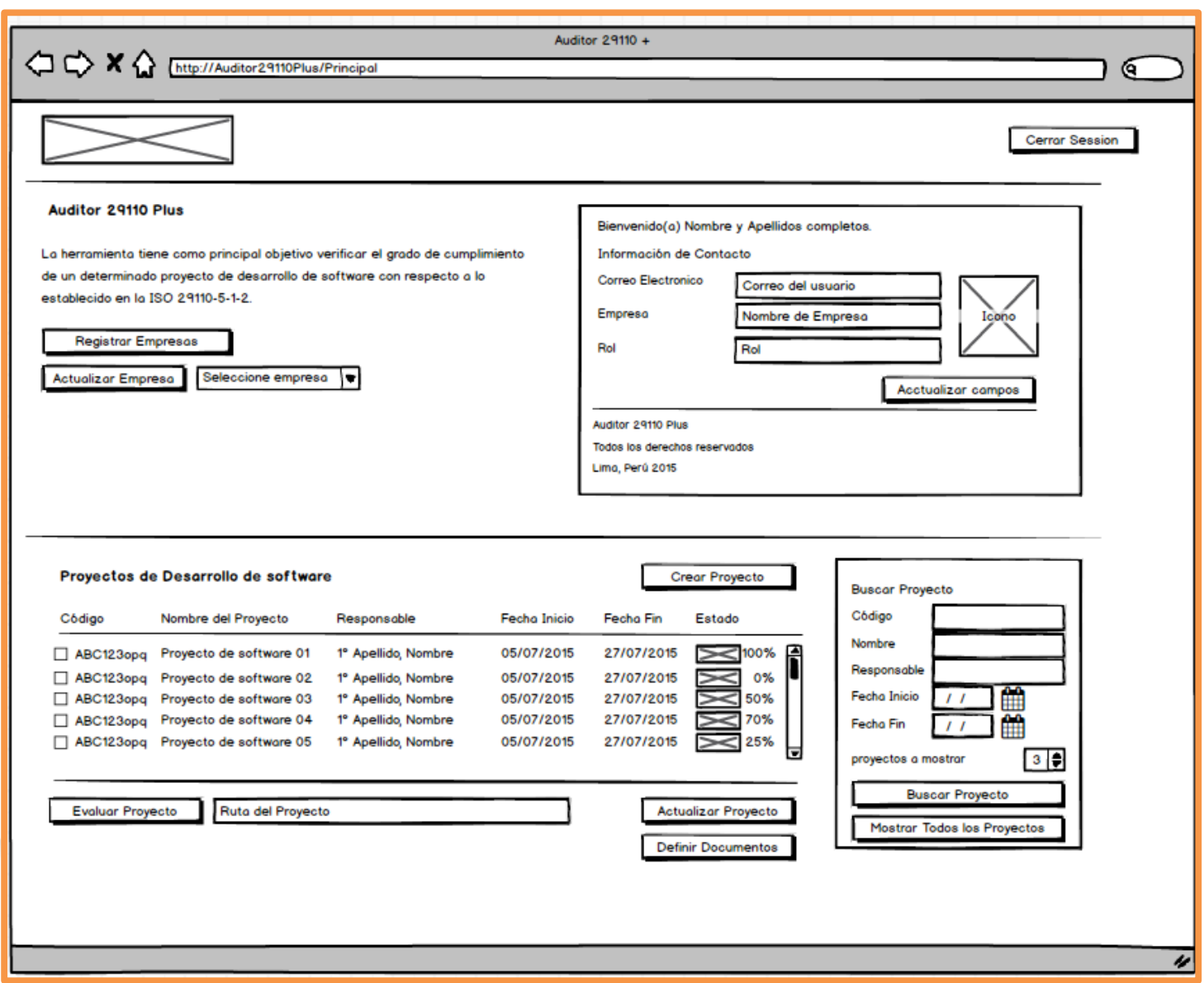

Figura 31 Interfaz Mostrar/Registrar Proyecto

Fuente: Elaboración Propia. 


\subsubsection{Definir Documentos}

\section{Funcionalidad}

Del conjunto de documentos (Productos de trabajo) desarrollados en un proyecto hecho bajo los lineamientos de la ISO 29110-5-1-2; el usuario debe poder definir que documentos están disponibles en su proyecto.

Adicionalmente, el usuario puede definir la estructura (Contenido) del documento.

El usuario puede acceder nuevamente a la opción "Definir documentos" para actualizar el proyecto.

- Diagrama de secuencia:

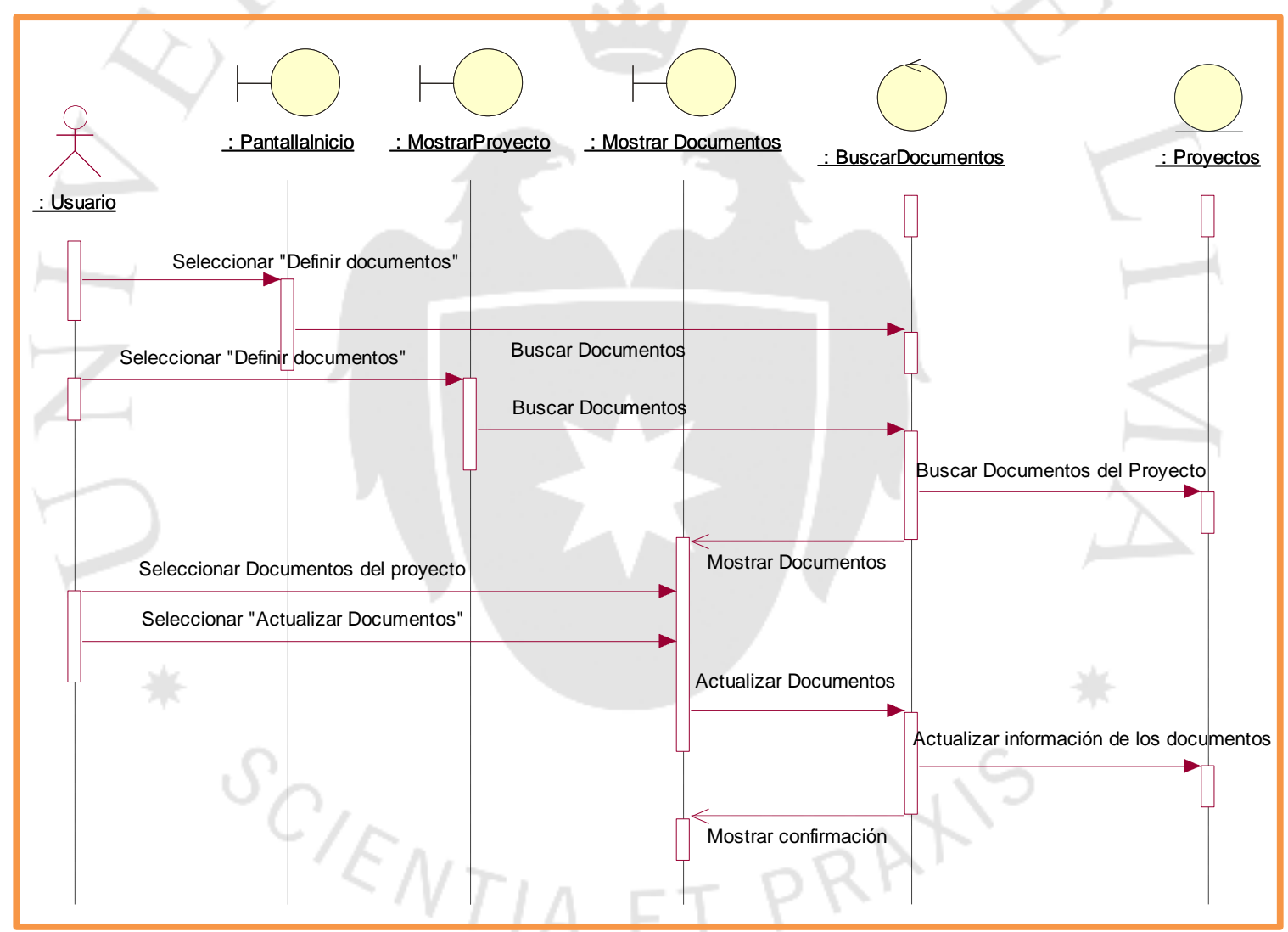

Figura 32 Diagrama de secuencia de la Herramienta de Software: Definir Documento Fuente: Elaboración Propia. 


\section{Interfaz de usuario: Definir Documentos}

En la Figura 33, se muestra el diseño base de la interfaz Definir Documentos.

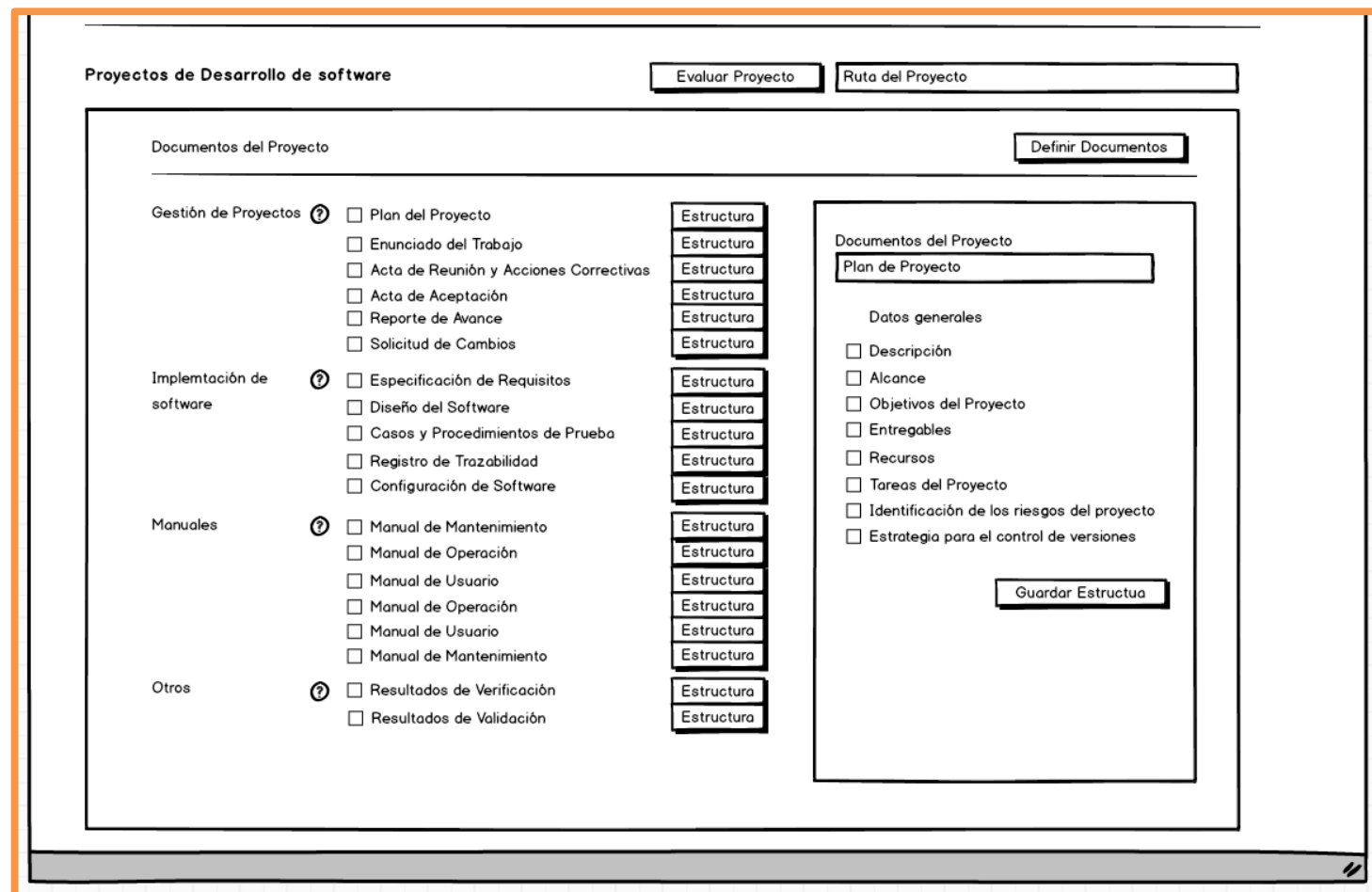

Figura 33 Interfaz Definir Documentos

Fuente: Elaboración Propia. 


\subsubsection{Evaluar Proyectos}

\section{Funcionalidad}

La herramienta verifica si los documentos ( $\mathrm{Y}$ la estructura de estos documentos) encontrados en la ruta especificada por el usuario cumplen con la definición del proyecto.

- Diagrama de secuencia:

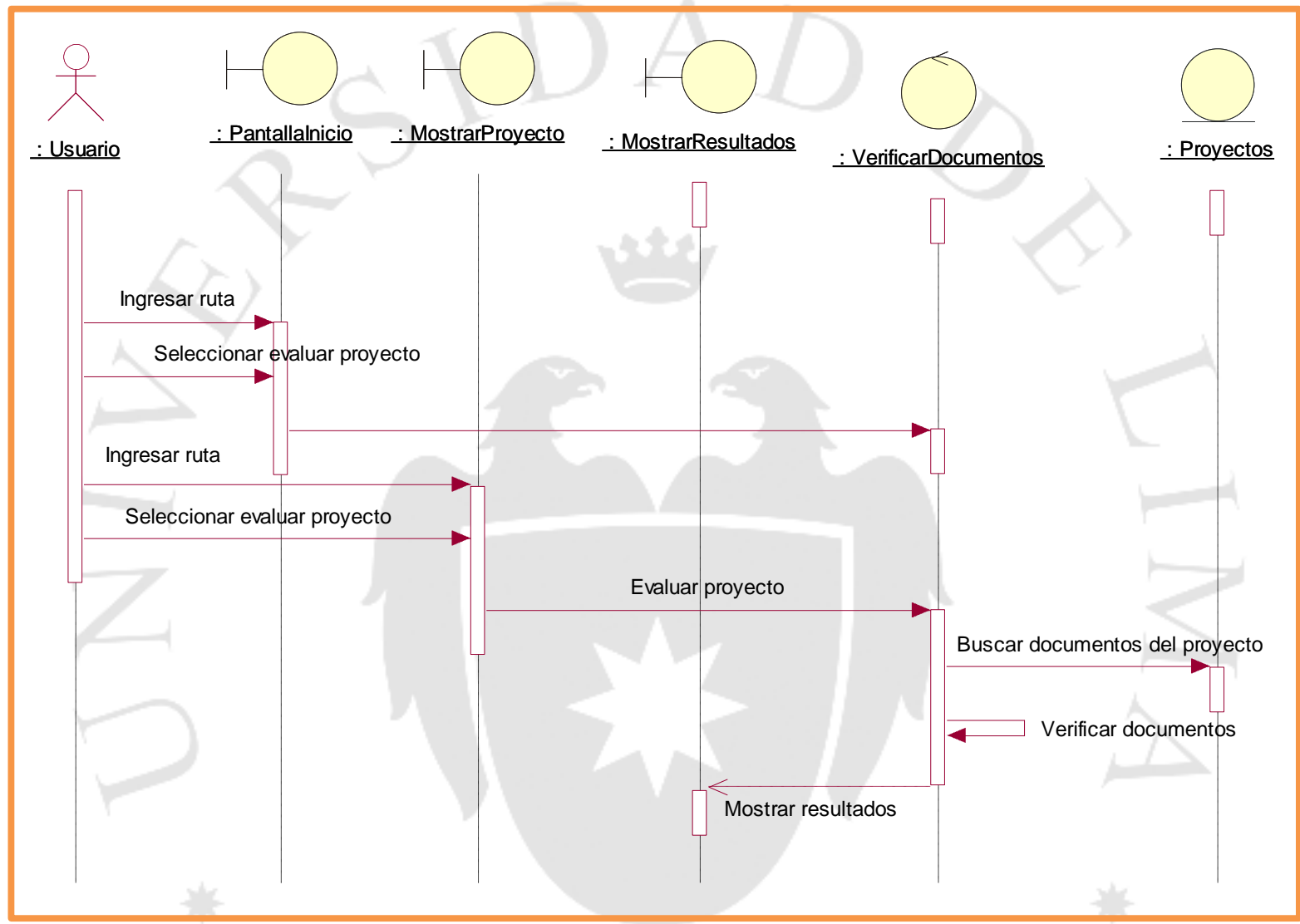

Figura 34 Diagrama de secuencia de la Herramienta de Software: Evaluar Proyectos Fuente: Elaboración Propia. 


\subsubsection{Diseño de la herramienta}

A continuación se describen de forma textual y gráfica la estructura de la herramienta.

\subsubsection{Diseño Arquitectónico}

Descripción del Diseño arquitectónico de la herramienta a desarrollar:

\section{Componentes de software requeridos}

\begin{tabular}{|l|l|}
\hline Componente & Descripción \\
\hline \multicolumn{2}{|c|}{ En el Servidor } \\
\hline Apache & $\begin{array}{l}\text { Servidor web, el cual permite enviar y comprender las } \\
\text { configuraciones definidas por el lenguaje de programación. }\end{array}$ \\
\hline PHP & Lenguaje de programación utilizado. \\
\hline MySQL & \multicolumn{1}{c|}{ En est cliente } \\
\hline \multicolumn{2}{|c|}{ Eer de Base de Datos utilizado. } \\
\hline HTML5 & Define la estructura visual del sistema \\
\hline JavaScript & $\begin{array}{l}\text { Lenguaje de programación el cual interactúa (intermediario) } \\
\text { entre el cliente y el servidor. }\end{array}$ \\
\hline Navegador web & $\begin{array}{l}\text { Necesario para la interpretación del sistema y el acceso al } \\
\text { mismo. }\end{array}$ \\
\hline
\end{tabular}

Tabla 34 Componentes de Software requeridos

Fuente: Elaboración Propia

\section{Relación entre los componentes de software}

El usuario (Cliente) accede a través de un navegador web al servidor donde se encuentra alojada la aplicación. El navegador web debe de soportar HTML5 y JavaScript. La aplicación se encuentra desarrollada en PHP, y el mantenimiento de la base de datos es utilizado en MySQL.

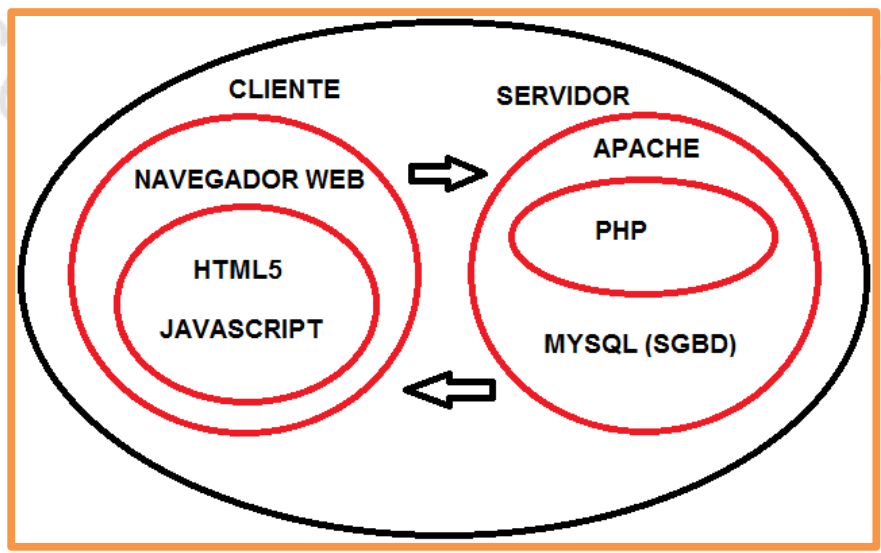

Figura 35 Relación entre los componentes de software Fuente: Elaboración Propia. 


\section{Características de desempeño de software}

Dentro de las características de desempeño, se puede mencionar:

- Características del servidor, recursos apropiados.

- $\quad$ Peticiones del cliente, transacciones inmediatas.

- Disponibilidad inmediata del sistema.

- $\quad$ Flexibilidad en los procesos.

\section{Interfaces de hardware, software y humanas}

A continuación, detallamos las interfaces que existen para interactuar con la aplicación:

\begin{tabular}{|l|l|l|}
\hline HUMANO & HARDWARE & SOFTWARE \\
\hline Interacción entre los distintos & Componentes habituales de una & En el servidor: \\
componentes. & computadora: & Apache \\
Petición del cliente al servidor. & Monitor & Php \\
& Cpu & MySQL \\
& Teclado & En el cliente: \\
& Mouse & Navegador web \\
\hline
\end{tabular}

Figura 36 Interfaces de hardware, software y humanas

Fuente: Elaboración Propia.

\section{Características de seguridad}

- $\quad$ Servidor seguro.

- Utilización de frameworks.

- $\quad$ Utilización de ORM (Base de datos).

- Validación de datos y procesos.

- Gestión de Permisos a usuarios.

- $\quad$ Utilización de triggers.

6. Requisitos de diseño de base de datos

- $\quad$ Erwin Data Modeler, para el diseño lógico (conceptual y detallado).

- $\quad$ MySQL/PHPMyAdmin, para la implementación del diseño físico. 


\subsubsection{Diseño Detallado}

Descripción del Diseño Detallado de la herramienta a desarrollar:

\section{Diseño del Sistema}

En la tabla 35 describimos las principales interfaces web de la aplicación:

\begin{tabular}{|c|c|}
\hline INTERFAZ & DESCRIPCIÓN \\
\hline $\begin{array}{l}\text { Registro de } \\
\text { Usuario }\end{array}$ & $\begin{array}{l}\text { Permite a los usuarios invitados registrarse en el sistema, para poder tener acceso a } \\
\text { este. }\end{array}$ \\
\hline $\begin{array}{l}\text { Acceso al } \\
\text { Sistema }\end{array}$ & Interfaz para acceder al sistema. \\
\hline $\begin{array}{l}\text { Gestión de } \\
\text { Empresas }\end{array}$ & $\begin{array}{l}\text { Esta interfaz permite editar los datos de las empresas existentes y a su vez generar } \\
\text { consultas. }\end{array}$ \\
\hline $\begin{array}{l}\text { Registrar } \\
\text { Empresas }\end{array}$ & El administrador puede registrar alguna empresa según lo requiera. \\
\hline $\begin{array}{l}\text { Gestión de } \\
\text { Usuario }\end{array}$ & $\begin{array}{l}\text { Esta interfaz permite editar los datos de los usuarios existentes y a su vez generar } \\
\text { consultas. }\end{array}$ \\
\hline $\begin{array}{l}\text { Perfil de } \\
\text { Usuario }\end{array}$ & Los usuarios registrados pueden editar su información desde esta interfaz. \\
\hline $\begin{array}{l}\text { Gestión de } \\
\text { Proyectos }\end{array}$ & $\begin{array}{l}\text { Esta interfaz permite editar los datos de los proyectos existentes y a su vez generar } \\
\text { consultas. } \\
\text { Muestra los detalles de los proyectos registrados para cada empresa; desde esta } \\
\text { interfaz se podrán definir los detalles de los proyectos. }\end{array}$ \\
\hline $\begin{array}{l}\text { Registrar } \\
\text { Proyectos }\end{array}$ & Permite registrar proyectos de desarrollo de software. \\
\hline $\begin{array}{l}\text { Definir } \\
\text { Documentos }\end{array}$ & $\begin{array}{l}\text { Esta interfaz permite definir la estructura de los documentos según el proyecto } \\
\text { seleccionado. }\end{array}$ \\
\hline $\begin{array}{l}\text { Evaluar } \\
\text { Documentos }\end{array}$ & $\begin{array}{l}\text { Los usuarios podrán cargar documentos, los cuales serán evaluados y procesados } \\
\text { para extraer los resultados de los mismos. }\end{array}$ \\
\hline $\begin{array}{l}\text { Revisar } \\
\text { Resultados }\end{array}$ & $\begin{array}{l}\text { Permite revisar los resultados generar en la etapa de evaluación, según el proyecto } \\
\text { seleccionado. }\end{array}$ \\
\hline
\end{tabular}

Tabla 35 Diseño del sistema desarrollado

Fuente: Elaboración Propia.

\section{Formato de entrada y salida de los datos}

Entrada de datos:

- Datos de la empresa.

- Datos de los proyectos.

- Documentos 
Salida de datos:

- Resultados de evaluación

- $\quad$ Reportes en general

\section{Especificaciones para el almacenamiento de los datos}

Se utiliza una base de datos MySQL, la cual emplea el motor inno DB. Los datos serán almacenados en la base de datos de acuerdo a las siguientes pautas:

- Los valores numéricos enteros serán almacenados en campos de tipo INT.

- Los valores numéricos reales serán almacenados en campos de tipo DOUBLE.

- Los valores de tipo alfanumérico serán almacenados en campos de tipo VARCHAR. De acuerdo al propósito de cada elemento, la longitud del campo variara.

- Los valores de fechas serán almacenados en campos de tipo DATETIME. Estos campos guardaran información tanto de la fecha como de la hora. En caso de no ser necesario guardar la hora, se guardara por defecto la hora 00:00:00.

- Los valores que sirvan de indicadores o de estado serán almacenados en campos de tipo CHAR, puesto que su valor será solo de un carácter. Este deberá ser siempre una letra en mayúsculas.

\section{Convenciones de denominación de los datos}

En la Tabla 36 describimos las convenciones para el ingreso de datos.

\begin{tabular}{|l|l|}
\hline INTERFAZ & DESCRIPCIÓN \\
\hline Registro de Usuario & $\begin{array}{l}\text { El nombre puede tener } 20 \text { caracteres como máximo. } \\
\text { El apellido puede tener } 20 \text { caracteres como máximo. } \\
\text { Los campos correo electrónico deben ser emails válidos y ambos } \\
\text { deben de coincidir. } \\
\text { Las contraseñas deben tener un mínimo de } 8 \text { caracteres y hasta un } \\
\text { máximo de } 20 \text { caracteres. Ambas deben de coincidir. }\end{array}$ \\
\hline Registrar Empresas & $\begin{array}{l}\text { El nombre de la empresa puede tener } 40 \text { caracteres como máximo. } \\
\text { La razón social puede tener } 40 \text { caracteres como máximo. } \\
\text { El Ruc solo admite } 11 \text { caracteres. } \\
\text { El usuario responsable debe ser un email válido y debe de estar } \\
\text { disponible. } \\
\text { El logo debe ser una imagen y no puede superar en tamaño a 1MB }\end{array}$ \\
\hline Registrar Proyectos & $\begin{array}{l}\text { El nombre del proyecto debe tener un mínimo de } 6 \text { caracteres y } \\
\text { hasta un máximo de } 80 \text { caracteres. } \\
\text { El código debe tener un mínimo de } 4 \text { caracteres y hasta un máximo }\end{array}$ \\
\hline
\end{tabular}




\begin{tabular}{|l|l|}
\hline INTERFAZ & DESCRIPCIÓN \\
\hline & $\begin{array}{l}\text { de } 8 \text { caracteres. } \\
\text { La fecha de inicio debe de tener el formato AÑO - MES -DIA. } \\
\text { La fecha de fin debe de tener el formato AÑO - MES -DIA. } \\
\text { La fecha de inicio no puede ser mayor a la fecha de fin. } \\
\text { El responsable del proyecto debe ser un email válido, debe de } \\
\text { pertenecer a la empresa y debe ser un gestor de proyectos. } \\
\text { La descripción debe tener un mínimo de 15 caracteres y hasta un } \\
\text { máximo de 150 caracteres. }\end{array}$ \\
\hline Definir Documentos & Los documentos deben tener diferentes nombres. \\
\hline Evaluar Documentos & Los documentos deben tener las extensiones: .doc, .dox, .xls, .xlsx \\
\hline
\end{tabular}

Tabla 36 Convenciones de denominación de los datos

Fuente: Elaboración Propia.

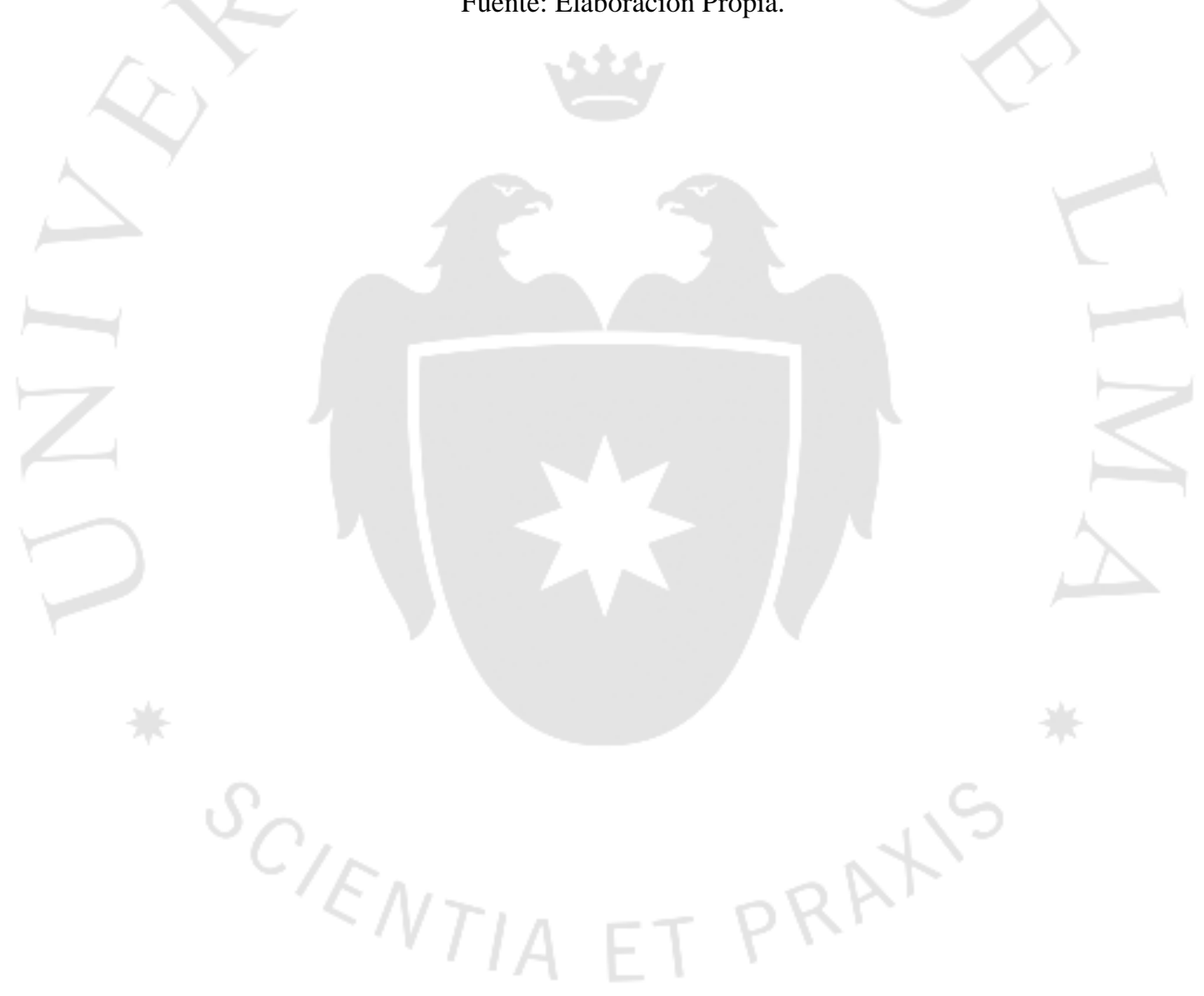




\section{Formato de las estructuras de datos}

En la Figura 37, presentamos la estructura de la base de datos de la aplicación, los atributos de cada una de sus entidades y su interrelación.

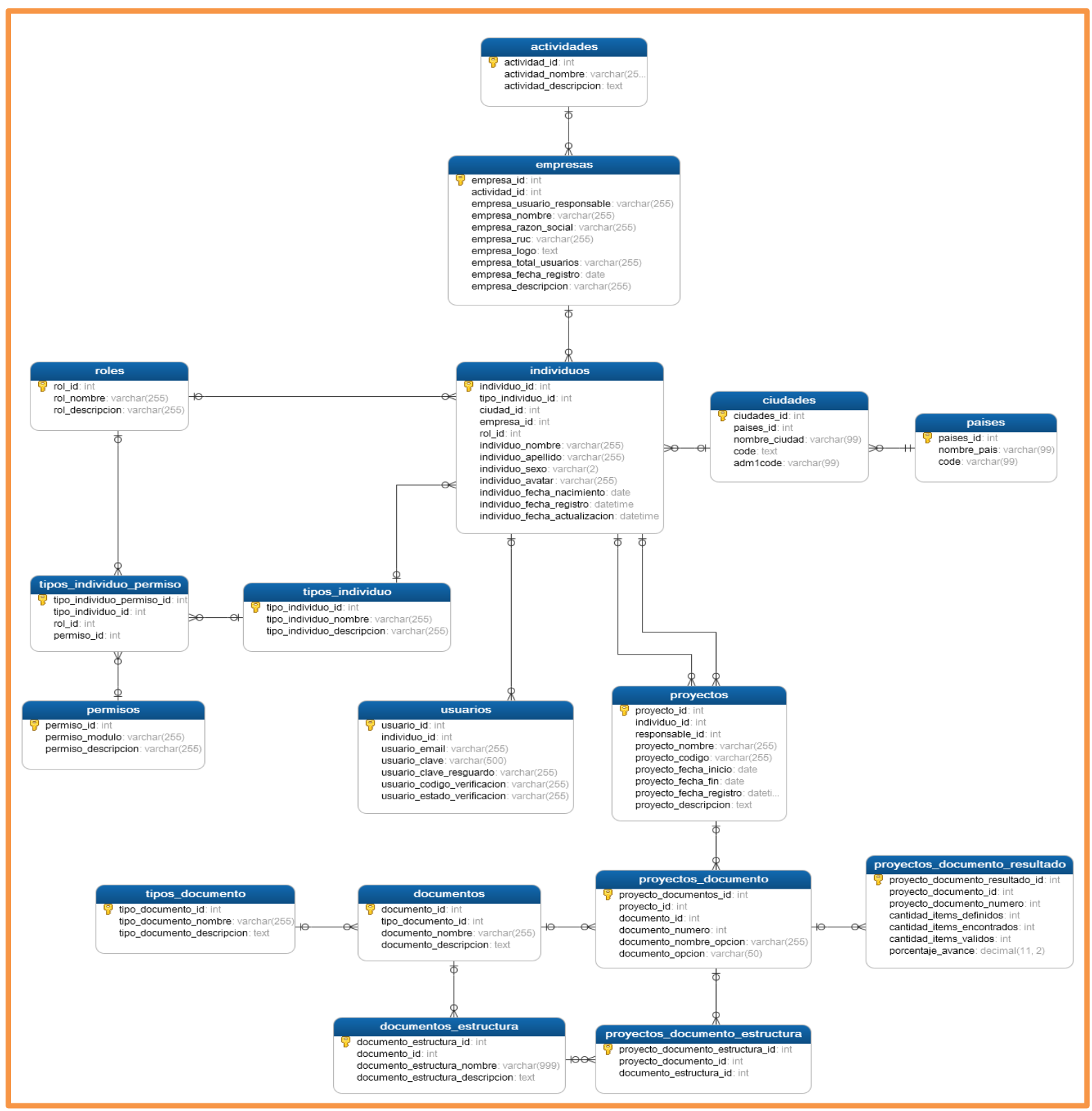

Figura 37 Estructura de datos de la herramienta desarrollada

Fuente: Elaboración Propia. 


\section{Campos de datos y el propósito de cada elemento de datos}

\begin{tabular}{|c|c|c|c|c|c|}
\hline $\begin{array}{l}\text { Nombre de la } \\
\text { Columna de la } \\
\text { Tabla }\end{array}$ & Nombre de la Columna & $\begin{array}{l}\text { Tipo de Dato } \\
\text { De la Columna }\end{array}$ & $\begin{array}{l}\text { Opciones } \\
\text { Null de la } \\
\text { Tabla } \\
\end{array}$ & $\begin{array}{l}\text { Columna } \\
\text { Primary } \\
\text { Key } \\
\end{array}$ & $\begin{array}{l}\text { Columna } \\
\text { Foreign } \\
\text { Key } \\
\end{array}$ \\
\hline \multirow[t]{3}{*}{ permisos } & permiso_id & CHAR(18) & NOT NULL & Yes & No \\
\hline & permiso_modulo & CHARACTER(20) & NULL & No & \\
\hline & permiso_descripcion & & & & \\
\hline \multirow[t]{3}{*}{$\begin{array}{l}\text { tipos_individuo } \\
\text { _permiso }\end{array}$} & permiso_id & CHAR(18) & & & Yes \\
\hline & tipo_individuo_id & 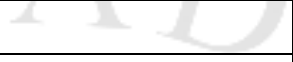 & & & \\
\hline & tipo_individuo_permiso_id & & NOT NULL & Yes & No \\
\hline \multirow[t]{3}{*}{ tipos_individuo } & tipo_individuo_id & & & & \\
\hline & tipo_individuo_nombre & CHARACTER(20) & NULL & No & \\
\hline & tipo_individuo_descripcion & & & & \\
\hline \multirow[t]{4}{*}{ individuos } & rol_id & CHAR(18) & & & Yes \\
\hline & empresa_id & -1 & & & 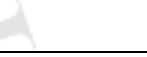 \\
\hline & ciudad_id & & & & \\
\hline & tipo_individuo_id & 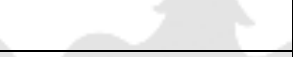 & 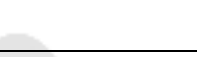 & & \\
\hline \multirow{2}{*}{ Hen } & individuo_id & & NOT NULL & Yes & No \\
\hline & individuo_nombre & CHARACTER(20) & NULL & No & \\
\hline \multirow{6}{*}{$\sqrt{2+2}$} & individuo_apellido & & & & 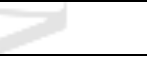 \\
\hline & individuo_sexo & & & & 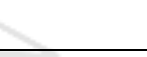 \\
\hline & individuo_fecha_nacimiento & DATE & & & \\
\hline & individuo_fecha_registro & & & & \\
\hline & individuo_fecha_actualizacion & & & & 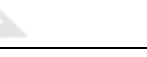 \\
\hline & individuo_avatar & CHARACTER & & & \\
\hline \multirow[t]{7}{*}{ usuarios } & usuario_id & CHAR(18) & NOT NULL & Yes & \\
\hline & individuo_id & & & + & Yes \\
\hline & usuario_email & CHARACTER(20) & NULL & No & No \\
\hline & usuario_clave & & & & \\
\hline & usuario_clave_reguardo & & & & \\
\hline & usuario_codigo_verificacion & & & & \\
\hline & usuario_estado_verificacion & 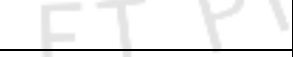 & & & \\
\hline \multirow[t]{3}{*}{ roles } & rol_id & CHAR(18) & NOT NULL & Yes & \\
\hline & rol_nombre & CHARACTER(20) & NULL & No & \\
\hline & rol_descripcion & & & & \\
\hline \multirow[t]{4}{*}{ empresa } & empresa_id & CHAR(18) & NOT NULL & Yes & \\
\hline & empresa_nombre & CHARACTER(20) & NULL & No & \\
\hline & empresa_descripcion & & & & \\
\hline & actividad_id & INTEGER & & & Yes \\
\hline ciudades & ciudad_id & CHAR(18) & NOT NULL & Yes & No \\
\hline
\end{tabular}




\begin{tabular}{|c|c|c|c|c|c|}
\hline $\begin{array}{l}\text { Nombre de la } \\
\text { Columna de la } \\
\text { Tabla }\end{array}$ & Nombre de la Columna & $\begin{array}{l}\text { Tipo de Dato } \\
\text { De la Columna }\end{array}$ & \begin{tabular}{|l|} 
Opciones \\
Null de la \\
Tabla \\
\end{tabular} & \begin{tabular}{|l|} 
Columna \\
Primary \\
Key
\end{tabular} & \begin{tabular}{|l|} 
Columna \\
Foreign \\
Key \\
\end{tabular} \\
\hline & ciudad_nombre & CHARACTER(20) & NULL & No & \\
\hline & ciudad_code & & & & \\
\hline & ciudad_adm1code & & & & \\
\hline & pais_id & CHAR(18) & & & Yes \\
\hline \multirow[t]{3}{*}{ países } & & & NOT NULL & Yes & No \\
\hline & pais_nombre & CHARACTER(20) & NULL & No & \\
\hline & pais_descripcion & 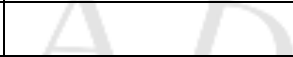 & & & \\
\hline \multirow[t]{3}{*}{$\begin{array}{l}\text { tipos_de_docu } \\
\text { mento }\end{array}$} & tipo_documento_id & INTEGER & NOT NULL & Yes & \\
\hline & tipo_documento_nombre & CHARACTER(20) & NULL & No & \\
\hline & tipo_documento_descripcion & CHARACTER & + & 8 & \\
\hline \multirow[t]{4}{*}{ documentos } & documento_id & INTEGER & NOT NULL & Yes & \\
\hline & documento_nombre & CHARACTER(20) & NULL & No & \\
\hline & documento_descripcion & CHARACTER & & & \\
\hline & tipo_documento_id & INTEGER & & $\square$ & Yes \\
\hline \multirow[t]{3}{*}{\begin{tabular}{|l|}
$\begin{array}{l}\text { documentos_es } \\
\text { tructura }\end{array}$ \\
\end{tabular}} & documento_estructura_id & & NOT NULL & Yes & No \\
\hline & documento_estructura_nombre & CHARACTER(20) & NULL & No & + \\
\hline & $\begin{array}{l}\text { documento_estructura_descripc } \\
\text { i }\end{array}$ & CHARACTER & & & \\
\hline 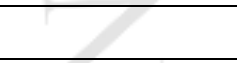 & documento_id & INTEGER & 8 & - & Yes \\
\hline \multirow[t]{5}{*}{$\begin{array}{l}\begin{array}{l}\text { proyectos_docu } \\
\text { mento }\end{array} \\
\end{array}$} & proyecto_id & & & & 8 \\
\hline & proyecto_documento_id & 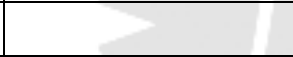 & NOT NULL & Yes & No \\
\hline & documento_numero & CHARACTER(20) & NULL & No & $D$ \\
\hline & documento_nombre_opcion & & & & \\
\hline & documento_opcion & & & & \\
\hline & documento_id & INTEGER & & $y^{2}$ & Yes \\
\hline \multirow[t]{3}{*}{$\begin{array}{l}\text { proyectos_docu } \\
\text { mento_estructu } \\
\text { ra }\end{array}$} & proyecto_documento_id & & NOT NULL & Yes & \\
\hline & $\begin{array}{l}\text { proyecto_documento_estructur } \\
\text { a_ }\end{array}$ & & & & No \\
\hline & documento_estructura_id & $5=$ & NULL & No & Yes \\
\hline \multirow[t]{6}{*}{$\begin{array}{l}\text { proyectos_docu } \\
\text { mento_resultad } \\
\text { o }\end{array}$} & proyecto_documento_id & {$[1$} & NOT NULL & Yes & \\
\hline & $\begin{array}{l}\text { proyecto_documento_resultado } \\
\text { i }\end{array}$ & & & & No \\
\hline & $\begin{array}{l}\text { proyecto_documento_resultado } \\
\text { nn }\end{array}$ & CHARACTER(20) & NULL & No & \\
\hline & cantidad_items_definidos & INTEGER & & & \\
\hline & cantidad_items_encontrados & & & & \\
\hline & cantidad_items_validos & & & & \\
\hline
\end{tabular}




\begin{tabular}{|l|l|l|l|l|l|}
\hline $\begin{array}{l}\text { Nombre de la } \\
\text { Columna de la } \\
\text { Tabla }\end{array}$ & Nombre de la Columna & $\begin{array}{l}\text { Tipo de Dato } \\
\text { De la Columna }\end{array}$ & $\begin{array}{l}\text { Opciones } \\
\text { Null de la } \\
\text { Tabla }\end{array}$ & $\begin{array}{l}\text { Columna } \\
\text { Primary } \\
\text { Key }\end{array}$ & $\begin{array}{l}\text { Columna } \\
\text { Foreign } \\
\text { Key }\end{array}$ \\
\hline & porcentaje_avance & FLOAT & & & \\
\hline proyectos & individuo_id & CHAR(18) & & & Yes \\
\hline & proyecto_id & INTEGER & NOT NULL & Yes & No \\
\hline & proyecto_nombre & CHARACTER(20) & NULL & No & \\
\hline & proyecto_codigo & & & & \\
\hline & proyecto_fecha_inicio & DATE & & & \\
\hline & proyecto_fecha_fin & & & & \\
\hline & proyecto_fecha_registro & Z & & & \\
\hline & proyecto_descripcion & CHARACTER & & & \\
\hline & actividad_id & INTEGER & NOT NULL & Yes & \\
\hline & actividad_nombre & CHARACTER(20) & NULL & No & \\
\hline & actividad_descripcion & CHARACTER & & & \\
\hline & & & & & \\
\hline
\end{tabular}

Tabla 37 Campo de datos de la herramienta desarrollada

Fuente: Elaboración Propia.

\section{Especificaciones de la estructura del programa}

Paradigma de programación Orientado a Objetos

\section{CLIENTE}

Petición del Cliente

\section{SERVIDOR}

Respuesta del Servidor

JavaScript - Ajax.- Leguaje que realiza

el Procesamiento de la información.

PHP.- Lenguaje que almacena la Lógica del sistema.

Tabla 38 Especificación de la estructura del programa

Fuente: Elaboración Propia.

\subsubsection{Documentos referentes a la herramienta}

En la Tabla 39, se muestra la lista de documentos elaborados en el proceso de desarrollo de la herramienta de software: 


\begin{tabular}{|l|l|l|l|}
\hline $\begin{array}{l}\text { Código del } \\
\text { Documento }\end{array}$ & $\begin{array}{l}\text { Nombre Del } \\
\text { Documento }\end{array}$ & Descripción & Anexo \\
\hline A001CP & $\begin{array}{l}\text { Casos y } \\
\text { Procedimientos de } \\
\text { Prueba }\end{array}$ & $\begin{array}{l}\text { Documento donde se describe los } \\
\text { elementos necesarios como también } \\
\text { los casos y procedimientos para } \\
\text { probar la herramienta. }\end{array}$ & $\begin{array}{l}\text { Anexo 7.1 Casos y } \\
\text { Procedimientos de } \\
\text { Prueba }\end{array}$ \\
\hline A001MU & $\begin{array}{l}\text { Manual de } \\
\text { Usuario }\end{array}$ & $\begin{array}{l}\text { Documento donde se describe el uso } \\
\text { del software en base a la interfaz de } \\
\text { usuario. }\end{array}$ & $\begin{array}{l}\text { Anexo 7.2 Manual de } \\
\text { Usuario }\end{array}$ \\
\hline
\end{tabular}

Tabla 39 Listado de Documentos referentes al software desarrollado

Fuente: Elaboración Propia

Adicionalmente, en el Anexo 8 presentamos una comparación de la herramienta desarrollada y las herramientas utilizadas por la empresa de estudio para la gestión de proyectos y control de versiones.

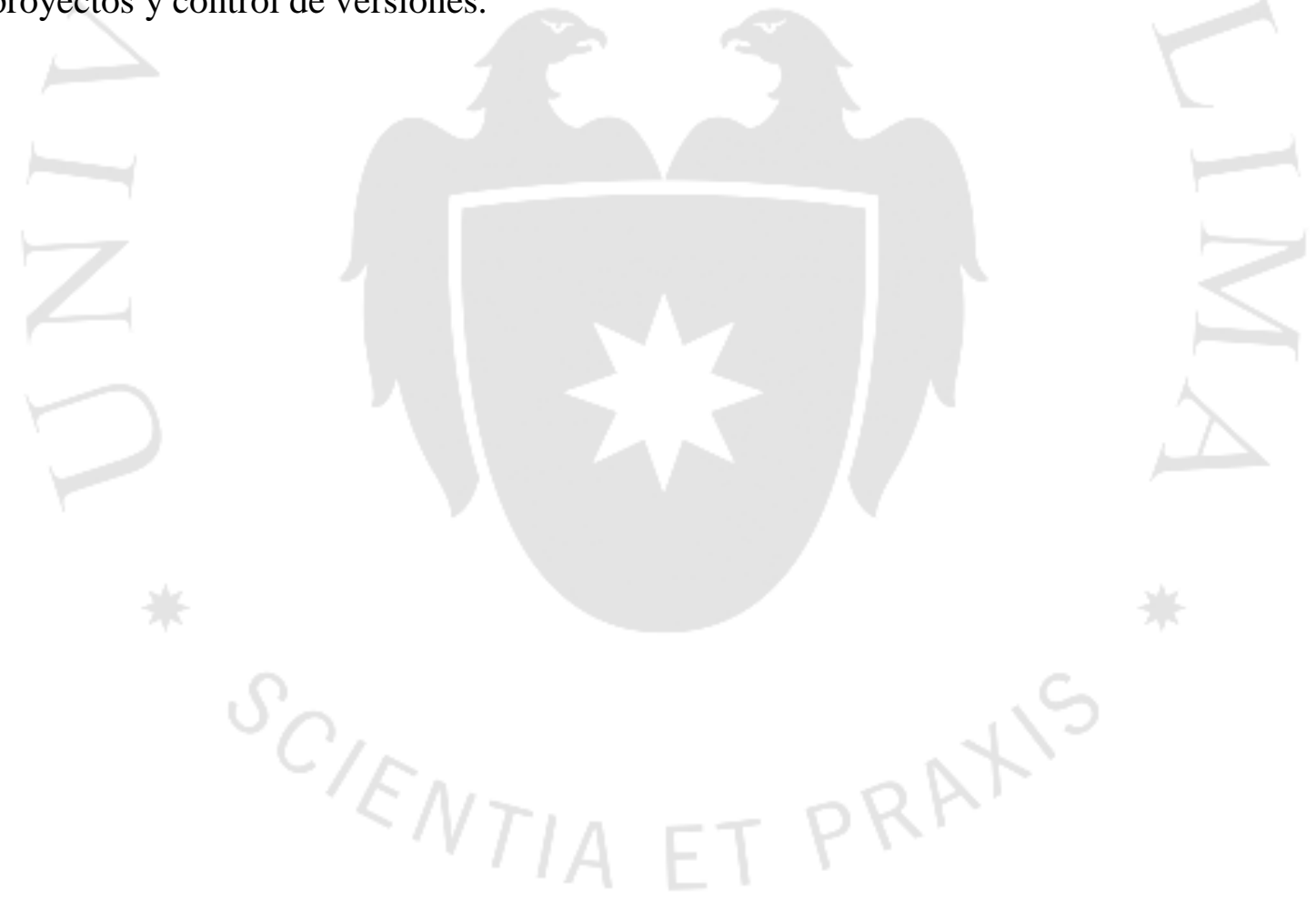




\section{CAPÍTULO VI: VERIFICACIÓN Y VALIDACIÓN}

\subsection{Análisis de resultados del Modelo de Mejora}

A continuación se presenta las observaciones y recomendaciones del equipo de trabajo de la empresa HOLINSYS respecto al Modelo de mejora entregado:

Evaluación y análisis del ciclo de vida del desarrollo de software

\begin{tabular}{|l|l|}
\hline Evaluación y Análisis & Observaciones y Recomendaciones \\
\hline Evaluación del Ciclo de & ¿Están conformes con los resultados de la evaluación? \\
Vida del Desarrollo de & -Resultado conforme, el diagrama Gestión del Proyecto e Implementación \\
Software: & de Software reflejan las actividades realizadas por la empresa HOLINSYS. \\
& -Se hace énfasis en que la actividad de Elaboración de la Propuesta del \\
-Gestión del Proyecto & Proyecto es realizada por el Área Comercial de la empresa. \\
Software &
\end{tabular}

Tabla 40 Observaciones y Recomendaciones respecto a la evaluación de la organización Fuente: Elaboración Propia

Propuesta de Mejora de los Productos de Trabajo

\begin{tabular}{|l|l|}
\hline Propuesta de Mejora & Observaciones y Recomendaciones \\
\hline Productos de Trabajo & $\begin{array}{l}\text { ¿Los productos de trabajo propuestos pueden ser implementados por la } \\
\text { organización? } \\
\text {-La empresa considera que los productos de trabajo presentados pueden ser } \\
\text { implementados en los proyectos de desarrollo de software realizados, debido } \\
\text { a que estos documentos reflejan la forma de trabajo de la empresa. } \\
\text { ¿Consideran que el producto de trabajo tiene alta complejidad? } \\
\text {-Se considera que en su mayoría los productos de trabajo son intuitivos y } \\
\text { fáciles de entender, sin embargo se presentan observaciones referentes a la } \\
\text { complejidad de los siguientes documentos: Registro de Verificación, } \\
\text { Registro de Validación, Acta de Reunión. } \\
\text { Se explicó la importancia de la sección "Estado del Documento" según lo } \\
\text { descrito en la ISO 29110-5-1-2, debido a que en un inicio no se entendía } \\
\text { claramente su uso e importancia. } \\
\text { ¿Genera valor a la empresa? } \\
\text {-Se considera que los productos de trabajo presentan un alto valor a la } \\
\text { empresa porque son considerados como una herramienta necesaria para el } \\
\text { cumplimiento de su objetivo: “Certificarse en la ISO 29110". } \\
\text { La empresa entiende que utilizar los productos de trabajo genera valor en los } \\
\text { proyectos de desarrollo de software realizados. }\end{array}$ \\
\hline
\end{tabular}




\begin{tabular}{|l|l|}
\hline Propuesta de Mejora & Observaciones y Recomendaciones \\
\hline $\begin{array}{l}\text { Registro de Verificación y } \\
\text { Registro de Validación }\end{array}$ & $\begin{array}{l}\text { ¿Consideran que los productos de trabajo "Registro de Verificación y } \\
\text { Registro de Validación" tienen alta complejidad? } \\
\text {-Inicialmente, se consideró que estos productos eran complejos debido a que } \\
\text { no son utilizados por la empresa y no todo el equipo estaba familiarizado con } \\
\text { los términos "verificación y validación". } \\
\text { ¿Genera valor a la empresa? } \\
\text {-Luego de explicar a la empresa el significado de los términos "Verificación } \\
\text { y Validación", la empresa entendió el valor agregado que la implementación } \\
\text { de estos productos generaría en sus procesos. }\end{array}$ \\
\hline $\begin{array}{l}\text { Acta de Reunión } \\
\text { ¿Consideran que el producto de trabajo "Acta de Reunión" tiene alta } \\
\text { complejidad? } \\
\text {-Se considera que el registro de ciertas secciones del documento generan un } \\
\text { tiempo de desarrollo adicional para la empresa. Estas secciones son: Otros y } \\
\text { Seguimiento. } \\
\text { ¿Genera valor a la empresa? } \\
\text {-Sí, debido a que la mayoría de secciones del producto de trabajo reflejan las } \\
\text { actividades realizadas en la organización. }\end{array}$ \\
\hline $\begin{array}{l}\text { Manuales: } \\
\text {-Manual de Usuario } \\
\text { de Manual } \\
\text {-Manual de Operación }\end{array}$ & $\begin{array}{l}\text { La empresa entiende que los manuales generan valor a los proyectos, sin } \\
\text { embargo, su ejecución se realiza según lo solicitado por el cliente. }\end{array}$ \\
\hline
\end{tabular}

Tabla 41 Observaciones y Recomendaciones respecto a la Propuesta de Mejora de los Productos de Trabajo Fuente: Elaboración Propia

\section{Manuales de funciones:}

\begin{tabular}{|c|c|}
\hline Manuales de funciones & Observaciones y Recomendaciones \\
\hline $\begin{array}{l}\text { MOF } \\
\text {-Analista de Calidad } \\
\text {-Programador } \\
\text {-Gestor del proyecto } \\
\text {-Líder Técnico }\end{array}$ & $\begin{array}{l}\text { ¿Los documentos pueden ser Implementados por la organización? } \\
\text {-Las funciones descritas en los manuales reflejan las actividades de los roles } \\
\text { de la empresa. } \\
\text {-El Manual de Funciones del Analista de Calidad ofrece mucho valor a la } \\
\text { empresa y está siendo revisado por el Área de Recursos Humanos, debido a } \\
\text { que este rol es nuevo en la empresa y posteriormente ser implementado como } \\
\text { parte de sus documentos de referencia. Cabe resaltar que este documento } \\
\text { cumple su papel al reflejar las tareas que el Analista de calidad hará para } \\
\text { apoyar en el cumplimiento de la ISO } 29110 \text {. } \\
\text { ¿Es Intuitivo y fácil de entender? } \\
\text {-La descripción de las funciones es clara y fácil de entender. } \\
\text { ¿Genera valor a la empresa? } \\
\text {-Sí, debido a que para la empresa es importante tener documentos de } \\
\text { referencia donde se expliquen cuáles son las funciones que debe realizar cada } \\
\text { miembro del equipo de trabajo. }\end{array}$ \\
\hline
\end{tabular}

Tabla 42 Observaciones y Recomendaciones respecto a los manuales de funciones Fuente: Elaboración Propia 


\subsection{Análisis de resultados de la Herramienta de Software}

En la Tabla 43, se presenta las observaciones y recomendaciones del equipo de trabajo de la empresa HOLINSYS respecto a las funcionalidades principales de la herramienta de software desarrollada:

\begin{tabular}{|l|l|}
\hline $\begin{array}{l}\text { Funcionalidades } \\
\text { Principales }\end{array}$ & Observaciones y Recomendaciones \\
\hline $\begin{array}{l}\text { Función Definir } \\
\text { Documentos }\end{array}$ & $\begin{array}{l}\text { Para agilizar esta funcionalidad, se recomienda poder agregar perfiles de } \\
\text { Definición de Documentos a los proyectos. Por ejemplo: } \\
\text { Perfil Genérico: Todos los Documentos y secciones de estos son obligatorios } \\
\text { para verificar el cumplimiento del Proyecto. }\end{array}$ \\
\hline Función Evaluar Proyecto & $\begin{array}{l}\text { Esta funcionalidad ofrece valor a la organización porque facilitaría el } \\
\text { seguimiento de los proyectos realizados, en especial por el Dashboard, donde } \\
\text { se muestra el nivel de cumplimiento de todos los proyectos. }\end{array}$ \\
\hline
\end{tabular}

Tabla 43 Observaciones y Recomendaciones respecto a la herramienta de software desarrollada Fuente: Elaboración Propia

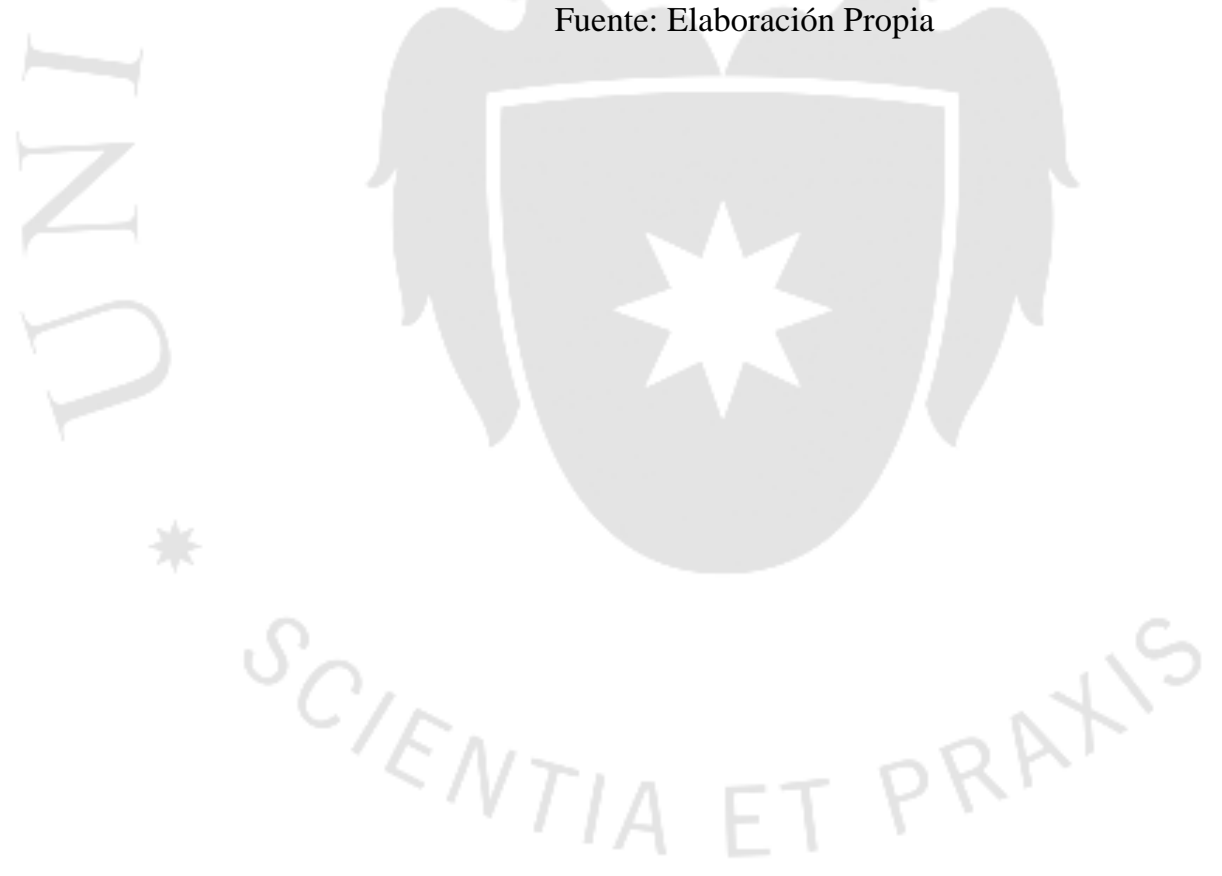




\section{CAPÍTULO VII: CONCLUSIONES Y RECOMENDACIONES}

\subsection{Conclusiones}

1. Al evaluar el ciclo de vida del desarrollo de software de la empresa no solamente se identificaron brechas sino también, durante la evaluación el gerente y el equipo de trabajo identifico actividades no realizadas por ellos y que generan valor a la empresa.

2. Una buena práctica para impulsar la adopción de nuevos productos de trabajo en el flujo de actividades de desarrollo de software, es que el equipo de trabajo reconozca la importancia y valor agregado de su uso. De esta manera el equipo de trabajo estará dispuesto a realizar sus nuevas tareas y actividades.

3. Debido a que una certificación requiere un esfuerzo adicional por parte del equipo de trabajo para adaptar sus procesos. En un inicio, este puede considerar que su forma de trabajo es la ideal y que no se requiere realizar cambios significativos como aumentar la documentación generada.

4. Al desarrollar los manuales de funciones de un equipo de trabajo se debe reflejar las actividades requeridas en los proyectos de desarrollo de software según la ISO 29110 , teniendo como base las funciones actuales desempeñadas por el equipo de trabajo.

5. En el presente trabajo de investigación se desarrolló el plan de implementación del modelo de mejora con la finalidad que la empresa lo implemente en sus proyectos al corto plazo.

6. Al desarrollar la herramienta de desarrollo de software se demostró la importancia de las actividades de análisis y diseño del software, debido a que ayudan a describir el alcance y los requerimientos del software como también los componentes y herramientas requeridas antes de iniciar con la codificación. 


\subsection{Recomendaciones}

1. Se puede asegurar el compromiso del equipo de trabajo fomentando su participación en la evaluación de los proyectos de la organización y dando a conocer los beneficios de la certificación para la empresa como también a su experiencia laboral.

2. Al momento de adaptar los procesos de una empresa teniendo como objetivo una certificación, se debe tomar en cuenta mantener las fortalezas de la empresa para hacer eficiente el proceso de adaptación y que la empresa mantenga su propuesta de valor como también para reducir la resistencia al cambio

3. Una buena práctica para el desarrollo de una herramienta de software que asegura el cumplimiento de un modelo es entender a la empresa que desea implementar este modelo e identificar que actividades se pueden automatizar para apoyar a la empresa.

4. Al momento de desplegar una herramienta web se recomienda el trabajar con un proveedor debido a la información brindada respecto a las características del Hosting y dominio de la herramienta desarrollada.

5. Para asegurar el entendimiento del valor generado por la herramienta, se recomienda demostrar como facilita el cumplimiento de la norma utilizando un caso de prueba similar a los desarrollados en los proyectos de la empresa. 


\section{GLOSARIO DE TÉRMINOS}

A continuación se presenta en orden alfabético el glosario de los términos vistos a lo largo del presente trabajo de investigación:

\section{Actividad:}

(NTP-RT-ISO/IEC TR 29110-5-1-2, 2012, pág. 4)

Conjunto de Tareas cohesionadas. La Tarea es un requisito, recomendación o acción permisible, que pretende contribuir al logro de uno o más objetivos de un proceso. Una actividad del proceso es el primer nivel de descomposición del flujo de trabajo del proceso y el segundo nivel es una Tarea.

\section{Aseguramiento de la calidad:}

(ISO 9000, 2005, pág. 10)

Parte de la gestión de la calidad orientada a proporcionar confianza en que se cumplirán los requisitos de la calidad.

\section{Auditoría:}

(NTP-ISO/IEC 12207, 2006, pág. 6)

Proceso sistemático, independiente y documentado para obtener evidencias de la auditoría y evaluarlas de manera objetiva con el fin de determinar la extensión en que se cumplen los criterios de auditoría.

\section{NOTA:}

Las auditorías internas, denominadas en algunos casos como auditorías de primera parte, se realizan por, o en nombre, de la propia organización para fines internos y puede constituir la base para la auto-declaración de conformidad de una organización.

Las auditorías externas incluyen lo que se denomina generalmente "auditorías de segunda o tercera parte": 
Las auditorías de segunda parte se llevan a cabo por partes que tienen un interés en la organización, tal como los clientes, o por otras personas en su nombre.

Las auditorías de tercera parte se llevan a cabo por organizaciones independientes externas. Tales organizaciones proporcionan la certificación o el registro de conformidad con requisitos como los de las Normas NTP-ISO 9001 e ISO 14001.

Cuando se auditan sistemas de gestión ambiental y de las calidades juntas, se denomina "auditoría combinada".

Cuando dos o más organizaciones auditoras cooperan para auditar a un único auditado, se denomina "auditoría conjunta".

La auditoría se refiere a productos y procesos de software. (NTP-ISO 9000).

\section{Calidad:}

(ISO 9000, 2005, pág. 8)

Grado en el que un conjunto de características inherentes cumple con los requisitos.

NOTA 1: El término "calidad" puede utilizarse acompañado de adjetivos tales como pobre, buena o excelente.

NOTA 2: "Inherente", en contraposición a "asignado", significa que existe en algo, especialmente como una característica permanente.

\section{Calificación:}

(NTP-ISO/IEC 12207, 2006, pág. 7)

Proceso para demostrar la capacidad para cumplir los requisitos especificados.

\section{NOTAS:}

1. El término "calificado" se utiliza para designar el estado correspondiente. 
2. La calificación se puede aplicar a personas, productos, procesos o sistemas. Por ejemplo: Proceso de calificación del auditor, proceso de calificación del material. (NTPISO 9000).

\section{Certificación:}

(ISO Certification, 2015)

La certificación puede ser una herramienta útil para agregar credibilidad, al demostrar que su producto o servicio cumple con las expectativas de sus clientes. Para algunas industrias, la certificación es un requisito legal o contractual.

ISO no realiza una certificación, esto se lleva a cabo por los organismos de certificación externos, por lo que una empresa u organización no pueden ser certificadas por la ISO.

\section{Conclusiones de la auditoría}

(ISO 9000, 2005, pág. 19)

Resultado de una auditoría que proporciona el equipo auditor tras considerar los objetivos de la auditoría y todos los hallazgos de la auditoría.

\section{Control de la calidad}

(ISO 9000, 2005, pág. 10)

Parte de la gestión de la calidad orientada al cumplimiento de los requisitos de la calidad.

\section{Defecto}

(ISO 9000, 2005, pág. 15)

Incumplimiento de un requisito asociado a un uso previsto o especificado

NOTA 1 La distinción entre los conceptos defecto y no conformidad es importante por sus connotaciones legales, particularmente aquellas asociadas a la responsabilidad legal de los productos puestos en circulación. Consecuentemente, el término "defecto" debería utilizarse con extrema precaución. 
NOTA 2 El uso previsto tal y como lo prevé el cliente podría estar afectado por la naturaleza de la información proporcionada por el proveedor, como por ejemplo las instrucciones de funcionamiento o de mantenimiento.

\section{Elemento de configuración:}

(NTP-ISO/IEC 12207, 2006, pág. 7)

Entidad dentro de una configuración que satisface una funcionalidad y que puede ser unívocamente identificada en un punto de referencia dado.

\section{Evaluación:}

(NTP-ISO/IEC 12207, 2006, pág. 8)

Determinación sistemática del grado en que una entidad cumple con los criterios especificados para ella.

\section{Evidencia de la auditoría}

(ISO 9000, 2005, pág. 19)

Registros, declaraciones de hechos o cualquier otra información que son pertinentes para los criterios de auditoría y que son verificables. La evidencia de la auditoría puede ser cualitativa o cuantitativa.

\section{Implementar:}

(Real Academia Española, 2015)

Poner en funcionamiento, aplicar métodos, medidas, etc., para llevar algo a cabo.

\section{Hallazgos de la auditoría}

(ISO 9000, 2005, pág. 19)

Resultados de la evaluación de la evidencia de la auditoría recopilada frente a los criterios de auditoría.

NOTA Los hallazgos de la auditoría pueden indicar conformidad o no conformidad con los criterios de auditoría, u oportunidades de mejora. 


\section{Línea base:}

(NTP-ISO/IEC 12207, 2006, pág. 8)

Versión formalmente aprobada de un elemento de configuración, independientemente del soporte, formalmente identificada y fijada en un momento dado de su ciclo de vida.

\section{Manual de Funciones:}

(República del Perú. , 2013)

Documento de gestión que describe las funciones específicas a nivel de cargos, desarrollados a partir de la estructura orgánica y funciones generales en el Reglamento de Organización y Funciones - ROF.

\section{Mejora continua:}

(ISO 9000, 2005, pág. 10)

Actividad recurrente para aumentar la capacidad para cumplir los requisitos.

NOTA El proceso mediante el cual se establecen objetivos y se identifican oportunidades para la mejora es un proceso continuo a través del uso de los hallazgos de la auditoría, las conclusiones de la auditoría, el análisis de los datos, la revisión por la dirección u otros medios, y generalmente conduce a la acción correctiva y preventiva.

\section{Modelo:}

(Real Academia Española, 2015)

Arquetipo o punto de referencia para imitarlo o reproducirlo.

Esquema teórico, generalmente en forma matemática, de un sistema o de una realidad compleja, como la evolución económica de un país, que se elabora para facilitar su comprensión y el estudio de su comportamiento.

\section{Modelo del ciclo de vida:}

(NTP-ISO/IEC 12207, 2006, pág. 8)

Marco de referencia que contiene los procesos, actividades y tareas involucradas en el 
desarrollo, operación y mantenimiento de un producto software y que abarca toda la vida del sistema desde la definición de sus requerimientos hasta el final de su uso.

\section{Modelo de mejora continua:}

(INSTITUTO NACIONAL DE CALIDAD, 2010)

Los Modelos de Mejora Continua son la principal herramienta del Premio Nacional de Calidad. Constituyen no solamente un instructivo para preparar un reporte para participar del Proceso del Premio, sino que también apuntan a ser:

Una definición de hecho de lo que se propone como Gestión Total de Calidad.

Una metodología completa que permite el autodiagnóstico.

Una guía didáctica sobre sistemas de Gestión de la Calidad.

El modelo de Mejora Continua es adaptable y no es prescriptivo. No pretende especificar el cómo ni el qué acciones tomar, sino indicar cuáles son las áreas que deberían abarcarse en un proceso de mejora.

\section{Paquete de Despliegue:}

(NTP-RT-ISO/IEC TR 29110-5-1-2, 2012, pág. 67)

Un Paquete de Despliegue es un conjunto de artefactos desarrollados para facilitar la implementación de un conjunto de prácticas, de las seleccionadas del Marco de Trabajo, en una PO. Pero, un Paquete de Despliegue no es un modelo de proceso de referencia completo. Los Paquetes de Despliegue no están diseñados con el propósito de impedir o desalentar el uso de directrices adicionales que las PO encuentren útiles.

\section{Proceso:}

(NTP-ISO/IEC 12207, 2006, pág. 8)

Conjunto de actividades mutuamente relacionadas o que interactúan, las cuales transforman elementos de entrada en resultados. 


\section{NOTAS:}

1. Los elementos de entrada de un proceso son generalmente resultados de otros procesos.

2. Los procesos de una organización son generalmente planificados y puestos en práctica bajo condiciones controladas para aportar valor.

3. Un proceso en el cual la conformidad del producto resultante, no pueda ser fácil o económicamente verificada, se denomina habitualmente "proceso especial".

\section{Producto}

(ISO 9000, 2005, pág. 12)

Resultado de un proceso.

\section{Producto de entrada:}

(NTP-RT-ISO/IEC TR 29110-5-1-2, 2012, pág. 3)

Productos necesarios para realizar el proceso y su origen correspondiente, que puede ser otro proceso o una entidad externa al proyecto, como el Cliente.

\section{Producto software:}

(NTP-ISO/IEC 12207, 2006, pág. 9)

Conjunto de programas de computadora, procedimientos y posible documentación y datos asociados.

\section{Productos de salida:}

(NTP-RT-ISO/IEC TR 29110-5-1-2, 2012, pág. 3)

Productos generados por el proceso y su destino correspondiente, que puede ser otro proceso o una entidad externa al proyecto, como el Cliente o la Alta Dirección.

\section{Productos internos:}

(NTP-RT-ISO/IEC TR 29110-5-1-2, 2012, pág. 3)

Productos generados y consumidos por el proceso.

\section{Proveedor:}

(NTP-ISO/IEC 12207, 2006, pág. 9) 
Organización que es contratada por el adquiriente para el suministro de un sistema, producto software o servicio software, bajo los términos del contrato.

\section{NOTAS:}

1. El término "proveedor" es sinónimo de contratista, fabricante, suministrador, productor o vendedor.

2. El adquiriente puede designar a parte de su organización como proveedor.

\section{Proyecto}

(PMBOK, 2008, pág. 5)

Un proyecto es un esfuerzo temporal que se lleva a cabo para crear un producto, servicio o resultado único. La naturaleza temporal de los proyectos indica un principio y un final definidos.

Todo proyecto crea un producto, servicio o resultado único. Aunque puede haber elementos repetitivos en algunos resultados del proyecto, esta repetición no altera la unicidad fundamental del trabajo del proyecto.

\section{Sistema}

(ISO 9000, 2005, pág. 9)

Conjunto de elementos mutuamente relacionados o que interactúan.

\section{Sistema de gestión}

(ISO 9000, 2005, pág. 9)

Sistema para establecer la política y los objetivos y para lograr dichos objetivos

NOTA Un sistema de gestión de una organización podría incluir diferentes sistemas de gestión, tales como un sistema de gestión de la calidad, un sistema de gestión financiera o un sistema de gestión ambiental. 


\section{Sistema de gestión de la calidad}

(ISO 9000, 2005, pág. 9)

Sistema de gestión para dirigir y controlar una organización con respecto a la calidad.

\section{Tarea:}

(NTP-RT-ISO/IEC TR 29110-5-1-2, 2012)

La Tarea es un requisito, recomendación o acción permisible, que pretende contribuir al logro de uno o más objetivos de un proceso.

\section{Usuario:}

(NTP-ISO/IEC 12207, 2006, pág. 11)

Individuo u organización que utiliza el sistema en operación para llevar a cabo una función específica.

NOTA: El usuario puede llevar a cabo otros papeles, tales como el de adquiriente, desarrollador, o responsable de mantenimiento.

\section{Validación:}

(NTP-ISO/IEC 12207, 2006, pág. 11)

Confirmación mediante el suministro de evidencia objetiva de que se han cumplido los requerimientos para una utilización o aplicación específica prevista.

\section{NOTAS:}

1. El término "validado" se utiliza para designar el estado correspondiente.

2. Las condiciones de utilización para validación pueden ser reales o simuladas. (NTP-ISO 9000).

\section{Verificación:}

(NTP-ISO/IEC 12207, 2006, pág. 11)

Confirmación mediante la aportación de evidencia objetiva de que se han cumplido los requerimientos especificados. 


\section{NOTAS:}

1. El término "verificado" se utiliza para designar el estado correspondiente.

2. La confirmación puede comprender acciones tales como:

- la elaboración de cálculos alternativos,

- la comparación de una especificación de un diseño nuevo con una especificación de un diseño similar aprobado,

- la realización de ensayos/pruebas y demostraciones y

- la revisión de los documentos antes de su actualización. (NTP-ISO 9000).

\section{Versión:}

(NTP-ISO/IEC 12207, 2006, págs. 11-12)

Ejemplar identificado de un elemento de configuración.

NOTA: Modificar una versión de un producto software dando como resultado una nueva versión, requiere una acción de gestión de configuración.

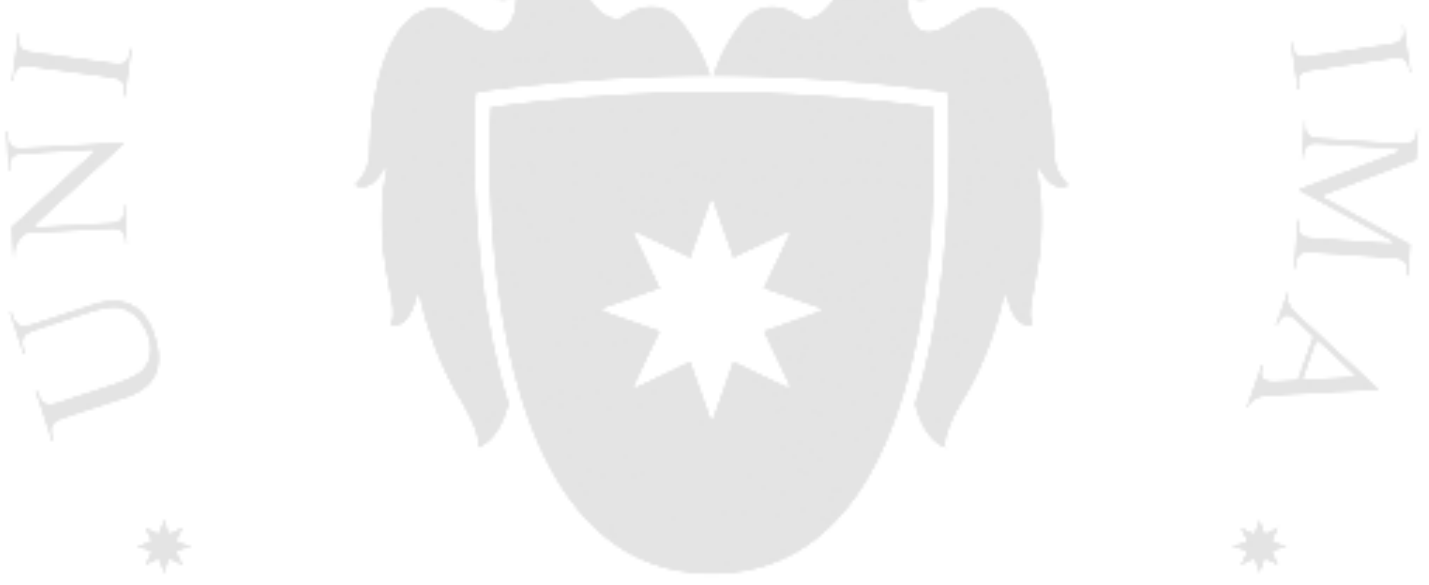




\section{REFERENCIAS}

Alarcón, González \& Rodríguez. (2011). http://revistavirtual.ucn.edu.co/. Recuperado el

10 de 07 de 2015 , de

http://revistavirtual.ucn.edu.co/index.php/RevistaUCN/article/viewFile/339/651

Arbulú, J. (13 de Abril de 2007). PYME: LA SOCIA MAYORITARIA DEL PERÚ. Diario El Peruano.

CMMI Architecture Team. (2007). Introduction to the Architecture of the CMMI® Framework.

COMPETISOFT. (2008). Mejora de Procesos para Fomentar la Competitividad de la Pequeña y Mediana Industria del Software de Iberoamérica.

Congreso de la República. (30 de Septiembre de 2008). DECRETO SUPREMO N ${ }^{o} 007$ 2008-TR. Obtenido de http://www.sunat.gob.pe/orientacion/mypes/normas/ds0072008.pdf

Debrauwer, L. H. (2013). UML 2 : iniciación, ejemplos y ejercicios corregidos .

Equipo del Producto CMMI. (2010). CMMI® para Desarrollo, Versión 1.3. CMMI-DEV, V1.3.

Esponda, S. \& Pesado P. (2011). http://sedici.unlp.edu.ar/. Recuperado el 2015 de 08 de 10, de http://sedici.unlp.edu.ar/bitstream/handle/10915/18728/Documento_completo.pdf?s equence $=1$

Fontela, C. (2011). UML: Modelado de software para profesionales.

Genero Bocco, M., Cruz-Lemus, J. A., \& Piattini Velthuis, M. (2014). Métodos de investigación en ingenieria de software. Madrid: Editorial Ra-Ma.

Goldenson \& Gibson. (08 de 2003). http://www.sei.cmu.edu/. Recuperado el 15 de 08 de 2015, de http://www.sei.cmu.edu/reports/03sr009.pdf

Hernández R. \& Fernández, C. \& Baptista, P. (2003). Metodología de la Investigación. México: McGraw-Hill.

Hurtado,Pino,Vidal,Pardo \& Fernández. (2008). Agile SPI: Software Process Agile Improvement, A Colombia Approach to Software Process Improvement in Small Software Organizations. Software Process Improvement for Small and Medium Enterprises: Techniques and Case Studies. USA: Idea Group Inc.

INSTITUTO NACIONAL DE CALIDAD. (2010). MODELO DE MEJORA CONTINUA. AUTODIAGNOSTICO Y ELABORACION DE UN PLAN DE MEJORA DE CALIDAD. URUGUAY.

ISO 9000. (2005). Sistemas de gestión de la calidad - Fundamentos y vocabulario. Traducción certificada.

ISO Benefits of International Standars. (2015). http://www.iso.org. Obtenido de http://www.iso.org/iso/home/standards/benefitsofstandards.htm

ISO Certification. (2015). http://www.iso.org/. Obtenido de http://www.iso.org/iso/home/standards/certification.htm 
ISO/IEC. (2011). ISO/IEC 15289, Systems and software engineering - Content of lifecycle information products (documentation).

ISO/IEC 29110-5-1-1. (2012). ISO/IEC 29110-5-1-1, Software engineering - Lifecycle profiles for Very Small Entities (VSEs) - Part 5-1-1: Management and engineering guide: Generic profile group: Entry profile.

ISO/IEC FDIS 29110-4-1. (2010). Software engineering — Lifecycle profiles for Very Small Entities (VSEs) - Part 4-1: Profile specifications: Generic Profile group.

ISO/IEC TR 15504-1:1998. (s.f.). Information Technology - Software Process AssesmentPart 1: Concepts and Introductory Guide.

ISO/IEC TR 29110-5-6-2. (2014). Systems and software engineering - Lifecycle profiles for Very Small Entities (VSEs) - Part 5-6-2: Systems engineering - Management and engineering guide: Generic profile group: Basic profile.

K. Kulpa, M., \& Kent A., J. (2008). Interpreting the CMMI (R): A Process Improvement Approach. Auerbach Publications.

Mon, Estayno \& Arancio. (2008). http://sedici.unlp.edu.ar/. Recuperado el 01 de 08 de 2015, de http://sedici.unlp.edu.ar/bitstream/handle/10915/21934/Documento_completo.pdf?s equence $=1$

Montilva, Barrios \& Rivero. (2009). Requisitos de capacitación y perfiles para ingenieros de software en Micro y Pequeñas Empresas. XXXV Conferencia Latinoamericana de Informática (CLEI). Brasil.

NTP-ISO/IEC 12207. (2006). TECNOLOGÍA DE LA INFORMACIÓN. Procesos del ciclo de vida del software.

NTP-RT-ISO/IEC TR 29110-5-1-2. (2012). INGENIERÍA DE SOFTWARE. Perfiles del ciclo de vida para las pequeñas organizaciones (PO). Parte 5-1-2: Guía degestión e ingeniería: Grupo de perfil genérico. Perfil básico.

OKTABA, Hanna \& otros. (2004). Metódo de Evaluación de procesos para la Industria de software EvalProSoft.

Per, K., \& Philippe, K. (2003). The Rational Unified Process Made Easy: A Practitioner's Guide to the RUP.

Pino, F., F. García y M. Piattini. (2007). Herramienta de soporte a la valoración rápida de procesos software. IEEE Latin America Transactions Vol. 5(4).

Pino, Garcia, Ruiz \& Piattini. (ABRIL de 2006). http://www.ewh.ieee.org. Obtenido de http://www.ewh.ieee.org/reg/9/etrans/ieee/issues/vol04/vol4issue2April2006/4TLA 2_04Pino.pdf.

PMBOK. (2008). GUIA DE LOS FUNDAMENTOS PARA LA DIRECCION DE PROYECTOS. CUARTA EDICION.

PROMPERU. (2011). Peru Portafolio Software.

Ramos, C. \& Mendoza, L. (Agosto de 2014). http://repositorioacademico.upc.edu.pe. Obtenido de http://repositorioacademico.upc.edu.pe/upc/bitstream/10757/336665/1/Tesis+Mend oza+-+Ramos.pdf

Rational. (2001). Rational Unified Process Best Practices for Software Development Teams .

Rational Software. (2001). Rational Unified Process Best Practices for Software Development Teams. 
Real Academia Española. (2015). http://www.rae.es/. Obtenido de http://www.rae.es/recursos/diccionarios/drae

República del Perú. . (2013). Resolución de SuperIntendencia Nº0000348-2013MIGRACIONES.

Schwaber, K., \& Sutherland, J. (2013 de Julio). SCRUMGUIDES.ORG. Obtenido de http://scrumguides.org/docs/scrumguide/v1/Scrum-Guide-ES.pdf\#zoom $=100$

Vergara, Dianne. (2008). http://tesis.pucp.edu.pe/repositorio/. (I. L. TRANSACTIONS, Ed.) Recuperado el 01 de 08 de 2015, de http://tesis.pucp.edu.pe/repositorio/bitstream/handle/123456789/358/VERGARA_D IANNE_MEJORA_DEL_PROCESO_SOFTWARE_DE_UNA_PEQUE\%C3\%91A _EMPRESA_DESARROLLADORA_DE_SOFTWARE_\%20CASO_COMPETIS OFT_PERU_LAMBDA.pdf?sequence=1

Viscardi, S. (2013). he professional ScrumMaster's handbook: A collection of tips, tricks, and war stories to help the professional ScrumMaster break the chains of traditional organization and management. . Birmingham: Packt Publishing. 


\section{BIBLIOGRAFÍA}

Arbulú, J. (13 de Abril de 2007). PYME: LA SOCIA MAYORITARIA DEL PERÚ.

Diario El Peruano.

COMPETISOFT. (2008). Mejora de Procesos para Fomentar la Competitividad de la Pequeña y Mediana Industria del Software de Iberoamérica.

Genero Bocco, M., Cruz-Lemus, J. A., \& Piattini Velthuis, M. (2014). Métodos de investigación en ingenieria de software. Madrid: Editorial Ra-Ma.

ISO/IEC. (2011). ISO/IEC 15289, Systems and software engineering - Content of lifecycle information products (documentation).

CMMI Architecture Team. (2007). Introduction to the Architecture of the CMMI®

Framework.

Marciszack, Cardenas, Castro \& Perez. (2012). http://sedici.unlp.edu.ar/. Recuperado el 07 de 2015, de

http://sedici.unlp.edu.ar/bitstream/handle/10915/18966/Documento_completo.pdf?sequenc $\mathrm{e}=1$ 


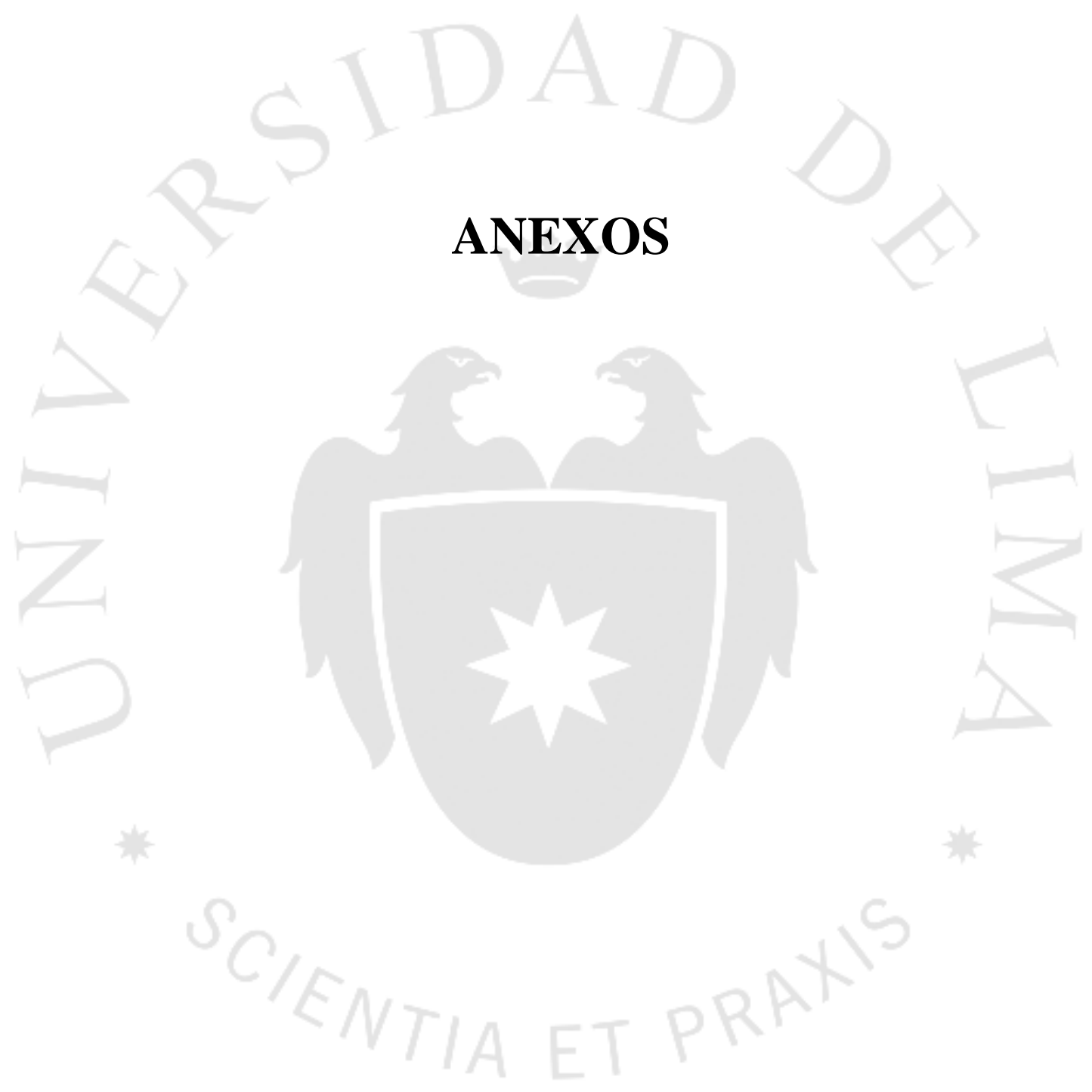




\section{ANEXO 1: Cuestionario de Preguntas referente al modelo de negocios Canvas}

A continuación se presentan las preguntas realizadas a la empresa HOLINSYS para la construcción del Modelo Canvas:

\begin{tabular}{|l|l|}
\hline Elementos clave del Modelo & \\
\hline Socios Clave & $\begin{array}{l}\text { ¿Cuáles son sus proveedores principales? } \\
\text { ¿Por qué consideran que son sus proveedores principales? }\end{array}$ \\
\hline Actividades Clave & $\begin{array}{l}\text { ¿Cuáles son las actividades más importantes que consideran necesarias para } \\
\text { la empresa? }\end{array}$ \\
\hline Propuesta de valor & $\begin{array}{l}\text { ¿Cuál es el valor agregado de la empresa? } \\
\text { ¿Qué necesidad están satisfaciendo? }\end{array}$ \\
\hline ¿Qué es lo que el cliente espera como resultado? \\
\hline Relación con el cliente & ¿Qué tipo de relación establecen para mantener a sus clientes? \\
\hline Segmentos de Clientes & ¿Para quiénes están creando valor? \\
\hline Recursos Clave & $\begin{array}{l}\text { ¿Cómo está conformado el equipo de trabajo? } \\
\text { ¿Cuáles son las herramientas que utilizan al desarrollar un proyecto? }\end{array}$ \\
\hline ¿Cómo están conformados sus ingresos?
\end{tabular}




\section{ANEXO 2: Productos de Trabajo Modelo del Ciclo de Vida del Desarrollo de Software}

A continuación se presenta los documentos Modelo elaborados para apoyar las actividades del ciclo de vida del desarrollo de software descrito en la ISO 29110:

\subsection{Plan del Proyecto}

\section{Plan de Proyecto [Identificación del Plan} de Proyecto] [Versión \#\#.\#]

[Código de Proyecto]- [Nombre del

\section{Proyecto]}

[Nombre de la Empresa]

\#\#/\#\#/\#\# [Fecha de creación del proyecto]

\section{Estado del Documento}

\begin{tabular}{|l|l|l|}
\hline Estado & Fecha & Responsable \\
\hline Verificado & [Nombres y Apellidos.] \\
\hline Aceptado & {$[$ Nombres y Apellidos.] } \\
\hline Actualizado & {$[$ Nombres y Apellidos.] } \\
\hline Revisado & [Nombres y Apellidos.] \\
\hline
\end{tabular}




\section{Datos del Proyecto}

\section{Código del Proyecto}

Nombre del Proyecto

Tipo de Proyecto

Área

Empresa Cliente

Representante de la

Empresa

Inicio del Proyecto

Inicio del Proyecto

Costo del Proyecto

\section{[Código de Proyecto]}

[Nombre del Proyecto]

[Naturaleza del Proyecto]

[Área de la Empresa]

[Nombre comercial de la empresa Cliente]

[Representante(s) de la empresa Cliente]

\section{[\#\#/\#\#/\#\#\#\#]}

[\#\#/\#\#/\#\#\#\#]

[S/.\#\#\#\#\#.\#\#/ \$/. \#\#\#\#\#.\#\#]

\section{Historial de Versiones}

\begin{tabular}{|c|c|c|c|}
\hline Fecha & Versión & Descripción & Autor \\
\hline \#\#/\#\#/\#\#\#\# & 1.0 & Creación del Proyecto. & $\begin{array}{l}\text { [Nombres y Apellidos- } \\
\text { Creador del Documento.] }\end{array}$ \\
\hline \#\#/\#\#/\#\#\#\# & 1.\# & $\begin{array}{l}\text { [Descripción del cambio en el } \\
\text { alcance del Proyecto.] }\end{array}$ & $\begin{array}{l}\text { [Nombres y Apellidos- } \\
\text { Quien actualizo el Doc.] }\end{array}$ \\
\hline \#\#/\#\#/\#\#\#\# & \#.\# & $\begin{array}{l}\text { [Descripción del cambio en el } \\
\text { alcance del Proyecto.] }\end{array}$ & $\begin{array}{l}\text { [Nombres y Apellidos- } \\
\text { Quien actualizo el Doc.] }\end{array}$ \\
\hline
\end{tabular}

\section{Firmas}

Nombre

[Cliente/Representante de

la empresa XXXXX]
Fecha

[\#\#/\#\#/\#\#\#\#]

\section{Firma}


Gestor de Proyectos:

[Nombre del Gestor]

Líder Técnico:

[Nombre del Líder

Técnico]

\section{[\#\#/\#\#/\#\#\#\#]}

[\#\#/\#\#/\#\#\#\#]

\section{Descripción}

Descripción del Producto de Software.

\section{Propósito}

[El propósito del producto de software (Software/ Modulo de un producto de Software) a desarrollar/ Modificar.]

\section{Requisitos generales}

[Requisitos generales hechos por el Cliente.]

\section{Alcance}

Alcance del Proyecto de Desarrollo de Software. Descripción de lo que está incluido y no está incluido en el producto de software a desarrollar.

\section{El proyecto de desarrollo de software incluye}

- [Funcionalidades impactadas por del proyecto.]

- [Ambientes impactados por el proyecto.]

- [Archivos impactados por el proyecto.]

- $[$ Otros. $]$

\section{Limitaciones y restricciones del proyecto}

- [Funcionalidades no impactadas por del proyecto.]

- [Ambientes fuera del el proyecto.] 
- $[$ Otros. $]$

\section{Objetivos del proyecto}

Objetivos del Proyecto de Desarrollo de Software.

- [Objetivo \#01 del Proyecto de desarrollo de Software.]

- [Objetivo \#02 del Proyecto de desarrollo de Software.]

- [Objetivo \#03 del Proyecto de desarrollo de Software.]

\section{Entregables}

Listado de productos de software que serán entregados al Cliente.

\section{Listado de Entregables}

\begin{tabular}{|c|c|c|c|c|}
\hline Entregable & $\begin{array}{l}\text { Descripción del } \\
\text { Entregable }\end{array}$ & $\begin{array}{l}\text { Fecha de } \\
\text { Entrega }\end{array}$ & $\begin{array}{l}\text { Lugar de } \\
\text { Entrega }\end{array}$ & Condiciones de Entrega \\
\hline $\begin{array}{l}\text { [Nombre del } \\
\text { Entregable } \\
01]\end{array}$ & $\begin{array}{l}\text { [Descripción breve del } \\
\text { Entregable 01] }\end{array}$ & $\begin{array}{l}\text { \#/\#\#/ } \\
\# \# \# \#\end{array}$ & $\begin{array}{l}\text { [Lugar } \\
\text { de } \\
\text { Entrega] }\end{array}$ & $\begin{array}{l}\text { [Condiciones de aceptación } \\
\text { del entregable.] }\end{array}$ \\
\hline $\begin{array}{l}\text { [Nombre del } \\
\text { Entregable } \\
\text { 02] }\end{array}$ & $\begin{array}{l}\text { [Descripción breve del } \\
\text { Entregable 02] }\end{array}$ & $\begin{array}{l}\# \# / \# \# / \\
\# \# \# \#\end{array}$ & $\begin{array}{l}\text { [Lugar } \\
\text { de } \\
\text { Entrega] }\end{array}$ & $\begin{array}{l}\text { [Condiciones de aceptación } \\
\text { del entregable.] }\end{array}$ \\
\hline $\begin{array}{l}\text { [Nombre del } \\
\text { Entregable } \\
\text { 02] }\end{array}$ & $\begin{array}{l}\text { [Descripción breve del } \\
\text { Entregable 02] }\end{array}$ & $\begin{array}{l}\# \# / \# \# / \\
\# \# \#\end{array}$ & $\begin{array}{l}\text { [Lugar } \\
\text { de } \\
\text { Entrega] }\end{array}$ & $\begin{array}{l}\text { [Condiciones de aceptación } \\
\text { del entregable.] }\end{array}$ \\
\hline
\end{tabular}

\section{Procedimiento de Entrega y Respaldo}

Procedimiento

de entrega

Procedimientos

de Respaldo
Tareas Requeridas para la Entrega de los Productos dl Proyecto.

Tareas de Respaldo del producto a ser entregado (Antes y Después de la entrega). 
*Lugar de Entrega: Forma y lugar donde el software será entregado. (Ejemplo: Instalación del software en las instalaciones del cliente, enviado a través de internet, etc.)

*Condiciones de aceptación del entregable: Las condiciones mínimas del entregable para que sea aceptado por el Cliente.

\section{Recursos}

Recursos necesarios para el proyecto de desarrollo de software.

\section{Recursos Humanos}

\begin{tabular}{|c|c|c|}
\hline Rol del Responsable & Código & Nombre \\
\hline Programador & PR & $\begin{array}{l}\text { [Nombre del Programador \#01] } \\
\text { [Nombre del Programador \#02] }\end{array}$ \\
\hline Analista de Software & AN & $\begin{array}{l}\text { [Nombre del Analista de Software \#01] } \\
\text { [Nombre del Analista de Software \#02] }\end{array}$ \\
\hline Analista de QA & QA & $\begin{array}{l}\text { [Nombre del Analista de QA \#01] } \\
\text { [Nombre del Analista de QA \#02] }\end{array}$ \\
\hline Líder Tectónico & LT & [Nombre del Líder Técnico] \\
\hline Equipo de Trabajo & LT & - \\
\hline Gestor del Proyecto & GP & [Nombre del Gestor del Proyecto] \\
\hline $\begin{array}{l}\text { Cliente - } \\
\text { Representante }\end{array}$ & $\mathrm{CL}$ & $\begin{array}{l}\text { [Nombre del Representante \#01] } \\
\text { [Nombre del Representante \#02] }\end{array}$ \\
\hline
\end{tabular}

*El equipo de Trabajo está conformado por los programadores, analistas de software, analistas de QA y el Líder técnico.

\section{Capacitación Requerida}

\begin{tabular}{|c|c|c|c|c|}
\hline Tema & Tipo & Detalle & Inicio & $\begin{array}{l}\text { Duración } \\
\text { Estimada }\end{array}$ \\
\hline $\begin{array}{l}\text { [Tema de la } \\
\text { Capacitación } \\
\# 01]\end{array}$ & $\begin{array}{l}\text { [Virtual } \\
/ \\
\text { Física] }\end{array}$ & $\begin{array}{l}\text { Información Adicional de la } \\
\text { Capacitación. }\end{array}$ & $\begin{array}{l}{[\# \# / \# \# /} \\
\# \# \# \#]\end{array}$ & $\begin{array}{l}{[\# \# / \# \# /} \\
\# \# \#]\end{array}$ \\
\hline
\end{tabular}




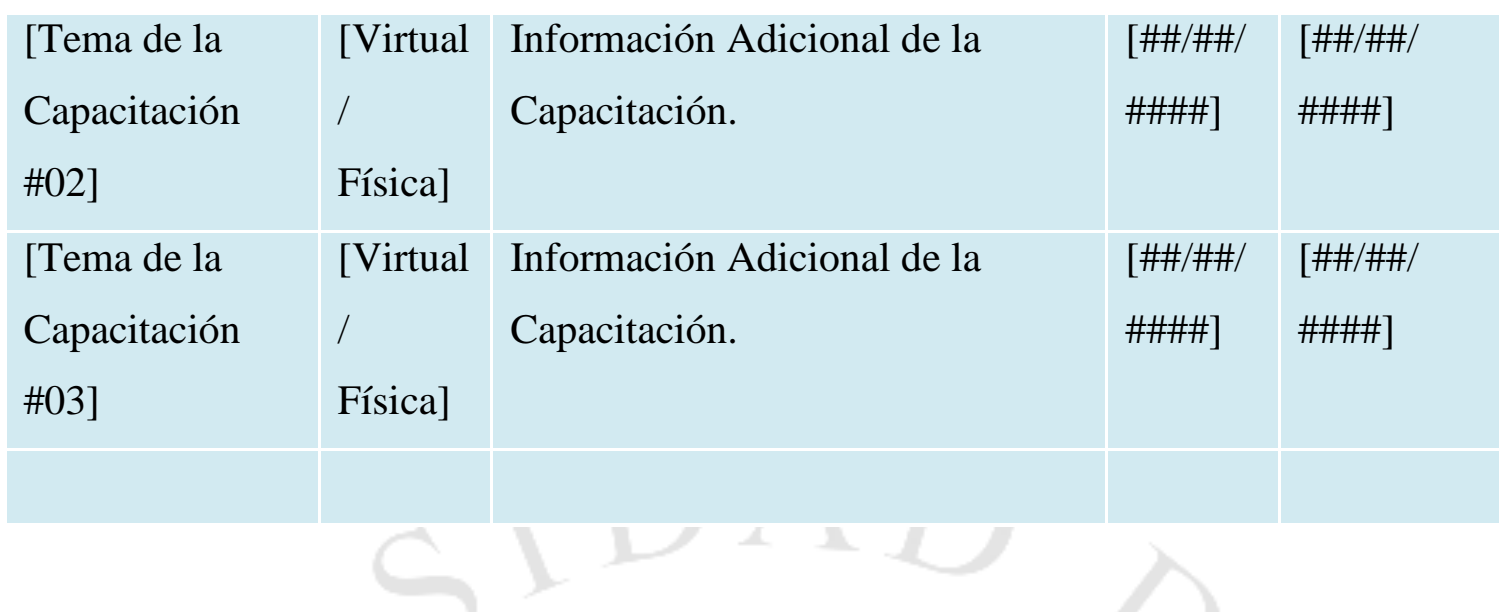

\section{Metodología}

Para el Proyecto de desarrollo de software se está utilizado un modelo cascada modificado según lo establecido en la ISO 29110-5-1-2.

\section{Herramientas de Hardware}

\begin{tabular}{|c|c|c|c|c|}
\hline Hardware & Cant & Detalle del uso & Inicio & \begin{tabular}{|l} 
Duración \\
Estimada
\end{tabular} \\
\hline $\begin{array}{l}\text { PC para } \\
\text { Desarrollo }\end{array}$ & $\#$ & $\begin{array}{l}\text { [Breve descripción del } \\
\text { uso.] }\end{array}$ & $\begin{array}{l}{[\# \# / \# \# / \# \# \# \#+} \\
]\end{array}$ & $\begin{array}{l}{[\# \# / \# \# / \# \# \# \text { }} \\
]\end{array}$ \\
\hline$\overline{P C}$ para $\mathbf{Q A}$ & \# & $\begin{array}{l}\text { [Breve descripción del } \\
\text { uso.] }\end{array}$ & $\begin{array}{l}{[\# \# / \# \# / \# \# \# \#} \\
]\end{array}$ & $\begin{array}{l}{[\# \# / \# \# / \# \# \# \#} \\
\text { ] }\end{array}$ \\
\hline [Servidor \#01] & \# & $\begin{array}{l}\text { [Breve descripción del } \\
\text { uso.] }\end{array}$ & $\begin{array}{l}{[\# \# / \# \# / \# \# \# \#} \\
]\end{array}$ & $\begin{array}{l}{[\# \# / \# \# / \# \# \# \#} \\
]\end{array}$ \\
\hline [Servidor \#02] & \# & $\begin{array}{l}\text { [Breve descripción del } \\
\text { uso.] }\end{array}$ & $\begin{array}{l}{[\# \# / \# \# / \# \# \# \#} \\
]\end{array}$ & $\begin{array}{l}{[\# \# / \# \# / \# \# \# \#+} \\
\text { ] }\end{array}$ \\
\hline [Servidor \#03] & $\#$ & $\begin{array}{l}\text { [Breve descripción del } \\
\text { uso.] }\end{array}$ & $\begin{array}{l}{[\# \# / \# \# / \# \# \# \#} \\
]\end{array}$ & $\begin{array}{l}{[\# \# / \# \# / \# \# \# \#} \\
]\end{array}$ \\
\hline
\end{tabular}




\section{Herramientas de Software}

\begin{tabular}{|c|c|c|c|c|}
\hline Software & Cant. & Detalle del uso & Inicio & $\begin{array}{l}\text { Duración } \\
\text { Estimada }\end{array}$ \\
\hline [Software \#01] & \# & $\begin{array}{l}\text { [Breve descripción del } \\
\text { uso.] }\end{array}$ & [\#\#/\#\#/\#\#\#\#] & [\#\#/\#\#/\#\#\#\#] \\
\hline [Software \#02] & \# & $\begin{array}{l}\text { [Breve descripción del } \\
\text { uso.] }\end{array}$ & [\#\#/\#\#/\#\#\#\#] & [\#\#/\#\#/\#\#\#\#] \\
\hline [Software \#03] & \# & $\begin{array}{l}\text { [Breve descripción del } \\
\text { uso.] }\end{array}$ & [\#\#/\#\#/\#\#\#\#] & [\#\#/\#\#/\#\#\#\#] \\
\hline
\end{tabular}

\section{Tareas del Proyecto}

Tareas, Roles y Esfuerzo (Tiempo estimado) necesario para producir los productos y/o Entregables del proyecto de desarrollo de software y asegurar la calidad en estos productos.

\section{Diagrama EDT del Proyecto [Nombre del Proyecto]}

El diagrama EDT a continuación muestra de forma simple y clara la relación entre entregables y actividades del ciclo de vida del desarrollo de software. 


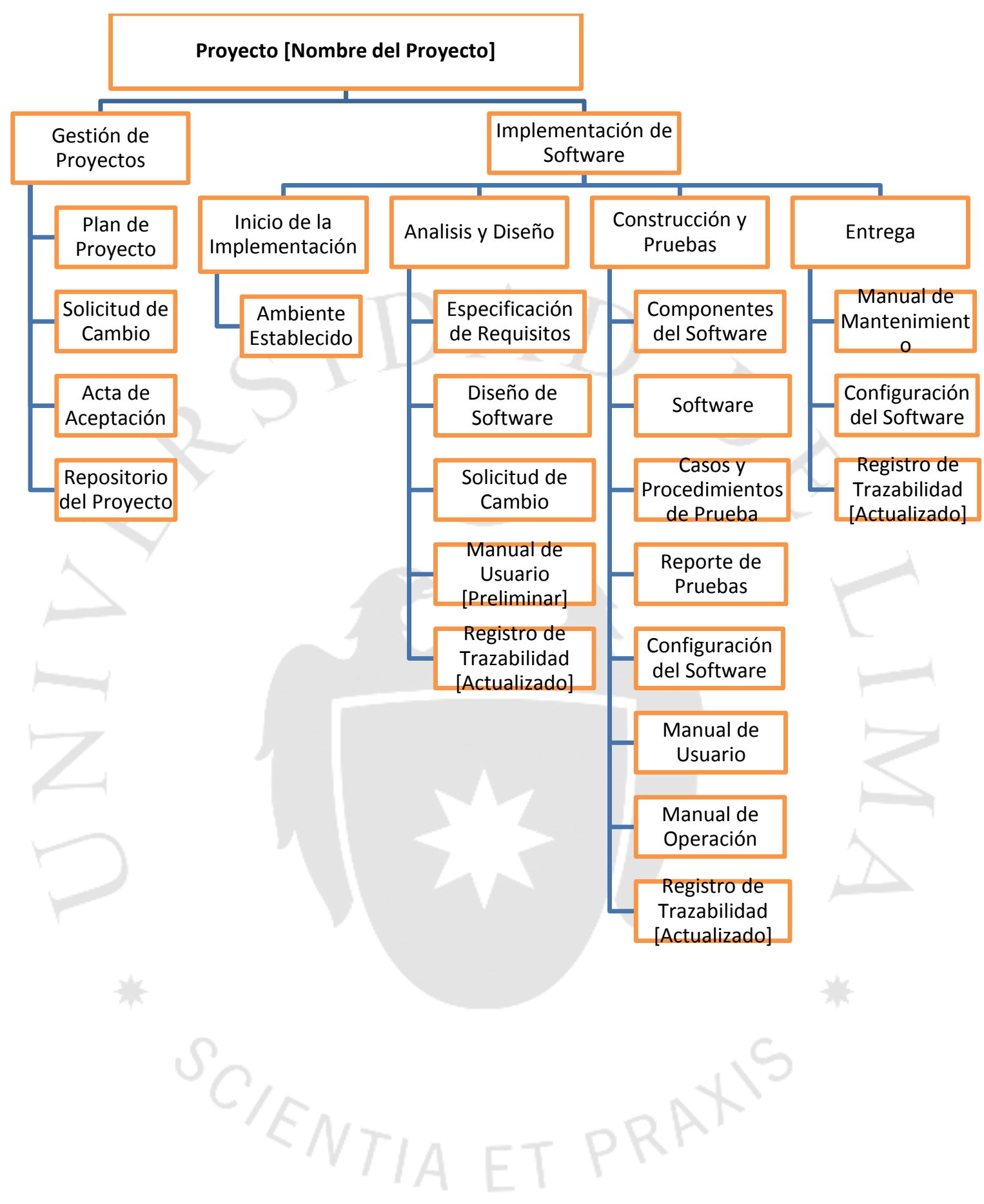




\section{Diccionario EDT}

El diccionario EDT a continuación muestra la relación entre Entregables, Tareas, Duración (Esfuerzo) y Responsables.

\section{Proceso \\ Gestión de Proyectos}

\section{Principales Productos de Trabajo:}

Plan de Proyecto

Tareas requeridas:

[Tarea Requerida \#01].

[Tarea Requerida \#02].

Duración Estimada: \#\# horas hombre.

Responsables:

[Rol del Responsable 01]

[Rol del Responsable 02]

Solicitud de

$$
\text { *Actividad Opcional }
$$

Cambio

Tareas requeridas:

[Tarea Requerida \#01].

[Tarea Requerida \#02].

[Duración Estimada]

Responsables:

[Rol del Responsable 01]

[Rol del Responsable 02]

Acta de

Tareas requeridas:

Aceptación

[Tarea Requerida \#01].

[Tarea Requerida \#02]. 


\begin{tabular}{|c|c|}
\hline & [Duración Estimada] \\
\hline & $\begin{array}{l}\text { Responsables: } \\
\text { [Rol del Responsable 01] } \\
\text { [Rol del Responsable 02] }\end{array}$ \\
\hline $\begin{array}{l}\text { Repositorio del } \\
\text { Proyecto }\end{array}$ & $\begin{array}{l}\text { Tareas requeridas: } \\
\text { [Tarea Requerida \#01]. } \\
\text { [Tarea Requerida \#02]. }\end{array}$ \\
\hline & [Duración Estimada] \\
\hline & $\begin{array}{l}\text { Responsables: } \\
\text { [Rol del Responsable 01] } \\
\text { [Rol del Responsable 02] }\end{array}$ \\
\hline Proceso & Implementación de Software \\
\hline Actividad: & Inicio de la Implementación \\
\hline Inicio Estimado: & \#\#/\#\#/\#\#\#\# \\
\hline Fin Estimado: & \#\#/\#\#/\#\#\#\# \\
\hline Dependencia: & Plan de Proyecto \\
\hline Principales Prod & s de Trabajo: \\
\hline $\begin{array}{l}\text { Ambiente } \\
\text { Establecido }\end{array}$ & $\begin{array}{l}\text { Tareas requeridas: } \\
\text { [Tarea Requerida \#01]. } \\
\text { [Tarea Requerida \#02]. }\end{array}$ \\
\hline & $\begin{array}{l}\text { [Duración Estimada] } \\
\text { Responsables: }\end{array}$ \\
\hline
\end{tabular}


[Rol del Responsable 01]

[Rol del Responsable 02]

\begin{tabular}{l|l}
\hline Actividad: & Análisis y Diseño \\
\hline Inicio Estimado: & \#\#/\#\#/\#\#\# \\
\hline Fin Estimado: & \#\#/\#\#/\#\#\#\# \\
\hline Dependencia: & Plan de Proyecto
\end{tabular}

Principales Productos de Trabajo:

Especificación de

Requisitos

Diseño de

Software
Tareas requeridas:

[Tarea Requerida \#01].

[Tarea Requerida \#02].

Verificación de la Especificación de Requisitos.

Validación de la Especificación de Requisitos.

\section{[Duración Estimada]}

Responsables:

[Rol del Responsable 01]

[Rol del Responsable 02]

Tareas requeridas:

[Tarea Requerida \#01].

[Tarea Requerida \#02].

Verificación de la Especificación de Requisitos.

[Duración Estimada]

Responsables:

[Rol del Responsable 01] 


\begin{tabular}{|c|c|}
\hline & [Rol del Responsable 02] \\
\hline \multirow[t]{2}{*}{$\begin{array}{l}\text { Solicitud de } \\
\text { Cambio }\end{array}$} & $\begin{array}{l}\text { Tareas requeridas: } \\
\text { [Tarea Requerida \#01]. } \\
\text { [Tarea Requerida \#02]. }\end{array}$ \\
\hline & $\begin{array}{l}\text { [Duración Estimada] } \\
\text { Responsables: } \\
\text { [Rol del Responsable 01] } \\
\text { [Rol del Responsable 02] }\end{array}$ \\
\hline \multirow[t]{2}{*}{$\begin{array}{l}\text { Manual de Usuario } \\
\text { [Preliminar] }\end{array}$} & $\begin{array}{l}\text { Tareas requeridas: } \\
\text { [Tarea Requerida \#01]. } \\
\text { [Tarea Requerida \#02]. }\end{array}$ \\
\hline & $\begin{array}{l}\text { [Duración Estimada] } \\
\text { Responsables: } \\
\text { [Rol del Responsable 01] } \\
\text { [Rol del Responsable 02] }\end{array}$ \\
\hline \multirow[t]{2}{*}{$\begin{array}{l}\text { Registro de } \\
\text { Trazabilidad } \\
\text { [Actualizado] }\end{array}$} & $\begin{array}{l}\text { Tareas requeridas: } \\
\text { [Tarea Requerida \#01]. } \\
\text { [Tarea Requerida \#02]. }\end{array}$ \\
\hline & $\begin{array}{l}\text { [Duración Estimada] } \\
\text { Responsables: } \\
\text { [Rol del Responsable 01] } \\
\text { [Rol del Responsable 02] }\end{array}$ \\
\hline Actividad: & Construcción y Pruebas \\
\hline
\end{tabular}




\section{Inicio Estimado:}

Fin Estimado:

\section{Dependencia:}

\section{Principales Productos de Trabajo:}

Componentes de

Software

Software

Casos y

Procedimientos de Prueba
Tareas requeridas:

[Tarea Requerida \#01].

[Tarea Requerida \#02].

[Duración Estimada]

Responsables:

[Rol del Responsable 01]

[Rol del Responsable 02]

Tareas requeridas:

[Tarea Requerida \#01].

[Tarea Requerida \#02].

[Duración Estimada]

Responsables:

[Rol del Responsable 01]

[Rol del Responsable 02]

Tareas requeridas:

[Tarea Requerida \#01].

[Tarea Requerida \#02].

[Duración Estimada]

Responsables:

[Rol del Responsable 01] 


\begin{tabular}{|c|c|}
\hline & [Rol del Responsable 02] \\
\hline \multirow[t]{2}{*}{ Reporte de Pruebas } & $\begin{array}{l}\text { Tareas requeridas: } \\
\text { [Tarea Requerida \#01]. } \\
\text { [Tarea Requerida \#02]. }\end{array}$ \\
\hline & $\begin{array}{l}\text { [Duración Estimada] } \\
\text { Responsables: } \\
\text { [Rol del Responsable 01] } \\
\text { [Rol del Responsable 02] }\end{array}$ \\
\hline \multirow[t]{2}{*}{$\begin{array}{l}\text { Configuración de } \\
\text { Software }\end{array}$} & $\begin{array}{l}\text { Tareas requeridas: } \\
\text { [Tarea Requerida \#01]. } \\
\text { [Tarea Requerida \#02]. }\end{array}$ \\
\hline & $\begin{array}{l}\text { [Duración Estimada] } \\
\text { Responsables: } \\
\text { [Rol del Responsable 01] } \\
\text { [Rol del Responsable 02] }\end{array}$ \\
\hline \multirow[t]{2}{*}{ Manual de Usuario } & $\begin{array}{l}\text { Tareas requeridas: } \\
\text { [Tarea Requerida \#01]. } \\
\text { [Tarea Requerida \#02]. }\end{array}$ \\
\hline & $\begin{array}{l}\text { [Duración Estimada] } \\
\text { Responsables: } \\
\text { [Rol del Responsable 01] } \\
\text { [Rol del Responsable 02] }\end{array}$ \\
\hline $\begin{array}{l}\text { Manual de } \\
\text { Operación }\end{array}$ & $\begin{array}{l}\text { Tareas requeridas: } \\
\text { [Tarea Requerida \#01]. } \\
\text { [Tarea Requerida \#02]. }\end{array}$ \\
\hline
\end{tabular}




\begin{tabular}{|c|c|}
\hline & [Duración Estimada] \\
\hline & $\begin{array}{l}\text { Responsables: } \\
\text { [Rol del Responsable 01] } \\
\text { [Rol del Responsable 02] }\end{array}$ \\
\hline $\begin{array}{l}\text { Registro de } \\
\text { Trazabilidad }\end{array}$ & $\begin{array}{l}\text { Tareas requeridas: } \\
\text { [Tarea Requerida \#01]. } \\
\text { [Tarea Requerida \#02]. }\end{array}$ \\
\hline & [Duración Estimada] \\
\hline & $\begin{array}{l}\text { Responsables: } \\
\text { [Rol del Responsable 01] } \\
\text { [Rol del Responsable 02] }\end{array}$ \\
\hline Actividad: & Entrega \\
\hline Inicio Estimado: & \#\#/\#\#/\#\#\#\# \\
\hline Fin Estimado: & \#\#/\#\#/\#\#\#\# \\
\hline Dependencia: & Plan de Proyecto \\
\hline Principales Produ & s de Trabajo: \\
\hline $\begin{array}{l}\text { Configuración de } \\
\text { Software }\end{array}$ & $\begin{array}{l}\text { Tareas requeridas: } \\
\text { [Tarea Requerida \#01]. } \\
\text { [Tarea Requerida \#02]. }\end{array}$ \\
\hline & $\begin{array}{l}\text { [Duración Estimada] } \\
\text { Responsables: } \\
\text { [Rol del Responsable 01] }\end{array}$ \\
\hline
\end{tabular}




\begin{tabular}{|c|c|}
\hline & [Rol del Responsable 02] \\
\hline \multirow{7}{*}{$\begin{array}{l}\text { Manual de } \\
\text { Mantenimiento }\end{array}$} & Tareas requeridas: \\
\hline & [Tarea Requerida \#01]. \\
\hline & [Tarea Requerida \#02]. \\
\hline & [Duración Estimada] \\
\hline & Responsables: \\
\hline & [Rol del Responsable 01] \\
\hline & [Rol del Responsable 02] \\
\hline \multirow{7}{*}{$\begin{array}{l}\text { Registro de } \\
\text { Trazabilidad } \\
\text { [Actualizado] }\end{array}$} & Tareas requeridas: \\
\hline & [Tarea Requerida \#01]. \\
\hline & [Tarea Requerida \#02]. \\
\hline & [Duración Estimada] \\
\hline & Responsables: \\
\hline & [Rol del Responsable 01] \\
\hline & [Rol del Responsable 02] \\
\hline
\end{tabular}

\section{Identificación de los riesgos del proyecto}

\section{Tipo de Riesgo}

Código:

[Código del Riesgo]

Impacto:

[Alto / Medio/ Bajo]

Probabilidad:

[Probabilidad que ocurra

\section{[Ejemplo: Asociado al Personal]}

Descripción del Riesgo:

[Descripción del Riesgo asociado al personal]

Ejemplo: Rotación del Personal. Fin de la relación con el Personal necesario.

Plan de Mitigación:

[Plan detallado de Mitigación del Riesgo] 


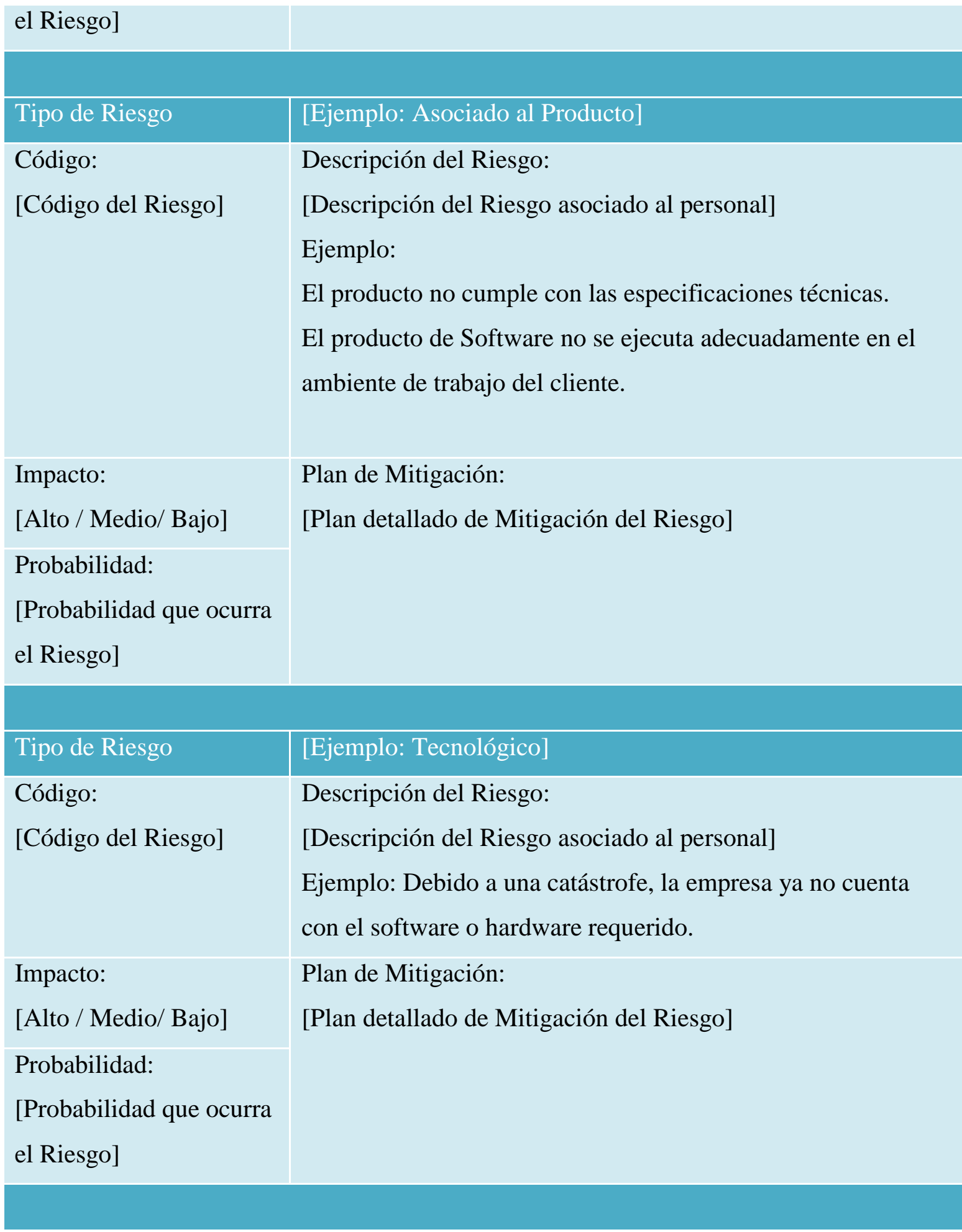




\section{Estrategia para el control de versiones}

\begin{tabular}{|c|c|c|c|}
\hline $\begin{array}{l}\text { Repositorio de } \\
\text { Archivos }\end{array}$ & $\begin{array}{l}\text { Ubicación } \\
\text { Física }\end{array}$ & Entregables & Tipo de Acceso \\
\hline $\begin{array}{l}\text { Herramienta de } \\
\text { Gestión de } \\
\text { Archivos \#01 }\end{array}$ & $\begin{array}{l}\text { Servidor } \\
\text { donde está } \\
\text { Instalado }\end{array}$ & $\begin{array}{l}\text { Plan de Proyecto. } \\
\text { Especificación de } \\
\text { Requisitos. } \\
\text { Diseño de Software. } \\
\text { Manual de Usuario. } \\
\text { Casos y Procedimientos de } \\
\text { Prueba. } \\
\text { Reporte de Pruebas. } \\
\text { Manual de Mantenimiento. } \\
\text { Acta de Aceptación. } \\
\text { Registro de Trazabilidad. }\end{array}$ & $\begin{array}{l}\text { [Publico/ Restringido/ } \\
\text { Privado] }\end{array}$ \\
\hline $\begin{array}{l}\text { Herramienta de } \\
\text { Gestión de } \\
\text { Archivos \#02 }\end{array}$ & $\begin{array}{l}\text { Servidor } \\
\text { donde está } \\
\text { Instalado }\end{array}$ & $\begin{array}{l}\text { Componentes de Software } \\
\text { Software }\end{array}$ & $\begin{array}{l}\text { [Publico/ Restringido/ } \\
\text { Privado] }\end{array}$ \\
\hline
\end{tabular}

\section{Respaldos}

\begin{tabular}{l|l|l|}
\hline Herramienta & Respaldo & Estrategia de Respaldo \\
\hline Herramienta de Gestión & $\begin{array}{l}\text { Descripción de la } \\
\text { de Archivos \#01 }\end{array}$ & $\begin{array}{l}\text { Cada cuanto tiempo y de qué forma } \\
\text { Se realizan Backups de los archivos. }\end{array}$ \\
\hline Herramienta de Gestión & $\begin{array}{l}\text { Descripción de la } \\
\text { Ubicación del }\end{array}$ & Cada cuanto tiempo y de qué forma \\
de Archivos \#02 & Respaldo de Archivos. & \\
& &
\end{tabular}




\section{Anexo}

Se presenta la trazabilidad entre las secciones de la plantilla y la descripción de documentos presentes en la NTP ISO/IEC 29110-5-1-2.

\begin{tabular}{|c|c|}
\hline Sección del Documento & Trazabilidad respecto a la NTP ISO/IEC 29110-5-1-2 \\
\hline Estado del Documento & $\begin{array}{l}\text {-Los estados aplicables son: verificado, aceptado, actualizado y } \\
\text { revisado. }\end{array}$ \\
\hline Datos del Proyecto & -NA. \\
\hline Descripción & -Descripción de producto, Propósito, Requisitos generales del Cliente. \\
\hline Alcance & $\begin{array}{l}\text {-Alcance descripción respecto de lo que está incluido y de lo que no } \\
\text { está incluido. }\end{array}$ \\
\hline Objetivos del Proyecto & -Objetivos del proyecto. \\
\hline Entregables & $\begin{array}{l}\text {-Entregables - lista de productos a ser entregados al Cliente. } \\
\text {-Instrucciones de entrega } \\
\text { Elementos requeridos para la liberación del producto (por ejemplo, } \\
\text { hardware, Software, documentación, etc.) } \\
\text { Requisitos de entrega } \\
\text { Tareas a realizar en orden secuencial } \\
\text { Liberaciones aplicables identificadas } \\
\text { Identifica todos los Componente de Software entregados con } \\
\text { información de la versión } \\
\text { Identifica cualquier procedimiento de copia de respaldo y } \\
\text { recuperación necesarios }\end{array}$ \\
\hline Recursos & $\begin{array}{l}\text {-Recursos (humanos, materiales, estándares, equipos y herramientas), } \\
\text { incluyendo la capacitación necesaria. Incluye la identificación y } \\
\text { programación de los Recursos. } \\
\text { - Composición del Equipo de Trabajo. }\end{array}$ \\
\hline
\end{tabular}




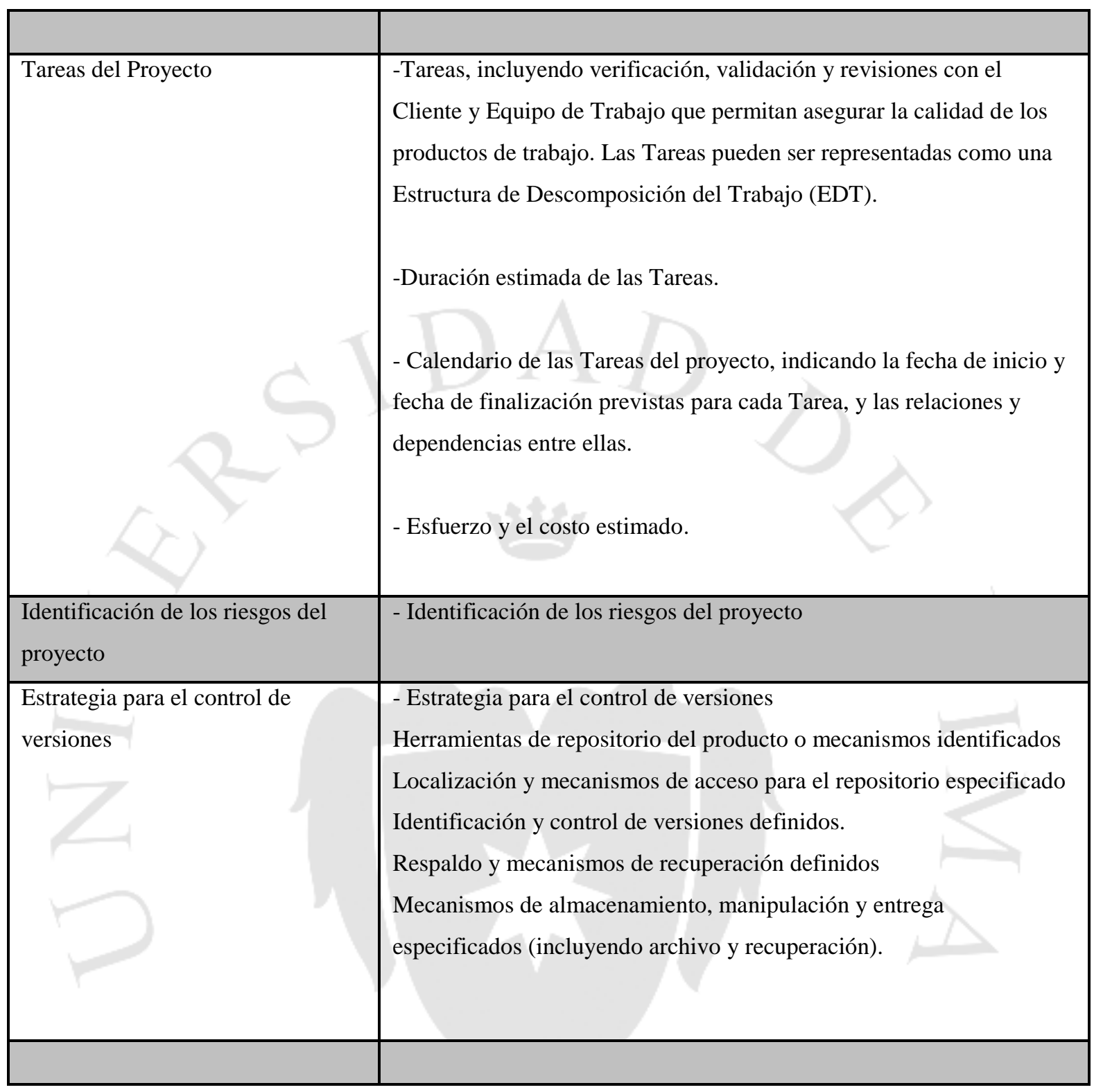

*NA: No Aplica

Registra el estado del proyecto contra el Plan del Proyecto. 


\section{Acta de Reunión [Identificación del Acta]}

\section{[Código de Proyecto]- [Nombre del}

Proyecto]

[Nombre de la Empresa]

\section{Estado del Documento}

\begin{tabular}{|l|l|l|}
\hline Estado & Fecha & Responsable \\
\hline Preliminar & [Nombres y Apellidos.] \\
\hline Verificado & [Nombres y Apellidos.] \\
\hline Validado & [Nombres y Apellidos.] \\
\hline Línea Base & [Nombres y Apellidos.] \\
\hline & & \\
\hline
\end{tabular}

\section{Datos del Proyecto}

\begin{tabular}{|c|c|}
\hline Código del Proyecto & [Código de Proyecto] \\
\hline $\begin{array}{l}\text { Nombre del } \\
\text { Proyecto }\end{array}$ & [Nombre del Proyecto] \\
\hline Lugar & [Instalaciones de la empresa/ empresa cliente] \\
\hline Fecha & [Fecha: \#\#/\#\#/\#\#\#\#], [Hora: \#\#:\#\#:\#\#] \\
\hline $\begin{array}{l}\text { Propósito de la } \\
\text { reunión }\end{array}$ & [Breve descripción del propósito general de la reunión] \\
\hline Asistentes & $\begin{array}{l}\text { Representante de la empresa Cliente } \\
\text { Equipo de Trabajo }\end{array}$ \\
\hline
\end{tabular}




\section{Cuestiones identificadas}

Cuestiones identificadas

1. Ejemplo \#01: Revisión y aprobación del acta de la reunión anterior. Acuerdos

[Acuerdos respecto a los temas Tratados]

Acuerdos

[Acuerdos respecto al tema tratado \#01]

[Acuerdos respecto al tema tratado \#02]

\section{Logros}

Logros de la Reunión

Listado de Logros

[Descripción del Logro \#01]

[Descripción del Logro \#02]

\section{Otros}

Otros temas a tratar.

Otros

[Descripción \#01- Sección no obligatoria]

\section{Seguimiento}

Seguimiento de las reuniones.

\begin{tabular}{|l|l|l|}
\hline Acta & Fecha & Detalle \\
\hline [ID del Acta \#\#] & {$[\# \# / \# \# / \# \#]$} & \\
\hline [ID del Acta \#\#] & {$[\# \# / \# \# / \# \#]$} & \\
\hline [ID del Acta \#\#] & {$[\# \# / \# \# / \# \#]$} & \\
\hline
\end{tabular}




\section{Anexo}

Para asegurar el cumplimiento de la plantilla "Acta de Reunión”, se presenta la trazabilidad entre las secciones de la plantilla y la descripción de documentos presentes en la NTP ISO/IEC 29110-5-1-2.

\begin{tabular}{|l|l|}
\hline Sección del Documento & Trazabilidad respecto a la NTP ISO/IEC 29110-5-1-2 \\
\hline Estado del Documento & Estados Aplicables: Actualizado. \\
\hline Datos del Proyecto & $\begin{array}{l}\text {-Asistentes, fecha, lugar, estado } \\
\text {-Propósito de la reunión }\end{array}$ \\
\hline 1. Cuestiones Identificadas & -Identifica cuestiones planteadas \\
\hline 2. Acuerdos & - Acuerdos \\
\hline 3. Logros & - Qué fue logrado \\
\hline 4. Otros & - Cualquier asunto abierto \\
\hline 5. Seguimiento & - Próxima reunión y reuniones previas \\
\hline & \\
\hline
\end{tabular}

*NA: No Aplica 


\section{Acciones Correctivas [Identificación del}

\section{Acta]}

\section{[Código de Proyecto]- [Nombre del Proyecto]}

[Nombre de la Empresa]

\section{Estado del Documento}

\begin{tabular}{|l|l|l|}
\hline Estado & Fecha & Responsable \\
\hline Preliminar & [Nombres y Apellidos.] \\
\hline Verificado & [Nombres y Apellidos.] \\
\hline Validado & [Nombres y Apellidos.] \\
\hline Línea Base & [Nombres y Apellidos.] \\
\hline
\end{tabular}

\section{Datos del Proyecto}

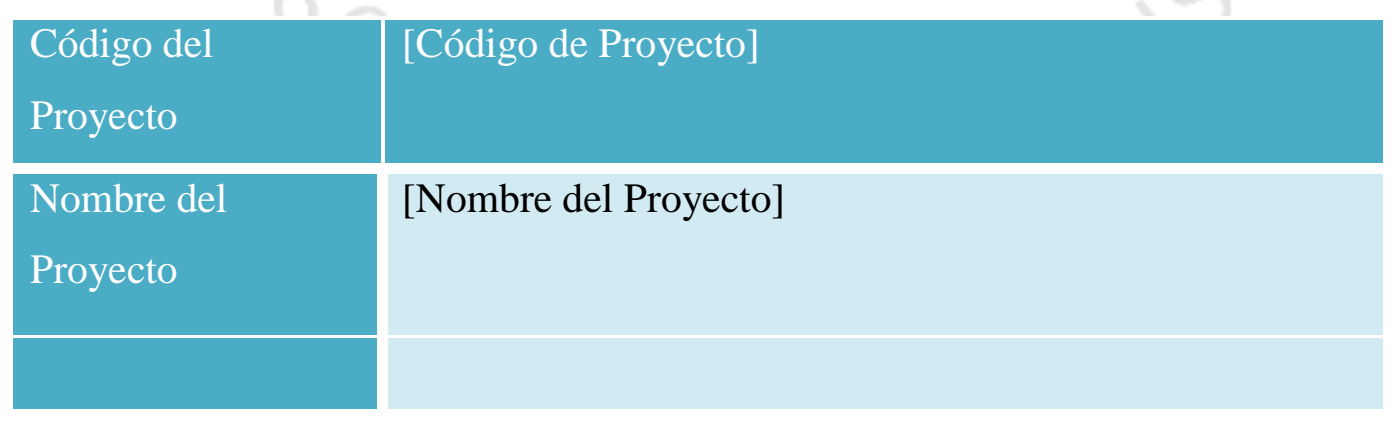




\section{Problemas identificados}

Problemas identificados

1. Ejemplo \#01: Retraso en las fechas comprometidas para la entrega el Modulo 1.

2. Ejemplo \#02: Error al cargar la aplicación utilizando un usuario con el Perfil "Gestor".

\section{Soluciones y Acciones Correctivas}

[Acuerdos, Soluciones y acciones correctivas respecto a los temas Tratados]

\section{Soluciones y Acciones Correctivas}

[Soluciones y Acciones Correctivas respecto al tema tratado \#01]

\section{\begin{tabular}{l|l} 
Apertura & Responsables
\end{tabular}}

[\#\#/\#\#/\#\#\#\#] [Nombres y Apellidos del Responsable \# 01]

Cierre [Nombres y Apellidos del Responsable \# 02]

[\#\#/\#\#/\#\#\#\#] [Nombres y Apellidos del Responsable \# 03]

\section{Seguimiento}

Seguimiento de las reuniones.

\begin{tabular}{l|l|l} 
Acta & Fecha & Detalle
\end{tabular}
[ID del Acta \#\#] [\#\#/\#\#/\#\#]
[ID del Acta \#\#] [\#\#/\#\#/\#\#]
[ID del Acta \#\#] [\#\#/\#\#/\#\#]

\section{Anexo}

Para asegurar el cumplimiento de la plantilla "Acciones Correctivas", se presenta la trazabilidad entre las secciones de la plantilla y la descripción de documentos presentes en la NTP ISO/IEC 29110-5-1-2. 


\begin{tabular}{|l|l|}
\hline Sección del Documento & Trazabilidad respecto a la NTP ISO/IEC 29110-5-1-2 \\
\hline Estado del Documento & -NA. \\
\hline Datos del Proyecto & -NA. \\
\hline 1. Problemas Identificados & -Identificación del Problema inicial \\
\hline $\begin{array}{l}\text { Correctivas } \\
\text { 3. Seguimiento }\end{array}$ & $\begin{array}{l}\text {-Soluciones, Acciones Correctivas (Responsable, fecha } \\
\text { esperado de la solución, estado) }\end{array}$ \\
\hline
\end{tabular}

*NA: No Aplica 


\section{Acta de Aceptación [Identificación del}

\section{Acta]}

[Nombre de la Empresa]

\section{Datos del Proyecto}

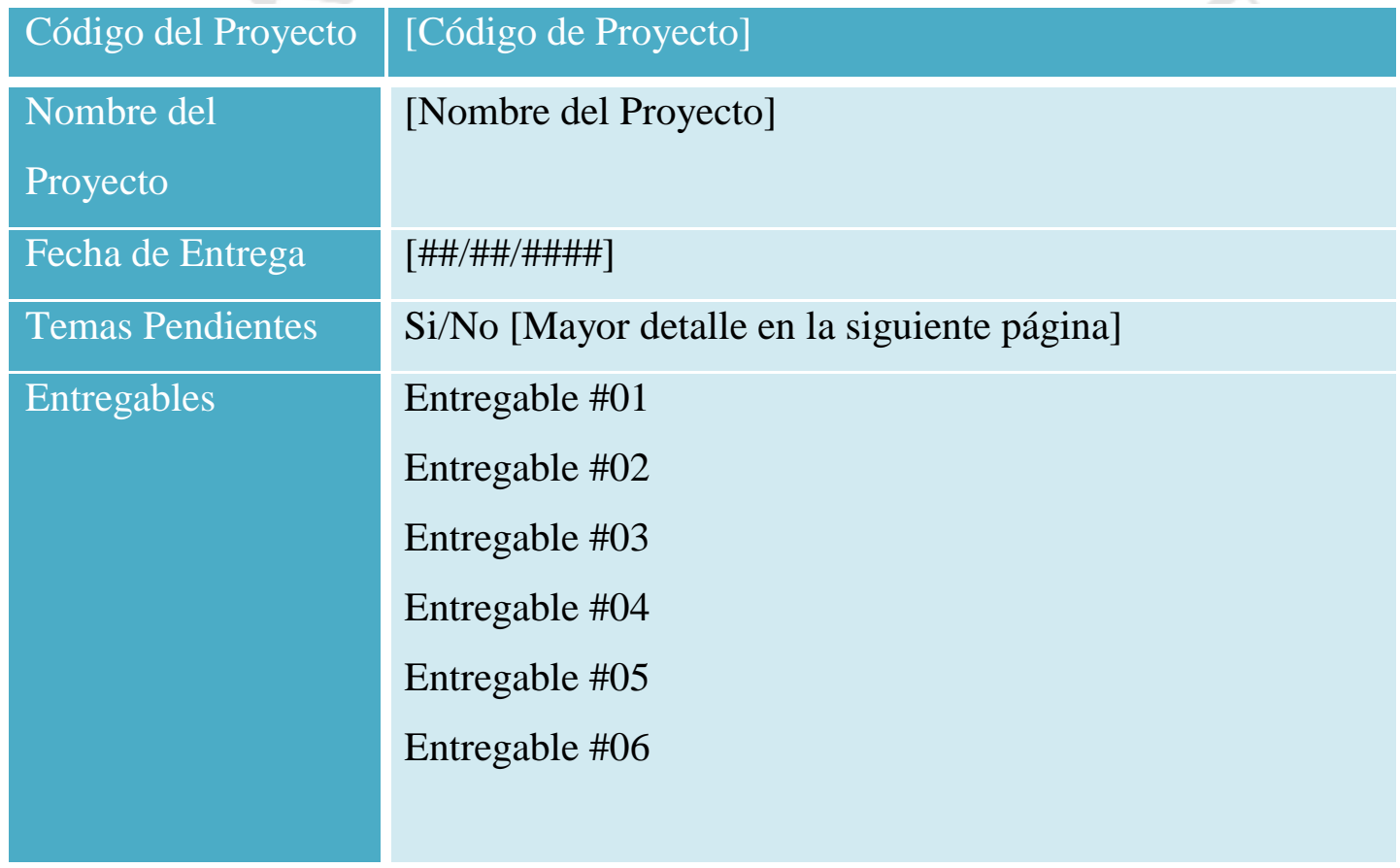

\section{Registro de Recepción de Entrega}

Firmar el documento al considerar que los entregables fueron recibidos.

\begin{tabular}{|l|l|l|}
\hline Responsable & Fecha & Firma \\
\hline $\begin{array}{l}\text { [Nombre completo del } \\
\text { Responsable \#01] }\end{array}$ & {$[\# \# / \# \# / \# \# \#]$} & \\
\hline [Nombre completo del & {$[\# \# / \# \# / \# \# \#]$} & \\
\hline
\end{tabular}


Responsable \#02]

[Nombre completo del [\#\#/\#\#/\#\#\#\#]

Responsable \#03]

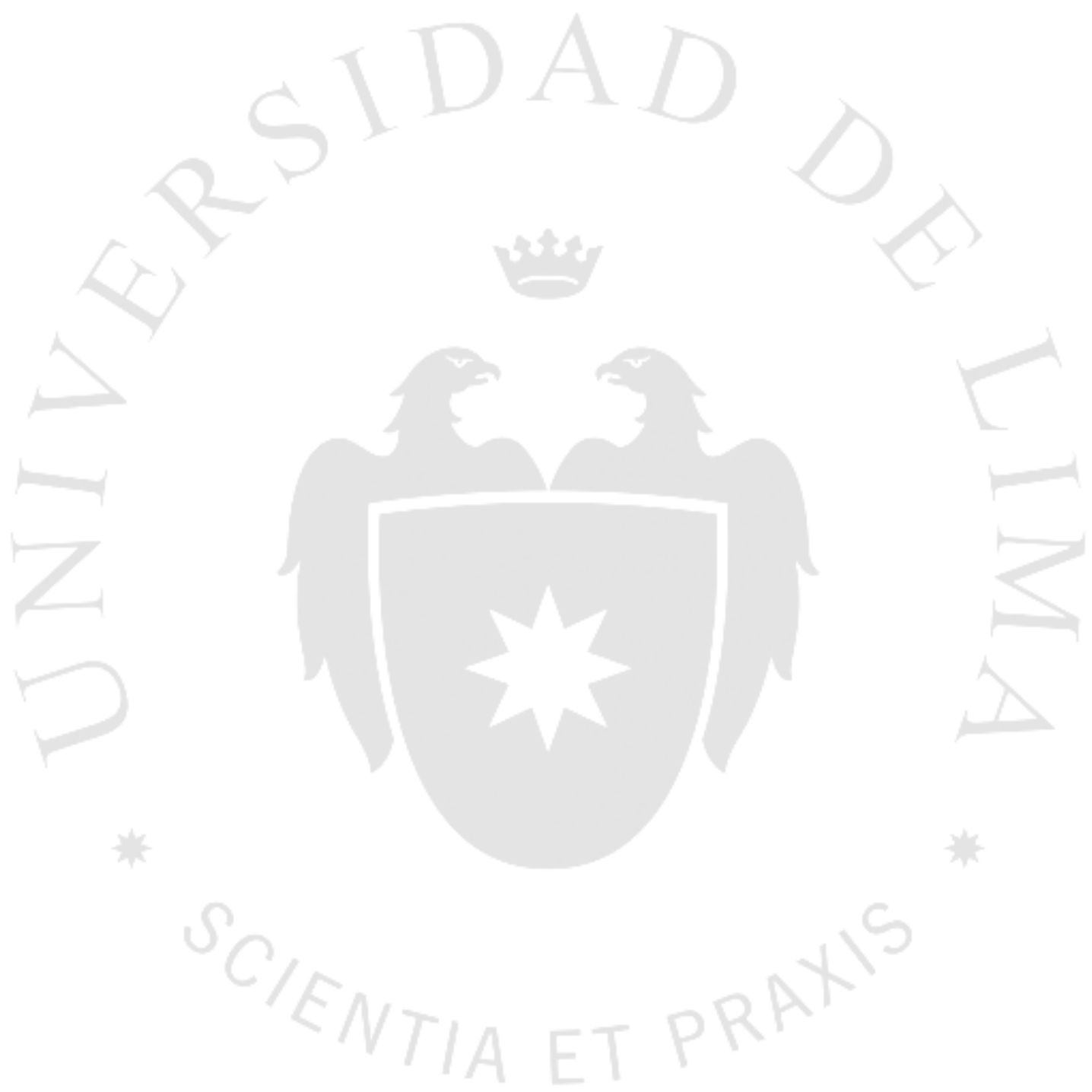




\section{Condiciones de Aceptación}

Listado de productos de software que serán entregados y las condiciones de aceptación

\section{Listado de Entregables}

\begin{tabular}{|c|c|c|}
\hline Entregable & $\begin{array}{l}\text { Descripción del } \\
\text { Entregable }\end{array}$ & Condiciones de Entrega \\
\hline $\begin{array}{l}\text { [Nombre del } \\
\text { Entregable } \\
01]\end{array}$ & $\begin{array}{l}\text { [Descripción breve del } \\
\text { Entregable 01] }\end{array}$ & [Condiciones de aceptación del entregable.] \\
\hline $\begin{array}{l}\text { [Nombre del } \\
\text { Entregable } \\
\text { 02] }\end{array}$ & $\begin{array}{l}\text { [Descripción breve del } \\
\text { Entregable 02] }\end{array}$ & [Condiciones de aceptación del entregable.] \\
\hline $\begin{array}{l}\text { [Nombre del } \\
\text { Entregable } \\
\text { 02] }\end{array}$ & $\begin{array}{l}\text { [Descripción breve del } \\
\text { Entregable 02] }\end{array}$ & [Condiciones de aceptación del entregable.] \\
\hline
\end{tabular}

\section{Condiciones de Aceptación}

Condiciones

de Aceptación

Lugar de

Entrega

Fecha de

Entrega
[Condiciones de Aceptación Generales]

[Lugar de Entrega]

[\#\#/\#\#/\#\#\#\#]

*Condiciones de aceptación del entregable: Las condiciones mínimas del entregable para que sea aceptado por el Cliente. 


\section{Pendientes}

[Identificación de Elementos Pendientes (Según lo descrito en el Plan del Proyecto]

\section{Listado de Pendientes}

NA. [No aplica]/ Descripción del Pendiente \#01.

\section{Anexo}

Se presenta la trazabilidad entre las secciones de la plantilla y la descripción de documentos presentes en la NTP ISO/IEC 29110-5-1-2.

\begin{tabular}{|l|l|}
\hline Sección del Documento & Trazabilidad respecto a la NTP ISO/IEC 29110-5-1-2 \\
\hline Datos del Proyecto & -NA. \\
\hline Registro de Recepción de Entrega & $\begin{array}{l}\text { - Identificación de la fecha de Recepción. } \\
\text { - Registro de recepción (Responsable y Firma). }\end{array}$ \\
\hline 1. Condiciones de aceptación & $\begin{array}{l}\text {-Identificación de los elementos entregados } \\
\text { - Registro de la verificación de los criterios de aceptación definidos } \\
\text { por parte del Cliente. }\end{array}$ \\
\hline 2. Pendientes & $\begin{array}{l}\text { - Identificación de cualquier asunto pendiente (en caso de ser } \\
\text { aplicable). }\end{array}$ \\
\hline & \\
\hline
\end{tabular}

*NA: No Aplica 


\section{Manual de Usuario [Identificación del}

\section{Manual de Usuario] [Versión \#\#.\#]}

[Código de Proyecto]- [Nombre del

\section{Proyecto]}

[Nombre de la Empresa]

\#\#/\#\#/\#\# [Fecha de creación del proyecto]

\section{Estado del Documento}

\begin{tabular}{|l|l|l|}
\hline Estado & Fecha & Responsable \\
\hline Preliminar & [Nombres y Apellidos.] \\
\hline Verificado & [Nombres y Apellidos.] \\
\hline Validado & [Nombres y Apellidos.] \\
\hline Línea Base & & \\
\hline
\end{tabular}




\section{Datos del Proyecto}

\begin{tabular}{|l|}
\hline Código del Proyecto \\
\hline Nombre del Proyecto \\
\hline Tipo de Proyecto \\
\hline Área
\end{tabular}

Empresa Cliente

Representante de la

Empresa

\section{Historial de Versiones}

\section{Fecha}

\#\#/\#\#/\#\#\#\#

(1.10

\#\#/\#\#/\#\#\#\#

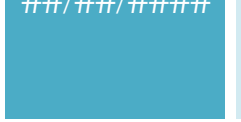

\#\#/\#\#/\#\#\#\#

\#.\#

\section{[Código de Proyecto]}

[Nombre del Proyecto]

[Naturaleza del Proyecto]

[Área de la Empresa]

[Nombre comercial de la empresa Cliente]

[Representante(s) de la empresa Cliente]

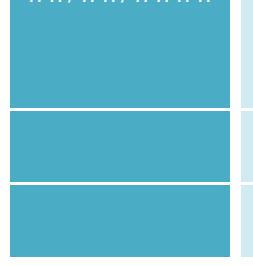

\section{Versión}

1.0

Descripción

Creación del Proyecto.

1.\# [Descripción del cambio en el alcance del Proyecto.]

[Descripción del cambio en el alcance del Proyecto.]

\section{Autor}

[Nombres y Apellidos-

Creador del Documento.]

[Nombres y Apellidos-

Quien actualizo el Doc.]

[Nombres y Apellidos-

Quien actualizo el Doc.]

\section{Firmas}

\section{Nombre}

[Cliente/Representante de

la empresa $\mathrm{XXXXX]}$

Gestor de Proyectos:

[Nombre del Gestor]

\section{Fecha}

[\#\#/\#\#/\#\#\#\#]

[\#\#/\#\#/\#\#\#\#]
Firma 
[Nombre del Líder

Técnico]

\section{Descripción General del Software}

[Descripción general del producto de software (Software/ Modulo de un producto de Software) a desarrollar/ Modificar.]

[Breve descripción del Uso Previsto del Software a Desarrollar/ Modificar.]

\section{Entorno operacional requerido}

[Entorno operacional requerido para el funcionamiento del software desarrollado/ Modificado.]

\section{Recursos provistos y requeridos}

[Recursos provistos y requeridos para el funcionamiento del software desarrollado/ Modificado.]

\section{Procedimientos de instalación y desinstalación}

[Procedimientos de instalación y desinstalación del software desarrollado/ Modificado.]

\section{Procedimientos para entrar y salir del Software}

[Procedimientos para entrar y salir del Software.]

\section{Funcionalidades del Software}

[Procedimientos del usuario para realizar Tareas específicas utilizando el Software.]

\section{Comandos del Software}

[Relación y explicación de comandos del Software y de los mensajes del sistema hacia el usuario.]

\section{Advertencias y Precauciones}

[Según corresponda a los riesgos identificados; este incluye advertencias, precauciones y notas con correcciones.] 


\section{Procedimiento para reportar problemas y asistencia técnica}

[Procedimiento para reportar problemas y asistencia.]

\section{Procedimientos para la solución de problemas y corrección de errores}

[Incluye los procedimientos para la solución de problemas y corrección de errores.]

\section{Anexo}

Para asegurar el cumplimiento de la plantilla "Manual de Usuario", se presenta la trazabilidad entre las secciones de la plantilla y la descripción de documentos presentes en la NTP ISO/IEC 29110-5-1-2.

\begin{tabular}{|c|c|}
\hline Sección del Documento & Trazabilidad respecto a la NTP ISO/IEC 29110-5-1-2 \\
\hline Estado del Documento & -Estados Aplicables: Preliminar, Verificado, Línea base. \\
\hline Datos del Proyecto & -NA. \\
\hline $\begin{array}{l}\text { 1. Descripción General del } \\
\text { Software }\end{array}$ & $\begin{array}{l}\text { - Breve descripción del uso previsto del Software (el concepto de } \\
\text { operaciones). }\end{array}$ \\
\hline $\begin{array}{l}\text { 2. Procedimientos de instalación } \\
\text { y desinstalación. }\end{array}$ & - Procedimientos de instalación y desinstalación. \\
\hline $\begin{array}{l}\text { 3. Recursos provistos y } \\
\text { requeridos }\end{array}$ & - Recursos provistos y requeridos. \\
\hline 4. Entorno operacional requerido & - Entorno operacional requerido. \\
\hline $\begin{array}{l}\text { 5. Procedimientos para entrar y } \\
\text { salir del Software }\end{array}$ & - Procedimientos para entrar y salir del Software. \\
\hline 6. Funcionalidades del Software & $\begin{array}{l}\text { - Procedimientos del usuario para realizar Tareas específicas } \\
\text { utilizando el Software. }\end{array}$ \\
\hline 7. Comandos del Software. & $\begin{array}{l}\text { - Relación y explicación de comandos del Software y de los mensajes } \\
\text { del sistema hacia el usuario. }\end{array}$ \\
\hline 8. Advertencias y Precauciones. & $\begin{array}{l}\text { - Según corresponda a los riesgos identificados; este incluye } \\
\text { advertencias, precauciones y notas con correcciones. }\end{array}$ \\
\hline
\end{tabular}




\begin{tabular}{|l|l|}
\hline $\begin{array}{l}\text { 9. Procedimiento para reportar } \\
\text { problemas y asistencia técnica. }\end{array}$ & Facilidad para reportar problemas y asistencia. \\
\hline $\begin{array}{l}\text { 10. Procedimientos para la } \\
\text { solución de problemas y } \\
\text { corrección de errores. }\end{array}$ & $\begin{array}{l}\text { - Incluye los procedimientos para la solución de problemas y } \\
\text { corrección de errores. }\end{array}$ \\
\hline & \\
\hline & \\
\hline
\end{tabular}

*NA: No Aplica 


\section{Manual de Operación [Identificación del}

Manual de Operación] [Versión \#\#.\#]

\section{[Código de Proyecto]- [Nombre del}

\section{Proyecto]}

[Nombre de la Empresa]

\#\#/\#\#/\#\# [Fecha de creación del proyecto]

\section{Estado del Documento}

\begin{tabular}{|l|l|l|}
\hline Estado & Fecha & Responsable \\
\hline Preliminar & [Nombres y Apellidos.] \\
\hline Verificado & [Nombres y Apellidos.] \\
\hline Validado & [Nombres y Apellidos.] \\
\hline Línea Base & [Nombres y Apellidos.] \\
\hline & \\
\hline & $\mid$ I \\
\hline
\end{tabular}




\section{Datos del Proyecto}

\begin{tabular}{|l|}
\hline Código del Proyecto \\
\hline Nombre del Proyecto \\
\hline Tipo de Proyecto \\
\hline Área
\end{tabular}

Empresa Cliente

Representante de la

Empresa

\section{Historial de Versiones}

\begin{tabular}{|c|c|c|c|}
\hline Fecha & Versión & Descripción & Autor \\
\hline \#\#/\#\#/\#\#\#\# & 1.0 & Creación del Proyecto. & $\begin{array}{l}\text { [Nombres y Apellidos- } \\
\text { Creador del Documento.] }\end{array}$ \\
\hline \#\#/\#\#/\#\#\#\# & 1.\# & $\begin{array}{l}\text { [Descripción del cambio en el } \\
\text { alcance del Proyecto.] }\end{array}$ & $\begin{array}{l}\text { [Nombres y Apellidos- } \\
\text { Quien actualizo el Doc.] }\end{array}$ \\
\hline \#\#/\#\#/\#\#\#\# & \#.\# & $\begin{array}{l}\text { [Descripción del cambio en el } \\
\text { alcance del Proyecto.] }\end{array}$ & $\begin{array}{l}\text { [Nombres y Apellidos- } \\
\text { Quien actualizo el Doc.] }\end{array}$ \\
\hline
\end{tabular}

\section{Firmas}

\begin{tabular}{|l|l|l|}
\hline Nombre & Fecha & Firma \\
\hline [Cliente/Representante de & {$[\# \# / \# \# / \# \# \#]$} & \\
la empresa XXXXX] & & \\
\hline Gestor de Proyectos: & {$[\# \# / \# \# / \# \# \#]$} & \\
\hline [Nombre del Gestor $]$ & & \\
\hline Líder Técnico: & {$[$ [\#\#/\#\#/\#\#\#] } & \\
\hline
\end{tabular}




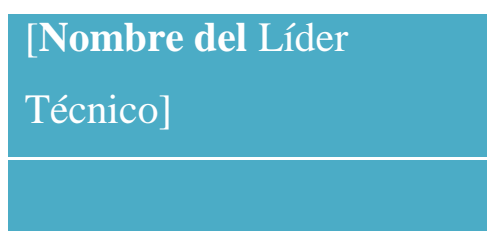

\section{Criterios para la operación}

[Criterios para la operación del software]

\section{Operación del Producto}

[Descripción de cómo operar el producto]

- Entorno operativo requerido

- Herramientas y material de apoyo requerido

- [Por ejemplo, manuales de usuario]

- Alertas de seguridad

- Preparativos y secuencia para la puesta en marcha

- Preguntas frecuentes

- Información adicional

- [Fuentes de Información adicional y ayuda para operar el producto]

5. Certificación y aprobaciones de seguridad

[Certificación y aprobaciones de seguridad]

\section{Garantía}

[Garantía e instrucciones de reemplazo según lo acordado entre el cliente y la empresa a cargo del desarrollo] 


\section{Anexo}

Para asegurar el cumplimiento de la plantilla "Manual de Operación", se presenta la trazabilidad entre las secciones de la plantilla y la descripción de documentos presentes en la NTP ISO/IEC 29110-5-1-2.

\begin{tabular}{|l|l|}
\hline Sección del Documento & Trazabilidad respecto a la NTP ISO/IEC 29110-5-1-2 \\
\hline Estado del Documento & Estados Aplicables: Verificado, Incorporado en línea base. \\
\hline Datos generales & NA. \\
\hline 1. Criterios para la operación & - Criterios de la operación \\
\hline 2. Operación del Producto & $\begin{array}{l}\text { - Una descripción de cómo operar el producto, incluyendo: } \\
\text { Entorno operativo requerido } \\
\text { Herramientas y material de apoyo requerido [Por ejemplo, manuales } \\
\text { de usuario] } \\
\text { Alertas de seguridad } \\
\text { Preparativos y secuencia para la puesta en marcha } \\
\text { Preguntas frecuentes } \\
\text { Información adicional [Información adicional y ayuda para operar el } \\
\text { producto] }\end{array}$ \\
\hline $\begin{array}{l}\text { 3. Certificación y aprobaciones } \\
\text { de seguridad }\end{array}$ & - Certificación y aprobaciones de seguridad (safety) \\
\hline 4. Garantía & - Garantía e instrucciones de reemplazo \\
\hline & \\
\hline
\end{tabular}

*NA: No Aplica 


\subsection{Registro de Trazabilidad}

\section{Registro de Trazabilidad del Proyecto "Proyecto Auditor}

\section{Plus"}

\begin{tabular}{|c|c|c|c|c|}
\hline $\begin{array}{l}\text { Especificación de } \\
\text { Requisitos }\end{array}$ & Requisitos funcionales & Diseño de Software & $\begin{array}{l}\text { Componente de } \\
\text { Software }\end{array}$ & Casos y Procedimientos de Prueba \\
\hline $\begin{array}{l}\text { [Identificación de la } \\
\text { especificación de } \\
\text { Requisitos] }\end{array}$ & $\begin{array}{l}\text { R1: [Requisito funcional } \\
\# 01]\end{array}$ & $\begin{array}{l}\text { [D1: Sección del Diseño } \\
\text { de Software \#01] }\end{array}$ & $\begin{array}{l}\text { S1: [Identificación del } \\
\text { Componente de Software } \\
\# 01]\end{array}$ & $\begin{array}{l}\text { T1: [Identificación del Caso y } \\
\text { Procedimiento de Prueba \#01] }\end{array}$ \\
\hline $\begin{array}{l}\text { [Identificación de la } \\
\text { especificación de } \\
\text { Requisitos] }\end{array}$ & $\begin{array}{l}\text { R1: [Requisito funcional } \\
\# 01]\end{array}$ & $\begin{array}{l}\text { [D1: Sección del Diseño } \\
\text { de Software \#01] }\end{array}$ & $\begin{array}{l}\text { S1: [Identificación del } \\
\text { Componente de Software } \\
\# 01]\end{array}$ & $\begin{array}{l}\text { T1: [Identificación del Caso y } \\
\text { Procedimiento de Prueba \#02] }\end{array}$ \\
\hline $\begin{array}{l}\text { [Identificación de la } \\
\text { especificación de } \\
\text { Requisitos] }\end{array}$ & $\begin{array}{l}\text { R2: [Requisito funcional } \\
\# 02 \text { ] }\end{array}$ & $\begin{array}{l}\text { [D2: Sección del Diseño } \\
\text { de Software \#02] }\end{array}$ & $\begin{array}{l}\text { S2: [Identificación del } \\
\text { Componente de Software } \\
\# 02]\end{array}$ & $\begin{array}{l}\text { T1: [Identificación del Caso y } \\
\text { Procedimiento de Prueba \#03] }\end{array}$ \\
\hline $\begin{array}{l}\text { [Identificación de la } \\
\text { especificación de } \\
\text { Requisitos] }\end{array}$ & $\begin{array}{l}\text { R2: [Requisito funcional } \\
\# 02 \text { ] }\end{array}$ & $\begin{array}{l}\text { [D2: Sección del Diseño } \\
\text { de Software } \# 02 \text { ] }\end{array}$ & $\begin{array}{l}\text { S2: [Identificación del } \\
\text { Componente de Software } \\
\# 02]\end{array}$ & $\begin{array}{l}\text { T1: [Identificación del Caso y } \\
\text { Procedimiento de Prueba \#04] }\end{array}$ \\
\hline
\end{tabular}




\title{
Registro de Verificación [Identificación del
}

\section{-Registro]}

\author{
[Nombre de la Empresa]
}

\section{Datos del Proyecto}

\begin{tabular}{l|l}
\hline Código del Proyecto & [Código de Proyecto] \\
\hline Nombre del Proyecto & [Nombre del Proyecto] \\
\hline Entregables del & $\begin{array}{l}\text { [Listado de Elementos generados en el ciclo de vida de } \\
\text { Desarrollo de Software que serán verificados]. } \\
\text { Entregable \#01 } \\
\text { Entregable \#02 }\end{array}$ \\
\end{tabular}

\section{Registro de Elementos}

[Listado de Elementos generados en el Ciclo de vida de desarrollo de software que serán verificados].

\begin{tabular}{|c|c|c|c|c|}
\hline Entregable & Responsable & $\begin{array}{l}\text { Fecha } \\
\text { Ver. }\end{array}$ & $\begin{array}{l}\text { Esfuerz } \\
\text { o HH }\end{array}$ & Estado \\
\hline $\begin{array}{l}\text { [Nombre del } \\
\text { Entregable } \\
01]\end{array}$ & $\begin{array}{l}\text { [Nombre del } \\
\text { Responsable de } \\
\text { realizar la } \\
\text { verificación] }\end{array}$ & $\begin{array}{l}\text { \#/\#\#/ } \\
\# \# \#\end{array}$ & $\begin{array}{l}\text { \#\# hrs. } \\
\text { \#\# min. }\end{array}$ & $\begin{array}{l}\text { [Aprobado/ No Aprobado/ } \\
\text { Verificación Pendiente] }\end{array}$ \\
\hline $\begin{array}{l}\text { [Nombre del } \\
\text { Entregable } \\
02]\end{array}$ & $\begin{array}{l}\text { [Nombre del } \\
\text { Responsable de } \\
\text { realizar la } \\
\text { verificación] }\end{array}$ & $\begin{array}{l}\text { \#/\#\#/ } \\
\# \# \#\end{array}$ & $\begin{array}{l}\text { \#\# hrs. } \\
\text { \#\# min. }\end{array}$ & $\begin{array}{l}\text { [Aprobado/ No Aprobado/ } \\
\text { Verificación Pendiente] }\end{array}$ \\
\hline
\end{tabular}




\section{Defectos Identificados}

[Listado de defectos encontrados durante la verificación].

\section{Entregable}

[Nombre del

Entregable

02]

\section{Descripción}

[Descripción de los defectos encontrados en los entregables durante la verificación en caso aplique].

\section{Anexo}

Para asegurar el cumplimiento de la plantilla "Registro de Verificación", se presenta la trazabilidad entre las secciones de la plantilla y la descripción de documentos presentes en la NTP ISO/IEC 29110-5-1-2.

\begin{tabular}{|l|l|}
\hline Sección del Documento & Trazabilidad respecto a la NTP ISO/IEC 29110-5-1-2 \\
\hline Datos del Proyectos & - Lista de comprobación para la verificación \\
\hline Registro de Elementos & - Lista de comprobación para la verificación \\
& - Participantes \\
& - Fecha \\
& - Lugar \\
& - Duración \\
& - Elementos aprobados por la verificación \\
& - Elementos no aprobados por la verificación \\
& - Elementos pendientes de la verificación \\
\hline Defectos Identificados & \\
\hline & - Documento de la ejecución de la validación \\
\hline & \\
\hline
\end{tabular}

*NA: No Aplica 


\title{
Registro de Validación [Identificación del -
}

\section{Registro]}

\author{
[Nombre de la Empresa]
}

\section{Datos del Proyecto}

\begin{tabular}{l|l}
\hline Código del Proyecto & [Código de Proyecto] \\
\hline Nombre del Proyecto & [Nombre del Proyecto] \\
\hline Entregables del & [Listado de Elementos generados en el Ciclo de vida de \\
Proyecto & $\begin{array}{l}\text { desarrollo de software que serán validados]. } \\
\text { Entregable \#01 } \\
\text { Entregable \#02 }\end{array}$ \\
&
\end{tabular}

\section{Registro de Elementos}

[Listado de Elementos generados en el Ciclo de vida de desarrollo de software que serán validados].

\begin{tabular}{|c|c|c|c|c|}
\hline Entregable & Responsable & $\begin{array}{l}\text { Fecha } \\
\text { Val. }\end{array}$ & $\begin{array}{l}\text { Esfuerz } \\
\text { o HH }\end{array}$ & Estado \\
\hline $\begin{array}{l}\text { [Nombre del } \\
\text { Entregable } \\
01]\end{array}$ & $\begin{array}{l}\text { [Nombre del } \\
\text { Responsable de } \\
\text { realizar la validación] }\end{array}$ & $\begin{array}{l}\text { \#/\#\#/ } \\
\# \# \#\end{array}$ & $\begin{array}{l}\text { \#\# hrs. } \\
\text { \#\# min. }\end{array}$ & $\begin{array}{l}\text { [Aprobado/ No Aprobado/ } \\
\text { Validación Pendiente] }\end{array}$ \\
\hline $\begin{array}{l}\text { [Nombre del } \\
\text { Entregable } \\
02]\end{array}$ & $\begin{array}{l}\text { [Nombre del } \\
\text { Responsable de } \\
\text { realizar la validación] }\end{array}$ & $\begin{array}{l}\text { \#/\#\#/ } \\
\# \# \#\end{array}$ & $\begin{array}{l}\text { \#\# hrs. } \\
\text { \#\# min. }\end{array}$ & $\begin{array}{l}\text { [Aprobado/ No Aprobado/ } \\
\text { Validación Pendiente] }\end{array}$ \\
\hline
\end{tabular}




\section{Defectos Identificados}

[Listado de defectos encontrados durante la validación].

Entregable

[Nombre del

Entregable

02]

\section{Anexo}

Para asegurar el cumplimiento de la plantilla "Registro de Validación", se presenta la trazabilidad entre las secciones de la plantilla y la descripción de documentos presentes en la NTP ISO/IEC 29110-5-1-2.

\begin{tabular}{|l|l|}
\hline Sección del Documento & Trazabilidad respecto a la NTP ISO/IEC 29110-5-1-2 \\
\hline Datos del Proyecto & - Lista de comprobación para la validación \\
\hline Datos del Proyectos & - Lista de comprobación para la validación \\
\hline Registro de Elementos & $\begin{array}{l}\text { - Lista de comprobación para la validación } \\
\text { - Participantes } \\
\text { - Fecha } \\
\text { - Lugar } \\
\text { - Duración } \\
\text { - Elementos aprobados por la verificación } \\
\text { - Elementos no aprobados por la validación } \\
\text { - Elementos pendientes de la validación }\end{array}$ \\
\hline Defectos Identificados & - Defectos identificados durante la validación \\
\hline
\end{tabular}

*NA: No Aplica

\section{Descripción} validación en caso aplique].
[Descripción de los defectos encontrados en los entregables durante la 


\section{ANEXO 3: Manual de Funciones del Equipo de Trabajo (MOFs)}

Se presenta el detalle de la información del Manual de Funciones, extraída de las entrevistas abiertas que se hicieron al equipo de trabajo, participantes en el proyecto de investigación.

\subsection{Manual de Funciones para Analista de Calidad}

\begin{tabular}{|c|c|}
\hline MANUAL DE FUNCIONES & MOF $\mathbf{N}^{\mathbf{0}}$ HO - 001 \\
\hline AREA: & \\
DESARROLLO DE SOFTWARE
\end{tabular}

1) PUESTO:

Analista de Calidad

\section{2) OBJETIVOS DEL CARGO:}

Asegurar la calidad del producto de software desarrollando en práctica estándares, procesos, herramientas y métodos de evaluación.

Revisar y evaluar las funcionalidades del software en base a los requerimientos del cliente.

\section{3) VALORES Y APTITUDES:}

\section{VALORES}

$>$ Ética

$>$ Responsabilidad

$>$ Lealtad y sentido de pertenencia

$>$ Comunicación efectiva

Adhesión a normas y políticas 
Puntualidad

Integridad

\section{APTITUDES}

Entusiasmo

Flexibilidad

$>$ Orientación a Resultados

4) PERSONAL A CARGO:

Ninguno.

\section{5) FUNCIONES:}

1. Elaborar y ejecutar los Casos de Pruebas y Procedimientos de Pruebas unitarias e integrales utilizando como base la Historia de Usuarios y el Diseño del Software.

2. Identificar los posibles riesgos que pueden tener un impacto negativo al proyecto.

3. Generar Solicitudes de Cambio en caso haya alguna observación en el tiempo y alcance previamente definidos en el proyecto.

4. Generar Solicitudes de Cambio en caso haya alguna observación en el tiempo y alcance previamente definidos en el proyecto.

5. Participar en las reuniones con el Equipo de Trabajo y Líder Técnico, las cuales permiten conocer los problemas, el estado de las tareas, registrar acuerdos y seguimiento oportuno hasta el cierre del proyecto.

6. Apoyar en la elaboración y revisión de los documentos: Manual de Usuario, Manual de Operación y Manual de mantenimiento.

7. Hacer seguimiento y asegurar el cumplimiento del Proceso de desarrollo de software de la empresa. 


\section{PERFIL DEL PUESTO:}

\section{FORMACION ACADEMICA:}

Profesional Universitario en las carreras de Ingeniería de Sistemas, Ingeniería Industrial, Ingeniería de Software, o Egresado de Instituciones Técnicas Superiores.

\section{EXPERIENCIA:}

Experiencia desempeñando funciones similares.

\subsection{Manual de Funciones para Analista Programador}

\begin{tabular}{|c|c|}
\hline MANUAL DE FUNCIONES & MOF $\mathbf{N}^{\mathbf{0}}$ HO - 002 \\
\hline AREA: \\
DESARROLLO DE SOFTWARE \\
\hline
\end{tabular}

\section{1) PUESTO:}

Analista Programador

2) OBJETIVOS DEL CARGO:

Analizar las necesidades del cliente y brindar una solución de desarrollo de software.

\section{3) VALORES Y APTITUDES:}

\section{VALORES}

$>$ Ética

$>$ Responsabilidad

$>$ Lealtad y sentido de pertenencia

$>$ Comunicación efectiva

Adhesión a normas y políticas

$>$ Puntualidad

Integridad 


\section{APTITUDES}

Entusiasmo

Flexibilidad

Orientación a Resultados

4) PERSONAL A CARGO:

Ninguno.

\section{5) FUNCIONES:}

1. Elaborar la Historia de Usuarios, donde se describe el análisis de los requerimientos del software utilizando como base el Plan del Proyecto.

2. Elaborar el Diseño de Software, donde se describe la arquitectura y diseño detallado utilizando como base el Plan del Proyecto.

3. Elaborar y ejecutar los Casos de Pruebas y Procedimientos de Pruebas unitarias e integrales utilizando como base la Historia de Usuarios y el Diseño del Software.

4. Construir y/o Actualizar los componentes de Software utilizando como base el Documento de Historia de Usuario y Diseño de Software.

5. Elaborar el Manual de Usuario, donde se describe el uso de las funcionalidades de la aplicación, utilizando como base la Historia de Usuarios.

6. Elaborar el Manual de Mantenimiento, donde se describe la configuración del software y el ambiente utilizado para el desarrollo y pruebas.

7. Elaborar el Manual de Usuario, donde se describe como instalar y gestionar el software.

8. Elaborar el Registro de Trazabilidad, donde se describe la relación entre los requisitos, elementos del diseño, Componentes y Casos y Procedimientos de Prueba.

9. Almacenar los documentos y componentes se software generados y/o actualizados según las políticas de gestión de versiones de la empresa.

10. Identificar los posibles riesgos que pueden tener un impacto negativo al proyecto.

11. Realizar reuniones con el Cliente del Proyecto

12. Generar Solicitudes de Cambio en caso haya alguna observación en el tiempo y alcance previamente definidos en el proyecto. 
13. Realizar reuniones con el Equipo de Trabajo y Líder Técnico, las cuales permiten conocer el estado de las tareas, acuerdos y realizar un seguimiento oportuno hasta el cierre del proyecto.

14. Elaborar reportes de avance del proyecto.

\section{PERFIL DEL PUESTO:}

\section{FORMACION ACADEMICA:}

Profesional universitario o Egresado de Instituciones Técnicas Superiores con conocimiento de las carreras de Ingeniería de Sistemas e Ingeniería de Software.

EXPERIENCIA: Experiencia desempeñando funciones similares.

\subsection{Manual de Funciones para Gestor del proyecto}

\begin{tabular}{|c|c|}
\hline MANUAL DE FUNCIONES & MOF $\mathbf{N}^{\mathbf{0}}$ HO - 003 \\
\hline AREA: & \\
\hline DESARROLLO DE SOFTWARE & \\
\hline
\end{tabular}

1) PUESTO:

Gestor del Proyecto

\section{2) OBJETIVOS DEL CARGO:}

Realizar el seguimiento y control a cada una de las actividades del proyecto, gestionando los recursos de los proyectos para satisfacer las necesidades del cliente cumpliendo con el tiempo, costo y alcance establecido.

\section{3) VALORES Y APTITUDES:}

\section{VALORES}

$>$ Ética

$>$ Responsabilidad

Lealtad y sentido de pertenencia 
Comunicación efectiva

Adhesión a normas y políticas

Puntualidad

Integridad

\section{APTITUDES}

Entusiasmo

Flexibilidad

Orientación a Resultados

4) PERSONAL A CARGO:

Ninguno.

\section{5) FUNCIONES:}

1. Elaborar propuestas para el inicio de un proyecto, donde se debe especificar los requerimientos del cliente. La propuesta incluye lo siguiente: Servicios Ofrecidos como son la Descripción del Servicio y Entregables, Tiempo de entrega, Consideraciones, precio y condiciones de pago del servicio.

2. Definir el alcance, objetivos y descripción del servicio, entregables, instrucción de entrega en c/u de los entregables y costo del proyecto estimado utilizando como base la Propuesta del Proyecto.

3. Describir y asignar los recursos humanos y tecnológicos, dependiendo del proyecto. Los recursos humanos deben ser asignados en base a los roles, habilidades y competencias.

4. Establecer las fechas de inicio y fin estimadas en cada una de las tareas elaborando un Diagrama de Gantt a fin de obtener un Cronograma de las Tareas del Proyecto verificando los recursos, secuencia, dependencia y holgura de las tareas.

5. Identificar los posibles riesgos que pueden tener un(os) impacto(s) negativo(s) al proyecto, en caso sea necesario.

6. Establecer la estrategia de control de versiones, dependiendo del proyecto.

7. Generar el Plan del Proyecto integrando los elementos previamente definidos.

8. Establecer reuniones con el Cliente del Proyecto. 
9. Habilitar el Repositorio del Proyecto en base a la estrategia de control de versiones.

10. Monitorear la ejecución del Plan del Proyecto a través del estado de las tareas generadas por el Equipo de Trabajo en el software Jira comparando con el tiempo estimado de las tareas establecidas anteriormente en el Diagrama de Gantt.

11. Analizar y evaluar el impacto que puede tener el proyecto en costo, tiempo y alcance.

12. Generar Solicitudes de Cambio en caso haya alguna observación o impacto en el proyecto.

13. Establecer reuniones con el Equipo de Trabajo y Líder Técnico, las cuales permiten conocer los problemas, el estado de las tareas, registrar acuerdos y seguimiento oportuno hasta el cierre del proyecto.

14. Evaluar el progreso del proyecto con respecto al Plan del Proyecto, comparando lo siguiente:

-Tareas reales (JIRA) contra las tareas planeadas (Diagrama de Gantt)

-Resultados o hitos reales contra los objetivos establecidos en el proyecto

-Recursos reales asignados contra los recursos planeados

-Tiempo real contra tiempo el tiempo estimado

-Riesgo real contra los riesgos identificados previos

15. Elaborar reportes de avance del proyecto.

16. Establecer acciones correctivas especificadas en el Acta de Reunión con el objetivo de contrarrestar los riesgos y problemas que afecten el cumplimiento del Plan del Proyecto.

17. Detectar si existen cambios en los requisitos del Proyecto para proceder a generar una Solicitud de Cambio y dar seguimiento oportuno.

18. Establecer una reunión con el cliente para formalizar la culminación del proyecto en base a las Instrucciones de Entrega en el Plan del Proyecto.

19. Almacenar y/o actualizar la documentación y Componentes de software en el Repositorio de datos.

\section{PERFIL DEL PUESTO:}

\section{FORMACION ACADEMICA:}

Profesional Universitario en las carreras de Administración, Gestión del proyecto, Ingeniería de Sistemas, o Egresado de Instituciones Técnicas Superiores. 


\section{EXPERIENCIA:}

Experiencia desempeñando funciones similares.

\subsection{Manual de Funciones para el Líder Técnico}

\begin{tabular}{|c|c|}
\hline MANUAL DE FUNCIONES & MOF $\mathbf{N}^{\mathbf{0}}$ HO - 004 \\
\hline AREA: \\
DESARROLLO DE SOFTWARE \\
\hline
\end{tabular}

\section{1) PUESTO:}

Líder Técnico

\section{2) OBJETIVOS DEL CARGO:}

Dirigir y apoyar al equipo de trabajo a fin de obtener el cumplimiento de las actividades y tareas del proyecto.

3) VALORES Y APTITUDES:

VALORES

$>$ Ética

$>$ Responsabilidad

$>$ Lealtad y sentido de pertenencia

$>$ Comunicación efectiva

Adhesión a normas y políticas

Puntualidad

Integridad

\section{APTITUDES}

\section{Entusiasmo}

\section{Flexibilidad}


Orientación a Resultados

4) PERSONAL A CARGO:

Programadores.

Analista.

\section{5) FUNCIONES:}

1. Revisar y Verificar de forma detallada el Plan del Proyecto.

2. Verificar y/o actualizar que el ambiente de trabajo se encuentre establecido.

3. Revisar y verificar los documentos Historia de Usuario y Diseño de Software.

4. Revisar y verificar los documentos Historia de Usuario y Diseño de Software.

5. Identificar los posibles riesgos que pueden tener un(os) impacto(s) negativo(s) al proyecto, en caso sea necesario.

6. Analizar y evaluar el impacto que puede tener el proyecto en costo, tiempo y alcance.

7. Generar Solicitudes de Cambio en caso haya alguna observación o impacto en el proyecto.

8. Participar en las reuniones con el Equipo de Trabajo y Gestor del Proyecto, las cuales permiten conocer los problemas, el estado de las tareas, registrar acuerdos y seguimiento oportuno hasta el cierre del proyecto.

9. Detectar si existen cambios en los requisitos del Proyecto para proceder a generar una Solicitud de Cambio y dar seguimiento oportuno.

10. Participar en las reuniones con el cliente.

\section{PERFIL DEL PUESTO:}

\section{FORMACION ACADEMICA:}

Profesional Universitario en las carreras de Ingeniería de Sistemas, Ingeniería de Software, o Egresado de Instituciones Técnicas Superiores.

\section{EXPERIENCIA:}

Experiencia desempeñando funciones similares. 


\section{ANEXO 4: Evidencia - documentos de la empresa HOLINSYS}

\subsection{Plan del Proyecto - Proyecto GUARDIAN}

Contenido General del Documento:

\section{Contenido}

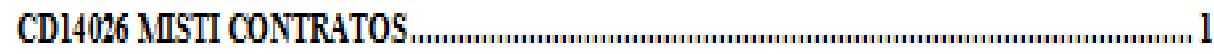

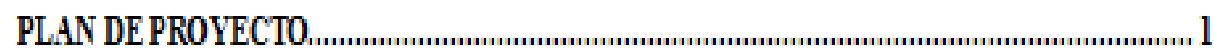

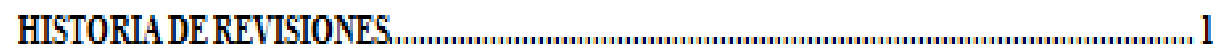

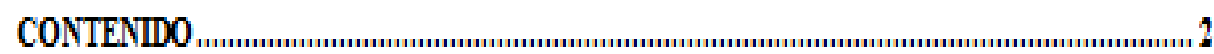

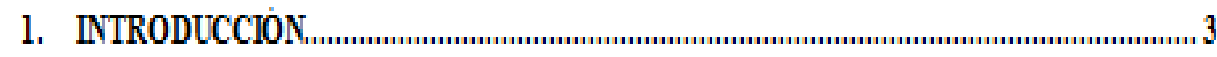

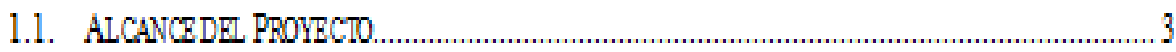

1.2. ENTREGABLLS DEL PROYECTO ................................................................................

1.3. ESTRATEGAAD CONIROL DE VERSDONES ..................................................................

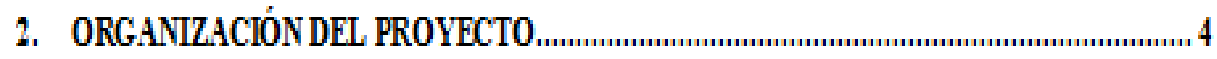

2.1. DADOSDER PROYECTO

2.2. ESTRUCTURA ORGANZACIONAL ......................................................................

2.2.1. Estructura Gentral ...........................................................................5

2.2.1. Estructura del Equipo de Trabajo ........................................................

2.3. AUTORDAD DEL PROYBCTO....................................................................

3. PROCESO DE GESTIÓN.......

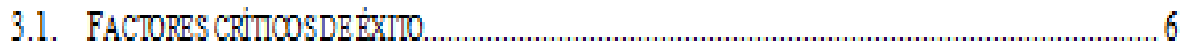

3.2. CONDCONES ASSMDAS,EXCLUSDNESY RESTRCCDONES........................................... 6

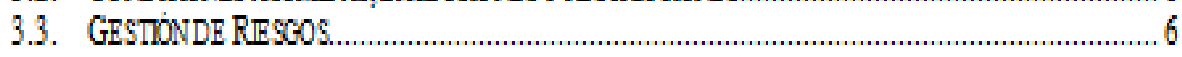

3.4. RECURSOS.................................................................................................

4. FECHAS DEL PROYECTO Y FIRMAS.

4.1. ESTIACDONDE FECHASA PROGRALAR.............................................................

4.2. CRONOCRANA DEL PROYECTO ……..................................................................

4.3. FRRAS........................................................................................................ 
A continuación, se describe algunas secciones del documento que reflejan las secciones establecidas por la ISO 29110:

- Introducción

\section{Introducción}

El proyecto consiste en la elaboración de un sistema web que permita sistematizar y facilitar la gestión de los contratos de la empresa GUARDIAN.

- Objetivos y Descripción del Producto/Servicio

\subsection{Alcance del Proyecto}

- Objetivos:

来

\begin{tabular}{|l|l|}
\hline \multicolumn{1}{|c|}{ Objetivos de la Organización } & \multicolumn{1}{c|}{ Objetivos del Proyecto } \\
\hline $\begin{array}{l}\text { Brindar mecanismos a la administración de } \\
\text { contratos de Corporación GUARDIAN para } \\
\text { realizar una gestión rápida y simple del } \\
\text { sistema. }\end{array}$ & $\begin{array}{l}\text { Buscar la rapidez y simplicidad en el } \\
\text { diseño y en la forma de uso del } \\
\text { sistema }\end{array}$ \\
\hline
\end{tabular}

\section{- Descripción del servicio:}

Plataforma Web para brindar un sistema que facilite la gestión de los contratos de Corporación GUARDIAN y que considere a su vez el mantenimiento del mismo. Esta contará con las siguientes características:

$\checkmark$ Desarrollado en HTML5, CCS3 y con backend en C\#. NET Framework 4.0.

$\checkmark$ Integrado con su sistema de intranet actual.

$\checkmark$ Responsive Design que permite una mejor experiencia en móviles y tablets.

$\checkmark$ Soporte a navegadores modernos.

$\checkmark$ Se manejarán diversos niveles de acceso dependiendo del perfil que maneje el usuario. 
- Entregables - Lista de Productos a ser entregados al cliente

1.2. Entregables del Proyecto
\begin{tabular}{|l|l|l|l|l|}
\hline $\begin{array}{l}\text { Identificación } \\
\text { Entregable }\end{array}$ & $\begin{array}{l}\text { Descripción } \\
\text { Entregable }\end{array}$ & $\begin{array}{l}\text { Fecha de } \\
\text { entrega }\end{array}$ & $\begin{array}{l}\text { Lugar de } \\
\text { entrega }\end{array}$ & $\begin{array}{l}\text { Condiciones } \\
\text { satisfacción }\end{array}$ \\
\hline Software & $\begin{array}{l}\text { Software } \\
\text { desarrollado } \\
\text { en el } \\
\text { proyecto }\end{array}$ & $\begin{array}{l}\text { Se entregará } \\
\text { instaladoen } \\
\text { el servidor } \\
\text { web de } \\
\text { producción }\end{array}$ \\
\hline Fuentedel software & & $\begin{array}{l}\text { Se entregará } \\
\text { en un CD }\end{array}$ \\
\hline
\end{tabular}

- Tareas y Duración estimadas (Calendario de Tareas)

\begin{tabular}{|c|c|c|c|c|c|c|c|c|c|}
\hline i & Modo & Task Name & Componente & - completad & Duración & Comienzo & Fin & - Preder. & $\begin{array}{l}\text { Nombres di } 19 \mathrm{go} \\
\text { los recursos } \mathrm{M}\end{array}$ \\
\hline & t & $\Delta$ GUARDIAN - Transportes & & $0 \%$ & 454 días & $\operatorname{mar} 20 / 05 / 14$ & vie $12 / 02 / 16$ & & \\
\hline & $\star$ & Inicio Proyecto & & $0 \%$ & Odías & $\operatorname{mar} 20 / 05 / 14$ & $\operatorname{mar} 20 / 05 / 14$ & & Holinsys \\
\hline & $\Rightarrow$ & Reunión Equipo - Revisión del Plan de Proyecto & & $0 \%$ & $1 \mathrm{hr}$ & $\operatorname{mar} 20 / 05 / 14$ & $\operatorname{mar} 20 / 05 / 14$ & 2 & Edward \\
\hline i & $F$ & Definición UX (Mockups) & & $0 \%$ & 2 hrs & $\operatorname{mar} 20 / 05 / 14$ & $\operatorname{mar} 20 / 05 / 14$ & 2 & Mario \\
\hline & 5 & Validacion & & $0 \%$ & 0.5 dias & $\operatorname{mar} 20 / 05 / 14$ & $\operatorname{mar} 20 / 05 / 14$ & 4 & GUARDIAN \\
\hline & $\Rightarrow$ & $\Delta$ Reuniones de Seguimiento & & $0 \%$ & 0.13 días & $\operatorname{mar} 20 / 05 / 14$ & $\operatorname{mar} 20 / 05 / 14$ & & \\
\hline & $\Rightarrow$ & Primera Reunión Virtual & & $0 \%$ & $1 \mathrm{hr}$ & $\operatorname{mar} 20 / 05 / 14$ & $\operatorname{mar} 20 / 05 / 14$ & & Edward \\
\hline & 风? & $\Delta$ Desarrollo de Sistema Web & & $0 \%$ & & $\operatorname{mar} 20 / 05 / 14$ & & & \\
\hline 唡申 & 5 & Preparacion de Historias de usuario & & $0 \%$ & $1 \mathrm{hr}$ & $\operatorname{mar} 20 / 05 / 14$ & $\operatorname{mar} 20 / 05 / 14$ & 2 & Mario \\
\hline 侖 & $F$ & $\begin{array}{l}\text { Reunión Equipo - Revisión de Historia de } \\
\text { Usuarios }\end{array}$ & & $0 \%$ & 30 mins & $\operatorname{mar} 20 / 05 / 14$ & $\operatorname{mar} 20 / 05 / 14$ & 9 & Todos \\
\hline$\phi$ & $F$ & Preparar Automatizador Web & & $0 \%$ & $2 \mathrm{hrs}$ & $\operatorname{mar} 20 / 05 / 14$ & $\operatorname{mar} 20 / 05 / 14$ & 9 & Mario \\
\hline & 5 & Preparar Automatizador Server & & $0 \%$ & $2 \mathrm{hrs}$ & $\operatorname{mar} 20 / 05 / 14$ & $\operatorname{mar} 20 / 05 / 14$ & 9 & Gustavo \\
\hline$\phi$ & $F$ & Preparar Documento Diseño de SW & & $0 \%$ & $2 \mathrm{hrs}$ & $\operatorname{mar} 20 / 05 / 14$ & $\operatorname{mar} 20 / 05 / 14$ & 11 & Mario \\
\hline & 5 & Reunión Equipo - Revisión de Diseño de SW & & $0 \%$ & $30 \mathrm{mins}$ & $\operatorname{mar} 20 / 05 / 14$ & $\operatorname{mar} 20 / 05 / 14$ & 13 & Todos \\
\hline & 5 & Preparación de Casos de Prueba & & $0 \%$ & $1 \mathrm{hr}$ & $\operatorname{mar} 20 / 05 / 14$ & $\operatorname{mar} 20 / 05 / 14$ & 10 & Fabiolla \\
\hline & 5 & Inicio de Programacion & & $0 \%$ & Odías & $\operatorname{mar} 20 / 05 / 14$ & $\operatorname{mar} 20 / 05 / 14$ & 14 & \\
\hline & 5 & Módulo Administrador & & $0 \%$ & 0.13 días & $\operatorname{mar} 20 / 05 / 14$ & $\operatorname{mar} 20 / 05 / 14$ & & Holinsys \\
\hline & $F$ & $\triangle$ Módulo Contratos & & $0 \%$ & 2.88 días & $\operatorname{mar} 20 / 05 / 14$ & vie $23 / 05 / 14$ & 17 & Holinsys \\
\hline
\end{tabular}




\begin{tabular}{|c|c|c|c|c|c|c|c|c|c|}
\hline i & 5 & Diagramacion de pantalla de busqueda & Modulo Contrato Web & $0 \%$ & 2 hrs & mar 20/05/14 & mié21/05/14 & & Mario \\
\hline & 5 & Servicio Resultados de Busqueda & Modulo Contratos Servicio & $0 \%$ & 3 hrs & mar 20/05/14 & mié21/05/14 & & Gustavo \\
\hline & 5 & Tabla anidada & Modulo Contrato Web & $0 \%$ & 4 hrs & mié21/05/14 & mié21/05/14 & 20 & Mario \\
\hline & 5 & Servicio Tabla Aniddada & Modulo Contrato Servicio & $0 \%$ & $2 \mathrm{hrs}$ & mié 21/05/14 & mié 21/05/14 & 21 & Gustavo \\
\hline & 5 & Interfaz contratos & Modulo Contrato Web & $0 \%$ & 6 hrs & mié21/05/14 & jue 22/05/14 & 23 & Gustavo \\
\hline & 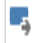 & Servicio Contratos & Modulo Contrato Servicio & $0 \%$ & 4 hrs & jue 22/05/14 & jue 22/05/14 & 24 & Gustavo \\
\hline & 5 & Interfaz Proveedores & Modulo Contrato Web & $0 \%$ & 6 hrs & mié 21/05/14 & jue 22/05/14 & 22 & Mario \\
\hline & 5 & Notificacion Vencimiento & Modulo Contratos Web & $0 \%$ & 4 hrs & jue 22/05/14 & jue 22/05/14 & 26 & Mario \\
\hline & 5 & Notificacion Vencimiento WS & Modulo Contratos Servicio & $0 \%$ & 4 hrs & jue 22/05/14 & vie 23/05/14 & 25 & Gustavo \\
\hline & 5 & Servicios Proveedores & Modulo Contratos Servicio & $0 \%$ & 4 hrs & vie 23/05/14 & vie 23/05/14 & 28 & Gustavo \\
\hline & K? & Fecha de Presentaci'on al Cliente & Hito & $0 \%$ & Odías & & & & \\
\hline & 5 & $\triangle$ Documentación & & $0 \%$ & 0.13 días & vie 23/05/14 & vie 23/05/14 & & \\
\hline 国 & 5 & Manual de usuario & Documentacion & $0 \%$ & 30 mins & vie23/05/14 & vie 23/05/14 & 19 & Mario \\
\hline & th & Manual de operacion & Documentacion & $0 \%$ & $0.5 \mathrm{~h}$ & vie23/05/14 & vie 23/05/14 & 19 & Gustavo \\
\hline & th & Reunión Equipo - Revisión Casos de Prueba & & $0 \%$ & $0.5 \mathrm{~h}$ & mar 20/05/14 & $\operatorname{mar} 20 / 05 / 14$ & 15 & Edward \\
\hline & $\star$ & Pruebas Integrales & & $0 \%$ & 4 hrs & vie 22/05/14 & lun 26/05/14 & 19 & Fabiolla \\
\hline & 5 & Capacitacion & & $0 \%$ & 1día & $\operatorname{lun} 26 / 05 / 14$ & $\operatorname{mar} 27 / 05 / 14$ & 35 & GUARDIAN \\
\hline & 5 & $>$ Documentación & & $0 \%$ & 0.5 dias & vie 23/05/14 & $\operatorname{lun} 26 / 05 / 14$ & & \\
\hline & 5 & Pase a Producción & & $0 \%$ & 0.25 días & $\operatorname{lun} 26 / 05 / 14$ & $\operatorname{lun} 26 / 05 / 14$ & 37 & Holinsys \\
\hline
\end{tabular}

- Recursos (humanos, materiales, estándares, equipos y herramientas)

\begin{tabular}{|l|l|l|}
\hline Nombre & Función & Capacitación \\
\hline Dany García & Frontend Dev & No requiere \\
\hline Elmer Méndez & Backend Dev & No requiere \\
\hline Fiorella Bendezu & QA & No requiere \\
\hline Milagros Zapata & Lider Técnico & No requiere \\
\hline Roberto Quispe C. & Gerente de Proyecto & No requiere \\
\hline
\end{tabular}

\begin{tabular}{|l|l|l|l|l|} 
R. Tecnológico & Cant. & Uso & Fecha Inicio & Tiempo de uso \\
\hline PC de Desarrollo & 2 & Desarrollo del Aplicativo & $20 / 05 / 2014$ & 2 semanas \\
\hline PC de QA Parcial & 1 & Revisión QA del sistema & $20 / 05 / 2014$ & parcial \\
\hline Servidor BD Oracle & 1 & BD usada durante el & $20 / 05 / 2014$ & 2 semanas \\
\hline
\end{tabular}




\begin{tabular}{|l|l|l|l|l|}
\hline DEV & desarrollo & & \\
\hline
\end{tabular}

- Instrucciones de Entrega

\section{Condiciones y asunciones:}

Se entregará la el sistema funcionando en el servidor del cliente al 100\%

Se utilizará el servidor web que ya se viene utilizando actualmente para su sistema de transportes

Se basará en lo desarrollado para el sistema de transportes.

Existe conectividad de red entre el servidor web y el servidor de base de datos de Oracle e-

Business Suite

\section{Exclusiones:}

\section{Restricciones:}

Documentación adicional (Tablas, Clases, Casos de Uso, etc)

Carga de datos inicial

Instalación del Servidor Web

La fecha límite de entrega del Proyecto es el 2 de Junio del 2014

El proyecto tiene un monto máximo de costo de 2,500.00 Nuevos Soles más IGV

- Gestión de Riesgos

\subsection{Gestión de Riesgos \\ Ninguno}




\subsection{Acta de Aceptación - Proyecto GUARDIAN}

A continuación, se describe algunas secciones del documento que reflejan las secciones establecidas por la ISO 29110:

- Registro de la Recepción de Entrega

- Identificación de la Fecha de Recepción

- Identificación de los elementos entregados

- Registro de la verificación de los criterios de aceptación definidos por parte del Cliente

- Identificación de cualquier asunto pendiente (en caso de ser posible)

- Firmado como recibido por parte del Cliente

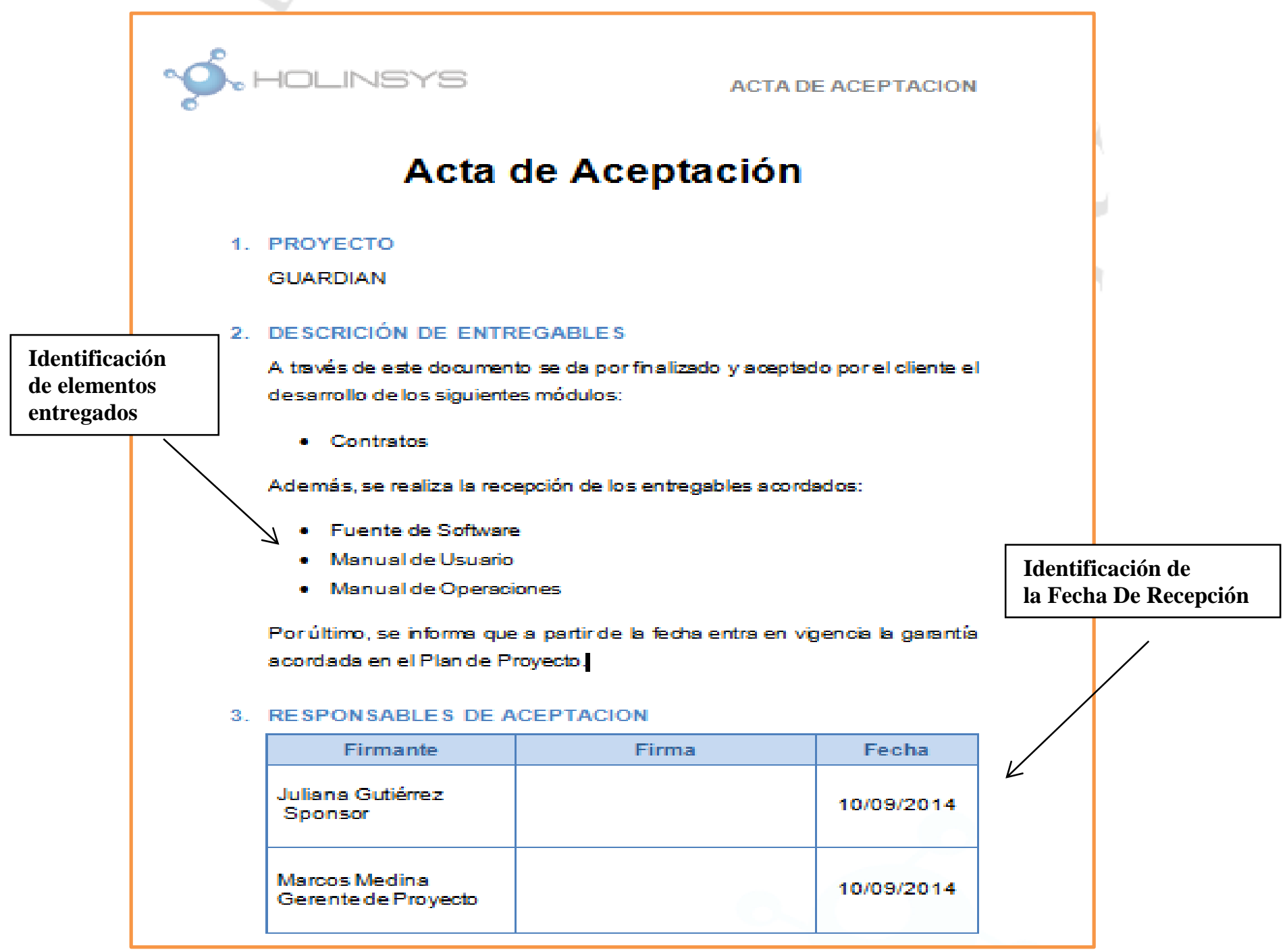




\subsection{Historia de Usuario - Proyecto RFID}

La Historia de Usuario tiene secciones que equivalen al documento "Especificación de Requisitos", nombre establecido por la norma ISO 29110.

Contenido General del Documento:

\section{INDICE}

1. OBJETIVO

2. ALCANCE

3. HISTORIA DE USUARIO 
A continuación, se describe algunas secciones del documento que reflejan las secciones establecidas por la ISO 29110:

- Introducción

\section{OBJETIVO}

Detallar el funcionamiento de la HY "Aplicativo Móvil RFID".

\section{ALCANCE}

El presente documento presentará el detalle a nivel funcional más no a nivel arquitectural de la historia de usuario, que incluye los siguientes módulos:

- Inicialización.

- Inicio.

- Inventario total.

- Búsqueda de producto.

- Carga de inventario.

- Grabador de tag.

- Configuración. 
- Descripción de los Requisitos:

- Funcionalidad

- Interfaz de Usuario

La Historia de Usuario es compuesta por diferentes módulos, los cuales tienen descritas su funcionalidad e interfaz de usuario.

\section{Módulo de Inicialización}
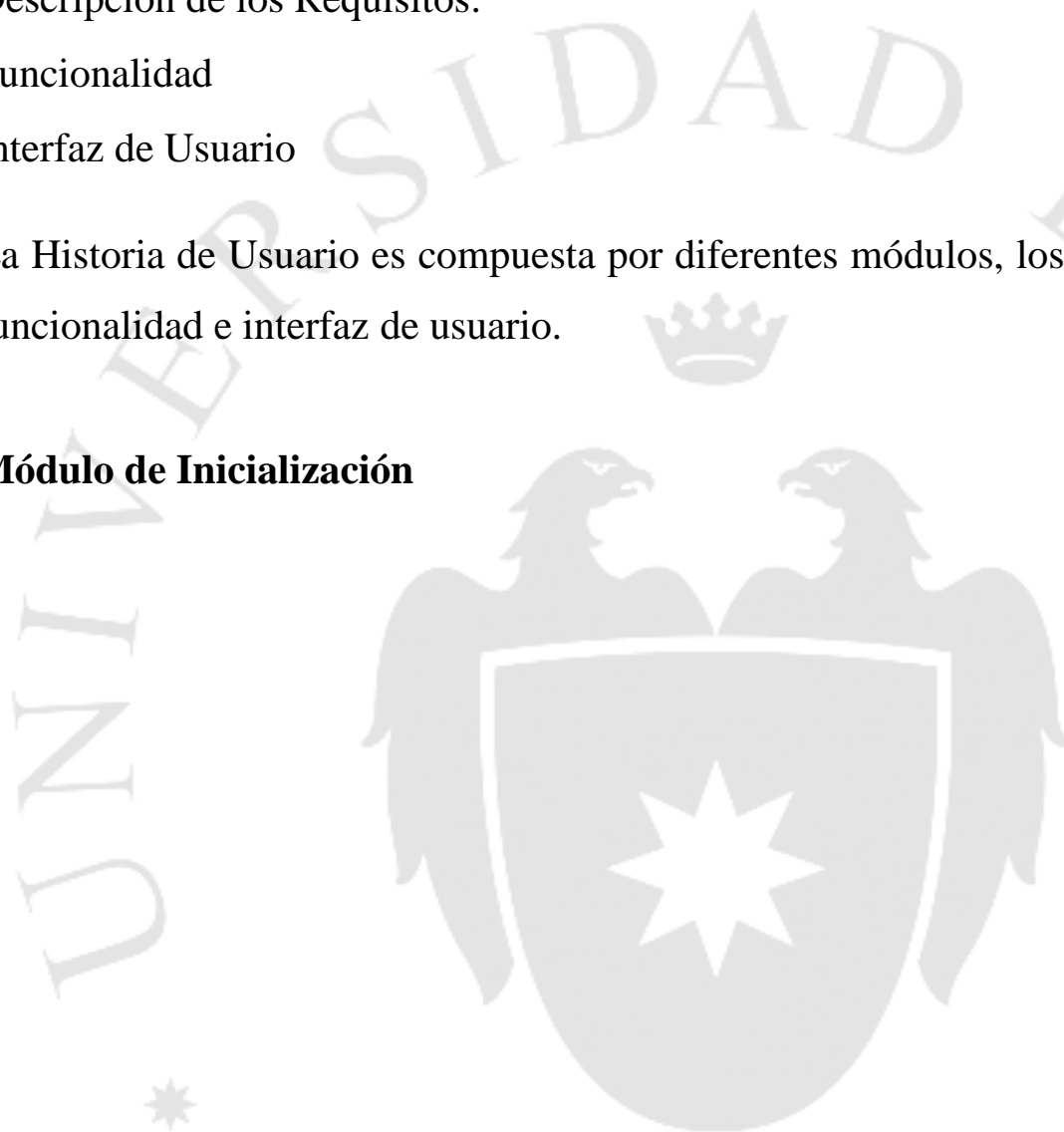


\section{HISTORIA DE USUARIO}

中

\section{Historia de Usuario}

Número: $\quad$ Usuario:

Nombre de historia: Aplicativo móvil RFID

Prioridad en negocio: $\quad$ Riesgo en desarrollo:

Duración estimada(Horas):

Programador responsable:

Descripción:

Módulo de Inicialización

Descripción:

La inicialización de la aplicación comprende los pasos que son necesarios realizar para poder empezar a usar la aplicación. La aplicación estará disponible para equipos que posean el sistema operativo Android 4.0 en adelante. 
La primera vez que se ejecute la aplicación, esta procederá a pedir un código de activación, el cual podrá ser uno de los diez distintos códigos que la aplicación manejará internamente. Esta lista de códigos será dada al distribuidor de la aplicación para que pueda administrarla. Cuando se ingrese el código de autorización dentro de la aplicación, ésta procederá a validar el código. De ser incorrecta, mostrará un mensaje notificando el error y solicitando otro código.

De ser correcta, la aplicación mostrará un pequeño formulario con los siguientes campos:

- RUC

- Nombre de la empresa

Estos datos sólo serán pedidos una sola vez y quedaran guardados dentro del equipo. Una vez ingresados estos campos, la aplicación procederá a mostrar la pantalla de Inicio.

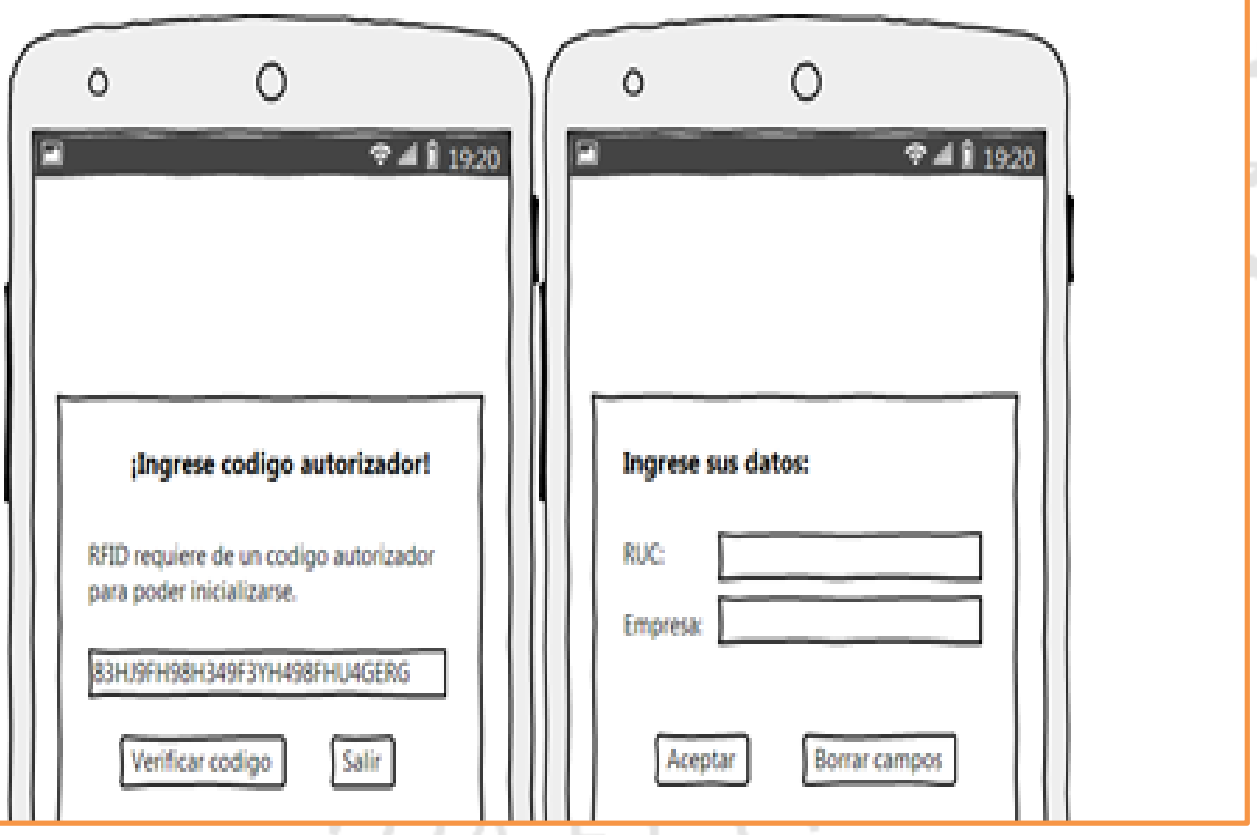




\section{Módulo de Inicio}

\section{Módulo de Inicio \\ Descripción: \\ Dentro de la pantalla de inicio se mostrarán las opciones para poder seleccionar que tipo de dispositivo se usará. Las opciones serán:}

- Conectar por Bluetooth: De seleccionar esta opción, la aplicación mostrará dos listas, una con los dispositivos cercanos que detecte, y otra inferior con los dispositivos con los que previamente se haya conectado, a modo de conexiones previas. En la parte inferior también se mostrará un botón para poder regresar a la selección de modo. El usuario podrá seleccionar una de las entradas de cualquiera de las listas y si la entrada corresponde con un lector UHFRFID, la aplicación procederá a establecer la conexión. En caso el celular tenga la opción de Bluetooth desactivada, en vez de las dos listas se mostrará un botón para redirigir hacia la configuración Bluetooth del celular.

- Conectar por puerto: De seleccionar esta opción, la aplicación quedará a la espera de que el usuario conecte el dispositivo por el puerto de audio.

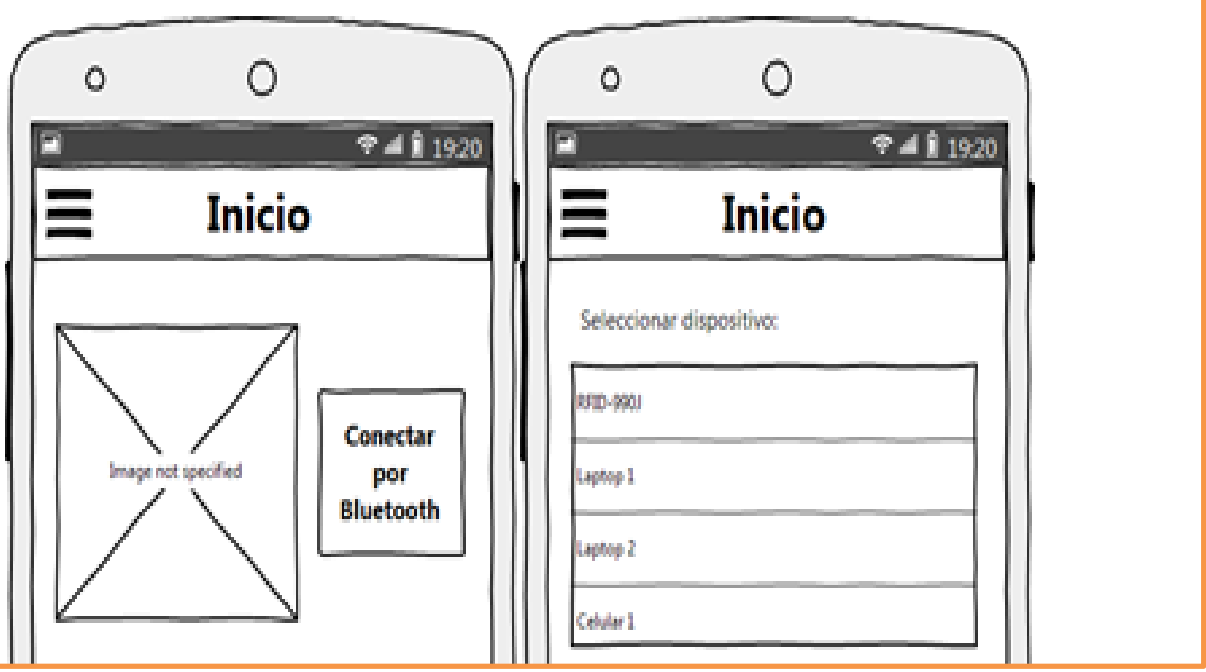


Módulo de Grabador de Tag

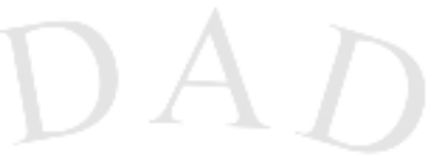

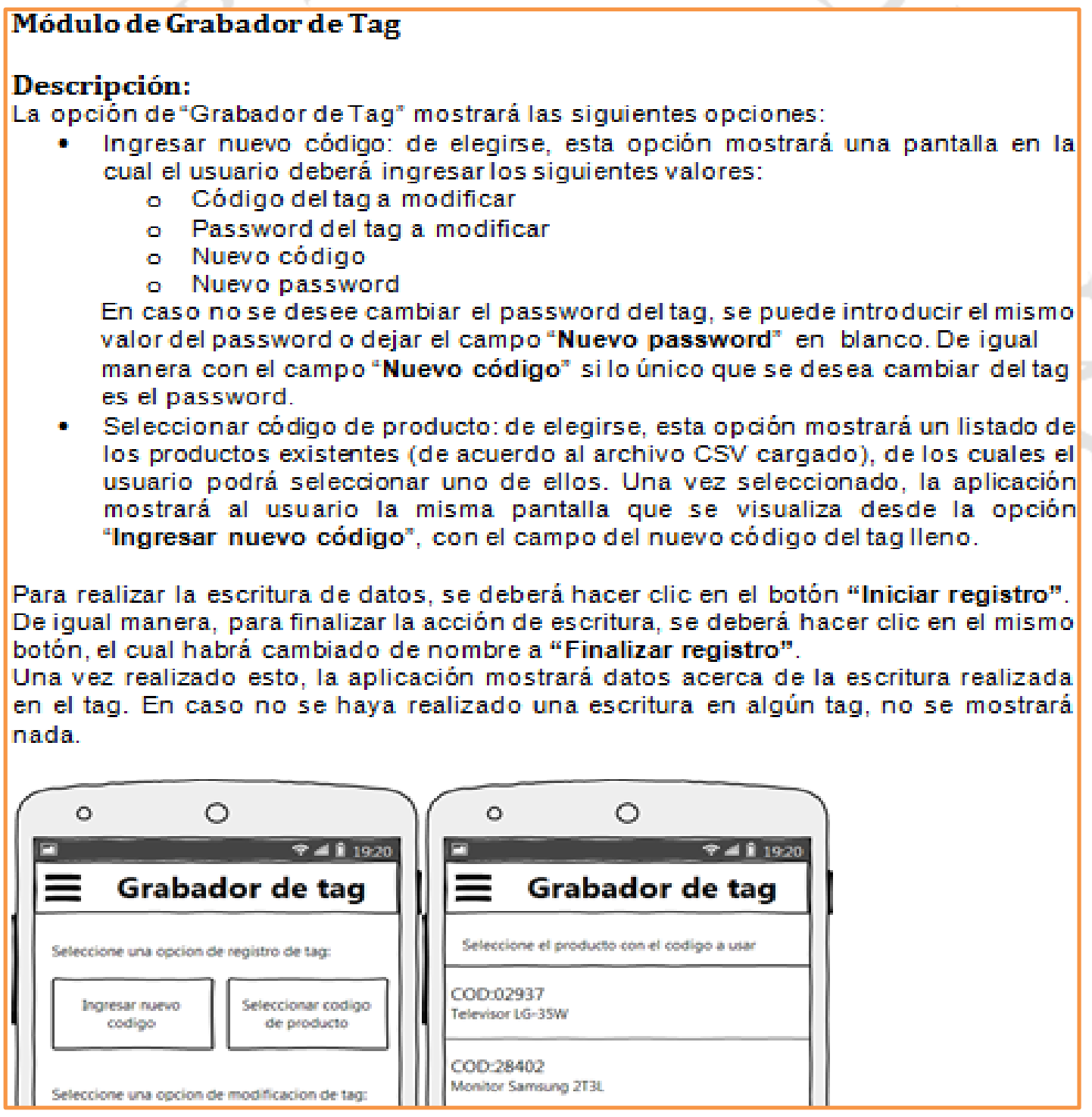




\subsection{Casos de Prueba - Proyecto RFID}

Contenido General del Documento:

\section{INDICE}

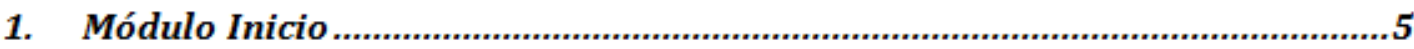

1.1. CAMR-51 Mostrar Intefaz Solicitud de código de activación...........................5

1.2. CAMR-52 Validar código de autorización....................................................5

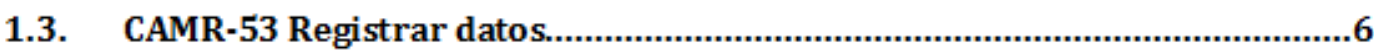

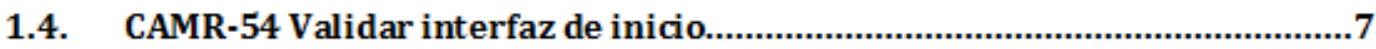

1.5. CAMR-55 Realizar conexión por bluetooth.......................................................

1.6. CAMR-56 Realizar conexión por bluetooth (Bluetooth off) ............................8

1.7. CAMR-57 Realizar conexión por puerto ............................................................

1.8. CAMR-58 Terminar conexión con dispositivo...................................................

1.9. CAMR-59 Visualizar pérdida de conexión..................................................... 10

1.10. CAMR-60 Visualizar menú de navegación..................................................... 11

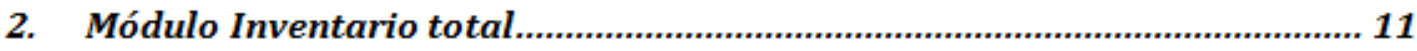

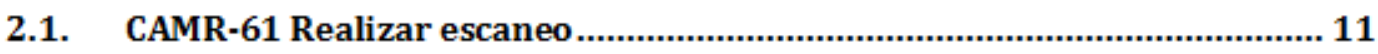

2.2. CAMR-62 Cancelar escaneo ….................................................................. 12

2.3. CAMR-63 Grabar inventario como archivo................................................. 13

2.4. CAMR-64 Reemplazar archivo existente ................................................ 13

2.5. CAMR-65 Enviar archivo por correo.......................................................... 14

2.6. CAMR-66 Visualizar detalle de producto..................................................... 15

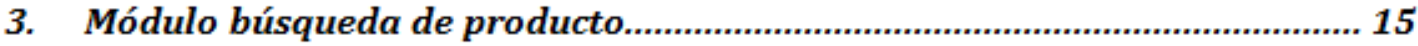

3.1. CAMR-67 Realizar Búsqueda por Rango de Códigos.................................... 15

3.2. CAMR-68 Realizar Búsqueda por Tipo de Producto ..................................... 16

3.3. CAMR-69 Grabar Producto Buscado ............................................................. 17

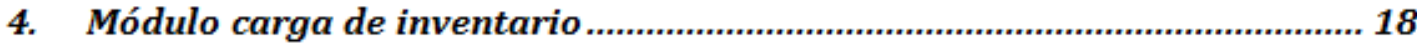

4.1. CAMR-70 Cargar archivo de inventario ......................................................... 18

4.2. CAMR-71 Cancelar cargar archivo de inventario........................................ 19 
Los Casos y Procedimientos de Prueba están compuestos por diferentes Módulos.

A continuación, se describe algunas secciones del documento que reflejan las secciones establecidas por la ISO 29110:

Casos de Prueba:

- Identificación del Caso de Prueba

- Elementos a probar

- Especificaciones de entrada

- Especificaciones de entrada

- Necesidades del entorno

- Requisitos de procedimientos especiales

- Dependencias de interfaz

Procedimientos de Prueba:

- Identificación: nombre de la prueba, descripción de la prueba y la fecha de finalización de la prueba

- Identificación de posibles problemas de implementación

- Identificación de la persona que complete el Procedimientos de Prueba

- Identificación de los requisitos previos

- Identificación de los pasos del procedimiento incluyendo el número de paso, la acción requerida por el probador y los resultados esperados 


\section{MÓDULO INICIO}

\subsection{CAMR-51 Mostrar Interfaz Solicitud de código de activación}

\section{Responsable Ejecución}

Elementos a Probar

Especificaciones de

Entrada

Especificaciones de

Salida

\section{Necesidades de}

Entorno

Dependencias de

Interfaz
CAMR-23 Crearvista de ingreso de código

Se debe ingresar a la aplicación.

Se debe visualizar, en la partalla, la solicitud del código autonizador. Para ello se mostrará un campo, donde se podrá ingresar el código y dos botones, uno para venficar el código y otro para salir de la aplicación.

Equipos que posean el sistema operativo Android 4.0

Ninguno

\section{Procedimiento}

Descripción Fecha de Finalización

Se verificará que se muestre una pantalla para poder activar el código de autorización del equipo desde la aplicación.

\section{\begin{tabular}{l|l}
\hline Requisitos Previos & Posibles Problemas \\
\hline
\end{tabular}}

Debe ser la primera vez que se ingrese a la aplicación. -No se visualice correctamente la partalla para la activación del código.

-No se permita ingresar el código en el campo mostrado.

-No funcionen los botones.

\section{Pasos}

1. Ingresar a la aplicación. 


\subsection{CAMR-52 Validar código de autorización}

\section{Responsable Ejecución}

Elementos a Probar

Especificaciones de

Entrada

Especificaciones de

Salida

Necesidades de

Entorno

Dependencias de

Interfaz

\section{Procedimiento}

Descripción

Se verificará que se valide correctamente el código autorizador según los códigos manejados internamente.

Requisitos Previos

Se debe haber registrado los códigos autorizados.

Pasos

1. Ingresar a la aplicación.

2. Ingresar el código

3. Clic en el botón "Verificar Código".
CAMR-23 Crear vista de ingreso de código -Ingresar uno de los 10 códigos que maneja la aplicación: (Códigos).

-Ingresar códigos diferentes a los que maneja la aplicación Validación correcta:

Se mostrará una pantalla con un formulario que contendrá los siguientes campos:

-RUC

-Empresa

Validación incorrecta:

Se mostrará un mensaje notificando el error y se solicitará otro código.

Equipos que posean el sistema operativo Android 4.0

Ninguno

\section{Posibles Problemas}

-No se realice la validación del código. 


\subsection{CAMR-53 Registrar datos}

\section{ResponsableEjecución}

Elementos a Probar

Especificaciones de

Entrada

Especificaciones de

Salida
CAMR-24 Crear vista login|

-RUC (obligatorio)

-Nombre de la Empresa (obligatorio)

Si los datos no son ingresados semostrará un mensaje solicitándolos.

Los datos ingresados se deben guardar.

Se debe mostrar la pantalla de inicio.

No se debe poder introducir más de 11 caracteres en el campo RUC.

Necesidades de

Entorno

Dependencias de

Interfaz

\section{Procedimiento}

Descripcion

Se verificará que los datos ingresados se guarden correctamente.

Se validará el ingreso de los campos obligatorios.

Se validará el número de caracteres del RUC.

\section{Requisitos Previos}

Ninguno

Equipos que posean el sistema operativo Android 4.0

Pantalla Solicitud Código Autorizador

solicitados.

Pasos

1. Ingresar RUC

2. Ingresar Empresa

3. Clic en el botón "Aceptar". 


\subsection{Solicitud de Cambio - Proyecto GALI}

A continuación, se describe algunas secciones del documento que reflejan las secciones establecidas por la ISO 29110:

- Identifica el propósito del cambio

- estado de la solicitud

- información de contacto del solicitante

- Sistema(s) impactado(s)

- Impacto en la operación de sistemas

- Impacto en la documentación asociada

- Criticidad de la solicitud y fecha en que se requiere

Información

De contacto del solicitante

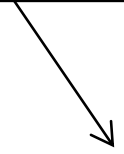

\begin{tabular}{|l|l|l|l|}
\hline Asunto: & \multicolumn{1}{|c|}{$\begin{array}{c}\text { Cambio de } \\
\text { Funcionalidades }\end{array}$} & Control ID: & \\
\hline Solicita: & Roberto Quispe & Fecha: & $08 / 02 / 2015$ \\
\hline Proyecto: & Gali & Requerido para: & Milagros Zapata \\
\hline
\end{tabular}




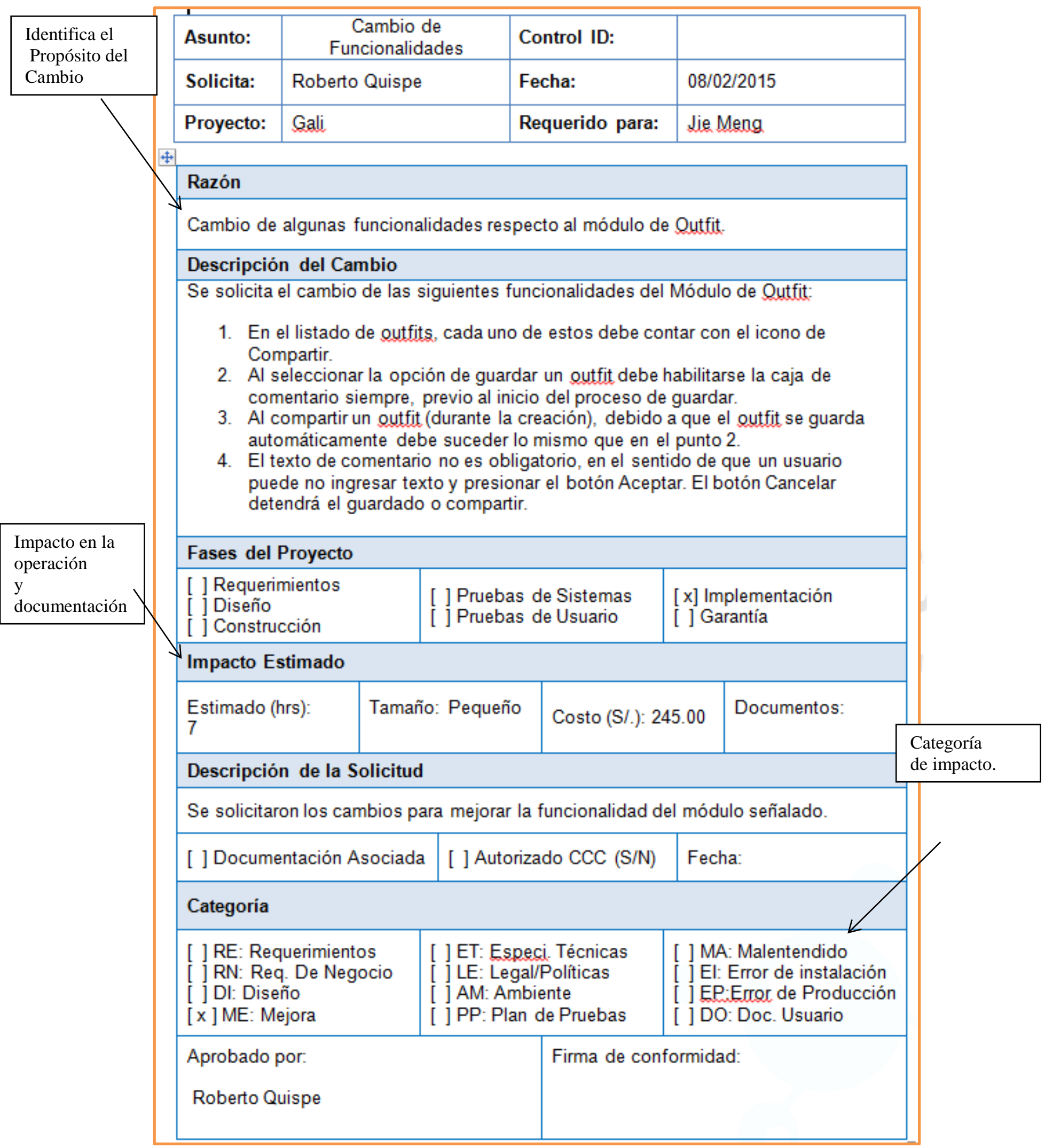




\subsection{Reporte de Pruebas - Proyecto GUARDIAN}

A continuación, se describe todas las secciones del documento que reflejan las secciones establecidas por la ISO 29110 :

- Resumen de cada defecto

- Identificación de los Casos de Prueba en cuestión.

- Nombre del probador que encontró cada defecto

- Severidad de cada defecto

- Identificación de la(s) función(es) afectada(s) por cada defecto

- Fecha en que cada defecto fue originado y fue resuelto

- Nombre de la persona quién resolvió cada defecto

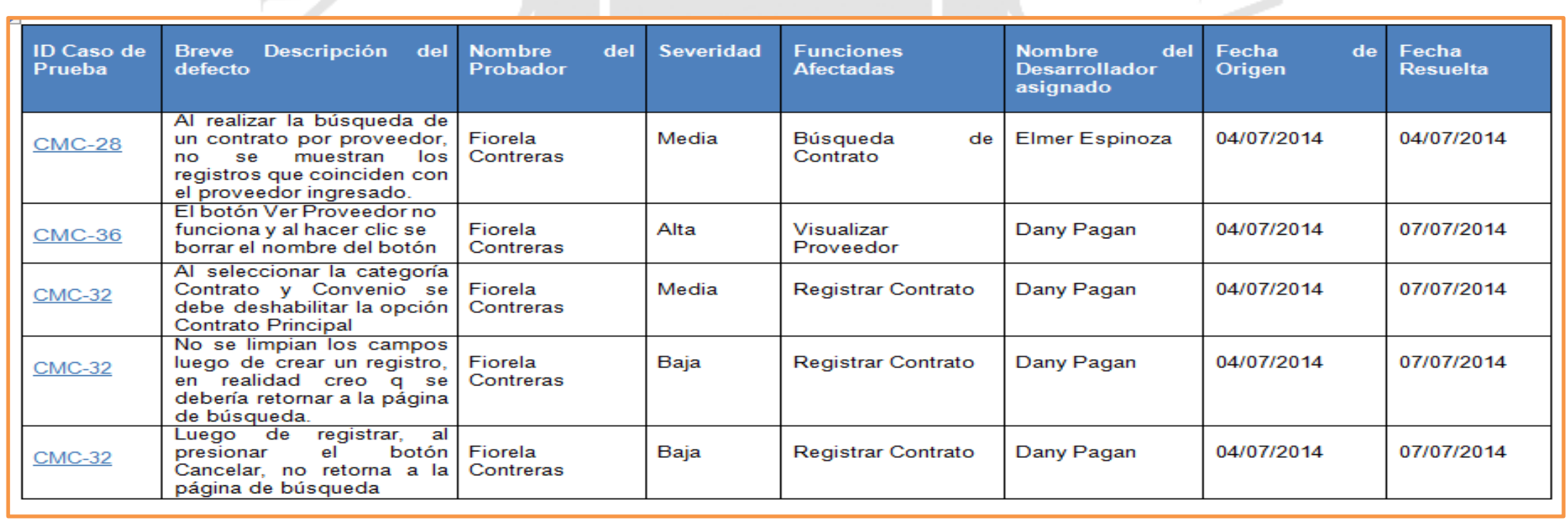




\subsection{Enunciado de Trabajo - Proyecto RFID}

Contenido General del Documento:

\section{Contenido}

Presentación .

3

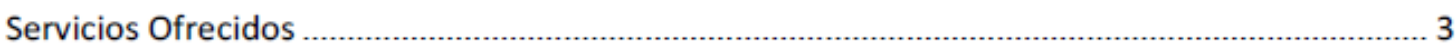

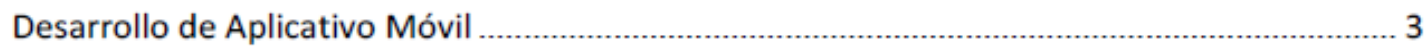

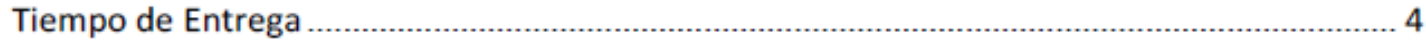

Consideraciones

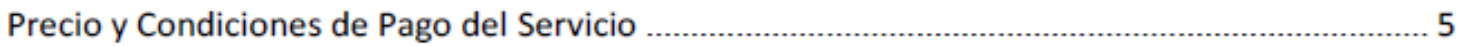

Precio 
A continuación, se describe todas las secciones del documento que reflejan las secciones establecidas por la ISO 29110:

- Descripción del producto

- Propósito

- Requisitos generales del Cliente

- Alcance

- Objetivos del proyecto

- Entregables
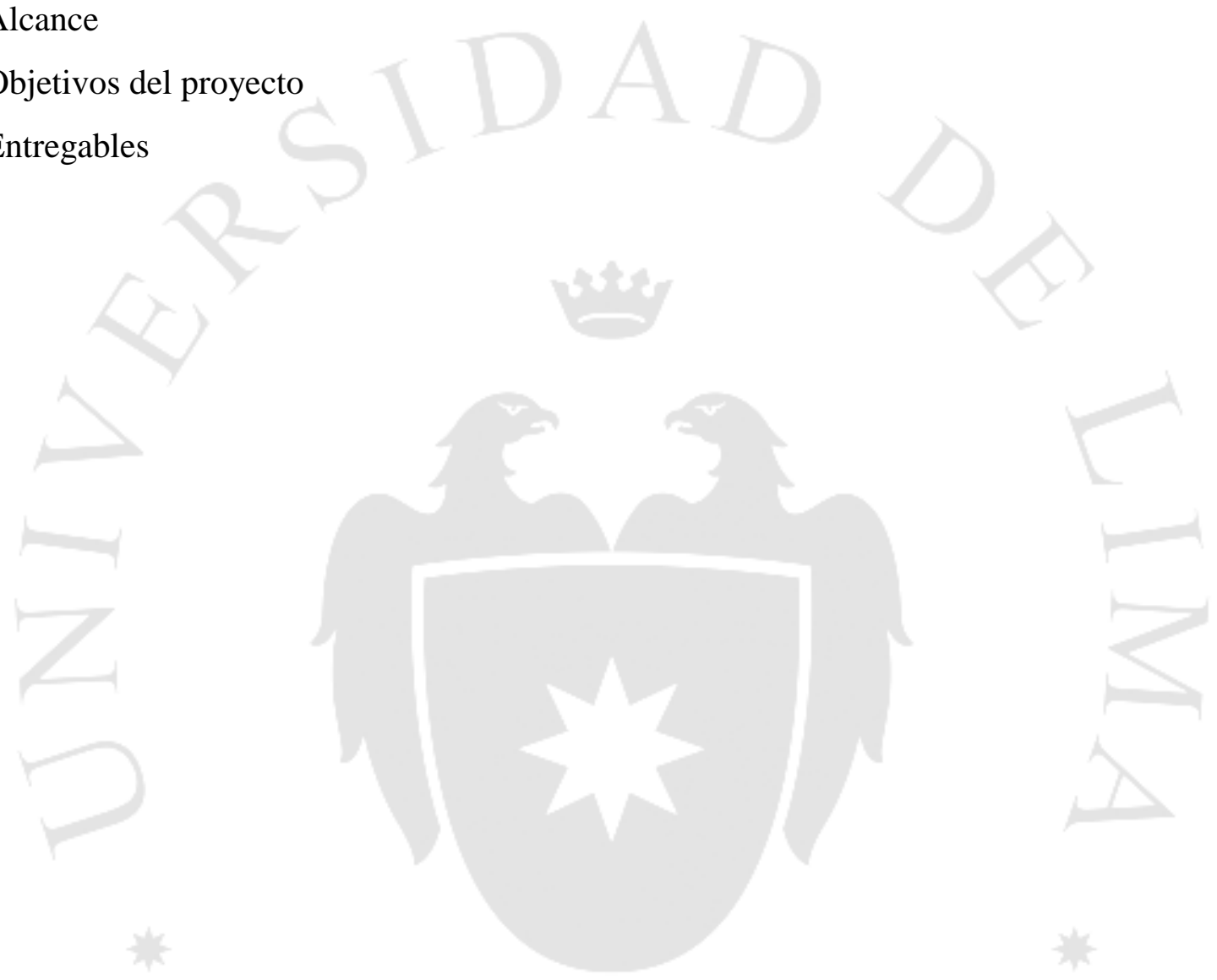
Descripción del

Producto

Y Propósito

\section{Servicios Ofrecidos}

$\searrow$

\section{Desarrollo de Aplicativo Móvil}

El cliente requiere del apoyo de Holinsys para la elaboración de un aplicativo móvil que permita utilizar los periféricos de lectura RFID. Este deberá cumplir con los siguientes requerimientos:

Módulo Inicio Sesión

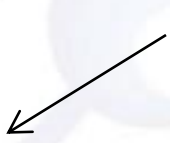

- Se solicitará el RUC de la empresa así como el nombre del usuario para iniciar sesion.

- Se solicitará una clave de inicialización en el caso no se haya validado el aplicativo en el equipo previamente. Estas claves serán predefinidas y brindadas en un listado inicial al cliente

\section{Módulo Inicio}

- El usuario podrá acceder al menú de opciones: Inicio, Inventario Total,Búsqueda de Producto, Carga de Inventario, registro de Tag y configuracion.

- Se podrá usar la opción inventario para validar el stock registrado en el teléfono contra las lecturas del dispositivo.

- Se tendrá la opción de realizar el inventario en modo total (todos los productos) o como resultado de una búsqueda, la cual estará basada en rango de códigos o tipo de productos, permitiendo agregar productos a la lista a inventariar.

- Se podrá visualizar el detalle del producto al presionar sobre un registro que lo describa. Este detalle no considerará foto del producto.

Entregables y requisitos generales del cliente:

El aplicativo Android será desarrollado sobre la Versión 4.0 y será optimizado para equipos de gama media.

Los ejecutables finales serán entregados en la tienda digital correspondiente.

Se entregará un manual de usuario explicando las funcionalidades del sistema. 
El cliente debe de proporcionar el servidor en el cual se va a subir la información a ser mostrada en los dispositivos móviles en caso sea necesario.

El cliente deberá brindar el logo del sistema en formato de curvas junto con el manual de identidad para su manipulación.

El registro de los datos será de responsabilidad del cliente.

No se están considerando las funcionalidades de pago.

No se entregará ningún tipo de documentación adicional a la resultante del proceso de desarrollo.

El desarrollo tendrá un periodo de garantía de seis (6) meses sobre el trabajo realizado una vez ha sido puesto en producción. Esta garantía será invalidada en caso se realicen modificaciones de forma externa no autorizadas por Holinsys.

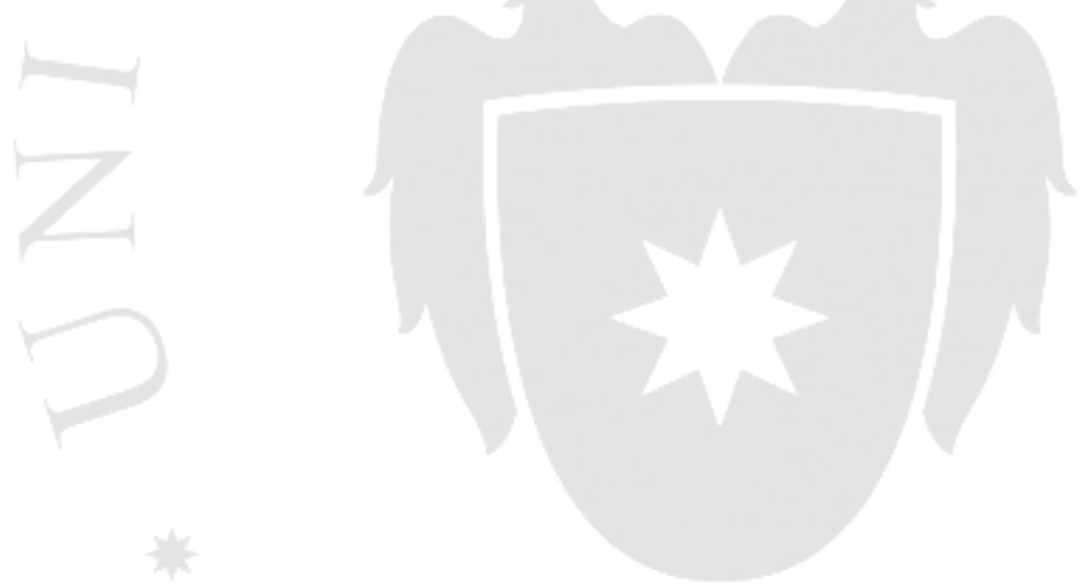




\subsection{Registro de Trazabilidad - Proyecto GUARDIAN}

A continuación, se describe la característica del documento "Registro de Trazabilidad" que reflejan las secciones establecidas por la ISO 29110:

Mapeo de los requisitos a los elementos del Diseño de Software, los Componente de Software, los Casos de Prueba y los Procedimientos de Prueba.

El documento de la empresa Holinsys sólo realiza el mapeo de los requisitos a los Casos de Prueba y Procedimientos de Prueba, más no al Diseño de Software y Componente de Software.

\begin{tabular}{|c|c|c|c|}
\hline \multicolumn{2}{|c|}{ New Feature } & \multicolumn{2}{|l|}{ Test Case } \\
\hline Key & Summary & Key & Summary \\
\hline \multirow[b]{2}{*}{ CAMR-23 } & \multirow[b]{2}{*}{ Crear vista de ingreso de código } & CAMR-51 & Mostrar Intefaz Solicitud de código de activación \\
\hline & & CAMR-52 & Validar código de autorización \\
\hline CAMR-24 & Crear vista login & CAMR-53 & Registrar datos \\
\hline CAMR-25 & Crear vista menú de navegación & CAMR-60 & Visualizar menú de navegación \\
\hline CAMR-26 & Crear vista inicio & CAMR-54 & validar interfaz de inicio \\
\hline \multirow[b]{2}{*}{ CAMR-27 } & \multirow[b]{2}{*}{ Crear vista detalle inventario } & CAMR-61 & Realizar escaneo \\
\hline & & CAMR-62 & Cancelar escaneo \\
\hline CAMR-28 & Crear vista de detalle de producto & CAMR- 66 & Visualizar detalle de producto \\
\hline CAMR-29 & $\begin{array}{l}\text { Función copiar/pegar información de producto en } \\
\text { memoria }\end{array}$ & CAMR-82 & Copiar Detalle de Producto \\
\hline \multirow[b]{2}{*}{ CAMR-30 } & \multirow[b]{2}{*}{ Función crear archivo de inventario total } & CAMR-63 & Grabar inventario como archivo \\
\hline & & CAMR-64 & Reemplazar archivo existente \\
\hline CAMR-31 & Función enviar archivo por correo & CAMR-65 & Enviar archivo por correo \\
\hline \multirow[b]{3}{*}{ CAMR-32 } & \multirow[b]{3}{*}{ Crear vista de parámetros de búsqueda } & CAMR-67 & Realizar Búsqueda por Rango de Códigos \\
\hline & & CAMR-68 & Realizar Búsqueda por Tipo de Producto \\
\hline & & CAMR-69 & Grabar Producto Buscado \\
\hline \multirow[b]{3}{*}{ CAMR-33 } & \multirow[b]{3}{*}{ Crear vista de resultado de la búsqueda } & CAMR-67 & Realizar Búsqueda por Rango de Códigos \\
\hline & & CAMR-68 & Realizar Búsqueda por Tipo de Producto \\
\hline & & CAMR-69 & Grabar Producto Buscado \\
\hline \multirow[b]{2}{*}{ CAMR-34 } & \multirow[b]{2}{*}{ Funcion cargar archivo producto } & CAMR-70 & Cargar archivo de inventario \\
\hline & & CAMR-71 & Cancelar cargar archivo de inventario \\
\hline \multirow[b]{3}{*}{ CAMR-35 } & \multirow[b]{3}{*}{ Crear vista de selección de modo } & CAMR-55 & Realizar conexión por bluetooth \\
\hline & & CAMR-56 & Realizar conexión por bluetooth (Bluetooth off) \\
\hline & & CAMR-57 & Realizar conexión por puerto \\
\hline CAMR-36 & Función ingresar nuevo código & CAMR-72 & Registrar tag - Ingresar nuevo código \\
\hline CAMR-37 & Función seleccionar código de producto & CAMR-73 & Registrar tag-Seleccionar código de producto \\
\hline CAMR-38 & Crear vista configuración & CAMR-76 & Realizar Cambios en Configuración \\
\hline CAMR-39 & Función detectar cambios en el dispositivo & CAMR-59 & Visualizar pérdida de conexión \\
\hline CAMR-40 & Función prender apagar dispositivo remotamente & CAMR-58 & Terminar conexión con dispositivo \\
\hline \multirow{3}{*}{ CAMR-41 } & \multirow{3}{*}{ Función cargar inventario total } & CAMR-61 & Realizar escaneo \\
\hline & & CAMR-62 & Cancelar escaneo \\
\hline & & CAMR-67 & Realizar Búsqueda por Rango de Códigos \\
\hline
\end{tabular}




\subsection{Reporte de Avance - Proyecto RFID}

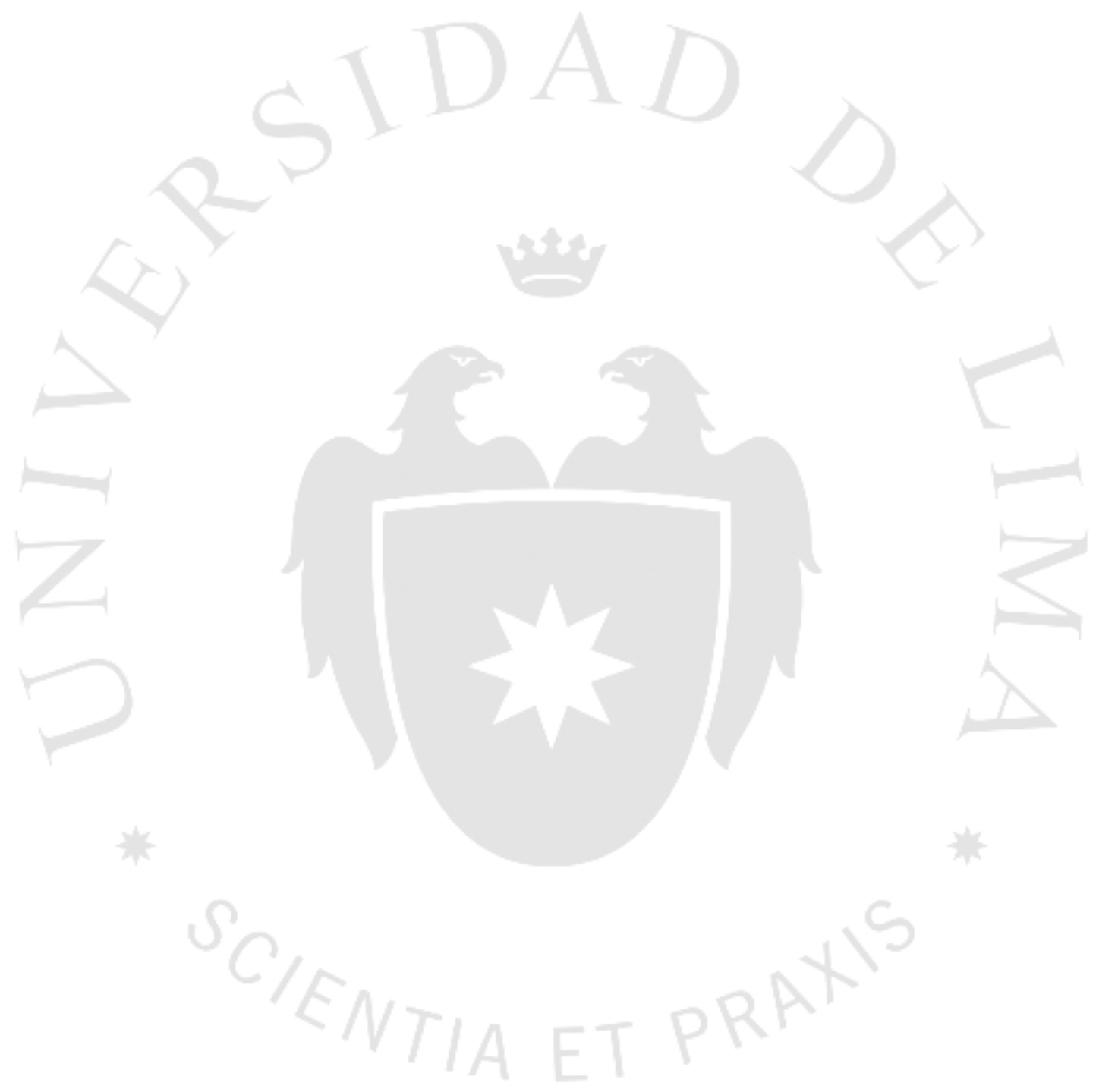




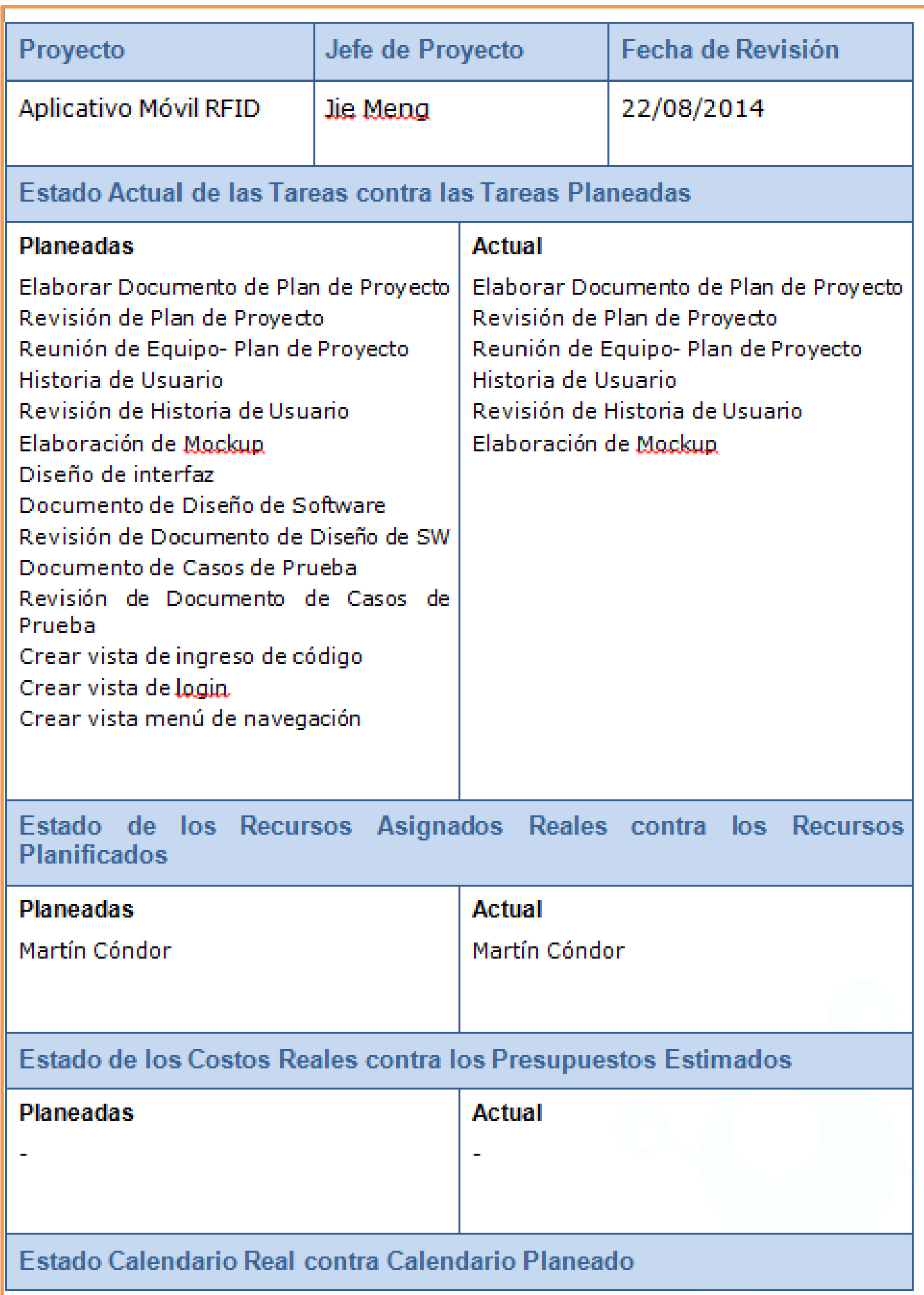




\section{Planeadas}

Se planeó que la fecha final del proyecto sería el 11/08/2014.

\section{Actual}

Hasta ahora se cuenta con un retraso de 5 días, por lo cual la fecha final del proyecto sería el $18 / 08 / 2014$

\section{Riesgos Actuales Identificados}

Debido al retraso que se tuvo a consecuencia de la demora en la revisión de las historias de usuario por parte del cliente se encontraron los siguientes riesgos:

Retraso de 5 días hasta ahora, debido a que se planteó solo 1 día para la revisión. Correcciones de HU debido a que se encontraron observaciones.

Correcciones de los mock-up debido a que se encontraron observaciones

\section{Registro de Cualquier Desviación de las Tareas Planeadas y su causa}

Se tendrá que tener en stand bx la elaboración del documento de Diseño de SW y los siguientes que dependen de este. 


\subsection{Manual de Usuario - Proyecto GUARDIAN}

Contenido General del Documento:

\section{INDICE}

1. OBJETIVO DEL SOFTWARE

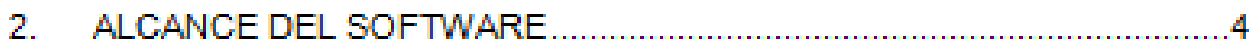

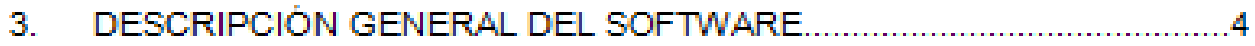

4. PROCEDIMIENTOS DE INSTALACION Y DESINSTALACION.................5

5. DESCRIPCION DE LAS FUNCIONALIDADES DEL SOFTWARE ............5

6. RELACION $Y$ DESCRIPCION DE COMANDOS Y MENSAJES...............16

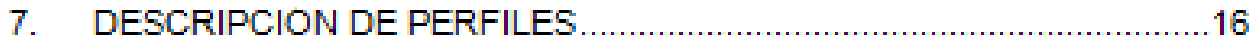

8. PROCEDIMIENTO PARA ENTRAR Y SALIR DEL SISTEMA ..................16

9. RECURSOS PROVISTOS Y REQUERIDOS …...................................17

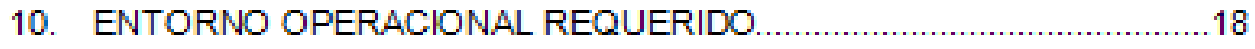


A continuación, se describe algunas características del documento que reflejan las secciones establecidas por la ISO 29110:

- Objetivo y Alcance del Software: Forma parte de la Descripción del uso del software. 1. OBJETIVO DEL SOF TWARE

El objetivo específico del sistema es el de facilitar la gestión de los contratos de la Corporación GUARDIAN.

\section{ALCANCE DEL SOFTWARE}

Los alcances del proyecto son los siguientes:

- El sistema permitirá realizar la búsqueda de los contratos que se encuentran registrados en el sistema por tres filtros (Tipo de Contrato: Contrato, Convenio; Proveedor; Rango de Fechas).

- El sistema permitirá visualizar los detalles de un contrato existente.

- El sistema permitirá registrar la información de un contrato.

- El sistema permitirá asignar un proveedor al registrar un contrato.

- El sistema permitirá adjuntar un archivo al registrar un contrato.

- El sistema permitirá actualizar la información de un contrato.

- El sistema permitirá registrar la información de un proveedor.

- El sistema permitirá actualizar la información de un proveedor.

- El sistema permitirá visualizar la información de un proveedor.

- El sistema permitirá realizar el registro de una adenda.

- El sistema permitirá visualizar las adendas asociadas a un contrato.

- Breve descripción del uso previsto del Software 


\section{DESCRIPCIÓN GENERAL DEL SOFTWARE}

El sistema permite realizar la gestión de los contratos existentes en Corporación GUARDIAN, según los roles definidos a continuación:

Rol de Administrador: Tendrán acceso a todas las funcionalidades del módulo Contrato.

- Procedimientos de instalación y desinstalación

\section{PROCEDIMIENTOS DE IN STALACIÓN Y DESIN STALACIÓN}

El procedimiento de instalación y desinstalación se detalla en el Manual de Operaciones.

- Procedimientos del usuario para realizar tareas específicas utilizando el software

\section{DESCRIPCIÓN DE LAS FUNCIONALIDADES DEL SOFTWARE}

\section{Módulo de Contratos}

\section{Búsqueda de Contratos}

El usuario que tendrá acceso a estas funcionalidades debe tener asignado el rol de "Administrador" y debe haber iniciado sesión.

Para realizar la búsqueda de los contratos existentes, seleccionar la pestaña "Contratos" y hacer clic en la opción "Listar".

\section{MISTI}

ammeniboc Fos fos asim

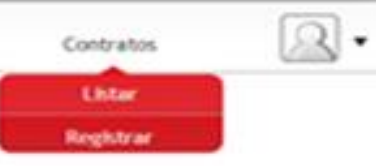

Se mostrarán las siguientes opciones de búsqueda:

Categoría: Filtro que se utilizará para buscar los contratos que cuenten con la categoría Contrato, Convenio o Adenda.

Proveedor: Filtro que se utlizará para buscar los contratos que se encuentren asociados a un determinado proveedor. 


\subsection{Manual de Operaciones - Proyecto GUARDIAN}

Contenido General del Documento:

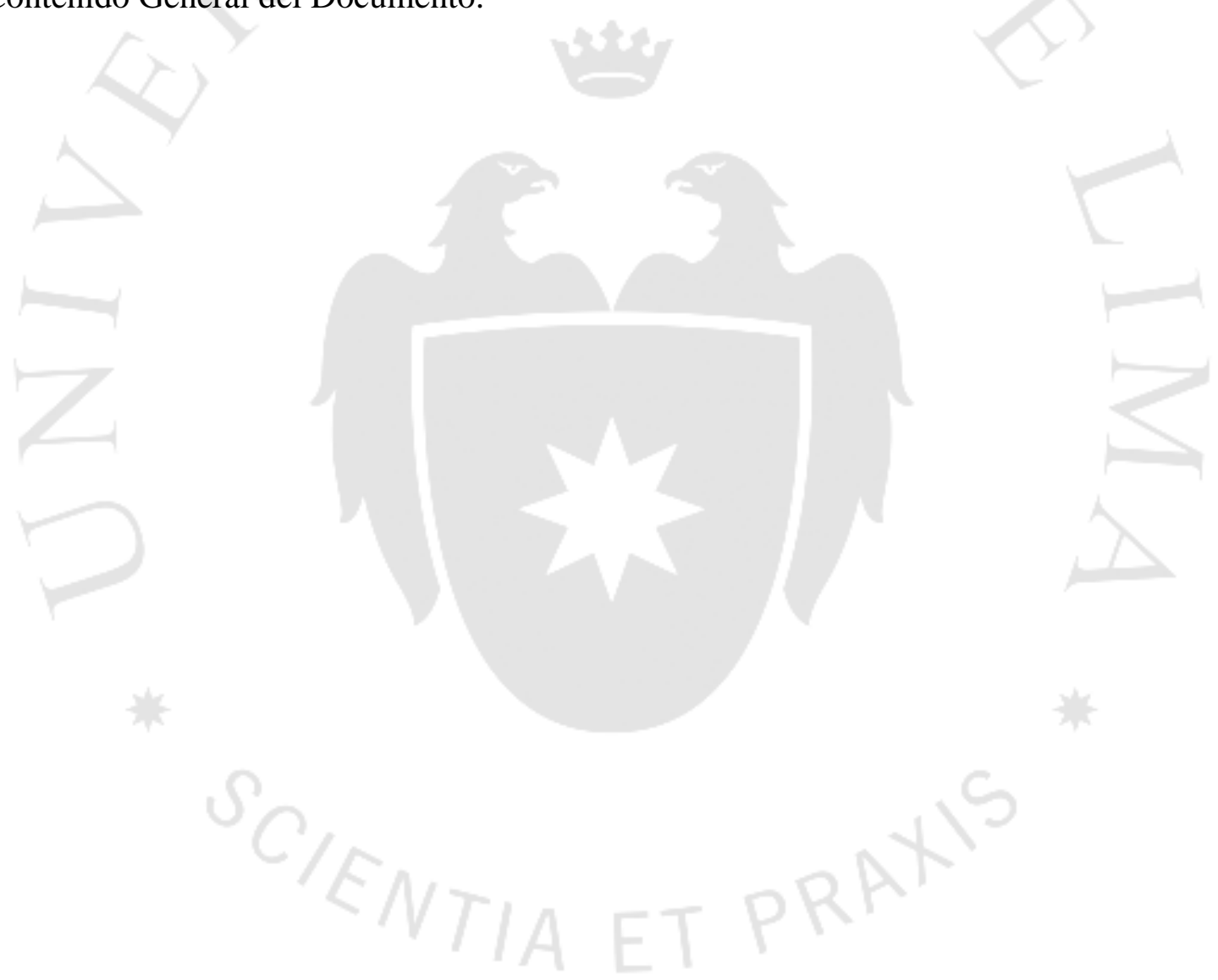


INDICE

1. INTRODUCCION

2. CRITERIOS PARA LA OPERACION DEL SOFTWARE ....................... 4

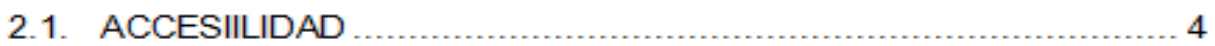

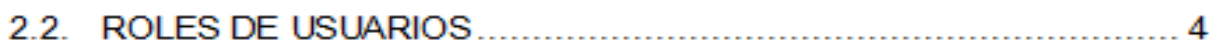

3. OPERACIÓNDEL SOFTWARE

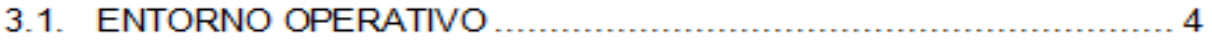

3.2. HERRAMIENTAS DE APOYO PARA OPERAR .......................... 5

3.3. PREPARATIVOS $Y$ SECUENCIA PARA LA PUESTA EN MARCHA ... 5

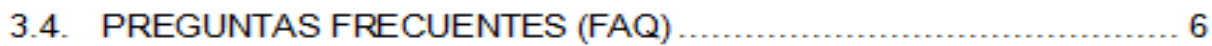

4. GARANTIA DE INSTRUCCIONES DE REEMPLAZO

A continuación, se describe algunas características del documento que reflejan las secciones establecidas por la ISO 29110:

- Criterios para la operación entorno operativo requerido 


\section{CRITERIOS PARA LA OPERACIÓN DEL SOFTWARE}

\subsection{ACCESIILIDAD}

Es necesario, para usar alguna funcionalidad del sistema, que el usuario inicie sesión en éste usando un nombre de usuario y clave que serán administradas por el área de Tecnologías de Información de la Empresa "GUARDIAN".

\subsection{ROLES DE USUARIOS}

Dentro del sistema "GUARDIAN Contrato" cada usuario tiene un rol asignado, y existen un tipo de rol: Administrador.

Cada rol tiene acceso a diferentes funcionalidades y diferente información dentro del sistema.

- Rol de Administrador:

- TODAS las funcionalidades del módulo Contrato.

- Herramientas y material de apoyo requerido

\subsection{HERRAMIENTAS DE APOYO PARA OPERAR}

Como se puede concluir de lo antes mencionado, hay tres cosas necesarias para poder operar el sistema web "Misti Contratos":

- Usuario y clave

- PC, laptop o dispositivo móvil con algún navegador de internet moderno

- Conexiónal servidor de la empresa

- Preparativos y secuencia para la puesta en marcha 


\subsection{PREPARATIVOSY SECUENCIA PARA LA PUESTA EN MARCHA}

El sistema ya terminado será entregado al cliente en un $C D$ que contiene los archivos del sistema y otros que serán ejecutados en el servidor, como por ejemplo scripts de base de datos.

La secuencia de la implementación consta de los siguientes pasos:

1. Se copiarán los archivos del sistema en el servidor de la empresa.

2. Se configurará el Windows Server 2003 para que estén habilitados los servicios dellIS 6 .

3. Se configurará la base de datos para que funcione en conjunto con el sistema "Misti Contrato".

4. Se ejecutarán los scripts para la creación de las tablas en la base de datos.

- Preguntas frecuentes

\subsection{PREGUNTAS FRECUENTES (FAQ)}

- ¿Se puede realizar un back up de la información en la base de datos?

Si, se puede exportar a scripots toda la información de base de datos para su posterior almacenamiento.

- ¿Afectará el sistema web "Misti Contrato" alguna funcionalidad del sistema ERP "EBS"?

No, el funcionamiento de "Misti Contrato" no afectará en ningún aspecto al ERP ${ }^{2}$ EBS"

- Garantía e instrucciones de reemplazo

4. GARANTÍA DE IN STRUCCIONES DE REEMPLAZO

Según el "Plan de Proyecto" se establece un PERIODO DE SEIS MESES DE GARANTIA que corresponde a un lapso de tiempo en el cual el cliente tiene derecho a hacer observaciones, pedir cambios o solicitar corrección de errores sobre el funcionamiento del sistema, siempre y cuando estas peticiones de cambio ESTEN BAJO LOS REQUERIMIENTOS DEL SISTEMA. Si estas peticiones de cambio corresponden a funcionalidades diferentes a los de los requerimientos no serán tratados dentro de la garantía. 


\subsection{Manual de Mantenimiento - Proyecto GUARDIAN}

En el manual de Mantenimiento también se encuentra implícitamente la configuración del software.

Contenido General del Documento:

\section{INDICE}

1. DESCRIPCION DE LOS ELEMENTOSDE LA CONFIGURACION DEL SOFTWARE4

2. ENTORNO UTILIZADO EN EL DESARROLLO DEL SOFTWARE................................4

2.1. COMPILADORES

2.2. HERRAMIENTAS DE DISEÑO .................................................................... 
A continuación, se describe algunas secciones del documento que reflejan las secciones establecidas por la ISO 29110:

- Elementos de la Configuración del Software:

\section{DESCRIPCION DE LOS ELEMENTOS DE LA CONFIGURACION DEL SOFTWARE}

\begin{tabular}{|c|c|}
\hline $\begin{array}{l}\text { ELEMENTOS DELA } \\
\text { CONFIGURACION DE SW }\end{array}$ & DESCRIPCION \\
\hline Historia de Usuario & $\begin{array}{l}\text { Documento donde se encuentran definidas } \\
\text { las funcionalidades de la aplicación a } \\
\text { desarrollar. La HU guardad como línea base } \\
\text { se encuentra en la versión } 1.2 \\
\text { (C:IDocumentación } \\
\text { Proyectos Proyectosl2.-Proyectos } \\
\text { NetiProyectos PendienteslCD 14072- } \\
\text { RFIDVmplementación del Proyectol2-- } \\
\text { Análisis de Requisitos de SW1.-Historia de } \\
\text { Usuarios) }\end{array}$ \\
\hline Documento de diseño & $\begin{array}{l}\text { Documento donde se encuentra definida la } \\
\text { arquitectura, los componentes, y las otras } \\
\text { características de la aplicación a desarrollar. } \\
\text { El Doc. de Diseño se encuentra en la versión } \\
\text { 1.1(C:I Documentación } \\
\text { Proyectos Proyectosl2.-Proyectos } \\
\text { NetlProyectos Pendientes } \backslash C D \text { de } \\
\text { RFIDVImplementación del Proyectol3.- } \\
\text { Arquitectura y Diseño de SW1.-Diseño de } \\
\text { SW) }\end{array}$ \\
\hline Matriz de trazabilidad & $\begin{array}{l}\text { Documento donde se muestra la trazabilidad } \\
\text { entre la especificación de los requerimientos } \\
\text { y los casos de prueba. Se puede generar } \\
\text { desde el Jira. }\end{array}$ \\
\hline $\begin{array}{l}\text { Casos de prueba y } \\
\text { Procedimiento de Prueba }\end{array}$ & $\begin{array}{l}\text { Documento donde se encuentran definidos } \\
\text { los casos de prueba que serán utilizados } \\
\text { para realizar las pruebas al sistema. El Doc. } \\
\text { de Casos de Prueba se encuentra en la } \\
\text { versión 1.0(C:IDocumentación de } \\
\text { ProyectosIProyectos } 2 \text {.-Proyectos } \\
\text { NetIProyectos PendientesiCD 14072- } \\
\text { RFIDVImplementación del Proyectol3.- } \\
\text { Arquitectura y Diseño de SWM 3.-Casos de } \\
\text { Prueba y Procedimientos) }\end{array}$ \\
\hline Componente de SW & $\begin{array}{l}\text { Compuesto por las diferentes líneas de } \\
\text { código según los requerimientos. El } \\
\text { componente se encuentra en el Mercurial }\end{array}$ \\
\hline Software & $\begin{array}{l}\text { Compuesto por las diferentes componentes } \\
\text { de software integrados. El software se }\end{array}$ \\
\hline
\end{tabular}




\begin{tabular}{|c|c|}
\hline & encuentra en el Mercurial \\
\hline Manual de Usuario & $\begin{array}{l}\text { Documento donde se encuentran definidos } \\
\text { los pasos que se deben seguir para realizar } \\
\text { las funcionalidades. Se encuentra en la } \\
\text { versión } 1.2 \text { (C:IDocumentación de } \\
\text { ProyectosiProyectos } 2 \text {.-Proyectos } \\
\text { Net\Proyectos PendientesiCD 14072- } \\
\text { RFIDVImplementación del Proyectol5.- } \\
\text { Integración y Pruebas de SW5.-Manual de } \\
\text { Usuario) }\end{array}$ \\
\hline Manual de Operaciones & $\begin{array}{l}\text { Documento que contiene información } \\
\text { necesaria para instalación el sistema. Se } \\
\text { encuentra en la versión } 1.0 \text { (C:I } \\
\text { Documentación de Proyectos\Proyectos } 12 \text {.- } \\
\text { Proyectos NetIProyectos PendienteslCD } \\
\text { 14072-RFID Implementación del Proyectol5.- } \\
\text { Integración y Pruebas de SW4.-Manual de } \\
\text { Operaciones) }\end{array}$ \\
\hline Reporte de Pruebas & $\begin{array}{l}\text { Documento que contiene información sobre } \\
\text { el resultado que se obtuvo al ejecutar los } \\
\text { casos de prueba. Este se puede obtener en } \\
\text { los testcase enlazados a cada issue. }\end{array}$ \\
\hline Manual de Mantenimiento & $\begin{array}{l}\text { Descripción de los elementos de la } \\
\text { configuración del software. Se encuentra en } \\
\text { la siguiente ruta C:IDocumentación de } \\
\text { ProyectosiProyectos } 12 \text {.-Proyectos } \\
\text { Net\Proyectos PendientesiCD 14072- } \\
\text { RFIDImplementación del Proyectol6.- } \\
\text { Entrega del Productol1.-Manual de } \\
\text { Mantenimiento }\end{array}$ \\
\hline
\end{tabular}




\subsection{Diseño del Software - Proyecto RFID}

Contenido General del Documento:

\section{INDICE}

1. DISEÑO DETALLADO DE ALTO NIVEL ..........................................................................

1.1. COMPONENTES DE SOFTWARE ....................................................................................4

1.2. RELACIÓN ENTRE LOS COMPONENTES DE SOFTWARE................................... 4

1.3. CARACTERÍSTICAS DE DESEMPEÑO DE SOFTWARE ..........................................4

1.3.1. Tiempo de Respuesta.........................................................................................

1.3.2. Uso de Recursos .................................................................................................

1.4. INTERFACES DE HARDWARE, SOFTWARE Y HUMANAS ...................................4

1.5. CARACTERÍSTICAS DE SEGURIDAD ........................................................................

1.6. REQUISITOS DE DISEÑO DE BASE DE DATOS ......................................................4

1.7. MANEJO DE ERRORES Y ATRIBUTOS DE RECUPERACIÓN................................4

1.7.1. Aplicación Web ............................................................................................................

1.7.2. Aplicación de Servicios ...............................................................................4

2. DISEÑO DETALLADO DE BAJO NIVEL .................................................................

2.1. REPRESENTACIÓN DEL DISEÑO DEL SISTEMA ...............................................

2.2. FORMATO DE ENTRADA Y SALIDA DE DATOS.....................................................

2.3. ESPECIFICACIÓN PARA EL ALMACENAMIENTO DE DATOS...............................

2.4. CONVENCIONES DE DENOMINACIÓN DE LOS DATOS ......................................

2.5. MODELO FÍSICO DE LA BASE DE DATOS ..............................................................

2.6. DEFINICIÓN DE TABLAS Y COLUMNAS ...................................................................5

2.7. ESPECIFICACIÓN DE LA ESTRUCTURA DEL PROGRAMA ................................. 
A continuación, se describe algunas secciones del documento que reflejan las secciones establecidas por la ISO 29110:

\section{Diseño Arquitectónico}

- Características de desempeño de Software

\subsection{CARACTERÍSTICAS DE DESEMPEÑO DE SOFTWARE}

\subsubsection{Tiempo de Respuesta}

La aplicación deberá estar en la capacidad de poder gestionar las respuestas a las acciones realizadas por el usuario en tiempo casi inmediato, tomando como máximo 3 segundos por respuesta. Esto no necesariamente se cumplirá en los siguientes eventos:

- Carga de un archivo de extensión csv, en cuyo caso la aplicación podría tardar más tiempo del esperado. En este caso, el tiempo que tardará esta operación estará relacionado con las especificaciones técnicas del celular (memoria, procesador, etc.) y el tamaño del archivo a cargar.

\subsubsection{Uso de Recursos}

El consumo de recursos por parte de la aplicación será de grado medio, debido al intenso empleo de conexiones Bluetooth, además de procesos de mayor complejidad como la carga de archivos en mempria. Para garantizar un nivel de rendimiento aceptable, la aplicación estará optimizada para equipos de gama media (con sistema operativo Android 4.0 o superior). 
- Interfaces de hardware, software y humanas

\subsection{INTERFACES DE HARDWARE, SOFTWARE Y HUMANAS}

Se han identificado las siguientes interfaces que existirán en el sistema:

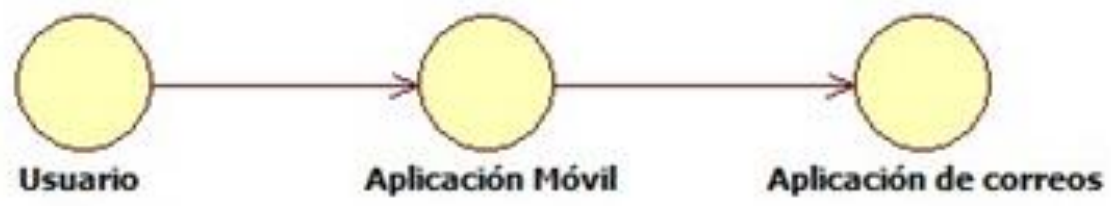

- Características de Seguridad

\subsection{CARACTERISTICAS DE SEGURIDAD}

Las características de seguridad que el sistema garantizará serán las siguientes:

- La aplicación solicitará un código autorizador para poder funcionar. Una vez ingresado, la aplicación recordará este código y no lo volverá a pedir.

- Se otorgarán 10 códigos autorizadores al dueño de la aplicación para que los administre. Estos códigos estarán encriptados usando el formato SHA-1.

- La aplicación manejará un log de transacciones el cual será usado cada vez que se registre una operación de lectura o escritura de datos en los tags, así como cuando se cargue un archivo.

- La edición, bloqueo y desactivación de los tags estará protegida por código y contraseña, reduciendo las posibilidades de alteraciones accidentales de tags. 
- Manejo de errores

\subsection{MANEJO DE ERRORES Y ATRIBUTOS DE RECUPERACIÓN}

La aplicación móvil los posibles errores que pudieran ocurrir, asegurando su funcionamiento a pesar de las incidencias registradas en las transacciones realizadas por el usuario. Cada vez que ocurra algún error, la aplicación notificará al usuario del error ocurrido.

En el caso de errores en la conexión Bluetooth con el dispositivo de lectura, la aplicación móvil intentará recuperar la conexión hasta un máximo de 3 veces. En caso la conexión no pueda ser reestablecida, se cancelará y/o se revertirá cualquier operación que haya quedado pendiente.

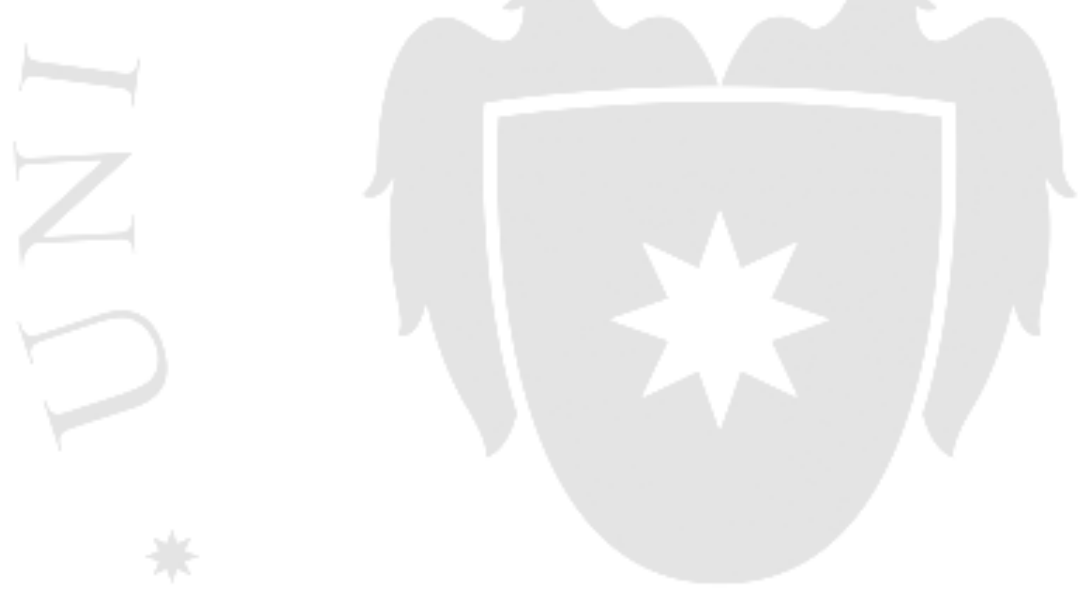




\section{ANEXO 5: Actas de Reunión}

Todas las actas presentadas contienen objetivos, tareas, temas a tratar, acuerdos y entregables durante el trabajo de investigación. Dichas actas son parte de la elaboración propia como evidencia de las reuniones programadas.

\subsection{Acta de Reunión $\mathrm{N}^{\circ} 1$}

$\overline{\text { En la primera acta de reunión, se expone la definición del alcance del proyecto, los temas a }}$ tratar, entregables pendientes, y la programación de las futuras reuniones.

\section{ACTA DE REUNIÓN N*1}

\begin{tabular}{|c|c|c|c|c|}
\hline \multicolumn{5}{|l|}{ CONTROLL } \\
\hline Nambre Propecto & \multicolumn{4}{|c|}{ 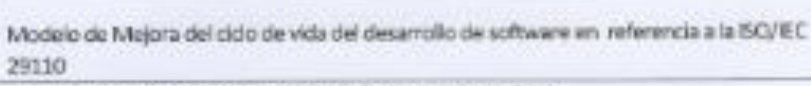 } \\
\hline werar & \multicolumn{4}{|c|}{ Ir. La ficresta 319 Dota 504 Sanclago de Surco, Lima - Penú } \\
\hline \multirow{2}{*}{ Fecha } & \multirow{2}{*}{$0 \mathrm{H} / 0 \mathrm{~T} / 2015$} & Horn Inicio & \multicolumn{2}{|l|}{ Drooam } \\
\hline & & Hore Fin & \multicolumn{2}{|l|}{$1100 \mathrm{pm}$} \\
\hline \multicolumn{5}{|l|}{ " } \\
\hline \multicolumn{5}{|l|}{ ASISTENCA * - } \\
\hline Cargo & \multicolumn{2}{|l|}{ Nambres yapellidos } & Empresa/Ansutudición & Firmas \\
\hline - & \multicolumn{2}{|l|}{ Horny the fig-aquas terrada } & Unversidas de Uima & \\
\hline - & \multicolumn{2}{|l|}{ Raul Alonso Nevamo Mocurf } & \multicolumn{2}{|c|}{ Unvenidad de ima } \\
\hline Gerente General & 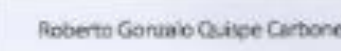 & & Hoinsgs & \\
\hline
\end{tabular}


TEMAS TRATADOS

\begin{tabular}{|c|c|c|}
\hline Tema & Descripcién & $\begin{array}{l}\text { Clanee } \\
\text { Request }\end{array}$ \\
\hline 1 & Exponec e wance del propecto de irvessocich. & \\
\hline 2 & 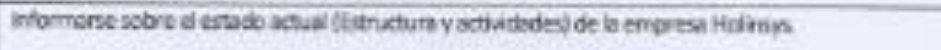 & \\
\hline 3 & 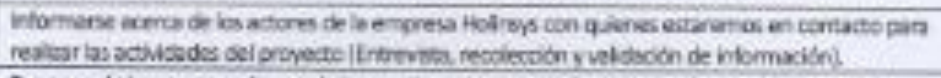 & \\
\hline 4 & 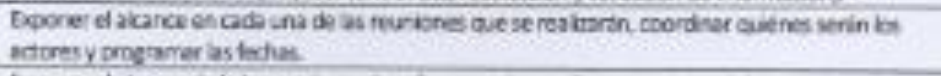 & \\
\hline 5 & 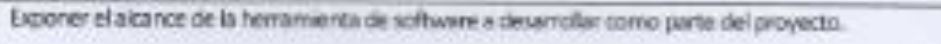 & \\
\hline
\end{tabular}

\section{ACUERDOS}

Frowimas reuniones cos ta empresa nidinsps.

Afrunión N/:

\begin{tabular}{|c|c|c|c|c|}
\hline Fecthe & Anedive & Aateris & Arspennatric & Achiridudes \\
\hline $\begin{array}{l}\text { Jueves } \\
\text { 09.07. } 2015\end{array}$ & Presencie! & $\begin{array}{l}\text { Anafists } \\
\text { delstes } \\
\text { dech }\end{array}$ & $\begin{array}{l}\text { Mintin Noneo } \\
\text { Cóndior Nufits }\end{array}$ & 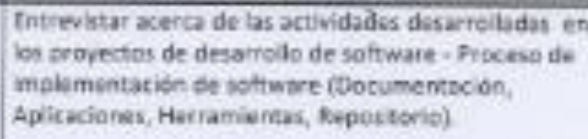 \\
\hline
\end{tabular}

Beunion $\mathrm{N}^{*} 3$ :

\begin{tabular}{|c|c|c|c|c|}
\hline fecthe & nagdes & Astones: & - Hepoingiry & Artinidistes \\
\hline $\begin{array}{l}\text { hueves } \\
16.022015\end{array}$ & Presentisi & $\begin{array}{l}\text { Cestor de } \\
\text { Provectes }\end{array}$ & Tanle Kamires & 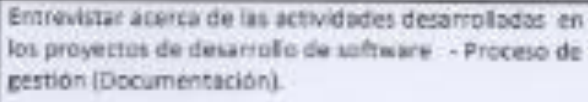 \\
\hline $\begin{array}{l}\text { Averes } \\
16.07 .2015\end{array}$ & Presenclal & $\begin{array}{l}\text { Analista } \\
\text { del area } \\
\text { de Qex }\end{array}$ & $\begin{array}{l}\text { Martin Alonse } \\
\text { Cendor Nuhier }\end{array}$ & 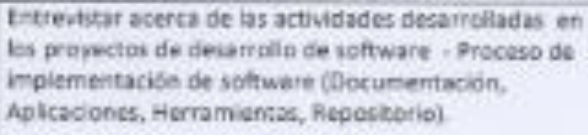 \\
\hline
\end{tabular}




\section{TEMAS TRATADOS}

\begin{tabular}{|c|c|c|}
\hline Terta & Descripción & $\begin{array}{l}\text { Change } \\
\text { Request }\end{array}$ \\
\hline 1 & 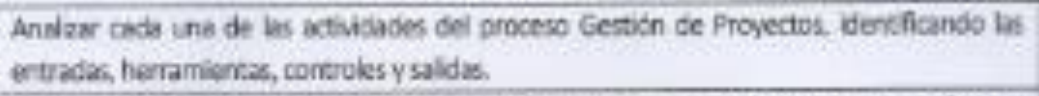 & \\
\hline 2 & 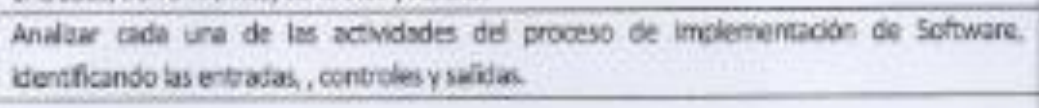 & \\
\hline & & \\
\hline & & \\
\hline
\end{tabular}

\section{ACUERDO5}

singuna

\section{PENDIENTES}

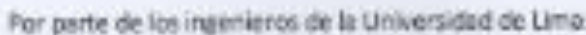

Diagramas del eitado actual del croceso de Gestion de Mropectid.

Diveramas de cada uns de las activitades de Mroceve de Gestidn de Provectod

Dagama de Parete e istieawa de cada una da las acthidades del Procese fiestion de Moyectei.

Matri fCoh de tada we de las actividades del Aroceso Gestión de Provectes.

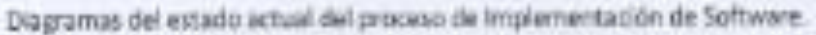

Dagrams ce code ura de lat actividudes del Proceso de implementadin de Seftware.

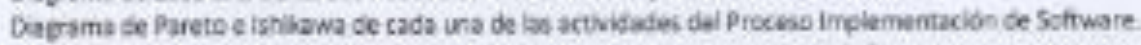

Necrí FOPA do cada una de ias activifactes del Procras imelementación de Sottware.

\begin{tabular}{|c|c|}
\hline & fis \\
\hline Nombres: & 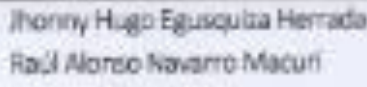 \\
\hline Unkersidad: & Univerviclad te Lma \\
\hline
\end{tabular}

\begin{tabular}{|c|c|}
\hline \multicolumn{2}{|c|}{ 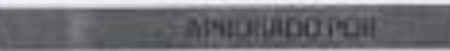 } \\
\hline Nombres: & $\begin{array}{l}\text { Ratberto Gonzalo Quspe } \\
\text { Cartons: }\end{array}$ \\
\hline Emprese: & Holnsps \\
\hline DN: 43 & $68 \sqrt{68}$ \\
\hline Frma: & \\
\hline
\end{tabular}




\subsection{Acta de Reunión $\mathbf{N}^{\circ} 2$}

En la segunda reunión, tuvimos como objetivo recopilar los datos como son las entradas, herramientas, controles y salidas del ciclo de vida del proceso Implementación de Software.

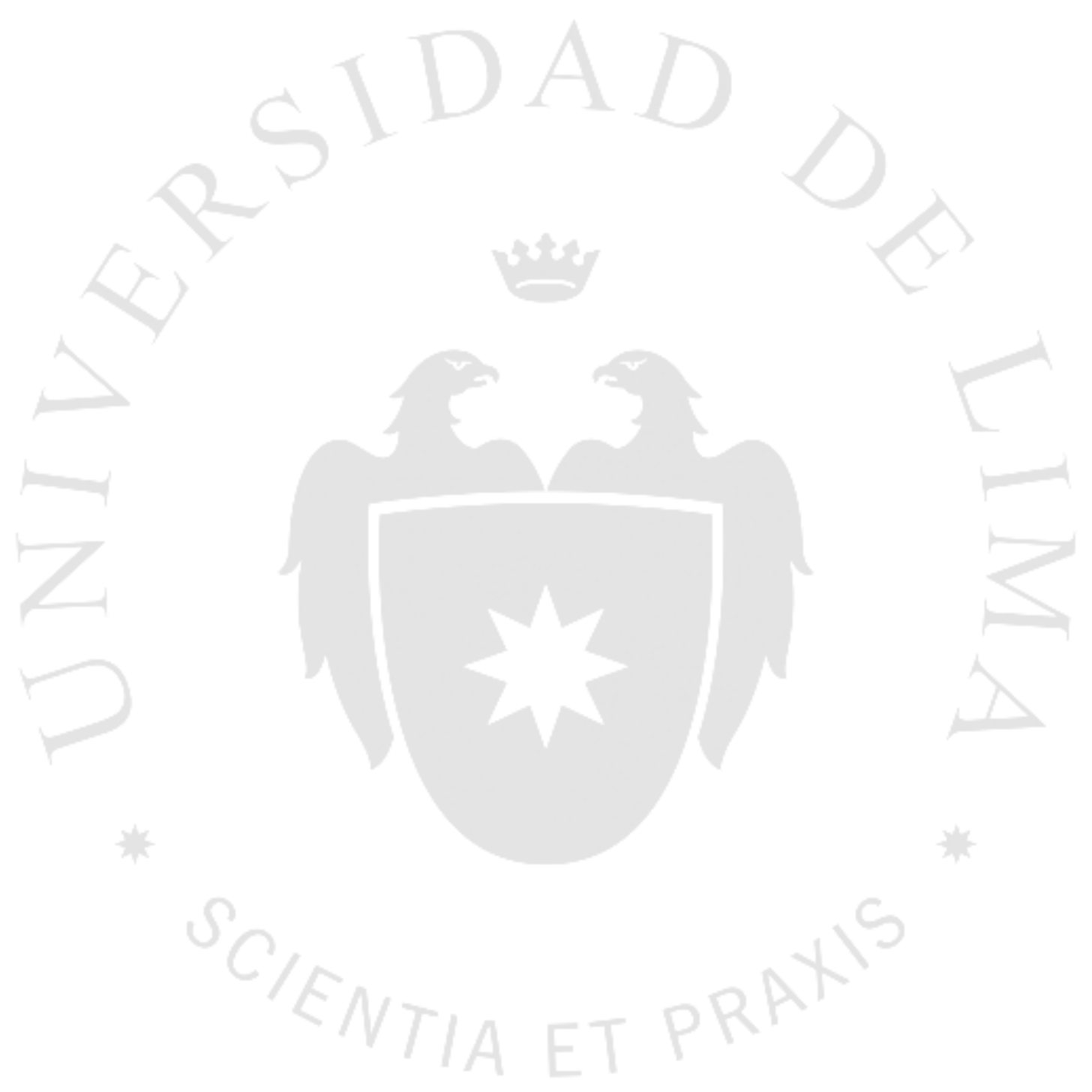




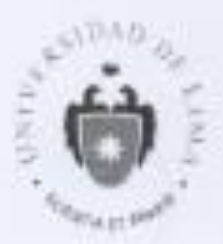

\section{ACTA DE REUNIÓN N*2}

Objetive: Recapilar las entracas, berramientas, controles, y salidas del cieie de vich del proceso implementación de Soltware.

\section{CONTROL}

\begin{tabular}{|c|c|c|c|}
\hline Nombre Proyecto & \multicolumn{3}{|c|}{$\begin{array}{l}\text { Nodelo de Mepore de dib de ude del desarmolo de schware en referencia a la sonte } \\
29110\end{array}$} \\
\hline Legr & \multicolumn{3}{|c|}{ 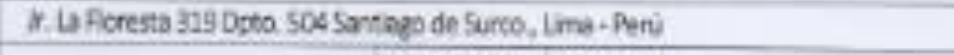 } \\
\hline \multirow{2}{*}{ Fecha } & \multirow{2}{*}{ as/07/2015 } & Hora Inico & 마:00 pm \\
\hline & & Han Fin & $0400 \mathrm{pm}$ \\
\hline
\end{tabular}

\section{ASISTENCIA}

\begin{tabular}{|c|c|c|c|}
\hline Cargo & Nombres yapelidos & Empresa/insthucén & firmas \\
\hline * & horry Hug Equsquica Iterrads & Whersidad de Ums & \\
\hline - & Rail Abreo Navarro Macari & Lriworidad of lim & \\
\hline Gerente Genera & Reterto Conzids Quspe Carbonal & Holinss & \\
\hline $\begin{array}{l}\text { Araista } \\
\text { Provartodor }\end{array}$ & Martin Abonso Condor HSes & Helings. & \\
\hline
\end{tabular}




\section{TEMAS TRATADO5}

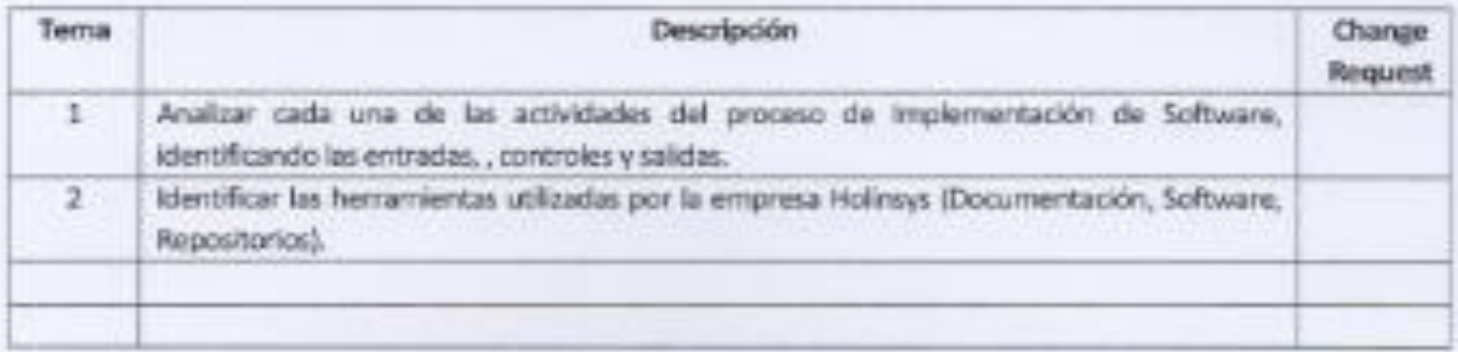

\section{ACUEROOS}

Nineino.

\section{PENDIENTES}

For poste de los ingenieros de la Universided de Lima:

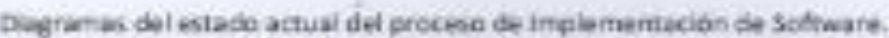

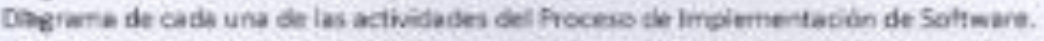

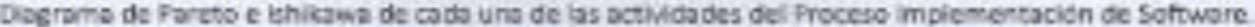

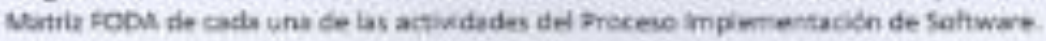

\begin{tabular}{|c|c|}
\hline Nombres: & henry Hugo Eeusguiza Hernacla \\
\hline & Ravi: Nonso Nevomo Mscun \\
\hline Unibersidat: & Universidad de lime \\
\hline
\end{tabular}

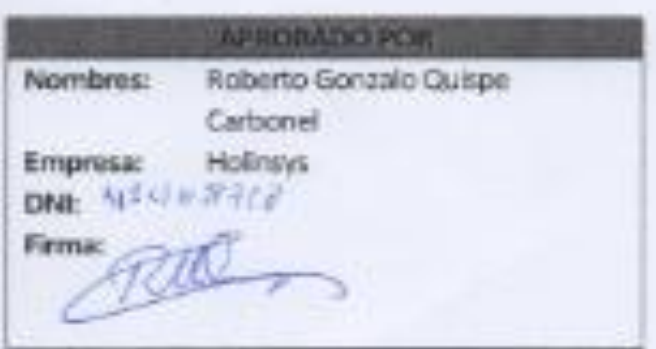




\subsection{Acta de Reunión $\mathbf{N}^{\circ} 3$}

En la tercera reunión, tuvimos como objetivo recopilar los datos como son las entradas, herramientas, controles y salidas del ciclo de vida del proceso Gestión del Proyecto.

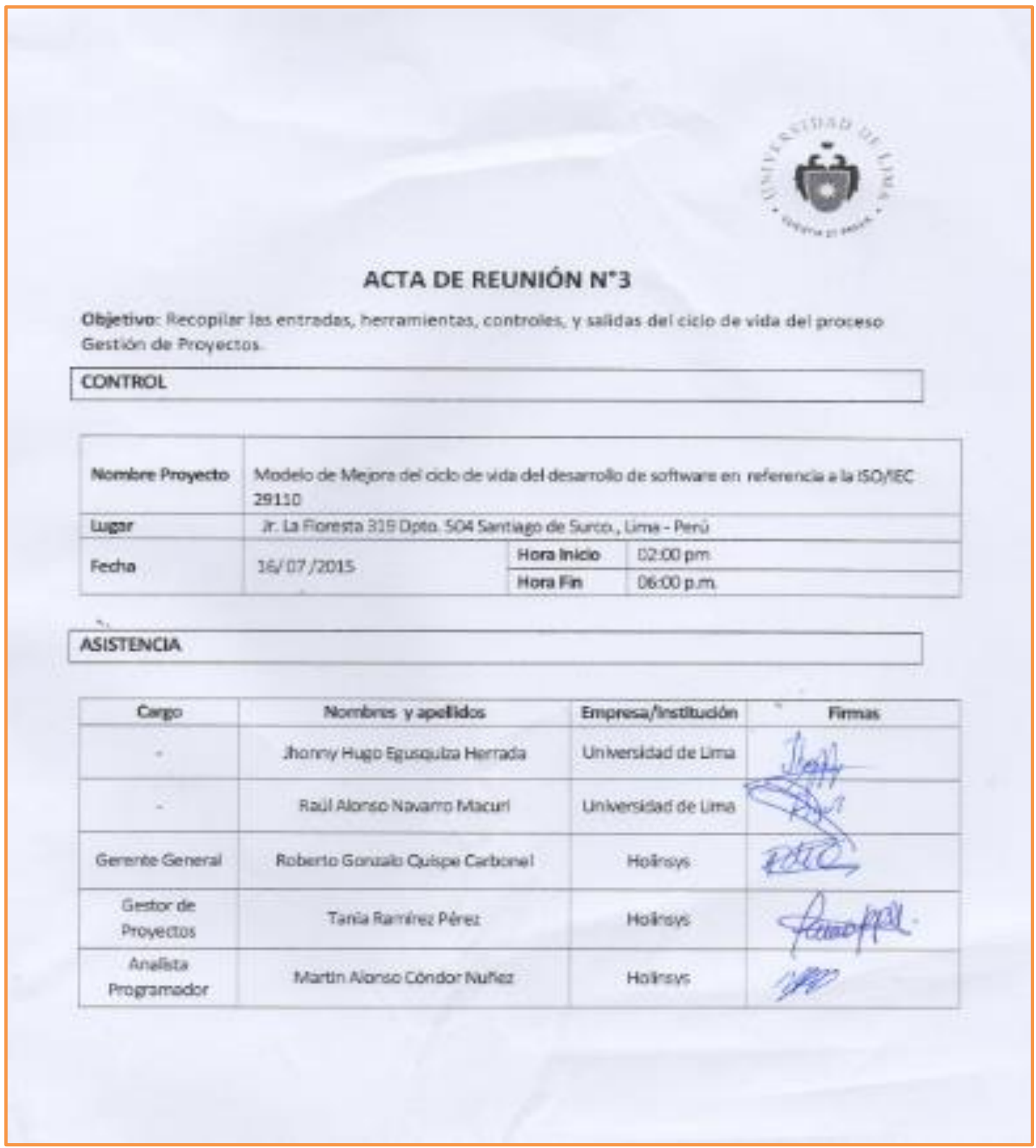


Presertatión de Reautsolos:

Anbisis de resultadon:

Cincramas del estado nctual del proceso de tuestion de Provectos.

Diagramas de cada wra de las actl-itases del Propeso de Geation de Proyectos.

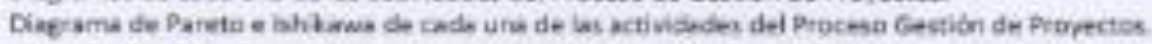

Matre Foga de cada una ae us actindades del Process Cestion de Proprecios.

Diseramas del escado actual del proceso de implemercación de Soltuace.

Diagrama de cada uns de las sctivitades del Froceso de implementacion ce Sottware.

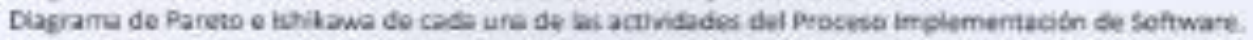

Mntrie FDOS de cads une de ler actividader del Process inplementacibs de Solwark.

\section{Models de Mejoen}

Dosramo del Froceso Geston de Frovectos zdsptsdo a la norma 150 25120.

Duarame del Procme impiementacidn de Software adaptado a la nome 15029120.

Documentas nectiarico pers ei nivel de cimplimiento en bese s la noma 5029110

Herramisnte de Sottware a desarrolbr.

heocmendaciones para uso de Herramienas de Soltware y Hardwere.

Onearierums de la emprese.

Mandel de fundanas.

$*$

\section{PENDIENTES}

Na exstes penalentes.

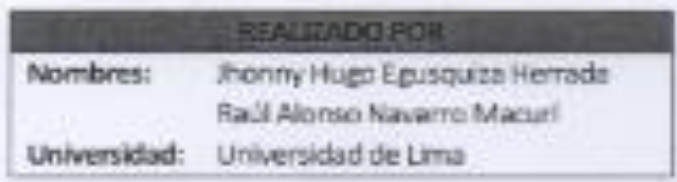

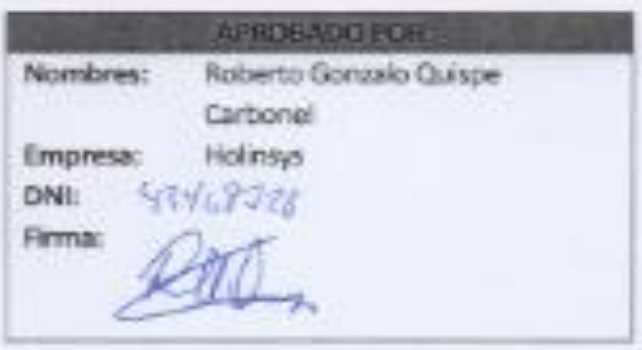




\subsection{Acta de Reunión $\mathrm{N}^{\circ} 4$}

En la cuarta reunión, se presentó los resultados de la evaluación del proceso de desarrollo de software de la empresa HOLINSYS como también la entrega de los Documentos y herramienta de software desarrollada.

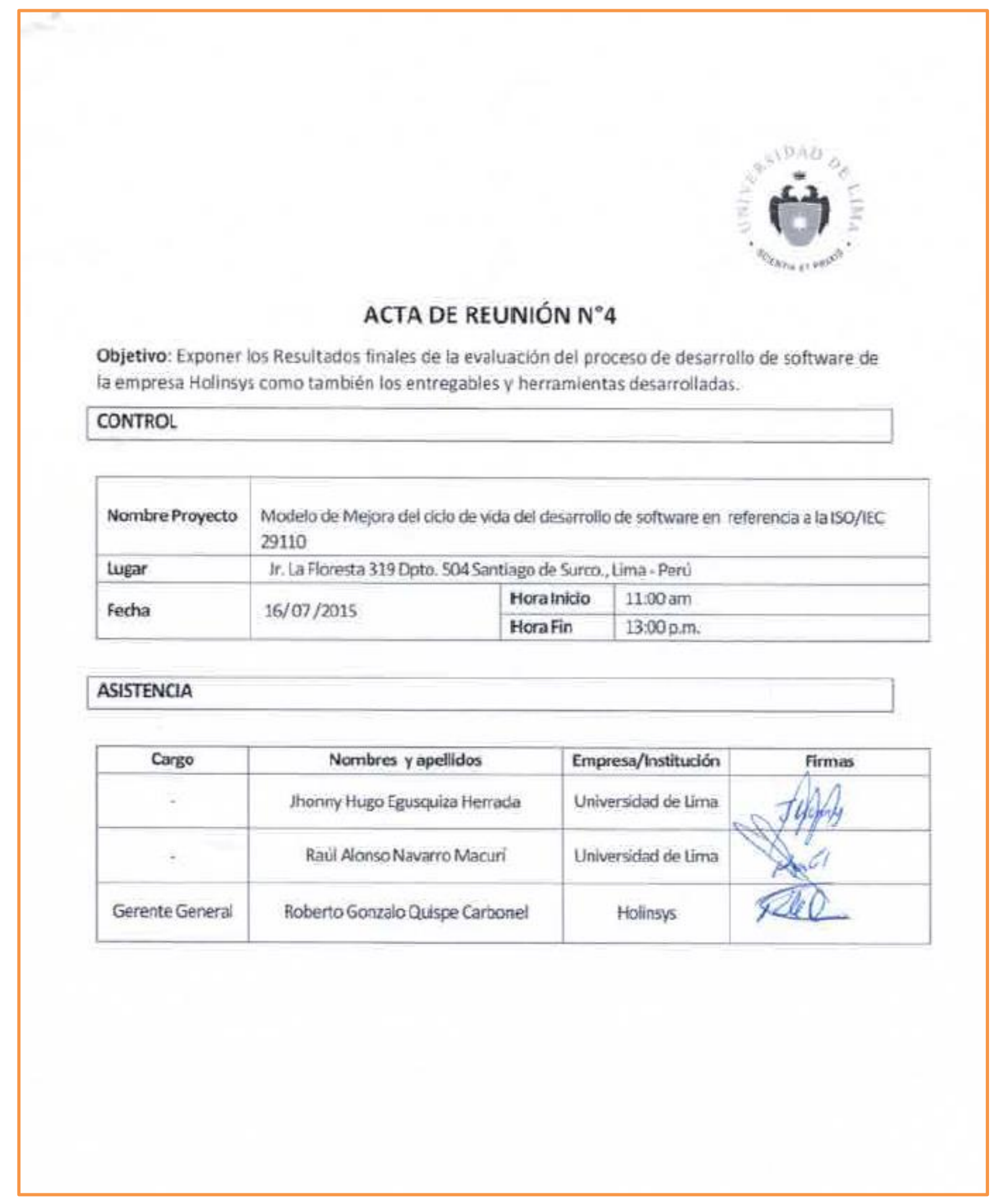


TEMAS TRATADOS

\begin{tabular}{|c|l|c|}
\hline Tema & \multicolumn{1}{|c|}{ Descripción } & $\begin{array}{c}\text { Change } \\
\text { Request }\end{array}$ \\
\hline 1 & Exponer Resultados de la Evaluación. \\
\hline 2 & $\begin{array}{l}\text { Exponer y Analizar los Diagramas del proceso de desarrollo de software de la empresa } \\
\text { Holinsys }\end{array}$ & \\
\hline 3 & Exponery Analizar los Documentos Modelo entregadosa la empresa. \\
\hline 4 & \begin{tabular}{l} 
Exponery Analizar los Manuales de funciones entregadios a bampresa. \\
\hline 5
\end{tabular} & $\begin{array}{l}\text { Exponer el sottware desarrollado para facintar el cumplimiento de lo establecida en la } \\
\text { isozg110. }\end{array}$ \\
\hline
\end{tabular}

\section{ACUERDOS}

Ninguno.

\section{PENDIENTES}

Ninguno.

\begin{tabular}{|c|c|}
\hline & PEALVADOPCR \\
\hline Nombres: & $\begin{array}{l}\text { Jhonny Hugo Egusquiza Herrada } \\
\text { Raul Alonso Navarro Macuri }\end{array}$ \\
\hline Universidad: & Universidad de Lima \\
\hline
\end{tabular}

APROBADO POR:

Nombres: Roberto Gonzalo Quispe

Carbonel

Empresa: Holinsys

DNI: 456(5)

Firma: 2010 


\subsection{Acta de Reunión $\mathrm{N}^{\circ} 5$}

En la quinta reunión, se validó la importancia de los entregables desarrollados.

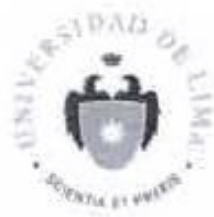

\section{ACTA DE REUNIÓN N 5}

Objetivo: Validar la importancia de los entregables finales indicando las observaciones y recomendaciones por parte de los representantes de la empresa.

\section{CONTROL}

\begin{tabular}{|l|l|l|l|}
\hline Nombre Proyecto & \multicolumn{2}{|l|}{$\begin{array}{l}\text { Modelo de Mejora del Proceso de implementación de Software en referencia a la ISO/IEC } \\
29110\end{array}$} \\
\hline Lugar & Jiron La Floresta 319 Dpto. 504 Santiago de Surco \\
\hline Fecha & $21 / 10 / 2015$ & Horalnicio & $01: 00 \mathrm{p} . \mathrm{m}$. \\
\cline { 3 - 4 } & Hora Fin & $02: 30 \mathrm{p} . \mathrm{m}$. \\
\hline
\end{tabular}

\section{ASISTENCIA}

\begin{tabular}{|c|c|c|c|}
\hline Cargo & Nombres y apellidos & Empresa/Institución & Firmas \\
\hline$=$ & Jhormy Huzo Eguscuiza Herrada & Universidad de Lima & \\
\hline - & Raúl Alonso Navarro Macurí & Universidad de Lima & \\
\hline Gerente General & Roberto Gonzalo Quispe Carbonel & Holinsys & \\
\hline $\begin{array}{l}\text { Gestor de } \\
\text { Proyectos }\end{array}$ & Tania Ramirez Perez & Hoilnsys & $\begin{array}{l}\text { LICENCIA POR } \\
\text { INUCDPACICAO tinvoret }\end{array}$ \\
\hline
\end{tabular}


TEMAS TRATADOS

\begin{tabular}{|c|l|c|}
\hline Tema & \multicolumn{1}{|c|}{ Descripción } & $\begin{array}{c}\text { Change } \\
\text { Request }\end{array}$ \\
\hline 1 & $\begin{array}{l}\text { Vatidar la importancia de los entregables finales, recopilando las observaciones } \mathrm{y} \\
\text { recomendaciones porparte de la empresa. }\end{array}$ & \\
\hline & & \\
\hline & & \\
\hline & & \\
\hline
\end{tabular}

\section{ACUERDOS}

Ninguno.

\section{PENDIENTES}

Acta de Aceptacion de los entregables finales por parte de los Bachilleres de ingertieria de Sistemas.

\section{REALIZADOPOR}

Nombres: Jhonny Hugo Egusquiza Herrada

Raúl Alonso Navarro Macuri

Universidad: Universidad de Lima

\section{APRORADO POR}

Nombres: Poberto Gonzalo Quispe Carbonel

Empresa: Holinsys

DN: $\quad 434,572\}$

Firma: 2010 
Se formalizó la entrega de los documentos y herramienta desarrollados.

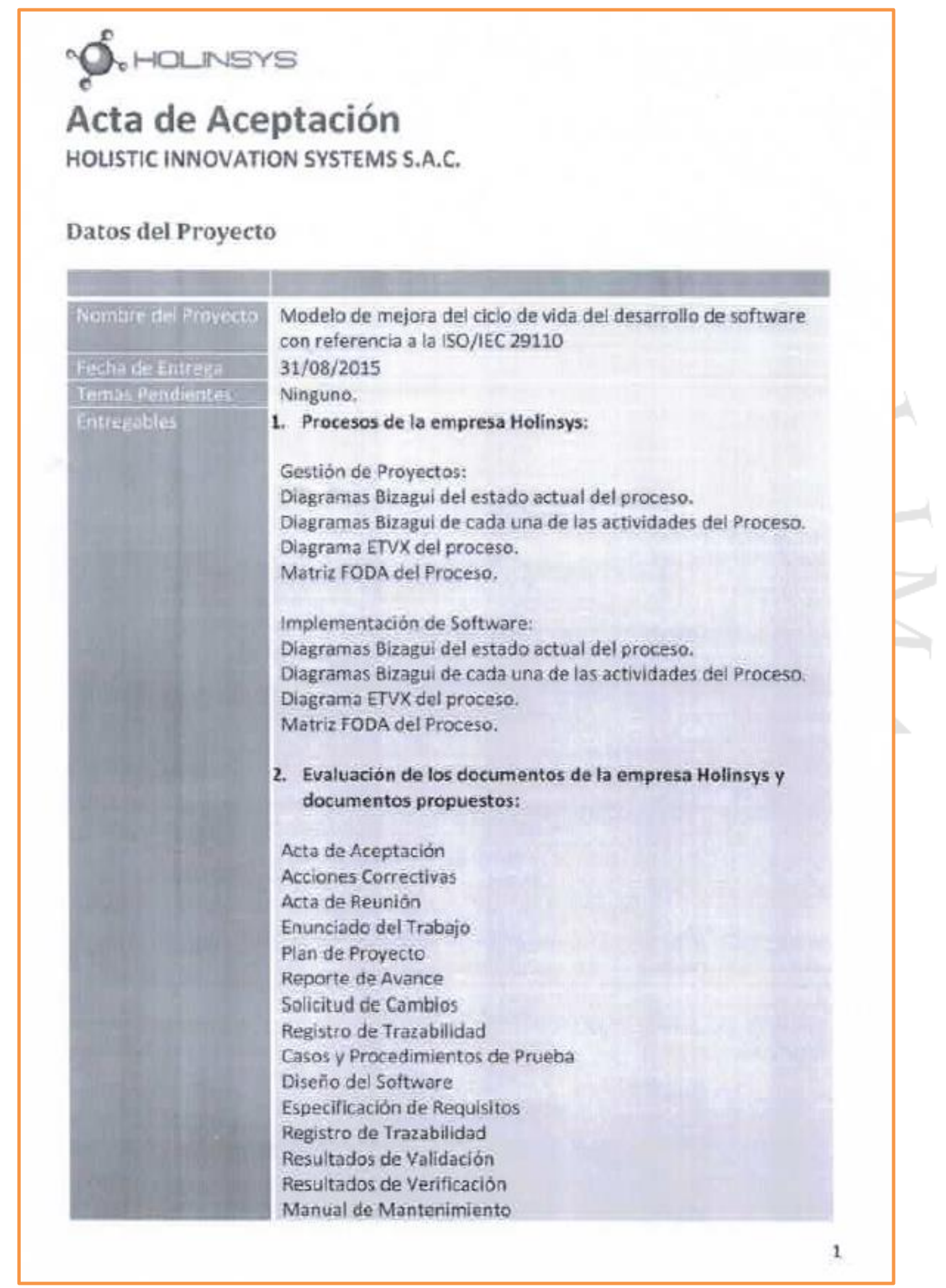


Q. Hownsts

Manual de Operación

Manual de Usuario

3. Evaluación de los Roles de la empresa Holinsys y MOFs:

Manual de Funciones del Lider Técnico.

Manual de Funciones del Gestor del Proyecto.

Manual de Funciones del Analista de Calidad.

Manual de Funciones del Analista Programador.

4. Herramienta de Software desarrollada:

Acceso a la herramienta de Software Desarrollada. (Trial por 30

Dias)

Manual de Usuario,

Registro de Recepción de Entrega

Firmar el documento al considerar que los entregables fueron recibidos.

\begin{tabular}{|c|c|c|}
\hline ifen mensilbig & Fentia & Filitigs \\
\hline $\begin{array}{l}\text { Roberto Gonzalo Quispe } \\
\text { Carbonel }\end{array}$ & $21 / 10 / 2015$ & \\
\hline Tania Ramirez Pérez: & $21 / 10 / 2015$ & 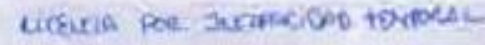 \\
\hline
\end{tabular}




\section{ANEXO 6: Análisis FODA del Resultado de la Evaluación de la Empresa HOLINSYS}

A continuación se presenta el análisis FODA de la evaluación de los procesos de la empresa HOLINSYS utilizando la herramienta mencionada en el Anexo 4.

Análisis FODA del proceso de Gestión del Proyecto

\section{Fortalezas}

-Buena negociación respecto al alcance del proyecto.

-Buena relación con el Cliente (Comunicación y seguimiento continuo).

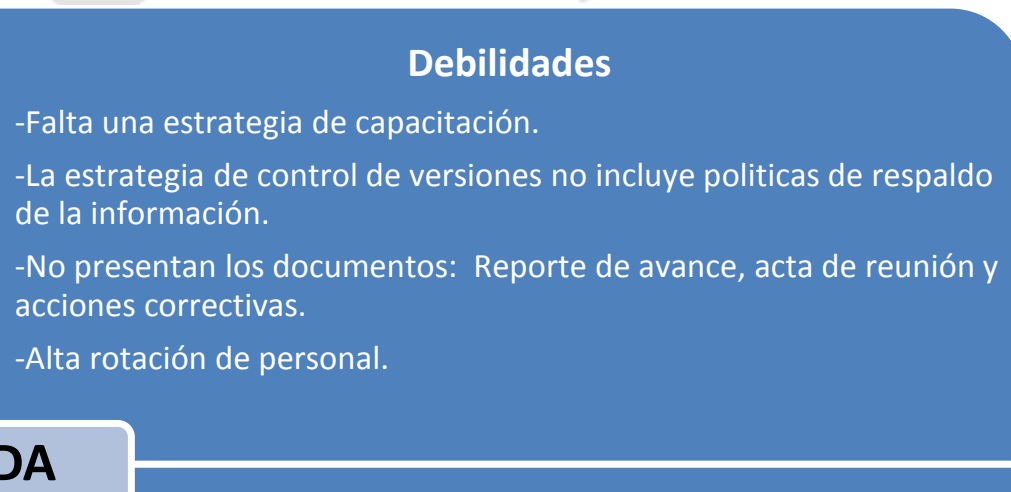

\section{FODA}

\section{Oportunidades}

-Implementar estrategia de capacitación del personal (Para miembros nuevos y actuales).

-Implementar estrategia para el control de versiones.

-Implementar los documentos Reporte de avance, acta de reunión y acciones correctivas para apoyar a las actividades de la organización.

-Utilizar herramientas de software para facilitar el cumplimiento de la documentación requerida por la ISO. 29110.

\section{Amenazas}

-Pérdida de la información generada en un proyecto de desarrollo.

-Falta de evidencia necesaria para demostrar que los procesos, actividades y documentación de la organización cumplen con lo solicitado en la ISO 29110. 


\section{Análisis FODA del proceso de Implementación del Software}

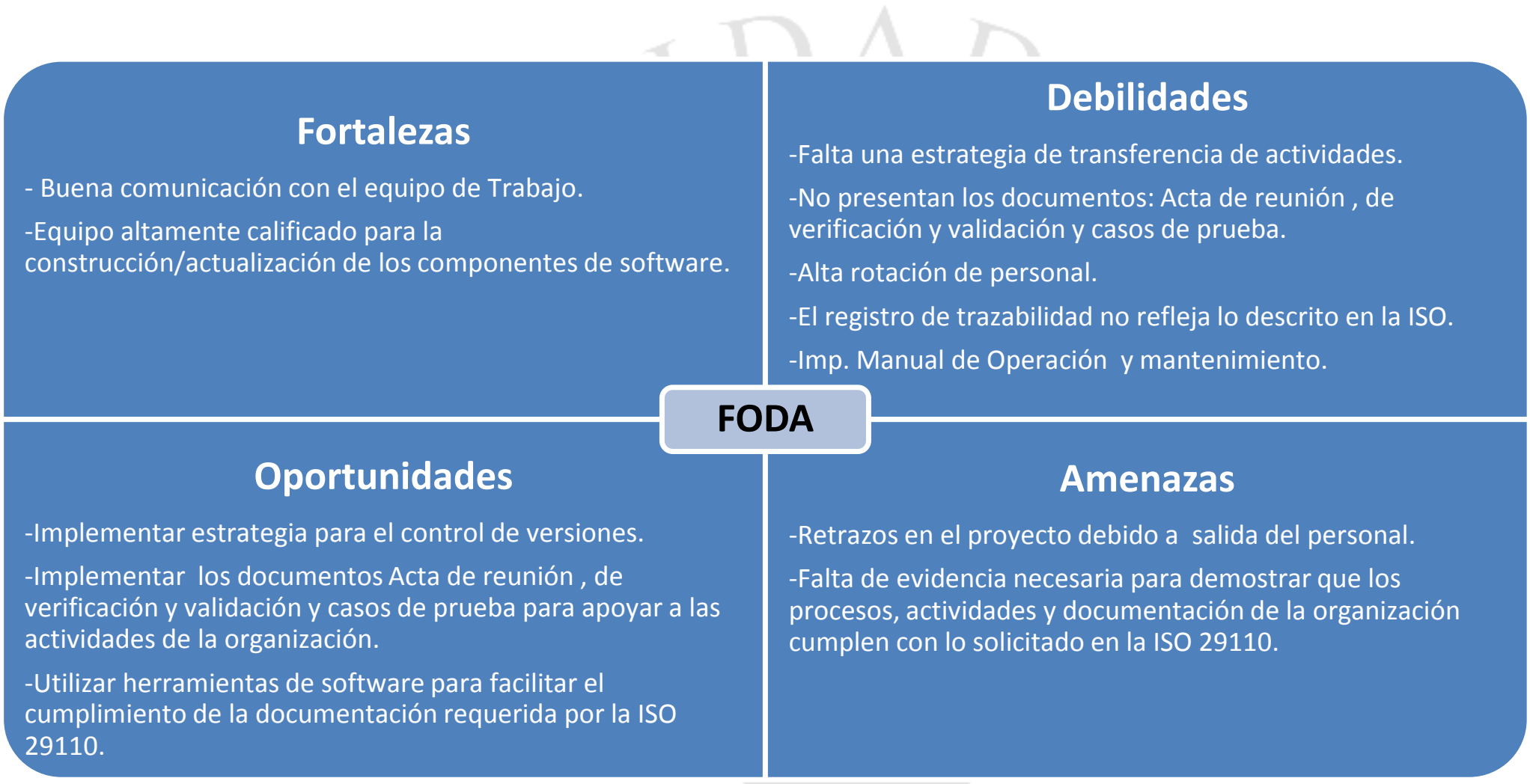




\section{ANEXO 7: Documentos para la elaboración de la Herramienta de Software}

\subsection{Casos y Procedimientos de Prueba}

Documento donde se describe los elementos necesarios como también los casos y procedimientos para probar la herramienta.

\section{Casos y Procedimientos de Prueba v.1.0 -}

\section{[A001CP]}

\section{Proyecto Auditor 29110 Plus -}

\section{[A001]}

Trabajo de Investigación: Modelo de Mejora del Ciclo de Vida del Desarrollo de Software

\section{Estado del Documento}

\begin{tabular}{|l|l|l|}
\hline Estado & Fecha & Responsable \\
\hline Creado & $10 / 09 / 2015$ & Navarro Macurí Raúl Alonso \\
\hline Verificado & $15 / 09 / 2015$ & Egusquiza Herrada Hugo Jhonny \\
\hline Validado & & \\
\hline Línea Base & & \\
\hline
\end{tabular}




\section{Casos y Procedimientos de Prueba}

[Descripción del Diseño arquitectónico de la herramienta a desarrollar/ Modificar]

\section{Módulo 01: Acceso a la herramienta}

Casos de Prueba relacionados al acceso a la herramienta.

\section{[AP0101] - Caso de Prueba: Registrar Usuario}

Registrar un nuevo usuario.

\section{Caso de Prueba}

\begin{tabular}{|c|c|}
\hline $\begin{array}{l}\text { Elementos a } \\
\text { probar }\end{array}$ & Interfaz "Registrar Usuario". \\
\hline Entradas & $\begin{array}{l}\text { Ingresar datos solicitados. } \\
\text { Dar clic en la opción Acepto las condiciones y Políticas de } \\
\text { uso. } \\
\text { Dar clic en el botón "Registrarse". }\end{array}$ \\
\hline Salidas & Mensaje de confirmación enviado al correo electrónico. \\
\hline $\begin{array}{l}\text { Necesidades del } \\
\text { entorno }\end{array}$ & Se requiere conexión a internet. \\
\hline $\begin{array}{l}\text { Procedimientos } \\
\text { especiales }\end{array}$ & No aplica. \\
\hline $\begin{array}{l}\text { Dependencias de } \\
\text { interfaz }\end{array}$ & No aplica. \\
\hline \multicolumn{2}{|c|}{ Procedimiento de Prueba } \\
\hline Descripción & $\begin{array}{l}\text { Se registra un nuevo usuario. } \\
\text { Se verifica el correcto funcionamiento de la aplicación. }\end{array}$ \\
\hline $\begin{array}{l}\text { Fecha de } \\
\text { Finalización }\end{array}$ & [Fecha de finalización de la prueba] \\
\hline Responsable & Navarro Macurí Raúl Alonso \\
\hline Requisitos previos & $\begin{array}{l}\text { El usuario no debe estar registrado. } \\
\text { La empresa debe estar registrada. } \\
\text { El correo electrónico debe ser válido. }\end{array}$ \\
\hline
\end{tabular}




\begin{tabular}{|l|l|}
\hline Pasos & Ingresar los campos solicitados. \\
Dar clic en la opción Acepto las condiciones y Políticas de \\
uso. \\
Dar clic en el botón "Registrarse". \\
Verificar que haya llegado el mensaje de confirmación al \\
correo electrónico. \\
Dar clic en el link recepcionado. \\
Acceder al sistema. \\
\hline El mensaje de confirmación enviado al correo electrónico \\
debe tener la estructura deseada. \\
Lsperados & $\begin{array}{l}\text { Luego de finalizar el registro, el usuario debe poder acceder } \\
\text { al sistema. }\end{array}$ \\
\hline Estructura del mensaje de confirmación incorrecta. \\
\hline posibles & Conforme \\
\hline Estado & \\
\hline
\end{tabular}

\section{[AP0102] - Caso de Prueba: Acceder a la herramienta}

Acceder a la herramienta utilizando usuario y contraseña previamente creados.

\section{Caso de Prueba}

\section{Elementos a probar}

Entradas

Salidas

Necesidades del

entorno

Procedimientos

especiales

Dependencias de

interfaz
Interfaz "Pantalla Acceso".

Ingresar usuario y contraseña.

Dar clic en el botón "Acceder".

Visualizar el mensaje Iniciando Sesión.

Acceder a la interfaz Pantalla Inicio.

Se requiere conexión a internet.

No aplica.

No aplica. 


\begin{tabular}{|c|c|}
\hline Descripción & $\begin{array}{l}\text { Se accede a la pantalla principal de la aplicación. } \\
\text { Se verifica el correcto funcionamiento de la aplicación. }\end{array}$ \\
\hline $\begin{array}{l}\text { Fecha de } \\
\text { Finalización }\end{array}$ & [Fecha de finalización de la prueba] \\
\hline Responsable & Navarro Macurí Raúl Alonso \\
\hline Requisitos previos & $\begin{array}{l}\text { El usuario debe estar registrado. } \\
\text { La contraseña debe ser la correcta. }\end{array}$ \\
\hline Pasos & $\begin{array}{l}\text { Ingresar los campos solicitados: Usuario y contraseña. } \\
\text { Dar clic en el botón “Acceder" }\end{array}$ \\
\hline $\begin{array}{l}\text { Resultados } \\
\text { Esperados }\end{array}$ & $\begin{array}{l}\text { Al registrarse, el mensaje de bienvenida debe ser la correcta. } \\
\text { Acceder correctamente al sistema. }\end{array}$ \\
\hline Posibles problemas & $\begin{array}{l}\text { No poder acceder al sistema. } \\
\text { Acceder al sistema con el usuario y contraseña incorrecta. }\end{array}$ \\
\hline Estado & Conforme \\
\hline $\begin{array}{l}\text { [AP0103] - Caso de P } \\
\text { Acceder a la herramier }\end{array}$ & rueba: Recuperar contraseña \\
\hline Caso de Prueba & \\
\hline Elementos a probar & Interfaz Olvidar contraseña \\
\hline Entradas & $\begin{array}{l}\text { Ingresar los datos solicitados. } \\
\text { Dar clic en el botón “Aceptar”. } \\
\text { Ingresar la nueva contraseña. } \\
\text { Dar clic en el botón “Aceptar". }\end{array}$ \\
\hline Salidas & $\begin{array}{l}\text { Visualizar el mensaje de ayuda al reestablecer su contraseña. } \\
\text { Mensaje de recuperación de contraseña enviado al correo } \\
\text { electrónico. }\end{array}$ \\
\hline $\begin{array}{l}\text { Necesidades del } \\
\text { entorno }\end{array}$ & Se requiere conexión a internet \\
\hline $\begin{array}{l}\text { Procedimientos } \\
\text { especiales }\end{array}$ & No aplica \\
\hline
\end{tabular}




\begin{tabular}{|c|c|}
\hline $\begin{array}{l}\text { Dependencias de } \\
\text { interfaz }\end{array}$ & Interfaz Pantalla Inicio \\
\hline \multicolumn{2}{|c|}{ Procedimiento de Prueba } \\
\hline Descripción & $\begin{array}{l}\text { Se registra una nueva contraseña. } \\
\text { Se verifica el correcto funcionamiento de la aplicación. }\end{array}$ \\
\hline $\begin{array}{l}\text { Fecha de } \\
\text { Finalización }\end{array}$ & [Fecha de finalización de la prueba] \\
\hline Responsable & Navarro Macurí Raúl Alonso \\
\hline Requisitos previos & El usuario debe estar registrado. \\
\hline Pasos & $\begin{array}{l}\text { Ingresar los campos solicitados: Correo electrónico, código captcha. } \\
\text { Dar clic en el botón “Aceptar”. } \\
\text { Verificar que haya llegado el mensaje de recuperación al correo } \\
\text { electrónico. } \\
\text { Dar clic en el link recepcionado. } \\
\text { Ingresar la nueva contraseña. } \\
\text { Dar clic en el botón “Aceptar”. }\end{array}$ \\
\hline $\begin{array}{l}\text { Resultados } \\
\text { Esperados }\end{array}$ & $\begin{array}{l}\text { El mensaje de recuperación enviado al correo electrónico debe } \\
\text { tener la estructura deseada. } \\
\text { Acceder correctamente al sistema. }\end{array}$ \\
\hline Posibles problemas & $\begin{array}{l}\text { No poder acceder al sistema con la nueva contraseña modificada. } \\
\text { Acceder al sistema con la contraseña anterior. }\end{array}$ \\
\hline Estado & Conforme. \\
\hline
\end{tabular}

\section{Módulo 02: Pantalla Principal}

Casos de Prueba relacionados a las funciones disponibles en la interfaz principal.

\section{[AP0201] - Caso de Prueba: Registrar Empresa}

Registrar una nueva empresa.

\section{Caso de Prueba}

Elementos a probar

Entradas
Interfaz Registrar Empresa

Ingresar los campos solicitados. 


\begin{tabular}{|c|c|}
\hline & Dar clic en el botón "Registrar empresa". \\
\hline Salidas & $\begin{array}{l}\text { Visualizar el mensaje de registro exitoso. } \\
\text { Mensaje de verificación al correo electrónico del encargado de la } \\
\text { empresa. }\end{array}$ \\
\hline $\begin{array}{l}\text { Necesidades del } \\
\text { entorno }\end{array}$ & Se requiere conexión a internet \\
\hline $\begin{array}{l}\text { Procedimientos } \\
\text { especiales }\end{array}$ & No aplica \\
\hline $\begin{array}{l}\text { Dependencias de } \\
\text { interfaz }\end{array}$ & No aplica \\
\hline \multicolumn{2}{|c|}{ Procedimiento de Prueba } \\
\hline Descripción & $\begin{array}{l}\text { Se registra una nueva empresa. } \\
\text { Se verifica el correcto funcionamiento de la aplicación. }\end{array}$ \\
\hline $\begin{array}{l}\text { Fecha de } \\
\text { Finalización }\end{array}$ & [Fecha de finalización de la prueba] \\
\hline Responsable & Navarro Macurí Raúl Alonso \\
\hline Requisitos previos & $\begin{array}{l}\text { La empresa no debe estar registrada. } \\
\text { El usuario responsable no debe pertenecer a otra empresa. }\end{array}$ \\
\hline Pasos & $\begin{array}{l}\text { Ingresar los campos solicitados. } \\
\text { Dar clic en el botón "Registrar empresa". } \\
\text { Dar clic en el botón "Salir". } \\
\text { Verificar que haya llegado el mensaje de verificación al correo } \\
\text { electrónico del usuario responsable de la empresa. } \\
\text { Dar clic en el link recepcionado. }\end{array}$ \\
\hline $\begin{array}{l}\text { Resultados } \\
\text { Esperados }\end{array}$ & $\begin{array}{l}\text { El mensaje de verificación enviado al correo electrónico del } \\
\text { usuario responsable de la empresa debe tener la estructura } \\
\text { deseada. } \\
\text { Luego de finalizar el registro, el usuario debe poder acceder al } \\
\text { sistema. }\end{array}$ \\
\hline Posibles problemas & Estructura del mensaje de verificación incorrecta. \\
\hline Estado & Conforme. \\
\hline
\end{tabular}




\section{[AP0202] - Caso de Prueba: Actualizar Datos del Perfil de Usuario}

Actualizar datos del usuario: contraseña, país y/o ciudad.

Caso de Prueba

\begin{tabular}{|c|c|}
\hline Elementos a probar & Interfaz Actualizar Datos Usuario \\
\hline Entradas & $\begin{array}{l}\text { Ingresar la contraseña, país o ciudad que desee modificar. } \\
\text { Dar clic en el botón Guardar cambios. }\end{array}$ \\
\hline Salidas & Visualizar el mensaje Perfil actualizado correctamente. \\
\hline $\begin{array}{l}\text { Necesidades del } \\
\text { entorno }\end{array}$ & Se requiere conexión a internet \\
\hline $\begin{array}{l}\text { Procedimientos } \\
\text { especiales }\end{array}$ & No aplica \\
\hline $\begin{array}{l}\text { Dependencias de } \\
\text { interfaz }\end{array}$ & No aplica \\
\hline
\end{tabular}

Procedimiento de Prueba

Descripción

Fecha de

Finalización

Responsable

Requisitos previos

Pasos

Resultados

Esperados

Posibles problemas

Estado
Se modifica un dato personal del usuario: contraseña, país y/o ciudad.

Se verifica el correcto funcionamiento de la aplicación.

[Fecha de finalización de la prueba]

\section{Navarro Macurí Raúl Alonso}

El usuario debe estar registrado.

La contraseña debe ser la correcta.

Ingresar la contraseña, país o ciudad a modificar.

Dar clic en el botón "Guardar cambios".

Dar clic en el botón "Salir".

Al modificar los datos, el mensaje de modificación debe ser la correcta.

Acceder correctamente al sistema.

Al modificar el dato personal, no se obtuvo alguna actualización.

Conforme 


\section{[AP0203] - Caso de Prueba: Registrar Proyecto}

Registrar un nuevo proyecto.

Caso de Prueba

Elementos a probar

Interfaz Registrar Proyecto

Entradas

Ingresar los campos solicitados.

Dar clic en el botón Registrar proyecto.

\section{Salidas}

Necesidades del

entorno

Procedimientos

especiales

Dependencias de interfaz

\section{Procedimiento de Prueba}

\section{Descripción}

Fecha de

Finalización

Responsable

Requisitos previos

Pasos

\section{Resultados}

Esperados
Visualizar el mensaje Registro exitoso.

Se requiere conexión a internet

No aplica

No aplica

Se registra un nuevo proyecto.

Se verifica el correcto funcionamiento de la aplicación.

[Fecha de finalización de la prueba]

\section{Navarro Macurí Raúl Alonso}

La empresa debe estar registrada.

El usuario debe estar registrado.

Ingresar los campos solicitados.

Dar clic en el botón "Registrar proyecto".

Dar clic en el botón "Salir".

$\mathrm{Al}$ registrar un proyecto, el mensaje de registro exitoso debe ser la correcta.

El proyecto debe aparecer en la Lista de Proyectos creados por la empresa donde pertenece el usuario.

Luego de finalizar el registro, el usuario debe poder definir y evaluar el proyecto.

Posibles problemas No poder acceder al proyecto. 
Acceder al proyecto con datos incorrectos.

\section{Módulo 03: Gestión de Usuarios}

Casos de Prueba relacionados al mantenimiento y gestión de Usuarios.

\section{[AP0301] - Caso de Prueba: Mostrar Usuarios (Administrador)}

El administrador visualiza a todos los usuarios creados y sus datos.

\section{Caso de Prueba}

\begin{tabular}{|c|c|}
\hline Elementos a probar & Interfaz "Gestión de Usuarios". \\
\hline Entradas & No aplica. \\
\hline Salidas & Visualizar la lista de usuarios previamente creados. \\
\hline $\begin{array}{l}\text { Necesidades del } \\
\text { entorno }\end{array}$ & Se requiere conexión a internet. \\
\hline $\begin{array}{l}\text { Procedimientos } \\
\text { especiales }\end{array}$ & No aplica. \\
\hline $\begin{array}{l}\text { Dependencias de } \\
\text { interfaz }\end{array}$ & No aplica. \\
\hline \multicolumn{2}{|c|}{ Procedimiento de Prueba } \\
\hline Descripción & $\begin{array}{l}\text { Se puede visualizar la lista de todos los usuarios en general, con la } \\
\text { empresa y proyectos vinculados. }\end{array}$ \\
\hline $\begin{array}{l}\text { Fecha de } \\
\text { Finalización }\end{array}$ & [Fecha de finalización de la prueba] \\
\hline Responsable & Navarro Macurí Raúl Alonso \\
\hline Requisitos previos & $\begin{array}{l}\text { La empresa debe estar registrada. } \\
\text { El usuario debe estar registrado. }\end{array}$ \\
\hline Pasos & No aplica. \\
\hline $\begin{array}{l}\text { Resultados } \\
\text { Esperados }\end{array}$ & $\begin{array}{l}\text { Al ingresar a la interfaz, se podrá visualizar el listado de usuarios. } \\
\text { Se podrá filtrar usuarios por empresa. }\end{array}$ \\
\hline
\end{tabular}




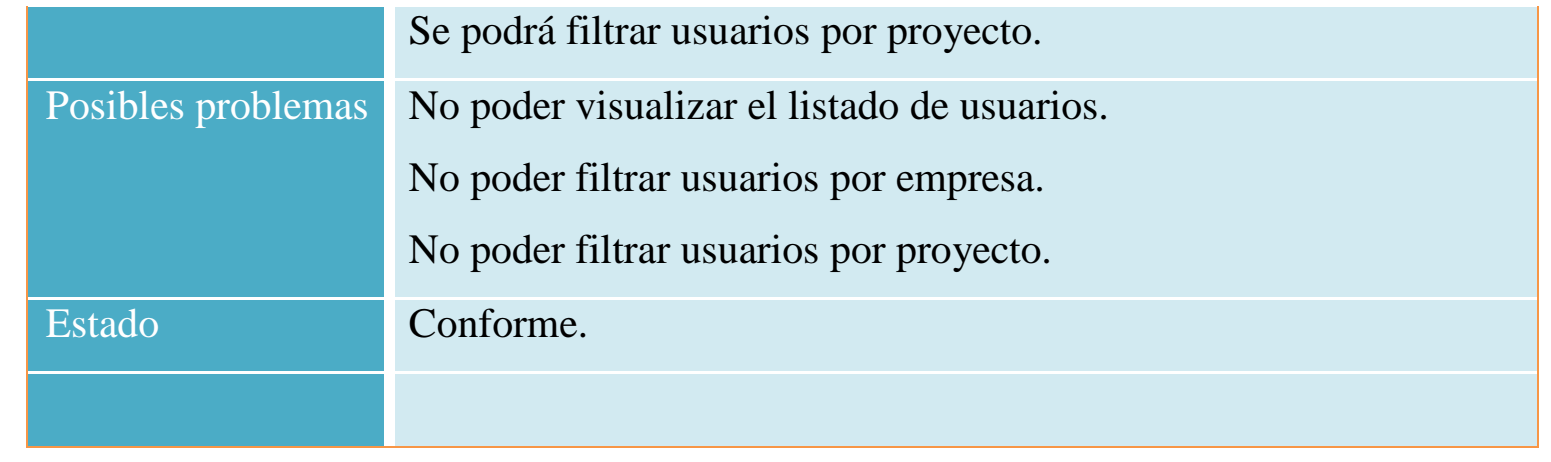

\section{[AP0303] - Caso de Prueba: Modificar Permisos - Asignación (Administrador)}

La principal función del administrador es asignar quien será el Encargado del Proyecto de una empresa.

\section{Caso de Prueba}

\begin{tabular}{|c|c|}
\hline Elementos a probar & Interfaz "Gestión de Usuarios" \\
\hline Entradas & $\begin{array}{l}\text { Dar clic en el botón "Editar". } \\
\text { Ingresar Tipo de Usuario "Encargado". } \\
\text { Dar clic en guardar cambios. }\end{array}$ \\
\hline Salidas & Visualizar al usuario como tipo "Encargado". \\
\hline $\begin{array}{l}\text { Necesidades del } \\
\text { entorno }\end{array}$ & Se requiere conexión a internet \\
\hline $\begin{array}{l}\text { Procedimientos } \\
\text { especiales }\end{array}$ & No aplica \\
\hline $\begin{array}{l}\text { Dependencias de } \\
\text { interfaz }\end{array}$ & No aplica \\
\hline
\end{tabular}

Procedimiento de Prueba

Descripción

Fecha de

Finalización

Responsable

Requisitos previos
Se asigna al encargado de la empresa.

[Fecha de finalización de la prueba]

\section{Navarro Macurí Raúl Alonso}

La empresa debe estar registrada.

El usuario debe estar registrado.

Dar clic en el botón "Editar".

Ingresar Tipo de usuario "Encargado".

Dar clic en "Guardar cambios". 
Resultados

Esperados

Posibles problemas

Estado
$\mathrm{Al}$ asignar el encargado de la empresa, el usuario deberá tener los permisos necesarios.

No tiene los permisos como encargado de la empresa: Crear

Proyecto, Definir documentos, Evaluar documentos, entre otros.

Conforme.

\section{[AP0304] - Caso de Prueba: Modificar Permisos - Estado (Administrador)}

El administrador puede activar o bloquear a un usuario.

\section{Caso de Prueba}

Elementos a probar

\section{Entradas}

Salidas

Necesidades del

entorno

Procedimientos

especiales

Dependencias de

interfaz

\section{Interfaz "Gestión de Usuarios"}

Dar clic en el botón "Estado".

Visualizar al usuario como Activo o Bloqueado.

Se requiere conexión a internet

No aplica

No aplica

\section{Procedimiento de Prueba}

\section{Descripción}

Fecha de

Finalización

Responsable

Requisitos previos

Pasos

Resultados

Esperados

Posibles problemas

Estado
El administrador activa o bloquea a un usuario.

[Fecha de finalización de la prueba]

\section{Navarro Macurí Raúl Alonso}

La empresa debe estar registrada.

El usuario debe estar registrado.

Dar clic en el botón "Estado".

$\mathrm{Al}$ activar o bloquear al usuario se debe visualizar su estado modificado.

No poder visualizar el estado modificado.

Conforme. 


\section{[AP0305] - Caso de Prueba: Modificar Permisos - Tipo y rol de usuario (Encargado de la empresa)}

El encargado de la empresa actualiza el rol de cualquier usuario de su empresa.

\begin{tabular}{|l|l|}
\hline Caso de Prueba & \\
\hline Elementos a probar & Interfaz "Gestión de Usuarios" \\
\hline Entradas & $\begin{array}{l}\text { Dar clic en el botón "Editar". } \\
\text { Seleccionar el rol a modificar. }\end{array}$ \\
\hline Salidas & Visualizar al usuario con el rol modificado. \\
\hline Necesidades del & Se requiere conexión a internet \\
\hline Procedimientos & No aplica \\
especiales & \\
\hline Dependencias de & No aplica \\
interfaz
\end{tabular}

\section{Procedimiento de Prueba}

Descripción

Fecha de

Finalización

Responsable

Requisitos previos

Pasos

Resultados

Esperados

Posibles problemas

Estado
El encargado de la empresa actualiza el rol de cualquier usuario de su empresa.

[Fecha de finalización de la prueba]

\section{Navarro Macurí Raúl Alonso}

La empresa debe estar registrada.

El usuario debe estar registrado.

Dar clic en el botón "Editar".

Ingresar el Rol a modificar.

Dar clic en "Guardar cambios".

[Identificación de Resultados Esperados]

No poder visualizar el rol modificado.

Conforme. 


\section{Módulo 04: Definir y Evaluar Proyectos}

Casos de Prueba relacionados al a las funciones definir documentos y evaluar proyectos.

\section{[AP0401] - Definir y Evaluar documentos}

Definir la estructura de todos los documentos que se desea evaluar según las siguientes secciones:

1. Gestión de Proyectos.

2. Implementación de Software.

3. Verificación y Validación.

\section{Caso de Prueba}

\section{Elementos a probar}

Entradas

Salidas

Necesidades del

entorno

Procedimientos

especiales

Dependencias de

interfaz

Procedimiento de Prueba

Descripción

Fecha de

Finalización

Responsable

Requisitos previos

Pasos
Interfaz "Definir documentos".

Dar clic en el botón "Estructura" del documento que desea evaluar.

Digitar el nombre del documento.

Seleccionar los campos que desea evaluar del documento.

[Especificaciones de entrada][ Ejemplo: Visualizar pantalla X]

Se requiere conexión a internet

No aplica

No aplica
[Descripción de la prueba ]

[Fecha de finalización de la prueba]

\section{Navarro Macurí Raúl Alonso}

[Identificación de los requisitos previos para realizar las Pruebas]

[Pasos necesarios y acciones requeridas por el responsable para realizar las pruebas]

[Paso del Procedimiento de Pruebas]

[Paso del Procedimiento de Pruebas] 


\section{[AP0402] - Definir y evaluar documentos (Documentos con Multi tipos)}

Definir Todos los documentos (Utilizando documentos Multi tipos) y evaluar secciones.

\section{Caso de Prueba}

\section{Elementos a probar}

Entradas

Salidas

Necesidades del

entorno

Procedimientos

especiales

Dependencias de

interfaz

\section{Interfaz Definir Documentos}

[Especificaciones de entrada][Ejemplo: Clic en la opción X]

[Especificaciones de entrada][ Ejemplo: Visualizar pantalla X]

Se requiere conexión a internet

No aplica

No aplica

Procedimiento de Prueba

\section{Descripción}

Fecha de

Finalización

Responsable

Requisitos previos

Pasos
[Descripción de la prueba ]

[Fecha de finalización de la prueba]

Navarro Macurí Raúl Alonso

[Identificación de los requisitos previos para realizar las Pruebas]

[Pasos necesarios y acciones requeridas por el responsable para realizar las pruebas] 
[Paso del Procedimiento de Pruebas]

[Paso del Procedimiento de Pruebas]

Resultados

[Identificación de Resultados Esperados]

Esperados

Posibles problemas

Estado

[Identificación de posibles problemas]

En proceso.

[AP0403] - Definir y evaluar documentos (Documentos Múltiples)

Definir Todos los documentos (Utilizando documentos Múltiples) y evaluar secciones.

Caso de Prueba

\begin{tabular}{|c|c|}
\hline Elementos a probar & Interfaz Definir Documentos \\
\hline Entradas & [Especificaciones de entrada][Ejemplo: Clic en la opción X] \\
\hline Salidas & [Especificaciones de entrada][ Ejemplo: Visualizar pantalla X] \\
\hline $\begin{array}{l}\text { Necesidades del } \\
\text { entorno }\end{array}$ & Se requiere conexión a internet \\
\hline $\begin{array}{l}\text { Procedimientos } \\
\text { especiales }\end{array}$ & No aplica \\
\hline $\begin{array}{l}\text { Dependencias de } \\
\text { interfaz }\end{array}$ & No aplica \\
\hline \multicolumn{2}{|c|}{ Procedimiento de Prueba } \\
\hline Descripción & [Descripción de la prueba ] \\
\hline $\begin{array}{l}\text { Fecha de } \\
\text { Finalización }\end{array}$ & [Fecha de finalización de la prueba] \\
\hline Responsable & Navarro Macurí Raúl Alonso \\
\hline Requisitos previos & [Identificación de los requisitos previos para realizar las Pruebas] \\
\hline Pasos & $\begin{array}{l}\text { [Pasos necesarios y acciones requeridas por el responsable para } \\
\text { realizar las pruebas] } \\
\text { [Paso del Procedimiento de Pruebas] } \\
\text { [Paso del Procedimiento de Pruebas] }\end{array}$ \\
\hline Resultados & [Identificación de Resultados Esperados] \\
\hline
\end{tabular}


Esperados

Posibles problemas

[Identificación de posibles problemas]

Estado

En proceso.

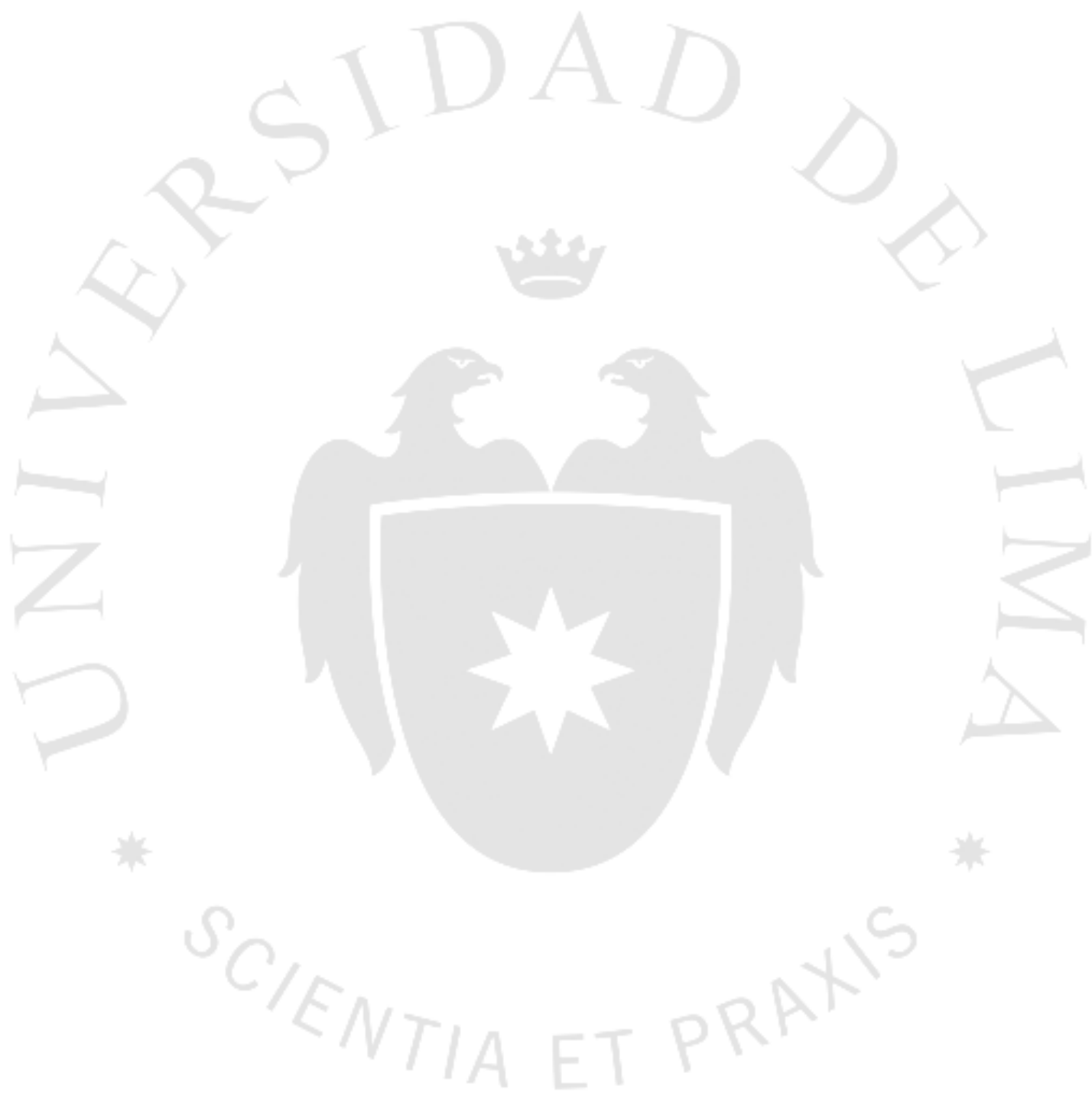


Documento donde se describe el uso del software en base a la interfaz de usuario.

\section{Manual de Usuario v1.0 [A001MU]}

\section{Proyecto Auditor 29110 Plus -}

\section{[A001]}

Trabajo de Investigación: Modelo de Mejora del Ciclo de Vida del Desarrollo de Software

\section{Estado del Documento}

\begin{tabular}{|l|l|l|}
\hline Estado & Fecha & Responsable \\
\hline Creado & $10 / 09 / 2015$ & Egusquiza Herrada Hugo Jhonny \\
\hline Verificado & $12 / 09 / 2015$ & Navarro Macurí Raúl Alonso \\
\hline Validado & & \\
\hline Línea Base & & \\
\hline
\end{tabular}




\section{Datos del Proyecto}

\begin{tabular}{|l|l|}
\hline Código del Proyecto & A001 \\
\hline Nombre del Proyecto & Proyecto Auditor 29110 Plus \\
\hline Tipo de Proyecto & $\begin{array}{l}\text { Desarrollo de Aplicación. } \\
\text { NA. }\end{array}$ \\
\hline Área & NA. \\
\hline Empresa Cliente & $\begin{array}{l}\text { Egusquiza Herrada Hugo Jhonny } \\
\text { Navarro Macurí Raúl Alonso }\end{array}$ \\
\hline Empresa & \\
\hline
\end{tabular}

\section{Historial de Versiones}

\begin{tabular}{|l|l|l|l|}
\hline Fecha & Versión & Descripción & Autor \\
\hline $14 / 09 / 2015$ & 1.0 & Creación del Documento. & $\begin{array}{l}\text { Egusquiza Herrada Hugo Jhonny } \\
\text { Navarro Macurí Raúl Alonso }\end{array}$ \\
\hline & & & \\
\hline & & & \\
\hline
\end{tabular}

\section{Firmas}

La tabla de Firmas [No aplica].

\begin{tabular}{|l|l|l|}
\hline Nombre & Fecha & Firma \\
\hline $\begin{array}{l}\text { [Cliente/Representante de } \\
\text { la empresa XXXXX] }\end{array}$ & {$[\# \# / \# \# \#]$} & \\
\hline $\begin{array}{l}\text { Gestor de Proyectos: } \\
\text { [Nombre del Gestor }]\end{array}$ & {$[\# \#$ /\#\#/\#\#\#] } & \\
\hline $\begin{array}{l}\text { Líder Técnico: } \\
\text { [Nombre del Líder }\end{array}$ & & \\
\hline Técnico $]$ & \\
\hline
\end{tabular}




\section{Descripción General del Software}

La herramienta a desarrollar tiene como principal objetivo verificar el grado de cumplimiento de la documentación de un determinado proyecto de desarrollo de software con respecto a lo establecido en la ISO 29110-5-1-2.

\section{Entorno operacional requerido}

La Aplicación debe ser ejecutada a través de un explorador de internet, las versiones mínimas requeridas son:

- Google Chrome versión 45

- Internet Explorer 11

- Firefox versión 40

\section{Recursos provistos y requeridos}

Para el uso de la aplicación, el usuario requiere un equipo o dispositivo móvil con acceso a internet.

\section{Procedimientos de instalación y desinstalación}

No Aplica.

La herramienta desarrollada no requiere instalación debido a que se encuentra alojado en un servidor. La instalación del software en el servidor es transparente para el usuario debido a que este solo necesita una cuenta para acceder a la aplicación.

\section{Procedimientos para entrar y salir del Software}

Previamente, el usuario debe registrar una cuenta asignada a una empresa determinada [Ver caso de prueba AP102].

Luego, el usuario deberá ingresar la identificación de su cuenta y una contraseña [Ver caso de prueba AP102].

\section{Funcionalidades del Software}


A continuación se describe las principales funcionalidades de la herramienta desarrollada:

\section{Módulo 01: Acceso a la herramienta}

\section{[AP0101] - Caso de Prueba: Registrar Usuario}

El usuario podrá registrarse en la herramienta colocando la siguiente información:

- Nombres y Apellidos

- Correo Electrónico y contraseña

- País y Ciudad

- Empresa y Rol dentro de la empresa

- Respuesta al mensaje de verificación

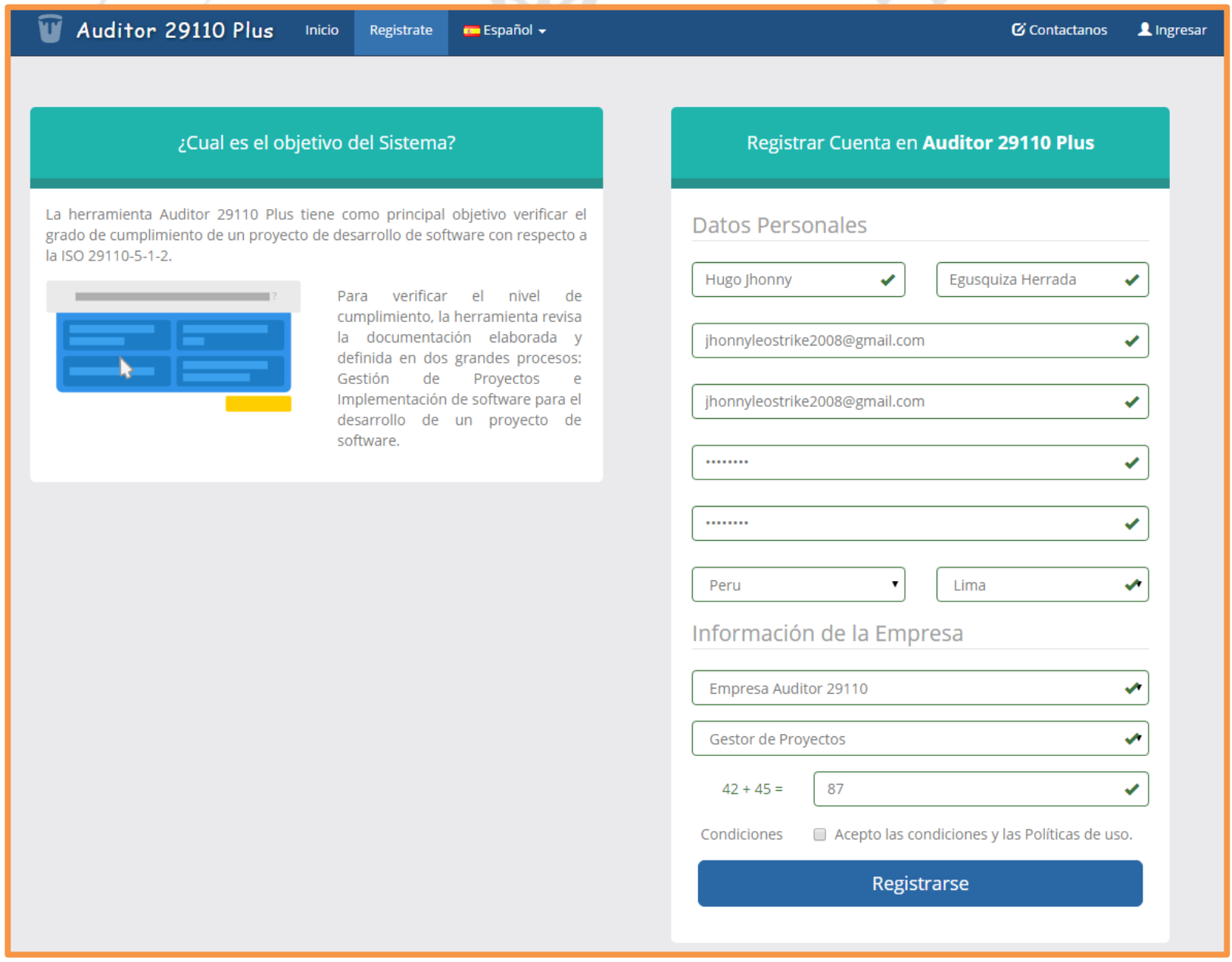

Si el registro se realizo correctamente, entonces se mostrara un mensaje, Acto seguido, el usuario deberá entrar a su correo electrónico y dar clic en el link del mensaje enviado: 


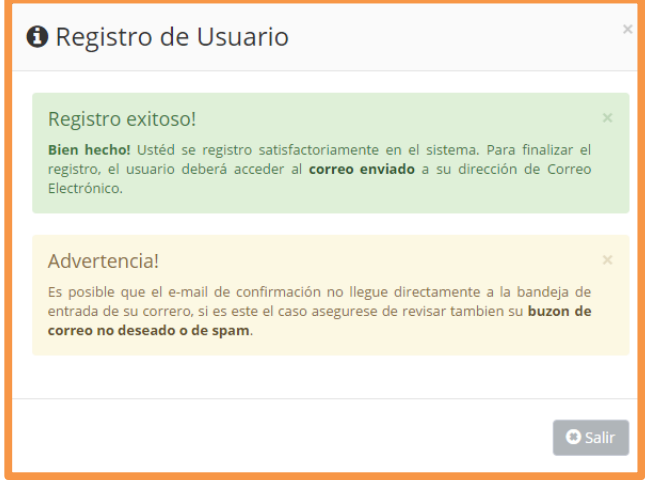

auditor29110@host.lintrb.com

para mi -

文 inglés $^{*}>$ español $・$ Traducir mensaje

Estimado(a) Hugo Jhonny

Sus datos han sido registrados satisfactoriamente en el sistema.

Email: jhonnyleostrike2008@gmail.com

ra verificar su cuenta de e-mail, por favor abrir el siguiente enlace: http?

adf73cc169278dd6daab5fe7d6cacb1fed537131/jhonnyleostrike $2008 \% 40$ am

\section{[AP0102] - Caso de Prueba: Acceder a la herramienta}

Para acceder a la aplicación, será necesario colocar un usuario y contraseña previamente registrados.

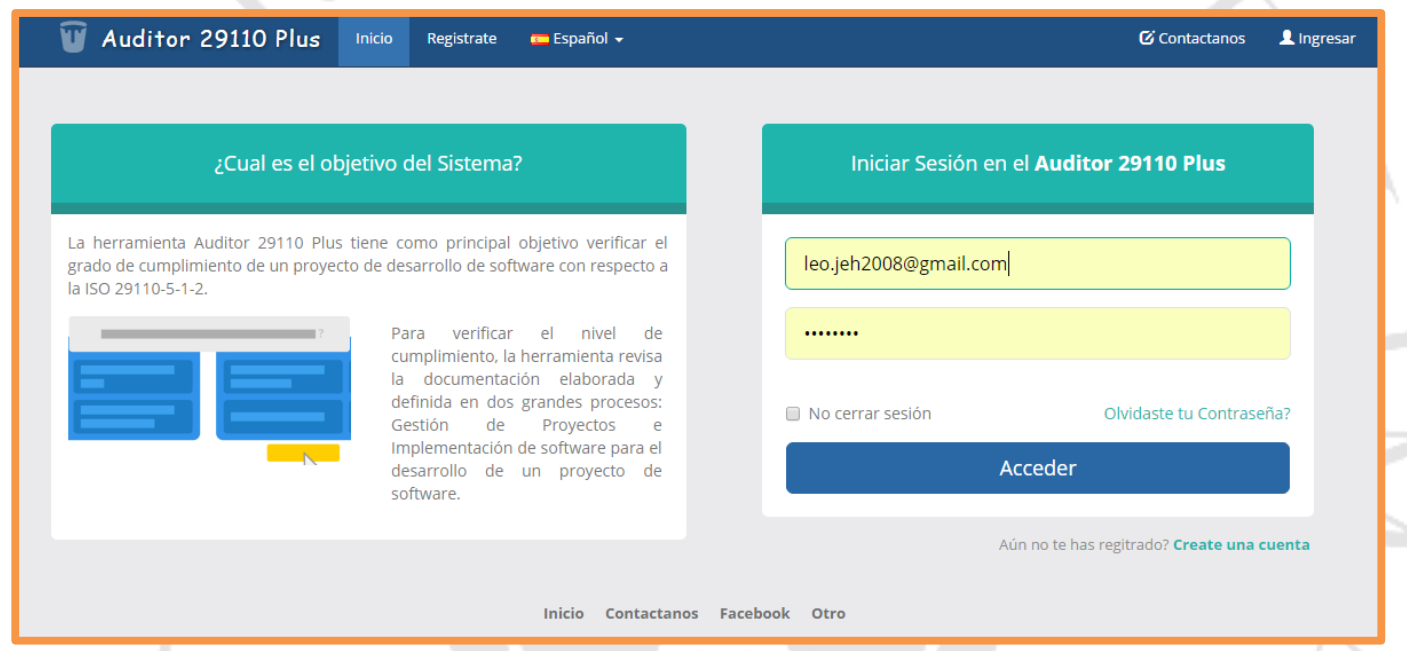

$\mathrm{Al}$ acceder a la aplicación de podrá ver el menú principal:

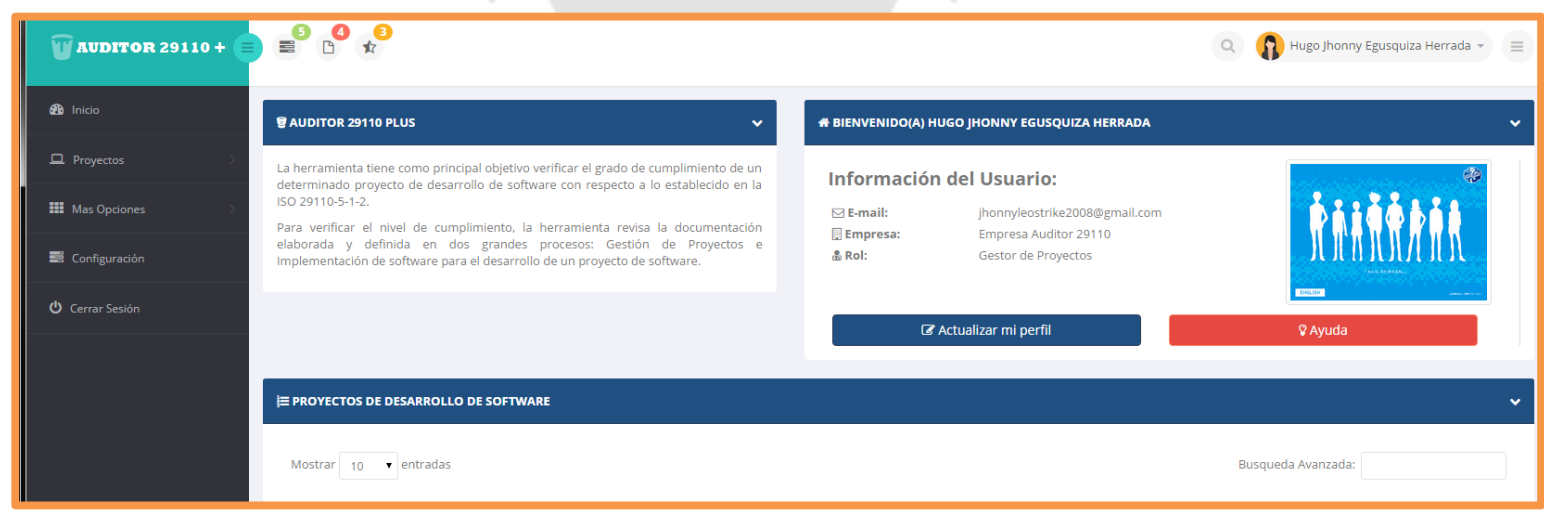

\section{3. [AP0102] - Caso de Prueba: Recuperar contraseña}

En caso olvides la contraseña de tu usuario, podrás acceder al link “Olvidaste tu contraseña" y colocar tu correo electrónico. 


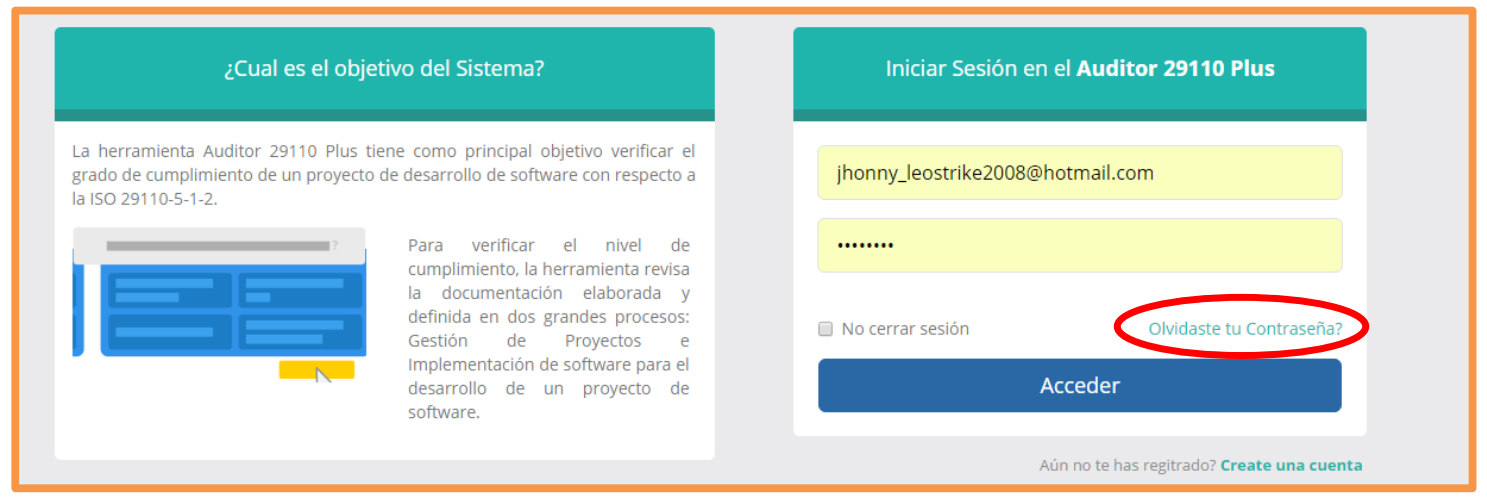

Luego, a la bandeja del correo en mención y acceder al enlace indicado
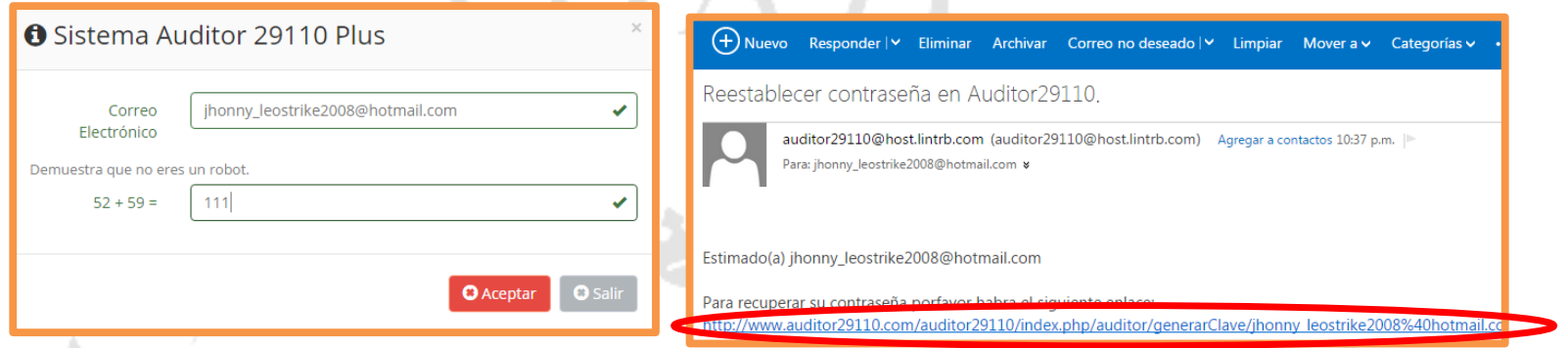

Finalmente se solicitara una nueva contraseña

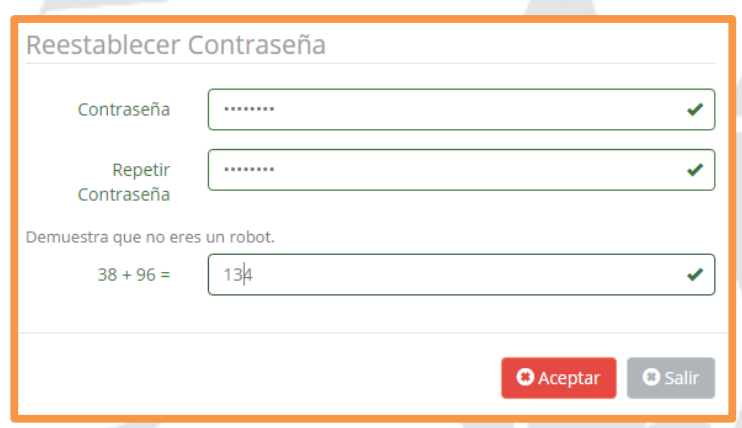




\section{Módulo 02: Pantalla Principal}

\section{1. [AP0201] - Caso de Prueba: Actualizar Datos del Perfil de Usuario}

Desde el Menú principal de la aplicación, acceder al botón Actualizar mi perfil

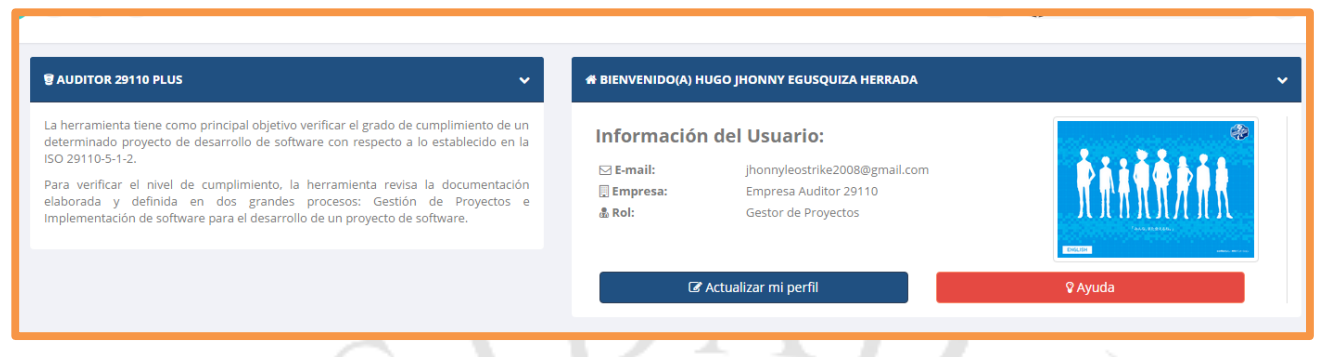

Desde esta nueva interfaz, se podrán actualizar la información general del usuario

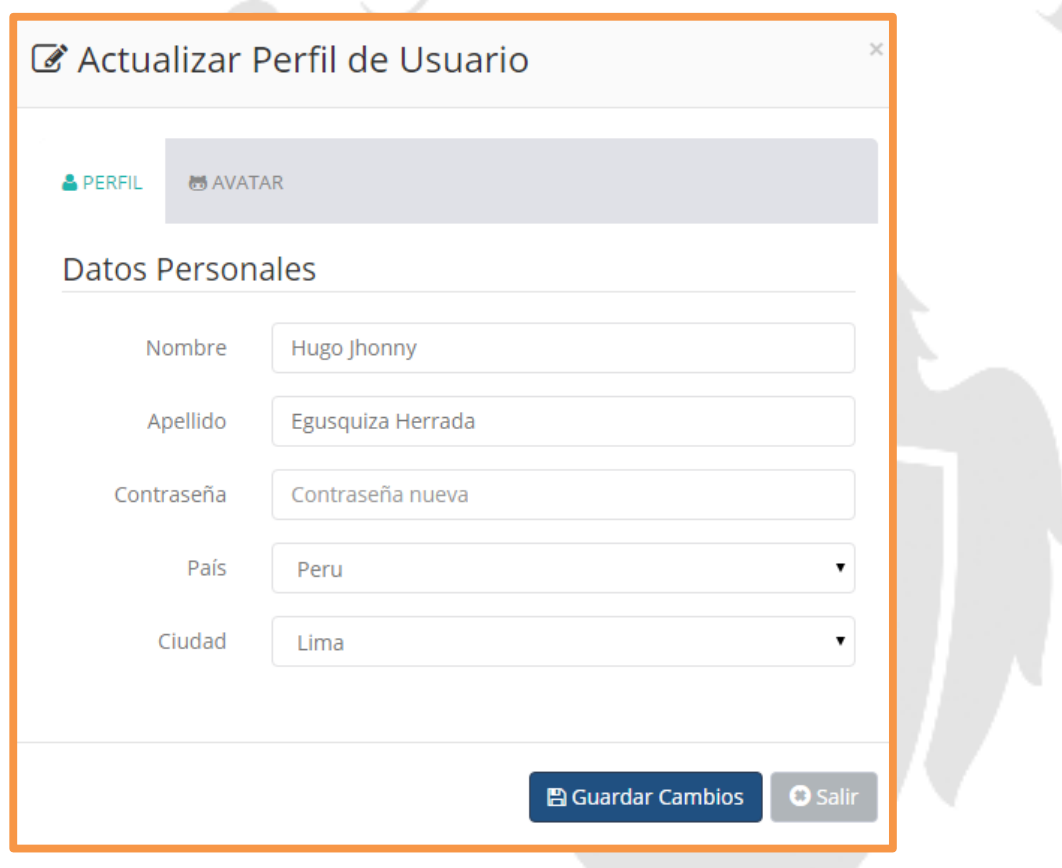

\section{2. [AP0203] - Caso de Prueba: Registrar Empresa}

Sólo para usuarios del Tipo: Administrador. Se deberá acceder a la opción "Registrar Empresa" y luego llenar todos los campos requeridos. 


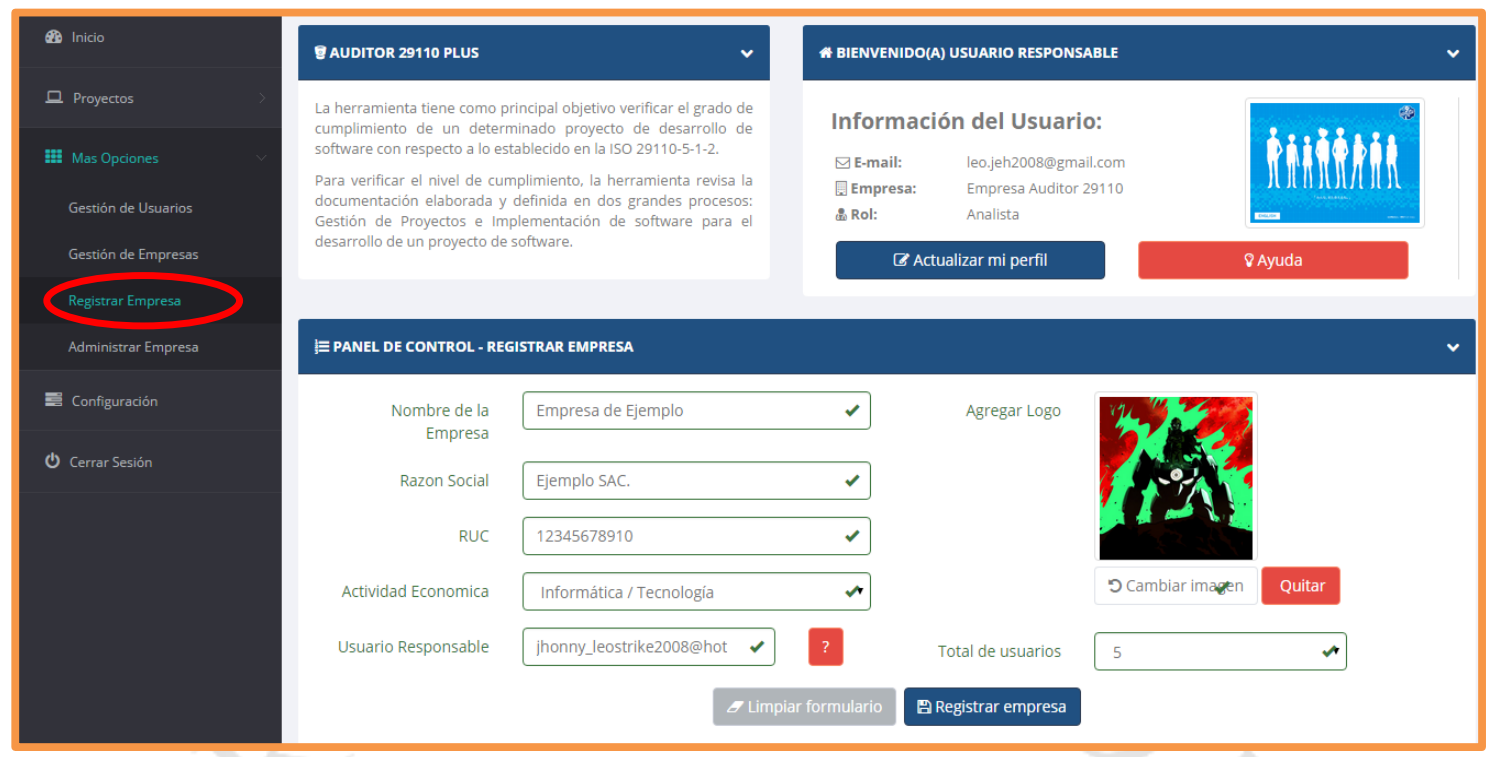

\section{3. [AP0204] - Caso de Prueba: Registrar Proyecto}

Solo para usuarios con el Rol: Gestor de Proyectos. Se deberá acceder a la opción

"Crear Proyectos" y luego llenar todos los campos requeridos.

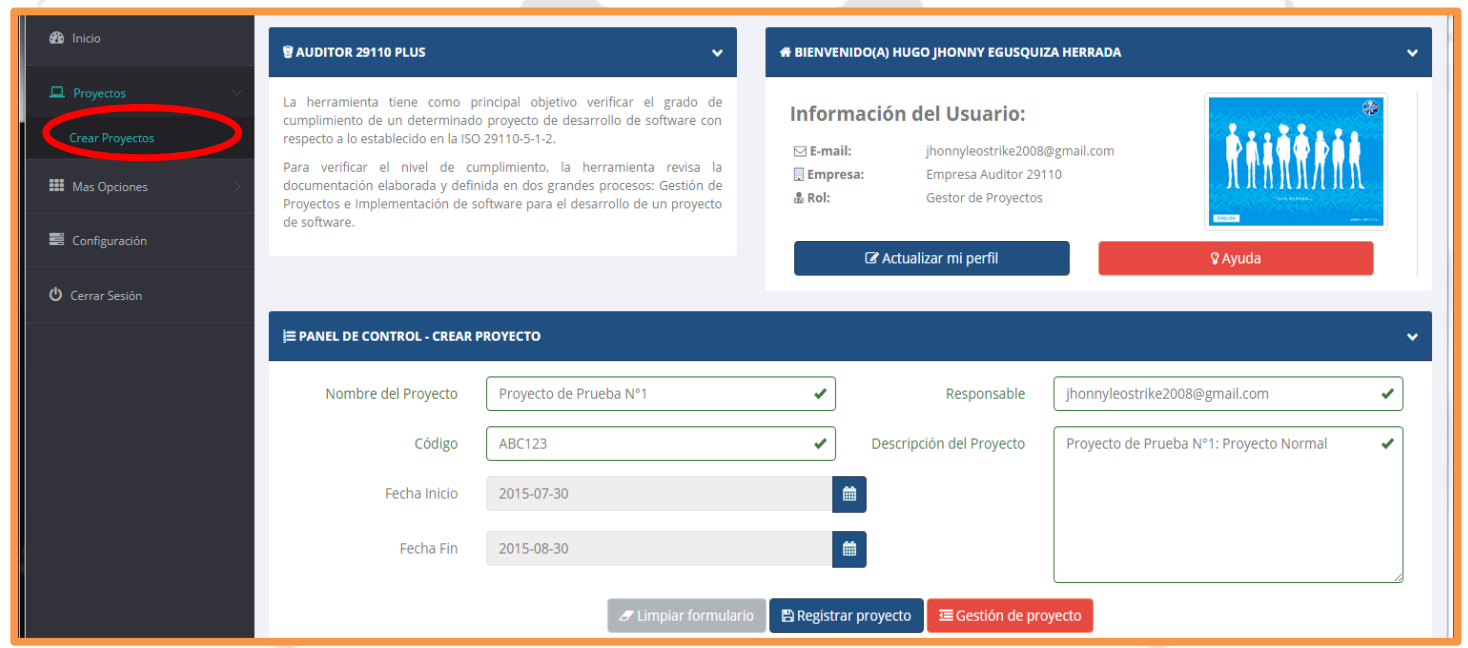

\section{Módulo 03: Gestión de Usuarios}

\section{1 [AP0301] - Caso de Prueba: Mostrar Usuarios}

Sólo para usuarios del Tipo: Administrador y Representantes. Estos usuarios podrán acceder a la opción "Gestión de Usuarios" y Visualizar todos los usuarios que cuentan con la aplicación. (El Representante de la empresa solo tendrá acceso a los usuarios de la misma empresa). 


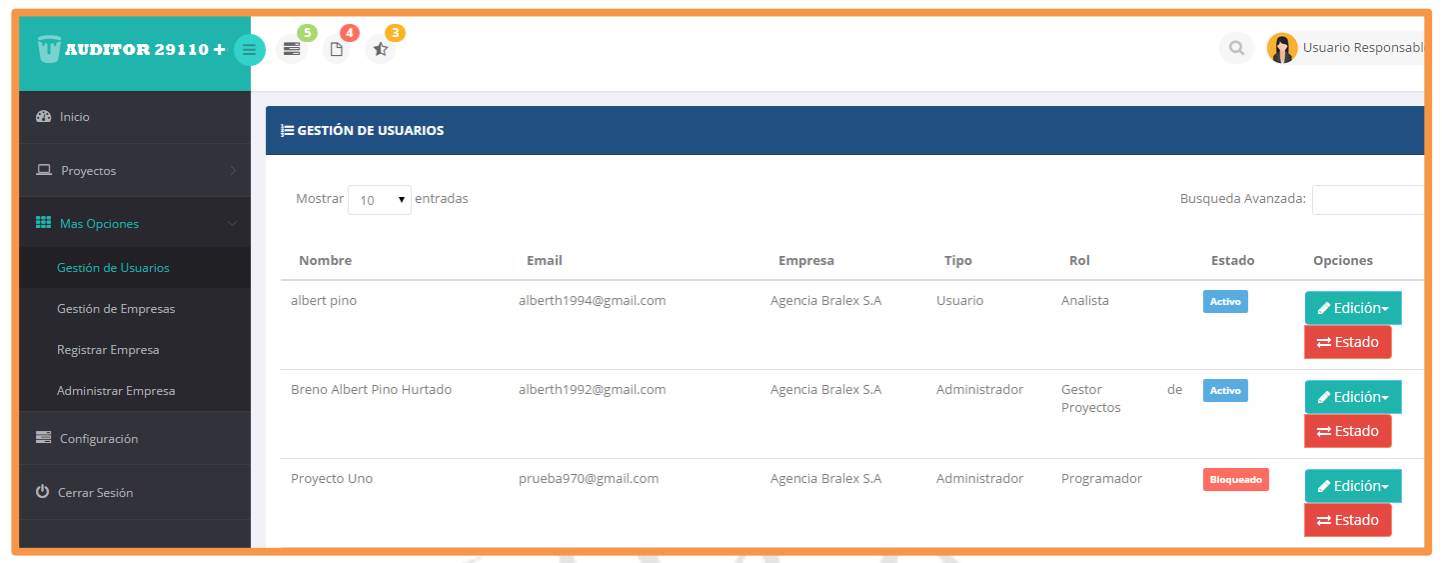

\section{2 [AP0302] - Caso de Prueba: Modificar Permisos}

Sólo para usuarios del Tipo: Administrador y Representantes. Estos usuarios podrán editar la información de los usuarios registrados en la aplicación (El Representante de la empresa solo tendrá acceso a los usuarios de la misma empresa).

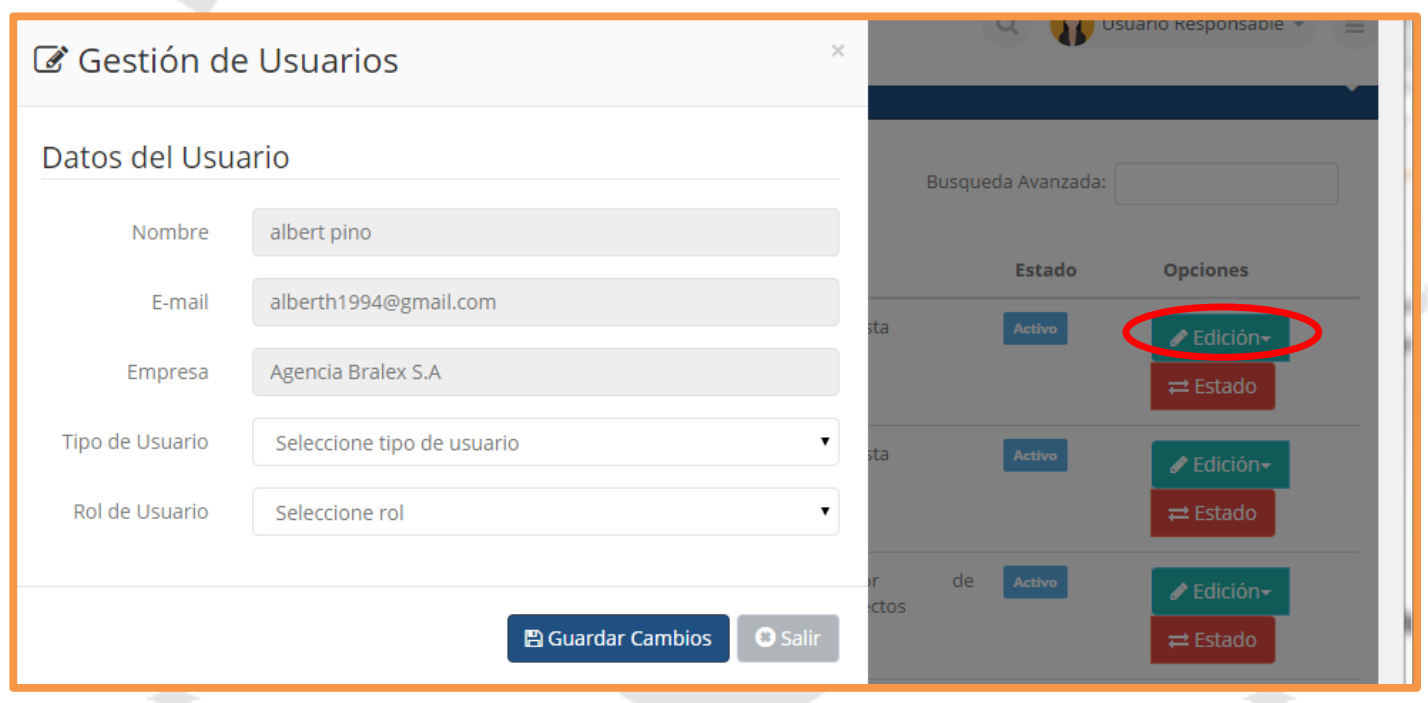

Módulo 04: Definir y Evaluar Proyectos

\section{1 [AP0401] - Definir Documentos}

Para definir documentos, se debe acceder a la opción "Definir Documentos del Listado de Proyectos". 


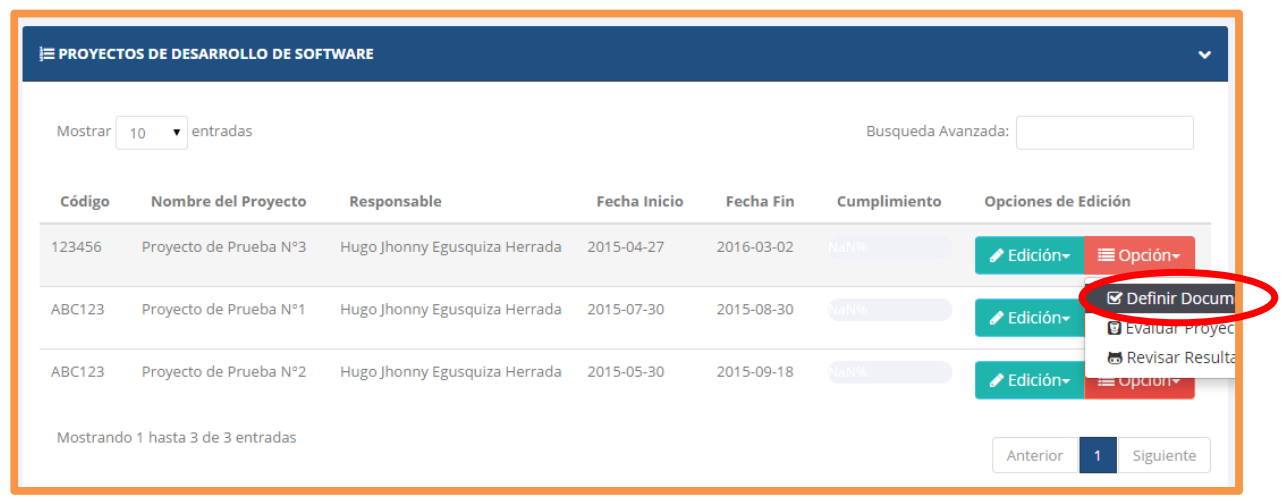

Para definir los documentos de un proyecto, primero debemos seleccionar que documentos serán necesarios dando clic en Estructura y luego definir con que secciones contara el documento y guardar la estructura.

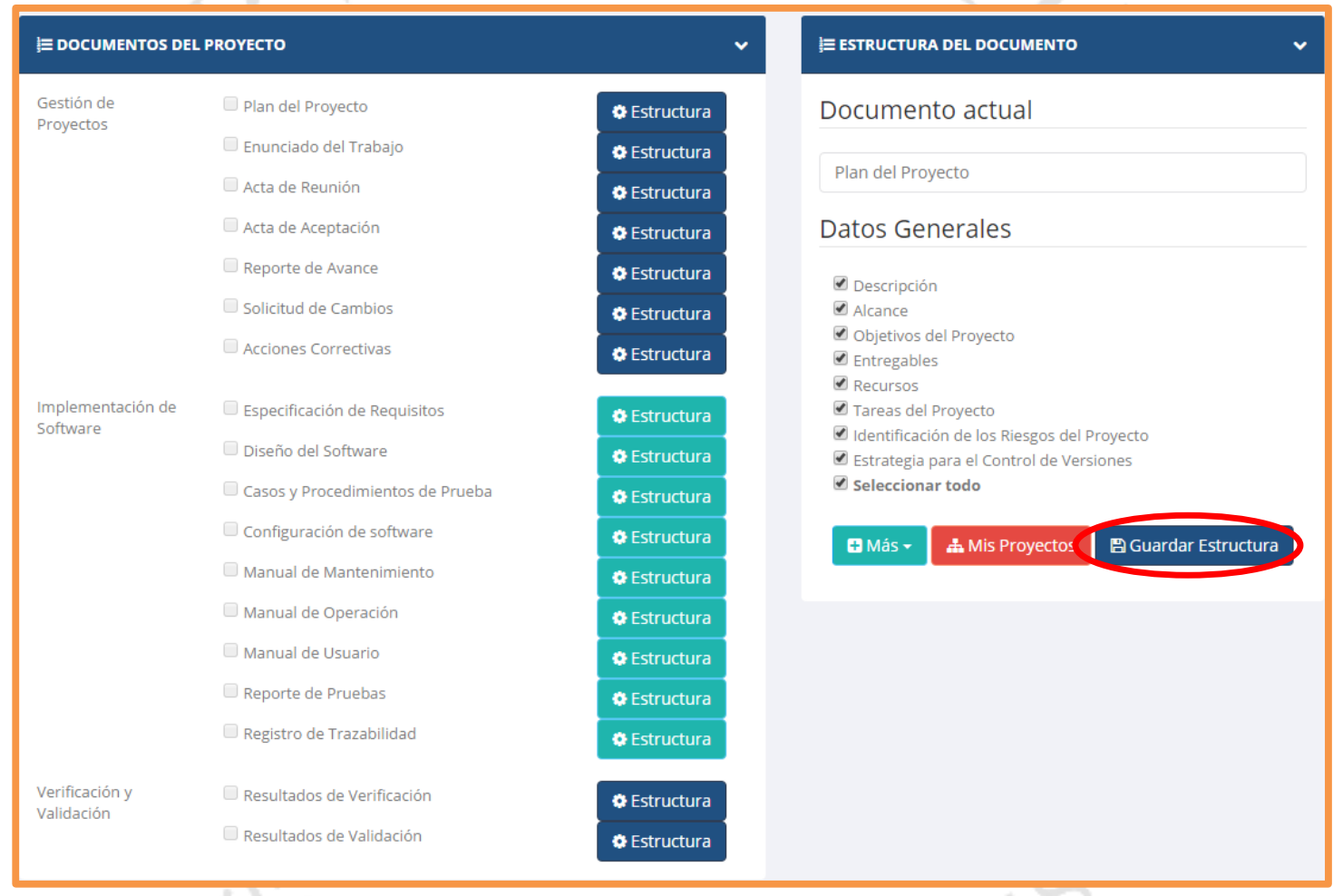

Luego, para evaluar el cumplimiento de los documentos del proyecto, se debe acceder a la opción "Evaluar Proyectos del Listado de Proyectos". 


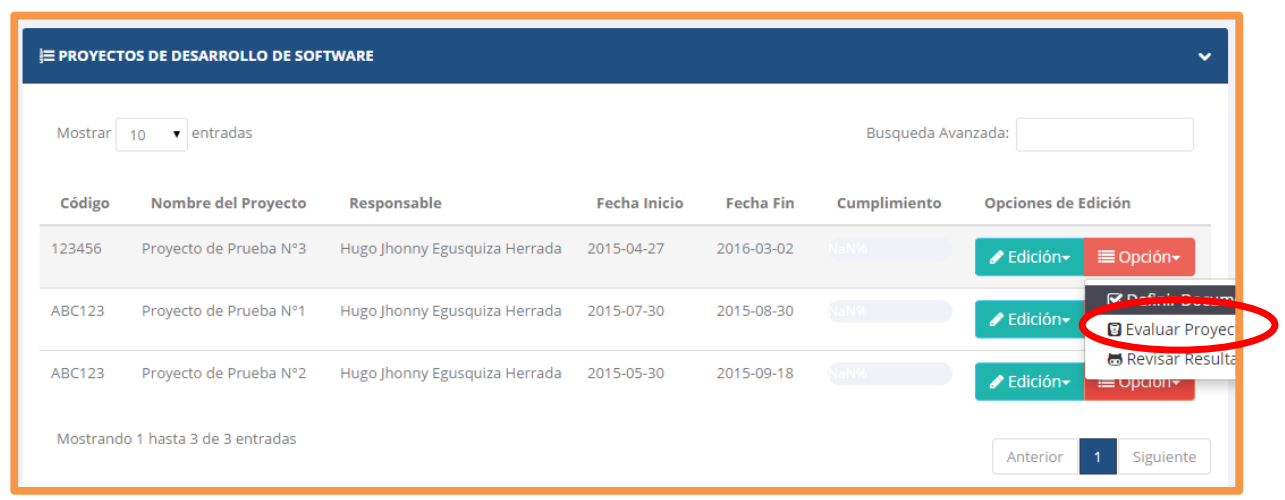

En esta interfaz se deben buscar o arrastrar los documentos que serán evaluados:

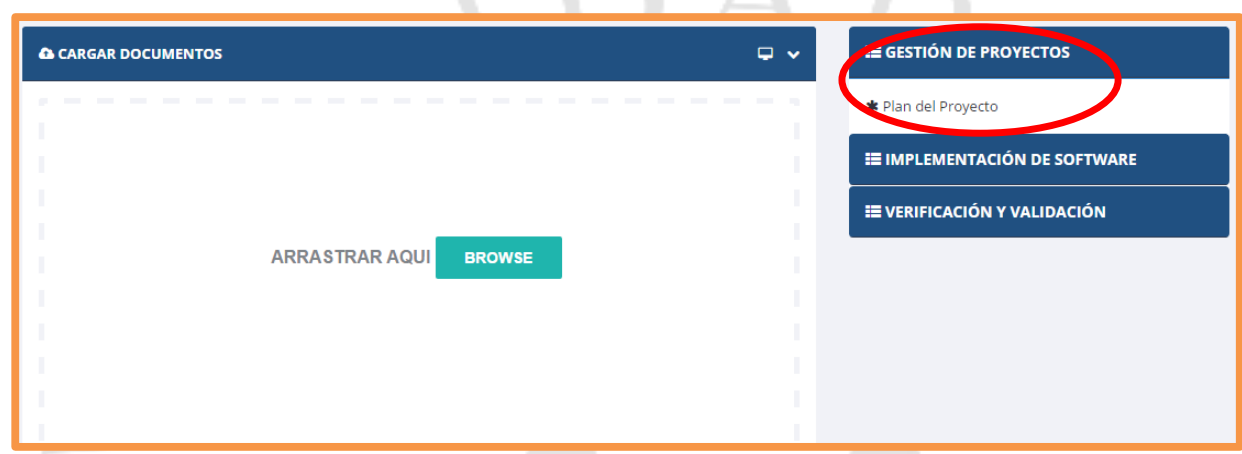

Al hacer clic en un proceso del proyecto, podemos ver los documentos que pertenecen a este.

Al realizar la evaluación se mostrada una alerta con el estado del documento evaluado:

\section{Alerta del Sistema}

ص Plan del Proyecto.docx

Se encontraron: 8 ITEMS de 8 (Secciones vacias: 0 - Secciones en proceso: 0) - Porcentaje

de avance: $8 / 8$ - $100 \%$

- Descripción Válido

- Alcance Válido

- Objetivos del Proyecto Válido

- Entregables Válido

- Recursos Válido

- Tareas del Proyecto Válido

- Identificación de los Riesgos del Proyecto Válido

- Estrategia para el Control de Versiones Válido

En el listado del Menú principal se puede ver el estado actual de los proyectos evaluados: 


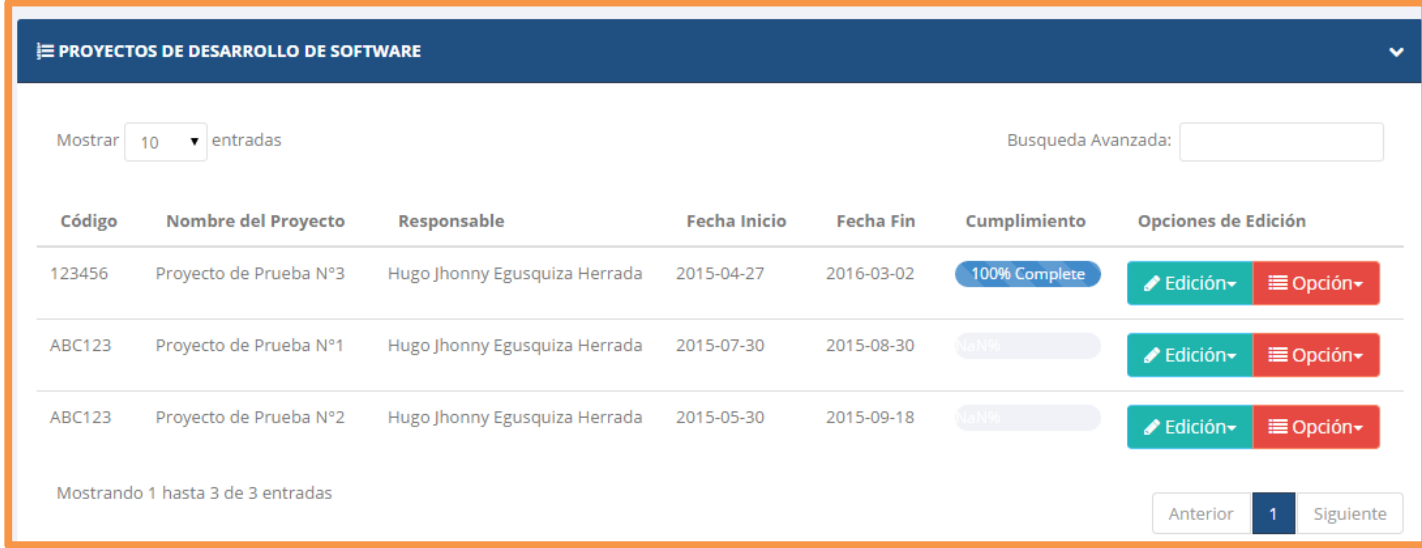

Finalmente, se podrán revisar los resultados de la evaluación al acceder a la sección Revisar resultados.

EP PROYECTOS DE DESARROLLO DE SOFTWARE

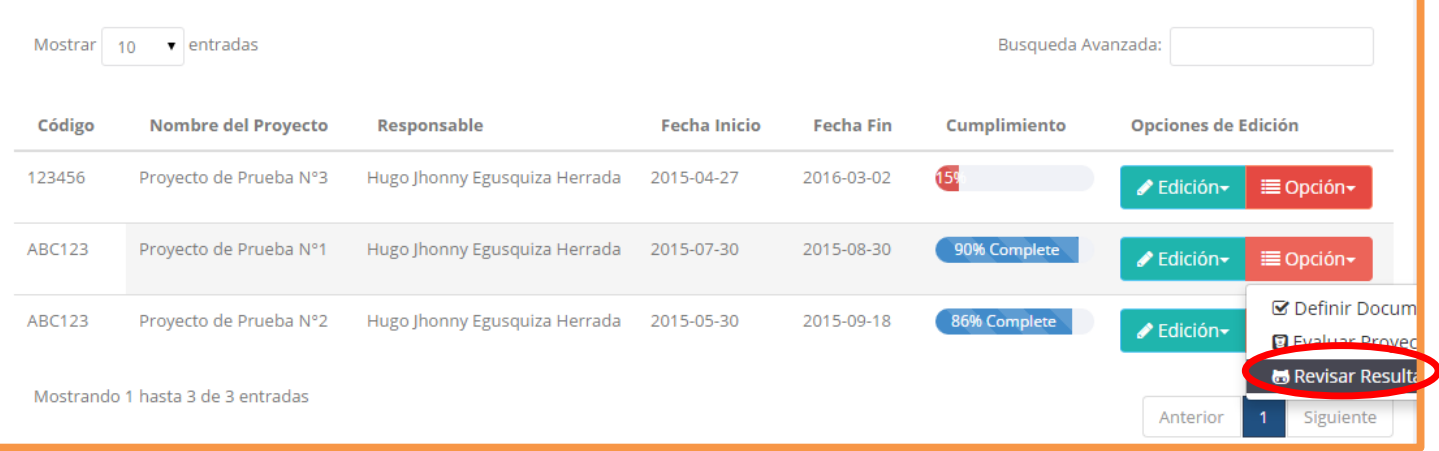


En esta interfaz podemos ver que documentos son requeridos para el proyecto como también el resultado de la evaluación.

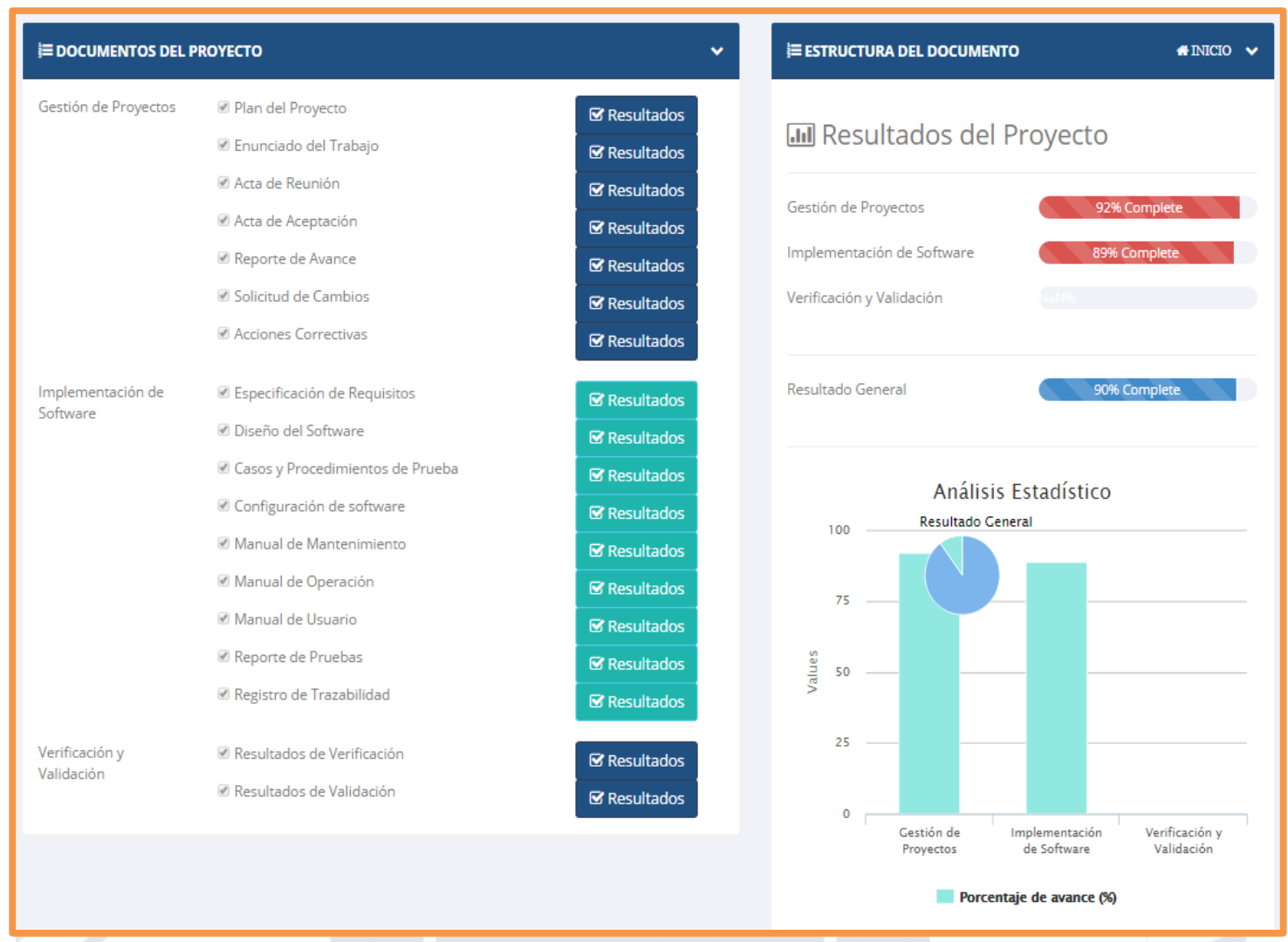

Al dar clic en alguno de los documentos del proyecto, podemos ver la evaluación de este. Ejemplo: Detalle del Plan del Proyecto.

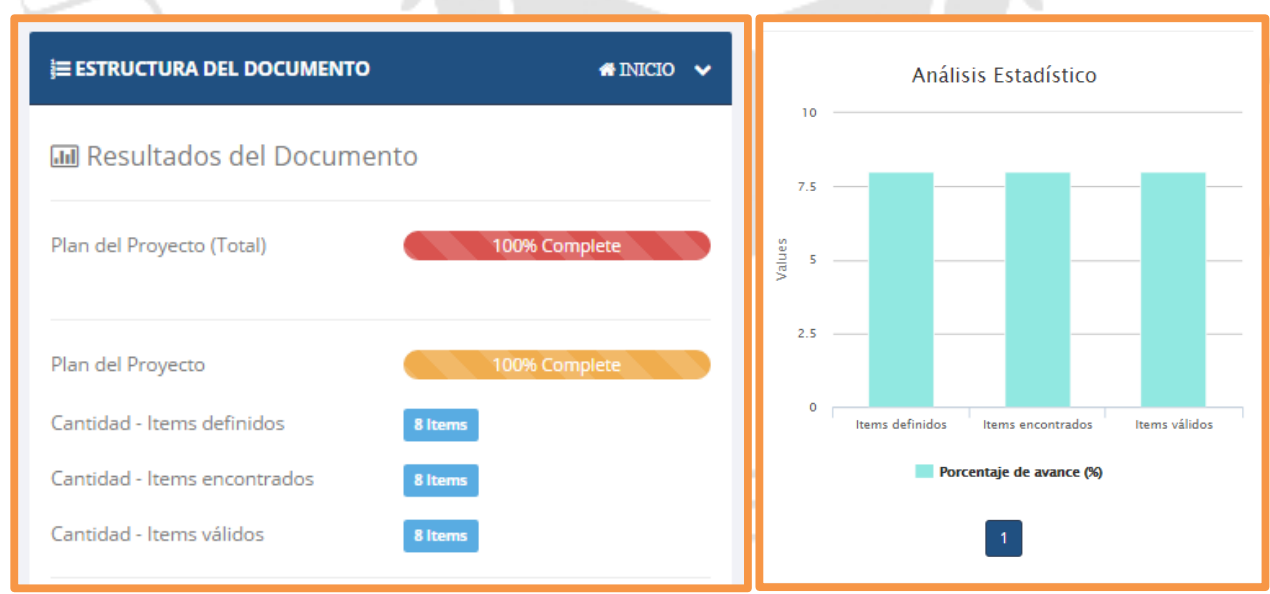

\section{Descripción}

- Ítems definidos: Secciones que debe poseer el documento

- Ítems encontrados: Secciones encontradas en el documento evaluado

- Ítems validados: Secciones encontradas en el documento evaluado y que poseen contenido. 


\section{[AP0402] - Definir y evaluar documentos (Documentos con Multi tipos)}

En este caso, tendremos un documento que hará referencia a dos (2) documentos de la norma:

- Nombre del Documento: Análisis y Diseño de Requisitos.

- Documentos a los que hace Referencia: Especificación de requisitos, Diseño del Software.

Para definir los documentos de un proyecto, primero debemos seleccionar que documentos serán necesarios dando clic en Estructura y luego definir con que secciones contara el documento y guardar la estructura.

La diferencia es el campo nombre del Documento (colocaremos el mismo nombre en ambos documentos).

\section{Especificación de requisitos}

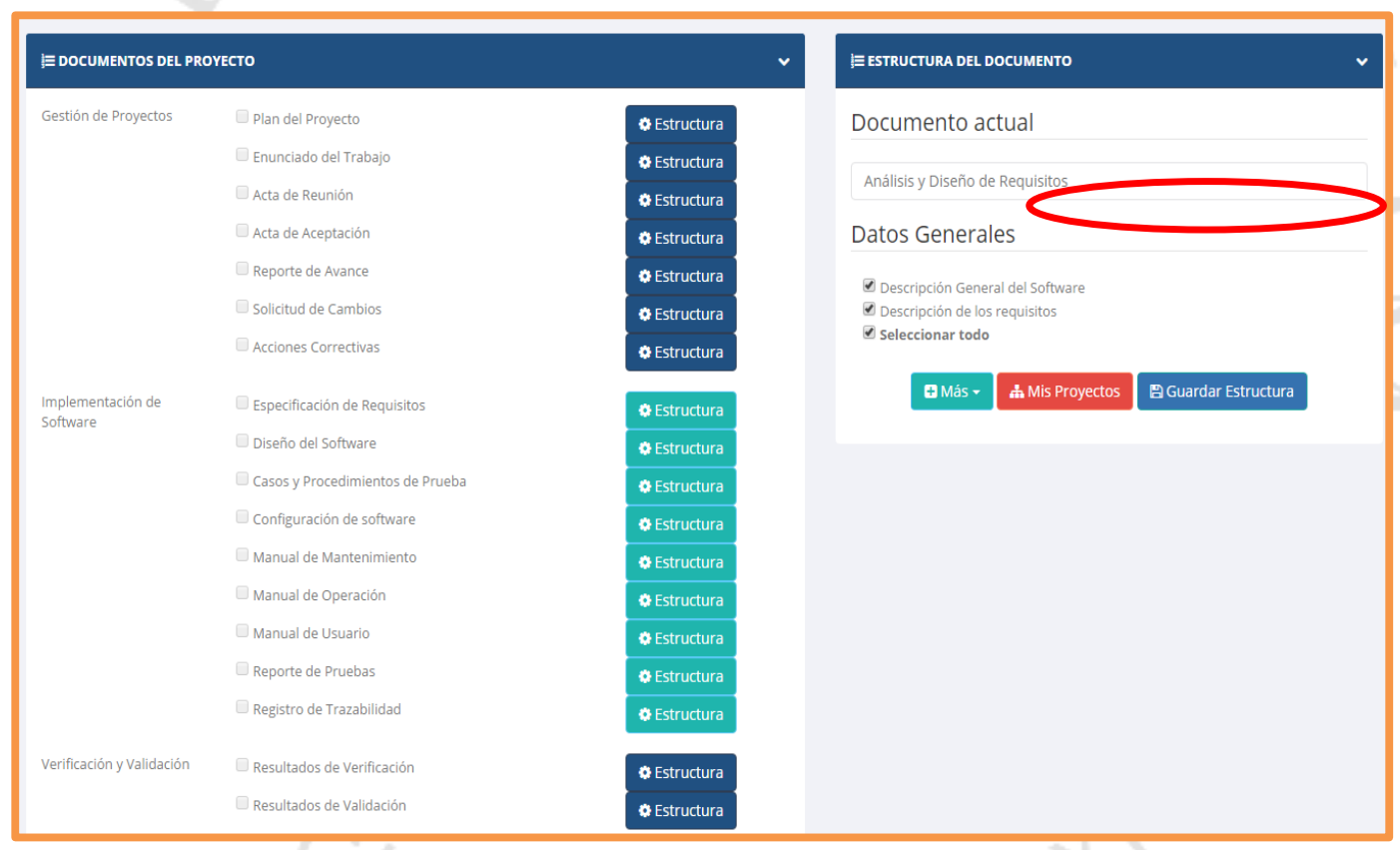

Nombre del Documento: Análisis y Diseño de Requisitos. 


\section{Diseño del Software}

\begin{tabular}{|c|c|c|c|c|c|}
\hline \multicolumn{2}{|c|}{ EDOCUMENTOS DEL PROYECTO } & & \multirow{2}{*}{\multicolumn{3}{|c|}{ 巨ESTRUCTURA DEL DOCUMENTO }} \\
\hline \multirow[t]{9}{*}{ Gestión de Proyectos } & Plan del Proyecto & Estructura & & & \\
\hline & Enunciado del Trabajo & Estructura & \multicolumn{3}{|c|}{ Documento actual } \\
\hline & Acta de Reunión & Estructura & \multicolumn{3}{|c|}{ Análisis y Di do Requisitos } \\
\hline & Acta de Aceptación & *structura & \multicolumn{3}{|c|}{ Datos Generales } \\
\hline & Reporte de Avance & * Estructura & \multirow{5}{*}{\multicolumn{3}{|c|}{$\begin{array}{l}\checkmark \text { Componentes de software requeridos } \\
\checkmark \text { Relación entre los componentes de software } \\
\checkmark \text { Características de desempeño de software } \\
\text { Interfaces de hardware, software y humanas } \\
\checkmark \text { Caracteristicas de seguridad }\end{array}$}} \\
\hline & $\square$ Solicitud de Cambios & * Estructura & & & \\
\hline & & & & & \\
\hline & Acciones Correctivas & * Estructura & & & \\
\hline & & & & & \\
\hline \multirow{11}{*}{$\begin{array}{l}\text { Implementación de } \\
\text { Software }\end{array}$} & $\checkmark$ Especificación de Requisitos & Estructura & \multirow{8}{*}{\multicolumn{3}{|c|}{ 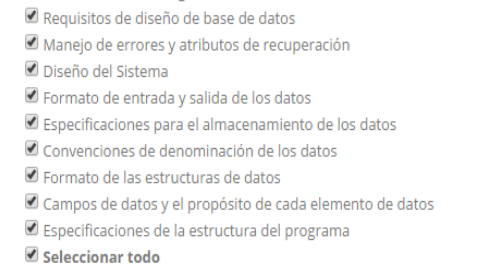 }} \\
\hline & Diseño del Software & A Ftructura & & & \\
\hline & & Whatula & & & \\
\hline & Casos y Procedimientos de Prueba & \$ Estructura & & & \\
\hline & Configuración de software & \$ Estructura & & & \\
\hline & Manual de Mantenimiento & * Estructura & & & \\
\hline & Manual de Operación & Estructura & & & \\
\hline & & & & & \\
\hline & Manual de Usuario & Estructura & & & \\
\hline & $\square$ Reporte de Pruebas & \$ Estructura & & 1 & \\
\hline & Registro de Trazabilidad & Estructura & & structura fue guardad & a correctamente. \\
\hline \multirow{3}{*}{ Verificación y Validación } & & & UMás - & क Mis Proyectos & G Guardar Estructura \\
\hline & $\square$ Resultados de Verificación & Estructura & & & \\
\hline & Resultados de Validación & Estructura & & & \\
\hline
\end{tabular}

Nombre del Documento: Análisis y Diseño de Requisitos.

Luego, para evaluar el cumplimiento de los documentos del proyecto, se debe acceder a la opción "Evaluar Proyectos del Listado de Proyectos".

EPROYECTOS DE DESARROLLO DE SOFTWARE

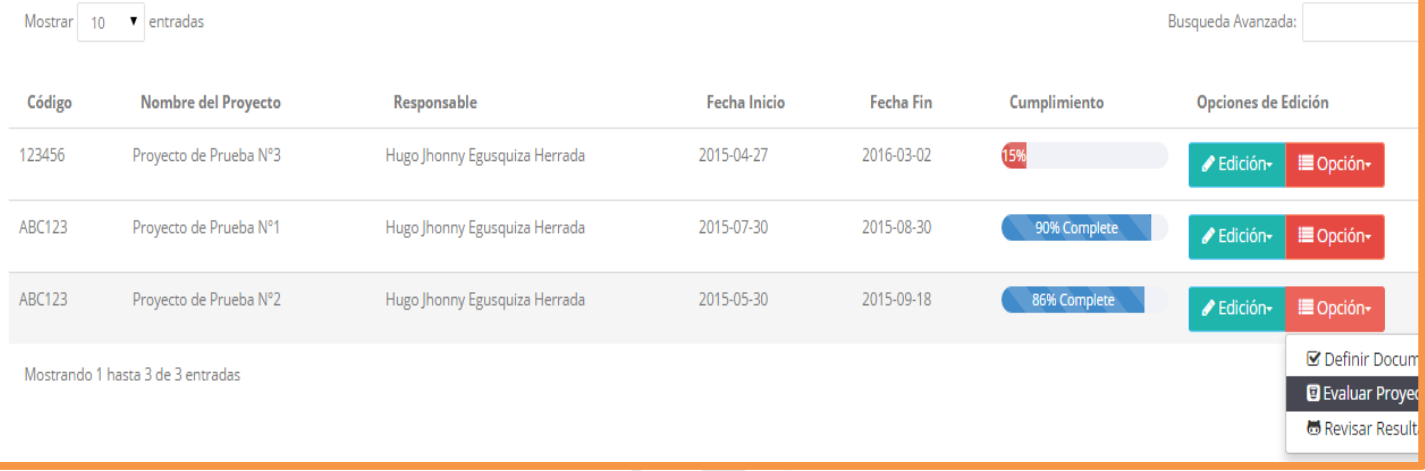


En esta interfaz se deben buscar o arrastras los documentos que serán evaluados:

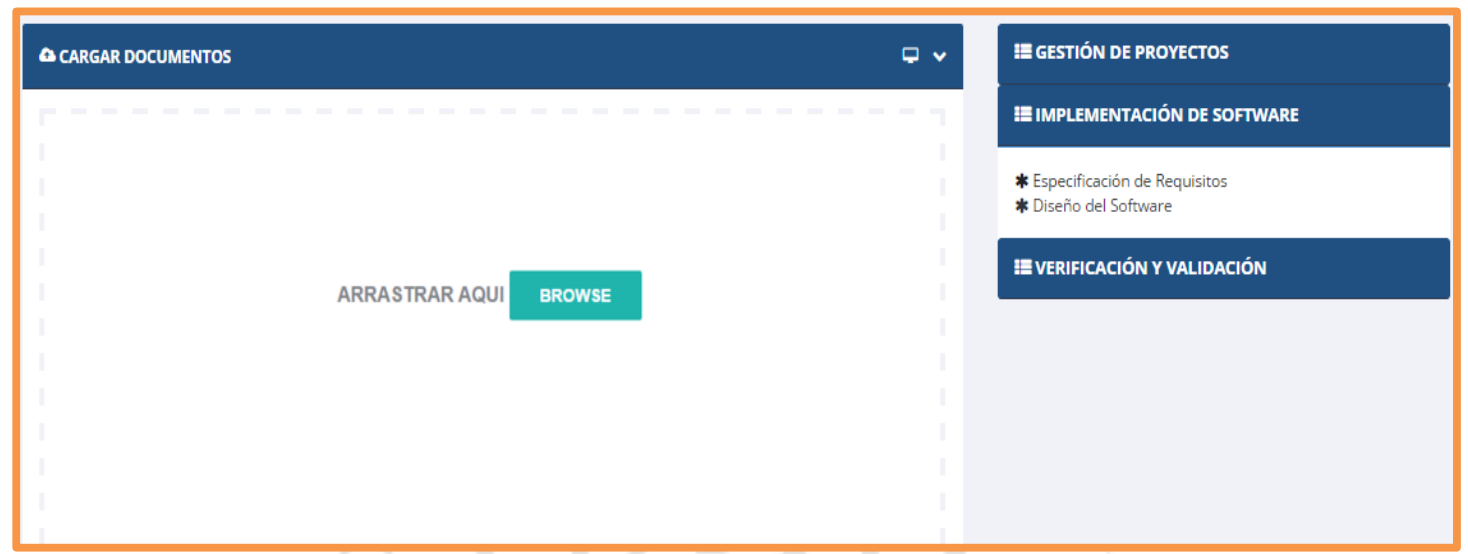

A continuación evaluamos el documento "Análisis y Diseño de Requisitos"

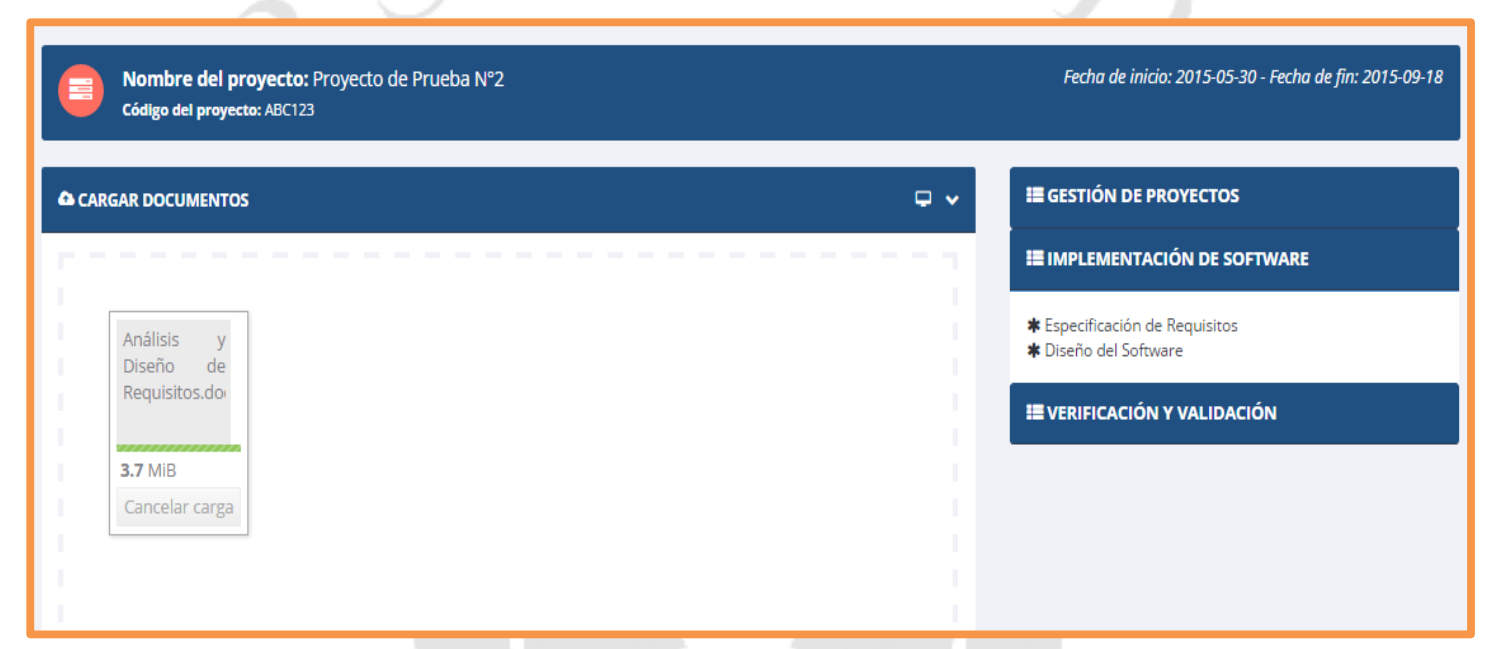

Al evaluar el documento, se cargara una vista rápida de la evaluación con respecto a los documentos:

- Especificación de requisitos.

- Diseño del Software. 


\section{Alerta del Sistema}

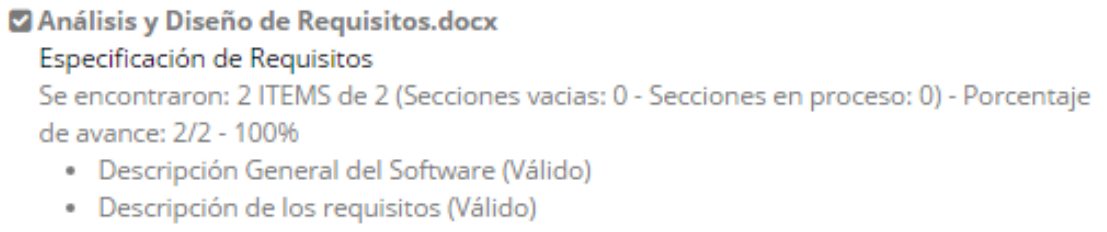

Finalmente, se podrán revisar los resultados de la evaluación en la sección revisar resultados.

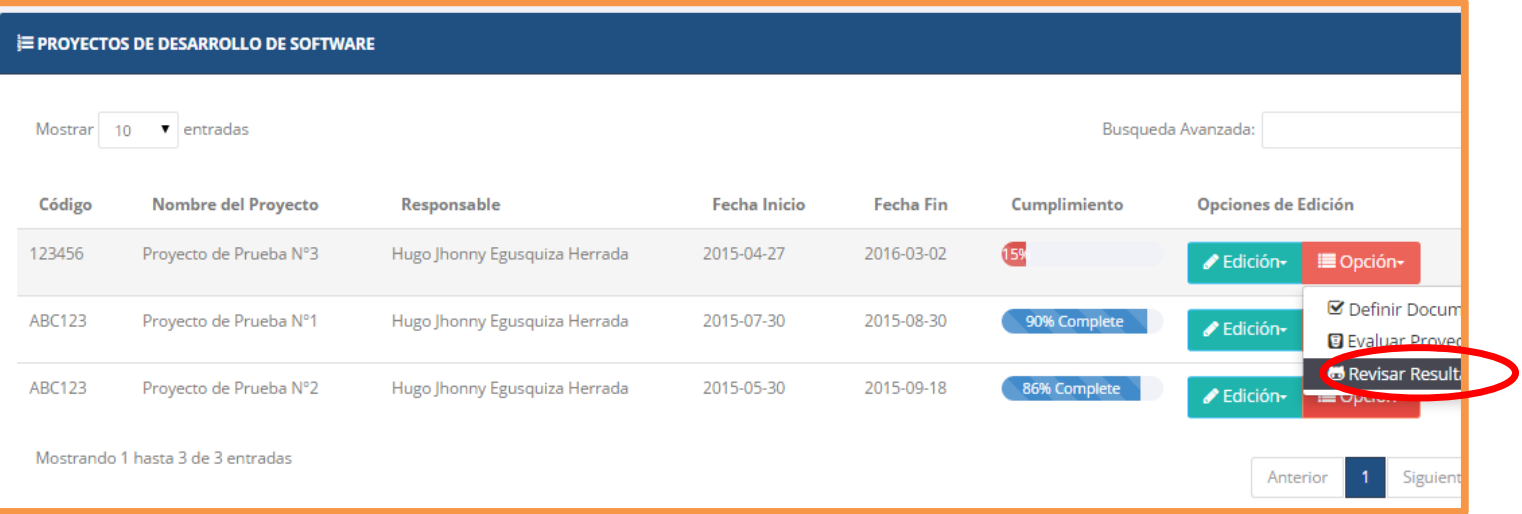

En esta interfaz podemos ver que documentos son requeridos para este proyecto como también el resultado de la evaluación.

Como el ejemplo del proyecto sólo tiene dos documentos y en promedio estos cumplen al 86\%, se considera que el Proceso de Implementación de Software donde se generó 
estos documentos, el resultado general del proyecto es del $86 \%$.

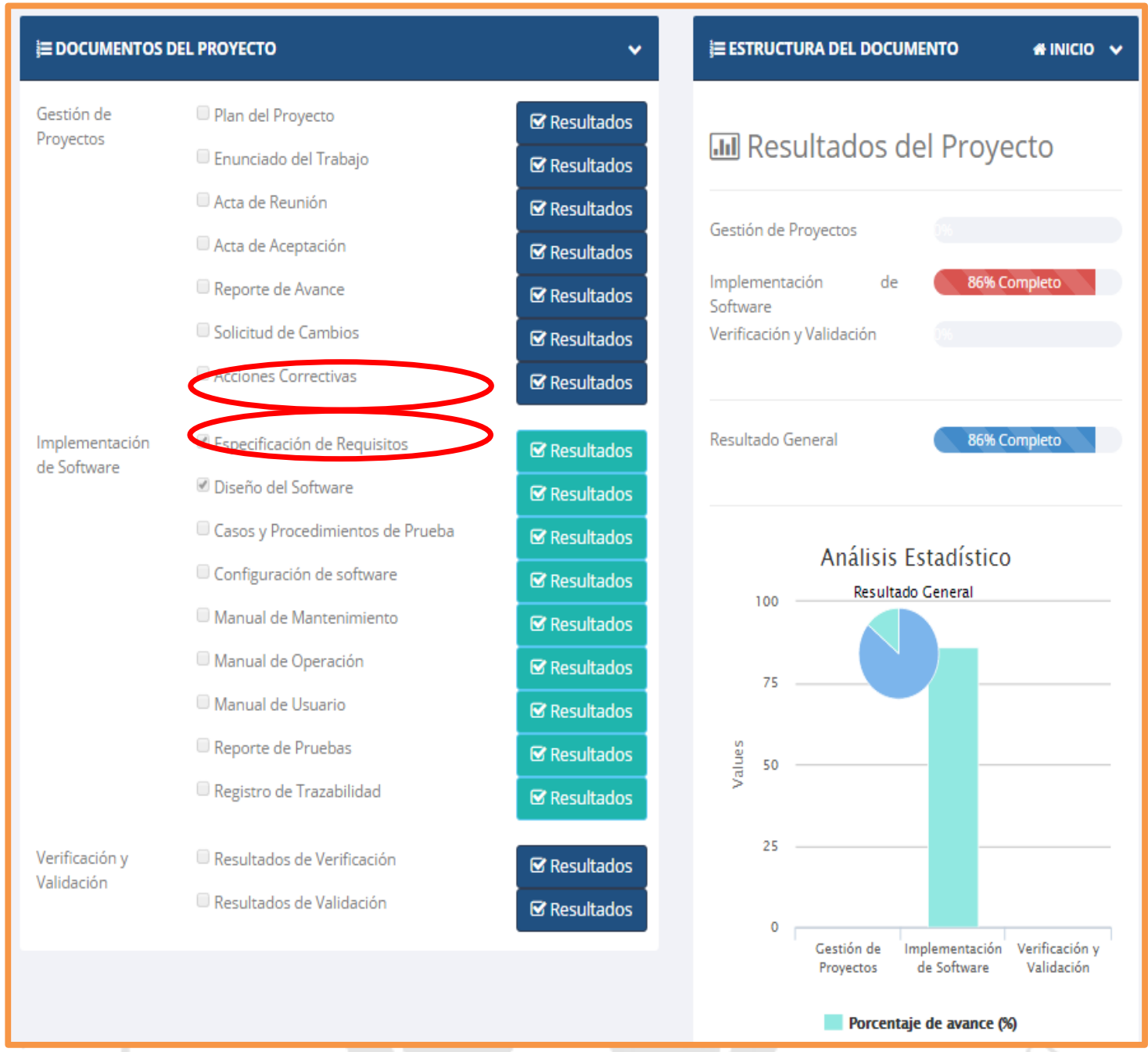

Si hacemos clic en cualquiera de los 2 documentos de la ISO 29110, podemos ver el nivel de cumplimiento individual de las 2 secciones del documento “Análisis y Diseño de Requisitos": 
- Resultados de Especificación de Requisitos

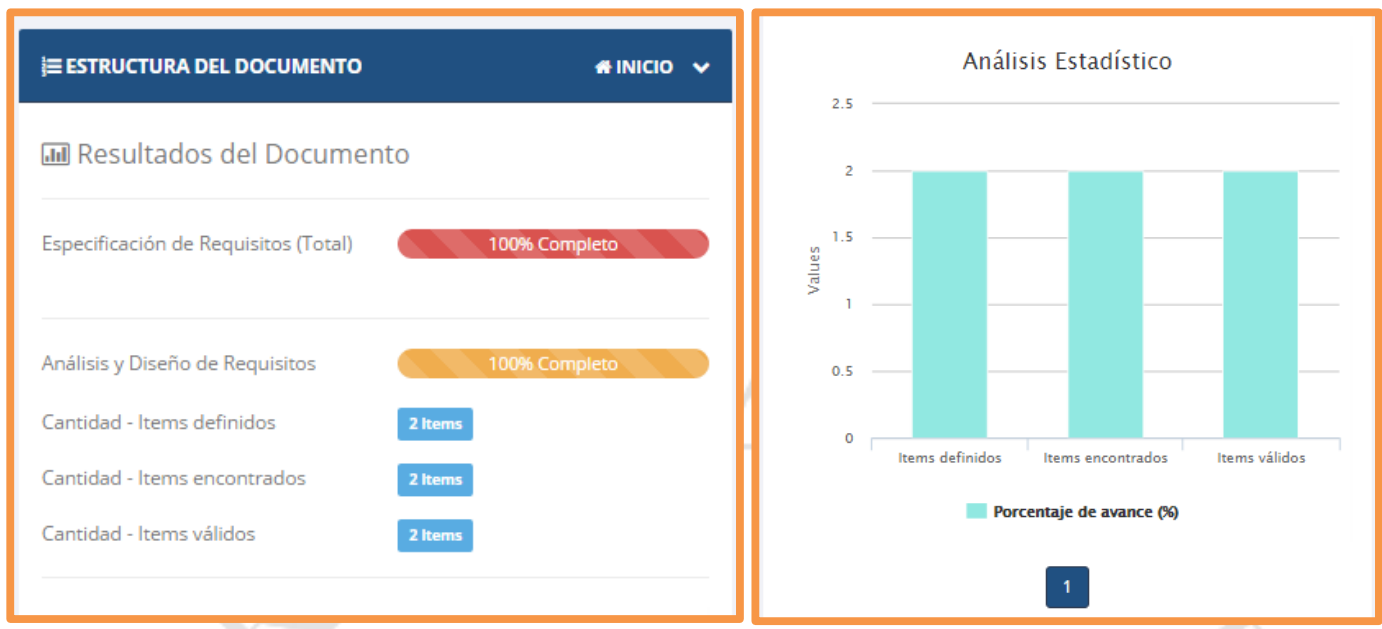

El documento “Análisis y Diseño de Requisitos" cumple al 100\% con las secciones de la Especificación de requisitos según la ISO 29110.

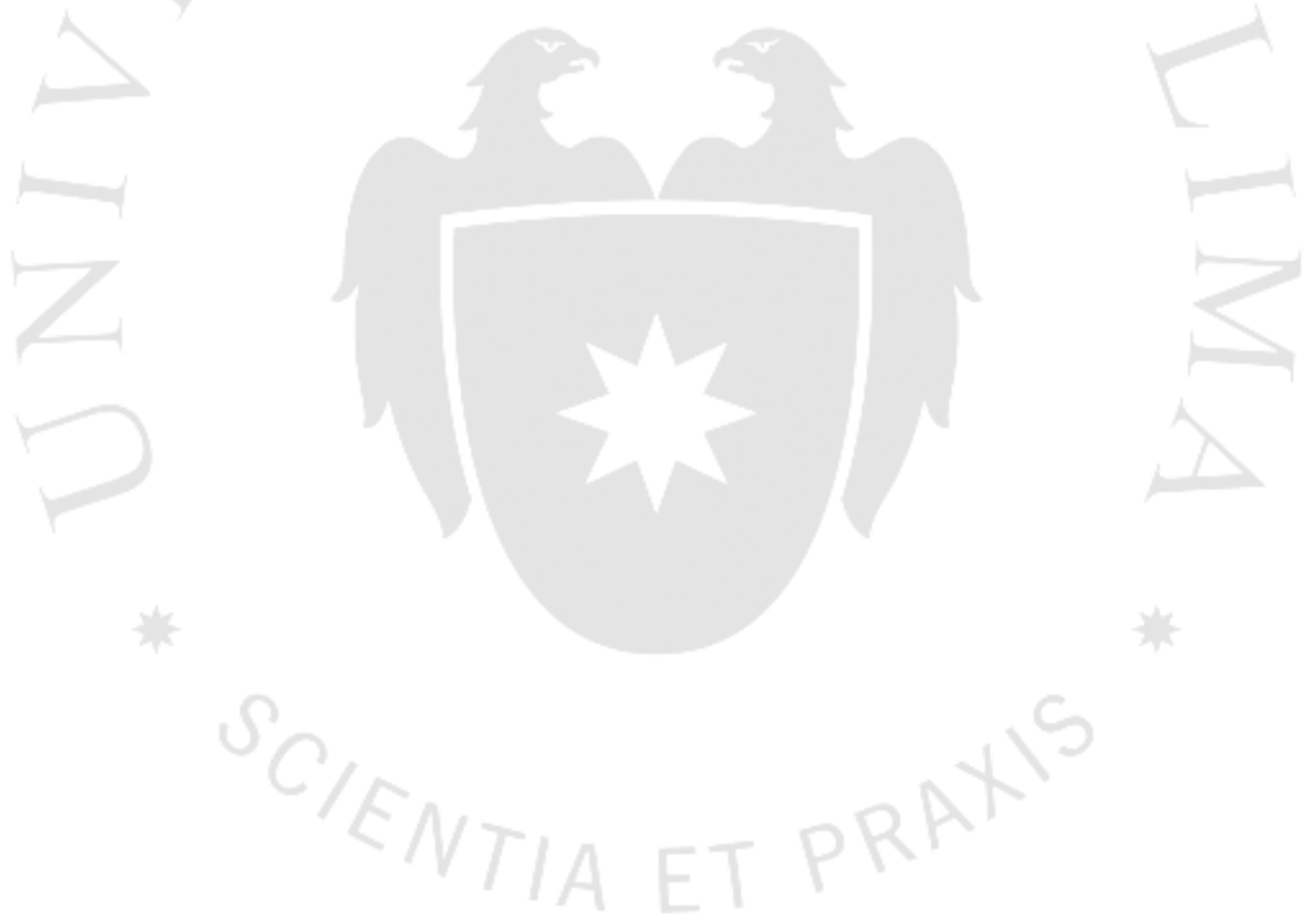


- Resultados de Diseño del Software
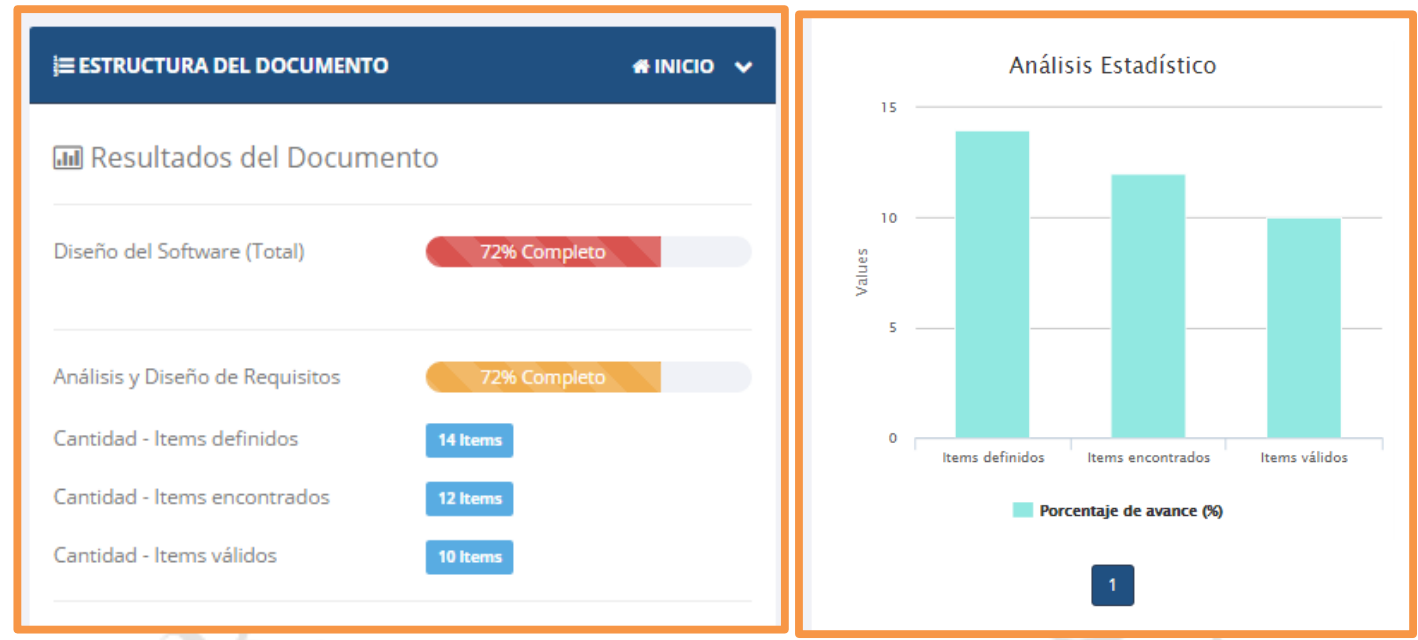

El documento “Análisis y Diseño de Requisitos” cumple al 100\% con las secciones del diseño del software según la ISO 29110.

\section{[AP0403] - Definir y evaluar documentos (Documentos Múltiples)}

En este caso, tendremos múltiples documentos que hagan referencia a un mismo documento de la norma.

- Documentos a los que hace Referencia: Plan del Proyecto

\section{- Nombre del Documento:}

- Plan del Proyecto 01

- Plan del Proyecto 02

○ Plan del Proyecto 03

Para definir los documentos de un proyecto, debemos primero seleccionar el documento necesario dando clic en "Estructura", y luego definir con que secciones contará el documento y la opción "Guardar Estructura”. 
Proyecto de Prueba $\mathrm{N}^{\circ} 3$

Gestión de Proyectos $\square$ Plan del Proyecto
$\square$ Enunciado del Trabajo
$\square$ Acta de Reunión
$\square$ Acta de Aceptación
$\square$ Reporte de Avance
$\square$ Solicitud de Cambios
$\square$ Acciones Correctivas

* Estructura

* Estructura

* Estructura

* Estructura

* Estructura

* Estructura

*. Estructura

En el Campo donde está el nombre del Proyecto digitamos: Plan del Proyecto 01

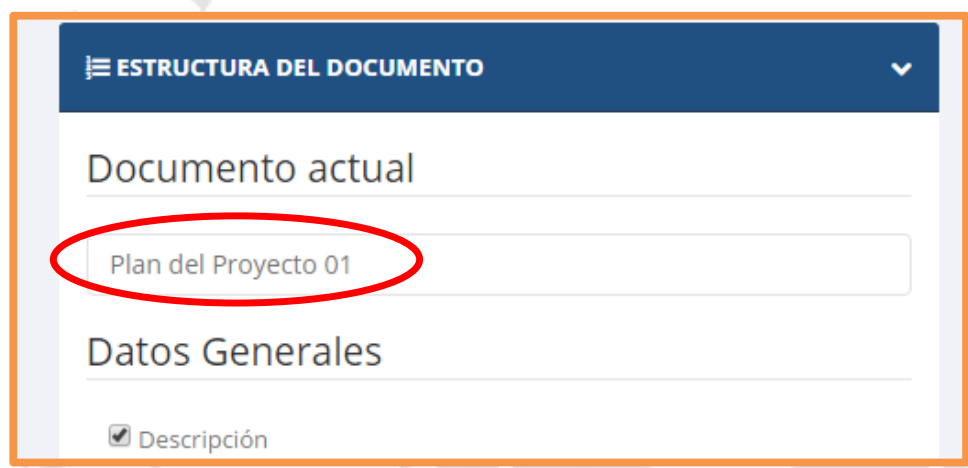

Luego, daremos clic en el botón "Más" y "Añadir documento".

\section{1}

La estructura fue guardada correctamente.
†Más -
mis Proyectos
(3) Eliminar documento actual
画 Eliminar todos los documento

回 Guardar Estructura

$\boxplus$ Añadir documento 
A los nuevos documentos les daremos un nombre y una estructura (Esta estructura puede variar). Luego de guardar la estructura de los 3 documentos podremos acceder a la estructura de cada uno a través de su numeración:

\section{Datos Generales}
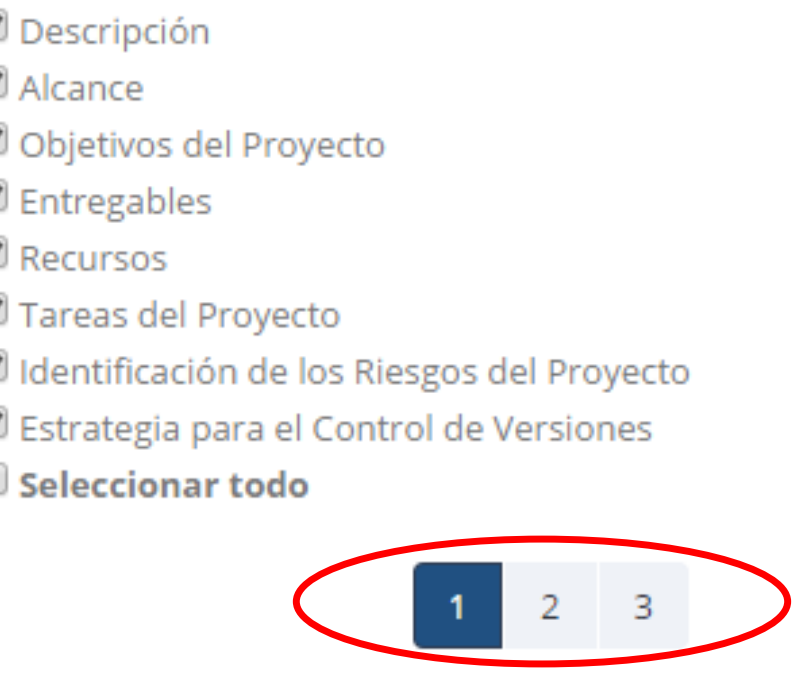

\section{† Más - \\ Mis Proyectos \\ 回 Guardar Estructura}

Luego, para evaluar el cumplimiento de los documentos del proyecto, se debe acceder a la opción "Evaluar Proyectos del Listado de Proyectos".

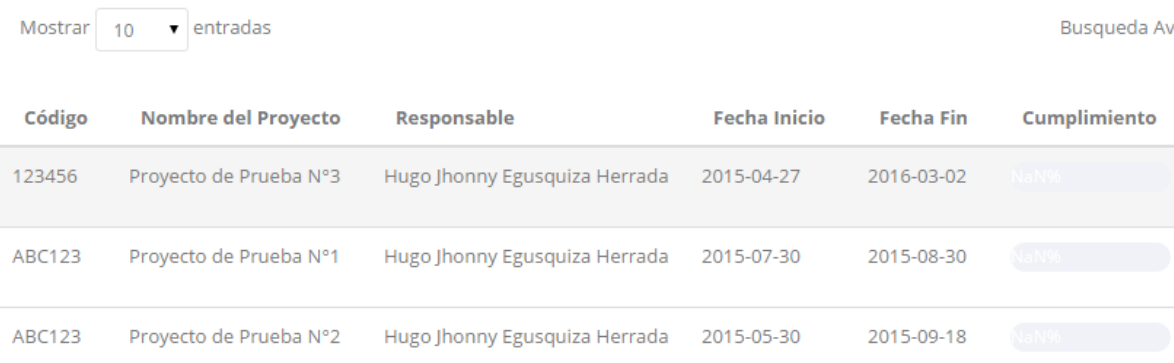

Mostrando 1 hasta 3 de 3 entradas
Opciones de Edición

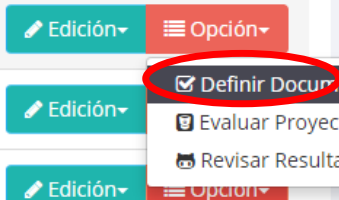

Edición-

En esta interfaz se deben buscar o arrastrar los documentos que serán evaluados: 


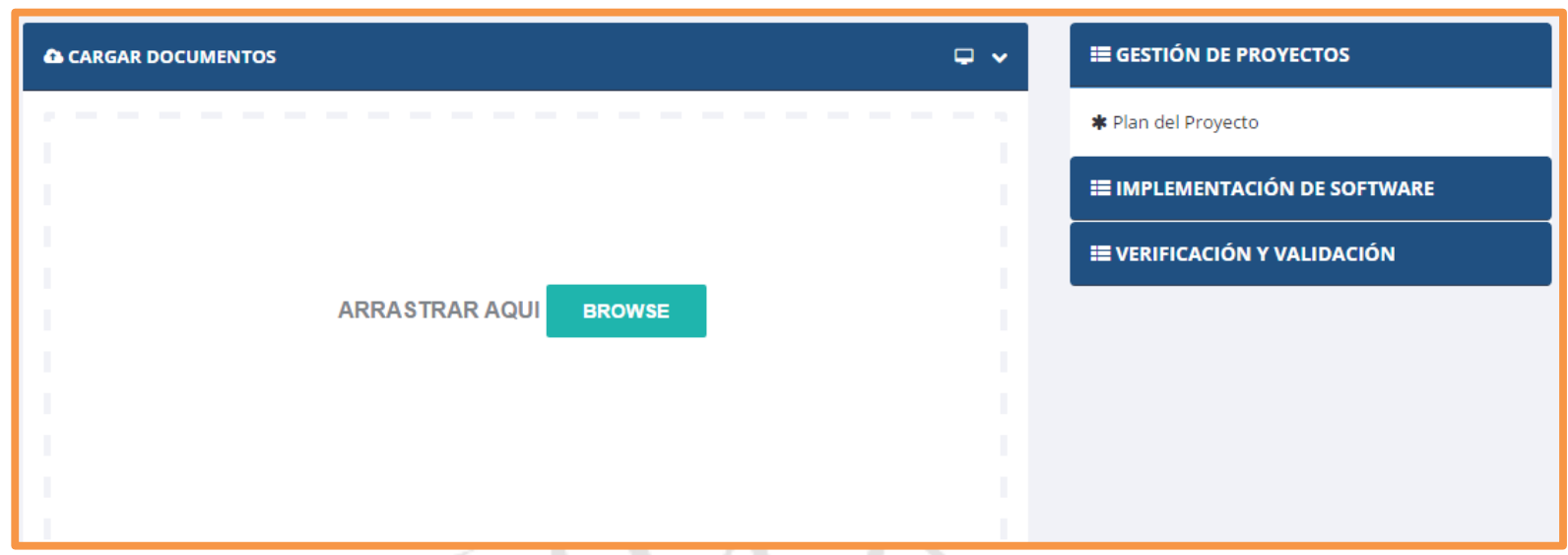

A continuación, evaluamos los documentos Plan del Proyecto 01, 02 y 03:

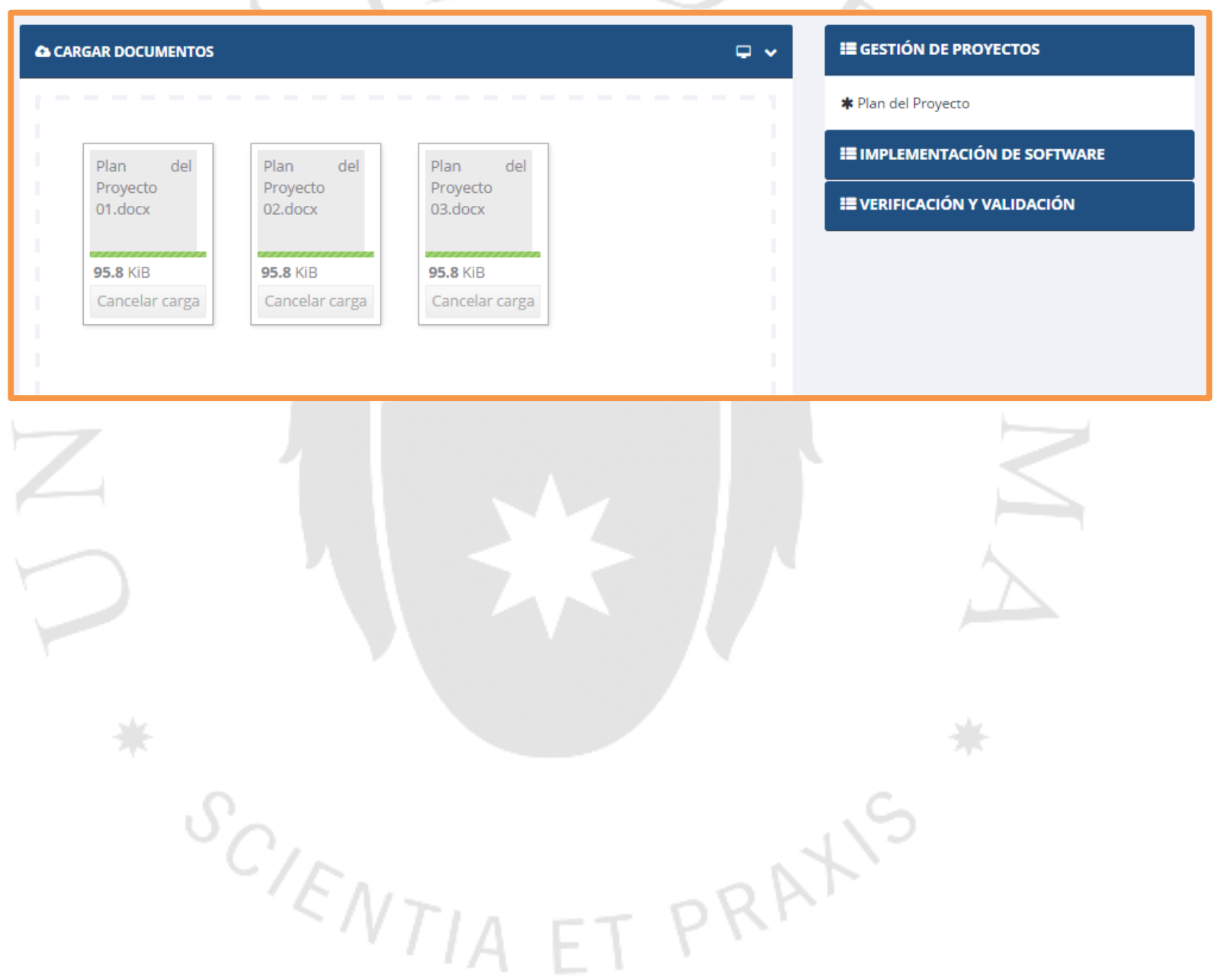


Al realizar la evaluación se mostrada una alerta con el estado de los documentos evaluados:

\section{Alerta del Sistema}

Plan del Proyecto 01.docx

Plan del Proyecto

Se encontraron: 8 ITEMS de 8 (Secciones vacias: 0 - Secciones en proceso: 0) - Porcentaje de avance: $8 / 8$ - $100 \%$

- Descripción (Válido)

- Alcance (Válido)

- Objetivos del Proyecto (Válido)

- Entregables (Válido)

- Recursos (Válido)

- Tareas del Proyecto (Válido)

- Identificación de los Riesgos del Proyecto (Válido)

- Estrategia para el Control de Versiones (Válido)

Plan del Proyecto 03.docx

Documento no requiere una estructura - Porcentaje de avance: $100 \%$

Plan del Proyecto 02.docx

Documento no requiere una estructura - Porcentaje de avance: $100 \%$

Los documentos Plan de Proyectos 02 y 03 tienen un nivel de cumplimiento del 100\% debido a que no requieren una estructura, solo se evalúa la presencia de estos documentos.

Finalmente, se podrán revisar los resultados de la evaluación en la sección revisar resultados.

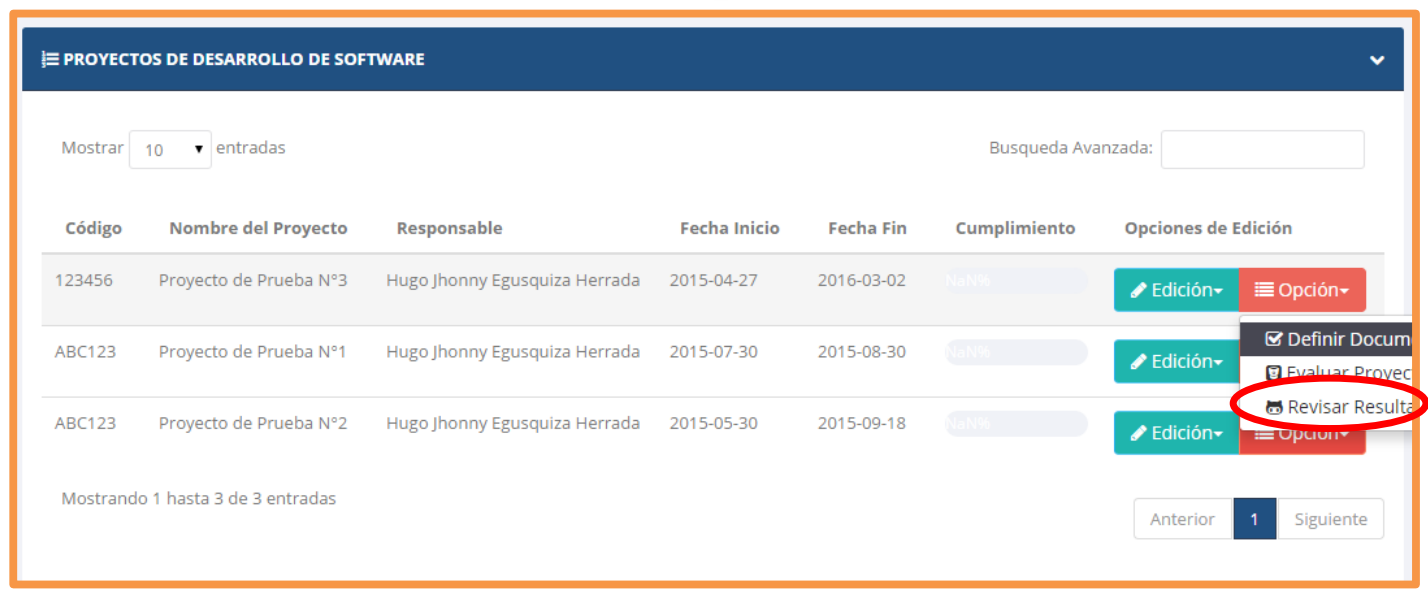


En esta interfaz podemos ver cuáles son los documentos requeridos para este proyecto, como también el resultado de la evaluación.

Como el ejemplo del proyecto tiene tres documentos y en promedio estos cumplen al 100\%, se considera que el Proceso Gestión del Proyecto donde se generó estos documentos, el resultado general del proyecto es del $100 \%$.

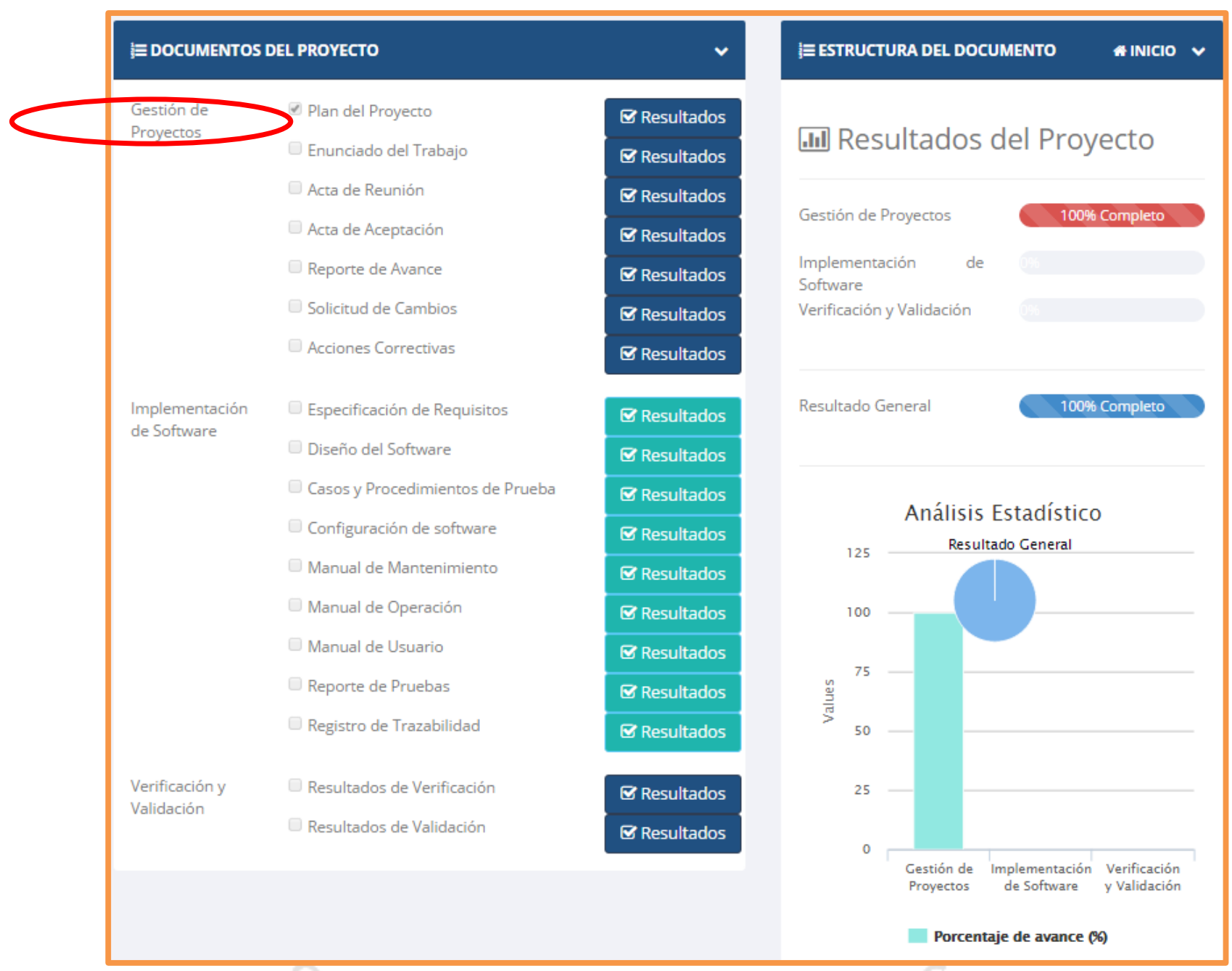

Si hacemos clic en el documento Plan del Proyecto de la ISO 29110, podemos ver el nivel de cumplimiento individual de los tres documentos a los que hace referencia.

- Plan del Proyecto 01 


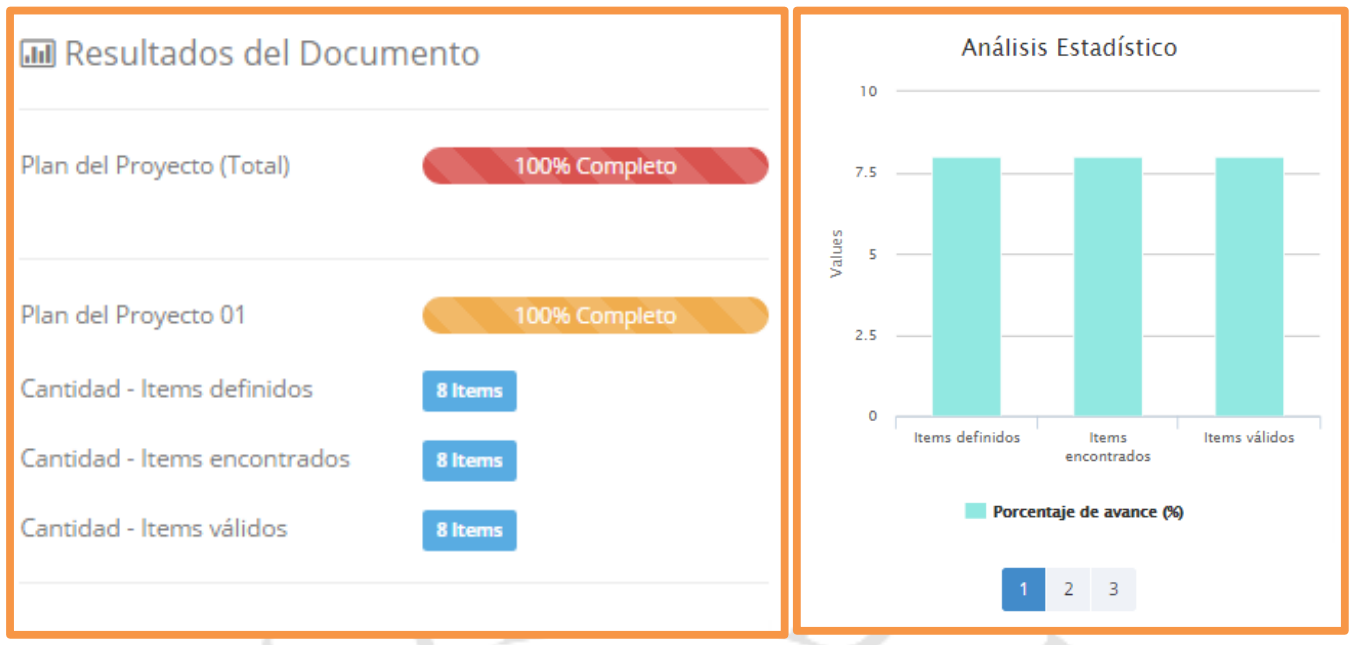

El Plan de Proyecto 01 cumple al 100\% con las secciones requeridas.

- Plan del Proyecto 02
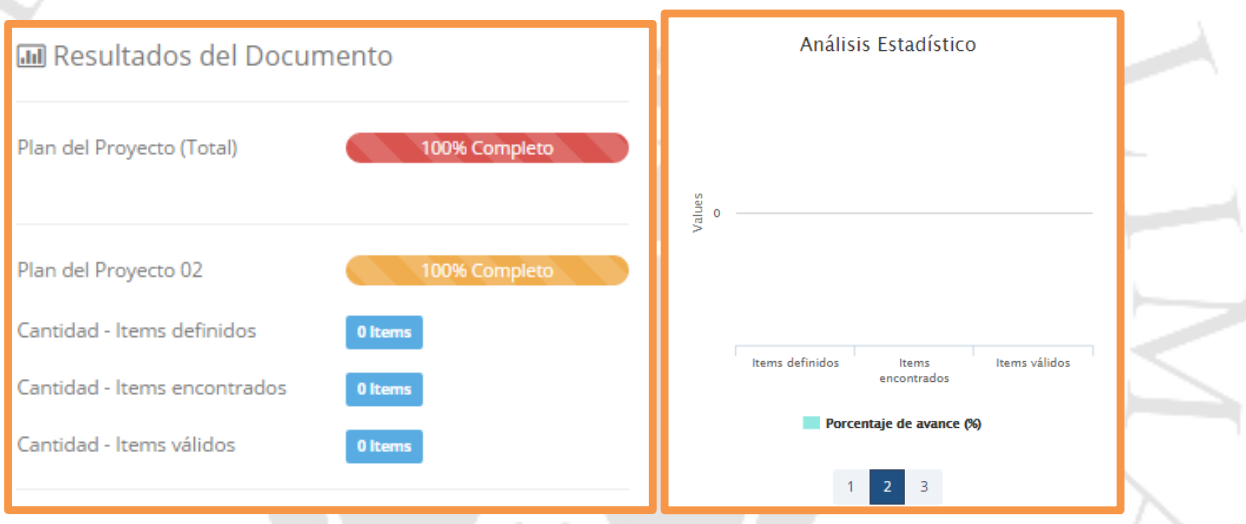

- Plan del Proyecto 03
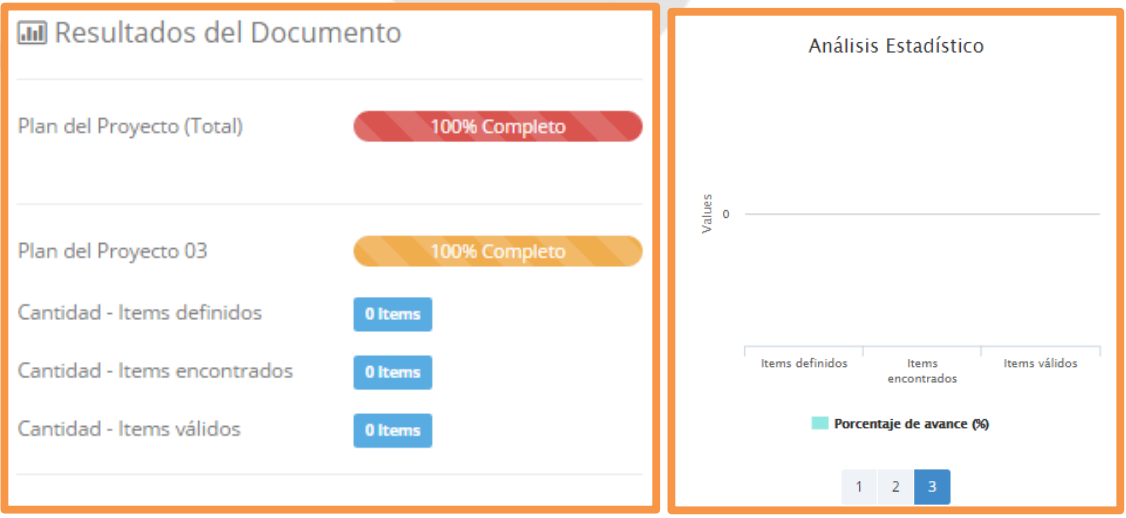

\section{Comandos del Software}

No Aplica.

\section{Advertencias y Precauciones}

No Aplica. 
11. Procedimiento para reportar problemas y asistencia técnica No Aplica.

12. Procedimientos para la solución de problemas y corrección de errores No Aplica. 


\section{ANEXO 8: Herramientas para la gestión de proyectos.}

A continuación, hacemos una comparación entre nuestra herramienta y las herramientas para el seguimiento y control de proyectos utilizadas por la empresa de estudio.

\begin{tabular}{|c|c|}
\hline Herramienta & Descripción \\
\hline $\begin{array}{l}\text { Auditor } 29110 \\
\text { Plus }\end{array}$ & $\begin{array}{l}\text { Herramienta para el control y evaluación de productos de trabajo } \\
\text { (Documentos) elaborados en un proyecto de desarrollo de software. } \\
\text { Su objetivo principal es validar si los documentos cumplen con las } \\
\text { secciones descritas por la ISO } 29110-5-1-2 \text {. }\end{array}$ \\
\hline JIRA Software & $\begin{array}{l}\text { Herramienta para la gestión y seguimiento de proyectos de desarrollo } \\
\text { de software utilizando como base el tiempo real y estimado para los } \\
\text { productos de trabajo (Entregables) del proyecto. }\end{array}$ \\
\hline $\begin{array}{l}\text { Visual Studio } \\
\text { Team } \\
\text { Foundation } \\
\text { Server }\end{array}$ & $\begin{array}{l}\text { Herramienta para la gestión y control de versiones de código y } \\
\text { documentos generados en proyectos de desarrollo de software. }\end{array}$ \\
\hline Google Drive & Herramienta para el almacenamiento de archivos en la nube. \\
\hline Mercurial & $\begin{array}{l}\text { Herramienta multiplataforma para la gestión y control de versiones } \\
\text { para código y documentos generados en proyectos de desarrollo de } \\
\text { software. }\end{array}$ \\
\hline & $P$ \\
\hline
\end{tabular}

Fuente: Elaboración Propia 